\title{
Plant Cover and Environment of Steep Hillsides in Pite Lappmark
}

By

Jim Lundqvist

\author{
UPPSALA 1968
}

ALMQVIST \& WIKSELLS BOKTRYCKERI AB 



\section{Plant Cover}

\section{and Environment of}

\section{Steep Hillsides in}

\section{Pite Lappmark}

avec un résumé en français

By

\section{Jim Lundqvist}

By due permission of the Faculty of Science

of the University of Uppsala to be publicly discussed

at the Institute of Ecological Botany

(Växtbiologiska Institutionen),

on May 24, 1968, at 10 a.m.,

for the degree of Doctor of Philosophy 
Illustrations printed with contribution from Längmanska Kulturfonden

Printed in Sweden by

Almqvist \& Wiksells Boktryckeri AB

Uppsala 1968 
To the Memory of my Mother 



\section{CONTENTS}

Preface

INTRODUCTION

\section{ENVIRONMENT} 13

Introductory remarks . . . . . . . . . 13

Altitude . . . . . . . . . . . . . . 14

Bedrock and soil . . . . . . . . . 15

The development of talus slopes . . . . . 15

The chemical properties of the bedrock and the soil ............ 18

Local climate and sun exposure . . . . . . . 29

Introduction . . . . . . . . . . . . . . . . 29

Measuring methods and gauges. Sources of error . . . . . . . . 32

The radiation climate of mountain slopes . . 33

The thermometer screens and their placing. . 36

Monthly mean temperatures of the stations and the dependence on the weather . . . . . . 37

Minimum temperatures . . . . . . . . . 42

Maximum temperatures . . . . . . . . 44

Soil temperatures . . . . . . . . 48

The snow conditions during thaw. . . . . 50

Phenology . . . . . . . . . . . 52

Supply of water . . . . . . . . . . . . 56

Precipitation and interception . . . . . . 56

Surface and sub-surface waters . . . . . 59

THE FLORA OF THE HILLSIDES . . . . . . 64

Introduction ............. 64

The flora of vascular plants . . . . . . 64

The bryophyte flora . . . . . . . . 74

Conclusions ........ 82

THE VEGETATION . . . . . . . . . 83

Introduction . . . . . . . . . . . . . . 83

Terminology and methodology ..... 83

The vegetation types of the hillsides . . . 86

Poeto-Lactucetum . . . . . . . . . . . . 87

Tortulo-Poetum . . . . . . . . . . . . . 88

Stands with Vaccinium vitis-idaea or other dwarf shrubs . . . . . . . . 92

Rhytidietum . . . . . . . . 93

Dicrano-Polytrichetum . . . . . . . . . 94

A comparison with the vegetation on talus slopes in Sikilsdalen . . . . . . . . . . 96

Zonation of vegetation on talus slopes . . . 96

The succession of vegetation . . . . . . 101
THERMOPHILOUS PLANT COMMUNITIES OUTSIDE THE HILLSIDE ECOSYSTEM . . . 103

The flora and vegetation of the Merk Gorge . 103 The flora and vegetation in an old river valley 105 Concluding remarks on the study of the vegetation

\section{HILLSIDES LOCATED IN THE CALEDONIAN} AREA . . . . . . 107

1. Mt. Akkapakte . . . . . . . . . 107

2. Mt. E Ramanpakte . . . . . . . . . 108

3. Mt. W Ramanpakte . . . . . . . . 108

4. Paktesuolo . . . . . . . . . . . . 109

5. Mt. Ardnapakte . . . . . . . . . 109

6. Mt. Kebnevare . . . . . . . . . 110

7. Mt. Kaldopakte . . . . . . . . 111

8. Mt. Jokkokvarats . . . . . . . . . 111

9. Mt. Laisvare . . . . . . . . . . . . 112

10. Mt. Fabmevare . . . . . . . . 112

11. Mt. Korpberget . . . . . . . . 113

12. Mt. Märkepakte . . . . . . . . 113

13. Mt. Storberget . . . . . . . . . . 114

14. Mt. Alep Nadok . . . . . . . . . . 116

15. Mt. Staburknösen . . . . . . . . 116

16. Mt. Aistjakk . . . . . . . . . 117

HILLSIDES LOCATED IN THE AREA OF PRI-

MARY ROCKS . . . . . . . . . 118

17. Mt. Pellavardo . . . . . . . . . 118

18. Mt. Lulep Istjakk . . . . . . . . . 118

19. Mt. Vuornats . . . . . . . . . . 120

20. Mt. Jutavare . . . . . . . . . . 120

21. Mt. Dalktjapakte . . . . . . . . 121

22. Mt. Ailesvare .. . . . . . . . . 121

23. Mt. Måfevare . . . . . . . . . . 122

24. Mt. Välbmapuoda . . . . . . . . 122

25. Mt. Kuottavare . . . . . . . . . . 122

26. Mt. E Stärpatsvare . . . . . . . . . 123

27. Mt. Fiskträskterget . . . . . . . . . . 124

28. Mt. Harrejaurliden . . . . . . . . . 124

29. Mt. Brunberget . . . . . . . . . . 125

30. Mt. Bärberget . . . . . . . . . 126

31. Mt. Gaddaberget . . . . . . . . 126

32. Mt. Hålberget . . . . . . . . . . . 127

RÉSUMÉ _. . . . . . . . . . 128

REFERENCES .............. . . 147

TABLES $1-2,5,13-14,17-31 \ldots$ (behind the text) 



\section{PREFACE}

The principal problems regarding the complex of biocoenoses and factors comprising the hillside ecosystem were summarized by Du Rietz (1954, pp. 174 et seq.). He gave a review of the earlier plant ecological and botanical literature and the principal theories and known facts with regard to the environmental factors. Du Rietz (op. cit., p. 183) concluded that "what would be desirable at the present time would be a differentiated analysis of the plant communities of the hillside vegetation in a way performed by Nordhagen (1943, pp. 542-567) ... and a fundamental special study of the ecology of every species of the hillside" (translated from the Swedish).

The aims of the present investigations were principally to investigate the environmental factors and the phytocoenoses or special pioneer communities in the way proposed and suggested by Du Rietz. The environmental factors were studied with the aim of giving the background of the later mainly synecological discussion of the book and not in the sense of producing causal facts about adaptation or requirement. In Du Rietz' definition of the term synecology was included the study of habitat factors, their ecological amplitudes and the interrelationships between the habitat factors and the plant communities. Stress was laid on the study of both the climatic and edaphic aspects. Autecological aspects remained less studied.

As regards the phytocoenoses and the fragmentary occurrences of only some single individuals grouped together because of similar demands on abiotic habitat, the principal aim was to define and classify special units. This was done without regard to habitat but on the basis of exclusive, preferential, differential and other indicator species.

In a few cases a comparative study was performed of some atypical warm sites outside the hillside ecosystem but containing a few southern species. This was done to supplement the study of the interrelations existing between a "southern" flora and its extreme northern habitats.

Some hillsides in Pite Lappmark, especially of exposures other than near $\mathrm{S}$, were not investigated by the present author, although a regional survey was regarded as important. Some hillsides, mainly of $\mathrm{S}$ aspect, have been visited only, by G. Wistrand who possesses lists of vascular plants from them. They are hardly of any definite value in the present discussion and have only to some extent been commented on in this book. The material will be published later by G. Wistrand who will also make a study of special groups of plants on the basis of the distribution types in N Scandinavia only.

The hillsides in other parts of Fennoscandia visited by the present author have been important for a wider view of the hillside ecosystem, but, with the probable exception of the hillsides of Sikilsdalen, S Norway, they have only very briefly been commented on. Especially important have been visits to the Kuusamo region in Finland, the Porsanger and Alta regions in Finnmark, N Norway, and the valleys of Junkerdalen and Dunderlandsdalen close to the boundary between Pite Lappmark and Nordland, N Norway.

On the suggestion of my teacher, the late Professor G. E. Du Rietz, who had recently published the inspiring paper just discussed, I decided (in 1956) to make an investigation of the plant ecology of the hillsides of Pite Lappmark. As soon as my academic degree was obtained (in 1958) I started out with my field work. My studies were always generously encouraged by my former teacher, who acted as a constant source of knowledge and information. I deeply regret that he did not see the work completed.

Professor H. Sjörs has always taken great interest in the problems of the ecological discussion and has kindly revised the manuscript.

I am much obliged to my teachers in meteorology, Professor T. Bergeron and Professor G. H. Liljequist, for much advice and interest in my climatological studies. The colleages at the Meteorological Institute, Uppsala, I thank for all kindness and help given me during past years.

Dr. G. Wistrand has been an inspiring comrade and friend always with valuable views on the plant geography of Pite Lappmark.

Several specialists have given me valuable help in checking the material of vascular plants. This is above all the case with Professor J. A. Nannfeldt. I also thank him for discussions and for information on the distribution of Dryopteris assimilis. I also received help from Professor N. Hylander and Dr. H. 
Smith; Professor E. Almquist and Mr. S. Nordenstam, Crown Forester, determined the material of Hieracium which will be published later.

In the field of bryology, many scientists have given me valuable help in the checking of difficult species. In earlier years, Dr. O. Mårtensson gave me much help. Later Mrs. E. Nyholm, Dr. S. Arnell, Dr. E. Sjögren, Dr. E. von Krusenstjerna and Dr. T. Koponen have given me special assistance. Dr. P. O. Nyman informed me on the bryology of the NW alpine and subalpine area of Pite Lappmark. Dr. H. Persson gave me information on his routes of travelling in Pite Lappmark in 1928 and 1930. The Keepers of the Botanical Museums at Lund, at Gothenburg and at Helsinki informed me on bryophyte material from Pite Lappmark.

Dr. G. Sandberg has given me inspiring advice especially in connection with his lecture series. Dr. A. Rapp I thank for discussions on the development of talus slopes, and Dr. P. Holmgren for discussions on the rate of photosynthesis under different conditions of environment.

Dr. R. Gorbatschev kindly determined the content of minerals in different rock stuffs. Dr. L. Gustafsson and Assistant A. Strautmanis the content of dissolved salts in seepage water. Miss D. Funcke assisted me with thermogram preparations, and $\mathrm{Mr}$. S. Jansson with the drawings of the figures of this book. Dr. M. Waern helped me with the manuscript.

Dr. Margaret Jarvis and Mr. Raymond Berger kindly revised the English text. Mr. R. Gauthier I thank for the translation of the Summary into French. Dr. I. Ruong deduced the meaning of the Lapp names.

I wish to thank several offices at the Swedish Meteorological and Hydrological Institute (SMHI) for their kind replies to my questions and for the loan of instruments, Bolidens Gruv AB for much support during my early stay at Uppsala (especially Dr. E. Grip for his help with determinations of rock stuffs) and Rikets Allmänna Kartverk for giving me some height values of mountain summits.

For all services received at the Institute of Ecological Botany, Uppsala, I am especially grateful. Without the inspiring environment, the kindness and the assistance received through the years this work would not have been completed. I include in my thanks all visitors to the Institute with which I have had many inspiring discussions.

During my field work, including my visits to Finland and Norway, I have come in contact with many people who have received my wife and me very kindly. My father assisted me in the field especially in early years.

In the summer of 1967 I had the opportunity of taking part in the International Phytogeographical Excursion through the Jura, organized by Professor Dr. R. Tüxen. I am indebted to Professor Dr. A. Quantin, Professor Dr. J. Géhu, Besançon, and Dr. J. L. Richard, Neuchâtel, for rich information on the dependence of vegetation on slope exposure in the Jura.

I am indebted to Mrs. and Mr. L. Bourschler for the very kind reception in their home during my halfyear stay at Gothenburg University in 1957-58.

My wife I thank for her never failing assistance and good comradeship.

I received financial support from the following funds and Institutions: Uppsala University, the Royal Swedish Academy of Science, Seth M. Kempe's, Lundbohm's and Ture Stenholm's. The illustrations have been supported by Längmanska Kulturfonden.

I am greatly indebted for all this support and help.

All photographs, when not otherwise stated, were taken by the author. The photographs taken by G. Wistrand have already been published (APhS 45, 1962).

Institute of Ecological Botany, Uppsala, May 1968 Jim Lundqvist 


\section{INTRODUCTION}

Pit a Lappmark (Lapponia pitensis, abbreviated PL) is an extensive area of land in the middle regions of Swedish Lappland from $65^{\circ} 9^{\prime}$ to $67^{\circ} 10^{\prime} \mathrm{N}$. Its total area is $20,715 \mathrm{~km}^{2}$, of which $13,645 \mathrm{~km}^{2}$ in the NW are the parish of Arjeplog and $6070 \mathrm{~km} 2$ in the SE are the parish of Arvidsjaur.

For historical reasons the parish of Malå $\left(1740 \mathrm{~km}^{2}\right)$ in the SE could also be considered to belong to Pite Lappmark (Bylund 1956, pp. 4, 40) since until 1868 the parish of Arvidsjaur included the present parish of Malå. Cf. the subdivision of provinces on the map in Holmberg: Hartmans Handbok i Skandinaviens flora, Heft 1 (1922), where the parish of Malå was excluded from PL. That subdivision is the one applied by most phytogeographers.

The Arctic Circle crosses the $\mathrm{N}$ part of Arjeplog (cf. the maps, Figs. 1 and 2).

There are large regions of barren land in the Caledonian mountains (the Scandes, see Ljungner 1948) in the NW. The alpine belt consists of regions above the upper limit of birch, Betula pubescens (tortuosa), at ca. $700-800 \mathrm{~m}$ above sea-level. The SE mountains, in SE Arjeplog and in Arvidsjaur, may have a tree limit formed by spruce, Picea abies, or pine, Pinus silvestris, in this respect different from the resi of NW Europe. In some cases the scattered occurrences of conifers at high altitudes give evidence of an amelioration of the climate during the last few decades (Wistrand 1965, p. 220).

The topographical features of the Scandian area in the NW are summarized by Arwidsson (1943, p. 13). A high mountain summit, Mt. Sulitelma (1914 m), is situated close to the NW corner of PL on the Norwegian side of the border, and another summit of the same mountain is the highest in PL (1869 m; the altitude values from recent geographical publications).

The woodland area in the SE of PL is largely made up of a gently sloping plateau, the main dipping direction of which is towards the SE, like the slope of the valley bottoms. Beyond the easternmost outliers of the Scandes the bedrock is Archaean, being part of the Fennoscandian Shield. Here are till-covered forested ridges and occasional isolated mountains or hills reaching as far SE as the great lakes or even farther.

The relative height of the larger features concerned is between 250 and $400 \mathrm{~m}$ and thus they should be designated "great hills" in the terminology used for N Swedish topography in recent publications (see Rudberg 1954, p. 418). In the present text "mountain" has been used as synonymous with "great hill". In consistency with this the regular form "mount" could be used for all the described localities but one (Paktesuolo islet, locality no. 4).

The names of the larger rivers and lakes are shown on the map (Fig. 2). A small area along the Pite River, where it leaves PL, is below the highest coastal line existing at the end of the glaciation (the lowermost point only $159 \mathrm{~m}$ above sea-level). The coast line is considered to have been $200-250 \mathrm{~m}$ higher than at present.

The existence of a "lake zone" at the fringe of the mountain chain in Sweden is generally considered to be a result of overdeepening by valley glaciers and the blocking by moraines. The depths of the lakes vary greatly (Lakes Uddjaure-Storavan 15 and $21 \mathrm{~m}$, respectively, Lake Hornavan ca. 227 m).

The SE low mountains and forested ridges are considered to be monadnocks of an older peneplane (Magnusson, Lundqvist \& Regnell 1963, p. 355). They may reach considerable altitudes (608 and 601 $\mathrm{m})$ even in the immediate neighbourhood of the SE border towards the coastal region. They have been submitted to much greater denudation than the considerably younger Caledonides in the NW and consequently usually have less abrupt profiles. Nevertheless there are local occurrences of high vertical rock walls and boulder screes in places.

The situation of the area investigated, with the 32 mountains forming the basis for this study, may be seen on the maps (Figs. 1 and 2). For closer examination of the topography, reference is made to the following sheets of Generalstabens Karta över Sverige (N part, edited 1890-1895): 19 Staika, 20 Qvikkjokk, 26 Löfmokk, 27 Arjepluog, 34, Storafvan, 35 Arvidsjaur and 43 Jörn. A new topographical map is now being issued of these parts of $\mathrm{N}$ Sweden, based on aerial photography and including revised geographical names, altitudes etc. Some geographical names given here in accordance with the old map are likely to be altered, especially Lapp names. The exact geographical positions have been given as latitude and longitude.

The important SE borderline of the Caledonian mountain rock formation in Scandinavia is formed 


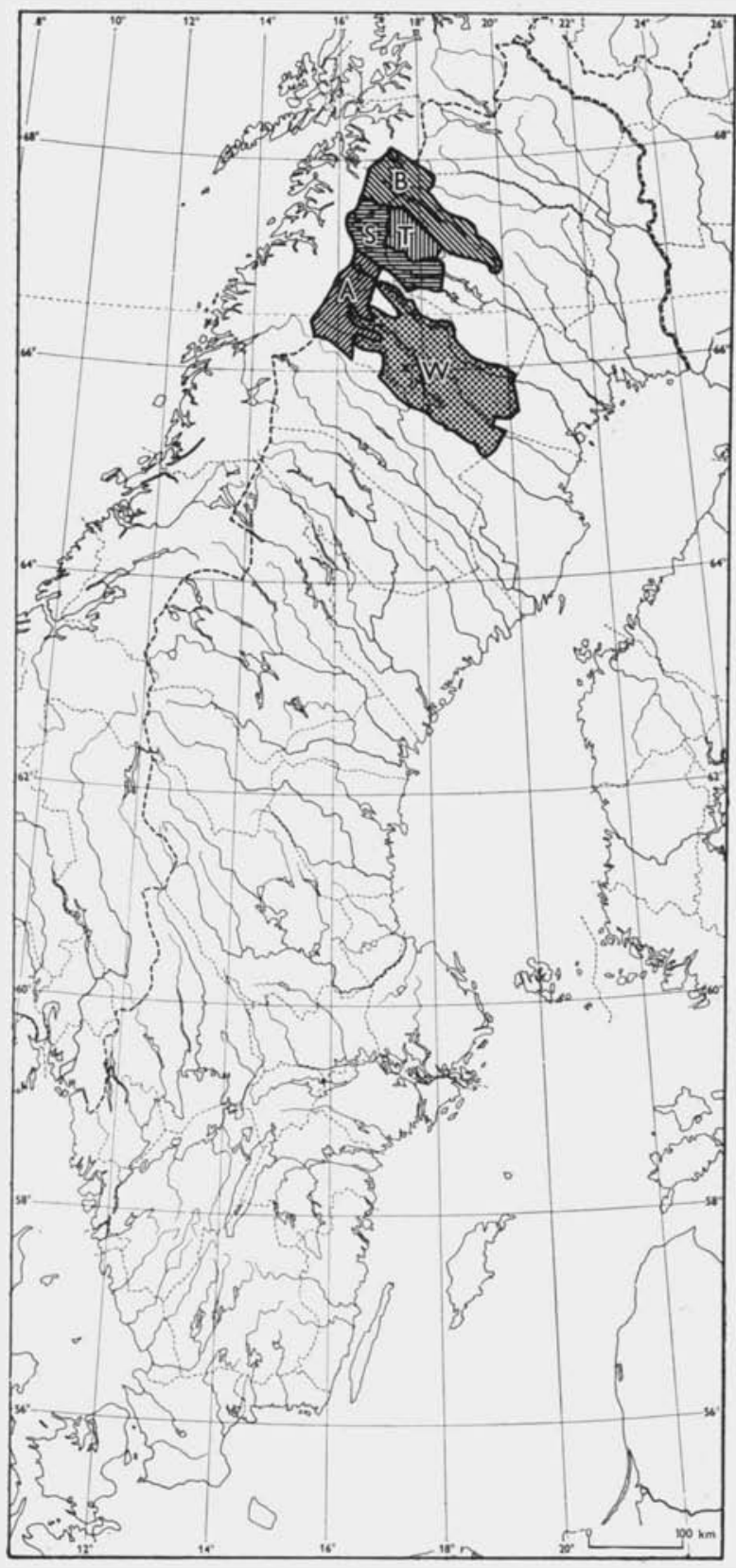

Fig. 1. The investigated area closely coincides with that of $\mathrm{Wi}$ strand (1962: $W$ ). The areas investigated by Arwidsson (1943: $A$ ), Selander (1950 $a, b: S)$, Tengwall (1920, $1925 a, b: T)$ and Björkman $(1939,1965: B)$.

by the autochthonous Eo-Cambrian and Cambro-Silurian. Of the mountains investigated, most of the NW ones are situated in the immediate neighbourhood of that line or another borderline situated somewhat more to the NW, viz. the borderline of the overthrust nappes (the "glint line", not marked on the map Fig. 2).

Geologically the area is thus divided into two major areas, viz. the Caledonian area in the NW and the area of Archaean rocks in the SE. The autochthonous border of the NW Caledonides consists of a narrow fringe of arkoses, mudstones, sandstone and shales, the age of which is Eo-Cambrian and Cambrian in the district concerned (Grip 1960). In the sandstone are found ore minerals consisting of galena, sphalerite and pyrite (see below p. 62). On top of the autochthonous series follow conglomerates, mylonites of Archaean rocks (mainly syenite and granite), sericite-chlorite schist, sparagmites, quartzites and phyllites. Mica schists occur frequently in some districts. As a rule the rock walls of the mountains consist of rocks resistant to weathering in the upper part, as e.g. the tenaceous mylonites or metamorphic Archaean rocks. The lower parts are generally considered to contain more easily weathered rocks, and these circumstances have been favourable for the formation of the typical topography. Quite a large number of hillsides in PL have vertical or nearly vertical walls facing SE to SW, or at least these aspects have bolder forms of topography than the others.

The autochthonous series is thus covered by the overthrust nappes to a large extent. In the area between Mt. Aistjakk and Mt. Fabmevare (nos. 16 and 10 , respectively) the autochthonous zone may be some $\mathrm{km}$ broad, in the easternmost parts even covered by monadnocks. Mt. Laisvare, no. 9, is such a monadnock, with some of its lowest parts consisting of the Eo-Cambrian Laisberg sandstone (see below). In the area around mountains nos. 1-6 the autochthonous series seems to be almost completely covered by the overthrust nappes. In this area Mt. Kebnevare (no. 6) forms another monadnock which is largely a parallel to Mt. Laisvare.

To the SE, the Pre-Cambrian, i.e. Archaean, rocks consist of intrusives of the quartz-diorite- and granite series (with local occurrences of syenite and pagmatite) and also of volcanics and sediments of the Kiruna-Arvidsjaur-series. In the Kiruna-Arvidsjaurseries there are acid lavas (dacite, keratophyre, quartz porphyry or liparite) and basic lavas (andesite and basalt) as well as quartzitic to calcareous sediments. Migmatized stages occur as gneissose rocks of various origin (gneisses). The area is highly denuded (the Pre-Cambrian peneplane). Of special interest are the Snavva-Sjöfall sediments, locally called the Skärfa-series, because there are rich occurrences of limestone in them, and the topography may be quite broken (Mt. Pellavardo, no. 17, Mt. Lulep Istjakk, no. 18). These mountains are transitional between the Caledonides in the NW and the more acid rocks in the SE, with regard to geographical situation and 


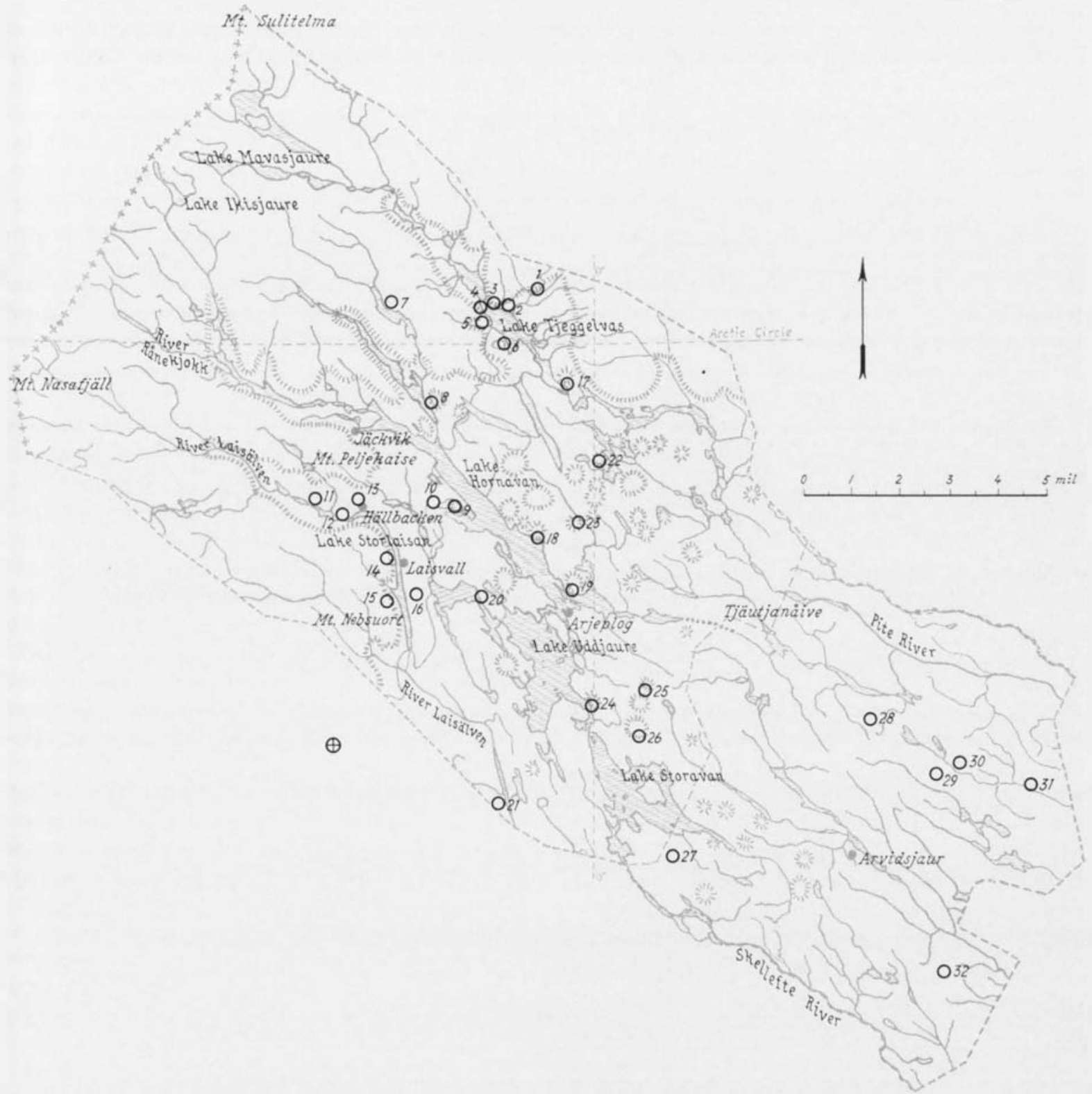

Fig. 2. Survey map of Pite Lappmark showing the mountains investigated (nos. 1-32). Some relevant gecgraphical names. The mountain slopes investigated:
1. Akkapakte
12. Märkepakte
2. E Ramanpakte
13. Storberget
22. Ailesvare
3. W Ramanpakte
(a) W part
(b) Central part
23. Måfevare
4. Paktesuolo
(c) E part
24. Välbmapuoda
25. Kuottavare
5. Ardnapakte
14. Alep Nadok
6. Kebnevare
15. Staburknösen
(b) E-facing slope
16. Aistjakk
7. Kaldopakte
8. Jokkokvarats
9. Laisvare
(a) SW-facing slope
26. E Stärpatsvare
27. Fiskträskberget
28. Harrejaurliden
29. Brunberget
(a) NE-facing slope
17. Pellavardo
(b) SE-facing slope
(a) Upper slope
(b) Lower slope
18. Lulep Istjakk
30. Bärberget
19. Vuornats
31. Gaddaberget
20. Jutavare
32. Hålberget
10. Fabmevare
21. Dalktjapakte

IIIII, In the NW the uppermost border of coniferous forest (in the SE some isolated alpine outliers); — donides; ---, boundaries of parishes; course of old river valley near Tjäutjanåive hill. $\oplus$ Peruken, Lycksele Lappmark. 
floristic composition of the flora. A more detailed description of the physical properties of the bedrocks in the mountains and hills will be given below p. 15 .

Wistrand (1962, p. 39) divided the area into the following zones, on the basis of features of geology, climate and vegetation.

A. The Scandian area (Swed. "fjällområdet"). This comprises the NW alpine and subalpine areas down to the coniferous forest limit. The main features are a cold summer climate (July not appreciably above $+10^{\circ} \mathrm{C}$ ), a high annual precipitation (1000 $\mathrm{mm}$ or even more), and a large number of alpine and montane species in the flora. Montane species, according to Wistrand (1962, p. 161), are those species which have their main area within the Scandes and which are a characteristic element in the montane (pre-alpine) mixed coniferous-birch wood, as well as in the subalpine and alpine areas. Alpine species, on the other hand, have their main area within the alpine barren land above the birch limit. A detailed description of the flora is given by Arwidsson (1943).

B. The coniferous woodland area, including (1) the chiefly Cambro-Silurian area and (2) the area of Archaean rocks. In the Cambro-Silurian area in this sense are included the NW occurrences of pine (Pinus silvestris) and spruce (Picea abies) woods up to the coniferous forest limit. The area does not coincide very well with the area with Cambro-Silurian bedrock in its NW parts but includes the more lowlying parts of the valleys with bedrock of other Caledonian type, to an upper limit of about $570-600 \mathrm{~m}$. The $N W$ coniferous woodland area would therefore probably have been a better name. The SE border of this coincides with the SE border of the Caledonides. The NW mountains described in this paper are situated within the area. The main features are a cool summer climate (July +10 to $+13^{\circ} \mathrm{C}$ ), quite high annual precipitation (ca. $500-700 \mathrm{~mm}$ ) and an abundance of lowland plants, e.g. Woodsia ilvensis, Athyrium filix-femina, Paris quadrifolia, Melica nutans. Roegneria canina, Populus tremula ( $P$. tremula nevertheless with quite elevated occurrences around the upper limit of birch) and Barbaraea stricta. Some plants, e.g. Geum rivale, Galium boreale etc. are definitely more common in this area than in the area of Archaean rocks.

The area of Archaean rocks or (probably better in this connection) the SE coniferous woodland area is usually covered by poorer types of vegetation, primarily by large expanses of trivial heath forest types (with Betula verrucosa) and mires. Beside the mountains described here, the shores of rivers, brooks and lakes have a more varied flora and vegetation (cf. Wistrand \& Lundqvist 1964) in which Convallaria majalis, Rosa majalis, Phalaris arundinacea and Lysimachia thyrsiflora, for example, are characteristic elements. These species may be regarded as indicators of the warmer, more continental summer climate prevailing in this area.

For discussion of the regional aspects and of cultural influences on the flora and vegetation of the woodland of Lappland, see the surveys in APhS 50 by Rune, S. (1965, p. 221) and Wistrand (1962, pp. 153 et seq.; 1965 , p. 226). 


\section{ENVIRONMENT}

\section{INTRODUCTORY REMARKS}

If we compare the vegetation and flora of mountainsides facing different directions we will notice a great difference prevailing in medium latitudes, as compared to tropical and polar areas. This is a consequence of the shape of the earth and its rotation, but the effect is modified with regard to season by the deviation of the ecliptic from the equatorial plane. Hence there are seasonal differences in the radiation climate of a horizontal surface, and still more marked differences on slopes. Troll (1941, p. 76) noticed that the greatest influences of differences in radiation climate are in the subtropical regions of the two hemispheres, thus somewhat nearer the Poles than the tropical circles (see the curves constructed for latitude $31^{\circ} 48^{\prime} \mathrm{N}$ by Ashbel, 1942, where the greatest difference in yearly insolation totals for $\mathrm{S}$ and $\mathrm{N}$-facing slopes is ca. $155 \mathrm{~kg}$. cal. $/ \mathrm{cm}^{2}$ for slopes of $60^{\circ}$. Boyko 1947 , p. 152 , used these curves to illustrate the geo-ecological law of distribution by insolation-exposure-amplitude of different plants). Here the effect of the angle of the sun's rays creates sun- and shade-sides with very different micro- and local-climatological conditions. Towards the Arctic the differences are less because in summer the sun is above the horizon almost all through the day and night and the variously exposed slopes are heated, as in the Tropics, during at least some period of the day.

At the Arctic Circle there are still quite large differences in vegetation and flora between the mountain-sides, especially where the climatological features are enhanced by vertical cliffs or by an open habitat where the solar radiation can penetrate down to the ground. The effect of strengthened radiation due to altitude is not negligible either. On the other hand, gently sloping hills and forested ridges generally show no noticable differences due to direction of exposure.

Comparison of the vegetation and flora of the thermally favoured mountain-sides throughout PL shows striking general differences between rich and poor localities. The richness of the flora may be measured by the number of species, and this number may be up to four times higher on a rich mountain than on a poor one. The general differences in the vegetation cannot be expressed numerically, but there is a clear contrast between the luxuriant herb meadows of the rich mountains and the heath-like vegetation of the poor ones.

It ought to be emphazised that a flora rich in species and a lush vegetation do not always coincide. Some mountains with luxuriant herb vegetation are nevertheless relatively poor in species.

Some of the most important ecological factors acting on the flora and vegetation in a limited area are the following:

1. Topography.

2. Altitude.

3. Bedrock and soil.

4. Climate.

5. Supply of water.

Many of these factors are of course interrelated. Thus the chemical nature of the bedrock is very important with regard to its physical properties and these, again, will influence the topography. The supply of water is in several ways influenced by all the other factors. To draw conclusions about the relative importance of a single factor is difficult, especially as the plants may exist as different ecotypes (ecoclines, ecotypic species) with inherited special demands on the environment which may differ from one area to another. Attention must be given to these circumstances when climatic factors are discussed (Turesson 1932, p. 27). Thus the various plant species (e.g. Fragaria vesca) may be of limited value as climate indicators. Plant geographical relics, including those in N Sweden, must be regarded with caution until their physiological adaptations have been elucidated, and some idea is obtained of the rate with which these have been acquired. However, in some cases, we have reason to believe that the adaptations took place at about the same rate as the climatic changes (see the discussion in Wulff 1950, p. 138). On the other hand, as pointed out by Boyko (see, e.g., 1947, p. 138), it is often possible to study the ecological amplitudes of plant species in a limited area by non-experimental methods. Thus, taking account of the topographic features of the distribution gives considerable possibilities for evaluation.

It has been suggested (Halden 1950, p. 546) that the importance of the southern aspect has been exag- 


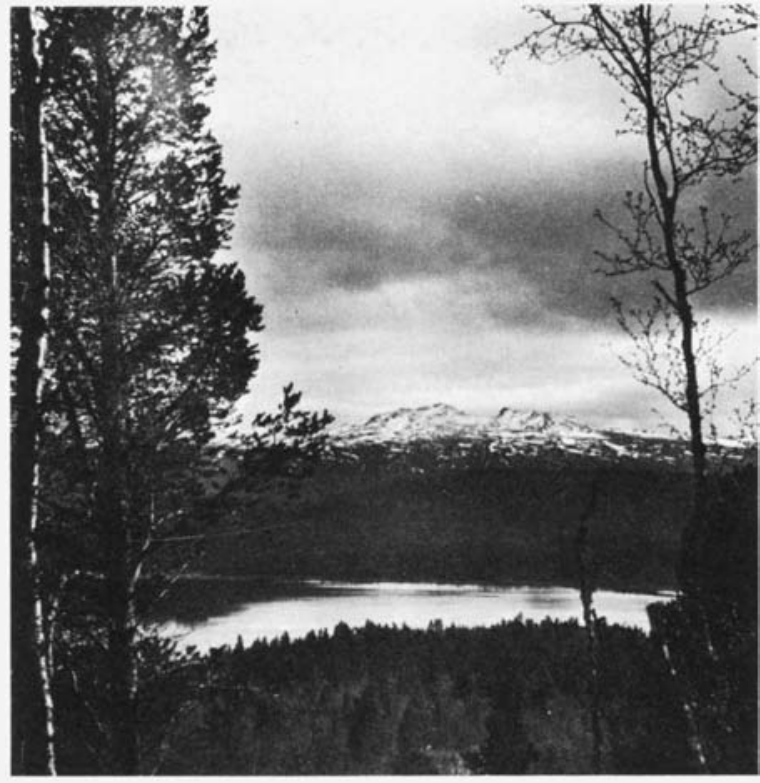

Fig. 3. Mt. Krappesvare $(1024 \mathrm{~m})$ seen across River Laisälven from Mt. Korpberget. There is still a lot of snow on the $\mathrm{N}$-facing side of the mountain, down to the subalpine belt. 9 June, 1964.

gerated and that the "romance of the S-facing hills" has little basis in fact. In the area dealt with, there seem to be several species both of vascular plants and of bryophytes which are not merely adapted to insolated hillsides but also demand a more or less southerly exposure, irrespective of whether the locality is rich or poor in lime. The topographically favoured localities are therefore ecosystems of great importance.

To elucidate the problem of the micro-distribution of southern plant species a few apparently nonfavoured sites (valley bottoms, shady sites) were investigated.

\section{ALTITUDE}

Theoretically a correlation would be expected between the altitude of a mountain-side (above sealevel) and the number of thermophiles in the flora. But the hillsides studied are unsuitable to elucidate this question. Many mountains in about the same geological area have rock wall bases at $500-600 \mathrm{~m}$ above sea-level and it is hardly possible to find any differences due to altitude within this small range. The greatest difference in altitude, from the easternmost to the westernmost mountain, is $324 \mathrm{~m}$, as measured at the rock wall base, the extremes being no. $31 \mathrm{Mt}$. Gaddaberget, $379 \mathrm{~m}$, and no. $7 \mathrm{Mt}$. Kaldopakte, $703 \mathrm{~m}$. However, the relatively great distance between these two means that they are in different climatic, geological and floristic areas.
There are other gradients than altitude affecting the climate, for example continentality and latitude. Other important factors diminishing the relative importance of altitude are the height above the valley bottom, which especially affects the nocturnal temperatures, and the direction of exposure. The uppermost talus slope (no. 7) only has one somewhat thermophilous vascular plant in its flora, viz. Erysimum hieraciifolium, thus indicating that this mountain is too cold to support any richer flora. In the range $500-600 \mathrm{~m}$ altitude, the climate is considerably better and the geological conditions are also favourable, and thus the number of thermophiles is fairly high. In the SE, on the other hand, the geological conditions create more apparent differences than do the differences in altitude.

The altitudinal belts (adapted from Wistrand 1962, p. 40; 1965, p. 219) are

1. The alpine belt (woodless). Typically developed in the NW (the Scandian area). Prevailing communities are dwarf-shrub heaths and alpine meadows (Du Rietz, 1942) together with chionophilous communities (Gjaerevoll 1965, p. 262), willow scrub and lichen- and moss-covered boulder fields and rocky ledges. The flora in PL was described by Arwidsson (1943). The isolated mountains in the SE are generally accepted as reaching into this region or belt (Wistrand 1965, p. 220). Typical for these alpine outliers are scattered occurrences of conifers as saplings and seedlings up to $800 \mathrm{~m}$ or more above sealevel, but there is hardly any birch at corresponding levels. The tree line has probably fluctuated because of forest fires chiefly during the last millenium (Wistrand, cf. also Högbom 1934).

2. The subalpine belt (pure birchwood, "birch belt"). Typically developed only in the NW. The under-vegetation of these birchwoods includes communities with high-grown herbs (Holmen 1965, pp. 240 et seq.) intermingled with the prevailing dwarfshrub and Deschampsia flexuosa heaths, and also willow and juniper scrub. Mires and other treeless areas are numerous.

3. The pre-alpine belt (birchwood with scattered trees of spruce or, in some districts, pine). It is typically developed in the NW coniferous woodland area but is not always present on the SE alpine outliers. In PL (Wistrand 1962, p. 40) there is a western facies with birch and pine (Wahlenberg's "pine region") and an eastern facies with birch and spruce. There tends to be a large proportion of birch on the valley bottoms, and the westernmost occurrences of conifers are almost invariably found on the $\mathrm{N}$ side of the valleys (with S-exposure), a bioclimatological feature of great interest. The under-storey in the forests is 
very similar to that of the subalpine be.t. The lower limit should be drawn somewhere about where Leclum pa'ustre and Betula verrucosa begin (Rune, S. 1965 , p. 225), i.e. at ca. $450 \mathrm{~m}$ in central Lappland.

4. The upper silvine belt (in typical cases pure spruce forest, "spruce belt"). This is a common feature on the SE isolated mountains, which may be completely surrounded by spruce forest. More to the NW (icetween mountains nos. 19 and 22) there are only smaller occurrences or exclaves. On Mt. Staburknösen (no. 15), in the immediate neighbourhood of Mt. Nebsuort, an occurrence of pure spruce wood reaches the Scandian area (Wistrand 1962, p. 42). Some species (Pteridium aquilinum, Calypso bulbosa, Viola riviniana and Oxalis acetosella) and vegetation types seem to be more frequent in spruce forest but are hardly confined to this particular belt. The extreme lichen heath forest (Pineto-Cladinetum) is absent.

5. Lower silvine belt (forests of spruce and pine, mixed or separate). This belt comprises the lowermost belt on the SE mountains (nos. 31 and 32) and the plateau land of SE PL. As was mentioned above, its flora and vegetation is more of a lowland character, especially around rivers and streams.

The major features of altitudinal zonation were recognized and defined in the early work by Wahlenterg (1808, 1812, 1824-26; cf. Rune, O. 1965, p. 64; Sjörs 1965, p. 58). The upper silvine belt (Wistrand) seems to have been recognized as an easterly part of the pre-alpine subregion (sensu Du Rietz, Du Rietz 1950, 1964: cf. the map of the forest regions of Sweden in Sjörs 1965, p. 51).

Methods. As it was highly desirable to obtain reliable figures for altitude of the climatological stations, the methods for obtaining these will be described here.

In the descriptions of the mountains the height (above sea-level) is given for three different points: the first figure is the height of the summit, as a rule read from the topographic map (Generalstaben 1 : 200,000: 1890-95; some summit heights are missing, others are somewhat uncertain, denoted - and ?, respectively). The second figure is the altitude of the lowermost point of the rock wall, like those for the climatological stations measured with a Paulin altimeter and corrected for temperature and barograph deviations. The third figure is the altitude of the valley bottom in the immediate neighbourhood of the mountain and was usually also taken from the topographic map.

The Paulin altimeter is calibrated assuming (1) latitude $45^{\circ}$, (2) air density at a temperature of $+10^{\circ} \mathrm{C}$, (3) water vapour pressure equal to $1 \%$ of the barometric reading, (4) zero point on the scale corresponding to an air pressure of $762 \mathrm{~mm}$ mercury. Svensson $(1965$, pp. 14, 15) mentions a maximum measuring accuracy for the altimeter of \pm 0.15 $\mathrm{mb}$ and for the barograph of $\pm 0.2 \mathrm{mb}$. The accuracy should primarily be dependent on the mechanical achievement of the instruments. In the barograph the quality of the recording paper is important, and there are many different qualities (Svensson, personal communication). A certain reading error is added to the atove errors, which taken together will give values of altitude within a range of $\pm 8 \mathrm{~m}$ from a calculated mean value for observations made at the same point on several occasions with different atmospheric conditions. The temperature corrections recommended by Paulin Ld. were first applied. The humidity of the air was determined from the difference between dry and wet bulb thermometer readings (Assman aspiration psychrometer was used). However, to be able to use the barometric altitude formula (see text-books on meteorology) one would have to know the exact air pressure at the original level and the virtual temperature lapse rate in the atmosphere above that level. Very exact altitude readings of this kind would also need a microbarograph installed in the immediate vicinity.

\section{BEDROCK AND SOIL}

\section{The development of talus slopes}

The steep hillsides are particularly valuable to the geomorphologist in demonstrating glacial erosion and mass-movements (cf. Rudberg 1954, pp. 413 et seq.).

The "flyggberg" (local dialect name for steep hillside of rock) "is a kind of huge roche moutonnée formed in the same way as 'truncated spurs' or a roche moutonnée of ordinary size. The steep sides of the flyggbergs are orientated parallel with the observed ice movement or slightly turning towards the leeside" (Rudberg 1954, p. 426). Thus the shaping forces were working during the glaciations but a preglacial influence is plausible as the longitudinal axes of the hills are approximately parallel to the drainage system of the larger rivers.

If the rock wall is formed from a hard, homogeneous bedrock the effect of frost action is small and little material is produced. This is the case above many screes containing Archaean rocks (granites, porphyries), especially where the rock walls are of small dimensions. Some rocks of the Caledonides are also quite hard and slowly weathered. Rudberg (1954, pp. 422, 239) established the following sequence from easily to less easily weathered rocks, viz. phyllite $<$ mica-schist $<$ migmatite gneiss $<$ granite $\leq$ amphibolite $<$ peridotite. 


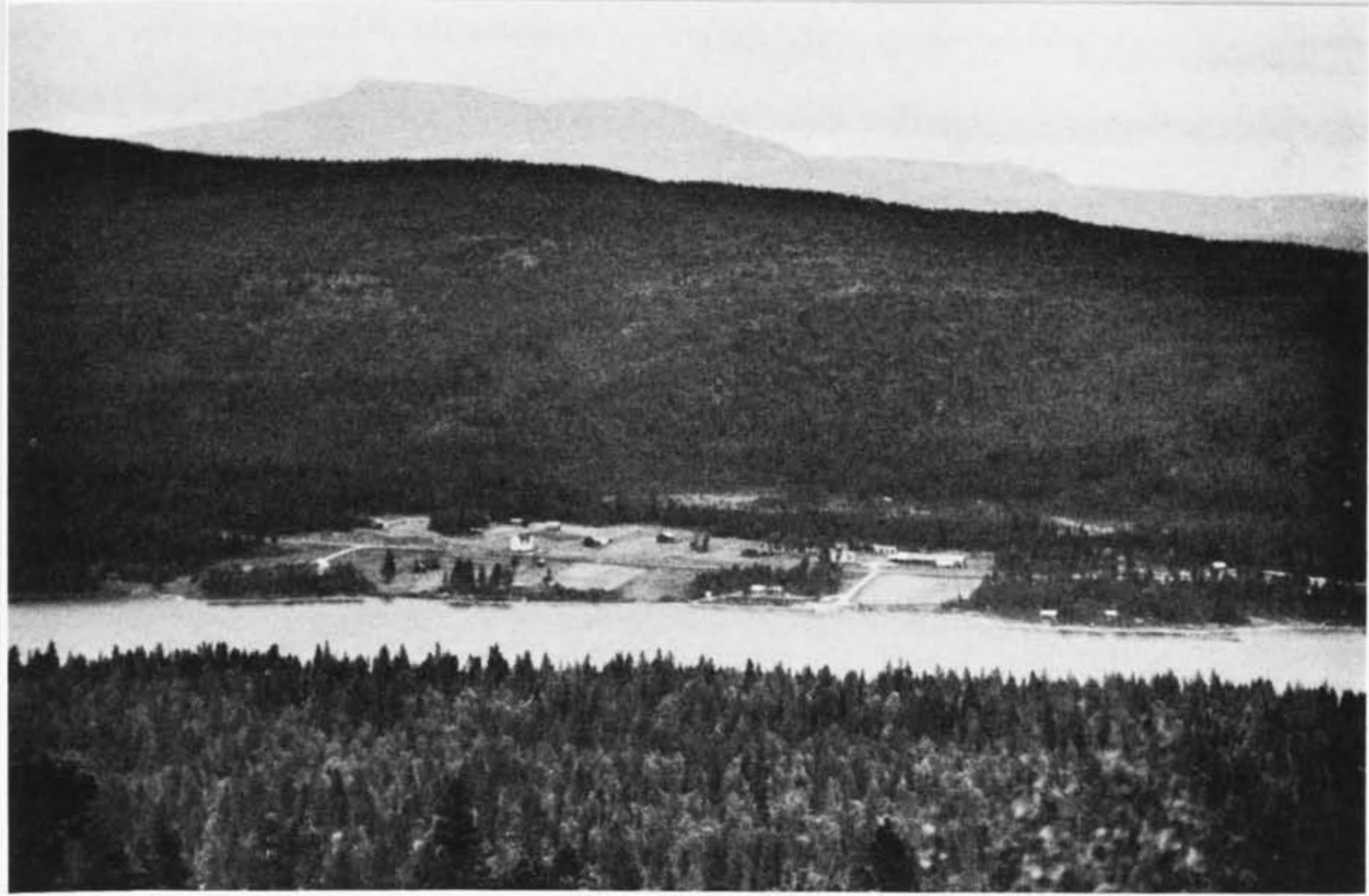

Fig. 4. Hällbacken seen towards Mt. Storberget, with Mt. Peljekaise (1122 m) in the distant background. Topographical conditions leading to the development of screes are present only in rather small sections of the mountain ridge immediately $\mathbf{N}$ of Hällbacken. Stations nos. 4 and 5 are situated below the depression between the two summits (the "ears") of Mt. Peljekaise (Lapp. "pelje" = "ear"). 19 August, 1965.

On poorly weathered slopes there are seldom to be seen any traces of fresh debris which has fallen down, at least rarely any coarse material. A single boulder or pebble will nevertheless break off now and then, taking with it some finer debris, which forms small spots of new soil on the scree. The fine scree is usually nearly stabilized and supports a full cover of vegetation where species sensitive to competition have few chances to colonize or settle. There is a correlation between the small effect of frost action and the scarcity of crevices and cracks in the rock wall. The water supply will then be sparse.

If the bedrock, on the other hand, is heterogeneous or if there are different rocks in the same slope, frost action will have a much greater effect and fall of debris will be frequent. Single boulders or pebbles break off successively at long intervals or more dramatic rock-falls occur. In the latter case the fine scree will be completely buried in patches, usually not very extensive, and the vegetation will have to re-colonize. During the colonization period the chances for immigrants to appear are quite good. An example of this type is Mt. Lulep Istjakk (no. 18) within the area of Archaean rocks. Here the traces of at least two large falls of debris can be seen. The same phenomenon can be observed on many slopes formed by metamorphic rocks in the area around the Caledonian border.

The largest fresh supply of material will occur on certain slopes formed by easily weathered allochthonous schists and phyllites. On these slopes there is a continuous breaking-off of schistose gravel from the rock wall. Boulders are also occasionally broken off, but there is a close connection between the physical character of the bedrock and the coarseness of the wasted material. Where there is seepage water, the material brought by the water is added (Rapp 1960 , p. 62).

Talus slopes with a copious supply of fresh material will never have a full cover of vegetation. Even if the wood communities of the upper wood on the talus slopes seem to be well stabilized, the shrubs do not cover the surface completely and there are large or small patches with open mineral soil. On pure schistose gravel true wood communities are hardly developed but small colonies or single individuals of 
Fig. 5. Telephotograph from the forested ridge $S$ of Hällbacken (taken from about the same place as Fig. 4). The valley of River Laisälven towards the W. The dome-shaped hill is Mt. Märkepakte $(538 \mathrm{~m})$. The very faint contour in the background is Mt. Tjäkt ja $(1085 \mathrm{~m})$. Mt. Svaipa $(1426 \mathrm{~m})$, a rounded mountain WNW of Mt. T jäktja was not observable because of haze. 19 August, 1965.

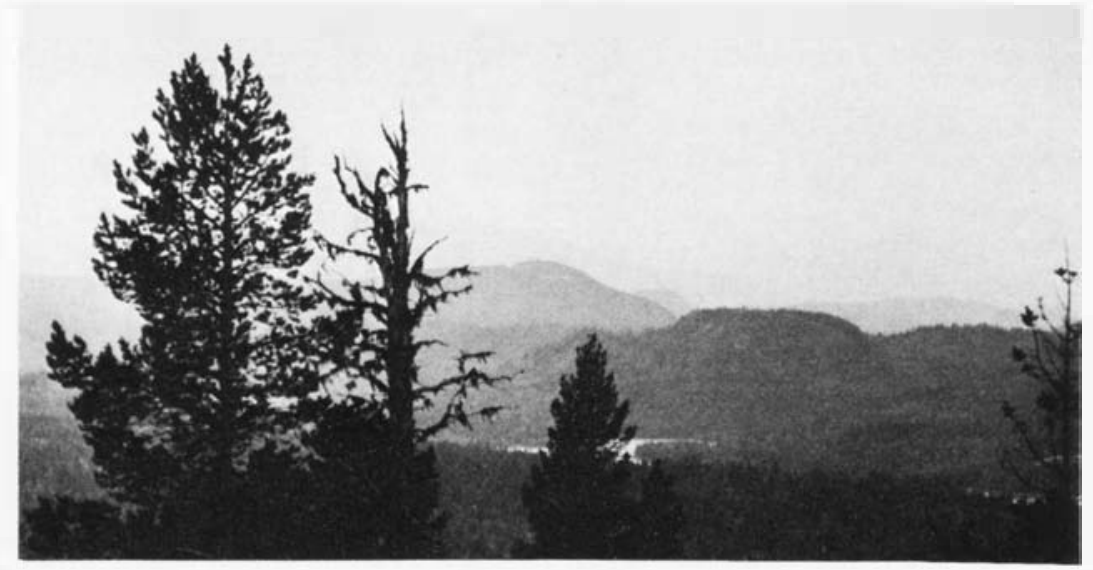

shrubs or trees occur. Because of the easily movable substrate there is almost no competition and very demanding plants are able to retain their positions. The best example of this is Mt. Svartberget (Lundqvist, J. 1961, p. 171) where Dryas octopetala, Salix reticulata and Saxifraga aizoides endure the conditions in lowlying habitats (ca. $430 \mathrm{~m}$ ). New colonization of annuals and other shortlived plants also demands a relatively open scree for their germinatio:1.

Plentiful occurrence of crevices in the rock are important not only to the frost action that supplies fresh material but also in creating paths for seepage water. Slopes of homogeneous bedrock are often poorly watered. This is particularly true of small hills but is also evident on the bigger ones. See further pp. 59 et seq.

In the following description of the topographical kinds of hills and mountains the word plateau is used only for the flat part of true plateau mountains. Their profile is different from that of the "blockmountains" characterizing an "undulating hilly country" (Rudberg 1954, p. 419). A cap is generally considered to consist of a geologically different kind of bedrock covering the summit area of a hill or mountain.

The names of the topographical units are adapted from Rapp (1960, 1961).

The cap (calotte) or plateau of the mountains will have a great influence on the vegetation lower down if it is large and shaped in such a way as to collect large quantities of precipitation (rain water or snow). Talus slopes that are formed on small mountains or near the peaks of big mountains mostly have insignificant recharge areas and receive a small supply of seepage water. Because of this the flora and vegetation is impoverished. Typical examples of this are the upper talus of Mt. Kebnevare (no. 6) and the talus of Mt. Kuottavare (no. 25). The surface of the plateau and the crack system of the underlying bedrock should not dip in a direction opposite to that of the talus slope. Some such factor causes the S-facing talus of Mt. E Ramanpakte (no. 2) to be fairly dry (see further pp. 107 et seq.).

The rock wall (mountain wall, cliff) is not always perpendicular over its whole exterit but many mountains have rock walls that have almost vertical sections. They are built up from vertical steps alternating with more or less broad shelves or ledges (terraces). Such is the case on Mt. Aistjakk (no. 16). In some mountains the rock wall tends to form rockfall chutes or funnels, overhangs, and caves. Caves are often formed in the lowermost part of the rock wall, especially where the layers are suitably directed, for instance on Mt. Kebnevare (no. 6), Mt. Laisvare (no. 9), and also on some short sections of the wall of Mt. Aistjakk (no. 16). In many mountains, e.g. Mt. Ailesvare (no. 22), the direction of the crevices is parallel to that of the surface of the rock wall, causing little action of the seepage water and less steep sloping of the rock wall.

There are great differences in the area in the microtopography of the rock wall. On certain mountains there is an almost crack-free rock wall with little or no vegetation on it (Mt. Akkapakte, no. 1). On others the cliff has many shelves different in exposure and water supply alternating with precipices, and is dissected by crevices from $0.5 \mathrm{~m}$ to only some millimetres broad. Some of the ledges on the rock wall cannot be reached by the investigator.

A geomorphological cycle leads to the "fossil stage" of a talus slope (cf. Rapp). The time needed for this process is highly dependent on the physiographic conditions, for instance the resistance of the rocks. The initial stages may lie as far back as the glacial epoch. However, post-glacial weathering has been relatively strong, because of the frequent freeze- 
and-thaw process in cool climates (Rapp 1961, p. 186). There are sectors where the screes have matured enough to be regarded as having reached the "fossil stage", being completely covered with trees and other vegetation. On more gently sloping mountainsides there is a cover of till, not scree. Such slopes do not provide such favourable conditions for herbs and certain mosses as the screes. They will be discussed only briefly in the sections about flora and vegetation.

A "talus slope (or scree slope) consists of rock débris which has fallen down more or less continuously from a weathering mountain wall (scarp) and formed an accumulation whose surface slopes about $30-40^{\circ}$ and has a straight or slightly curved lateral profile" (Rapp 1960, p. 4). The uniform retreat of the rock wall will produce a simple talus slope below a non-dissected mountain wall with a coarse scree in the distal (lower) parts and a fine scree (Swed. "finur") in the proximal parts just in front of the rock wall.

Swed. "finur" corresponds to the earlier given terms "lövängsur" (Sernander 1920, p. 112) and "ängsur" (Wistrand 1962 , p. 45). There might be also some finer debris in the coarse scree, especially at some depth in the profile, see below.

The finer fractions (clay, silt, sand, gravel, pebbles and cobbles) accumulate in this fine scree (also some single boulders: clay and silt are mainly secondary products of the weathering of coarser material). The particle size of the debris as well as the breadth and slope angle of the scree depends on the chemical and physical properties of the bedrock, the shape of the rock wall and the rate of accumulation (see Rapp). Because of this there are great variations in the mountains investigated. The breadth of the fine scree beneath the rock wall varies from nothing in some places on mountains of Archaean rocks (Mt. Kuottavare, no. 25) to several tens of metres.

The retreat of a dissected rock wall will produce rockfall chutes or funnels and below these talus cones (Rapp 1960, p. 5). This is frequent in the NW mountains where the bedrock is less hard and more variable. The upper mantle of the cones is frequently an easily movable substrate which nevertheless often supports quite a luxuriant vegetation (Fig. 43, p. 101). Such talus cones occur e.g. on Mt. Märkepakte, no. 12, Mt. Lulep Istjakk, no. 18. However, smoothly sloping screes formed from non-dissected but crackand ledge-rich rock walls (cf. above) are most frequent. Intermediate types are numerous.

There are no exact measurements of the depth of the talus in the area but in some mountains the talus slopes are very steep locally just below the rock wall. This indicates solid rock at little depth. For instance on Mt. Laisvare (no. $9 a$ ) there are even edges of solid rock protruding from the upper talus a little way down the talus slope (the so-called "Richter's slope"). Another example is the talus of Mt. Pellavardo (no. 17). The maximum depth in the central parts of the talus slope may amount to some tens of metres, as Rapp (1957, p. 197) reported values up to $35 \mathrm{~m}$ for similar slopes.

The most important features of the fine scree are not so much those related to its topography but rather those connected with the formation of the soil, details of which are discussed later (pp. 23 et seq.).

The most important features of the coarse scree (boulder talus) are its extent, its depth and the size of the boulders. The extent is very variable in different mountains. The talus of Mt. E Ramanpakte (no. 2) has a vertical height of up to $150 \mathrm{~m}$ between the distal and the proximal parts and heights of 70 to $100 \mathrm{~m}$ seem to be usual (Mt. Aistjakk, Mt. Lulep Istjakk etc.). On some mountain-sides there are no coarse screes (none or very little of the debris is of boulder size), e.g. On the upper slope of Mt. Kebnevare (no. 6) and Mt. Storberget (no. 13).

On the more extensive coarse screes, reaching the depths discussed above, there is almost no vegetation of vascular plants, at least on the central parts, but epilithic bryophytes and lichens are generally abundant. Trees are sparse on the coarse screes but there are local exceptions, e.g. on Mt. Aistjakk where there are occasional trees, although only of small size (ca. 5-7 m). On the lateral and lowermost parts of the screes there are larger forest trees. Small screes may also have almost no trees, however.

The climatic importance of a high well-exposed coarse scree is clear, because it creates good conditions with respect to radiation climate on the upper part of the slope. But the importance of that factor must not be exaggerated, for some screes with no coarse part can be just as rich in species of vascular plants as are the others. Only the plants requiring most warmth are likely to be excluded, by the shade from the adjacent forest.

The ground below the base of the talus, generally constituting the foot of the mountain, is distinct from the talus itself, topographically, but the ecological conditions there may be influenced by the proximity to the mountain, especially by its impact on the water supply and the chemical material carried in the water.

The chemical properties of the bedrock and the soil A scientific treatment of the chemical properties of the bedrock would be impossible without mineral analyses of the bedrock, and soil analyses. Such 
Fig. 6. Mt. Laisvare, the scree below the sandstone cliff. Where the cliff is overhanging the uppermost part of the scree is nearly horizontal with closely packed fine earth and only sparse vegetation. In the background Mt. Peljekaise. Photo: G. Wistrand, 6. July, 1938.

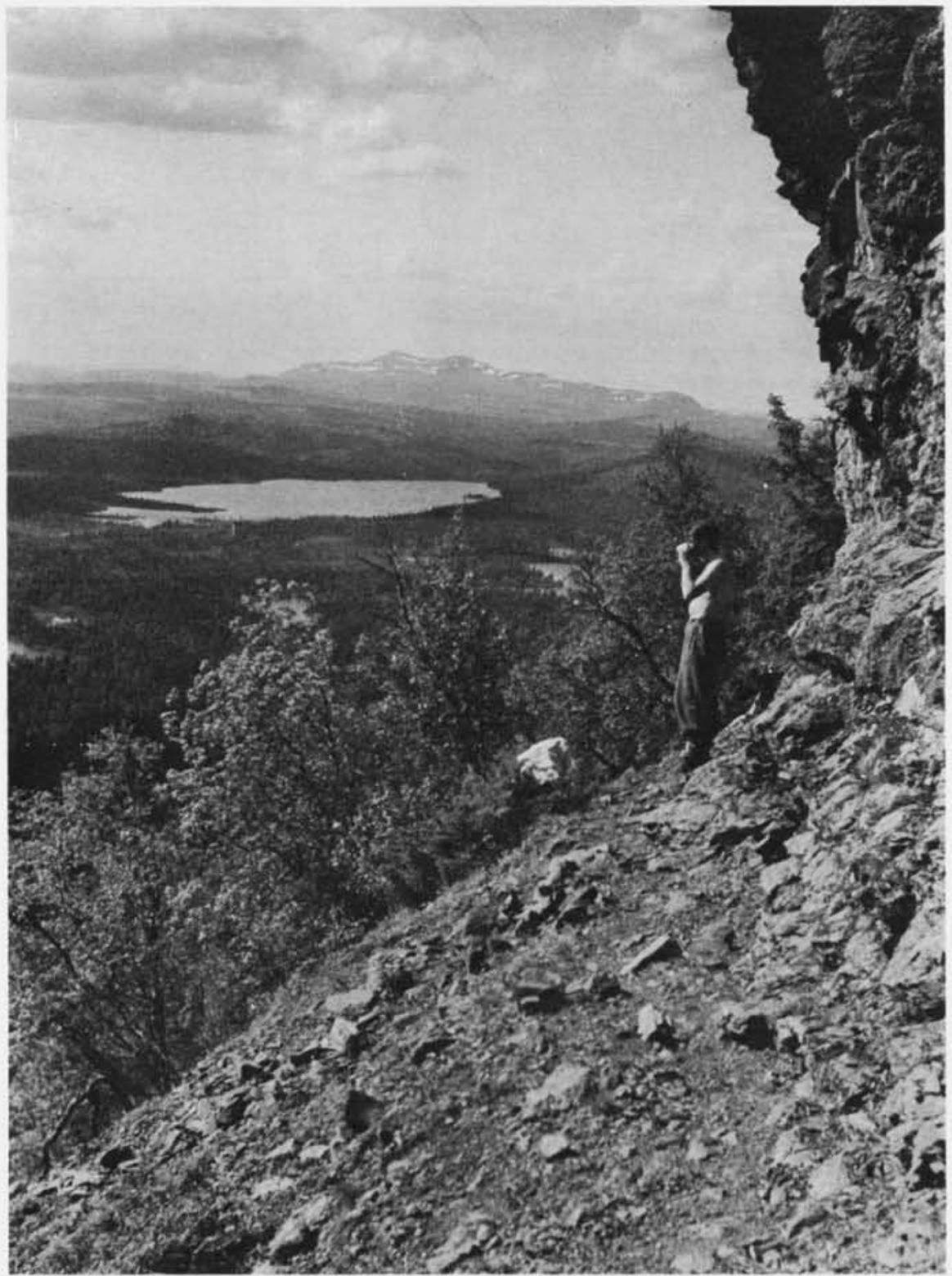

studies have been made especially in order to elucidate the long discussed problem of the calcium factor. Bedrock analyses were primarily made in connection with the determination of the ionic content of the seepage water.

The importance of the presence of calcareous rocks and soils to mountain plants in Scandinavia was clearly understood by Tengwall (1916) who emphasized (p. 34) that certain southern species in their mountain-side localities were calciphiles. Why they were distributed mainly on the S-facing sides of mountains was vaguely explained by the invariable presence of calcite on these sides. Halden (1950, pp. 535-549) even suggested the introduction of the term "calcareous slopes" (Swed. "kalkbrant") for these slopes. The unsuitability of this term was emphasized by Du Rietz (1954, p. 182) and by Wistrand (1962, p. 25). Laine (1965, p. 13) for N Finnish localities produced evidence that plants belonging to a contrasting group, northern species, are also distributed in a way to show that they are calcicolous, and even more so than the southern plants in the same area. $\mathrm{He}$ also stated that the S-facing sides of mountains support a southern group of plants that contains a 
somewhat lower percentage of calciphile plants (Finn. "kalkkiasuosivi", i.e. "basocline”, cf. Selander 1950 , p. 134) than does the northern group.

A comparison between different mountains within PL clearly shows that only mountains with some sort of supply of calcareous minerals can support a flora rich in species and a real meadow-dominated vegetation. However, the calcium content can be quite low. This is, for example, shown by Mt. Märkepakte (no. 12) where the calcium content in almost pure mineral soil may be as low as ca. $0.3 \%$ Ca (p. 99) and Mt. Vuornats (no. 19) where the bedrock consists almost exclusively of Archaean rocks with low content of calcareous minerals. Nevertheless the flora of the crevices of Mt. Vuornats is quite rich. Small occurrences of Tortella tortuosa and $T$. fragilis may indicate presence of calcareous minerals, and there are meadow fragments on the fine scree.

It is evident that the soil conditions on the fine scree and on the ledges of the rock wall are not only influenced by the mineralogical conditions at the surface, but also by the conditions deeper inside the rock wall. The seepage water passes layers of changing character and takes up mineral ions, transporting them to the surface of the cliff. In this way, slopes that are poor in lime and other easily soluble minerals at the surface get an addition derived from minerals that cannot be investigated. This will somewhat reduce the possibility of correlating the flora with the properties of the bedrock.

In the SE part of the area many talus slope localities show practically no traces of a lime effect. The forested ridges of this area are remarkably little influenced by the occurrences of basic Archaean rock within the Arvidsjaur area. Only on a few mountains, viz. Mt. Harrejaurliden (no. 28) and Mt. Gaddaberget (no. 31) is a certain effect of lime discernible but this is probably overshadowed by the favourable local climate on these mountain-sides.

The talus slopes on Archaean rock poor in calcareous minerals have a heathlike vegetation and between 25 and 35 species of vascular plants, mostly oligotrophic or not overdemanding eutrophic species. There is a small group of typical talus species, more or less alien to other habitats in the area. Although they seem to prefer the talus slopes to other habitats, they appear able to grow without lime. However, this group of talus plants hardly contains any truly southern (thermophilous) plant within a narrow delimitation (see p. 82). Nor are these species present on all talus slopes poor in lime. Some of them have large gaps in distribution. Sporadically, a few other talus species, among which one or two are southern plants, may grow even on these slopes lacking lime (or prob- ably containing traces of calcite). These species will be considered in the section on vegetation (see pp. 83 et seq.).

Since even talus slopes without traces of lime affecting the vegetation may support a specific flora which may include some southern species, the term "calcareous slope" as a generalized term for all mountain-sides with southern plants seems to be definitely unsuitable. It is also a misleading term in cases where the talus slope does contain some lime or other basic mineral.

W of the Cambro-Silurian border the lime content of the bedrock exposed in cliffs and screes everywhere seems to be sufficient for the needs of a calcicolous flora and vegetation. This seems to be true not only for the easily weathered autochthonous sediments, but for the hard and tenacious more or less metamorphic rocks as well. The limiting factors are here of other kinds, primarily the supply of water.

The important minerals of the area and their effect on the soil conditions and the plants will be described briefly.

Quartz (density 2.65) is of great importance in Swedish bedrock types, especially in the Archaean rock, making up the greater part of the bedrock on the SE mountains of PL (up to ca. $40 \%$ ). Usually it weathers to sand but may also form finer particles.

Feldspars (densities of the calcium-poor feldspars 2.552.65). These minerals always contain silica and aluminium, and also potassium, sodium or calcium, in most cases two of these metals. There are three main groups of feldspars, $\mathrm{K}, \mathrm{Na}$ and $\mathrm{Ca}$ feldspars.

$\mathrm{K}$ feldspars (orthoclase and microcline) usually contain some $\mathrm{Na}$ in solid solution. The most Na-rich phase is called anorthoclase. $\mathrm{K}$ feldspars are abundant all over the area, making up $30 \%$ or more of certain bedrocks. Being resistant to weathering, its importance to plants as a source of potassium ions is moderate, especially when the mineral soil contains few fine-grained particles.

$\mathrm{Na}$ feldspar (albite, = Ab) forms a continuous solid-solution series with calcium-rich feldspar (anorthite), the intermediate phases being oligoclase, andesine, labradorite, bytownite. This series is collectively called plagioclase. The most important plagioclase is oligoclase, which is quite poor in $\mathrm{Ca}\left(\mathrm{Ab}_{\Omega 0}-\right.$ $\left.A b_{\tilde{\tau} 0}\right)$. It makes up ca. $20 \%$ by weight of normal N Swedish forest soils (Tamm 1941, p. 53). Because of its relatively poor weathering, its content of $\mathrm{Ca}$ may not be much available to the plants and the soil remains poor in $\mathrm{Ca}$ ions if no other minerals rich in $\mathrm{Ca}$ are present.

Ca feldspar (anorthite; density 2.76) is a plagioclase feldspar low in albite $\left(A b_{10}-A b_{0}\right)$. The Ca-rich plagioclase is less common than the other feldspars in the bedrock or soil. In rocks belonging to the so-called greenstones it is more abundant. It weathers quite easily and is an important source of $\mathrm{Ca}$ ions to the soils and plants.

Mica minerals (density $>2.71$ ) are a large group of soft cleavable minerals. Usually on weathering they disintegrate into very fine particles. They make up an important part of sedimentary rocks, especially those originating from clay. Be- 
cause of this they are more abundant in the NW, where the bedrock mostly consists of metamorphic sedimentary rock.

The mica minerals are bright mica (aluminous mica, e.g. muscovite) and dark mica (Fe-Mg mica =biotite). Both are phyllosilicates of $\mathrm{Al}$ and $\mathrm{K}$. The most abundant mica is biotite which is easily weathered. In the soil this mineral will give a large supply of soluble $\mathrm{K}$, in contrast to the feldspars.

Chlorite is a phyllosilicate related to biotite but chlorite containing no potassium. It seems to be quite important in most of the bedrocks of the area.

Amphibole (widely represented in the hornblende series) and pyroxene are two closely related $\mathrm{Fe}-\mathrm{Mg}$-silicate groups of minerals of a dark, somewhat greenish or brownish or nearly black colour and of medium hardness. Augite is the most important pyroxene mineral. They seem to be quite rare in an unweathered state in the soils. Together with biotite they constitute the dark grains in gneisses and igneous rocks. The presence of these minerals in significant amounts (producing a high base mineral index) has a definitely favourable effect on the soil conditions. The extent of weathering of hornblende is a measure of the intensity and time of weathering of soils in cool, humid regions (Bear 1964, p. 84).

Other silicate minerals are garnet, epidote, olivine, serpentine (most of which have densities $>3.00$, serpentine, 2.57, being an exception). They are mostly present in very small quantities but are nevertheless important as a source of the minor elements of the soil beside certain ore minerals. These elements include copper, manganese, zinc, boron, molybdenum, etc., several of which are required by the plants.

Apatite is a calcium phosphate present in most bedrocks and easily weathered (density 3.00). As the main source of $P$ it is very important to the vegetation, playing a major part in the phosphate cycle (Bear 1964, p. 381) in soils.

Ca carbonate (calcite; density 2.72) is an important constituent wherever it is present, as it is in some of the mountains described. $\mathrm{Ca}$ ions are not only a plant nutrient but make the $\mathrm{pH}$ of the soil favourable in other respects, in particular for $\mathbf{N}$ nutrition. Only very small quantities of the easily weathered calcite $(\leqslant 1 \%)$ will support a luxuriant vegetation where the amount of water is suitable.

Methods. The mineral composition of the bedrock was estimated at the Institute of Mineralogy and Petrology, Uppsala, by point-counting under the polarizing microscope 200 to 500 points in thin-sections. The use of 200 points is naturally not so accurate as the use of 500 or 1000 points, but still provides a good estimate of the amount of main minerals given as volume percentages of the bedrock. Another way of estimating the content of heavy minerals (in disintegrated rocks) is to calculate Tamm's base mineral index, obtained by weighing the fraction sinking in a dense fluid (density $=2.680$; Tamm, O. 1934, pp. 231 et seq.). Such analyses were made on the fine sand fraction of soil samples from the fine debris scree, as a part of the soil analyses (see further p. 27).

A summary of the geology has been given pp. 9-10. Only a few mountains are dealt with below. See also the descriptions of the mountains (pp. 107 et seq.).
Mt. Akkapakte (no. 1). Banded tectonites of sedimentary origin together with cataclastic acid archean igneous rocks generally make up the large overthrust nappes of the northernmost district, forming the "raman" type of mountain, i.e. an elevated plateau abruptly terminated towards the E (SE), where a high perpendicular cliff is formed, along the "glint" line (Svenonius, F. 1894, pp. 2, 3). On Mt. Akkapakte, as well as on Mt. Ramanpakte (nos. 2 and 3), mylonitized gneisses in part pass into mylonite-mica schists. Since they are hard-weathered and quite acid, they do not provide any favourable substrate for the vegetation. Mt. Akkapakte has a particularly infertile look (p. 108).

The bedrock sample, consisting of mylonite mica schist, shows that the rock may originally have contained a great deal of biotite and/or hornblende which was destroyed during the metamorphism. The mineral content is rather difficult to determine in such types of rocks, but the percentages by volume are approximately $20-25 \%$ of phyllosilicates (muscovite and chlorite) with intergrown titanite, 20-25\% of quartz, and the rest plagioclase and microcline. Accessory minerals are apatite, garnet, ores, tourmaline and epidote. The anorthite content in the plagioclase was presumably not above $10 \%$. Cf. analyses of water and soil on the same spot, Tables 1 and 14 .

Mt. Laisvare (no. 9, water sample no. 3, cf. water sample no. 4, Table 14). The bedrock has been briefly described (p. 10). Above a peneplaned Pre-Cambrian surface (here plunging with a dip of about $\mathbf{1}^{\circ}$ under the Caledonian border) of deeply weathered Archaean basement rocks there are arkoses, mudstone-like shales, and conglomerates. The "Lower Laisberg Sandstone" following above these series is an "evengrained, mostly white or grey-white, slightly feldspar-bearing sandstone with small bands of shale" (Grip 1960, p. 151). The average composition of the lead ore in the mine at Laisvall is the following (cf. Grip):

$\begin{array}{llllllll} & \% & & \% & & \% & & \% \\ \mathrm{SiO}_{2} & 89.6 & \mathrm{Na}_{2} \mathrm{O} & 0.05 & \mathrm{~F} & 0.1 & \mathrm{Cd} & 0.02 \\ \mathrm{Al}_{2} \mathrm{O}_{3} & 1.3 & \mathrm{~K}_{2} \mathrm{O} & 0.9 & \mathrm{~Pb} & 4.1 & \mathrm{Co} & 0.006 \\ \mathrm{MgO} & 0.2 & \mathrm{BaO} & 1.2 & \mathrm{Fe} & 0.5 & \mathrm{Ni} & 0.003 \\ \mathrm{CaO} & 0.3 & \mathrm{CO}_{2} & 0.1 & \mathrm{Zn} & 0.03 & \mathrm{~S} & 1.1\end{array}$

Accessory trace elements are $\mathrm{Cu}, \mathrm{Bi}, \mathrm{Sb}, \mathrm{Ag}, \mathrm{Au}$, $\mathrm{Hg}, \mathrm{Ge}, \mathrm{As}$ and $\mathrm{Se}$.

The average lead content at the site of the water sample in the mine is $2.5 \%$. The thickness of the overlying sandstone is $20.0 \mathrm{~m}$. The thickness of the Cambrian shale following above the sandstone is 7.0 $\mathrm{m}$ at this locality. Far-transported nappes of the Kaskajaure and Yraf complexes (Kautsky 1940, p. 121) 
and sericite-chlorite schist $(>40 \mathrm{~m})$ follow above the autochthonous series.

On Mt. Laisvare, as well as on the other hills along the SE border of the Caledonides, the stratigraphy is largely the same as in the mine (cf. p. 62). Here the sandstone is very bright and without any observable traces of ore minerals. The overlying rocks are even thicker (ca. $130 \mathrm{~m}$ to the summit of the mountain).

Mt. Märkepakte (no. 12). The geology is characterized by a southern facies of the Kaskajaure-complex (Kautsky 1940, p. 128). This is a geologically interesting sparagmitic series of Pre-Cambrian or SubCambrian age, which in the region concerned is inverted above the autochthonous series. In the area around Mt. Märkepakte this series, which could be followed as terrestrial sediments far from the $S$ in the Caledonides, partly vanishes and shows a more marine character towards the $\mathrm{N}$. On Mt. Korpberget (no. 11), $7 \mathrm{~km} \mathrm{NW}$ of Mt. Märkepakte, there is a predominance of quartzites and shales with calcite in series of definite marine character. Together with the sparagmite there often occur mylonitized primary rocks of syenitic or granitic origin constituting parts of the same nappe. On Mt. Märkepakte the predominating rock is syenite-mylonite, but green sparagmites are also seen.

The samples were taken in syenite-mylonite. They showed very intimate intergrowths (microperthite) of sodic plagioclase and potassic feldspar crystals. Separate crystals of plagioclase and microcline also occur. The refraction of the perthite is low, because of the low anorthite content of the plagioclase component (not above 10\% An). There are disseminations of iron oxyhydrates, chlorite, and calcite. The chlorite seems to be a transformation product of mafic minerals (hornblende?) and often occupies fissures. The approximate mineral contents are: microperthite $70 \%$, plagioclase and microcline $5 \%$, ores and chlorite 5\%; accessories are biotite, quartz, titanite, apatite, sericite, epidote and calcite (the calcite may locally amount to $2-4 \%$ ). Cf. water sample no. 5 , Table 14, and soil analyses, Table $2 \mathrm{~A}$.

Mt. Lulep Istjakk (no. 18). The geology is mainly characterized by the presence of sediments of the Skärfa-series (p. 10) and the conditions prevailing at the outer limits of these near the contact with the Arvidsjaur and Arjeplog granites (Grip 1946, p. 19). The sediments are in places dominated by conglomerates and calcareous quartzites, feldspathic quartzites being less important. The granites are mainly aplitic and pegmatitic, making up the greater parts of the rock wall. There are veins of pure quartz as well as of pure calcite.
The conditions described here refer to the place of the belt transect (p. 99, cf. Figs. 41 and 42). In this place the lower part of the rock wall consists of pegmatite and aplite (mineral contents see below). The large amount of conglomerates in the talus at some distance from the cliff is presumably caused by a greater abundance of Archaean sediments at a greater height. This is illustrated by a count of the larger pebbles taken at the surface of square no. 18 , $21.5 \mathrm{~m}$ from the rock wall:

1. Conglomerates of different kinds
2. Pegmatite
3. Calcareous quartzites
4. Granite, aplitic, fine-grained
5. Feldspathic quartzite

$\mathrm{Kg}$

3.55

1.68

0.63

0.22

0.10

6.18

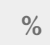

The pegmatitic granite (partly aplite) in which the water sample was taken (Table 14) has the following mineral content: quartz $33 \%$, microcline $33.5 \%$, plagioclase $27 \%$, chlorite $2.5 \%$, muscovite (to a large extent recrystallized sericite) $2.5 \%$, ores $1.0 \%$. Accessories, $<0.5 \%$ : apatite, titanite, zircon, epidote and biotite. Allanite and fluorite are of more rare occurrence. The anorthite content of the plagioclase varies in different samples between 7 and 22\% An.

Mt. Dalktjapakte (no. 21). The cap of the mountain is mainly acid porphyry and because of this the talus slope also mostly contains this reddish rock, which is quite unfavourable for the vegetation. The area around the mountain is covered by Sorsele granite, a granite resembling the Arjeplog granite (Ödman 1957; supplementary map 1958). Associated with the Sorsele granites there occur "acid porphyries with dense or fine-grained matrix containing phenocrysts of quartz and/or alkali feldspars" (Ödman 1957, p. 143).

The sample contained quartz- and microclineperthite phenocrysts. Accumulations of chlorite are probably alteration products of unstable femic minerals (biotite or hornblende?) of early crystallization. The ore grains are partly secondary after biotite. Mineral content: quartz $34.5 \%$, plagioclase $29.5 \%$, microcline $31 \%$, ores $2.5 \%$, chlorite and biotite $2.0 \%$, apatite and titanite $0.5 \%$. The anorthite content in the plagioclase is $10 \pm 2 \%$.

Mt. Måfevare (no. 23). This mountain is only 8 $\mathrm{km} \mathrm{E}$ of Mt. Lulep Istjakk. The rock is Arvidsjaur granite, strongly migmatized in later times. According to Grip (1946, p. 13) the content of some important chemical constituents is the following: $\mathrm{SiO}_{2}$ $74 \%, \mathrm{Al}_{2} \mathrm{O}_{3} 13 \%, \mathrm{Fe}_{2} \mathrm{O}_{3}$ and $\mathrm{FeO} 2.5 \%, \mathrm{MgO} 0.35 \%$, $\mathrm{CaO} 1.2 \%, \mathrm{Na}_{2} \mathrm{O} 3.4 \%, \mathrm{~K}_{2} \mathrm{O} 4.4 \%$. Trace elements 


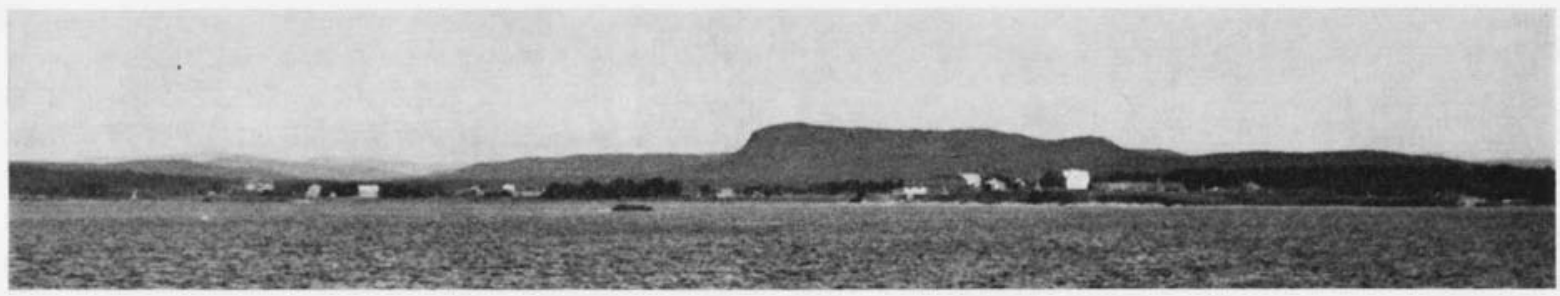

Fig. 7. Mt. Aistjakk, towards the NW, with the village of Båtsjaur in front of it. The steep SW-facing slope and the more gently sloping NE-facing side are conspicuous. 14 August, 1965.

are $\mathrm{Ti}, \mathrm{S}, \mathrm{Ba}, \mathrm{Mn}, \mathrm{P}, \mathrm{Cl}, \mathrm{F}$ and $\mathrm{Sr}$. $\mathrm{Ca}$ is obviously mainly feldspathic as the influence on water and soil ion content is very insignificant. Cf. the description of Mt. Stärpatsvare and Mt. Gaddaberget below and water sample no. 7, Table 14.

Mt. E Stärpatsvare (no. 26). The dominant rock is Arvidsjaur granite but in the cap of the mountain there are also garnet gneiss and feldspathic gneisses which have originally been sediments. These sediments are closely associated with the volcanic rocks of the area and are considered to have been deposited by water in restricted basins, in contrast to the Skärfa-series of Mt. Lulep Istjakk which was deposited in larger basins. There are also dikes of amphibolitized greenstones of diabase type which have a very restricted occurrence. A recrystallized and transformed garnet gneiss was the substrate of the only specimen of Poa glauca seen on the S-facing side. All three rocks were analyzed to find out their mineralogical composition:

1. Granite: quartz $33 \%$, microcline $31 \%$, plagioclase $34.5 \%$ (anorthite contents ca. 10\%), epidote, chlorite and ores $1.5 \%$, accessory titanite, zircon and allanite.

2. Amphibolite: amphibole $36.5 \%$, plagioclase incl. sericite $37.5 \%$ (anorthite contents ca. $20-25 \%$, sericite ca. $5 \%$, biotite $21 \%$, titanite $3.5 \%$, apatite, epidote and chlorite $1.5 \%$.

3. Garnet gneiss: quartz $36.5 \%$, microcline $2.8 \%$, plagioclase $55.5 \%$ (anorthite contents ca. 10-15\%), chlorite $1.0 \%$, epidote $1.0 \%$, biotite $0.3 \%$, ores $2.1 \%$, allanite $0.2 \%$, zircon $0.1 \%$, titanite $0.4 \%$, garnet $0.1 \%$, traces of apatite. The garnet has to a great extent been transformed to epidote, chlorite and ore minerals.

Cf. soil analyses 34-35, Table 1 .

Mt. Harrejaurliden (no. 28). The mountain is situated in the contact zone between Arvidsjaur granite in the NE and liparite and andesite in the SW. The granite has influenced on the porphyry series. Epidotization and sulphatization are common (Grip, personal communication). Bedded tuffs are intercalated in the lavas. The two most common rocks in the rock wall seemed to be liparite (quartz porphyry) and associated tuff. The mineral content was not determined.

Mt. Gaddaberget (no. 31). The geological setting is characterized by the predominance of Arvidsjaur granite, in which occur veins similar to those of Mt. Stärpatsvare (see above). The only extensive amphibolite vein is seen in the Gully (p. 25 and p. 127). The mineral contents of the granite were:

Quartz 29.6\%, plagioclase $29.5 \%$, microcline 31.8 $\%$, both in perthitic intergrowth (the anorthite content of the plagioclase was only ca. $5 \%$ ), biotite $4.7 \%$, chlorite $1.7 \%$, ores $0.7 \%$, epidote $0.2 \%$, zircon $0.3 \%$, fluorite $0.7 \%$, titanite $0.2 \%$, apatite $0.1 \%$, sericite $0.4 \%$.

The soil catena (Milne 1935, p. 193) is the typical sequence of soil types in valleys of moderate topography, from the watershed down to the valiey floor. This concept was initially introduced to make soil mapping easier, as there are obviously nearly identical soil types in corresponding sites within an area provided the kind of parent material is the same. Thus the influence of valley topography on soil formation has long been understood. In Sweden, research has been carried out on the interrelations between the forest types and the soil characteristics of slopes (Troedsson 1955) including the hydrology and the chemical properties of the water.

On the mountain plateau erosion is slow, percolation is vertical, and the leaching processes lead to the formation of podsol soils, hardpans etc. On the slope, on the other hand, percolation is largely lateral and the water may be successively enriched in nutrients. At a certain angle of inclination, depending on soil type and amount of precipitation (in arctic-alpine areas also on permafrost), erosion is augmented by transport of mineral grains by the water, by local land slides and (in winter) by avalanches. Frequently these conditions create extrazonal types of brown earths, especially under canopies of broad-leaved trees (Tamm, O. 1930, 1931). The nearly vertical 
bare cliffs are extreme examples of very steep topography.

The substrate for the vegetation of screes is formed through weathering of parent material derived from the debris from the rock wall (cf. above). To this substrate is added annually a fresh supply of litter, quite abundant in sites overgrown with tall herbs and trees, and frequently sufficient to cover any newly fallen debris, up to the size of boulders. There are all types of intermediates between covering mats of vegetation and entirely bare scree.

Following the supply of fresh material and the weathering of the rock debris come profile development ard transport of material. By profile development is meant the vertical movement of matter, including the decomposition and turnover of litter and humus. Through the mineralization of humus, nitrogen, phosphorus and sulphur become available to plants. Chenical weathering, including hydration and oxidation, as well as physical and biological weathering eventually will produce a quantity of fine particles and agglomerations in the soil. The transport of material, by which is understood the movement of material down the talus slope, is in stabilized screes primarily a result of water movement. By this process the finest particles are moved unless they are already part of a fixed structure pattern of the soil. In unstabilized screes, transport takes place at intervals, as slides or creep. Finally there may be removal of material from the base of a talus slope, e.g. by river erosion.

The scree soils are favourable substrates for the vegetation and flora as they are renewed successively hy fresh material from the rock wall. Leaching processes are obstructed, processes that are otherwise characteristic of most $\mathrm{N}$ Swedish forest soils on stable ground which is not steeply sloping. The amount and rate of supply of fresh material must therefore be a factor of fundamental importance. Great variations occur in this respect within the area, largely because of the physical and chemical composition of the bedrock, and the topography of both rock wall and scree (see above).

According to Jenny-Lips (1930, p. 129) three major layers may often be recognized in screes as a result of profile development. These are "upper stone-air-layer" (Germ. "obere Steinluftschicht”), "fine-earth-layer" (Germ. "Feinerdeschicht") and "lower stone-air-layer" (Germ. "untere Steinluftschicht"). The uppermost layer has been depleted of fine particles by the action of the water. No fine roots are able to develop in this layer, especially if it is easily movable. Instead it is penetrated only by plants with root systems adapted for such substrates, or by stem-bases, runners etc. According to JennyLips (see also Weaver 1919) it is quite important in protecting the soil from desiccation. In this way it enables the plants to endure even fairly long periods of drought (cf. pp. 46 and 49).

The fine earth layer is the plant root zone. Although there may be frequent open spaces, the plants find a rich supply of nutrients in it. In the lower talus slopes where the houlders are large it may be found at depths of $50 \mathrm{~cm}$ and more (Mt. Aistjakk, no. $16 a$ ). Therefore, if there are any higher plants at all here they consist of trees and shrubs.

The lowermost layer of the scree soil is again very poor in fine earth (according to Jenny-Lips; no investigations of this were made in $P L$ ) and thus it would not be expected to be of any great importance as a substrate for plants.

As pointed out by Jenny-Lips (1930, p. 130) an enrichment in organic matter occurs at the top of the profile where there is a prolific growth of plants. Thus on the proximal parts of the talus slopes described here, immediately below the rock wall, the upper stone-air-layer is often replaced or partially replaced by a stone-litter-air-layer (cf. Lundqvist, J. 1961 , p. 169). The depth of this layer is variable depending on the weathering and decomposition rates of the materials. If the turnover rate is low, as is the case when the rocks are poorly weathered or when the exposure is unfavourable, the depth of this layer may be considerable provided the litter supply is good. As there are small fragments of finer debris, a type of humus layer resembling mull may be developed, especially on top of the boulders and cobbles, where the plants have quite good nutrition. The development of cushions of mosses or vascular plants on fine screes is not very pronounced.

Investigations on the soils have primarily been made to elucidate the difference between the SE Archaean area and the NW Caledonides in respect of the soil character under the main plant communities. The soil differences between the upper wood just below the cliff and the transition down on to the open scres were also studied in this respect. Where interesting thermophiles have been observed in other ecosystems than insolated hillsides, the soil conditions of the habitats have also been studied.

In all, 82 samples of soil (including some samples of more or less unhumified litter) were taken. Seven of these samples were taken outside PL, viz. 3 samples from the talus of Sikilsdalen, S Norway, the flora and vegetation of which were investigated by Nordhagen (1943, pp. 542 et seq.) and the present author (see p. 96), and 4 samples from the S-facing talus on Mt. Peruken, Lycksele Lappmark, 14 km 
SW of the S border of PL (the situation of the hill was marked on the map Fig. 2; unnamed on the topographical map). These four were mainly taken to illustrate a phenomenon found only rarely in similar sites in PL, viz. the development of forest mull types of soils instead of ordinary mull types on unstable scree soils quite high in calcium (Table 1, samples nos. 51-54). Such types of soils are practically never seen on insolated fine-grained screes on CambroSilurian bedrock in PL.

The soil analyses were summarized in Tables 1-2, the last one of which shows the conditions of belt transects pp. 98 et seq.

The humus types studied are mainly "mild humus" types developing under meadow vegetation. In such sites there is a fairly abundant supply of litter to the soil. The decomposition rate of the litter differs to a large extent depending on its origin. In places where slowly decomposing aspen leaves (cf. Julin 1948 , p. 37) are heaped as the main constituent of the litter, and also in other places under highly productive stands (belt transect, p. 99), the organic component of the top-soil is extremely high (ca. $85 \%$ loss on ignition), whereas in other places even the top-soil is nearly pure mineral soil. An equilibrium will be reached, depending primarily on the kinds of minerals in the soil, the grain-size, the aeration, the climate, the supply of litter and the contents of living organisms in the soil (cf. Stålfelt 1960, p. 144). For the development of "mild humus" a certain content of basic minerals is necessary even in these climatologically favoured sites. Although there is some delivery of new mineral to the soil (p. 16) edaphically very unfavourable conditions are met with if the exposure is unfavourable, for example on the NEfacing side of Mt. Aistjakk (samples 24-27). As a rule, basic and oxygen-rich water is present in these places, a favourable factor that will in a way compensate for the lower temperature and the lower phosphate and calcium content of the humus.

Besides differences in clay content and humus percentage, the activity of earthworms, snails etc. is of primary importance for the development of various types of crumb structure in typical mull soils (see e.g., Sjörs 1961, p. 9). Fairly well developed crumb structures are often observed even in the soils dealt with here, despite the high latitude, but the general types of humus layer in these rather cool climates, including those developed in thermally favoured sites, tend to less well-developed crumb structure even in mild humus. The deciding factor may be the predominance of smaller animals and a rather slow rate of decomposition, and slow chemical and physical processes interrelated with the humifying process. Other

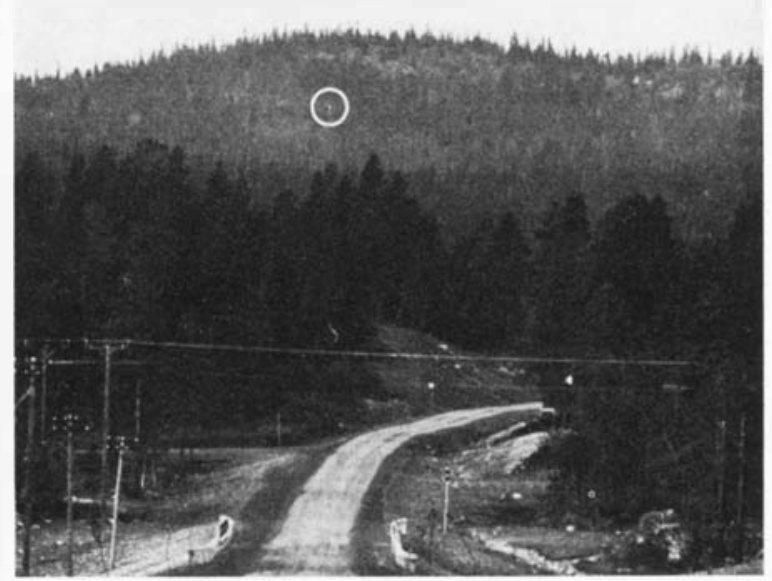

Fig. 8. The NE-facing slope of Mt. Aistjakk. Station no. 8 denoted with an open circle. Photo Sören Dahlberg. September, 1967.

typical characteristics of the mull are a rather smeary consistency when wetted, a dark, sometimes almost black colour and a reasonably well developed microstructure. The chemical properties also fall very well within the range of Swedish mull types developed in natural sites. However, other types of soils may develop, especially on more acid Archaean rocks, and in unfavourable exposure.

On Archaean rocks where the delivery of finegrained material is slow and the scree thus more or less stabilized the vegetation is dominated by coniferous trees and forest heath. Where the content of basic minerals in the soil is low or the exposure unfavourable, nitrification seems to be slow or absent. In places there may even be a raw humus layer resembling the one developed on ordinary till-covered ground (the raw humus layer is also called mor). A mycorrhiza-layer may also develop on top of quite poor forest mull types. Such types of mull develop under vegetation of very low productivity. There is no intimate association between the organic and mineral fractions and fungal hyphae (mycorrhiza) occur in abundance, while small animals and microorganisms other than hyphae are seemingly of less importance. In the forest mull types studied on Mt. Gaddaberget (samples nos. 39-41) there was a mycorrhiza-rich carpet on top of the soil profile, and the almost pure mineral soil below it showed different degrees of accumulation of ferric oxides, a process deve'oping in the $\mathrm{B}$ horizon of podsol soils. Typical mull profiles were seen only in the Gully (ca. $5 \mathrm{~m}$ broad and $20 \mathrm{~m}$ deep niche in the rock wall with ordinary scree on bottom; see p. 29, samples nos. 42-44, Table 1). This is practically the only 
place in the S-facing scree below the cliff where there is a rich assemblage of tall herbs giving a highly productive stand. The delivery of new material to screes on Archaean rock is often very slow, coniferous forest trees invade and produce acid litter, and frequently the undergrowth will be typical of heath forest with sparse herbs intermingled. The conditions thus prevail for creating raw humus with a lowhumified fermentation layer, even though the exposure may be near S. Only fairly undemanding plants are able to colonize, and meadow plants disappear from the extreme sites.

In PL broad-leaved trees are practically the only constituents of the upper wood below the cliff on Cambro-Silurian bedrock. The field layer is made up of herbs, only occasionally with some Vaccinium dwarf shrubs or Arctostaphylos uva-ursi (these lastmentioned shrubs may be present partly because of the conditions during thaw, p. 92). In no case on S-facing scree was there seen any definite forest mull type of soil resembling the one just described from the area of Archaean rocks. A reasonably good example of development in a case with coniferous trees on Cambro-Silurian scree was seen on Mt. Peruken (cf. above), where there were some spruces below the rock wall on the fine scree. The soil profile down to the "lower stone-air-layer" (p. 24) at $60 \mathrm{~cm}$ depth seems to have evolved from a fairly well developed mull soil to the present condition with piling up of low-humified mycorrhiza-rich litter and destruction of the original profile. Herbs which were growing in the immediate neighbourhood were totally absent from the less favourable acid substrate close to the spruces. Because of a fairly high content of clay in almost humus-free mineral soil below the mull layer, the chemical results are probably somewhat too high expressed on the ignition loss basis. This type of soil, here designated "forest mull", evidently also develops when there is some ion-rich seepage water from the cliff $(\mathrm{pH}=7.6)$ and the effect of soluble minerals is great. See further soil samples nos. 51-54, Table 1.

With regard to the vertical distribution of nutrients in the soils, it seems that total contents of P, K and $\mathrm{Ca}$ usually decrease towards the surface while ALsoluble extractives increase. The tendency is not universal, at least not for soils on Archaean rocks. The difference between total contents and AL-soluble extractives varies greatly according to growing increment and biological activity in the soil (see below). A possible difficulty with calcareous soils which might exist in a few cases is that carbonate is dissolved from the mineral fraction of the soil, a fraction generally containing non-exhangeable calcium ions. As a rule calcium shows a marked increase with depth and towards the edges of stands of tall plants (Fig. 9). The latter increase is probably because of the higher evapo-transpiration and less leaching. The importance of leaching may be illustrated by the example of a belt transect on Mt. Lulep Istjakk (Table 2) where the lowest content of $\mathrm{Ca}$ occurs in the centre of the tall community where, as one might expect, the soil may be moistened by sprinkling of rain water from the rock wall (shown by the remarkab!e high content of water in the soil, point $c$ ). The extremely high content of $\mathrm{Ca}$ in front of the rock wall, on the other hand, seems to be partly due to the supply of ion-rich water from the cliff.

The great depths at which humus is found on screes is surprising, but it should be emphasized that these types of mull are always low in combustible matter (ca. 4-10\%) and in their structure and lighter colour they represent transition forms to the mineral soil probably existing below the mull layer. In some fine screes with rapid delivery and turnover rate there might even be no humus-free mineral soil in the fine-earth layer.

Methods. To provide data suitable for comparison (Sjörs 1961, p. 5) the values should be computed per unit of humus content. Ignition loss should therefore be determined. The mineral grains present in the humus layer are thus regarded as a comparatively inactive addition to the humus colloids. However, inorganic colloids may also act as ion exchangers, and in addition there is the possibility of certain minerals dissolving. Exchange capacity of clay minerals and humus in different soils may vary. The data available for natural soils should at least be comparable and as far as possible be determined by the same analytical methods. Unfortunately, in the present case, only commercial methods were carried out in the laboratory (by Statens Lantbrukskemiska Laboratorium) and dried samples were used. A difficulty arising when sampling is to achieve representative samples for the various communities. This was to a certain extent overcome by sampling in several places of similar habitat (e.g. along belt transects) and by taking several subsamples at the same level around a sampling pit and mixing them. As digging in bouldery scree presents problems, only a smaller number of sampling places could be chosen, and the investigated depth was not usually more than $50 \mathrm{~cm}$.

In the field, it was not possible to take a sample of a predetermined volume of soil, using sampling cylinders, because of the bouldery character of the investigated soils. The volume weight of the total sample is of little importance as it is highly influenced by the random content of the coarser material in the sample. The samples were sieved, the coarser 
fraction removed and weighed separately. The fine material frequently sticking to boulders and pebbles in mull soils must first be loosened. In the determination of water content, which was performed only on Mt. Lulep Istjakk (samples Table 2), the fresh samples were weighed as soon as possible and reweighed after drying (loss in weight was determined as percentage of the air-dried sample). When sampling, a representative amount of coarser material (gravel) must be included. Furthermore, large roots and dense root mats must be avoided. As there are always some organisms and rootlets the organic part of the soil does not entirely consist of "humus", defined as humified litter.

Holmen (1964, pp. 136 et seq.) showed that the concentrations of some important constituents may vary to a large extent in a plant community and that they are largely overlapping in peat under adjacent communities. To obtain a true picture of the distribution pattern of a certain element a very large number of analyses must be made, preferably in a fixed pattern, the communities and topographical characters of which are investigated in detail. Some similar method of investigation must be used in other kinds of soils when evaluating the tolerance limits of certain plant communities in a special locality. However, this was not feasible in the present study. The value of such a network of samples would in any case be doubtful because of the great local variation in content of fine material, soil depth, moisture conditions, etc.

Volume weight (apparent density, bulk density) was obtained in the sieved air-dried sample (dried at $25-35^{\circ} \mathrm{C}$ ) and is the mass of the dry fine soil per unit volume of fine soil $(\mathrm{g} / \mathrm{ml})$. No special apparatus was used for humus-rich soils. For mineral-rich soils shaking was used. Because of the small residual volume of fine soil left after removal of the coarser fractions, the results could not be expressed more exactly than to two figures. They are, of course, not comparable to values for soil in the undisturbed state, and are generally lower.

Ignition loss. 2-5 g air-dried fine soil was dried at $100^{\circ} \mathrm{C}$ for at least 5 hours, then cooled and weighed (called dry matter or dry substance). Ignition was in a furnace at $600{ }^{\circ} \mathrm{C}$ for about one hour, then the sample was cooled and weighed. One hour might be somewhat too long and the temperature somewhat high. Ignition loss was expressed as percentage of the oven-dry weight, and should represent the content of organic matter fairly well in the samples examined. The values for $\mathrm{P}, \mathrm{K}$ and $\mathrm{Ca}$ obtained from Statens Lantbrukskemiska Laboratorium were calculated from the air-dry weight (sample dried at 25$35^{\circ} \mathrm{C}$ ) and there is therefore some inconsistency (of little significance, see Sjörs 1961, p. 17) affecting the values in the tables calculated on the ignition loss

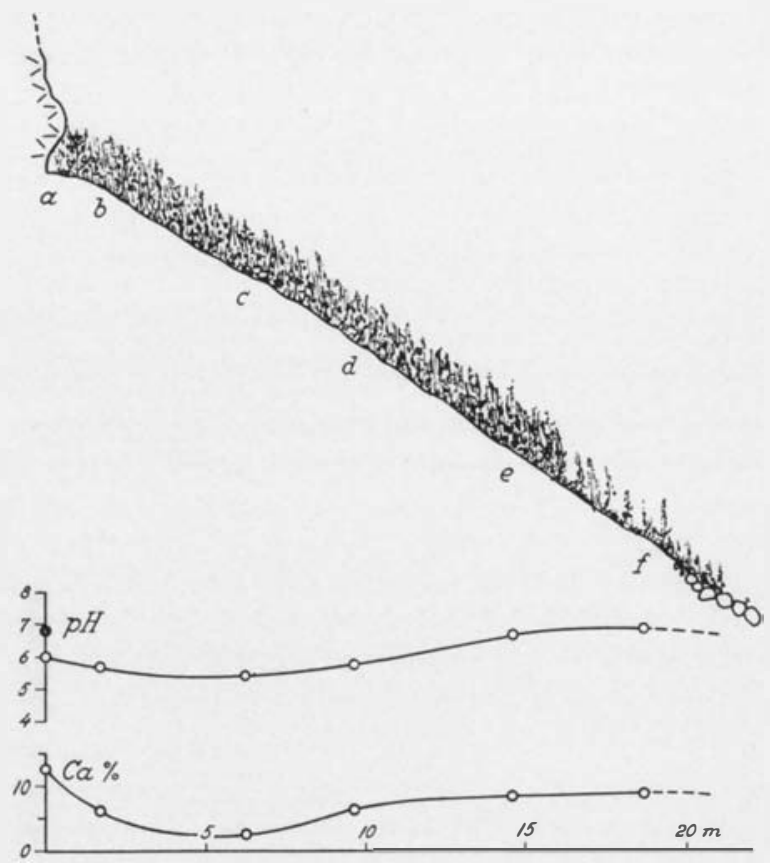

Fig. 9. The belt transect studied on Mt. Lulep Istjakk in 1961. Schematized section showing the height and abundance of the herb layer down on to the open scree. $a-f$, Soil sampling places. The variation of $\mathrm{pH}$ (extract from dried samples: open circles; filled circle denotes $\mathrm{pH}$ of the seepage water on the rock wall) and $\mathrm{Ca}$ in $\%$ of the humus at $10 \mathrm{~cm}$ depth.

basis. The content of hygroscopic moisture was probably very low, as the clay content in most samples does not exceed $10 \%$. When humus content was calculated by the Laboratory a correction value ( 1.0 for mull soils) was subtracted from ignition loss. That correction value was not used when calculating the values in the tables.

Mechanical analyses were made of a limited number of samples. The coarser fractions (down to gravel) were removed and weighed in the field laboratory, the rest of the analyses were performed commercially by sieving and decantation, usually after ignition.

The specific conductivity at $+20^{\circ} \mathrm{C}(\mathrm{ohm}-1 \mathrm{~cm}$ $-{ }^{1} \times 10^{6}$ ) was measured using a bridge with electronic radiation indicator, after shaking a suspension of $10 \mathrm{~g}$ fine soil and $90 \mathrm{ml} \mathrm{CO}$-free distilled water for one hour. As in the water analyses (p. 62), the conductivity due to the hydrogen ions would be expected to be negligible for circumneutral soils.

Hydrogen ion activity $(\mathrm{pH})$. This was measured with a glass electrode meter in a suspension of soil and distilled water in volume proportions about $1: 2$ (1 part soil in 2 parts of the suspension) after stirring and leaving the samples overnight. With this method there may be a considerable influence of the varia- 
tion in colloid content in mineral soils as compared to organic soils (cf., e.g. Holmen 1964, p. 139) in terms of buffer capacity, etc. As in these cases only more and less humus-rich soils are compared the degree of dilution of active components in the soil would not be expected to be of any great importance. On the other hand, because only dried samples were used and the analyses were done some time after sampling, the values might be lower than in fresh samples (Sjörs 1961, pp. 11, 12).

$\mathrm{P}, \mathrm{K}, \mathrm{Ca}$. The old method in agricultural chemistry was to give the so-called lactate value for easily extractable $\mathrm{P}_{2} \mathrm{O}_{5}$, meaning $\mathrm{mg}^{2} \mathrm{P}_{5}$ in $100 \mathrm{~g}$ of the air-dried sample. The reagent was a lactate solution, $0.01 \mathrm{M}$ Ca-lactate and $0.01 \mathrm{M}$ hydrochloric acid, with $\mathrm{pH}$ 3.7. $\mathrm{K}$ was given as $\mathrm{mg} \mathrm{K} . \mathrm{O}$ per $100 \mathrm{~g}$ air-dry matter and extracted in a solution of $0.1 \mathrm{M}$ monochloroacetic acid and $0.005 \mathrm{M}$ Ca-monochloroacetate. Since the buffering capacity of the extractants was too low, considerable inconvenience was experienced, especially in soils with a high content of free calcium carbonate. This was largely overcome by using a new extractant solution (ALsolution) of $0.1 \mathrm{M}$ ammonium lactate and $0.4 \mathrm{M}$ acetic acid. Moreover, the same solution ( $\mathrm{pH}$ 3.75) could be used for the determination of $\mathrm{P}$ and $\mathrm{K}$. The values are given per unit of loss on ignition in the tables. The soil is shaken with the solution for 1.5 $\mathrm{h}$ at $20 \pm 1{ }^{\circ} \mathrm{C}$ (Egnér, Riehm \& Domingo 1960, pp. 199 et seq.). For comparison with older plant ecological investigations a number of analyses were made (Table 2) according to the lactate method and the lactate values listed beside the AL-values for the same sample. Note that lactate values are given as mg $\mathrm{P}_{2,} \mathrm{O}_{\tilde{j}}$ (net P) per $100 \mathrm{~g}$ air-dry fine-soil (not on the loss-on-ignition base) and thus must be recalculated before they are compared with AL-values. See also Karlsson \& Jonsson 1959, p. 20.

Holmen (1964, p. 169) found a negative relation between the annual increment of growth of the tree stands and the contents of $\mathrm{P}-\mathrm{AL}$ in the soil. The $\mathrm{AL}$ method for determination of easily extractable $\mathbf{P}$ in the so:l of natural plant communities may be of limited value (l.c.). The availability of $\mathbf{P}$ in soils is closely linked with the increment of growth and also with the activities of microorganisms and the equilibrium established with the hydroxyl ion concentration and with iron compounds, possibly also with calcium compounds. Thus it seems plausible to believe that the equilibrium is very variable within a particular site, both in time and in microspace, because of the microclimate, and because of the activities exerted by the different plants in a special environment. It is not known in detail how the different sampling and storing methods affect the particular sample.

Reserves of nutrients ( $P, K$ ) are extracted with hydrochloric acid in agricultural chemistry (Egnér et a!. 1960). Ca was also determined in the same solution, $2 \mathrm{M} \mathrm{HCl}$, after 2 hours on a steam-bath, by versenate titration. The method for determination of $\mathrm{Ca}$ may not be suitable for soils containing $\mathrm{CaCO}_{3}$ and other methods have frequently been used, especially for the determination of total $\mathrm{Ca}$ in mineral soils.

Sampling sites. Sampling was carried out in some cases only as a complement to rock and water analyses, whereas in other cases the profiles were also investigated. Vegetation analyses were made (see the section on vegetation), enabling a more complete and comprehensive knowledge of the sites to be acquired. Due to consideration of space, only concise statements and descriptions of the sites and soil profiles are given below. The order of the samples is the same as for the mountains. See Table 1 (behind the text).

1. Mt. Akkapakte. Waterlogged soil of the uppermost layer $(0-3 \mathrm{~cm})$ in front of the rock wall where the water and rock samples were taken. Mull. Vegetation p. 108.

2. Mt. E Ramanpakte. Highly productive stand of dominant Aconitum septentrionale, p. 88 , quadrat no. 4, at 2-5 cm depth. Mull.

3. Mt. Märkepakte, the S-facing slope. Fruticeto-Tortuletum, quadrat no. 5, Table 3, Lundqvist, J. 1961, pp. 161, 170, at $3-5 \mathrm{~cm}$ depth. Litter, partly mull.

4-5. The same quadrat, at $14-15 \mathrm{~cm}$ depth, and at $45-50$ $\mathrm{cm}$ depth. Mull.

6-8. Mt. Märkepakte, the SE-facing slope. Stable scree almost covered with Hylocomium splendens, different kinds of low-humified humus near the surface. See Lundqvist, J. 1961, pp. $163,169$.

9-10. The same site, low-humified humus at $15 \mathrm{~cm}$ depth.

11-13. Merk Gorge. Drought-resistant meadow near rain gauge no. 2, p. 57, and dominated by Festuca ovina. 11, litter at the surface; 12 , mull at $10 \mathrm{~cm}$ depth; 13 mull at 30 cm depth. See p. 104.

14-17. Merk Gorge. Matteuccia struthiopteris community near rain gauge no. 4 , p. 57.14 , litter at $0-2 \mathrm{~cm}$ depth; 15 , mull at $10-12 \mathrm{~cm}$ depth; 16 , mull at $30 \mathrm{~cm}$ depth; and 17 , mull at $60 \mathrm{~cm}$ depth.

18-20. Merk Gorge. Grey alder wood on the bottom of the Gorge, the same transect as the foregoing (Fig. 29). 18, low-humified humus at 2-5 cm depth; 19, mull at 10-12 $\mathrm{cm}$ depth; 20 , mull at $22-25 \mathrm{~cm}$, immediately below the groundwater surface at the time of sampling. At about $40 \mathrm{~cm}$ depth pure mineral soil, mainly consisting of coarse schistose gravel derived from alum schist.

21-23. Mt. Aistjakk, the SW-facing slope, near to station no. 7 (p. 36). Fruticeto-Tortuletum, quadrat no. $5.2 .5 \mathrm{~m}$ from the rock wall (p. 91). 21, low-humified humus at $0-3$ $\mathrm{cm}$ depth; 22, mull at 12-15 cm depth; 23, mull at $30 \mathrm{~cm}$ depth. Very thin litter layer. At $25 \mathrm{~cm}$ depth the mull changes colour from dark brown to light brown.

24-25. Mt. Aistjakk, the NE-facing slope, near to station no. 8 (p. 36). Picea abies-Vaccinium myrtillus-Hylocomium splendens-type near the open boulder scree. At ca. $12 \mathrm{~cm}$ depth lower stone-air layer, see p. 24. 24, low-humified humus at $2-5 \mathrm{~cm}$ depth; 25 , forest mull at ca. $10 \mathrm{~cm}$ depth.

26-27. The same slope, only $1 \mathrm{~m}$ below the rock wall. Phegopteris polypodioides-Calamagrostis purpurea meadow 
Fig. 10. The SW-facing scree on Mt. Aistjakk, immediately $\mathrm{W}$ of station no. 7. Transition from luxuriant herb stands with dominant Anthriscus silvestris to open scree. Groups of birches (Betula pubescens), but no closed stands of trees. 14 August, 1965.

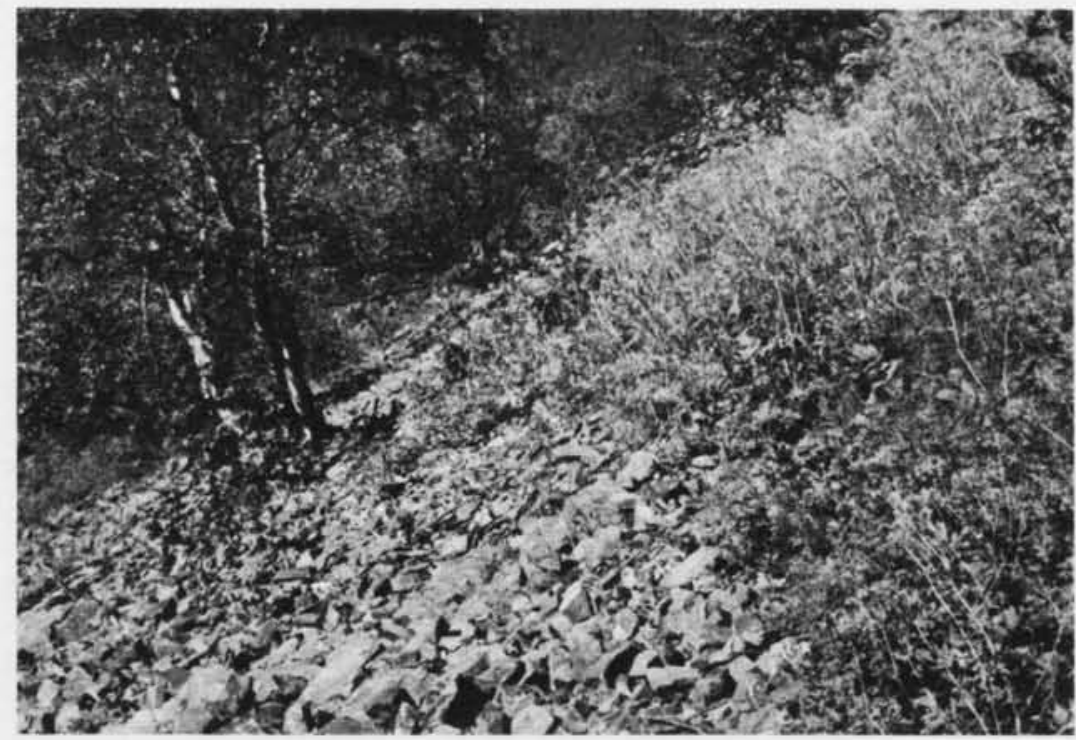

well-moistened with drops from the rock wall (no forest shrubs). 26, low-humified humus at $2-5 \mathrm{~cm}$ depth; 27 , forest mull at $12-15 \mathrm{~cm}$ depth.

28-30. Mt. Lulep Istjakk, the S-facing slope. PopuletoTortuletum community. See Lundqvist, J. 1961, pp. 156-157. 28 , litter at $3-5 \mathrm{~cm}$ depth; 29 , mull at $14-15 \mathrm{~cm}$ depth; and 30 , mull at $40-50 \mathrm{~cm}$ depth.

31-32. Mt. Lulep Istjakk, the "scrub zone", FruticetoTortuletum with occasional dominance of Roegneria canina, op. cit., pp. 158-159, 31, litter at the surface; 32, low-humified humus at $20 \mathrm{~cm}$ depth.

33. Mt. Dalktjapakte, the NE-facing slope below the rock wali, Lactucion alpinae with dominant Aconitum septentrionale and Brachythecium salebrosum. Low-humified humus at $5-10 \mathrm{~cm}$ depth.

34-35. Mt. E Stärpatsvare, the S-facing slope below the rock wall. Vaccinium myrtillus heath with admixture of some herbs. 34, low-humified humus at $3-5 \mathrm{~cm}$ depth; 35 , almost pure mineral soil at $25-30 \mathrm{~cm}$ depth.

36-37. Mt. Fiskträskberget, the S-facing slope below the rock wall. Dicrano-Polytrichetum, p. 95, quadrat no. 4. 36, low-humified humus at $2-5 \mathrm{~cm}$ depth; 37 , almost pure mineral soil at $25-30 \mathrm{~cm}$ depth.

38. Mt. Harrejaurliden, the S-facing slope below the rock wall. Poeto-Lactucetum with dominant Lactuca alpina. Mull at $12-20 \mathrm{~cm}$ depth. The dark mull-layer is very thin, only 2-9 $\mathrm{cm}$.

39. Mt. Gaddaberget, the S-facing slope below the rock wall. Pinus-Vaccinium heath on bouldery talus (few herbs). Sandy soil of light brown colour immediately below raw humus carpet.

40. A similar site and layer as the foregoing, heath type with herbs intermingled. Rust-brown sandy soil.

41. Mt. Gaddaberget, a wide ledge on the rock wall with dominant Polytrichum juniperinum (p. 95). The same layer as the two foregoing, $3-5 \mathrm{~cm}$ below the surface. Very dark rust-brown sandy soil.

42-44. Mt. Gaddaberget, the Gully. Poeto-Lactucetum dominated by Dryopteris filix-mas (p. 88). 42, low-humified humus at 5-8 cm depth; 43 , mull at $15-18 \mathrm{~cm}$ depth; and 44 , mull at $25-30 \mathrm{~cm}$ depth.
45-47. Simselet (Lundqvist, J. 1966, p. 194). Community with Cypripedium calceolus (transition type of moist forest h.eath to meadiow birch forest). Quadrat no. 7 (l.c.). 45, litter; 46, low-humified humus at $3-5 \mathrm{~cm}$ depth; and 47 , mull at $10-15 \mathrm{~cm}$ depth.

48-50. Old river valley near Tjäutjanåive hill (situation see map Fig. 2). Picea forest on valley bottom with Viola riviniana (p. 106). 48, low-humified humus at $8-12 \mathrm{~cm}$ depth; 49 , deeply rust-brown humus-rich soil at $25-30 \mathrm{~cm}$ depth; 50 , almost humus-free rust-brown mineral soil at $45-55 \mathrm{~cm}$ depth.

51. Mt. Peruken, Lycksele Lappmark (see above), the Sfacing slope below the rock wail. Waterlogged soil of the uppermost ground layer $(0-3 \mathrm{~cm})$ immediately in front of the rock wall where there was some seepage water. Mull.

52-54. The same place, ca. $5 \mathrm{~m}$ further down on the scree, immediately outside the canopy of 3 high Picea trees. 52 low-humified humus at $3-7 \mathrm{~cm}$ below the surface; 53, forest mull at $30 \mathrm{~cm}$ depth; 54 , almost humus-free lightbrown mineral soil at $50 \mathrm{~cm}$ depth.

55-57. Sikilsdalen, Norway, extensive talus slope on the $\mathrm{N}$ side of Lake Upper Sikilsdalsvatn, see Nordhagen 1943, p. 543, Fig. 186. "Chamaenerium-Convallaria-Poa nemoralissosiasjon", p. 96. 55 . litter at $0-3 \mathrm{~cm}$ depth; 56 , mull at 10$12 \mathrm{~cm}$ depth; 57 , mull at about $30 \mathrm{~cm}$ depth.

\section{LOCAL CLIMATE AND SUN EXPOSURE}

\section{Introduction}

Wahlenberg was one of the first botanists who made a phytogeographical description that took into account different demands of climate, and edaphical and historical factors. He (1812, p. XLI) calculated figures for temperature, air moisture and precipitation, and on this basis he was able to distinguish the different regions of Lappland with regard to climate, and also with respect to dominant plant species. 
As far as Lappland is concerned Wahlenberg's regions have on the whole remained valid up to the present time as a classification of the general zonation of vegetation even though the regions have been given more appropriate names by other investigators. The important thing is that, like such pioneers as Soulavie and Saussure, he clearly understood the conclusive importance of climate, and that in the different regions he saw the expression of the change in seasonal climate with latitude and altitude. He certainly did not mean to bring about confusion as to climatic and biotic zonation but wanted to elucidate the problems of interaction in nature, problems which form the basis of ecological science.

Thus the classification of biotic communities or biocoenoses ought to be based exclusively on the grouping of plants and animals, no matter what the name of the single unit may be in the rich flora of terms, without being deflected by such characters of the habitat as for instance climate or edaphical factors, nor by historical evidence (cf. Du Rietz, compendium 1961, pp. 68-69). Confusing the vegetation and the environmental factors acting on it hides the clues for the solution of the problem of interaction which was meant to be studied. Instead there might be a danger of a vicious circle arising. The vegetation is thus not to be classified in terms of some factor of the environment. A certain factor of environment in the local facies of the biocoenose in question can be partly or wholly substituted by another factor in a nearby situated facies (Riibel 1935, pp. 336 et seq.). Because of this and the manifold variety of the vegetation it is frustrating, for example, to try and base a classification of the vegetation on its dependence on soil calcium content, on its higher or lower temperature demand, and so on. The ecosystem concept established for the unit of biosphere including both vegetation and factors of environment (Sjörs 1955, p. 156) will have to be looked upon as a system for understanding the complexity of interacting forces in nature, the interactions of which were meant to be understood in relation to each other and the biota of the world.

The present investigation of the thermal factors of the sun-exposed hillsides of PL was consequently not meant to be a help in the classification of the plant communities of this special ecosystem but perhaps rather to be a link of importance for the understanding and interpretation of certain very outstanding phytogeographical and edaphical circumstances. These factors have already been thoroughly discussed in the classical work of Andersson \& Birger (1912) and have more recently also been described to some extent from PL by Wistrand (1934, 1962, pp. 24 et seq.). The Swedish term "sydberg" actually means a "S-facing hill or mountain" but has by most authors, including Andersson \& Birger and Wistrand, been taken as a term for the ecosystem of precipitous, not always S-facing hillsides with southern plants. As has already been mentioned, other terms were substituted e.g. by Halden (1950) and Du Rietz (1954). One must try to identify the thermal factors in relation to important edaphical factors, an idea which is supported by a great many observations by different investigators.

The general climatic factors of PL have been described and discussed by Wistrand in his survey (1962, p. 28).

The copious botanical literature on S-facing sides of hills and mountains gives much evidence for the favourable local climate of these (cf. Lundqvist 1965, p. 216). The term "local climate" has here been applied to a climate which is highly dependent on the existence of hilly country and consequently could not possibly pass under the term "macroclimate", by which large areas are generally taken into consideration. In fact, one could also talk about the "microclimate" of S-facing slopes, but this term would rather refer to the climatic features in special habitats and in special plant communities, e.g. the climate as studied at the soil or rock surface or in the layer nearest the ground. Other terms have been proposed for the different topoclimates, especially in the German language, but will not be discussed here.

The dependence of the climate on exposure has been treated thoroughly by numerous investigators, of which only a few will be mentioned here (most of them have been more completely discussed by Geiger 1965, pp. 369 et seq. Cf. also Blüthgen 1964, pp. 398 et seq., and Munn 1966). Wollny (1878) and Kerner (1891) made important studies on soil temperatures of slopes of different exposure in Central Europe. Young (1921) studied nocturnal temperature inversion in Oregon and California. Valuable accounts of the importance of exposure for vegetation have been given from Central Europe by Geiger in cooperation with Künkele (1925), by Geiger (1927-29) and by Geiger, Woelfle \& Seip (193334). Suzuki (1941) described a very favourable cultivation climate on slopes in Japan. Schnelle (1948) found a thermal belt at an altitude of $300 \mathrm{~m}$ where winter rye first developed. Shanks \& Norris (1950) studied the danger of late frosts on slopes in Tennessee. Parker (1952) showed climatic differences between $\mathrm{N}$ and $\mathrm{S}$ slopes in Idaho to be highly determinable for forest distribution. Other important investigations from Central Europe are those of Heigel (1955 and 1957), Baumgartner, Kleinlein \& Waldmann (1956) and Waldmann (1959). Koch (1961) gave a full account of the situation of the thermal belt. More recent important studies on the effect of climate on the water relations of soils on slopes in England (Jarvis, M. 1963) and climatological and ecological studies at Kevo Research Station in N Finland (Laine 1965) may also be mentioned. In Sweden Frödin (1915) found clear positive anomaly for a S-facing hillside in Lule Lappmark during a period of bright weather. Bylund \& Sundborg (1952) gave climatological evidence for human settlement in Lappland preferably being located to thermal hill- 
Fig. 11. Mt. Aistjakk, stations nos. 6 and 7 (no. 7 seen as a little white dot below the rock wall of the hill). Taken at a moment $(09.15 \mathrm{~h})$ when the sun is beginning to shine on the whole scree. 14 August, 1965.

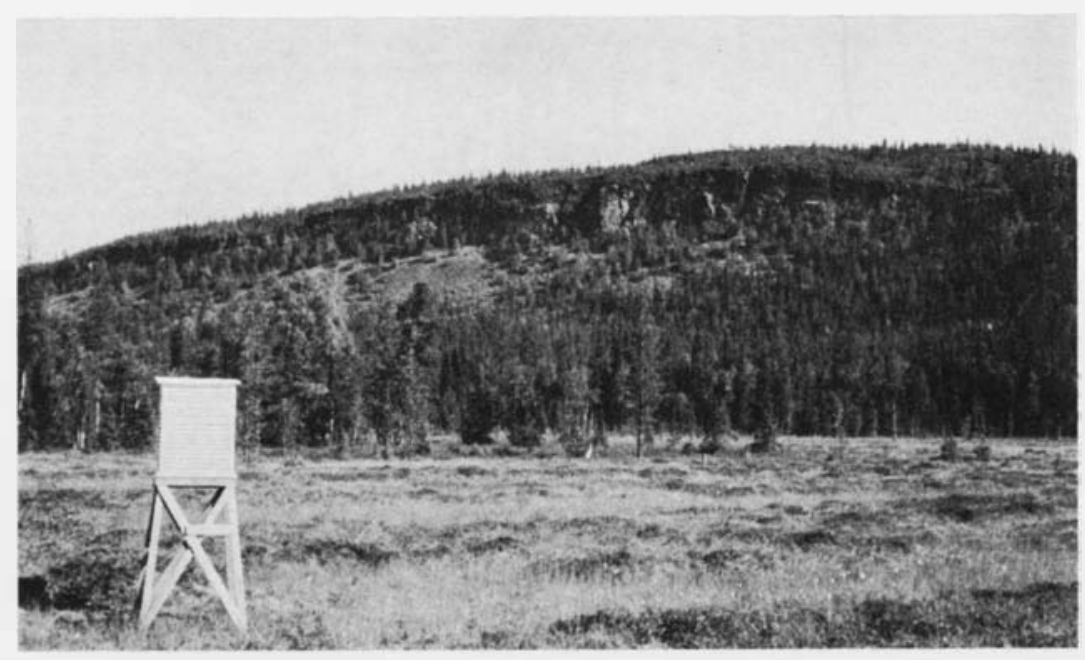

sides (cf. also Rudberg 1957, pp. 69 et seq.). At Abisko in northernmost Lappland there have been long-term continuous climatological and plant ecological studies on slopes (Sandberg 1960, Bringer 1962). Most of the climatological material is unpublished. Odin (1964) studied the influence of exposure and height on tree growth. In addition animal ecological studies with references to the climatologically favoured hillsides of $\mathrm{N}$ Sweden have also been published recently (Andersson, J. S. 1961) or are in preparation (S. Gaunitz).

The investigation here presented was undertaken during the vegetation periods of the years 1959-62 and 1965-66 at Mts. no. 12 (Märkepakte), no. 13 (Storberget) and no. 16 (Aistjakk, SW and NE side). Mt. Aistjakk is situated on the very edge of the overthrust nappes of the Caledonides, the other two mountains somewhat NW of no. 16. The area seems to be definitely more oceanic than the more easterly situated meteorological station at Arjeplog (cf. below p. 41) but not quite as much as Tärnaby $100 \mathrm{~km}$ to the SW. Furthermore Tärnaby is at a favourable latitude in comparison with the stations studied, while Kvikkjokk to the NNE is favoured because of its low altitude. In the investigated area there are some relatively high mountains (Mt. Nebsuort 912 m, Mt. Krappesvare $1024 \mathrm{~m}$ and Mt. Peljekaise 1122 $\mathrm{m})$ with forested ridges or lower mountains and hills between them (Mt. Aistjakk 646 m, Mt. Märkepakte $538 \mathrm{~m}$ and Mt. Puoudak $744 \mathrm{~m}$ ). The valley bottoms are at 419 and $424 \mathrm{~m}$, respectively. The topography has been advantageous for the investigations carried out with the aim of elucidating the problem of thermophilous plant communities and their connection with the local climate and the microclimate of the locality.
The principal aims of the present climatological studies have been

1. To record temperatures (screen values) on hillsides throughout the vegetation period and to compare these with values from the meteorological network of Sweden. J. van Eimern (1964, p. 71) writes: "Zum Verständnis eines Bestandsklimas ist an sich eine Basisstation nicht notwendig. Wenn jedoch Basiswerte benötigt werden, etwa zum Vergleich von Untersuchungen an verschiedenen Orten, dann kommt nur die Wetterhütte in Frage, weil auch in Zukunft die mit der Wetterhütte gemessenen Werte zum Vergleich der verschiedenen Klimazonen herangezogen werden und weil die Wetterhïtten immer das Grundnetz der meteorologischen Beobachtungen bilden werden."

Little attempt was made to study stations at different levels above the valley bottom or rock wall base (cliff line). Such studies have already been made by a number of microclimatologists with the proper resources. Much experience has been acquired of general climatological features with regard to exposure and level.

Discussions of the climate of the S-facing mountain-sides of $\mathrm{N}$ Sweden have mostly been about the positive anomalies of bright days and calm clear nights, during the vegetation period.

2. In addition, to study purely microclimatological features on a few occasions to get an idea of $(a)$ soil and soil surface temperatures $(b)$ temperatures of the rock wall $(c)$ temperatures of typical plant communities.

3. To state light conditions and energy balance on a couple of occasions. In general characteristics, conditions on slopes exposed in different directions could be calculated theoretically (cf. Lunelund 1940). 


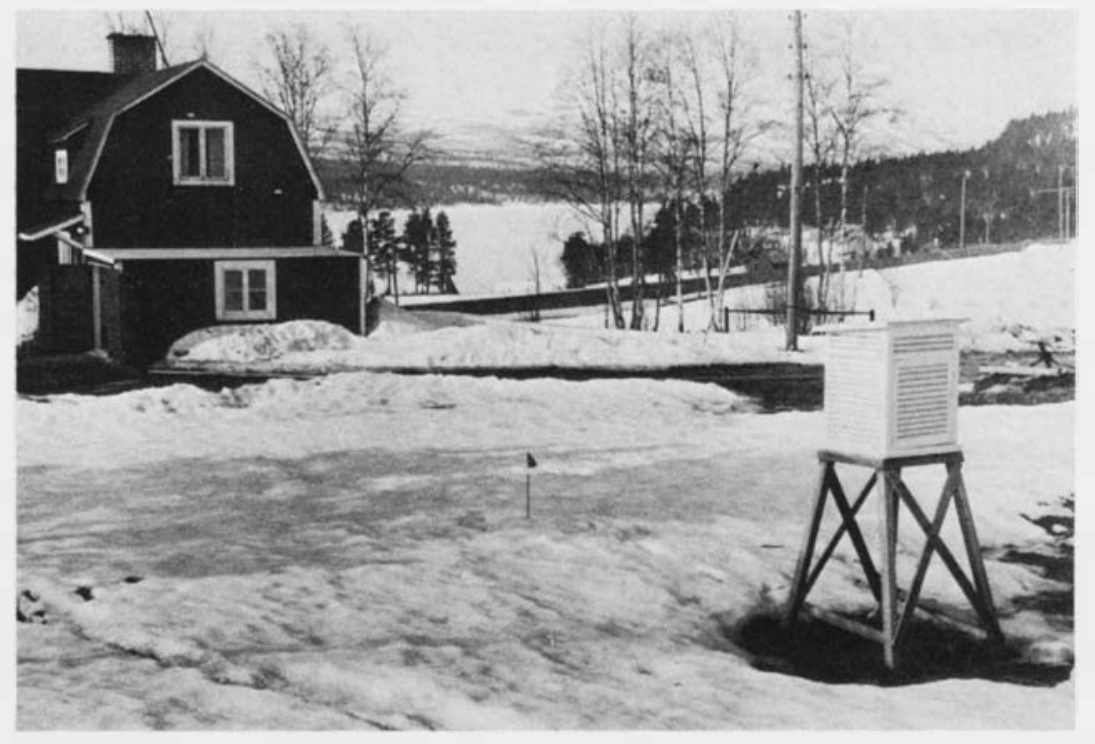

Fig. 12. Station no. 2 towards the SW, with Lake Storlaisan and Mt. Krappesvare $(1064 \mathrm{~m})$ in the background. Rod for measuring snow depths. 3 May, 1961.
4. The phenology of the favoured slopes in spring and early summer together with some notes on the phenology of autumn.

5. To study snow conditions of late winter and spring (thaw phase).

6. To elucidate the problems concerning the hydrological conditions of the slopes (in a later section).

\section{Measuring methods and gauges. Sources of error}

The instruments used for the temperature observations were usually made by R. Fuess, Berlin-Steglitz. In 1965 bimetallic thermographs made by Lamprecht, Göttingen, were used. The Fuess bimetallic thermographs had a writing height of $1.2 \mathrm{~mm}$ for $1{ }^{\circ} \mathrm{C}$, and the lowest possible reading was $-5^{\circ}$. The thermographs were controlled at stable temperatures (indoors) against the Assman aspiration psychrometer ard exact corrections at various scale values were made. On one occasion the following corrections were obtained for thermographs C 7241 and D 1032. (The first 9 calibrations were made outdoors at hign air kumidity.)

\begin{tabular}{llllll}
\hline $\begin{array}{l}\text { No. of } \\
\text { calibrations }\end{array}$ & 9 & 7 & 9 & 15 & $\begin{array}{l}\text { Average } \\
\text { corrections }\end{array}$ \\
\hline Scale value $\left({ }^{\circ} \mathrm{C}\right)$ & $\begin{array}{l}2-5^{\circ} \\
+0.1^{\circ}\end{array}$ & $\begin{array}{l}8-11^{\circ} \\
+0.1^{\circ}\end{array}$ & $\begin{array}{l}13-18^{\circ} \\
+0.2^{\circ}\end{array}$ & $\begin{array}{l}24-29^{\circ} \\
+0.6^{\circ}\end{array}$ & $+0.3^{\circ}$ \\
C 7241 & $+0.2^{\circ}+0.4^{\circ}$ & $+0.1^{\circ}$ & $+0.5^{\circ}$ & $+0.3^{\circ}$ \\
\hline D 1032 & & & & &
\end{tabular}

Thus the thermographs had the tendency to read too low at higher temperatures but this was disregarded in practice as the screens are heated by the sun at temperatures between 24 and $30^{\circ}$. Because of the heating by the sun the errors may amount to as much as $1.5^{\circ}$, at least when wind velocities are low.

The thermographs were also checked against the maximum and minimum thermometers. These (including the soil thermometers) were graded in $1 / 5^{\circ}$ C. The maximum thermometers and soil thermometers, which were mercury thermometers, had a maximal correction of $\pm 0.2^{\circ}$, the minimum thermometers (alcohol) $\pm 0.8^{\circ}$. In one observation period the corrections were generally stable. The thermometers were checked in clean snow (or ice) and distilled water in a thermos flask.

In every screen, one thermograph, one maximum and one minimum thermometer were used and checked against each other. Because of the different response time of the instruments the average correction against the maximum thermometer of one single observation period was found to be, e.g., $+0.5^{\circ}$, against the minimum thermometer $\pm 0.0^{\circ}$ (the above calculated corrections were first applied). This is due to the fact that the maximum values last for a very short period, as in the middle of the day the air is turbulent, and the mercury thermometer has not time enough to reach the actual value (the time constant of the mercury thermometer was about twice as great as that of the bimetallic thermometer). In the night the minimum values last quite a long time and the minimum thermometer, although its time constant was three times as great as that of the bimetal and its reaction thus was slow, will reach the same value as the thermograph. Beside these faults there are effects caused by too strong cooling during clear calm nights (maximal error $0.5^{\circ}$ ), the influence of the surroundings, etc. 
With regard to calculation of average air temperatures, it should be noted that during some short intervals no temperature curves were obtained because of accidental breaks etc. For the few days when hourly values were not available, the averages and the curves obtained by the other instruments were compared and in this way reasonably good averages were calculated. An example of a week-long stop which occurred on one occasion is given, Table 5. The principles and methods in calculating averages have been the same as those used by the SMHI (The Swedish Meteorological and Hydrological Institute), Årsbok 29 (1947) II:2, Stockholm 1953, pp. V-VI. When calculating monthly averages the more precise method of using 24 hourly values a day was also used for comparison (true means, cf. Modén 1939, p. 3). In all cases the values are referable to a height of $150 \mathrm{~cm}$ above the ground, i.e. the ground surface vertically below the sensor of the instrument.

For measuring wind velocities, temperatures of the ground and rockwall surfaces, and the air temperatures at different levels up to $150 \mathrm{~cm}$ above the ground, a combined glow-filament anemometer and thermistor thermometer made by Wallac Oy, Helsinki, was used. With this were used three separate sensors, viz. Ni 125-ANE (a combined sensor for velocity and temperature of the air in a radiation shelter tube), Ni 103 (an elastic surface temperature sensor), and $\mathrm{Ni} 106$ (a pointed rod sensor for measuring temperatures of the litter). This instrument was easy to handle and made it possible to read wind velocities and temperatures within very short intervals. At unstable air temperatures the instrument was read at $10 \mathrm{sec}$. intervals for 2 minutes and averages were calculated. The separate sensors were checked with the Assman aspiration psychrometer and with clean snow.

Robitzsch bimetallic actinographs of Japanese construction (sensitive area: 70.5 by $77.5 \mathrm{~mm}$, consisting of 4 parted strips each $17 \mathrm{~mm}$ broad) were used for the radiation measurements. These were calibrated against the Moll-Gorczynski solarimeter used at the Marsta Observatory near Upsala. By calibration with clear sun calibration constants were obtained for different sun heights indicating gradually decreasing response for higher light intensities. The original value was that obtained at $45^{\circ}$ elevation of the sun above the horizon. This original value was shown to coincide closely with the calibration constant given on the instrument. When recalculating the values actually obtained on the instrument, account was taken of the calculated elevation of the sun. In the case of diffuse light the calibration constant given on the instrument was used. In the light summer nights no
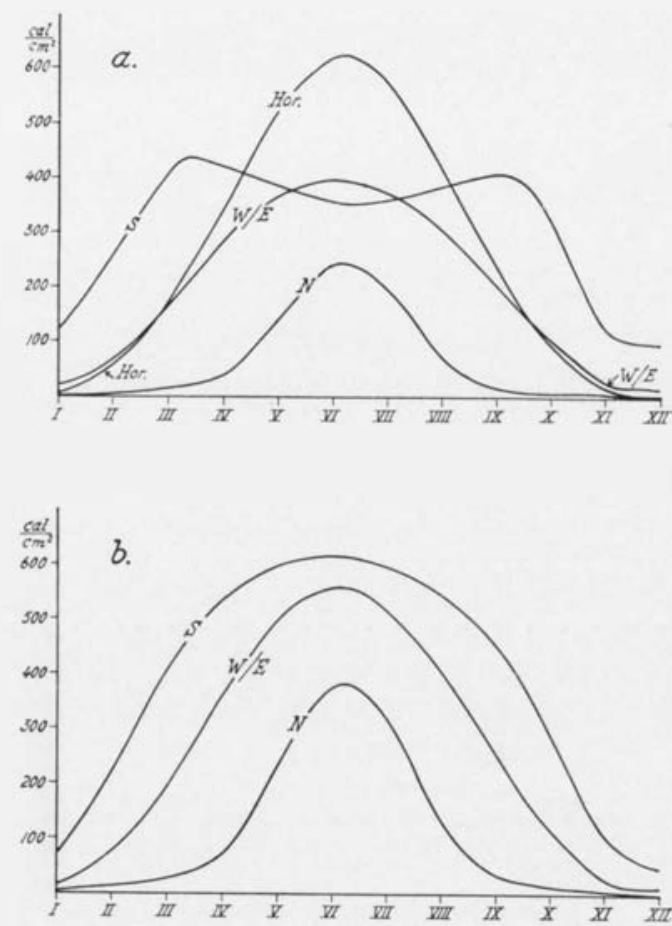

Fig. 13. Total short-wave radiation, "global radiation" (300$3000 \mathrm{~m} \mu)$ at $66^{\circ} \mathrm{N}$ lat. with clear sky, diurnal totals. Curves based on values from Aurén (1939, p. 24), horizontal surface, and interpolated values from Lunelund (1940) for vertical walls and variously exposed slopes. The values are given according to the international pyrheliometric scale. Roman numerals designate the 15 th in each month. (a) The horizontal surface and variously exposed vertical walls; (b) variously exposed slopes at $45^{\circ}$ inclination to the horizontal.

exact value for the diffuse light could be calculated because of the fact that the O-value on the actinogram was not reached and the inertia constant unknown. However, the O-value is very low as the sensitivity of the instrument is high.

\section{The radiation climate of mountain slopes}

It has always been clear that the climate of slopes is primarily dependent on the amount of solar radiation or energy that falls on the various inclined surfaces as compared to a horizontal surface (cf. the deduction of the originally Greek word climate). Not until the present time have methods of investigation and the available instruments been accurate enough to permit an evaluation of the radiation climate of different sites (Anderson, M. 1964, Geiger 1965). However, the methods used have never been exactly the same, nor are the results of these investigations strictly comparable. With regard to the light climate of slopes we have, for example, to compare the results of Grunow (1952) with those worked out for more northern latitudes by Lunelund (1940, cf. Fig. 


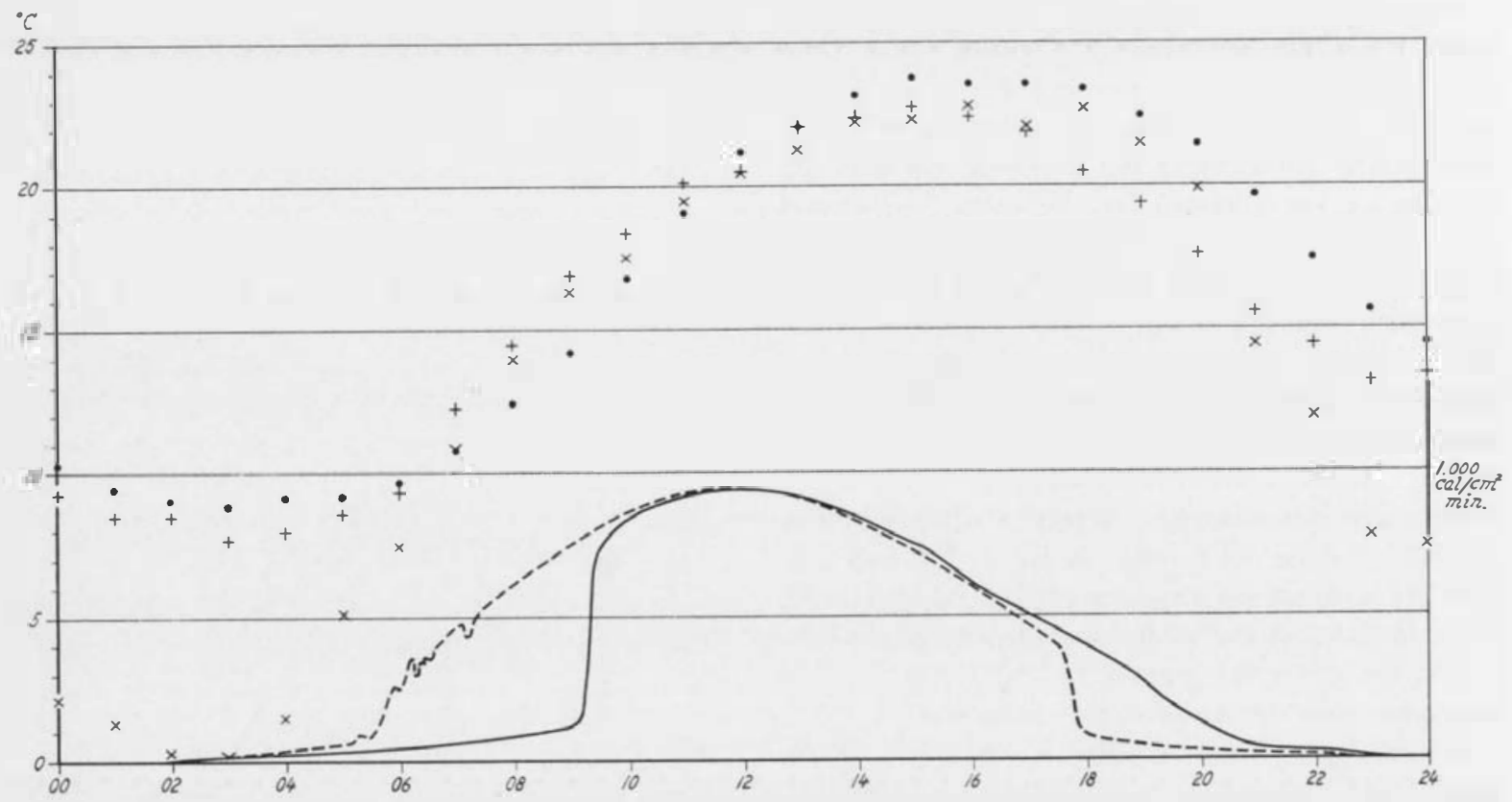

a

Fig. 14. (a) Air temperatures at $01.00,02.00 \mathrm{~h}$. CET, etc., at stations nos. $2(\times), 4(+)$ and $7(\cdot)$, and the simultaneous insolation curves of stations nos. 4 (---), and 7 (-) on 7 June, 1965, with clear sky (horizontal surface). The diurnal sums were 524 ly (4) and 454 ly (7), thus $13 \%$ lower sum for station no. 7 . The diffuse component in the middle of the day cut off by the vertical cliffs (nearly half the sky shaded) would be expected to be about $0.020 \mathrm{ly} / \mathrm{min}$. The diffuse light in the middle of the night not recorded by the instrument amounts to ca. $0.010 \mathrm{ly} / \mathrm{min}$. (b) The light conditions on Mt. Märkepakte at forenoon on 14 June, 1966. Upper curve: full sunlight on open level ground according to Lunelund (1940, p. 4, reduced to international pyrheliometric scale). Lower curve: leafless aspenwood of belt transect (Figs. 39 and 40). The lower curve was obtained using a bimetallic actinograph, the upper curve was calculated. Horizontal surface.

The following values were valid for the horizontal surface illustrated by the upper curve in Fig. $14 b$. Long-wave radiation balance was calculated according to Brunt's formula. Thermal

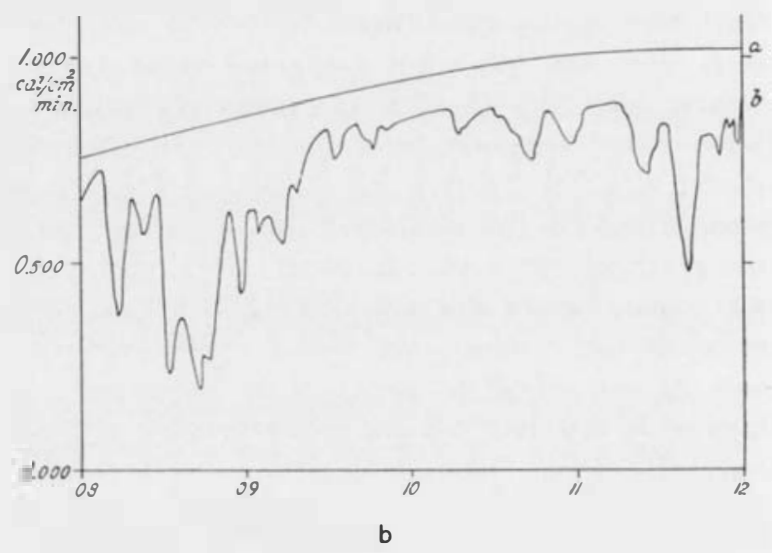
radiation in $\mathrm{cal} / \mathrm{cm}^{2} / \mathrm{min}(\mathrm{ly} / \mathrm{min})$.

$\begin{array}{llllll}\text { İime } & \text { Air temp. } & \begin{array}{l}\text { Water } \\ \text { v.p. }(\mathrm{mb})\end{array} & \begin{array}{l}\text { Long-wave } \\ \text { radiation balance }\end{array} & \begin{array}{l}\text { Total short-wave } \\ \text { radiation }\end{array} & \begin{array}{l}\text { Net thermal } \\ \text { radiation }\end{array} \\ 08.00 & +22.4 & 9.5 & -0.186 & 0.753 & 0.567 \\ 10.00 & +25.5 & 8.4 & -0.201 & 0.945 & 0.744\end{array}$

13). Lunelund showed very remarkable differences between the differently exposed slopes, partly due to the fact that the turbidity of the air decreases abruptly between latitudes 30 and $60^{\circ} \mathrm{N}$., making the diffuse component of light relatively small in the $\mathrm{N}$. In the extreme $\mathrm{N}\left(70^{\circ} \mathrm{N}\right.$. lat.) the conditions on slopes exposed to other directions than the $\mathrm{S}$ again become less inferior to those of the S-exposed slope, in summer, as the diurnal light period extends in length or even becomes continuous for a period.

The radiation curves for the year, taken as the radiation sum on clear days, have been calculated for $66^{\circ}$ N. Lat. (Fig. 13) and are based on values taken from publications by Aurén $(1939$, p. 24) for the horizontal surface and interpolated values from Lunelund (1940) for differently exposed slopes and vertical surfaces. The curves of Fig. $13 a$ are thus applicable to the conditions at vertical cliffs, except that for the horizontal surface, whereas the curves of Fig. $13 b$ are approximately applicable to the lower talus slopes. Immediately below a cliff the talus slope is shaded for some period of the day, and the condi- 
Table 3. The energy balance of a horizontal surface at a rise of the dark cliff of $60^{\circ}$ behind the measuring point (a) and the vertical cliff $(b)$, in the middle of the day and in the early morning before sunrise, in April, on the $S W$ exposed slope of Mt. Aistjakk

Long-wave radiation balance was calculated according to Lauscher using Brunt's formula (see the text). Total short-wave radiation was obtained by actinograph measurements. Assman aspiration psychrometer was used for obtaining air temperature and water vapour pressure at $150 \mathrm{~cm}$ above the ground. Clear or almost clear sky. Thermal radiation in $\mathrm{cal} / \mathrm{cm}^{2} / \mathrm{min}(\mathrm{ly} / \mathrm{min})$

\begin{tabular}{|c|c|c|c|c|c|c|c|c|c|c|}
\hline \multirow[b]{2}{*}{ Date } & \multirow[b]{2}{*}{ Time } & \multirow{2}{*}{$\begin{array}{l}\text { Air } \\
\text { temp. }\end{array}$} & \multirow{2}{*}{$\begin{array}{l}\text { Rockwall } \\
\text { temp. }\end{array}$} & \multirow{2}{*}{$\begin{array}{l}\text { Water } \\
\text { v.p. } \\
\text { (mb) }\end{array}$} & \multicolumn{2}{|c|}{ Wind vel. $\mathrm{m} / \mathrm{s}$} & \multicolumn{2}{|c|}{$\begin{array}{l}\text { Long-wave radiation } \\
\text { balance }\end{array}$} & \multirow{2}{*}{$\begin{array}{l}\text { Total } \\
\text { short wave } \\
\text { radiation } \\
\text { (a) }\end{array}$} & \multirow{2}{*}{$\begin{array}{l}\text { Net } \\
\text { thermal } \\
\text { radiation } \\
\text { (a) }\end{array}$} \\
\hline & & & & & hor. & vert. & (a) & (b) & & \\
\hline 22.4 & 13.30 & +0.4 & +20.0 & 2.8 & 2.2 & - & -0.135 & -0.135 & 0.881 & 0.746 \\
\hline 28.4 & 06.00 & -1.5 & +0.4 & 4.5 & 0.0 & 0.2 & -0.123 & -0.075 & 0.072 & -0.051 \\
\hline 28.4 & 07.00 & -0.3 & +1.5 & 4.6 & 0.5 & 0.2 & -0.124 & -0.076 & 0.131 & +0.007 \\
\hline 28.4 & 08.00 & +1.3 & +2.7 & 4.7 & 0.3 & 0.2 & -0.127 & -0.076 & 0.172 & +0.045 \\
\hline
\end{tabular}

tions are to some extent more similar to those of the cliff. The averages of the curves (not shown in the figures) will be applicable to the SW, NW, NE and SE directions.

The processes involved in the energy balance of these slopes are related to incoming and outgoing radiation and the difference between these, net (thermal) radiation. Thermal radiation is a term introduced to mean the total emission of electromagnetic waves, heat, light, or radio waves, by virtue of the temperature of an object (cf. Gates 1962, p. 60). Special attention must be paid to the two dissimilar topographic elements, cliff and talus slope, the radiation climates of which differ to a large extent, especially during late winter and spring. The shading effect of the cliff must be kept in mind, because it makes the adjacent sites relatively colder during certain parts of the day (Fig. 14 a, cf. also diagrams Fig. 16).

In the spring and early summer of 1966 some attempt was made to study the energy balance of the two opposite sides of Mt. Aistjakk near to stations 7 and 8 . The net thermal radiation could only be estimated approximately (cf. Geiger 1965, pp. 2022), and so could the evaporation, because of lack of instruments, but the other factors involved, air and soil temperatures at different levels, the temperature of the rock wall and the wind velocity (horizontal and vertical), were measured on the same occasions, during clear or almost clear days and nights.

During the month of April there are often very low minima at night followed by strong heating during the day especially of the rock wall which is already snow-free. Meltwater percolates into the crevices during the day, and, if the cooling at night is strong enough, it freezes, causing the rock to break. Stonefalls are often observable below the rock wall, in the month of April, through the marks they have made in the snow. However, the temperature condi- tions at night are indeed very favourable on mountain slopes, as compared to flat country. This is partly due to nocturnal inversion caused by reduction of the outgoing radiation from sloping country, in this case the precipitous cliff. A cliff that is heated during the day will be able to keep itself and the immediate vicinity warm even at air temperatures well below freezing-point. It will thus give rise to very early impulses initiating growth of the vegetation dormant there. The insolation on the cliff during the day is increased markedly by reflection from the snow covering the rest of the landscape. The conditions prevailing on four different occasions are shown above (Table 3 ).

When calculating the effective outgoing radiation we must assume approximately the same temperature conditions for the recording instrument, the ground and the cliff. The intensity of the diffuse light falling on the cliff in the early morning might be quite as large as that falling on a horizontal surface, because of light reflected from the snow, thus causing the net radiation to be positive. The calculations were also made with the assumption that the water vapour pressure at $150 \mathrm{~cm}$ above the ground was constant. It is possible to show mathematically that the effective outgoing radiation of a vertical cliff is half that of a horizontal surface completely open to the sky with atmosphere free from water vapour. Lauscher (according to Geiger 1965, p. 24) found a value of $39.2 \%$ at $5.4 \mathrm{~mm} \mathrm{Hg}$ or $7.2 \mathrm{mb}$ water vapour pressure. As the water vapour pressures were quite low in these cases the effective outgoing radiation was assumed to be somewhat higher than that calculated according to Lauscher. The formula used was Brunt's formula, with the constants ${ }^{1}$ given by

\footnotetext{
1 The constant 0.60 in the equation $R_{B}=\sigma T_{0}^{4}(0.48+0.60$
} $\sqrt{\varepsilon_{0}}$ ) should be 0.060 (Liljequist, personal communication). 
Table 4. The position of the thermometer screens and the numbers and heights of the stations

The heights given are averages of about 5 readings. The deviation of a single reading from the average calculated is $\pm 8 \mathrm{~m}$ (Paulin altimeter)

\begin{tabular}{lllllr}
\hline Station no. & Topography & Ground & $\begin{array}{l}\text { Slope and } \\
\text { exposure }\end{array}$ & $\begin{array}{l}\text { Height } \\
\text { above sea } \\
\text { level, } \mathrm{m}\end{array}$ & $\begin{array}{l}\text { Height above } \\
\text { the valley } \\
\text { bottom }\end{array}$ \\
\hline 1 & Peninsula & Forest heath & $0^{\circ}$ & 427 & 3 \\
2 & Pasture & Grass plain & $0^{\circ}$ & 442 & 18 \\
3 & Mire & Mire peat & $0^{\circ}$ & 437 & 13 \\
4 & Slope & Scree & $36^{\circ} \mathrm{S}$ & 584 & 160 \\
5 & Hill-top & Rock & $0^{\circ}$ & 644 & 220 \\
6 & Mire & Mire peat & $0^{\circ}$ & 455 & 36 \\
7 & Slope & Scree & $33^{\circ} \mathrm{SW}$ & 555 & 136 \\
8 & Slope & Scree & $32^{\circ} \mathrm{NE}$ & 557 & 138 \\
\hline
\end{tabular}

Möller (1951, p. 39). Angström's formula (1916) gave about the same results. The media were taken to be completely black (in the case of the rock wall the measured temperatures of the dark surfaces were taken into account).

During the dry and warm period of 8-21 June there was a great difference in wind velocities and thus in turbulence of the air between the two opposite slopes of Mt. Aistjakk, even at night. This was due to SE to SW winds which tended to last throughout day and night. As the predominant winds in these parts of Lappland are normally from a WSW direction during the warm season (cf. Angström 1958, p. 96, also the author's own experience), there is an energy loss because of this from the SW slope, which should not be neglected.

In the weeks around midsummer the diffuse light at nights is quite strong at this latitude and is said to be sufficient for the plants to carry out photosynthesis (Müller 1928, pp. 22 et seq.). Björkman \& Holmgren (1963, p. 896) found net photosynthesis at $22{ }^{\circ} \mathrm{C}$ in most plants of Solidago virgaurea at light intensities lower than $0.014 \mathrm{ly} / \mathrm{min}$; in low temperatures carbon dioxide uptake is initiated at even lower light intensities.

Very little is known about questions of photosynthetic response in different plant ecotypes (ecoclines) in regard to their photosynthetic activity in nature at very low light intensities. It is possible that ecological races in different habitats in the same area might reacting quite differently to light of different intensities. There is also the question of changing seasonal response to light of different wavelengths and the interaction of temperature, soil conditions and eventual diseases (Jarvis, P. G. 1964).

Another factor giving the sun-exposed habitats an advantage is the late foliation of the aspen trees, which cast very little shade in spring and thus allow an early almost explosive development of the field layers (Figs. $14 b$ and 39). Even in the middle of the summer when the leaves are developed the intercepted diffuse component of daylight may be quite low and amount to about 15-30\% (Mt. Märkepakte, actinograph measurements).

\section{The thermometer screens and their placing}

The thermometer screens used in the present investigation have been constructed according to those used in the meteorological network of Sweden, cf. the description in Handbok för väderleksobservatörer (1944, p. 22), and Grundmann's description in Linke's Meteorologisches Taschenbuch, III. Band (1957, p. 274). The thermometers were placed at a height of ca. $160 \mathrm{~cm}$ above the ground, while the bimetal strip in the thermographs was at a height of ca. $150 \mathrm{~cm}$.

As is apparent from the profile (Fig. 15) through the terrain around Hällbacken $\left(66^{\circ} 14^{\prime} \mathrm{N}, 16^{\circ} 58^{\prime}\right.$ E), the screens were set up at different levels and in places with different local climate on the mountain $\mathrm{N}$ of Hällbacken and in the valley. In 1965, screens were also set up on the sides (nos. 7 and 8) of Mt. Aistjakk $\left(66^{\circ} 5-6^{\prime} \mathrm{N}, 17^{\circ} 16^{\prime} \mathrm{E}\right)$, situated $20 \mathrm{~km} \mathrm{SE}$ of Hällbacken, and on a nearby mire (no. 6).

Station no. 1, the Peninsula: In this screen there were only maximum and minimum thermometers. The station was placed at the highest watermark level of Lake Storlaisan (average lake level $424 \mathrm{~m}$ ) at the edge of a pinewood on the shore rim. The screen was freely exposed towards the S and SW. For practical reasons the station had to be put in this position, to some extent influenced by the nearby wood, although a better place would have been on a small bare islet off the peninsula. This station was set up in order to study the lake climate as compared especially with the mountain climate and that of the valley. The lake at this place is $1 \mathrm{~km}$ wide and its greatest depth is ca. $30 \mathrm{~m}$. 
Station no. 2, the Pasture: in this place a thermograph was also placed. The station is on open grassland ca. $20 \mathrm{~m}$ from the nearest building and $10 \mathrm{~m}$ from a little birch wood (Fig. 12). It is freely exposed in all directions. Pine forest occurs at about $50 \mathrm{~m}$ from the screen. Although the ground is quite level at the station, the general inclination in this place ( $200 \mathrm{~m} \mathrm{~N}$ of the Lake) is towards the S, thus giving the station a favourable valley bottom situation.

Station no. 3, the Hällback Mire. Only maximum and minimum thermometers have been used in this screen. The ground was drained mire peat on a large, open and partly cultivated mire. The mire peat is covered by grass and sedge with willows, in some places. The depression in which the mire is situated is some $500 \mathrm{~m}$ long and $200 \mathrm{~m}$ wide. There is forest at a distance of ca. $75 \mathrm{~m}$ from the screen.

Station no. 4, the Slope of Mt. Storberget. The station is freely exposed towards the $\mathrm{S}$ and there are no trees in the immediate neighbourhood. The ground is scree covered by meadow vegetation (partly tall herbs). The screen is $3 \mathrm{~m}$ from the cliff, which is small, only about $10 \mathrm{~m}$ high and $50 \mathrm{~m}$ broad, and consists of dark schist. The talus slope is also low, ca. $10 \mathrm{~m}$, with birch forest immediately below (Fig. 24).

Station no. 5, the Hill-top (Mt. Storberget is still higher behind, as shown on Fig. 4). This station was used only for short periods. Maximum and minimum temperatures were observed. The ground is open bare rock in front of low-grown birchwood. At the same level, about $50 \mathrm{~m} \mathrm{~N}$ of the screen there is a $5 \mathrm{~m}$ tall pine (Pinus silvestris). This is the highest recorded occurrence of pine on the hill.

Station no. 6, the Aistjakk Mire. This screen was placed in a small "flark" (mud-bottom area) and thus was in quite a wet place on the mire. The nearest forest is about $100 \mathrm{~m}$ from the screen. This means that this station is the one most freely exposed.

Station no. 7, the SW Slope on Mt. Aistjakk. The habitat is similar to that of station no. 4. There is no tree layer. The distance to the rock wall, which consists of sandstone, arcose and schist, is $3 \mathrm{~m}$. The cliff above is precipitous in most places and ca. 20$30 \mathrm{~m}$ high. It extends laterally for several hundred metres. The talus slope below the station is about $65 \mathrm{~m}$ in vertical height.

Station no. 8, the NE Slope of Mt. Aistjakk. The habitat is boulder scree, in the upper part overgrown with Picea-Vaccinium-wood with herbs intermingled. The cliff above is about $10 \mathrm{~m}$ high; the distance to it, along the slope, is $14.5 \mathrm{~m}$; the distance to the level

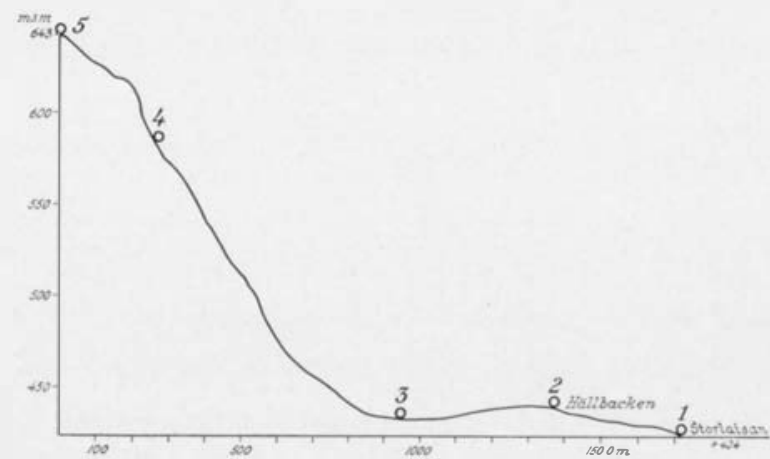

Fig. 15. Cross section at Hällbacken showing the stations nos. $1-5$. The height scale is somewhat exaggerated.

forest ground below the scree, $15 \mathrm{~m}$. The screen is not shaded by trees.

\section{Monthly mean temperatures of the stations and the dependence on the weather}

One of the usual ways of defining a climate is to give figures for the mean monthly and yearly temperatures. As only certain parts of the vegetation period have been included in the study, an account will be given of the monthly means during the vegetation period in fairly interesting years (1965-66) when all the important stations were in use. By studying the local climate of the observation stations, which are generally in localities differing more or less from the macroclimate of the area, we get an idea of the general climatological features of the localities and their dependence on the weather fluctuations. In comparing them with the meteorological network of Sweden, one will have to make comparisons with stations the local features of which differ to a large extent due to their situation. In the Swedish mountains they are as a rule valley bottom stations set up in inhabited areas and differing microclimatologically in the height of the instruments above the valley bottom and the ground surface, the exposure to average winds and to the sun, etc. Except for the height above valley bottom and ground surface (Table 5), these differences could not be defined more closely.

The local climate at stations nos. 2, 4, 6, 7 and 8 was thus compared to the standard climate of some nearby stations of the meteorological network of Sweden. Of these, Arjeplog is the nearest, situated 30 $\mathrm{km} \mathrm{E}$ of stations $6-8$, and $47 \mathrm{~km}$ ESE of stations I-5 (in use only since 1946). Kvikkjokk is $90-100$ $\mathrm{km}$ NNE and Tärnaby $100 \mathrm{~km}$ SW of the stations. The stations used for comparison have in general a favourable valley bottom situation and have quite high average temperatures during the warm seasons. 

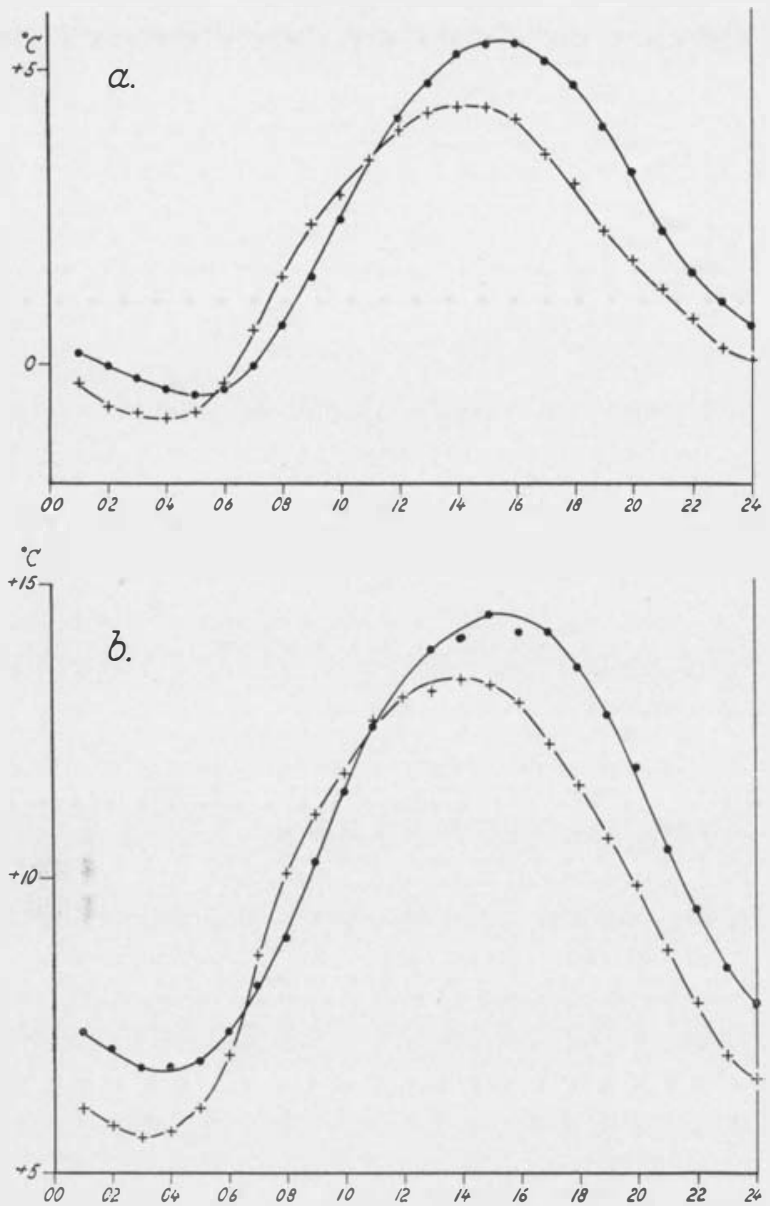

Fig. 16. Diurnal temperature variation, in average, at some mountain and valley bottom stations during the vegetation periods of 1965-66. Weather conditions, see text. (a) In May, 1965, in spite of a general sunshine deficit, there was a conspicuous difference between the S- and the SW-facing sides of Mt. Storberget (St. no. 4) and Mt. Aistjakk (7). The more westerly situation of station no. 4 is probably of some significance as a temperature lowering factor, together with the narrower valley, and probably also the difference in exposure and the shape and height of the cliff, whereas the difference in elevation is almost negligible $(\mathrm{ca} .30 \mathrm{~m})(b)$ In June 1965 there were similar tendencies to May, when the two slopes are compared. (c) The difference between the slope of Mt. Storberget (4) and the valley bottom (2) has been thoroughly dealt with in the text. The difference in the diurnal variations is presented according to thermograph data for July 1965. (d) The valley bottom at Hällbacken (2) which has a favourable valley bottom situation and is at a lower elevation is nevertheless definitely colder than the SW side of Mt. Aistjakk (7). The climate of this slope would be expected to be representative of the SW-exposed slopes with cliffs of the Caledonian border in the region (Fig. 2). The mire near Mt. Aistjakk (6) has the least favourable situation, although it is $100 \mathrm{~m}$ lower. July 1965. (e) The month of August shows similar tendencies to July, and thus the SW slope is strikingly warmer. Only for a short time in the morning, while the SW slope is in shade, is the mire warmer than the slope. $(f)$ In September the conditions are changed. The higher temperature of the slope during periods of insolation is now quite inconspicu-
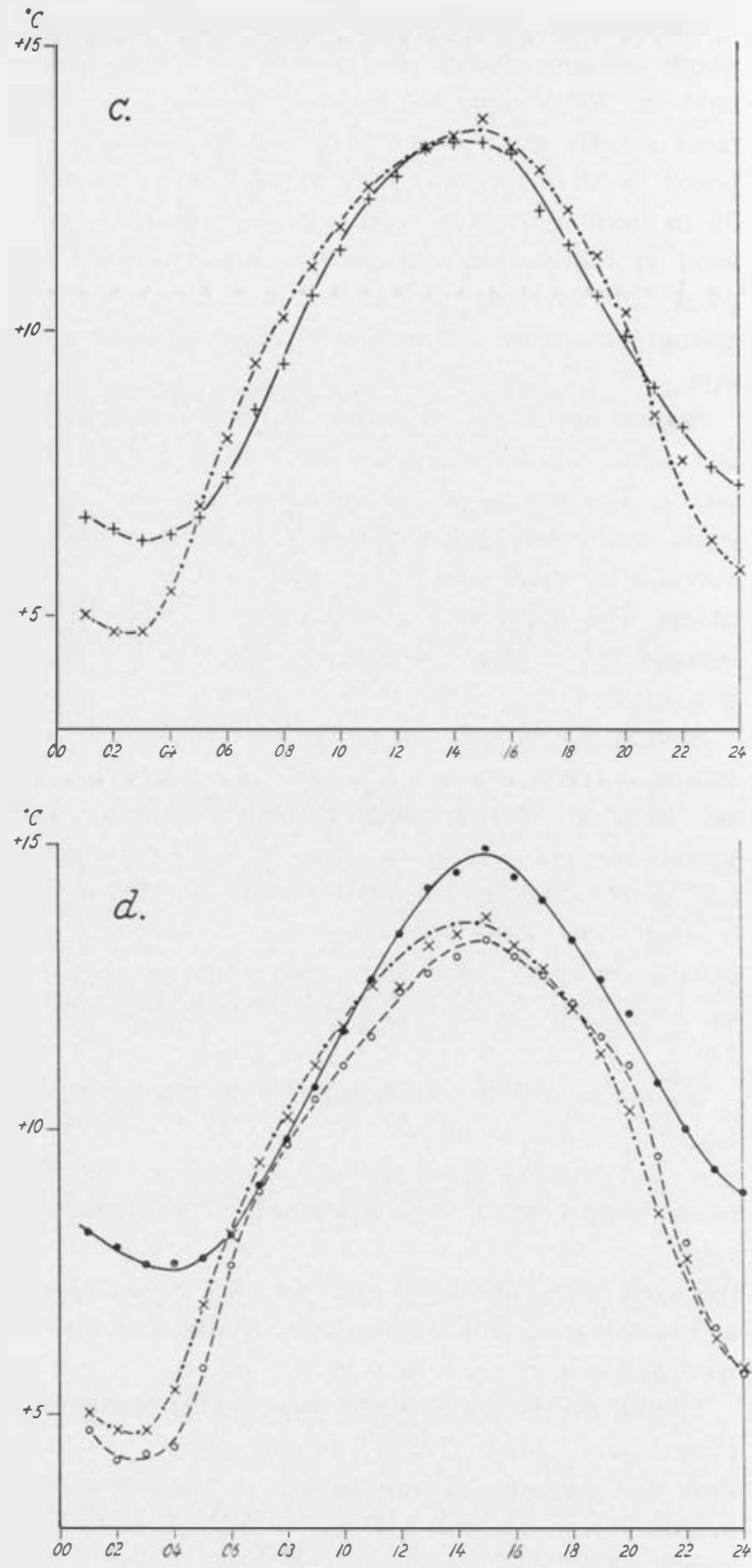

ous, while it is still warmer at minimum temperatures because of the inversions at night. $(\mathrm{g})$ June 1966 was very sunny and warm (see text) and the temperatures of the SW slope (7) were much higher during the warm part of the day, than those of the NE slope of the same mountain (8). (h) July 1966 was quite cool and low in sunshine compared with June. Therefore the SW slope received less extra heat energy during the day. The differences in monthly mean temperature (day and night) between stations nos. 7 and 8 are quite insignificant both for June $\left(0.5^{\circ}\right)$ and for July $\left(0.4^{\circ}\right)$. The symbols are as follows: Hällbacken (2): -*-x ---; Mt. Storberget (4): $-+\_$; The Aistjakk mire (6): $---\mathrm{O}---;$ Mt. A., SW slope (7): —_-_ (8): --- $\square---$. 

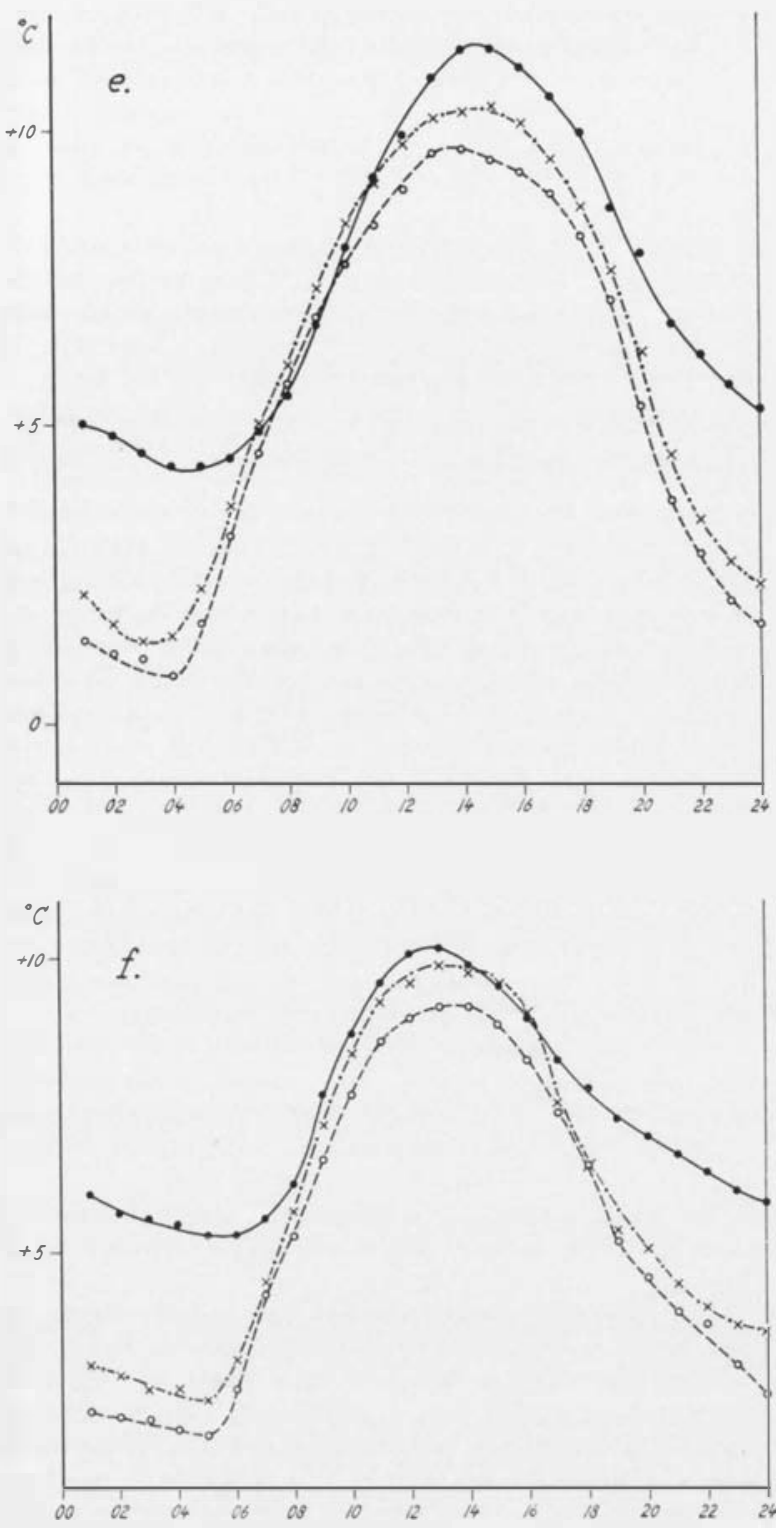

Tärnaby is more influenced by Atlantic winds, due to its considerably more $\mathrm{W}$ situation.

To get a real picture of the favourable effect of the mountain-sides one would have to recalculate the values of the compared stations to coincide in height and latitude with the station in question. With regard to the difficult question of the dependence of temperature on height and latitude for $\mathrm{N}$ Swedish stations, reference may be made to investigations by Johansson (1927), Ångström (1938), and Rudberg (1957, p. 41). Another important factor to remember when comparing the stations is the deviation from the normal temperatures which differs to a large extent from month to month and from station to station. Considering all these factors, we get positive
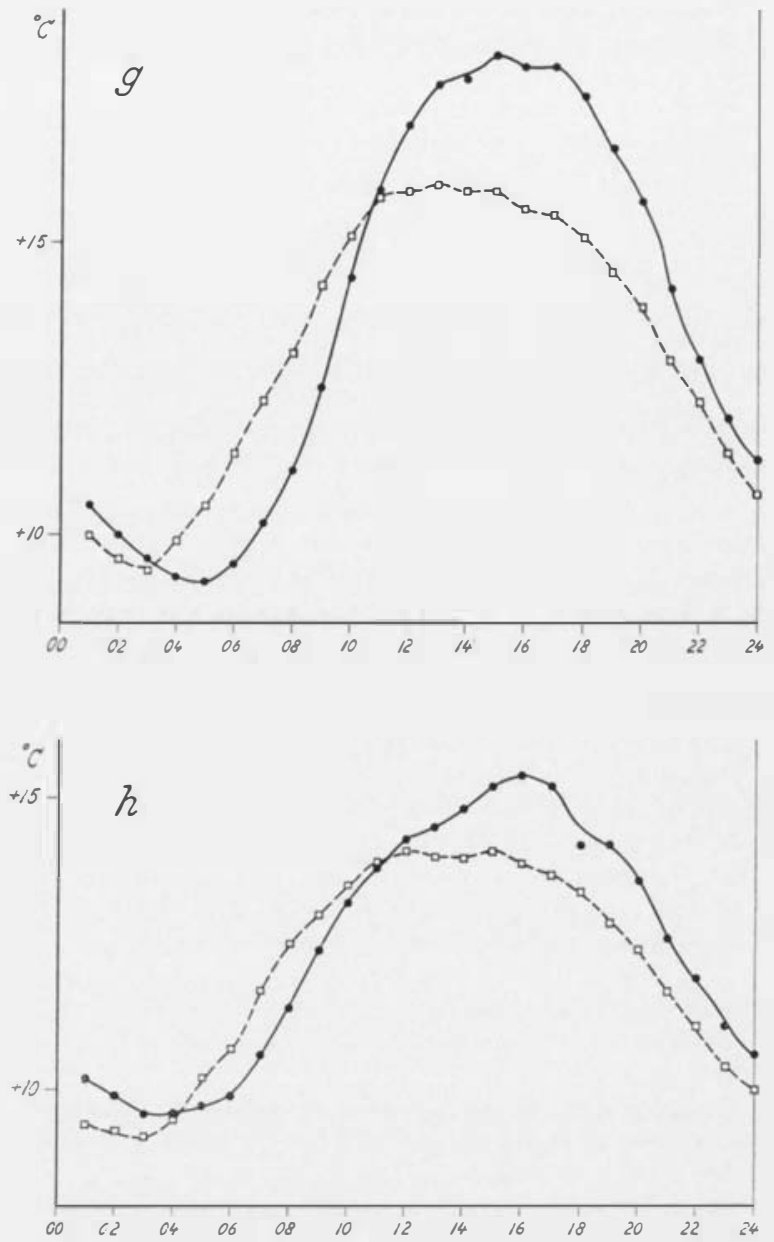

anomalies for the mountain stations that are quite remarkable. See Table 5 (behind the text).

A short account of the weather fluctuations in the different months of 1965-66 follows, as they are of some interest in interpreting the values recorded. See also, Fig. 16. The situation of the provinces are obtained in The Plant Cover of Sweden (APhS 50, 1965, p. X).

May 1965. The weather was colder than normal over the whole country and there were night frosts until the last days of the month even on mountain slopes. The deviations from the normal temperature values were largest in the $\mathrm{E}$ of Lappland, where the deficit was more than $3^{\circ}$. A larger deficit than $3^{\circ}$ occurs only about once in 30 years in this area. The period 15-22 May was especially cold with heavy snow fall even in inland areas of $\mathrm{S}$ Sweden. The maximum temperatures were unusually low as there were no warm periods, e.g. at Kiruna $+3.8^{\circ}$ was the highest temperature of the month.

Snow cover in the Swedish mountains was deeper than normal and even at the end of the month there were unusually large masses of snow.

Sunshine duration was less than normal in the $\mathrm{N}$, the deficit at the most amounting to $15-20 \%$.

June 1965. The cold Polar Sea air that dominated the 
weather in Sweden during May was replaced by definitely warmer air masses in $\mathrm{N}$ Sweden at the beginning of June. On 3 June an anticyclone became established over Scandinavia and the temperature was considerably higher over the whole country. In N Sweden colder air began to penetrate on 9 June. On 15 June the weather situation was radically changed and moist SW winds from the Atlantic pushed up to N Europe. Unstable weather dominated until the end of the month. The mean temperature showed no large departure from the normal; the largest departures were in northernmost Sweden with a deficit about $1^{\circ}$.

The sunshine duration was lower than normal in the whole country except at Abisko, N Lappland, where there was an excess of ca. $20 \%$. In the rest of $\mathrm{N}$ Sweden there were deficits of $5-10 \%$.

July 1965. At the beginning of the month there was a deep low over N Scandinavia and a high over Iceland and Greenland. Because of this, an unusually chilly northwesterly air current prevailed over Sweden. The weather was unstable with rain showers. The first half of July was the coldest this century. On 15-16 July there was a complete change in the weather situation. A high pressure spread from the Norwegian Sea out over Scandinavia, remained there and built up still more. In Sweden the nights were remarkably cold for a time $\left(-4.0^{\circ}\right.$ on 16 July at L.jusnedal, Härjedalen) because of the large outward radiation flux through the dry and clear air, but the day temperatures rose considerably. After 24 July cold air again began to stream down from the Polar Sea, causing cool and unsteady weather during the last week of the month. Deficits of $2.5-3.5^{\circ}$ in the mean temperature of the month were general.

Deficits of $10-20 \%$ of the normal duration of sunshine were general in the North.

August 1965. At the beginning of August the unsteady and cool weather that had obtained during the greater parts of July continued. There was rain in the whole country. About 10 Aug. a high pressure over the North Sea and the Norwegian Sea slowly penetrated into W Scandinavia. Because of this the weather improved in $\mathrm{W}$ Sweden where the day temperatures rose to quite high values. During the clear nights there was frost here and there in Norrland and even in N Svealand. On 20 Aug. the weather again entered an unstable phase with several depressions and rain areas. Cool air from the Polar Sea penetrated down into W Europe, while there were warm southerly winds in E Europe. Sweden was in a border area and parts of the country were at times touched by the warm air. Norrland was warmer than usual after about 24 Aug.

For the whole country the mean temperature for August lay below the means for the period 1931-60. The smallest deficits, ca. $1^{\circ}$, were in the inland parts of Lappland. There was frost in the inland parts of $\mathbf{N}$ Sweden, on as many as 5 occasions at some stations.

The recorded sum of sunshine hours was lower than normal at practically all the Swedish stations. In the $\mathbf{N}$ of Norrland there were only $0-2$ days with clear weather. The total number of days with completely cloudy weather was $15-20$ in the greater part of Norrland.

September 1965. During the earliest days of the month Scandinavia lay under a ridge of high pressure and the weather was bright over practically the whole country. On 3 Sept. a depression over Central Europe caused unstable weather. After that a high pressure area over Central Europe dominated until a depression on 18 Sept., while deepening, was moving from Ireland to the North Sea. The next day the depression had its centre over Finland. Within a strong south- westerly air current over the $\mathrm{N}$ Atlantic and $\mathrm{N}$ Scandinavia a series of feeble rain areas moved eastwards. On 24 Sept. a high pressure centre had moved to $\mathrm{W}$ Russia and a warm southerly to south-easterly air current was established over Scandinavia. Haze and mist characterized this air mass. At the end of the month rain areas moved northwards from the $\mathrm{S}$.

The mean temprature in $\mathrm{N}$ Sweden (Norrland) was $1-2^{\circ}$ higher than normal. It was especially during the first and the last third of the month that the temperature stayed above the normal for the season. The maximum temperature in Norrland lay as a rule between 17 and $21^{\circ}$ (on 2-4 Sept.).

The days with cloudy weather were most numerous, a little over 20, in the Scandes of Lappland and $\mathbf{N}$ Jämtland. The duration of sunshine hours was definitely less than normal.

June 1966. The first week was cool in the whole country. There was some rain due to a low pressure area passing Scandinavia. On 7 June a high pressure was built up over Scandinavia and $\mathrm{N}$ Russia giving successively increasing day temperatures. In $\mathbf{N}$ Sweden there were finally values quite unique for the month of June and severe drought was developed due to the relatively windy weather. (In the Scandes where snow remained very late no real damage was seen.) In Norrbotten and Lappland the maximum temperature was generally above $+30^{\circ}$ on $19-20\left(+33.8^{\circ}\right.$ on 19 at överkalix, Norrbotten). After 20 June there was a retreat of the warm weather and on 22 a cold front gave rain mixed with snow in northernmost Lappland, with day temperatures about $20)^{\circ}$ lower than they had been two days earlier. During the last days of the month the day temperatures were again increasing in the $\mathbf{N}$ and central parts of the country.

The mean temperature of the month was higher than normal over the whole country. The greatest excesses, $3.5-4.0^{\circ}$ were in the central parts of Norrland. The mean temperature +16.2 at Härnösand, Angermanland, is the highest recorded there for June since observations started in 1859 .

The sunshine duration was longer than normal in Norrland, especially in the area around Abisko in northernmost Lappland.

July 1966. The weather was cool and unstable during the first half. Low pressure areas dominated over $\mathrm{N}$ Eırope. On 17 July there was a change to more stable but still quite cool weather, due to cool westerly winds over $\mathrm{N}$ Norrland. After that followed a period of rainy but relatively warm weather lasting till 29 July. Then cold air from the Polar Sea streamed down over the area bringing about a striking drop in temperature. At the end of the month a low pressure area dominated $\mathbf{N}$ Europe bringing rain in most places.

The mean temperature of the month was $\left(0-1^{\circ}\right.$ lower than normal in most of Sweden, with deficits of somewhat more than $1^{\circ}$ in $\mathrm{W}^{\prime}$ and $\mathrm{S}$ Lappland and some other parts of Norrland.

Sunshine duration in Norrland was as a rule somewhat less than normal; in the Scandes there were larger deficits.

A gradient of great importance in the c.imate of $\mathbf{N}$ Sweden is the degree of continentality, which is dependent on the distance from the Atlantic and, to a certain extent, from the Gulf of Bothnia. In Angström's (1938) terms, the major parts of the Swedish mountains are included in a local maritime area. Its E boundary varies in its distance to the Atlantic, being influenced by the location of large fiords on the Norwegian coast, large massifs of high mountains 
Table 6. Comparison of the stations Arjeplog and Jäckvik

Distance from the Atlantic coast 200 and $150 \mathrm{~km}$, respectively. Average monthly and yearly means for the period $1946-60$

\begin{tabular}{|c|c|c|c|c|c|c|c|c|c|c|c|c|c|c|}
\hline & $\begin{array}{l}\text { Height } \\
\text { (m) above } \\
\text { sea level }\end{array}$ & $\begin{array}{l}\text { Janu- } \\
\text { ary }\end{array}$ & $\begin{array}{l}\text { Feb- } \\
\text { ruary }\end{array}$ & March & April & May & June & July & August & $\begin{array}{l}\text { Sep- } \\
\text { tember }\end{array}$ & $\begin{array}{l}\text { Oc- } \\
\text { tober }\end{array}$ & $\begin{array}{l}\text { No- } \\
\text { vember }\end{array}$ & $\begin{array}{l}\text { De- } \\
\text { cember }\end{array}$ & Year \\
\hline Jäckvik & 430 & -14.6 & -13.9 & -7.8 & -1.7 & +4.2 & +10.0 & +12.9 & +11.0 & +6.4 & -0.1 & -6.4 & -10.6 & -0.8 \\
\hline Arjeplog & 429 & -13.6 & -13.0 & -7.7 & -1.6 & +4.1 & +10.0 & +13.4 & +11.7 & +7.0 & +0.3 & -5.9 & -10.0 & -0.5 \\
\hline
\end{tabular}

etc. Along this boundary, the heights are much more influenced by the maritime air than are the valleys, which tend to be more continental (also as a result of frequent nocturnal invarsions). As a general rule, heights above $500 \mathrm{~m}$ can be referred to the localmaritime area (Ångström 1958, p. 33). This means that the easterly stations generally show a comparatively continental type of climate but that the localmaritime influences at a particular point are highly dependent on its altitude and especially on its height above the valley bottom. The expressions of maritimity differ with season. In winter the trees immediately below the upper limit of the forest in the area studied are often free of snow and hoar-frost, while in the lower parts of the valley the conifer trees are heavily snow-clad and the birches hoar-frosted, thus indicating that thaw and other maritims influence has been only at higher altitudes. The coldest minimum temperatures are found both in the mountain valleys and to the $\mathrm{E}$ of the Swedish mountains; thus the situation of local cold-centres in and $\mathrm{E}$ of the Swedish mountains is very variable (cf. Atlas över Sverige, 25-26). On average, for longer periods of years, the early cover of ice in the Gulf of Bothnia has an influence on the continentality of the climate in winter (Ångström). In summer the more easterly stations will generally have the highest temperatures. Although the distance to the Gulf of Bothnia is somewhat greater than to the Atlantic the path is not obstructed by mountains, and when winds are easterly the weather prevailing near the Bothnian coast easily influences the $E$ parts of the Swedish mountains.

The difference in maritimity-continentality is observable over quite short horizontal distances; thus Arjeplog has a distinctly more continental type of summer climate than the stations nos. 1-8. Pairs of stations may be used for a more elaborate comparison. Such pairs are Jokkmokk (E) and Kvikkjokk (W) in Lule Lappmark (Hamberg 1908, p. 24; Ångström 1938), or in PL Arjeplog (E) and Jäckvik $\left(\mathrm{W}\right.$; at $66^{\circ} 23^{\prime} \mathrm{N}, 16^{\circ} 59^{\prime} \mathrm{E}$; meteorological observations since 1931). A comparison between the latter two stations (Table 6) is valuable as Jäckvik is situated only $15 \mathrm{~km} \mathrm{~N}$ of station no. 2 Hällbacken (along a line almost parallel to the Atlantic shore), so that the maritimity at Jäckvik should be almost the same as at Hällbacken, at least in summer.

Thus in winter Jäckvik, the more westerly situated station, is more continental while the reverse is true in summer. In spring and autumn, differences are insignificant.

A comparison of Hällbacken (station no. 2) and Jäckvik involves the influence of valley exposure. Jäckvik is a valley bottom station to the $\mathrm{N}$ of a high mountain (Mt. Peljekaise, Fig. 4), and Hällbacken (stations nos. 1-5) is to the $\mathrm{S}$ of it. However, no general trend due to the valley exposure is evident, because of the capriciousness of temperatures in the Swedish mountains.

Angström (1938) used "standard" stations for the construction of anomaly charts after the values were

Table 7. Comparison of Hällbacken (station no. 2, true means) and other stations in unfavourable (Jäckvik) and favourable (Arjeplog, Kvikkjokk, Tärnaby) valley bottom locations

Means for single months during the vegetation periods of 1960-62

\begin{tabular}{|c|c|c|c|c|c|c|c|c|}
\hline & \multicolumn{2}{|l|}{1960} & \multicolumn{3}{|l|}{1961} & \multicolumn{3}{|l|}{1962} \\
\hline & July & August & May & June & July & July & August & September \\
\hline Hällbacken & +13.6 & +11.4 & +3.7 & +10.7 & +12.7 & +11.0 & +8.8 & +4.3 \\
\hline Jäckvik & +12.9 & +11.8 & +4.1 & +10.8 & +13.6 & +10.3 & +8.7 & +4.3 \\
\hline Arjeplog & +14.5 & +12.7 & +3.7 & +11.4 & +13.9 & +11.9 & +10.4 & +5.3 \\
\hline Kvikkjokk & +14.9 & +12.7 & +4.7 & +11.8 & +14.1 & +11.8 & +9.9 & +5.5 \\
\hline Tärnaby & +13.5 & +11.7 & +4.0 & +10.2 & +12.0 & +10.7 & +9.3 & +5.3 \\
\hline
\end{tabular}


Table 8. Number of frost nights (a), and frost frequency in $\%(b)$ of stations 1-5

\begin{tabular}{|c|c|c|c|c|c|c|c|c|c|c|c|}
\hline \multirow[b]{2}{*}{ Period } & \multirow[b]{2}{*}{ Season } & \multicolumn{2}{|c|}{$\begin{array}{l}1 \\
\text { Peninsula }\end{array}$} & \multicolumn{2}{|c|}{$\begin{array}{l}2 \\
\text { Pasture }\end{array}$} & \multicolumn{2}{|c|}{$\begin{array}{l}3 \\
\text { Mire }\end{array}$} & \multicolumn{2}{|c|}{$\begin{array}{l}4 \\
\text { Slope }\end{array}$} & \multicolumn{2}{|c|}{$\begin{array}{l}5 \\
\text { Hill-top }\end{array}$} \\
\hline & & (a) & (b) & (a) & (b) & (a) & (b) & (a) & (b) & (a) & (b) \\
\hline \multicolumn{12}{|l|}{1959} \\
\hline 9-31 July & High summer & 0 & 0 & 2 & 9 & 4 & 17 & 0 & 0 & 0 & 0 \\
\hline 1-23 Aug. & Late summer & 0 & 0 & 3 & 13 & 5 & 22 & 0 & 0 & 0 & 0 \\
\hline 24 Aug.-15 Sept. & Early autumn & 1 & 4 & 4 & 17 & 6 & 26 & 1 & 4 & 0 & 0 \\
\hline 16 Sept.-8 Oct, & Late autumn & 9 & 39 & 9 & 39 & 12 & 52 & 10 & 44 & - & 一 \\
\hline 9-31 Oct. & Early winter & 14 & 61 & 14 & 61 & 16 & 70 & 15 & 65 & - & - \\
\hline \multicolumn{12}{|l|}{1960} \\
\hline 9-31 July & High summer & 0 & 0 & 0 & 0 & 0 & 0 & 0 & 0 & 0 & 0 \\
\hline 1-23 Aug. & Late summer & 0 & 0 & 0 & 0 & 1 & 4 & 0 & 0 & 0 & 0 \\
\hline
\end{tabular}

reduced to sea-level. By this means he computed the average long-term conditions of climate. Should somewhat more "extreme" stations than those referred to for comparison (Kvikkjokk, Tärnaby and here also Arjeplog) be used, he suggested (p. 22) that the anomaly charts would have a more detailed character. Only when the long-term values for the differently exposed slopes are included on such charts could the real characters of the exposure and valley bottom climates be estimated.

With regard to the classification of continentality by Angström it must be emphasized (cf. Hintikka 1963, p. 15) that the same yearly course of temperature is regarded as either oceanic or continental depending on the latitude at which the temperature is observed and the time of year. Reducing the mean monthly values to sea-level as done by Angström enables an evaluation of the oceanity-continentality gradient, but is not the only climatological method used by meteorologists and phytogeographers for the classification of these factors in NW Europe (see Hintikka 1963). Classifying the oceanity-continentality gradient according to the unreduced means for the warmest and coldest months for a series of years (op. cit. pp. 6-8, for the climatological features of PL see especially observation stations nos $\mathrm{S} 9,11,15,21)$ and having regard also to the amount of precipitation during the vegetation period (op. cit., p. 10), good agreement is obtained with the phytogeographical characters of PL. Because of the relatively high winter minima to be expected (Fig. 19; see also above) and the good supply of precipitation on the windward side of steep hillsides (see below p. 59), there should also be a fairly good agreement between this climatic classification and the phytogeographical characteristics emphasized (see the chapters on the flora and the vegetation below).

\section{Minimum temperatures}

The investigation started out with the observation of maximum and minimum temperatures which were related to the prevailing weather conditions. Attention was drawn to the importance of nocturnal inversions and the freque:ncy of night frosts during the vegetation period.
To compare the frost frequency at the different stations the vegetation period was divided into periods of 23 days each, and the frost nights at the different stations counted. By dividing the vegetation period in such a way better agreement is obtained for special periods of summer to early winter than the usual dividing into months.

It is evident from the above (see also, Fig. 18) that the S-facing slope, as far as nocturnal minima in 1959 are considered, was at an advantage during late summer, but that this advantage rapidly diminished during autumn and early winter. This advantage of the S-facing slope is dependent on the weather situation. During the late summer of 1959 , stable and dry weather was prevalent over N Scandinavia, and a stable high pressure promoted a large outgoing radiation flux at night (continental air mass, cf. Geiger 1965, p. 436). Because of this the differences in minimum temperatures between the valley bottom and the mountain slope were usually large. During late August 1959 there was a change to cold maritime air with windy weather which diminished the advantage of the S-facing slope in this respect (Lundqvist, J. 1965, p. 217). This was also true of the conspicuous lowering of the temperature at the lake surface, the high temperature of which was evidently due to high insolation in early August.

In a particular region there is a regular recurrence of special meteorological conditions the character of which is related to the area of origin of a moving air mass (see text-books on meteorology). In summer the strongest temperature inversions and hottest days occur in connection with continental air masses (abbreviated $c$, see Figs. 18-19). The winds are often slack and the turbidity is high. With maritime air of polar maritime origin, are associated brisk winds, high cloudiness and air humidity and small temperature inversions, also lower day temperatures (see Geiger, Woelfle \& Seip 1933-34, who made a comprehensive study of the importance of the different air mass conditions and the climate of elevated sites). 
In high summer, 1960, the weather conditions were quite different from the corresponding period in 1959. Scandinavia was then mostly in a border area between very warm air over Russia, Finland and the Baltic States and cold air over the North Sea and the British Isles. Thunder fronts with rain occurred, frequently followed by warm air brought into the $\mathrm{N}$ parts of Scandinavia. There were unusually high minimum temperatures and temperature inversions were feeble.

During the late summer of 1960 (1-23 August), the weather situation was again quite normal, although temperatures were above normal in $\mathrm{N}$ Sweden. The temperature inversions were far less striking than during the corresponding period of 1959.

Similar examples to those mentioned above were observed in all the years when climatological studies were made, but, as they are largely of the same type, reference may be made to Figs. 18-20, dealing with one valley-bottom station (2) and one mountain slope station (4). Change from periods with strong nocturnal inversions to periods with less pronounced inversions is again markedly' influenced by the weather situation and air mass prevailing.

Naturally the extremes are quite important to plant growth as lethal conditions might be reached (cf. Dahl, E. 1966) but one will never be able to ignore the average conditions of climate as expressed in some single parameter or in the combination of an arranged coordinate system (Hintikka 1963). Calculation of the average minima for the corresponding periods in 1959-60 gives still clearer evidence about the favoured situation of the S-facing scree with regard to the nocturnal minima in summer.

\begin{tabular}{lcccc}
\hline \multicolumn{5}{c}{ Station no. } \\
\cline { 2 - 5 } Period & 1 & 2 & 3 & 4 \\
\hline 1959: & & & & \\
9-31 July & +5.9 & +4.4 & +3.6 & +7.3 \\
1-23 Aug. & +6.4 & +4.7 & +3.7 & +8.6 \\
24 Aug.-15 Sept. & +4.5 & +3.5 & +2.2 & +3.8 \\
16 Sept.-8 Oct. & +1.7 & +0.7 & -0.1 & +1.4 \\
9-31 Oct. & -2.1 & -2.9 & -3.8 & -2.3 \\
1960: & & & & \\
9-31 July & +10.5 & +9.5 & +9.4 & +10.5 \\
1-23 Aug. & - & +7.4 & - & +9.6 \\
\hline
\end{tabular}

The values of station no. 5 (Hill-top) were ignored as they differ very little from those of no. 4 .

The mean minimum monthly temperatures were calculated for 1965-66 and these were compared with the meteorological network of Sweden (Tab'e 5). It is evident that the mountain slope stations
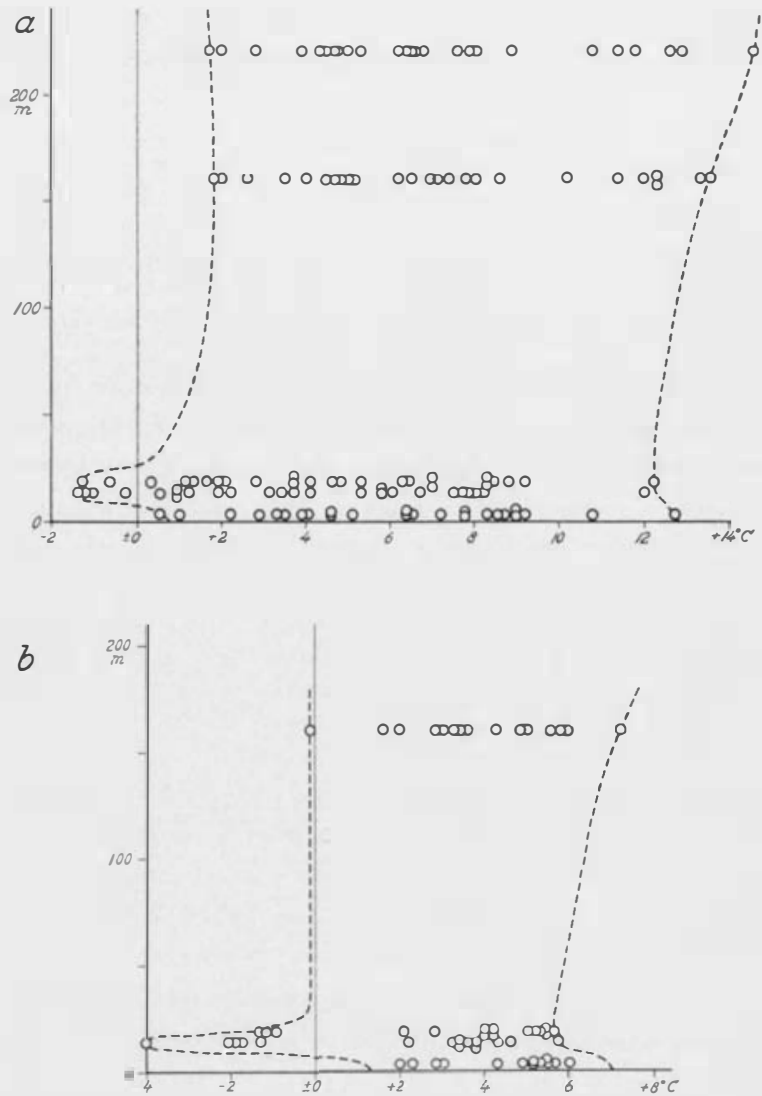

Fig. 17. Graph showing the distribution of minimum temperatures during two separate periods in 1959. On the ordinate the altitude above the valley bottom. (a) The three last weeks of July, 1959; (b) the two first weeks of September, 1959.

(nos. 4, 7 and 8) have higher temperatures in summer than the other stations, which are situated in valley bottoms. Arjeplog, although a valley bottom station, has quite high minima. This is probably because it is in a very broad valley with many large lakes. As we have seen from the above (no. 1, Peninsula) the nocturnal minima are higher in the proximity of the lake.

The term "thermal belt" (Swed. "varm bergszon", Germ. "warme Hangzone") can be applied to a height zone where the minimum temperatures during the vegetation period do not fall below $0^{\circ} \mathrm{C}$ on any occasion. How far down this zone reaches is not apparent from climatological readings. An indication that it reaches far down the slope is the fact that the lowest occurrences of southerly plants such as Epilobium collinum, Galeopsis bifida and Carex ornithopoda are at $450 \mathrm{~m}$ on the $\mathrm{E}$ part of the mountain. If we enter the height above the valley bottom as ordinate on a diagram and the minimum temperatures as abscissa we get an indication of the thermal 
belt and the range of the temperatures in the different zones (Fig. 17). The graphical representation clearly shows the effect of the lake in the valley bottom in producing warm nights. However, this area near the lake is not quite as warm as the mountain-side. Sandberg (1960, p. 18) provided additional evidence for the existence of local maritimity in the area adjacent to large lakes in Lappland.

From what is well known about temperature inversions in clear weather the results given here are by no means unexpected. In fact, about the same phenomena are anticipated to occur, for instance, in Central Europe. In a clear summer night one will feel the temperature difference while walking downslope from a high hill to the valley bottom. The present continuous observation series shows that this situation is far more common than is generally believed. It is well known (SMHI) that quite a number of frosts occur in N Sweden even during the warmest part of the year. However, this and other investigations have shown that there are only rare frosts in some sites. In certain places they are so rare that one can expect an interval of several years between injurious frosts during the vegetation period.

With regard to the effect of climate on vegetation, the general frequency of low minima during the vegetation period seems to be more important than occasional phenomena such as some frost nights in summer. The duration of certain low or high temperatures may also be very important to plants. This is evident in spring, when different phenological phases are easy to observe (see the section about phenology). The nocturnal inversions are familiar to the farmers of these districts, who have traditionally located their potato fields on high slopes to keep them free from frost (Andersson \& Birger 1912, pp. 66-67; Bylund 1956; Rudberg 1957). They also mention the advantageous local climate of the zone near the shore of large lakes (cf. Bylund \& Sundborg 1953 , p. 34). Fuss (1959) dealt with the favourable climatic conditions on hillsides (generally S-facing) for vineyard cultivation in Central Europe.

\section{Maximum temperatures}

The recorded differences in diurnal maxima are also strongly dependent on the weather situation. In conditions of clear sky and strong insolation, there is a warm air cushion in front of the rock wall. Under favourable circumstances (feeble wind, little turbulence) this extends a little way down the slope. Such circumstances are, however, rare in the Scandes. To some extent, the rise of the warm air will counteract its warming-up. Even if there is calm weather on the valley bottom there may be relatively strong winds at a higher level. Such conditions will cause chilling that is more severe at the higher levels, such as the rock wall and the more exposed parts of the talus slope. The results obtained by Frödin (1915) refer to a period of bright, calm weather which had practically no counterpart during the observation period of 1959-62. Only some single months of the investigation period showed more than 10 maxima that were higher on the S-facing slope than on the valley bottom. More frequently there was the normal or nearly normal adiabatic decrease of temperature with height. Somewhat different results were obtained during the investigation period of 1965-66 when measurements were made on the more favoured SW-facing slope of Mt. Aistjakk. In addition, especially during June 1966, the weather was very warm and sunny and high maximum temperatures were recorded on the slope. To obtain comparable differences between the S- and the SW-exposed slope it is imperative that the observation points be at the same distance from the cliff (in this case $3 \mathrm{~m}$ ).

In earlier, mostly Central European investigations, it has been shown that the diurnal maximum on a mountain is highest on the SW-exposed slope. The effect is the same for the day temperatures dealt with here. The day temperatures of S-facing slopes in general reach their maximum relatively early in the day, before the heating by the sun has reached its peak. In a S-exposed situation they will as a rule not exceed the values measured on horizontal ground on the valley bottom. In a SW-exposure the evaporation and drying-out may continue some time longer with a very favourable angle of incidence of solar radiation and still higher temperatures are reached.

However, as regards local climate of S- and SWexposed slopes we cannot disregard their relative advantage during bright days in comparison with the surroundings (Fig. 16). As has been shown, the microclimate (to a certain degree also the local climate) is dependent to a large extent on the degree of insolation, which for large parts of the Scandinavian mountains is not very favourable in summer time. In this respect the mountains around Abisko in NW Lappland are the most favoured, because of low precipitation and long sunshine duration in summer.

The maximum temperatures to which plants are exposed on insolated mountain-sides are of course much higher than any temperatures measured in a meteoro!ogical screen (Fig. 21). Dahl recently (1966, cf. above) elucidated the problem of the climate to which plants are adapted and correlated (cf. also Dahl, E. 1951) the distribution limits of some alpine plants in Scandinavia with the summer maximum temperature isotherms. The air temperature on a 

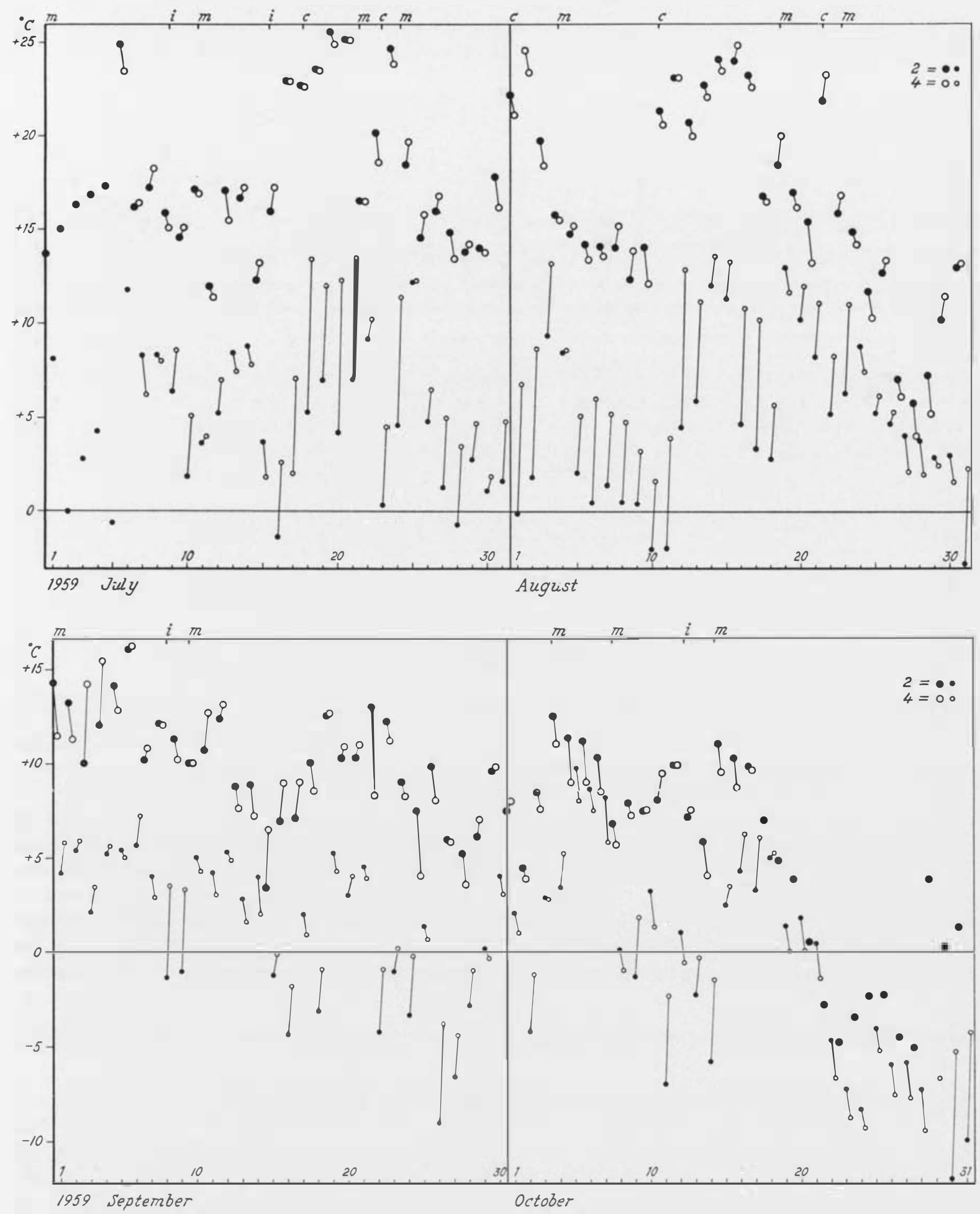

Fig. 18. The maximum and minimum temperatures at stations nos. 2 and 4 during the investigation period of 1959. The prevailing air mass has been indicated, $m$, meaning maritime air mass: $c$, continental air mass of different origine and $i$, indeterminate air mass (often a cool air mass at lower levels, a warm air mass at higher levels). Air masses according to the daily German and Swedish weather bulletins and the series Die Grosswetterlagen Mitteleuropas (Amtsblatt des Deutschen Wetterdienstes) for the relevant months. Corresponding diurnal values of maximum and minimum temperatures have been joined. Within each day the values have been given in a fixed sequence, independent of the exact time. In this way, lines sloping to the left mean temperature inversion, i. e. higher temperature on the slope than in the valley, and lines sloping to the right mean adiabatic decrease of temperatures with height.

- $\bigcirc$, Maximum values; $\bullet$, minimum values. 


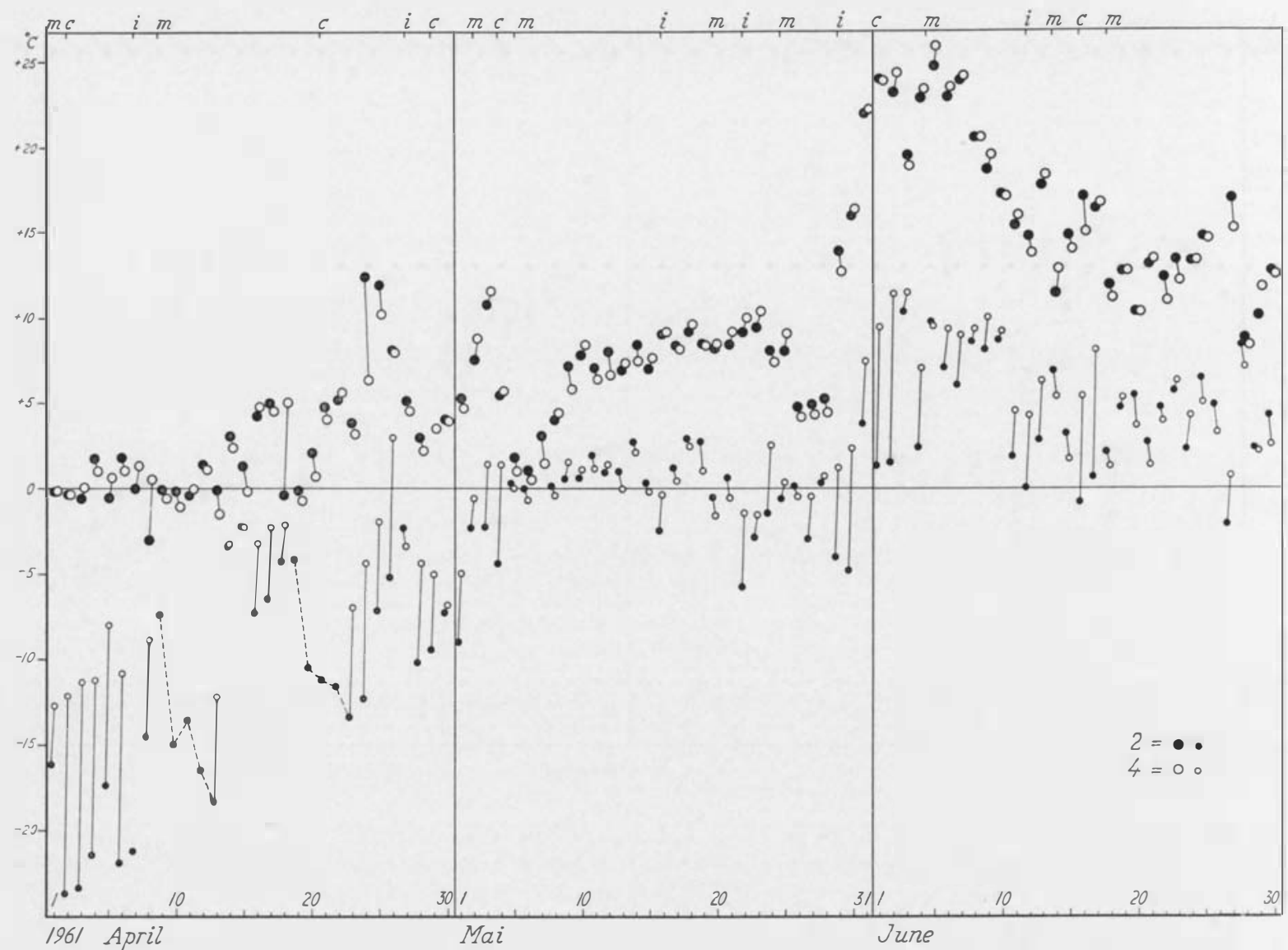

Fig. 19. The maximum and minimum temperatures of stations nos. 2 and 4 during the investigation period of 1961. The prevailing air masses indicated as on Fig. 18.

given occasion corresponds to a certain temperature of the plants and the ground and it is possible to calculate this with some degree of accuracy when the factors involved are known (1966, p. 124). The lethal temperatures of plants can be found in the laboratory and the maximum tissue temperatures reached in the field can be compared with these.
During the extremely dry and warm period of 8-21 June, 1966, maximum temperatures were measured that were quite extreme for Lappland and thus valuable for a study of possible damage caused by too strong heating. In normal summers absolute maximum temperatures are $23-26^{\circ} \mathrm{C}$ but in the summer of 1966 a temperature of $30.7^{\circ}$ was re-

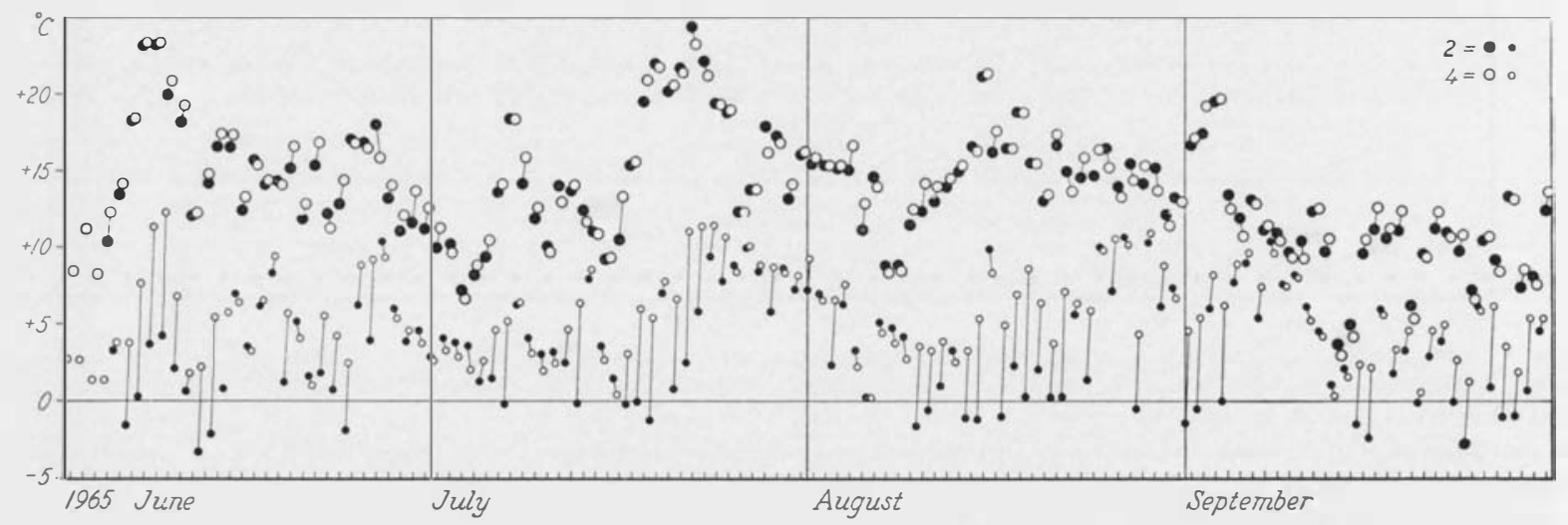

Fig. 20. The maximum and minimum temperatures of stations nos. 2 and 4 during the investigation period of 1965. The weather conditions are discussed in detail in the text. 


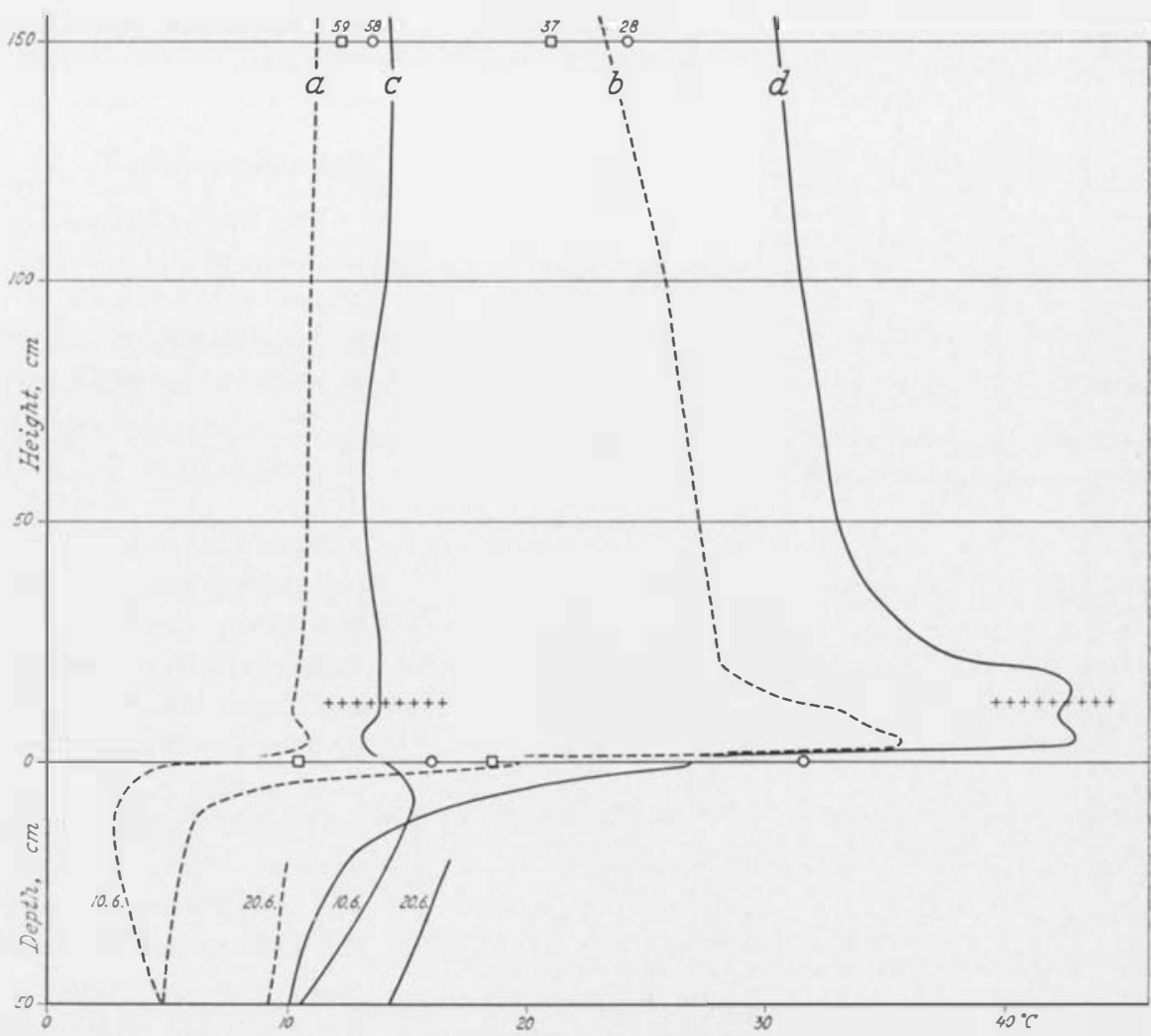

Fig. 21. The microclimatological conditions at night and by day on two talus slope habitats of opposite aspect, near stations nos. 7 and 8, during an early phase of the warm period of 8-21 June, 1966. Soil temperatures (including, on 20 June, the highest recorded at $20-50 \mathrm{~cm}$ below the ground surface during the vegetation period of 1966), rock wall temperatures (denoted on the 0 -line), air temperature at different heights and relative humidity together with the temperature measured inside the screen $150 \mathrm{~cm}$ above the ground (denoted on the 150-line together with figures for relative humidity). The wind profiles nearly simultaneous with these occasions are shown on Fig. $23 a$ and $b$, the energy balance in Table 9. The average height of the herb layer (station no. 7) on occasions $c$ and $d$ has been marked ++++++ (maximum height $20 \mathrm{~cm}$ ). The Vaccinium myrtillus heath at station no. 8 had not started to develop. Clear sky, sunrise at $00.40 \mathrm{~h}$ at station no. 8. St. no. 7: — $\bigcirc$, thermophilous Fruticeto-Tortuletum. $c$, 10 June 01.30-02.00; $d, 9$ June 13.30-14.00. St. no. 8:--- $\square$, open Picea-Vaccinium-wood. $a, 10$ June 00.00-00.30; $b, 10$ June 09.00-09.30.

corded (150 cm above the ground) on the SW-facing side of Mt. Aistjakk. There were quite appreciable wind velocities on the hottest days $(1.5-2.0 \mathrm{~m} / \mathrm{s}$ above the plant cover), and actually no damage was observed. On still more unfavourable occasions damage might occur.

Because of the remarkable temperature differences in periods of bright weather on slopes of exposures around $\mathrm{S}$ as compared to slopes of $\mathbf{N}$ exposures, it has been suggested (cf., e.g., Fabijanowski 1950, p. 42, Jalas 1950, p. 208) that the climate of slopes of $\mathrm{S}$ exposures is more "continental" than that of the slopes of $\mathrm{N}$ exposures. However, as was already shown by Wollny (1878), the long-term climate of slopes is highly dependent on the yearly course of insolation and, for instance, the SW-exposed slope is the warmest one only in periods when the cloudiness and turbidity of the air permits the strongest insolation in the middle of the day and the afternoon. In NW Scandinavia, where the oceanity is interrelated with high cloudiness and precipitation, giving less extreme averages, the oceanity even of the SW-exposed mountain-side is pronounced, and this is confirmed by the oceanic trend of the flora. See Blytt 1869, p. 18 and Kotilainen 1933, p. 35 and below, p. 67.

In Fig. 21 are illustrated the conditions at an ordinary summer maximum on the two opposite sides of Mt. Aistjakk. We observe that the diurnal maximum of the NE-facing slope was recorded at 09.00 $\mathrm{h}$, immediately before the sun left that slope, while on the SW-facing slope the maximum was measured (in this case) at 13.30. As previously mentioned (p. 35) the long-wave radiation balance was calculated according to a modification by Möller (1951) of Brunt's formula, and values for the air temperature and the relative humidity $150 \mathrm{~cm}$ above the ground were used. For the vertical surface, which was taken to be completely black, a correction was made for the actual surface temperature. The wind velocities were given as averages during 2 minutes (10 sec. intervals), at $50 \mathrm{~cm}$ above the ground, both 


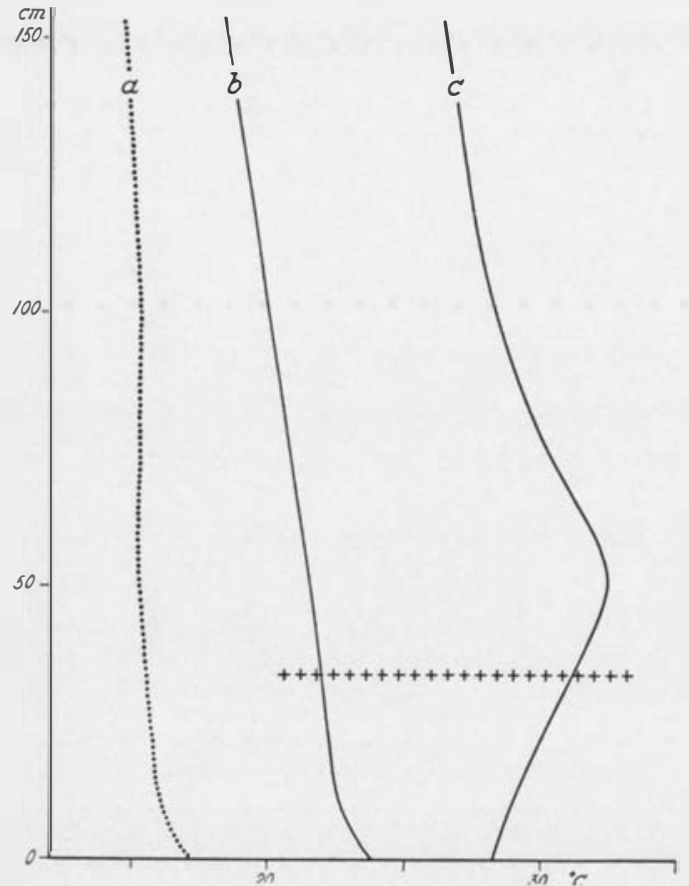

Fig. 22. The microclimatological conditions at station no. 7 with a fully grown herb layer up to $90 \mathrm{~cm}$ in height at midday on a clear summer day with normal temperature and wind conditions $\left(\max .+18.3^{\circ}, \mathrm{min} .+4.0^{\circ}, \max .1 .4 \mathrm{~m} / \mathrm{s}\right.$ at $150 \mathrm{~cm}$ height $)$. For comparison, data for a Picea forest of Gymnocarpium-Vaccinium type (shade temperatures) below the slope have been included. Nearly simultaneous conditions in the thermophilous treeless Fruticeto-Tortuletum immediately below the cliff about $80 \mathrm{~m}$ in vertical height above the Picea forest situated on level ground. According to the thermograph, the simultaneous temperature in the screen was +16.6 to $+17.3^{\circ}$ while the measurements in the Picea forest were made, and $+17.4^{\circ}$ constantly during the observations near the screen. The irisolated dark-coloured parts of the rock wall, mostly consisting of SW-exposed almost vertical surfaces, had an average temperature of $+37.5^{\circ}$ (at $15.15 \mathrm{~h}$ ). 13 August, 1965. (a) Picea forest below the slope (shaded thermometer); (b) thermophilous Fruticeto-Tortuletum (shaded thermometer); (c) thermophilous Fruticeto-Tortuletum (exposed thermometer). horizontal and vertical velocities were given (see also Fig. 23).

\section{Soil temperatures}

The energy balance of a site affects the temperatures of the plants and of the ground surface (cf. above, p. 35). This is strikingly expressed by the heating of the ground on bright days when the sun exerts a strong effect by irradiation or by the cooling of the plants on clear nights when there is strong eradiation from the earth. The greatest fluctuations due to transfer of heat will take place at the actual surface where one medium meets the other, but the real temperature conditions regarding the interface are hardly determinable with conventional instrumentation. By conduction, heat gained by the soil surface on hot days will be transferred further down into the ground and stored there until again the earth loses energy.

It might be expected that soil temperatures as such have an effect on plant growth. The importance of soil temperature as compared to air temperature, and the interrelations between the two, are still not clearly understood (cf. Millar 1965, p. 17). In nature the conditions are variable because plant communities of different structure cover the ground surface. Also the drying out as a result of a higher soil temperature can be inter-related with other important factors (Jarvis, M. 1963). The drought factor operating during prolonged rainless periods may indeed be a limiting factor for certain plants, preventing them from growing on the very dry and warm slopes of southerly aspect.

To study the importance of exposure on slopes facing in different directions a set of soil thermometers were inserted close to the screens of stations nos. 7 and 8 in 1966. Both sets are situated on scree but the soil profiles are not directly comparable. The

Table 9. The energy balance of the horizontal surface at a rise of $60^{\circ}$ behind the measuring point (I) and the rock wall (2) on the NE- (denoted - - , curves $a$ and $b$ in Fig. 21) and the SW-exposed side (-, curves $c$ and $d$ ) of Mt. Aistjakk on 9-10 June, 1966

Thermal radiation in $\mathrm{cal} / \mathrm{cm}^{2} / \mathrm{min}(\mathrm{ly} / \mathrm{min})$. Dash: no data available

\begin{tabular}{|c|c|c|c|c|c|c|c|c|c|c|c|}
\hline \multirow[b]{2}{*}{ Date } & \multirow[b]{2}{*}{ Time } & \multirow[b]{2}{*}{ Curve } & \multirow{2}{*}{$\begin{array}{l}\text { Air } \\
\text { temp. }\end{array}$} & \multirow{2}{*}{$\begin{array}{l}\text { Rockwall } \\
\text { temp. }\end{array}$} & \multirow{2}{*}{$\begin{array}{l}\text { Water } \\
\text { v.p. } \\
\text { (mb) }\end{array}$} & \multicolumn{2}{|c|}{ Wind vel.m/s } & \multicolumn{2}{|c|}{$\begin{array}{l}\text { Long-wave-radiation } \\
\text { balance }\end{array}$} & \multirow{2}{*}{$\begin{array}{l}\text { Total } \\
\text { short-wave } \\
\text { radiation } \\
\text { (1) }\end{array}$} & \multirow{2}{*}{$\begin{array}{l}\text { Net } \\
\text { thermal } \\
\text { radiation } \\
\text { (1) }\end{array}$} \\
\hline & & & & & & hor. & vert. & (1) & $(2)$ & & \\
\hline 10.6 & 00.30 & $a$ & +12.2 & +11.4 & 8.5 & 0.2 & 0.2 & -0.129 & -0.072 & - & - \\
\hline 10.6 & 09.00 & $b$ & +21.0 & +18.5 & 9.4 & 0.5 & 0.4 & -0.141 & -0.074 & 0.780 & 0.639 \\
\hline 10.6 & 02.00 & $c$ & +12.6 & +16.0 & 8.6 & 0.4 & 0.3 & -0.129 & -0.086 & - & - \\
\hline 9.6 & 13.30 & $d$ & +23.2 & +31.6 & 8.2 & 0.6 & 0.4 & -0.151 & -0.118 & 0.900 & 0.749 \\
\hline
\end{tabular}


NE-facing slope (no. 8) is wetter and a thin layer of fine debris occurs only immediately below the cliff. The boulders here are mostly covered with low-humified litter and open spaces occur frequently. Special care was taken that the thermometers should be surrounded by soil or litter as little disturbed as possible. As to the difference in soil temperatures between various stony surface layers, see Troedsson (1956).

The observations, which unfortunately could not be made simultaneously, were usually made early in the morning when there had still been very little sunshine (or none at all) on the SW-facing slope, but the hour of maximum insolation was just passing on the NE-facing slope (critical hour 09.00 when the sun left the NE-facing slope and passed over to the SW-facing slope, see Fig. 11). Thus, at this time the NE-facing slope would in all likelihood have the maximum advantage over the slope facing SW, if the sun was shining. Weather conditions, see p. 40.

Nevertheless, the general advantage of the SWfacing slope is evident from these observations, although because of the early time for observation the temperatures at $2 \mathrm{~cm}$ depth are quite high on the NE-facing slope and frequently exceed those of the SW-facing slope. At a depth of $50 \mathrm{~cm}$ there were only very small fluctuations from one week to the next. There was a general rise in temperatures throughout the observation period, but even at the greater depths the warm period from 8 to 21 June caused a temperature increase. An after-effect of this was observed as late as 27 June.

The soil temperatures may also differ a great deal in different habitats on the S- to SW-facing screes. These differences will be greatest in the uppermost layers. Where there is a tree layer the predominant effect will be caused by the shade from the trees, at least when the sun is high. When the sun is low, for example in the mornings, shading by the cliff will be included in the effect. The lower parts of the talus slopes get more morning sun, which will have a conspicuous effect on the soil temperatures in the scrub zone (Lundqvist. J. 1961, p. 155) as this zone is situated further down the slope than the upper wood of the scree. This effect was seen on the Sfacing slope of Mt. Märkepakte on a bright summer morning (Table 11). Later in the day the differences are caused only by the shade of the trees. The strong irradiation of the scrub zone on bright days thus makes this habitat the most favourable with regard to soil and air temperatures, but the higher soil moisture tension which could be a result of this and of the higher wind velocities (Fig. 23) is evidently a disadvantage for some plants. The striking difference in

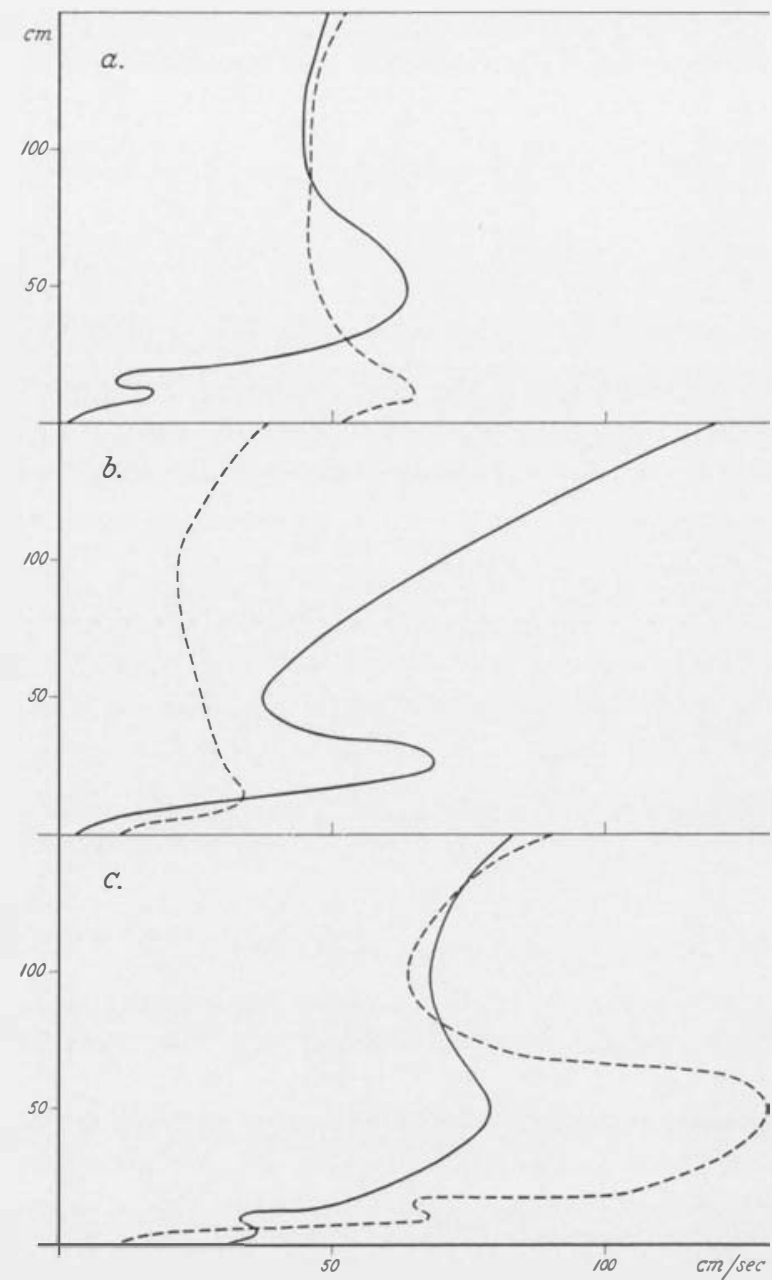

Fig. 23. Wind profiles on three separate occasions nearly coinciding in time and place with the other microclimatological measurements (see the text). (a) Conditions during a calm day on the two opposite sides of Mt. Aist jakk. ——, SW-facing side, 9 June, 1966, around $13.30 \mathrm{~h}$; ---, NE-facing side, 10 June, 1966, around $09.00 \mathrm{~h}$. Note the dissimilarities depending on the vegetation cover. (b) The same mountain-sides during a windy night. - SW-facing side, 10 June 1966, around $02.00 \mathrm{~h}$; ---, NEfacing side, 10 June, 1966 , around $03.00 \mathrm{~h}$ (at $00.30 \mathrm{~h}$ unmeasurable) The wind direction was from the SE and SW on these occasions. (c) The wind conditions on the S-facing slope of Mt. Märkepakte on 14 June, 1966, measured at $08.30-10.00 \mathrm{~h}$, wind direction SE. —- The aspen wood; ---, the scrub zone. The greater turbulence at the fringe of the wood is reflected in greater changes in the wind speed. At every level the actual value was obtained as average of values read every $10 \mathrm{sec}$ for $2 \mathrm{~min}$.

vegetation is probably largely a response to these special conditions.

In Fig. 21, the temperature of the litter immediately below the surface was measured using a stickrod sensor. The other soil temperatures were measured with mercury thermometers. There are breaks in the curves of Fig. 21 at the interface because it 
Table 10. Soil temperatures in 1966 on the two opposite sides of Mt. Aistjakk near to stations nos. 7 and 8 , at depths of 2, 10, 20 (St. no. 7) and $50 \mathrm{~cm}$

\begin{tabular}{|c|c|c|c|c|c|c|c|c|c|c|}
\hline Date... & June & 6 & 13 & 20 & 27 & July 4 & 11 & 18 & 25 & Aug. 1 \\
\hline $\begin{array}{l}\text { Time (7) } \\
\text { SW (7) }\end{array}$ & $\begin{array}{r}2 \\
10 \\
20 \\
50\end{array}$ & $\begin{array}{r}09.00 \\
+10.6 \\
+10.0 \\
+10.0 \\
+\quad 8.7\end{array}$ & $\begin{array}{r}08.30 \\
+12.7 \\
+13.6 \\
+13.6 \\
+11.7\end{array}$ & $\begin{array}{r}08.00 \\
+17.3 \\
+17.2 \\
+16.8 \\
+14.3\end{array}$ & $\begin{array}{r}10.15 \\
+12.3 \\
+12.1 \\
+12.4 \\
+12.4\end{array}$ & $\begin{array}{r}09.00 \\
+11.2 \\
+11.0 \\
+11.2 \\
+11.2\end{array}$ & $\begin{array}{r}09.40 \\
+13.0 \\
+12.4 \\
+11.9 \\
+11.1\end{array}$ & $\begin{array}{r}08.30 \\
+12.2 \\
+12.0 \\
+12.0 \\
+11.5\end{array}$ & $\begin{array}{r}10.40 \\
+15.5 \\
+14.2 \\
+13.4 \\
+11.8\end{array}$ & $\begin{array}{r}14.00 \\
+15.2 \\
+12.4 \\
+12.4 \\
+12.3\end{array}$ \\
\hline $\begin{array}{l}\text { Time (8) } \\
\text { NE (8) }\end{array}$ & $\begin{array}{r}2 \\
10 \\
50\end{array}$ & $\begin{array}{r}10.30 \\
+\quad 5.7 \\
+\quad 1.1 \\
+\quad 2.8\end{array}$ & $\begin{array}{r}09.10 \\
+20.1 \\
+\quad 6.7 \\
+\quad 6.0\end{array}$ & $\begin{array}{r}11.00 \\
+17.1 \\
+10.3 \\
+\quad 9.2\end{array}$ & $\begin{array}{r}11.00 \\
+10.3 \\
+\quad 6.3 \\
+\quad 7.7\end{array}$ & $\begin{array}{r}09.45 \\
+14.4 \\
+\quad 7.6 \\
+\quad 6.6\end{array}$ & $\begin{array}{r}10.20 \\
+13.8 \\
+\quad 9.3 \\
+\quad 6.7\end{array}$ & $\begin{array}{r}09.00 \\
+13.6 \\
+\quad 8.6 \\
+\quad 7.0\end{array}$ & $\begin{array}{r}11.40 \\
+16.3 \\
+11.3 \\
+\quad 7.4\end{array}$ & $\begin{array}{r}12.30 \\
+12.0 \\
+\quad 9.8 \\
+\quad 8.2\end{array}$ \\
\hline Cloudiness & & $\begin{array}{l}\text { Overcast, } \\
\text { rain }\end{array}$ & Clear & Clear & Overcast & $\begin{array}{l}\text { Occasional } \\
\text { sun }\end{array}$ & $\begin{array}{l}\text { Occasional } \\
\text { sun }\end{array}$ & Overcast & $\begin{array}{l}\text { Half } \\
\text { clear }\end{array}$ & $\begin{array}{l}\text { Over- } \\
\text { cast }\end{array}$ \\
\hline
\end{tabular}

was impossible to obtain any reliable values for this (cf. Munn 1966, p. 23). The temperature of the rock wall surfaces was measured wit'. an elastic thermistor sensor and should be more reliable, although approximate.

\section{The snow conditions during thaw}

In the spring of 1961 some observations were made of the course of the snow thaw, since this might be important in aiding understanding of the favourable climate of insolated mountains (see the diagram in Lundqvist, J. 1965, p. 217). As evident from investigations in Central Europe (Friedel 1952, Kreeb 1954, Roller 1953, Waldmann 1959) and also in the N of Europe (Fries, Th. 1925, Keränen 1920, 1929, Dahl 1956, with references p. 251) the course of the thaw is closely related to the local climate and the microclimate of the locality. Good indications are obtained of the favourable character of the habitats in terms of climate and phenology in spring.

On 1 April rods for measuring snow depths were put out in various places near stations $1-5$. The two measuring points of especial interest here were situated as follows:

Measuring rod 2 was placed on grassland near station no. 2 where the ground was level (Fig. 12). Rod 4 was placed on the same scree as thermometer screen no. 4, about $5 \mathrm{~m}$ downslope from the steep $\mathrm{S}$-facing cliff. The ground slopes $36^{\circ}$ to the $\mathrm{S}$ and the rock is fine schist. The snow cover was quite homogeneous, although much more compact on the slope than in the valley. By simultaneous temperature measurements, partly with thermographs, and partly with mercury thermometers, the importance of the radiation and the exposure was assessed. At first the thaw proceeds only slowly because of the compact snow-cover at station no. 4 , but towards the end it is successively faster. Bare ground is exposed about two weeks earlier on the S-facing slope (cf. Fig. 25).

The greatest rate of thaw does not coincide with the maximum day temperatures. Instead the higher irradiation, the sloping ground (which receives more energy), the eradiation from the cliff, and the decreasing wind velocities in front of the cliff, seem to have a more important effect. The higher night temperatures of the mountain slope are probably also of some importance. During the month of April these can exceed those of the valley bottom considerably (e.g. the nocturnal minima on 3 April, 1961: station no. $2-23.4^{\circ}$, station no. $4-11.3^{\circ}$. Cf. p. 35 and Fig. 19).

As a consequence of these conditions the uppermost part of the talus slope first becomes snow-free along a line parallel to the mountain wall (Fig. 24). The snow-line then moves downward on the talus slope. In the snow-free area conditions for plants are at first very severe, because of the strong irradiation during the day and the strong cooling during the night. There are considerable differences in the vegetation cover of the uppermost part of the scree in places (p. 92), differences which might depend on ecological factors connected with the snow cover and its melting. According to Keränen $(1920$, p. 88; 1929 , p. 215), a rather thin snow cover might diminish the winter cold considerably and there may even be no frost where snow cover is sufficient (cf. Holmen 1965 , p. 245; Havas 1965, p. 22). Because no snow collects on the cliff in winter the deepest snow cover is immediately in front of it before the snow starts melting, and the conditions change even more during thaw. Snow drifts burying the thermometer screens at $2.0 \mathrm{~m}$ height have generally been observed at stations nos. 4 and 7 .

The above results are by no means unique for in- 
Table 11. Measurements of air and soil temperatures and humidity in different habitats on Mt. Märkepakte $\left(66^{\circ}\right.$ $13^{\prime} \mathrm{N}$ ) in the morning of $5 \mathrm{July}, 1962$

Simultaneous observations of cloudiness $(0=$ clear, $10=$ overcast $)$, cloud type, sunlight depletion $\left(S^{\circ}=\right.$ sun not observable, $S^{\triangleleft}=$ sun completely unobscured, sunshine duration during the preceding hour and (approximate) wind direction and velocity. For comparison, thermograph measurements from stations nos. 2 and $4 \mathrm{ca} .4 \mathrm{~km}$ away, have been included. The points (p 8-p14) are the same as those used for rain measurements in 1961 (Fig. 40) except for point 10, which is a little inside the wood. Point P (the Pine wood) is 11.0 $\mathrm{m} \mathrm{S}$ of point 14. After $13.00 \mathrm{~h}$ a thunder front passed over. It gave very heavy rain and a temperature decrease of $7.5^{\circ} \mathrm{C}$ at $150 \mathrm{~cm}$ above the ground during the course of half an hour. Each series of measurements was made in the 10 minutes following the time indicated. Air temperatures and relative humidities were recorded at $50 \mathrm{~cm}$ above the ground (except for the thermograph records; Assman aspiration psychrometer was used)

\begin{tabular}{|c|c|c|c|c|c|c|c|}
\hline Time ... & 07.00 & 08.00 & 09.00 & 10.00 & 11.00 & 12.00 & 13.00 \\
\hline Cloudiness ... & 1 & 4 & 3 & 5 & 8 & 2 & \\
\hline Cloud type... & Cirrus & $\begin{array}{l}\text { Cirrus } \\
\text { cumulus }\end{array}$ & $\begin{array}{l}\text { Cirrus } \\
\text { cumulus }\end{array}$ & Cumulus & Cumulus & Cumulus & Cumulus \\
\hline Sunlight depletion... & $\mathrm{S}^{4}$ & $\mathrm{~S}^{3}-\mathrm{S}^{4}$ & $\mathrm{~S}^{3}-\mathrm{S}^{4}$ & $\mathrm{~S}^{4}$ & $\mathrm{~S}^{0}$ & $\mathrm{~S}^{4}$ & $S^{4}$ \\
\hline Sunshine duration, $\min \ldots$ & 60 & 55 & 55 & 58 & 42 & 25 & 58 \\
\hline Wind (Beaufort) ... & E $0-1$ & E $0-1$ & E $0-2$ & E $0-2$ & E $1-3$ & E $1-3$ & E $1-3$ \\
\hline St. no. 2 & +13.3 & +16.1 & +17.8 & +19.4 & +19.0 & +20.5 & +20.1 \\
\hline $\begin{array}{l}\text { St. no. } 4 \\
\text { p } 8\end{array}$ & +13.0 & +14.2 & +17.5 & +18.9 & +18.2 & +19.8 & +20.8 \\
\hline Air temp. & +13.4 & +16.8 & +19.0 & +22.4 & +18.1 & +22.5 & +23.4 \\
\hline Rel. hum. & 74 & 62 & 57 & 50 & 54 & 40 & 33 \\
\hline \multicolumn{8}{|l|}{ Soil temp. } \\
\hline $2 \mathrm{~cm}$ depth & +12.3 & +14.9 & +19.3 & +21.3 & +21.2 & +22.9 & +23.2 \\
\hline $10 \mathrm{~cm} \mathrm{depth}$ & +11.5 & +11.8 & +12.3 & +13.6 & +14.9 & +15.7 & +16.3 \\
\hline \multicolumn{8}{|l|}{ plo } \\
\hline Air temp. & +13.4 & +16.8 & +18.8 & +21.8 & +18.2 & +22.6 & +23.7 \\
\hline Rel. hum. & 74 & 62 & 53 & 46 & 54 & 37 & 31 \\
\hline \multicolumn{8}{|l|}{ p 11} \\
\hline Air temp. & +13.4 & +17.0 & +20.0 & +23.1 & +19.4 & +23.3 & +24.3 \\
\hline Rel. hum. & 71 & 61 & 52 & 45 & 51 & 42 & 33 \\
\hline \multicolumn{8}{|l|}{ Soil temp. } \\
\hline $2 \mathrm{~cm}$ depth & +13.5 & +16.4 & +20.9 & +25.7 & +24.3 & +26.5 & +28.9 \\
\hline $10 \mathrm{~cm} \mathrm{depth}$ & +12.0 & +12.5 & +13.4 & +15.1 & +16.9 & +18.1 & +19.1 \\
\hline \multicolumn{8}{|l|}{ pl2 } \\
\hline Air temp. & +13.5 & +16.8 & +19.8 & +21.2 & +19.5 & +23.0 & +22.9 \\
\hline Rel. hum. & 73 & 61 & 56 & 47 & 48 & 41 & 32 \\
\hline \multicolumn{8}{|l|}{ p 13} \\
\hline Air temp. & +13.2 & +16.4 & +18.2 & +20.4 & +19.9 & +23.0 & +22.5 \\
\hline Rel. hum. & 75 & 64 & 60 & 53 & 51 & 41 & 38 \\
\hline \multicolumn{8}{|l|}{ pl4 } \\
\hline Air temp. & +12.8 & +16.4 & +18.0 & +19.0 & +19.0 & +19.6 & +20.6 \\
\hline Rel. hum. & 75 & 70 & 60 & 55 & 52 & 46 & 38 \\
\hline \multicolumn{8}{|l|}{ pP } \\
\hline Air temp. & +12.9 & +14.9 & +18.0 & +18.4 & +19.6 & +19.9 & +19.8 \\
\hline Rel. hum. & 75 & 70 & 60 & 58 & 52 & 51 & 38 \\
\hline
\end{tabular}

solated mountains. On 2 and 16 May, 1961, the following observations were made on Mt. Aistjakk. A snow map was made which gave about the same results as the above but included some other habitats. The figures below are averages of a large number of measurements (snow depth in $\mathrm{cm}$ ):

\begin{tabular}{|c|c|c|c|c|c|c|}
\hline $\begin{array}{l}\text { Date, } \\
\text { May } 1961\end{array}$ & Mire & $\begin{array}{l}\text { Picea forest } \\
\text { below slope }\end{array}$ & $\begin{array}{l}\text { Lower talus } \\
\text { slope }\end{array}$ & $\begin{array}{l}\text { Open central } \\
\text { parts of talus }\end{array}$ & $\begin{array}{l}\text { Upper talus } \\
\text { slope }\end{array}$ & Rock wall \\
\hline 2 & 46 & 70 & $45-36$ & 0 & scattered spots & 0 \\
\hline 16 & 20 & 30 & $15-0$ & 0 & 0 & 0 \\
\hline
\end{tabular}

In this case the deep Picea forest was very late in regard to the thaw (only the deepest parts between the trees were measured). The vegetation period of sun-exposed mountains thus starts at least some weeks earlier in comparison with the surrounding forest.

The snow conditions in April-May described above may be considered as normal. In years when 


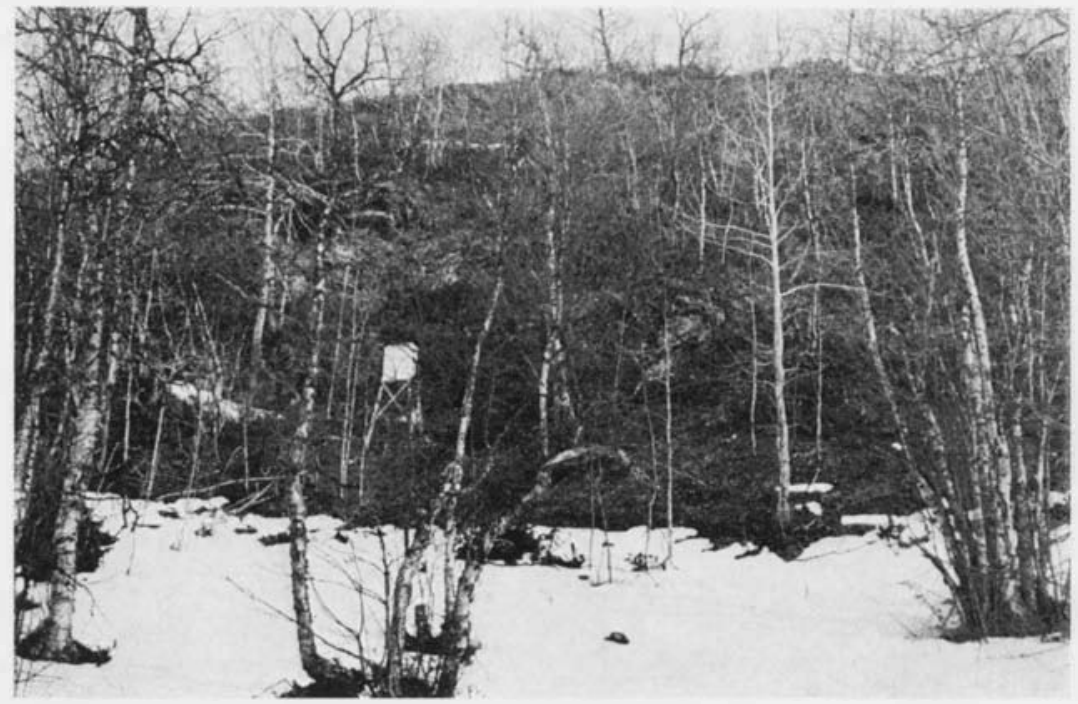

Fig. 24. Station no. 4 towards the N. The cliff is much fractured, consisting of several smaller scarps. Note the edge of the snow, which is almost parallel to the rock wall base. Snow depth where the photograph was taken was about $50 \mathrm{~cm}$ between the tree groups (Betula pubescens, and on the slope also Populus tremula). 3 May, 1961. spring is late there is a snow cover on these slopes till the middle of May or even longer, but the relative advantage of the insolated mountain-sides still prevails. All the aspects of a mountain are favoured if there is an open scree with a precipitous slope above. In 1966 the SW-facing slope on Mt. Aistjakk was snow-free on 15 May. On 1 June a practically snowfree talus slope was observed on the NE-facing side of the same mountain (near station no. 8) but large and deep snow beds remained in the forests around the mountain, especially at higher elevations (cf. Arnborg 1943, pp. $207 \mathrm{ff}$.). Open places in the forest were bare, e.g. the mires. In the high mountains above the forest line there was still much snow (only Eimpetrum heaths were bare).

\section{Phenology}

From the snow conditions during the thaw we can presume an early bud break of the vegetation on the insolated talus slopes. This phenomenon has long been described in the literature. We might expect bud break to be about two weeks earlier on the slope than in the valley. In dense forests, such as the Picea forest below Mt. Aistjakk, the vegetation is delayed, and bud break would lag behind even that in the valley.

Other conditions could give the mountain-sides still more advantage after the snow is gone and the vegetation starts to grow. The strong effect of insolation on a dark ground (even in deciduous woods (p. 36) as the aspen trees develop very slowly in spring), the strong emission of radiation from the heated cliff behind, and the high nocturnal minima have already been mentioned (p. 42). This, together with the good water supply in spring, will give the insolated slopes a luxuriant appearance even in spring, not encountered elsewhere at this latitude.

Some observations of phenological development were made in the same spring as the snow depths were measured (1961). On 2 May there were already green and almost fully developed basal leaves in Anthriscus silvestris, Valeriana sambucifolia, Turritis glabra, and Hackelia deflexa on Mt. Aistjakk (Fig. $26 a$ ). There were small seedlings of Galeopsis hifida, a spring-germinating annual (Fig. 26 b). Daphne mezereum had buds ready to open, in one place even flowers on a twig near the ground. Prunus Fadus, Ribes spicatum v. lapponicum, and Betula pubescens, a common tree on the SW-slope of this mountain, had green swelling buds. Vipers were aiso observed (Vipera berus), including newborn young, on the uppermost part of the open talus slope (Fig. 27), an observation probably unique for Lappland at this time of the year. Prunus padus, in which bud break is earlier than in the other broad-leaved trees, showed frost damage on 16 May (Fig. $26 d$ ) probably caused during the advection frost on 4-7 May (when there was also some snow). On 16 May a humble-bee was also observed on Mt. Aistjakk.

Other phenological observations were made on Mt. Storberget and the surroundings during May and the beginning of June (cf. the collation below). The terminology used corresponds to that given in German by Seyfert (1959, general phenological observations) and Baumgartner, Kleinlein \& Waldmann (1956, p. 290, phases of development). In Table 12 (right column) these phases are given for Vaccinium myrtillus, a widely distributed and easily observable plant. Measuring the shoot-length of this plant by the method of Geiger, Woelfle \& Seip (1934, p. 363, 
Fig. 25. The SW-facing side of $\mathrm{Mt}$. Aistjakk (no. 16), showing the snow conditions. 2 May, 1961.

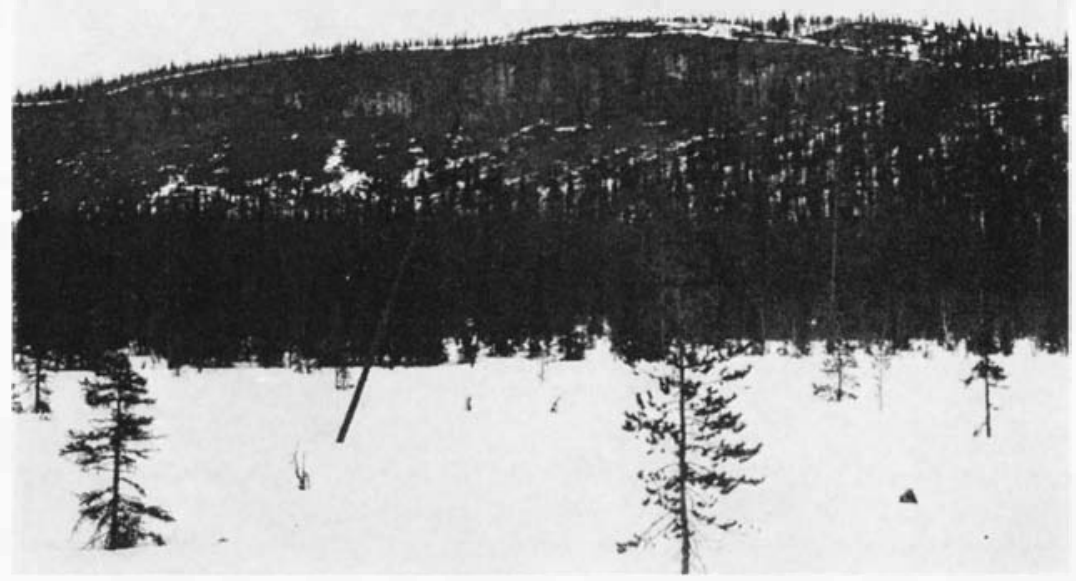

see the table) was not possible because the shoots are much shorter here at the corresponding phases of development.

The warm weather at the end of May and the beginning of June 1961, was exceptional, with maximum temperatures between 18 and $26^{\circ} \mathrm{C}$. At the same time the insolation was maximal because of little cloudiness and clear air. The plants particularly observed were Betula pubescens and Vaccinium myrtillus (Fig. 28). Again, development on the SW-facing slope was several days in advance of that in the valley bottom. While Vaccinium on 4 June had reached phase $b$ near station no. 1 , it had reached $d$ on the slope. On 6 June the development of the leaves of Betula pubescens was nearly complete on the slope; at station no. 1 the same stage was reached 6 days later. Stations no. 2 and no. 3 were always intermediate. Some investigations in Central Europe have given about the same results (see the literature cited in Geiger et al. 1934, and Baumgartner et al. 1956). The normal phenological gradient, i.e. a delay with increasing altitude on the mountain-side, is here inverted on the steeper slopes. See also Holmboe 1912, pp. 99 et seq., and Fries, Th. C. E. 1919.

Fries, Th. C. E. (1919, pp. 43 et seq.) found that birches from different altitudes in Torne Lappmark reacted dissimilarly with regard to their phenology in spring. Birches from valley bottoms reacted faster when temperature conditions were identical. No such investigation of the present material was made. It is evident that the same conditions might exist in PL, as the delay of the valley bottom in relation to the S-facing hillside was even greater during thaw.

Some production analyses were made in 1966 (cf. the studies in similar communities of Lactucion alpinae, Holmen 1965 , p. 247). One $\mathrm{m}^{2}$ of a repre-

sentative stand of Fruticeto-Tortuletum with dominant Anthriscus silvestris (p. 91) was analysed in respect of all green parts of plants inside the square (all shoots and leaves developed in the current year), on Mt. Storberget and Mt. Aistjakk. The plant material was weighed fresh and air-dry. The analysis was repeated twice, i.e. a new square was harvested in about the same vegetation near the first sample square. The first sample square was analysed on Mt. Aistjakk on 1 June, when there was still no development of the vegetation on the NE-facing side of the same mountain (the snow had just thawed). The

Table 12. Phenological phases of Vaccinium myrtillus (Heidelbeere) according to the literature

Note that the phases noted by the two teams do not correspond. Phases $a, c$ and $d$ (left column) are referable to other plant species. In Lappland the shoots are much shorter

Phase Geiger, Woelfle \& Seip 1934

$a$

das Erreichen einer Trieblänge von 2 $\mathrm{cm}$ bei der Heidelbeere

$d$

Trieblänge von 4 $\mathrm{cm}$ bei der Heidelbeere
Baumgartner, Kleinlein \& Waldmann 1956

Schwellen der Knospen, erkennbar auch an der helleren Färbung der Knospenschuppen, bei der Heidelbeere wird die grüne Triebspitze sichtbar

Herausschieben des frischgrünen Triebes

Seitliche Entfaltung des Triebes

Öffnen der Blütenknospe (nicht identisch mit Erscheinen der Blüte) 


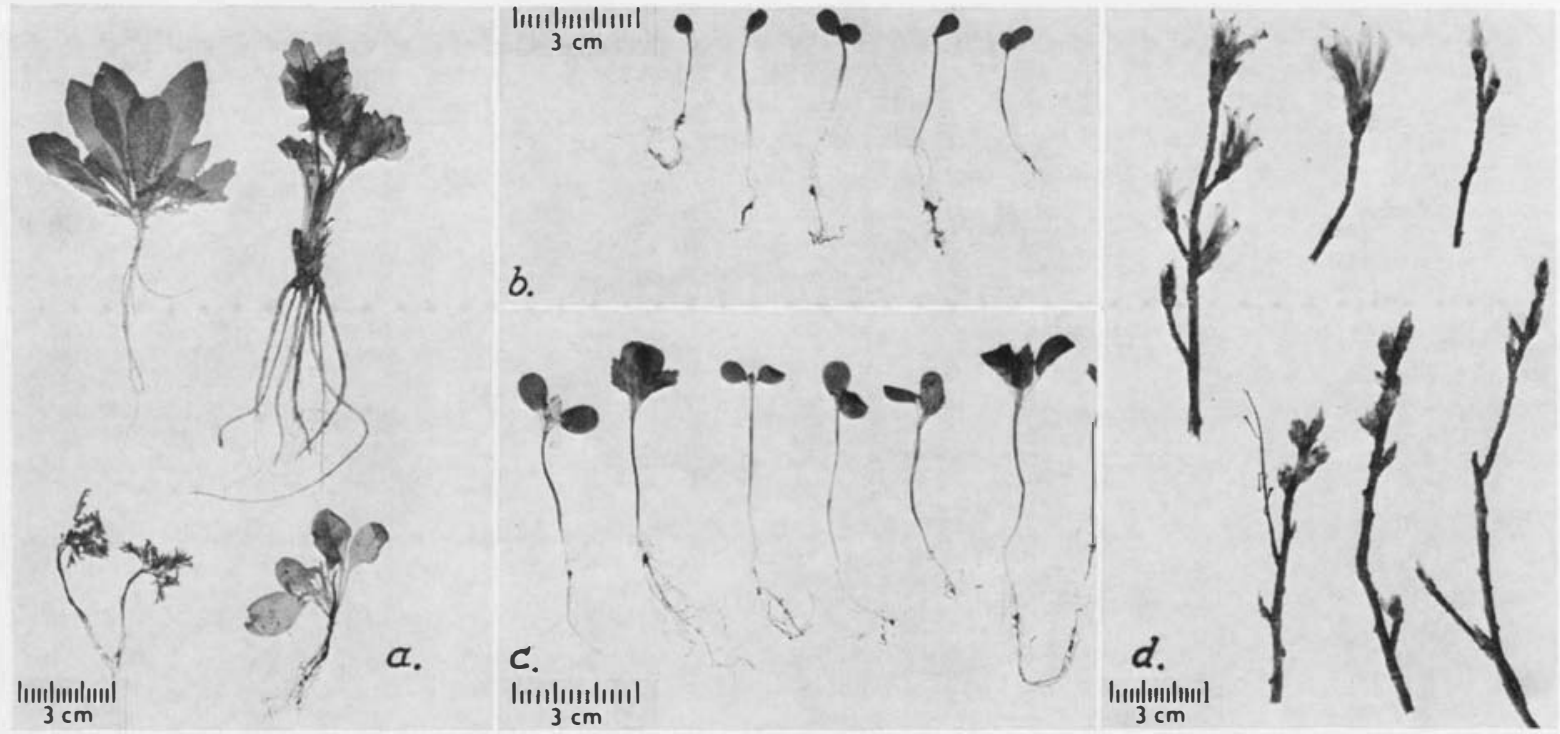

Fig. 26. (a) Green basal leaves of Turritis glabra, Valeriana sambucifolia, Anthriscus silvestris and Hackelia deflexa on 2 May, 1961. (b) Seedlings of Galeopsis bifida on 2 May, 1961. (c) Seedlings of Galeopsis bifida on 16 May, 1961. (d) Twigs damaged by frost (upper part of the figure on 16 May, 1961) on Prunus padus, an early developing tree or shrub. For comparison, the lower section with twigs taken on 2 May, 1961. SW-facing slope of Mt. Aist jakk, immediately below the rock wall.

second analysis was done on Mt. Aistjakk on 20 June to show the enormous development during the remarkably warm period of June.

\begin{tabular}{llllll}
\hline Date... & 1 June & & & \multicolumn{2}{l}{20 June } \\
\cline { 2 - 3 } \cline { 6 - 6 } & Fresh w. & Dry w. & & Fresh w. & Dry w. \\
\hline St. no. 4 & $124 \mathrm{~g}$ & $20.8 \mathrm{~g}$ & & - & \\
St. no. 7 & $329 \mathrm{~g}$ & $63.8 \mathrm{~g}$ & & $1580 \mathrm{~g}$ & $245.2 \mathrm{~g}$ \\
\hline
\end{tabular}

For the rest of the summer and the autumn no exact observations were made, but there is considerable reason to believe that there is an extended vegetation period in autumn, with retarded autumnal stages. At least the aspen trees seem to turn yellow later on the insolated slopes than in the valley (observed in particular in autumn, 1966, on Mt. Lulep Istjakk), thus indicating more favourable conditions of climate.

\section{Collation of phenological phases in 1961}

3-4 May: Vaccinium myrtillus. Phase $a$ acc. to Baumgartner, et al. reached on the S-exposed slope near station no. 4, the slope below Mt. Östreberget, a bare spot NE of the Hällback Mire, and the open place of the village. On the lake (the $\mathrm{N}$ shore) closed buds.

Empetrum hermaphroditum. On the bare spot NE of the Mire one specimen with two or three open flowers near the top was found (open flower $=$ stamens and petals free, but the anthers do not shed pollen). All other flowers in other habitats of the valley were ready to open. On the S-exposed slope near station nr. 4: first flowering on open scree, but only in single individuals, uppermost flowers.

It was noted that the zone near to the shore of Lake Storlaisan (where there was ice until the first week in June) was some days behind, and that Vaccinium vitis-idaea had not yet begun its development in any locality except in sunexposed situations (at any altitude). In all other habitats except the shore of the lake the development was at about the same stage.

17 May: Betula pubescens. Green, swelling buds except on the Hilltop (station no. 5), where the buds had not yet begun to swell. Otherwise there were no remarkable differences between localities.

Vaccinium myrtillus. Bud break (phase $b$ ) had only been reached on the S-exposed slope near station no. 4, in an open situation. Near the Lake and the Mire the development seemed to be later.

Daphne mezereum. Only at station no. 4 were there some flowers fully opened $50-70 \mathrm{~cm}$ above the ground (first flowering). Most flowers were still closed or half-closed. Only two days later there was full flowering in places with sun exposure $(580 \mathrm{~m})$; farther down, even in S-facing positions, not all flowers were out.

Empetrum hermaphroditum. Near station no. 4 about $90 \%$ of the fertile specimens were flowering and "steaming" from pollen in open places when touched. The top shoots were visible here and thus beginning to develop on all spec:mens. On the W-facing side of the mountain, in a pine forest, about $5 \%$ were flowering, up to an altitude of $500 \mathrm{~m}$, where there were still no flowers out. On the S-exposed slopes of the valley about $25 \%$ were out.

21 May: Vaccinium myrtillus. Phase $b$ seemed to correspond with full flowering of Empetrum, and had now reached the earliest snow-free areas of the valley bottom, but still not the Mire.

Empetrum hermaphroditum. Most of the fertile specimens 
were in flower on the valley bottom: the earliest snow-free areas on drier ground, i.e. the S-exposed river bank from the shore 10-20 m upward into the pine forest, and dry hills in S-exposure, but not the neighbourhood of the Mire. Here flowering seems to be $2-3$ days more behind.

Bare ground was observed on the $\mathbf{N}$ side of Lake Storlaisan, up to an altitude of about $630 \mathrm{~m}$ (only insignificant snow spots in forests)

Ice situation: quite a broad channel near the shore, max:mum thickness of the ice about $40 \mathrm{~cm}$.

28 May. Betula pubescens. Still green and swelling buds in all the habitats of the S-exposed localities.

Vaccinium myrtillus. Phase $c$ had reached the S-exposed localities on the mountain-side. The neighbourhood of the Mire had now reached phase $b$.

Empetrum hermaphroditum. Full flowering in all localities

4 June: Betula pubescens. Fig. 28. Bud break had now started in most localities except the zone near the shore Flowering had begun on the slope near station no. 4

Vaccinium myrtillus. Phase $c$ had now also reached the valley bottom on most aspects, but still not the neighbourhood of the Mire nor that of the Lake.

6 June. Betula pubescens. Because of the very warm weather (p. 53), but break had even reached the neighbourhood of the Mire and the Lake (Fig. 28). On the S-aspect near station no. 4 the birch was almost fully leafed.

Vaccinium myrtillus. Phase $c$ had now also reached the zone near the shore which at this time was considerably behind all other habitats (cf. Fig. $28 \mathrm{c}$ ). On the S-exposed slope of the mountain there was already full flowering.

Daphne mezereum. On the S-exposed slope near station no. 4 already small green fruits, the petals falling off. On the valley bottom full flowering.

For other species on this date: At station no. 4: Arabis hirsuta, single specimens in flower. Trientalis europaea, most of the plants flowering. Aconitum septentrionale, about 40 $\mathrm{cm}$ tall. Myosotis silvatica, in flower. Viola biflora, in flower. On the mire: Rubus chamaemorus, full flowering.

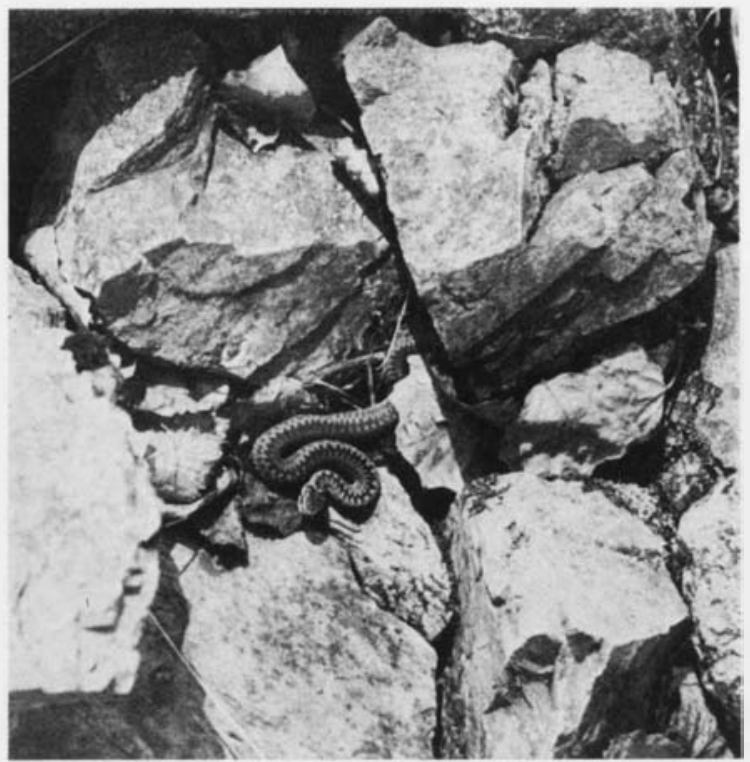

Fig. 27. Young viper (Vipera berus) on the SW-facing slope of Mt. Aistjakk on 2 May, 1961. For size, compare the aspen leaves. Near its upper limit of distribution, the viper preferentially selects warm localities.

\section{Conclusions}

This investigation was made to elucidate some features of the local climate of valleys and mountainsides in $\mathrm{N}$ Sweden. The effect of factors such as altitude, latitude and local-maritimity were studied in relationship to the "normal" temperature as established by meteorologists for the relevant area (cf.
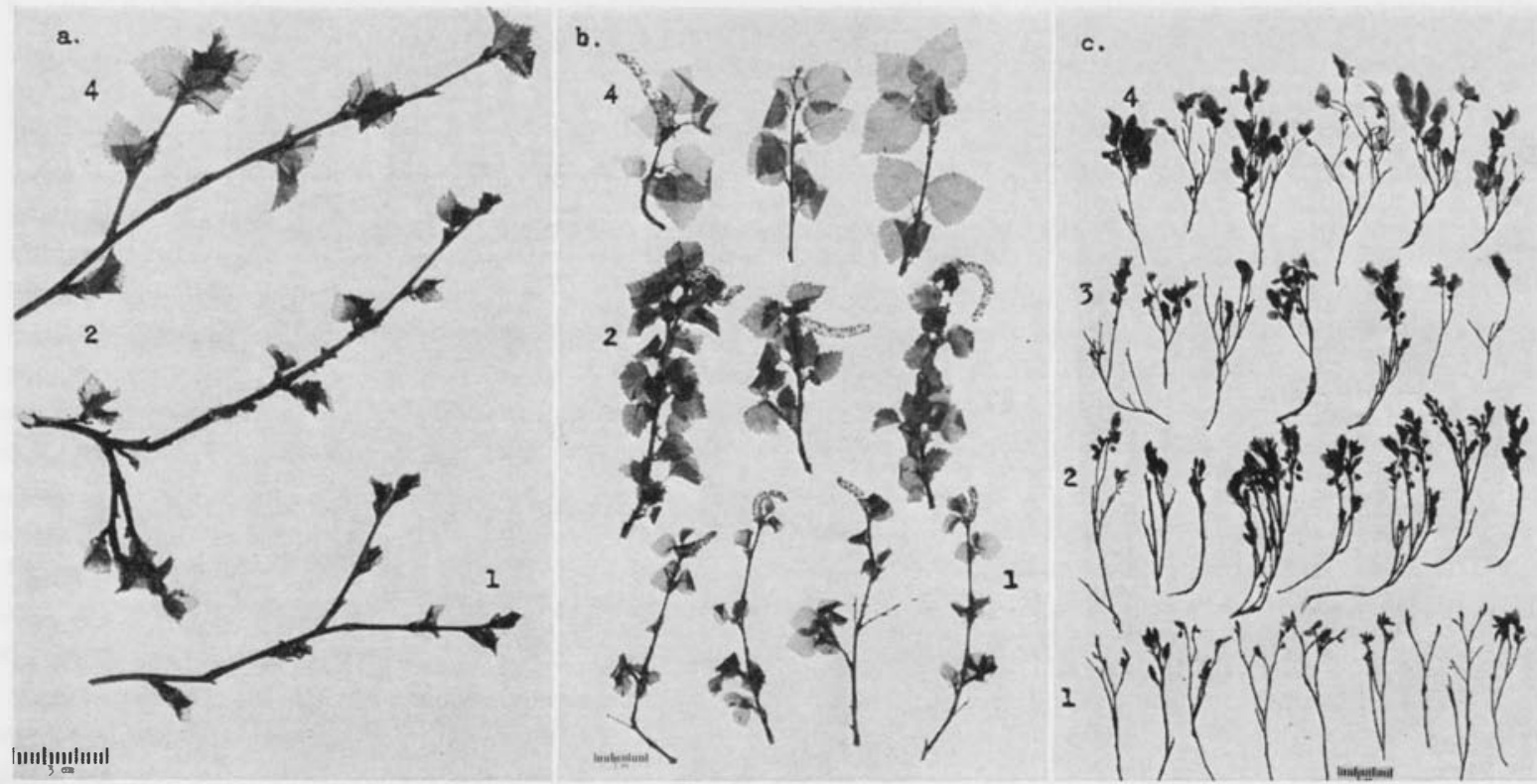

Fig. 28. (a) Twigs of birch (Betula pubescens) taken at the different stations near Hällbacken on 4 June, 1961; (b) the same trees on 6 June, 1961; (c) twigs of bilberry (Vaccinium myrtillus) taken in the same places on 6 June, 1961. 
Angström 1938, p. 27). Thus the average monthly values of temperature measured were compared with those for some stations of the meteorological network of Sweden. Through international convention, periods of 30 years starting with the period 1901-30 have been recommended as standard periods for the characterization of present-day climate. This time interval is agreed to be long enough to eliminate accidental variations. The standard period used here for comparison was 1931-60.

In Lappland high maxima recorded by the meteorological network are chiefly in local-continental areas and in low-lying valleys, but there are no stations of this network on very steep slopes, for obvious reasons.

On the other hand, when conditions within a limited area are considered, for instance a valley, high temperatures would be recorded especially for SW-exposed slopes below high vertical cliffs. Frödin (1915, pp. 202-203) showed that the insolated mountain-sides have large positive anomalies during bright periods. The present investigation shows that in daytime the thermal advantage is largely limited to bright weather. This is primarily because of the thermal energy incident on the inclined surfaces during periods of sunshine, although the time of insolation may be comparatively short on the steeper slopes. During the night there is less eradiation from a slope than from horizontal ground. Therefore there is less cooling at mountain-side stations and frequent nocturnal temperature inversions result. The mountain-side stations escaped frost during the periods from 1 June to 15 September in the years of investigation (1959 to 1962 and 1965-66). In regard to night temperatures, especially minima, the slopes are thus remarkably favourable. The sites with lowest night temperatures are the mires in the valleys.

The microclimate within different habitats of the mountains is highly variable. The warmest zone seems to be the scrub zone along the edge of the wood. The relative humidity of the air is comparatively low here, and the air flow is rapid. These conditions give rise to a more drought-resistant type of vegetation than elsewhere on the slope.

The snow conditions and the main hydrological features may be summarised as early thaw and usually a good water supply during the vegetation period (see below). Even in extraordinarily warm weather no injury to the plants was detected.

Phenological observations show earlier development on the slopes in spring and a prolonged vegetation period extending well into the autumn.

\section{SUPPLY OF WATER}

\section{Precipitation and interception}

For conditions of precipitation during the years of investigation in middle Lappland, reference is made to publications by SMHI. Average precipitation is mapped by Wallén, C. C. 1953 (Atlas över Sverige) and discussed by Wistrand 1962 (pp. 31 et seq.). The average annual precipitation for the period 1922-44 (Wistrand) is between $395 \mathrm{~mm}$ (Jäkna) and $565 \mathrm{~mm}$ (Jäckvik), the recorded extremes for the area studied. There are great variations from year to year, in monthly, seasonal, and annual totals. Thus at Arjeplog (SMHI, cf. below) in June, 1961, $87 \mathrm{~mm}$ fell, against $51 \mathrm{~mm}$ average for the period 1931-60, while in July the rainfall was $140 \mathrm{~mm}$, against an average of $76 \mathrm{~mm}$. Similar variation characterizes the run-off, i.e. surplus of precipitation, as calculated from average annual precipitation and temperature (Tamm 1959, pp. 5 et seq.) by means of an empirical formula. De Martonne's "humidity index", i.e. precipitation/ (annual temp. +10 ) is between 32 and 40 for the studied area (Angström 1958, p. 74, see also Atlas över Sverige). In Hesselman's (1932, p. 542) terminology it would be transitional between the sub-arid and the sub-humid areas. Tamm introduced the term "normal-humid" for an area covering the major inland parts of Sweden. There are no great differences in average precipitation during the vegetation period (Atlas över Sverige), from the SE border of the Caledonides to the border of Lappland towards the coastal districts. However, when local features such as valleys and mountain plateaux are considered there is great variation (Wistrand). Such conditions should be expected, as recent rainfall studies using dense networks (Bergeron $1960 a, b$, 1961; Andersson, T. 1963) make it evident that even small orographic obstacles produce an immediate response as increased amounts of precipitation. In this way forests, especially when growing on somewhat elevated ground, definitely receive greater quantities of rain than treeless areas. To some extent this counteracts interception. Cf. Sjörs 1948, p. 25.

There is a copious ecological literature dealing with differences in vegetation on hillsides as caused by varying amounts of precipitation reaching the slopes (cf., e.g., Degelius 1935, pp. 270 et seq.; Persson 1944, pp. 339-40; v. Krusenstjerna 1945, pp. 19 et seq.). These investigations show that floristic composition and vegetation of mosses and lichens are dependent on the amount of soil moisture on the differently exposed slopes. The results obtained by meteorologists are nowadays slightly contradictory, in regard to the proportions of precipitation reaching 
the different hillsides (cf. Hudleston 1928, p. 268; Grunow 1953; Geiger 1965, pp. 419-20). When measurements are made with horizontal collecting surfaces small hills receive the greatest quantities of rain on the lee side (Hudleston). When the collecting surface is parallel to the slope, relatively more rain and snow is received on the windward than on the lee side, especially at high wind speeds. As Grunow showed, the latter method is preferable for evaluation of precipitation on a sloping site.

The richer moss and lichen flora on the lee sides of hills in S Scandinavia was chiefly explained by the higher amounts of precipitation reaching these slopes in certain places, and by the difference in exposure to drying-out wind and sun. In N Scandinavia, where there is an abundant supply of precipitation through the year and also less drying-out during the vegetation period because of a high degree of cloudiness, suboceanic lichen species may even be found on SW aspects (Normandina pulchella on Mt. Strömnäsberget, a mountain slope immediately $\mathrm{W}$ of $\mathrm{Mt}$. Lulep Istjakk, no. 18, Hasselrot 1948, p. 185. Cf. Degelius 1945, p. 391, who mentions Pannaria pityrea from a somewhat more shaded habitat below the talus slope on a S-facing hillside in Torne Lappmark). In the $\mathbf{N}$, the moss flora on mountain-sides facing SE to SW is fairly rich, too (see below, pp. 78 et seq.). Thus the problem is more complex than it was thought to be.

In the summer of 1961 some measurements were made on Mt. Märkepakte (no. 12) at different levels on more or less wooded slopes in order to evaluate the distribution of precipitation. A number of gauges of SMHI's new type (1956) with horizontal catchment area were used. They have a mean area of $204.4 \mathrm{~cm}^{2}$ (standard deviation $2.2 \mathrm{~cm}^{2}$ with 20 gauges, Andersson, T. 1964 , p. 363). The variation in area was neglected. As was mentioned earlier, Grunow's investigations show that the values on the slope are not directly comparable with those obtained on horizontal open ground if a horizontal catchment area is used. However, the values on the same slope should be directly comparable when the inclination and the wind speed around the vessel is about the same. The so-called Jevon's effect, depending on the deflection of the the wind passing different kinds of obstacles, should be kept in mind. The total measured amounts of rain on the S-facing side of $\mathrm{Mt}$. Märkepakte from 23 June to 12 July are shown as columns on Fig. 40 (gauges nos. 8-14). Not only the interception by vegetation was studied but also the importance of the overhanging cliff. The gauges were placed directly on the ground.

The placing of the rain gauges. Nos. 1-4 were in

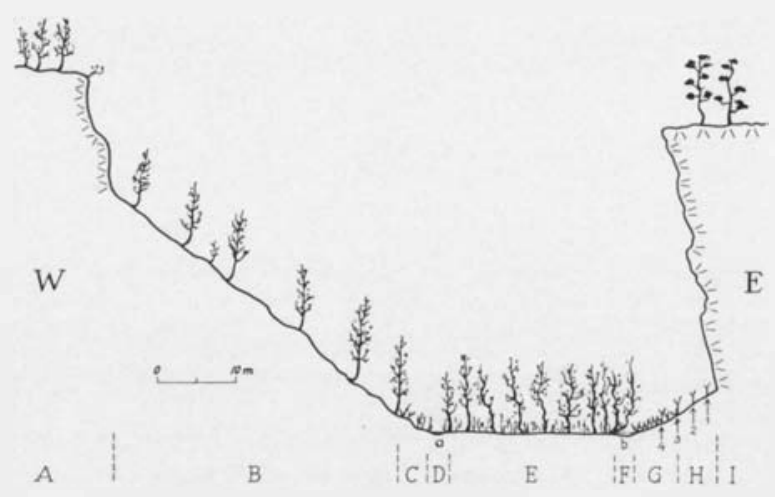

Fig. 29. The position of the rain gauges nos. 1-4 in the Merk Gorge in the summer of 1961, as seen on a schematized section of the Gorge at the owl's nest (Bubo bubo). The sites $E$ and $G$ have been subjected to vegetation analyses. $A$, Mountain wall facing $\mathrm{E} ; B$, scree consisting of schistose gravel; $C$, the lowermost part of the scree containing some few boulders; $D$, the western furrow of the stream; $E$, the grey alder wood (Alnus incana) with Circaea alpina; $F$, the eastern furrow of the stream; $G$, part with dominant Matteuccia struthiopteris; $H$, part with drought-resistant grasses dominant (beyond rain gauge no. 1 only stands of Chamaenerion angustifolium along the foot of the rock wall); I, overhanging rock wall (scattered pine trees (Pinus silvestris) on the plateau).

the Merk Gorge immediately E of Mt. Märkepakte (Lundqvist, J. 1966, Fig. 1). Here the gauges were placed on a $\mathrm{W}$-exposed slope of about $30^{\circ}$, below a $30 \mathrm{~m}$ high overhanging rock wall (Fig. 29). The rock wall has an even inclination and the top projects about $7 \mathrm{~m}$ over the bottom. Because of this the uppermost part of the scree, below the rock wall, is only rarely reached by rain, and there is very sparse vegetation in spite of a copious water supply from the cliff at times (Fig. 32). From this it was concluded that the seepage water was insufficient to support the extraordinarily luxuriant vegetation which grows in other parts of the Gorge. The gauges were placed on a straight line at right angles to the cliff:

1. $1.2 \mathrm{~m}$ from the cliff, at the uppermost edge of a Roegneria canina community. Nearer the cliff there is no vegetation.

2. $3.5 \mathrm{~m}$ from the cliff at the lower edge of the Roegneria community.

3. $5.5 \mathrm{~m}$ from the cliff where there is a sharp border-line with a Matteuccia community farther down the slope. The inclination of the slope is $29^{\circ}$ at this point, which coincides with the "drop zone" during heavy rains.

4. $8.0 \mathrm{~m}$ from the cliff, in the centre of the Matteuccia community just outside a vertical line down from the outermost edge of the cliff. $12.0 \mathrm{~m}$ from the cliff there is a grey alder stand on the bottom of the Gorge. See further, p. 103. 


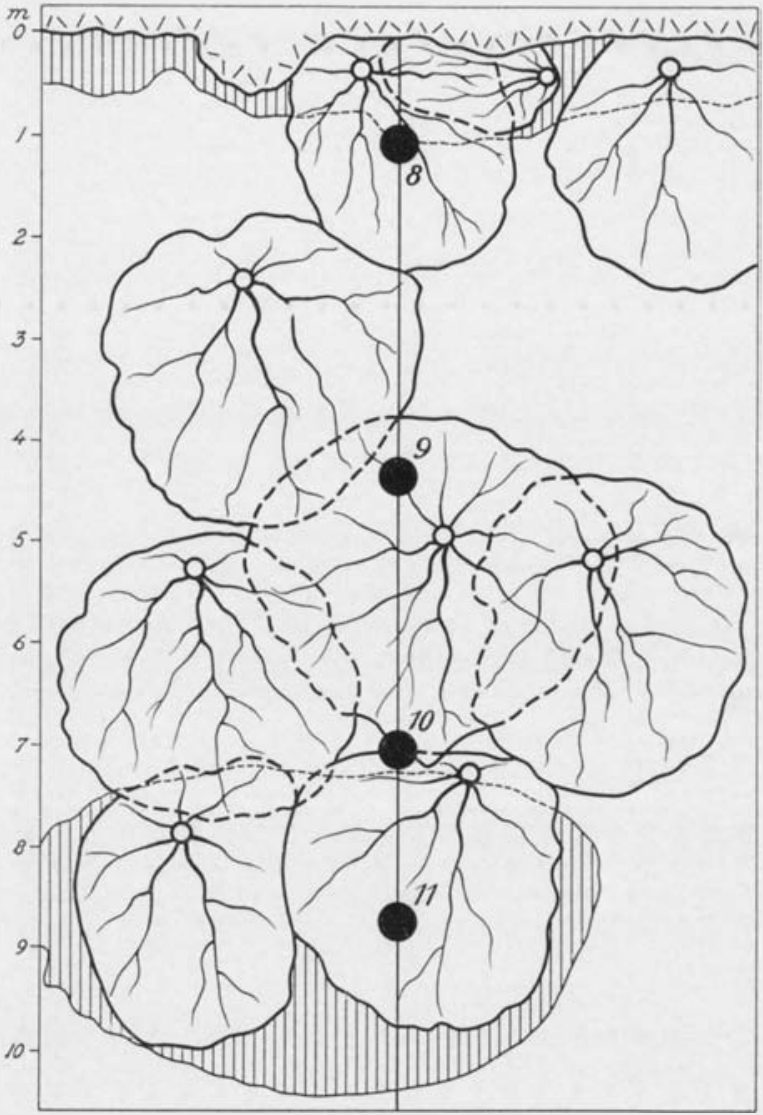

Fig. 30. The position of the rain gauges no. 8-11 (see Fig. 40) seen at straight angle towards the S-facing scree of Mt. Märkepakte. Juniperus scrubs hatched; the trees are aspen (Populus tremula). The analysed belt transect marked by a filled line in the middle of the figure.

The rain gauges nos. 5-7 were on the SE-facing side of Mt. Märkepakte, $200 \mathrm{~m}$ from nos. 1-4.

$5.3 .0 \mathrm{~m}$ from the quite low vertical ciiff in a community dominated by Rubus saxatilis and Melica nutans under a canopy of birch and bird-cherry (Prunus padus). There was a gap in the canopy towards the $\mathrm{S}$.

6. $8.0 \mathrm{~m}$ from the cliff just outside the wood but under overhanging bird-cherry and birch.

7. $11.0 \mathrm{~m}$ from the cliff, centrally on the talus slope. No tree cover. At the lower edge of the talus slope there was birch wood at a distance of $4.5 \mathrm{~m}$ from the gauge.

As was mentioned earlier, gauges nos. 8-14 were on the S-facing side of Mt. Märkepakte and were placed on a straight line at a right angle to the cliff, which is almost vertical. They were placed centrally in a belt transect described on p. 98. Their placing is made clear by Figs. 30 and 40 .

15 , finally, is the reference gauge placed on top of the hill plateau $\mathrm{E}$ of the Merk Gorge at about the same height as gauges nos. 5-14. Trees (pine) are very sparse and the ground is level. See Table 13 (behind the text).

All the measuring points could not be studied at the same time because of the limited number of gauges available.

Shielding by the overhanging rock wall is shown to be great although the exposure was westerly. The shielding effect of a S-facing rock wall is nil when it is nearly perpendicular, at low wind velocities. During heavy rain with stronger winds from a westerly or north-westerly direction, the protecting effect of the rockwall increases. This was seen on Mt. Lulep Istjakk on 6 July, 1961. Local thunderstorms were passing above Lake Hornavan from a west- to northwesterly direction. At the observation point near the S-exposed perpendicular cliff of Mt. Lulep Istjakk there was only a small amount of rain in spite of the absence of protecting trees, while heavy rains were striking the talus slope further downslope.

Most of the rain falling during the vegetation period is likely to occur with the prevailing winds from W or SW. Thunderstorms with strong winds of varying direction are too rare even during the warmest part of the summer to have much effect. Thus rain from the $\mathrm{E}$ and $\mathrm{SE}$ is less frequent.

There have been a large number of publications about interception and the water-holding capacity of different kinds of trees (cf. Geiger 1965, pp. 323 et seq.). Much less precipitation will reach the ground in a dense forest than in an open habitat, but the particular conditions prevailing during the rainy weather will exert a strong influence. The ground under dense trees will not get wet during a light rain even though it lasts for hours. On the other hand, when the rain is heavy and consists of large drops a much higher percentage of the precipitation will reach the ground. In woods with a thin canopy, like those on the slopes investigated, the interception is moderate. Because tree crowns may have very variable density, differences in the distribution of precipitation occur round each tree in the wood. Several methods have been used to study the average distribution in a forest (cf. Geiger), the best method being some kind of strip sampling. In this investigation the rain gauges were placed under a canopy of variable density to produce a fairly reliable average value for the wood when the different records were totalled. The shielding or deflecting importance of the S-exposed cliff was presumably of little importance during the observation period (cf. above).

As a complement to the values in Table 13, an oc- 
casion when there was a very light wind and the drops presumably fell almost perpendicularly to the ground (except sprinkle in the wood) may be included. This shower was of moderate intensity and lasted exactly an hour in the middle of the day on 12 August, 1961. The values for the S-exposed slope of Mt. Märkepakte were then:

$\begin{array}{lllllll}\text { Gauge no. } & 8 & 9 & 10 & 11 & 12 & 14 \\ \text { Amount, mm } & 3.7 & 3.3 & 4.8 & 3.0 & 4.2 & 3.6\end{array}$

Gauge no. 10 was under a hole in the canopy at the edge of the wood and suggests therefore that sprinkle and drops from the periphery of the tree crown might locally increase the precipitation amount over that in the open, represented by a gauge on the treeless talus (no. 12, cf. Fig. 40). Gauge no. 9 demonstrates interception in the aspen wood $(21 \%$ of the value for the open talus, which may be taken as a reliable value for comparison).

When estimating the moisture available to the vegetation of the upper talus slope we must not neglect the amount flowing down the steep cliff when it is openly exposed to rain. Of this amount the greater part will at first moisten the soil in the immediate vicinity of the cliff. This is clearly seen on the Sfacing side of Mt. Gaddaberget (no. 31) where there is a cliff completely free of water-delivering cracks sloping about $60^{\circ}$ in one place. At this point there are moisture-demanding vascular plants as far as 50 $\mathrm{cm}$ from the cliff (Fig. 31) although the rest of the scree is covered by undemanding Vaccinium heath. Some of the water will of course continue to run down the rock surface under the talus, but much of it will evaporate from the warm slope. Water rising to the soil surface by capillarity will also evaporate. As was seen in the Merk Gorge, where there is a normal content of finer fractions but no humus content in the scree below the rock wall at one point, little water moves away from the cliff. It is rarely wet enough to supply any significant amount of water to the fine debris scree. When on non-overhanging cliffs the force of flow of the water reaching the scree is strong, movement away is increased. This is the normal pattern on these mountains, as there are generally only small parts of the cliff which are overhanging, forming "ceilings" over caves at the base of the rock wall. On the cliff the shelves generally have a discharge of rapid movement.

Concluding remarks. As was shown by Hudleston (1928) and Geiger (cf. Geiger 1965, p. 419) the wind field largely determines the distribution of precipitation around hills. Thus the distance of steep rises from the point of measurement must be taken into account. At almost vertical surfaces the shielding

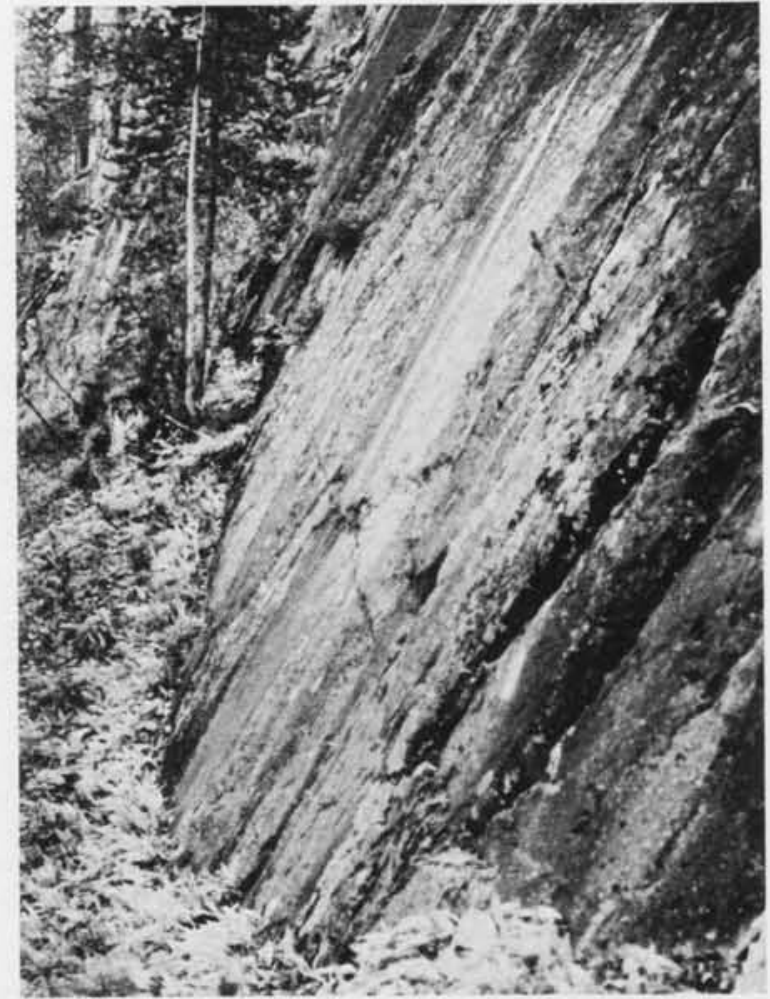

Fig. 31. Scree dominated by Vaccinium myrtillus with no herbs changing to a moisture-demanding community (with Convallaria majalis, dominant, Melica nutans and Cirsium heterophyllum) immediately in front of the cliff. See text. Mt. Gaddaberget, the S-facing sije. 15 September, 1967.

and deflecting effects are much increased. Evidence of this is easily seen in winter, since snow is more easily deflected than rain. Snow is normally deflected from the windward side of moderately steep hills and collected into huge drifts on the lee side. Balow an over-hanging cliff, however, the deflection of snow on the windward side is diminished because of the sudden slowing down of the wind, and rain, at least, may eventually be completely shielded if the overhang is sufficient. On the lee side a $90^{\circ}$ cliff has practically no precipitation, increasing amounts being found at increasing distances from the cliff. The inclination of a steep slope that will shield off a measuring point completely on the lee side is dependent on wind velocity and lee whirls and the distance of the gauge from the shield, and, above all, on the type of precipitation.

\section{Surface and sub-surface waters}

The hydrologic cycle comprises an interdependent system of atmospheric, surface, and ground water (Davis \& DeWiest 1966, p. 15). The waters at greater depths which may occasionally enter the hydro!ogic 


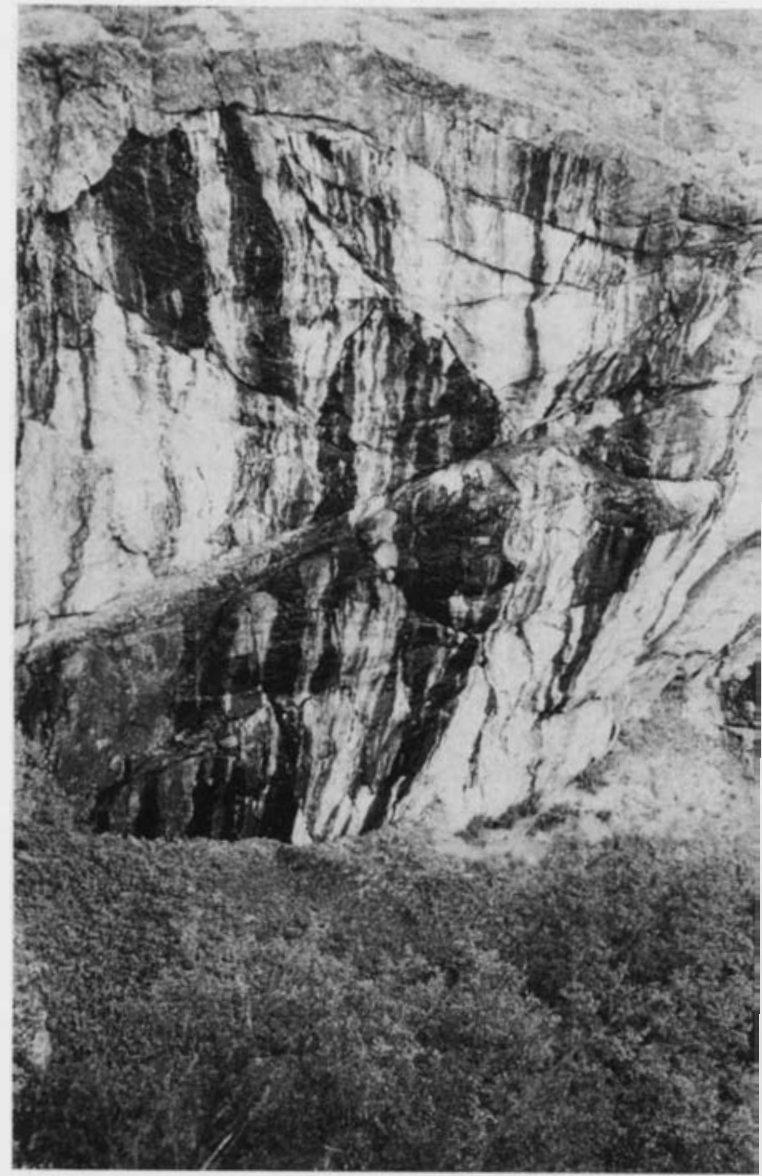

Fig. 32. The overhanging W-facing cliff of the Merk Gorge. The cliff is ca. $30 \mathrm{~m}$ high. See Fig. 29. The cliff of mylonitized rock (mainly syenite-mylonite). White stripes of calcium carbonate are numerous. July, 1961.

cycle, as, e.g., magmatic water and juvenile water, will not be discussed here.

Before or after entering the ground a large amount of water is returned to the atmosphere by evapotranspiration, in which the plants play an important part. As was shown indirectly by measurements of temperature and wind speed, large differences in evapotranspiration may be expected on mountain slopes of different aspect and in different habitats on the S-facing slope. Although the interception of precipitation was shown to be low in the woods concerned, a certain amount evaporates immediately after rainfall; and if the rainfall is light relatively large percentages are intercepted. After reaching the soil the water is retained as soil water until the saturation point is reached. After that, excessive water will be discharged laterally as surface or subsurface runoff. Infiltration and percolation take place in an intermediate zone between soil water and ground water (vadose zone). However, especially along rock surfaces and in soils containing boulders, a direct passage from the surface down to the ground water is of ten possible (Troedsson 1955, p. 156). Any root channel or other wide vertical pore or crack may provide such a rapid by-pass, and the percolation through the soil will be very uneven when the soil has an unequally distributed resistance to water movement.

Generally only ground-water flow is designated as sub-surface runoff. Where the ground-water table is horizontal and the flow thus slow, the water levels in wells very closely correspond to the water table. The zone of phreatic water (op. cit., p. 39) is the zone below the ground-water table. In stratigraphic sequences of hydrologically different deposits several water-tables or phreatic zones may exist. Aquifers are the water-bearing portions in any bedrock or geological deposit.

The term "seepage water" (Swed. "sippervatten", "bergsega") has here been used to designate any out-flow of vadose or phreatic water on steep mountain-sides. These are generally small temporary springs during the vegetation period, i.e., surface seepages of the seventh or eighth magnitude according to Meinzer's classification (1923; op. cit., p. 62). Somewhat larger springs (probably of the sixth magnitude, Mt. Laisvare, sample no. 3) persist during the vegetation period but dry out or freeze in winter. From this may be concluded that the topography is not favourable to springs (see, op. cit., p. 327) as compared with less steep slopes and valleys.

The term "bergsega" or "bergssega" has been used in recent plant ecological literature meaning "seepage water". In older Swedish literature it was probably used as a name for rock oil or petroleum (Swed. bergolja, Germ. Steinöl, cf. Svenska Akademiens Ordbok öfver Svenska Språket, 3rd Vol., 1906). Sernander $(1912$, p. 812$)$ introduced the term to designate the black communities of algae that are often formed on rock walls below fissures where groundwater percolates. "Vid konstant vattentillförsel betäckas dessa ytor af de karaktäristiska svarta algsamhällen, för hvilka jag från folkspråket upptar namnet bergssegor. Dessa bildas äfven ofta på klippväggar nedanför remnor, där grundvatten bryter fram."

The flow from a spring is dependent primarily on the amount of precipitation, the recharge area and the bedrock. Because of the differences in precipitation and bedrock within PL we might expect to find great variations in spring discharge. The permeability and porosity of the rocks is higher in the NW than in the SE, but the dip of beds in the NW is often unfavourable, and the cliffs are also generally steeper. The longer persisting outflow in the NW in early summer is caused by the later thaw.

An important effect of seepage water is caused by 
Fig. 33. Sampling place for seepage water immediately above the studied plant community and station no. 7 . Small crack delivering sparse water from the upper part of the rock wall during rainy periods. Samples from the sampling point vertically above the bottle had a higher $\mathrm{pH}$ than the open crack with rapid runoff.

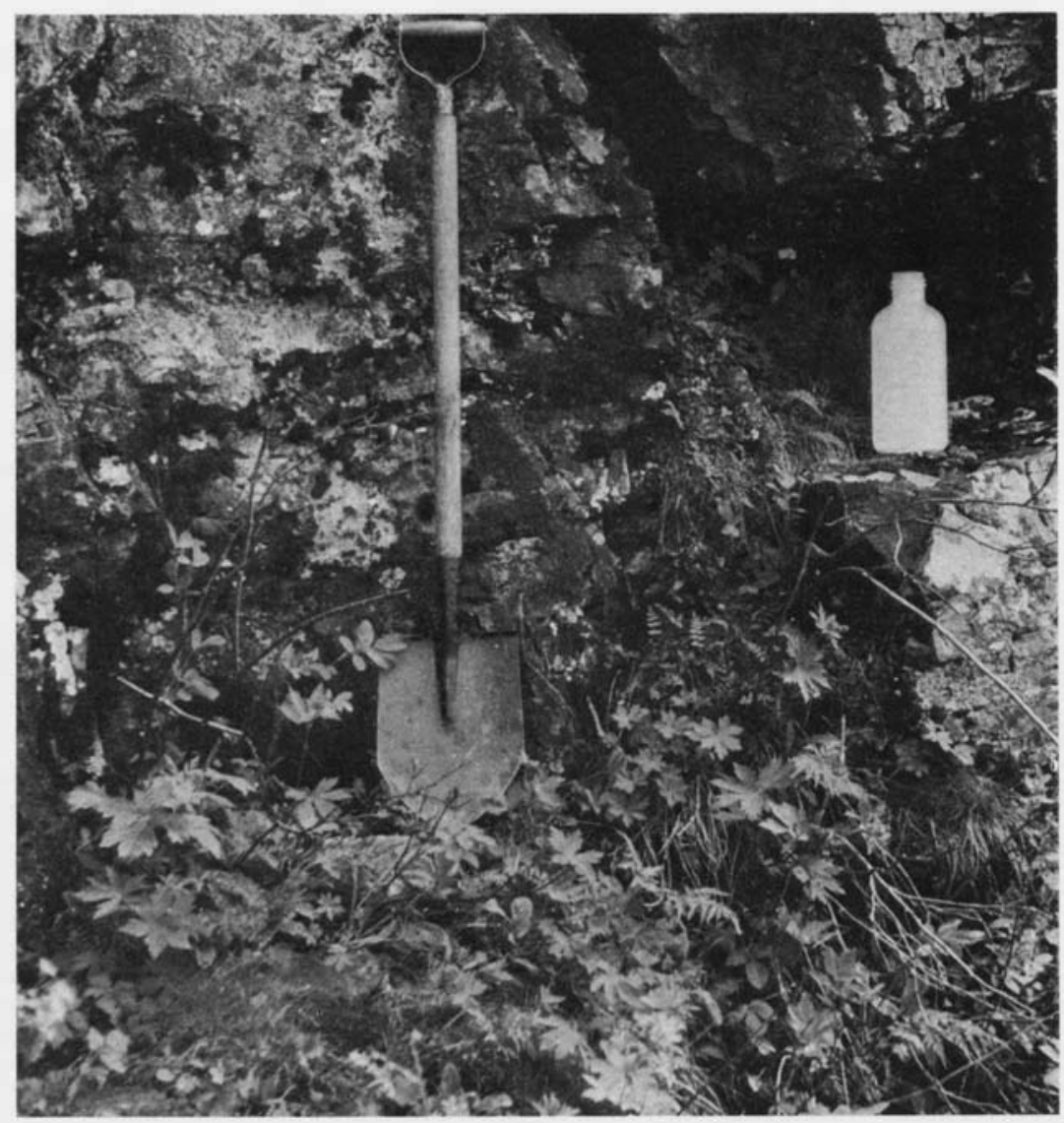

its high content of dissolved salts, enriching the otherwise easily leached parts of the scree. The rapid ground-water recharge in screes will cause a low ground-water table, in coarse materials probably not extending outside the rock core. In periods of amp'e water supply, after the culmination of the thaw or after rain periods, most of the fine scree will be saturated. In drier periods the most exposed zone near the boulder scree will dry out first, especially quickly as open spaces occur frequently. Immediately in front of the cliff some recovery through capillaries in the soil should be possible, which may explain the generally less drought-resistant, rather luxuriant vegetation growing there. Local variations in water content are due to humus and clay content etc., see be!t transect on Mt. Lulep Istjakk, the soil conditions of which were described on pp. 26-27.

Seepage water and potential chemical enrichment have long been discussed in the literature as important site factors on mountain-sides with southern plants (cf. Du Rietz 1954, p. 181). A large number of chemical analyses of water in rocks have been published. The mobility of the elements is influenced by the solubilities of different solids under the conditions prevailing in the pores inside the rock, includ- ing temperature and pressure which are important for the dissociation and for the equilibrium of dissolved gases. The chemical equilibrium is thus easily changed. In particular, when the water appears near the surface there is a sudden large reduction in pressure, and a further change when the water eventually comes into contact with the outside air. Stepwise, the content of gases in solution, especially $\mathrm{CO}_{2 .}$, will diminish and $\mathrm{pH}$ will be increased. This may finally result in precipitation of calcium carbonate as white stripes on the rock walls even where the bedrock is silicious.

Chemical investigations of seepage water on mountain-sides in $\mathrm{N}$ Sweden were published by Halden (1956, pp. 212 et seq.) who emphasized the determining role of the bedrock and the water supply to plants. In strongly oligotrophic areas he found a $\mathrm{Ca}$ content of ca. $2 \mathrm{mg} / 1$ (Mt. Omneberget, granite) while $29 \mathrm{mg} / \mathrm{l}$ was found in water from amfibolite probably with a macroscopic content of calcite.

From investigations in PL (Table 14) it is evident that $\mathrm{Ca}$ and $\mathrm{SO}_{4}$ are the ions with most variable concentration in different seepage waters. This is to be expected from the physiographical conditions. The content of gypsum may be especially high in the 
Laisberg sandstone (samples nos. 3 and 4). This sandstone occurs in an open cleft on Mt. Laisvare (Laisberget), from which it has got its name. It forms beds in the autochthonous series of Eo-Cambrian and Cambro-Silurian sedimentary rocks along the SE border of the Caledonides. In the SW of PL, lead and zinc mineralization occur in the Eo-Cambrian sandstone series. The Laisvall deposit, where there has been a mine producing lead ore since 1942, is wellknown to geologists. The ore minerals are mostly galena, together with some sphalerite and pyrite (Grip 1960, p. 153).

The metals can be detected in waters over a large area. Nevertheless the waters from this sandstone are potable. As calcite, barite and fluorite are present as large poikiloblasts (Grip 1960, p. 154) the amount of ions in the water is exceptionally high for PL. The water has probably been subjected to high pressures as the overlying overthrust nappes often reach a thickness of $100 \mathrm{~m}$ or even more. On Mt. Laisvare the bedrock and the water seem to have a favourable influence on the vegetation (see the description of Mt. Laisvare below). In spite of the extraordinarily high content of minerals in the water, no poisonous effects were observed nor were precipitated crystals seen on the plants.

Quite dissimilar waters of ten come from the same bedrock, depending on their hydrological origin. In the Laisberg sandstone in the mine water samples (with temperatures of between 3.8 and $5.9^{\circ} \mathrm{C}$ ) were taken, with conductivity values between 129 and 141 , thus definitely lower than those listed in the table. Such water might be transported from the underlying Archaean rock or (in a tunnel immediately below Lake Storlaisan) be filtered lake water. A thorough description of the geological conditions of the mining district is given in Grip (op. cit.). The rocks from which the waters were derived are described above (p. 21).

Methods. Collection of samples of seepage water for analysis of ten requires special precautions. It may be difficult to obtain in a reasonable time a sample, the chemical character of which is characteristic for the bedrock in question. If the seepage is very slow a certain amount of water will evaporate. Part of the water that seems to ooze constantly from the cliff is in reality temporary seepage caused by rainy weather before sampling, etc. The value of an analysis of such water is doubtful, especially if phreatic artesian water was sought (some indication is given by the temperature of the water, see below). $\mathrm{pH}$ measurements could also give some idea, although quite high $\mathrm{pH}$ values are obtained in some bedrocks after a very short distance of percolation. An example is a Cambro-Silurian shale from Mt. Aistjakk (mountain no. $16 a$ ) where $\mathrm{pH}$ increased from 6.6 to 7.2 after a percolation distance of ca. $25 \mathrm{~cm}$ (Fig. 33).

Sampling was done in such a way as to avoid misleading results. The sampling places were selected carefully with regard to the general character of the water, the $\mathrm{pH}$ (see below), specific conductivity and temperature of which were measured immediately in the field. When a choice of fissures was possible the one supplying the coldest water of highest conductivity was selected as being likely to have the highest content of dissolved salts. (An exception from this rule is the sample no. 6 from Mt. Lulep Istjakk where there was colder water but in insufficient amounts for sampling.) The waters were as a rule not contaminated biologically. See Table 14 (behind the text).

$p H$ measurements were made at Centrala Analyslaboratoriet, Uppsala, when they could not be made in the field (see below). The instrument used in the laboratory was a Beckman pH-meter with glass electrodes. As these analyses were made 1-2 months after sampling the values are likely to be too low. In one case (Mt. Lulep Istjakk) the determinations were made colorimetrically.

The very high $\mathrm{pH}$ values in some of the samples were outside the range of the set of indicators brought for colorimetric determination in the field. However, for a few samples the "fresh" values could be estimated approximately. By kind cooperation from the laboratory of the mine at Rönnskärsverken, values for 9 samples in the range 7.9 to 8.6 , average 8.3 , were obtained for a level just where the author's sampling was done. The laboratory of the mine made their analyses the day after the sampling. On 21 August, 1964, a reliable value was obtained for the same water as that for which the chemical analyses were carried out, $\mathrm{pH} 8.2$ at a water temperature of $4.8^{\circ}$ (sampled by the author and immediately read electrometrically with a glass electrode meter for field use), on Mt. Laisvare.

Conductivity has here been given as the specific electric conductivity at a water temperature of $20^{\circ} \mathrm{C}$, multiplied by $10^{\text {s. }}$. A newly collected sample was measured in the field with a Triib \& Teuber bridge using alternating current from a buzzer and a Philips Microcell PR 9512/00 with platinum electrodes. The measuring volume was $4 \mathrm{~cm}^{2}$ and the cell constant $1 / 1.38$. The temperature corrected value was calculated according to the formula $\varkappa_{20}=C / R_{t} \times 1.02^{20-t}$ (see Sjörs 1950, p. 246). This value was checked on a few occasions by warming the sample. A stable electrical resistance of the sample was obtained by gentle movement of the Microcell. The equivalent conductivities of the hydrogen ions are very low at the pH values concerned (op. cit. p. 247) and were thus neglected.

The following analyses were made at Centrala Analyslaboratoriet, Uppsala.

$\mathrm{Na}, \mathrm{K}, \mathrm{Ca}$ were determined by flame photometry. When measuring $\mathrm{Ca}$, disturbances were eliminated by addition of a solution containing $\mathrm{LaCl}_{3}, \mathrm{NaCl}, \mathrm{KCl}$ and $\mathrm{HCl}$.

$\mathrm{Mg}$ was determined spectrophotometrically using titan yellow according to a modified method by Sandell (1959, p. 591). 
$M n$ was determined spectrophotometrically after oxidation with persulphate (Nydahl 1949, pp. 144 et seq.), with the exception of a sample from Mt. Måfevare in which it was determined spectrophotometrically with formaldoxim according to Goto, Komatsu \& Furukawa (1962, pp. 331 et seq.).

$\mathrm{SO}_{4}$ was reduced by hydriodic and hypophosphorous acids in acetic acid solution to sulphuretted hydrogen and determined as methylene blue (Gustafsson 1960, pp. 236 et seq.).

$\mathrm{Cl}$ was determined by potentiometric titration with $\mathrm{AgNO}_{3}$ (Kolthoff \& Kuroda 1951 pp. 1304 et seq.), but in the sample from Mt. Måfevare by spectrophotometric determination using $\mathrm{Hg}(\mathrm{SCN})_{2}$, a modified method by Iwasaki et al. (1956, pp. 860 et seq.).
Si was determined spectrophotometrically (reduction of silicomolybdenic acid to blue silicomolybdate, Mullin \& Riley 1955, pp. 162 et seq.).

$\mathrm{HCO}_{s}, \mathrm{~Pb}, \mathrm{Zn}$ and water colour were determined by methods described in "Anvisningar för bakteriologiska och fysikalisk-kemiska vattenundersökningar" (1953).

Suspended grains were determined by using special paper filters (OA and OOM) and by igniting the filters at 600$700^{\circ} \mathrm{C}$. For sample no. 4 (Laisvall lead mine) the value obtained by the laboratory of the mine was used. Since in this case a membrane filter with low transmission was used $(1 \mu)$ the values are hardly comparable. 


\section{THE FLORA OF THE HILLSIDES}

\section{Introduction}

Arising from the study of the distribution pattern, ezology and history of the separate species on Sfacing hillsides there have been extensive discussions about the floral elements. In the classical work by Andersson \& Birger (1912) the relationship between some important groups of vascular plants and the climatic factor were discussed in detail. An arrangement in classes of increasing thermophily formed the basis of the ecological discussion in this work, the most thermophilous element being called "S Scandinavian species". The least thermophilous group was "mountain species" (Swed. "fjällarter”, op. cit., p. 70; later, Sjörs 1950, p. 177, used the words "Scandian plants" to designate species chiefly found in the Scandes). These were, however, found to be quite well represented even on S-facing cliffs. The distribution of the latter group as well as that of the " $S$ Scandinavian species" could consequently be supposed to be highly influenced by the competition factor. The ecology of the two groups, especially the intrinsically difficult problem of thermophily, could still be dealt with only in broad terms.

When evaluating the ecology of the different plants, we have to deal with plants of which the history and main ranges round the pole differ in some way or other, although many of them have very similar distributional ranges. The present ranges of all plants in the area concerned here are results of changing climate during postglacial time. In the mountainous areas the topography has been of major importance. At higher altitudes the conditions on the mountains reflect the conditions closer to the poles, and on slopes of favourable exposures, the conditions are similar to the milder climates nearer the Equator. The talus localities have thus been regarded as relic sites reminiscent of warmer periods (see p. 103). During the warm postglacial period the thermophilous element is thought to have had a more extensive and general distribution. Later the distributional areas of plants belonging to this element became more restricted and were eventually limited to the "warm sites". The Scandian element, which was thought to have "hibernated" to a large extent on refuges on the Norwegian coast, migrated into the Scandes after the ice had left. There these plants succeeded in surviving the warm period only on the higher peaks. The postglacial changes in climate and flora also resulted in the stabilization of forest communities. Only in the few open habitats of the forest did adequate sites for thermophilous elements persist. These elements, but also most of the Scandian plants, thrive almost exclusively in more or less unshaded habitats, and other parts are left to a very sparse forest flora, at least on terrestrial mineral soils.

\section{The flora of vascular plants}

The basic concepts in a discussion of the microdistribution of plant species (their topography, de Candolle 1855; see Wulff 1950 , pp. 28 et seq.) are the taxonomic units systematically subdivided as far as possible. Then the total range might be considered for all the units occurring in the region concerned (see Meusel 1943, Böcher 1943, Meusel 1959, Meusel, Jäger \& Weinert 1965). As Graebner (1910, p. 191) pointed out, when he considered the climatic effect on the distribution of species, there is for many species a "region of compact distribution" where the species finds good conditions for its growth in many sites, and areas close to the "absolute limit of distribution" where the species is restricted to certain localities with special habitat conditions. Initially there is a centre of propagation of the species which may coincide with a centre of frequency within the area concerned ("Frequenzcentrum", Samuelsson 1910 , p. 7; see also Wulff 1950 , 1. c.). From the centre of propagation more or less equiformal progressive areas (Kulczynski 1924, Hultén 1937) are formed by dispersal. The factor of form-genesis acting throughout epochs on the genetic material creates a centre of maximum variation (Turrill 1939). Theoretically the widest genetic variation would be found in the initial centre of the area and a gradual decrease in variation towards the periphery. Under certain conditions, during the course of its dispersal from the primary centre, a species may give rise to new form-genesis by which secondary centres of variation will arise. On the other hand, a species may disappear from a whole area and then there may be recolonization from centres of preservation ("Erhaltungsgebiete", Irmscher 1929).

Hence it may be concluded that it is of importance 


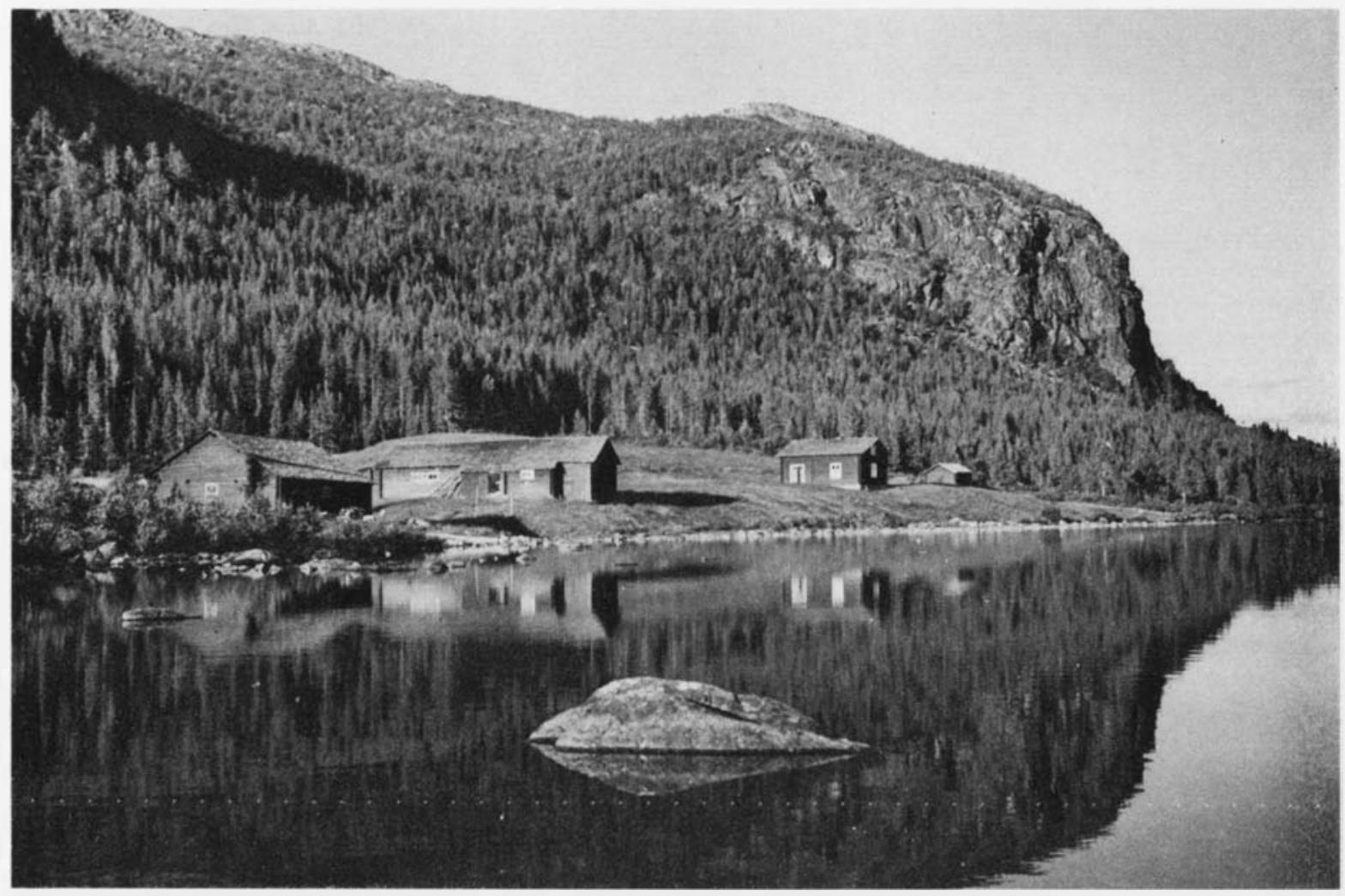

Fig. 34. Mt. Lulep Istjakk towards the E, with a small farmstead (now abandoned) in the foreground. The S-facing cliff in profile. Another steep slope on the same mountain (Mt. Strömnäsberget) shades the left corner. On the cliff of this slope Wistrand found the suboceanic lichen Normandina pulchella, in SW-exposure (Hasselrot 1948). Photo: G. Wistrand, 2. July, 1936.

when examining the distribution within a small area to consider the general geographical distribution, since we may get an estimate of the present dispersal direction. By studying the autecology of the separate species the location of the regions where conditions for the species are better than in the area investigated may be deduced. The conformity of species to natural laws make them valuable quantitative indicators of ecological factors (cf. Boyko 1947, p. 140).

These considerations made it necessary to take into account the total ranges, especially of those climatically demanding elements that are near the edge of their distributional ranges. There are of course many types of ranges among the plants, which could primarily be a result of edaphic, climatic or historical factors. A combined system taking into account all these types of ranges would be complicated and inadequate for the present study. Instead it would be highly desirable to construct a system for the evaluation of the different climatological trends that there are among the majority of plants. The analyses of climatic groups would show that there are great variations in abundance and vigour. For these reasons, Böcher (1943, p. 353) stated that a system taking into account the different biological distribution types, and above all the dependence of the species on the climate, would be very valuable.

Thus when considering the ranges or areas of distribution reference must be made to the floral zones or regions occupied by the separate species, as has been done in modern atlases of the distribution of plant species (see Meusel et al. 1965, p. 15). This is because the chorology of species is a reflection of the vegetational trends of the earth (Schmid 1954 , p. 8). Vegetation gives us an estimate of the total effect of climatic impact on life better than single climatic variables (cf. Sjörs 1963, p. 110). There are very similar situations regarding regional zonation of the earth although the European one is much displaced towards the $\mathrm{N}$. Thus when considering different longitudinal sectors of the earth the factors of oceanity and continentality have an impact on corresponding biotic regions. In NW Europe, the species showing oceanic or continental trends are more or less influenced in vigour, abundance and frequency by the $\mathrm{W}-\mathrm{E}$ variable. They have distributional ranges with centres in the more extreme continental parts of the continents, or distribution or 
frequency limits parallel to the coastal lines. Oceanity or continentality in the biogeographic sense should include the regional position of the outermost occurrences. The $\mathrm{S}-\mathrm{N}$ variable represents meridionality versus boreality. Meridionality and boreality in the biogeographic sense includes the zonal position of the outermost north or south occurrences of the species. If taxonomic units are characterized with reference to special regions and zones, it is sometimes possible to make a comparison of the biogeographic and bioclimatic trends of larger regions.

For practically all the species concerned here (Table 16), up to and including the Leguminosae, the area diagnosis constructed by Meusel et al. (1965) could be used. In other cases the maps given in the works by Hultén $(1950,1958,1962)$ were consulted. Some uncertainties arise here and there in the material for which ranges given by Hegi (1909 et seq.) and in some other Floras were used. By studying the $\mathrm{S}-\mathrm{N}$ as well as the $\mathrm{W}-\mathrm{E}$ biogeographic variables in the flora concerned (Fig. 35), the general characteristics of the flora and vegetation going from the extreme NW to the extreme SE could be deduced. Only hiological aspects were considered for the analyses (cf. above).

In assigning the symbols (Table 16), only the northermost part of the Holarctic flora region was considered if a species showed different behaviour in oceanity or continentality in the $\mathrm{N}$ and $\mathrm{S}$ parts. Plants with faintly expressed tendency of oceanity or continentality were also used in the statistical analysis on which Fig. 35 was based. There is an additional group of species indeterminate in oceanity or continentality. The symbols are (cf. Böcher 1943, p. 360; and Meusel et al. 1965, p. 19):

Symbols
in Böche
1943
$\mathrm{O}_{1}$
$\mathrm{O}_{2}$
$\mathrm{O}_{3}$
$\mathrm{X}$
$\mathrm{C}_{3}$
$\mathrm{C}_{2}$
$\mathrm{C}_{1}$

\begin{tabular}{|c|c|c|}
\hline Used for & $\begin{array}{l}\text { Symbols } \\
\text { in Meusel } \\
\text { et al. }\end{array}$ & $\begin{array}{l}\text { Symbols } \\
\text { used } \\
\text { here }\end{array}$ \\
\hline Oceanic (euoceanic) & $\mathrm{oz}_{1}$ & \\
\hline $\begin{array}{l}\text { Suboceanic } \\
\text { Widely distributed with }\end{array}$ & $\mathrm{Oz}_{2}$ & 0 \\
\hline & $\begin{array}{l}\mathrm{Oz}_{3} \\
-\end{array}$ & I \\
\hline $\begin{array}{l}\text { Widely distributed with } \\
\text { cont inental tendency } \\
\text { Subcontinental } \\
\text { Continental (eucontinental) }\end{array}$ & $\begin{array}{l}\mathrm{k}_{3} \\
\mathrm{k}_{2} \\
\mathrm{k}_{1}\end{array}$ & C \\
\hline
\end{tabular}

The oceanity and continentality symbols in parenthesis mean (as in Meusel et al.) that the species shows only faint oceanic or faint continental tendency.

It must be emphasized that Meusel et al. used the symbols for a broad mapping of the different oceanity regions and that the two systems may not in all details correspond with each other. As there are no sharp limits in nature the subjective ideas of the investigator play an important role (Böcher 1943, p. 368 ) but as with the lifeforms there are no objections about the significance of the different types and classes. In this case the statistics of the lifeform classes (see below) were used to support the theory of different bioclimatic elements in the flora concerned.

Taking the thermophily into consideration, interest is focused on the group comprising the southern vascular plants of N Scandinavia or plants (in Meusel et. al. 1965) given the area diagnosis hardly ranging farther $\mathrm{N}$ than the Boreo-nemoral zone (i.e. "Boreo-meridional plants", with the symbols used here, $\mathrm{M}$, meaning range not or only locally extended $\mathrm{N}$ of the Boreo-nemoral zone, and (M) some more occurrences in the Boreal zone; terminology of the zones in accordance with Sjörs 1963, p. 111). All these plants should be studied according to their relation to the insolation-exposure factor (see Boyko 1947 and above, p. 13). In this way it would be possible to understand better the behaviour of the plants with respect to the thermal factors on different substrates and to the factors of oceanity-continentality involved. Until the autecology of the different species is better investigated we may only come to some general conclusions based on very subjective classing. As is shown by the examples here (Fig. 35, see also above, p. 41) the flora of the S- or nearly S-facing hillsides of PL has a degree of oceanity which may be greater or smaller depending on the type of classing and the breadth of terms involved. In this case it is important that the contrasting group of continental plants is comparable as regards the terminology. The examples show that the oceanity as taken in the biogeographic sense used here is sometimes even greater on $\mathrm{S}$ - than on $\mathrm{N}$ - or nearly $\mathrm{N}$-facing slopes (e.g. Mt. Aistjakk, no. 16). The relationship is on the other hand a probable parallel to the fact that the N-facing slopes are even less "Boreal" than the S-facing slopes.

The term "Boreal" has here been ascribed to a plant species when its Arctic and Boreal ranges are only locally extended $\mathrm{S}$ of the Boreal zone (symbol B, Table 16), or when there are some more occurrences in the Nemoral to Meridional zones but preferably in the subalpine and alpine belts of the mountains (symbol (B)).

The ubiquitous "trivial" flora comprising the rest of the species are definitely more abundant in unfavourable exposures, and the $\mathrm{N}$-facing cliffs and screes are less extensive and too shaded for lightdemanding plants. The great majority of the southern plants of $\mathbf{N}$ Scandinavia show an expressed 
Fig. 35. (a) The different flora groups of the mountain localities studied, percentages of the total number of species. The area characteristics (mainly founded on Meusel et al. 1965) given in Table 16 were used as the basis for these figures. Note that the various groups include plants designated in the text by the capitals in brackets.

(b) Percentages of Chamaephytes $(C h)$, Geophytes $(G)$ and Therophytes $(T h)$ in the total number of species of flowering plants on every mountainside. Hemicryptophytes and Phanerophytes were omitted. See the text.
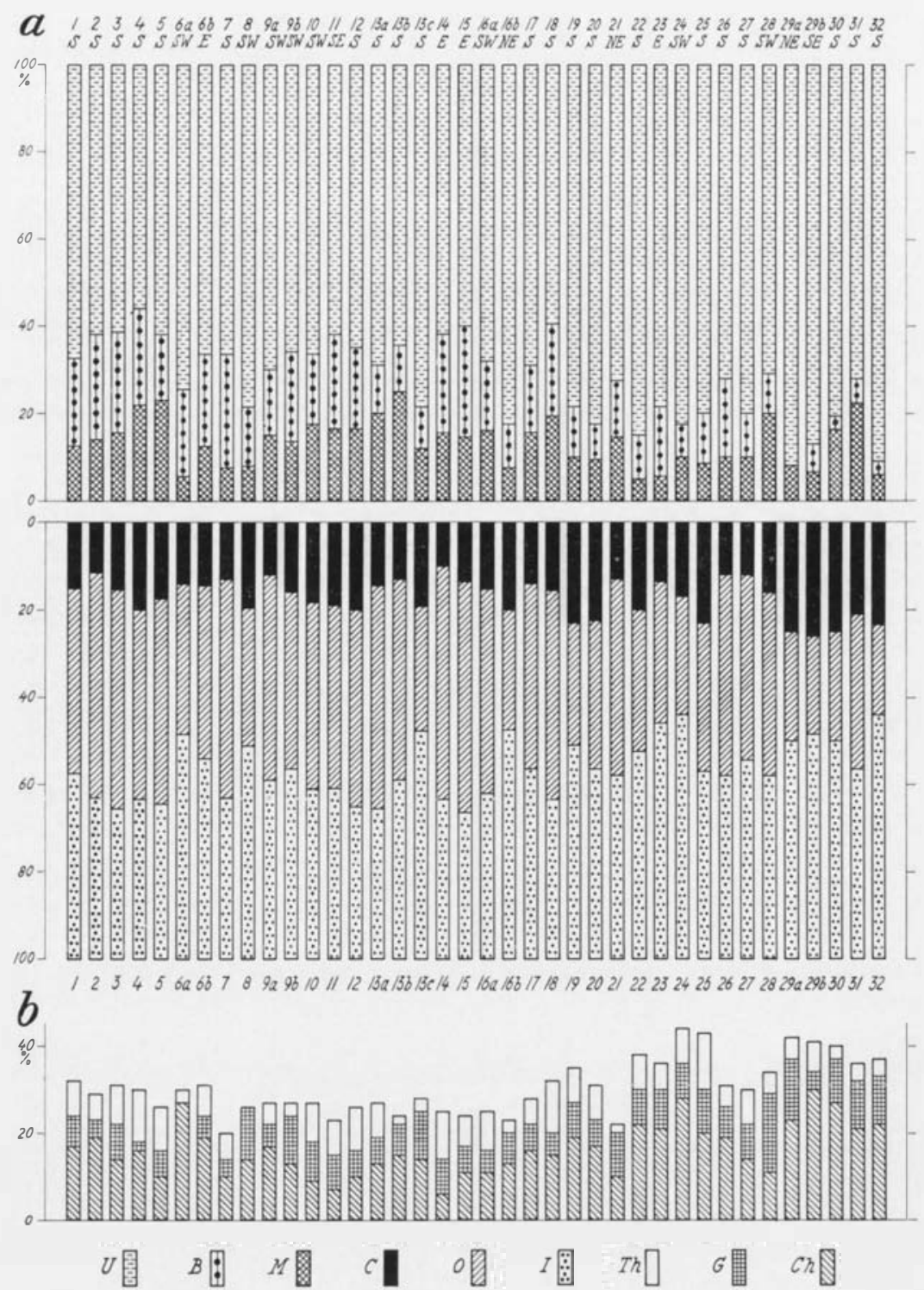

affinity to the more oceanic parts of W Fennoscandia, so that the oceanity might be expected to be the most important feature of thermophilous plants. In fact the sides of hills and mountains with southern plants are the most oceanic parts of the valleys when local climate over long periods is considered. (Cf. on the other hand short-term microclimate which may be rather "continental", Fabijanowski 1950, pp. 42, 64 , Jalas 1950 , p. 208 , or the relative continentality ascribed to the subalpine birch zone of Lappland, Hämet-Ahti 1963, p. 31, cf. Rune, O. 1965, p. 73). See also p. 47.

It is also easy to realize that plants showing oceanic tendencies when growing this far inland, seek the climatically most favoured sites. The two strictly
Boreo-meridional plants of $\mathrm{N}$ Scandinavia showing oceanic tendencies, Polygonum dumetorum and Myosotis stricta, even seem to avoid the outer coastal districts where the early summer temperatures are lower than further inland, thus appearing less oceanic towards the $\mathrm{N}$. Even inland, localities are very few. Fragaria vesca, on the other hand, is much more frequent on the Norwegian coast and also fairly frequent inland on S-facing ridges and hillsides. Several other examples could be mentioned (see below). Examples are also given showing that several of the Boreo-meridional plants, taken in the wider sense to include also (M) plants, may grow at quite high altitudes on the mountains (e.g. Carex panicea) because the factor of humidity for this plant 
with oceanic tendencies is probably much more important than the thermal factor.

Unfortunately no insolation-exposure diagram could be constructed for the study of thermophily. For this study it would be highly desirable to know in detail the microdistribution of different plants on different substrates in terms of exposure and degree of slope. The plant material for such a study should at least primarily be the plants that hardly reach the Boreal zone with the probable exception of SW Fennoscandia where the southern plants of $\mathrm{N}$ Sweden may have fairly frequent localities.

As was shown by Wistrand (1962, p. 185) there are two main groups of thermophiles in PL differing in horizontal distribution, viz. species the areas of which are directly connected to their $\mathrm{E}$ and SE ranges near the Bothnian Coast and species which are more or less isolated in the central parts of PL, near tre SE border of the Caledonides. Thermophilous plants with SE ranges nearly always grow in and around water in valleys, in groves around brooks and in calcareous fens but, with a few exceptions, not on screes. This is probably because these plants are the more continental group of plants with centres of ranges in SE Europe and Asia. As is seen below, the Boreo-meridional plants with continental types of areas (symbol (M) C), are only rarely seen on screes, but probably towards the NW they show a greater preference for S-facing slopes at the lower altitudes of the valleys or for extremely calcareous fens. Some of them are forest plants, predominantly in coniferous forests. The other group of thermophilous plants (Wistrand, I.c.) those with central and northwestern distribution in PL, are identified as mainly those plants with more oceanic areas which have scattered occurrences on S-facing screes (see above).

It may be interesting to compare the northwestern thermophiles of PL with respect to their chorology and ecology in the Alps and the Jura as reflected by their restriction to particular vegetation belts (Vegetationsgiirtel, cf. Schmid 1954 , p. 3). This comparison (see, e.g., Saxer 1955, pp. 30 et seq.) will make clear that they are mainly confined to the Fagus-Abies belt and especially to the less elevated sites favourable in respect of soil and climate. Some of them closely coincide with the demands made by beech (Fagus silvatica), thus avoiding late frosts, too shaded and moist localities (but also too dry localities), preferring a vegetation period of at least five months and very good soil conditions (Saxer 1955, p. 15; the behaviour of beech in Central and SE Europe was also discussed by Hjelmquist 1940, pp. 16 et seq.). With regard to epiontology, there is found a close correlation between the particular species and the belt to which it is confined (Saxer 1955, p. 27). Extreme northern localities and other peripheral occurrences are considered by Schmid and his pupils to be relic occurrences in atypical habitats which are of minor value in the evaluation of restriction to a particular belt within the main distribution area, see Schmid 1954, p. 8.

The postglacial history of the two groups is not considered, but it is obvious that the plants with oceanic or suboceanic areas could have been dispersed from S or SW Fennoscandia at least during the more oceanic period of postglacial time. They were probably already established in their localities in the E during a warm but not too dry period of postglacial time.

"The only measure of the biological value of the factors is given by the plants themselves, that is to say their lifeform, which is the sum of the organic structure by which plants are related to their environment. What we have to do is to make use of this measure." (Raunkiaer 1908, p. 42: English translation 1934, p. 111).

As was stated in the early works by Raunkiaer, the biological spectrum of vascular plants is primarily a reflexion of the way they reproduce and hibernate. This was the foundation of the life-form system, accepted and used universally although with much criticism especially regarding certain tropical life-forms, see Hedberg 1964, p. 80 et seq. It is possible to make a fairly relevant statement related to the bioclimate of a special area by studying its life-form spectrum, i.e. the percentage of the primary lifeforms present. The pteridophytes were omitted from the statistics by Raunkiaer, as the knowledge of these plants was then too imperfect. To make a comparison possible with the "plant-climates" constructed by Raunkiaer on a statistical basis, (although there might be some objections with regard to the use of the term "plant-climate") it is obviously important that the material of life-form groups is classified in the same way, only small and exactly defined modifications being allowable. Such modifications are inevitable as regards some of the Therophytes and the biennial Hemicryptophytes, as they might react dissimilarly in different regions. Some normally autumngerminating plants are probably in some cases spring germinators, in some other cases even true biennial plants. In the absence of investigations of the behaviour of many of the hapaxanthous plants in scree localities, even truly biennial plants were classed as Therophytes. This makes very little difference when treating the plant-rich localities of the NW, where the Therophytes form a rather large percentage of the flora. Making this small modification (cf. Pettersson 1958 , p. 9) we get the following figures for the different groups according to Raunkiaer. (Table 15 ).

This tells us of a flora typical of a Hemicryptophyte climate as defined by Raunkiaer and the 
Table 15. The percentage distribution of the species of flowering plants among the life-forms.

$\mathbf{M}=$ Meso- and Microphanerophytes; $\mathbf{N}=$ Nanophanerophytes; $\mathbf{C h}=$ Chamaephytes; $\mathbf{H}=$ Hemicryptophytes; $\mathbf{G}=\mathbf{G e o p h y t e s ;}$ $\mathrm{Th}=$ Therophytes. Helophytes absent with one probable exception: Potentilla palustris. The data are for the flora of the hillsides nos. 1-32. The primary groups $\mathrm{M}$ and ( $\mathrm{M}$ ) Boreo-meridional, B and (B) Boreal, $\mathrm{C}$ and (C) plants with continental, and $\mathrm{O}$ and (O) plants with oceanic tendencies, were used with the same limitations as on Fig. 35

The percentage distribution of the species among the life-forms

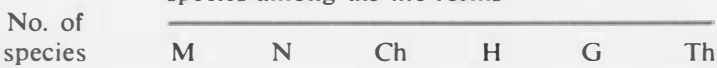

Total flora

of the mountains

Boreo-meridional

Boreal

Continental

Oceanic

196
36
56
35
103

$\begin{array}{rr}4 & 5 \\ - & 3 \\ - & 9 \\ 9 & 14 \\ - & 2\end{array}$

10
6
16
3
8

$\begin{array}{rrr}60 & 10 & 11 \\ 56 & 17 & 19 \\ 67 & 2 & 7 \\ 49 & 14 & 11 \\ 69 & 8 & 13\end{array}$

biological characteristics of the flora. The groups should be compared in pairs (e.g. Boreo-meridional and Boreal) as they do not exclude each other. Thus it is evident that the Therophyte percentage of the total flora is fairly high, and also that this Therophyte group is better represented among the Boreomeridional than among the Boreal plants, and somewhat hetter among the species with oceanic than with continental tendencies. The Chamaephyte percentage is greater among the Boreal than the Boreo-meridional plants, while the Geophytes are better represented among the Boreo-meridional plants than among the Boreal ones, and better among the species with continental than with oceanic tendencies. This is all in agreement with the results of Raunkiaer.

When making up a spectrum for each of the different mountain-sides concerned (Fig. 35 lower section) we could in some ways use the results obtained above to estimate the degree of oceanity versus continentality and the degree of boreality versus meridionality. A high Therophyte percentage should in all likelihood be characteristic of the mountains of the NW coniferous woodland area, while a high Geophyte percentage should be most conspicuous in the flora of the SE. Although the differences might be small and the results highly variable because of local deviations, the tendency, especially for the most extreme SE mountains, is obvious. With regard to the Chamaephytes, which are characteristic for the Boreal climate, the result may be somewhat doubtful. In these cases the role of forest Chamaephytes is evidently more prominent in the SE where the number of herbs diminishes conspicuously.

The following list of the southern plants of PL is to some extent compiled to show some general distributional and ecological trends of the species, together with some observations of interest about
PL and some nearby areas. The descriptions will show that there are in many cases no expressed demands of $\mathrm{S}$ exposures, and that any climatic classing into "thermophilous" groups may be unsuitable. For the group of Eurasiatic Boreo-montane plants, defining any limits between degrees of meridionalityhoreality is very difficult and in some cases even impossible. Some doubtful plants are Matteuccia struthiopteris, Dryopteris filix-mas, Carex ornithopoda, Melandrium rubrum, Poa nemoralis and Gymnadenia conopsea.

A plant species which is placed within the group of southern plants by some authors because of its fairly few localities in the $\mathrm{N}$ is Saxifraga adscendens L. (See the discussion, pp. 103-104.)

\section{MO}

Following the area diagnosis given by Meusel et al. (1965) only two plants in the flora concerned could be listed as strictly "Boreo-meridional". Climatically they could probably be considered to be the most demanding (see above). They are found only in the most favoured sites of the fine screes. For the ecology of the two species in PL, see pp. 100-101.

\section{Polygonum dumetorum L.}

The plant has extensive areas in the Nemoral zone of the old world (referred to the group of $W$ European-S Siberian plants by Hultén, 1950, p. 69, like Myosotis stricta). It is partly apophytic and hemerophilous in S Sweden. As far as is known, the localities in PL are the furthest $\mathbf{N}$ in the northern Hemisphere. There are only the three listed occurrences (Table 16) in the whole of PL (all of them on S-facing screes).

\section{Myosotis stricta Link.}

The range of this species is a close parallel to that of the previous one. Also strongly hemerophilous in S Sweden (cf. Almquist 1965, p. 212). Reported from the same areas in the 
N. In Sweden it goes further $\mathrm{N}$ along the glint-line (to Torne Lappmark). In PL found also on the scree adjacent to no. 18, Mt. Strömnäsberget, in SW-exposure (Johansson 1933, p. 491 , see also ?. 57 above).

(M) $C$

Among this group of southern plants are species which mostly prefer other kinds of habitats than screes. Potentilla multifida is the only one confined to rocks facing $\mathrm{S}$. Although this group mostly have more continental types of distributions, the demands for warm, sunny places are less than in the previous group with oceanic tendencies. In the same way, the $\mathrm{N}$-facing slopes of mountains may support a flora with more continental tendencies than the S- or SWfacing slopes (cf. Mt. Aistjakk above and Fig. 35).

The species have recently been found in new localities, indicating that they may be more widely distributed towards the $\mathrm{N}$ than thought before.

\section{Poa remota. Fors.}

This plant has its main distribution in temperate E Europe and $W$ Siberia, reaching the coast only in Norway. The species does not extend appreciably $\mathrm{N}$ of the Arctic Circle and is found in meadow birch forests and similar places, more seldom on screes, as in the only known locality in PL (Arwidsson 1943, p. 162; but it was not verified growing on this scree). In adjacent parts of Norway it is also known from the birch belt (Dahl 1912, p. 141) as is also the case on a S-facing slope near Nedre Kramasclet, Vindel River (ca. $600 \mathrm{~m}$ ), Lycksele Lappmark, Sjörs \& Wassén 1964, personal communication. For the character of the climatic continentality of this species as seen in a temperature-precipitation coordinate system, see Hintikka 1963, p. 18.

\section{Cypripedium calceolus $\mathrm{L}$.}

This plant (excluding American varieties) is most frequent in the Nemoral zone of Europe. Until recently it was unknown to PL (cf. Lundqvist 1963, p. 79). Several localities are now known, none of which is on screes. The ecology of the plant has been studied in detail (Lundqvist, J. 1965, pp. 194 et seq., and this paper, p. 29). In its NW localities it seems to prefer S-facing moist meadow slopes on calcareous ground. The same is true for its northernmost localities in Troms (N Norway: Benum 1958, p. 106).

\section{Potentilla multifida L. (s.1.)}

The species in its widest sense includes many closely related species or subspecies, the centres of which seem to be Central and E Asia and Pacific N America. From Fennoscandia and Spitzbergen are known P. lapponica (Nyl.) Juz. (the species concerned here) and $P$. pulchella $\mathrm{R}$. Br., respectively. Since the first find in the Scandinavian Peninsula in 1892 by Nyman on Paktesuolo (Nyman 1895, p. 126) it has been found in some other localities in PL (Wistrand 1962, p. 115) and northwards in Sweden (Frödin 1917). It always grows on sunny rockledges and on the sides of deep crevices. The Muddus locality in Lule Lappmark (Sjörs $1946 a$, p. 85; Moskoskorso, Arnborg 1963, p. 618) is at a very low altitude. According to Polunin (1959, p. 277) all the different races in the $\mathrm{N}$ have a variety of habitats from dry to damp open places.

\section{Pyrola chlorantha Sw.}

This species, which is circumpolar, too, is quite widespread in Nemoral coniferous forests but more rare in the Boreal zone. It is rare as far $\mathrm{N}$ as Troms and Finnmark (Benum 1958, p. 306; Dahl 1934, p. 374; Laine 1964, p. 115). It ascends to the $\mathrm{E}$ part of the $\mathrm{SE}$ coniferous woodland area of PL. On Mt. Bärberget (no. 30) it was found in the coniferous wood of the boulder scree facing $\mathrm{S}$ and on Mt. Gaddaberget (no. 31) in the wood below the scree (Wistrand 1962 , p. 129). Very little is known about the exposure of habitats farther northwards, but in all likelihood it seems to prefer warmer slopes.

\section{(M) $O$}

This group of southern plants comprises species which have a more or less oceanic distribution. As the grouping has been based only on the distribution types the ecological demands within this group vary very greatly, the only common feature being the oceanic areas. As in the preceding group, some species extend far northwards, being quite undemanding in their thermal or edaphical requirements, while others are restricted, for instance, to the warmest and driest places. The requirement for oceanity means that some species extend far northwards on the Norwegian coast, and in great abundance, too, while they have a definitely more southern trend in the E, compensating for the very long and cold winters there.

As already stated, the number of species with oceanic tendencies on mountain slopes in PL is always considerable in relation to species with continental tendencies. The more pronounced oceanic tendency of the flora of the NW mountains, including mountains nos. 17-21, is dependent on the group concerned (cf. Fig. 35).

\section{Matteuccia struthiopteris (L) Tod.}

The species was referred by Hultén $(1950$, p. 57) to a group with a Boreal-montane tendency among the circumpolar plants. Its oceanic status is not apparent in Fennoscandia. Anyhow it prefers sheltered places with southerly exposures (cf. Benum 1958, p. 71). In PL it is abundant in some meadow birch forests on rich moist ground, in groves around brooks etc., irrespective of exposure. Because it prefers quite good soils it is rare in the area of Archaean rocks. Analyses, Table 30 .

\section{Dryopteris filix-mas (L) Schott.}

This plant is also a Boreal circumpolar plant with an oceanic trend. It is frequent on the Norwegian coast up to Troms and has scattered localities in Finnmark. It seems to prefer rather dry habitats and is more often found on screes than the previous species. Although it ascends up to the subalpine belt it shows a preference for $\mathrm{S}$ exposure and sheltered places.

\section{Dryopteris spinulosa (MII.) Ktze.}

As there has been some confusion regarding the $D$. spinulosa complex (Nannfeldt 1966, pp. 136 et seq.) the distribution 
area of $D$. spinulosa is not completely known. It seems that it may occasionally have been confused with the two species $D$. dilatata and $D$. assimilis in nature, and these probably differ ecologically. Anyhow, D. spinulosa is definitely southern in Fennoscandia. With regard to its ecological requirements, it is known from various habitats, in PL, including a moist habitat below the S-facing scree of Mt. Storberget (no. $13 b$ ) and a rather dry place among boulders on scree (no. 21) and in forests (Wistrand \& Lundqvist 1964, p. 41). Also found in a depression behind the cap of Mt. Vuornats (no. 19).

\section{Asplenium septentrionale (L.) Hoffm.}

The species is fairly frequent in Central Europe and $\mathrm{S}$ Sweden, growing on non-calcareous rocks. In the $\mathrm{N}$ it is found in crevices on better substrates, preferring $\mathrm{S}$ exposure. It is found in a few localities as far $\mathrm{N}$ as Troms and Finnmark, N Norway (Benum 1958, p. 68). The two localities in PL have been published earlier (see Wistrand 1962, p. 53).

\section{Polypodium vulgare $\mathrm{L}$.}

This circumpolar species has a great variety of forms and races (some of them regarded as subspecies), the majority of which seem to belong in the Meridional to Nemoral flora zones. In Fennoscandia it is quite frequent in the $\mathrm{S}$ and along the coastal districts of Norway to Finnmark and Kola Peninsula. Towards the $\mathrm{N}$ it has a preference for rocks and screes facing $\mathrm{S}$ and is very undemanding with regard to the substrate, at least in the SE part of PL. In some cases it has been found on a N exposure (cf. Wistrand 1962, p. 53) and ascends to the upper forest limit.

\section{Melica nutans $\mathrm{L}$.}

According to Hultén $(1950$, p. 70$)$ this species belongs to a group of Eurasiatic plants with southern tendency in Fennoscandia. Like the preceding ones, it is often quite abundant on the Norwegian coast and goes as far $\mathbf{N}$ as Finnmark and Kola Peninsula. It may occasionally ascend to the lower alpine belt (Benum 1958, p. 130) but prefers S-facing screes in the Scandes. In the SE coniferous woodland area it may also be found in more unfavourable habitats, moist heath forests with Gymnocarpium, groves along streams, etc.

\section{Convallaria majalis $\mathrm{L}$.}

Except for closely related taxa from E Asia and N America, Convallaria majalis is a European species concentrated in the Submeridional to Nemoral flora zones. In W Scandinavia it extends as far $\mathrm{N}$ as the Arctic Circle and is abundant along the shores of some of the larger rivers of PL but also on S-facing slopes of the SE mountains. In the parish of Arjeplog it was found in two localities only, an E-facing slope (Wistrand 1962, p. 58) and on level ground near Ribbraurjokk at the E boundary of the parish (Wistrand 1966, personal communication). In some places it is fairly abundant on stabilized screes with trivial dwarf shrub heaths, if the exposure is favourable. It was found immediately $\mathrm{S}$ of the $\mathrm{S}$ border of PL, on Mt. Nalovarde (Gaunitz, D. \& C. B. 1924, p. 134; Lycksele Lappmark), a mountain immediately S of Mt. Dalktjapakte (no. 21), on S-facing scree (found again by the present author).

\section{Carex panicea $\mathrm{L}$.}

The species is native to Europe and W Asia but regarded as introduced in E North America (Hultén 1958, p. 120).
The centre of its distribution is Submeridional to Boreal. In the $\mathrm{W}$ parts of Fennoscandia it thrives far towards the $\mathrm{N}$ and is still frequent in Troms and Finnmark (Benum 1958, p. 175). It seems to have a preference for eutrophic fens, wet meadows and shores. Localities on rocky hillsides are rare, at least in PL. It is prevalently a lowland plant, but ascends to the subalpine belt of the Scandes.

\section{Carex pallescens $\mathrm{L}$.}

The range is like that of the previous species, both being frequent in Troms (Benum 1958, p. 174). It is very rare in PL and until recently found only on S-facing hillsides. Recently also found in a pinewood on rocks near Pite River, on a $\mathrm{N}$-facing slope ca. $260 \mathrm{~m}$ above sea-level (Wistrand \& Lundqvist 1964, p. 22). The species is found only once in pasture in PL (Västerfjäll, Nordenstam \& Wistrand, 1966, personal communication). In other parts of Scandinavia it is of ten found in hayfields and pastures, Benum (1.c.), Almquist 1965, p. 116.

\section{Carex digitata L. s. str.}

This Nemoral European-N Siberian plant is known to be basocole at least in the British Isles but is mainly basocline in N Sweden (cf. Wistrand 1962, p. 80: "indifferent"). It is frequent in some areas of S Fennoscandia and less so on the Norwegian coast to southernmost Troms (Norman 1900, p. 1201). Towards the $\mathrm{N}$ it prefers rather dry and grassy hill-slopes and forests among boulders or cliffs in areas near the sea. Only known in four localities in PL (all of them first published by Wistrand (1.c.), in the SE coniferous woodland area, with a preference for $\mathrm{S}$ exposure.

\section{Carex ornithopoda Willd.}

This plant is referred by Hultén (1950, p. 54) to the group of European, Boreal-montane plants with separate $\mathrm{N}$ and $\mathrm{S}$ areas. Many of these plants are southern in their $\mathrm{N}$ area according to Hultén (l.c.). Cf. Saxifraga adscendens p. 103 and Epilobium collinum below. Some of them are native only to Öland and Gotland in Scandinavia. As with C. ornithopoda their ranges may be dependent on the prevalence of calcareous sites. $C$. ornithopoda in its northernmost localities seems to be sparse in the vegetation of screes, but is mostly found on $\mathrm{S}$ exposures and on shores, e.g. on the shores of Lake Rebnisjaure $(500 \mathrm{~m})$, PL. Rarely ascending to the subalpine belt.

\section{Melandrium rubrum (Weig.) Garcke}

Referred by Hultén (1950, p. 54) to the European Borealmontane plants with no gap in their distribution. The total area is thus definitely larger than the previous species, extending further $\mathrm{N}$ along the Norwegian coast, common in Troms (Benum 1958, p. 216). Fairly abundant in its $\mathrm{N}$ localities. In PL on talus slopes (of different exposure), in groves along rivers, and in meadow birch forests of the NW. Also frequently found around farmsteads of the SE.

\section{Actaea spicata $\mathrm{L}$}

This species has an oceanic tendency (although avoiding the outer coastal districts), contrasting in this respect with $A$. erythrocarpa, which is continental. $A$. spicata is similar to the other Eurasiatic species mentioned earlier with some localities in the coastal districts of Fennoscandia as far $\mathrm{N}$ as Troms (Benum 1958, p. 221) and Finnmark. An interesting point is that the species prefers deciduous forests, in contrast 
to $A$. erythrocarpa, which is more often seen in (mixed) conif erous forests (Meusel et al. 1965, p. 484). Nevertheless, the two may be found together in some habitats, with their hybrid (Table 18): Wistrand 1962, p. 104). In PL A. spicata is mainly seen on S-facing hillsides and in meadow birch forests of the NW. It rarely ascends to the forest limit on the mountains.

\section{Sedum acre $\mathrm{L}$.}

The species is Eurasiatic, in E North America considered to be introduced. In its distribution pattern it resembles many of the previous species, being abundant in S Scandinavia and on the Norwegian coast up to Troms and Finnmark (also on Kola Peninsula). In the northernmost localities it prefers rocky or sandy seashores, dry grassy hills etc., at low altitudes. In PL found in a locality in the subalpine belt, a Sfacing hillside (Arwidsson 1943, p. 214, first published by Birger 1921, p. 21). The other (verified) locality is Mt. Lulep Istjakk (no. 18; Johansson 1933, p. 496), on a cliff facing SW.

\section{Anthyllis vulneraria L.}

See Jalas 1950, pp. 27 et seq., p. 269. The plant, like Sedum acre and Viola riviniana is referred to a group of socalled W European-Central Siberian plants by Hultén (1950, p. 66). These plants have a large variety of thermal requirements towards the $\mathrm{N}$, as many of them do not go futher $\mathrm{N}$ than oak (Quercus robur), while others are found at the Arctic Ocean. Anthyllis vulneraria s.l. is extraordinary rich in forms, extremely hemerophilous in S Sweden (Almquist 1965 , p. 177), introduced in NE North America (Meusel et al. 1965, p. 546). In the extreme $\mathrm{N}$ it is found on dry, sandy-gravelly soil (Benum 1958, p. 275) in the lowlands or on rocks or rocky hillsides, primarily of $S$ exposure. In PL it was found in one locality in the lower alpine belt (Mt. Lairo, S-facing scree, Arwidsson 1943, p. 223; the locality was described by Almén \& Almén 1959 I p. 308). The other two localities of the NW are S-facing (Mt. Märkepakte) and SW-facing screes (Mt. Strömnäsberget, cf. p. 65, Johansson 1933, p. 484). Found also in SE Arvidsjaur (Svartliden, Pilström 1966, p. 208) as anthropochorous element near road.

\section{Viola riviniana $\mathrm{Rchb}$.}

The species is more widely distributed northwards in Fennoscandia than is apparent from the distribution map in Hultén (1950, map 1262). It is fairly frequent in Troms (Benum 1958, p. 290) but probably not yet found in Finnmark. It has a large variety of different habitats in the $\mathrm{N}$, from dry to moist places in woods, on rocks or rock-ledges, grassy hills etc. up to the forest limit. In PL around a little stream on the S-facing side of Mt. Gaddaberget (no. 31) and in a spruce forest (described p. 105, see also Lundqvist J. 1966, p. 196) near Tjäutjanåive hill (see the map, Fig. 2).

\section{Daphne mezereum L.}

The species was referred to species with oceanic tendencies, like Actaea spicata for example, which has a similar total area, although it has some continental trend in E Europe (see Hultén 1950, p. 76). The plant is known as far $\mathrm{N}$ as Finnmark and Kola Peninsula (not in Troms). It prefers somewhat calcareous soils but is not calcicole, and grows on different exposures, mostly in meadow birch forests, Vaccinium forests with Gymnocarpium, and screes. The apparent gap in the distribution in Central PL (cf. Wistrand 1962, p. 125) will probably be gradually filled (one locality in the spruce forest near the site with Viola riviniana (p. 105): not published earlier.

\section{Epilobium montanum L.}

This plant is Eurasiatic, referred by Hultén (1950, p. 68) to the group of $\mathrm{W}$ European-Central Siberian plants (see the note under Anthyllis vulneraria). It is fairly frequent along the Norwegian coast to Troms (cf. Benum 1958, map 403). In its northernmost localities it is found on sandy, humusrich or manured soil in the lowland, predominantly on Sfacing hillsides (in PL found also in E-exposure) or in groves of grey alder (Benum 1958, p. 296).

\section{Epilobium collinum Gmel.}

Like Luzula sudetica, Carex ornithopoda, Silene rupestris, Saxifraga adscendens, etc., the species is referred by Hultén $(1950$, p. 54) to the European Boreal-montane plant group with separate $\mathrm{N}$ and $\mathrm{S}$ distribution areas. (Hultén's Group 12 comprises species which are more or less isolated in Fennoscandia. None of them is very frequent, but $E$. collinum is one of the most widely distributed. Some of the group are Scandian plants in Sweden or are Boreal. Some have isolated areas in Central Scandinavia). Cf. Saxifraga adscendens p. 103. In its northernmost localities, E. collinum prefers dry sandy-gravelly hillsides on talus, crevices and rock-ledges on cliffs preferably of $\mathrm{S}$ exposure. Nevertheless the localities may at times be somewhat shaded, for instance crevices or open caves in the lowermost part of the rock wall. Found only in Central and NW PL and thus probably calciphile (basocline, cf. Benum 1958, p. 294). Seldom above the upper limit of pine or spruce.

\section{Veronica officinalis L.}

The species is referred to the group of W European-Central Siberian plants by Hultén $(1950$, p. 66$)$. See the note under Anthyllis vulneraria. Its distribution area is very similar to that of $A$. vulneraria. It is generally found in S-facing talus localities, even in more sparse parts of these, e.g. among Vaccinium, but preferring more open communities. According to Benum $(1958$, p. 337) it is fairly frequent as far $\mathrm{N}$ as Troms and Finnmark, here also common in the pastures, (as an anthropochorus species), and on rocky calcareous hills near the sea. In PL also found once in birch forest with dwarf shrubs near meadow birch forest on Mt. Storberget (no. 13) on level ground (ca. $550 \mathrm{~m}$ ). As it is quite undemanding about the substrate it grows fairly abundantly in its SE localities, if the sun exposure is favourable. In PL hardly found above the upper limit of pine or spruce (cf. Wistrand 1962, p. 137).

\section{(M) (O)}

The next group of southern plants comprises species which show only faint oceanic tendencies (cf. Meusel et al. 1965) or which in some cases may even be considered to be continental by some investigator (e.g. Pyrola media, see Hultén 1950, p. 77). Most species are rather infrequent on the Norwegian coast, sometimes even absent (e.g. Luzula pallescens), having a frequency centre somewhere in Russia or W Siberia. From W Siberia eastwards there is on the other hand 
a decrease, and as a rule they are completely absent from the most extremely continental parts of Eurasia. Hence the whole oceanity symbol has been put within parentheses (as in Meusel et al. 1965, p. 20).

\section{Pteridium aquilinum (L.) Kühn.}

The species grows in great abundance in Nemoral forests, but is more or less rare towards the $\mathbf{N}$, in the extreme $\mathbf{N}$ probably only introduced by cultivation (Benum 1958, p. 67). In the SE coniferous woodland area of PL it occurs in a spruce forest on level ground near the Pite River (Wistrand \& Lundqvist 1964, p. 55), altitude $165 \mathrm{~m}$, and on higher ground with a S-exposure in the NW of PL (Holmberg 1922, p. 27). The new locality recorded here is on stabilized scree overgrown with forest (Fig. 46). Səe further, p. 123.

\section{Luzula pallescens Sw.}

The total range of this plant is not known in detail (Meusel et al. 1965, p. 439), at least not its Asiatic range. It seems to be an introduced plant in SE England, in Iceland and in $\mathrm{N}$ America. It is fairly frequent in Finland up to Finnish Lappland and has some localities further $\mathrm{N}$ on Kola Peninsula and Finnmark (Norway). In Troms only known in a single locality as anthropochorous (Benum 1958, p. 103). In PL mainly as anthropochorous but also known from a few localities on screes. It does not ascend above the coniferous belt.

\section{Poa nemoralis L.}

This circumpolar plant is fairly widespread in Fennoscandia except for the northernmost parts of Finland and Kola Peninsula, where it is infrequent. It occurs without preference for a particular exposure in meadow birch forests, in groves along streams, on river shores (in the NW at least, not too windy) or on talus slopes and grassy hills. Some ecotypes of the very variable species seem to prefer talus slope localities (cf. Benum 1958, p. 134), one form approaching Poa glauca (f. glaucicolor Lindm.). Poa nemoralis ascends up to the lower alpine belt.

\section{Gymnadenia conopsea (L.) R. Br.}

The centre of the genus seems to be E Asia (Meusel et al. 1965, p. 451). G. conopsea is Eurasiatic and only occasionally extends as far $\mathrm{W}$ and $\mathrm{N}$ as the Norwegian coast, Finnmark and Kola Peninsula. It prefers grassy wet or moist slopes of various exposures, and is abundant in some calcareous fens on sloping ground. The only locality published here (Mt. Laisvare, no. $9 b$ ) is a stabilized scree with an abundant water supply in places. It occurs with diminished frequency up to the lower alpine belt (Arwidsson 1943, p. 182).

\section{Arabis hirsuta (L.) Scop. s.l.}

This plant is often said to be circumpolar but is probably not indigenous to $\mathrm{N}$ America (Pedersen 1958, p. 198). As it is present in the $\mathrm{W}$ coastal districts of Europe it should not be considered to be continental (cf. Hultén 1950, p. 77, and above). It occurs as far $\mathbf{N}$ as Troms and Finnmark, preferring screes or rocky hillsides but also found in pastures (Benum 1958, p. 245). In PL always restricted to S-facing hillsides, even in shaded habitats or on other types of substrates than screes (in more open coniferous forest on the
S-facing slope of Mt. Laisvare no. $9 \mathrm{~b}$ ). (See also Wistrand 1962 , p. 110). It ascends to the subalpine belt.

\section{Arabidopsis thaliana (L.) Heynh.}

This plant is referred to the W European-S Siberian plants by Hultén (1950, p. 70). Localities in $\mathrm{N}$ America, $\mathrm{S}$ and $\mathrm{E}$ Africa, Japan and Australia are generally considered to be anthropochorous (cf. Pedersen 1958, p. 197). It is very rare in N Fennoscandia (in Troms one locality, Benum 1958, p. 244). In PL found exclusively on S- or SW-facing screes. Beside the locality published here there is a locality on Mt. Strömnäsberget, Johansson 1933, p. 484. See p. 65.

\section{Turritis glabra L.}

Like the other crucifers just mentioned this one is hemerophilous in the $\mathrm{S}$ part of the distribution area (cf. Almquist 1965 , pp. 157, 158), and has been brought by man to new parts of the world (Pedersen 1958, p. 254). It is quite rare towards the $\mathbf{N}$, found in a few localities in Troms (Benum 1958, p. 246) and S Kola Peninsula. In PL found only on S-facing screes and rocky ledges of cliffs. Never found above the coniferous belt.

\section{Fragaria vesca $\mathrm{L}$.}

This plant has also been widely spread from its original areas by man, e.g. to E North America and E Asia. The centre of distribution seems to be the Submeridional to Nemoral flora zones of Eurasia (Meusel et al. 1965, map $218 c$ ). It is quite frequent along the Norwegian coast to Troms (Benum 1958, p. 260). Also in Finnmark and on Kola Peninsula. In its northernmost localities it occurs on sandy-gravelly humus-rich soils on S-facing hills, on rockledges, groves of grey alder (Benum, 1.c.) S-facing forests of the Vaccinium-with-herbs type, or meadow birch forests (e.g. on Mt. Storberget, no. 13) on rather level ground. It rarely ascends into the subalpine belt.

\section{Potentilla argentea $\mathrm{L}$.}

The plant is introduced into E North America and is largely anthropochorous in S Scandinavia. It is infrequent in NW Fennoscandia but occurs as far $\mathrm{N}$ as Troms (Benum 1958, p. 262). In PL it occurs exclusively on screes and rock-ledges with S- or nearly S-exposure, in some cases somewhat shaded, but generally in open communities. It was not found above the upper limit of spruce or pine.

\section{Pyrola media $S w$.}

This plant is referred by Hultén $(1950$, p. 77$)$ to W Siberian, continental plants (thus the same group as Cypripedium calceolus) but there are also localities on the Norwegian coast as far $\mathrm{N}$ as Troms and Finnmark (Benum 1958, p. 306). Because of this the plant is not strictly continental and in the system used here must be regarded as showing faint oceanic tendencies (cf. Norman 1895, p. 438). The greater frequency in the rest of Fennoscandia, except the $\mathbf{N}$ parts where it is infrequent or rare, places the species among the southern elements. It occurs in mixed and more or less open coniferous forests on slopes of various exposures, or among Vaccinium dwarf shrubs on stabilized screes preferably with exposures around $\mathrm{S}$. It was never found above the upper limit of coniferous forest in PL, and is also a lowland plant in Troms (Benum, l.c.). 


\section{(M) I}

The last group of plants comprises species which are indeterminate with regard to oceanity or continentality. They have total ranges without any significant distribution gaps, stretching throughout Eurasia or both Eurasia and $\mathrm{N}$ America (circumpolar plants). In two cases we are concerned with species which ar: considered to have been spread by man throughout their ranges. Most of the species are extremely hemerophilous, Paris quadrifolia being the only one that is not favoured by the presence of man.

\section{Paris quadrifolia $\mathrm{L}$.}

The species is Boreal and Nemoral Eurasiatic, occuring fairly frequently also in the $\mathrm{W}$ of Europe as far $\mathrm{N}$ as Troms (Benum 1958, p. 95), and with some localities in Finnmark and on Kola Peninsula. In PL it is most frequent in sheltered shaded woods of birch and alder (meadow birch forests), on hillsides with talus slopes of various exposures. It rarely ascends to the lower alpine belt of the mountains.

\section{Arenaria serpyllifolia $\mathrm{L}$.}

This plant is referred to the W European-S Siberian plants by Hultén $(1950$, p. 68 ; cf. Arabidopsis thaliana). In Troms, it is widespread on crags and rocks near the sea (Benum 1958 , p. 205). It is strongly hemerophilous, spread also by man towards the $\mathrm{N}$ but considered to be indigenous in PL (Wistrand 1962, p. 100), where it is only found on screes facing $S$ (no farmstead localities). Never above the upper limit of pine or spruce.

\section{Prunella vulgaris $\mathrm{L}$.}

This is a Boreal circumpolar plant, fairly frequent on the Norwegian coast to Troms, and with scattered localities in Finnmark, Kola and N Finland. There are good reasons to believe that the species exists both as anthropochorous and indigenous ecotypes (Sclander $1950 \mathrm{II}$, p. 15). The plant is found now and then in the pastures around farmsteads, evidently often spread to them from localities along the shores of lakes and rivers, where it is frequent, but only below the upper limit of coniferous forest. In the present material, occasional occurrence in one locality only (no. 9).

\section{Galeopsis bifida Boenn.}

The species is spread by man almost throughout the Holarctic region and to other parts of the world. It is infrequent in NW Fennoscandia, but occurs in Troms-Kola Peninsula. It has been confused with $G$. tetrahit L., with which it was earlier considered to be identical (Benum 1958, p. 331). The plant is common on cultivated ground, on roadsides etc. and occurs also on S-facing screes with open habitats. Seldom reaching the subalpine belt (Mt. Avatjåkko, Arwidsson 1943, p. 233).

\section{Veronica serpyllifolia L. ssp. euserpyllifolia Hyl.}

Originally this plant may have been a European-W Siberian plant (Hultén 1950, p. 82) now spread by man over the Holarctic zones round the world and naturalized in many other parts of the world. It is frequent along the Norwegian coast to Troms (Benum 1958, p. 338) and is also found in Finnmark, Kola Peninsula and N Finland. Commonly spread in fields, along roads etc. In PL there is only one locality (published here) for $V$. serpyllifolia, on S-facing scree (Mt. Fiskträskberget, no. 27). For ecotypes on the shores of rivers and lakes, see Selander (1950 II, p. 15) and Wistrand (1962, pp. 136-137).

\section{Crepis tectorum L.}

Eurasiatic plant (Hultén 1950, p. 70) reaching the coast of W Europe and fairly frequent up to S Scandinavia, with scattered localities up to Finnmark and Kola Peninsula. It was probably originally introduced by man into most parts of Fennoscandia although it may be indigenous in some localities, including those on S- or SW-facing screes (Andersson \& Birger 1912, p. 204; Johansson 1933, p. 488; Wistrand 1962, p. 149). In Troms it also occurs on sandy flats and shelly sand near the sea or on cliffs and mossy crags, but nowhere far from inhabited places (Benum 1958, p. 374). In PL it is rare even on cultivated ground (Wistrand, 1.c.).

\section{The bryophyte flora}

A great deal more is known today about the detailed distribution of thermophiles in $\mathrm{N}$ Sweden than in 1912 when Andersson \& Birger published their study. However, with regard to the mosses and hepatics observations are still rather incomplete. Beside the general statements on distribution-supplemented by some scattered notes on localities-in general Floras (e.g. Möller 1911-1936, Brotherus 1923, Jensen 1939, Arnell-Nyholm 1954-1966), there are only few statements in the literature on the bryophyte flora of PL. Botanists who have made important bryological collections in PL include S. O. Lindberg (who visited PL in 1856 and 1859), Hj. Möller (1918), C. Stenholm (1919), H. Persson (1928, 1930 see Persson 1929, 1932), A. Hülphers (1933), W. R. Uggla (1933); Th. \& A. Arwidsson; P. O. Nyman, S. Arnell, G. Een (1949-1960) and G. Wistrand. Most of the collections of these investigators are to be found in the Riksmuseum herbarium (HS).

A close study of the bryophyte flora of the mountain-sides in PL was not initiated until 1963. It started as a survey of the most common and most abundant of the species on the rock walls. As the work proceeded some rare species were found and, in addition, ecological aspects were investigated. The bryophytes were assumed to reflect the factors of the microhabitats more precisely than would the vascular plants alone. Furthermore some of the bryophytes are good indicator species, within the synusiae of crevices, rock walls and bare scree. Such synusiae have been described from other parts of N Sweden (cf., e.g., v. Krusenstjerna 1940, 1954). All bryophytes noted in the vegetation analyses were included in the list (Table 17; behind the text). Species were added from those parts of the scree with an unbroken cover 
Table 16. The flora of vascular plants of hillsides nos. 1-32.

Nomenclature of plant names mainly in accordance with Hylander 1953, 1955, 1966, and Wistrand (1962, pp. 47 et seq.).

The numbers of the mountains refer to the map, Fig. 2; exposure and statistics on the flora of the mountains, see Fig. 35. The list is founded primarily on the author's own observations, complemented with findings recorded in the literature (in some cases personal communications by Wistrand). Taraxaca and Hieracia were excluded from the list. Area diagnosis, see the text. The abbreviated symbols of these, on which the column diagram Fig. 35 (upper part) is founded, are:

$\mathbf{M}=$ Boreo-meridional, southern species (range not or only locally extended $\mathbf{N}$ of the Nemoral zone), (M) $=$ range including also some more occurrences in the Boreal zone

B = Range only locally extended S of the Boreal zone, $(B)=$ including also species with subalpine or alpine areas in Central Europe

$\mathrm{U}=$ Ubiquitous species, distributed in most of the Holarctic zones or in all of them, (U) = recent distribution is caused by anthropochorous distribution

$C=$ Species with continental tendency, $(C)=$ species with faint continental tendency, (see the text)

$\mathrm{O}=$ Species with oceanic tendency, $(\mathrm{O})$ = species with faint oceanic tendency, (see the text)

(species with indeterminate continental or oceanic tendency, i. e., all other species, I, for these species noted only in the text and Fig. 35).

When not otherwise stated, the area diagnoses refer to a taxonomic unit in broad sense. See also the Addenda below.

The life-forms (Raunkiaer, with some modifications as to the Therophytes, see the text) are: $\mathrm{Ph}=\mathrm{Phanerophyte,} \mathrm{Ch}=\mathrm{Chamaephyte,}$

$\mathbf{H}=$ Hemicryptophyte, $\mathbf{G}=$ Geophyte, $\mathbf{T h}=$ Therophyte. The hapaxanthous plants were marked: $\bigcirc$ annual, developing in spring;

$\odot$ annual, developing in autumn; $\bigcirc \bigcirc$ biennial.

$Q$ in front of the plant name refers to species which are certainly originally anthropochorous but now fully naturalized in PL. Occasional anthropochorous plants met with in some localities were omitted from the list but put (within brackets) in the Addenda below, in most of the cases the occasional occurences were recorded in the literature but the species not found again.

${ }^{c}$ obligate cliff element.

$(+)$ record from untypical habitats beside screes and rock wal s.

\section{Addenda (ı Table 16)}

In the following list are included the names of the taxa actually present, e.g. when the names and area diagnoses of the Table refer to a collective species. Finds of an uncertain character, of hybrids or of occasional anthropochorous species etc. were noted.

Woodsia glabella R. Br. was first reported by Wahlenberg (1812, p. 279: see Wistrand 1962, p. 51). Also on Mt. Svartberget (p. 113), find by the present author.

Cystopteris fragilis (L.) Bernh. ssp. dickieana (Sim.) Hyl.: $16 a, 17$ (collected and determined by the present author).

[Luzula multiflora (Retz.) Lej. ssp. occidentalis V. Krecz.: 17, 18, 20 (occasional occurrences; see Wistrand 1962, p. 62).]

Poa pratensis L. Refers (probably in ail localities) to ssp. alpigena (Fr.) Hiit. See Wistrand 1962 , p. 65.

Agrostis tenuis Sibth. X A. stolonifera L.: 18 (collected by the present author; confirm. K.-G. Widen).

Carex norvegica Retz. ssp. inferalpina (Wg) Hult. (= C. media $\mathrm{R}$. Br.). The area diagnosis refers to C. angarae Steud. ssp. angarae according to Meusel et al. 1965, map no. $71 \mathrm{~b}$.

Salix caprea L. Refers (probably in all localities) to S. caprea L. X S. coaeranea (Hartm.) Flod. Sce Wistrand 1962 , p. 89.

Rumex acetosa L. Refers (probably in all localities) to ssp. pratensis (Wallr.) B1. \& D. See Wistrand 1962 p. 94.

Stellaria nemorum L. Refers to ssp. montana (Pierrot) Murb. See Wistrand 1962, p. 96.

[Stellaria media (L.) Vill.: I, 9 (occasional occurrences, see Wistrand 1962, p. 97).]

Cerastium al pinum L. Refers mainly to ssp. lanatum (Lam.) Asch. \& Graebn. (Wistrand 1962, p. 98).

Cerastium alpinum L. X C. glabratum Hartm.: 11 (collected by Arwidsson in 1938, see Wistrand 1962, p. 98).

Cerastium holosteoides Fr.; Hyl. var. vulgare (Hartm.) Hyl. Localities reported by Wistrand (1962, p. 99).

[Silene cucubalus Wib.: 18. Reported by Johansson 1933, p. 496. Recently found again by Wistrand (personal communication).] Actaea spicata L. X A. erythrocarpa Fisch.: 31 (Wistrand 1962, p. 104).

[Capsella bursa-pastoris (L.) Med.: 9 (occasional occurrence, Wistrand 1962, p. 108).]

Draba hirta L.; O. E. Schulz: 18 (first reported by Grapengiesser, 1917, p. 266. Not found again.)

Ribes spicatum Robs.; Hyl.: 14 (?) A somewhat more hairy type than the common $R$. spic. var. lapponicum Hyl. was collected by the author.

Rubus saxatilis L. X R. arcticus L.: 28 (Wistrand 1962, p. 114).

Dryas octopetala L.: (4, Johnsson 1930, p. 138). Not found on the S-facing side by the present author.

Anthyllis vulneraria L. Refers to ssp. lapponica (Hyl.) Jalas.

Viola canina L.: $16 a$ (?) A somewhat uncertain collection was taken by the present author (vidi $\mathrm{H}$. Smith).

[Prunella vulgaris L.: 9 (Andersson \& Birger 1912, p. 207). Occasional occurrence. See above.]

[Euphrasia brevipila Burn. \& Gremli ssp. tenuis (Brenn.) Wettst. This species was reported erroneously by Wistrand (1934, p. 12). See the following species.]

Euphrasia cf. hyperborea E. Jörgensen. Some collections of Euphrasia from PL containing also the present collection (mistaken for E. brevipila by Wistrand, see the previous species) were preliminarily determined to E. hyperborea by G. E. Du Rietz.

Pedicularis lapponica L. Reported by Andersson \& Birger 1912, p. 204.

Hieracium spp. The most common species seem to be $H$. arctogenum Norrl., H. diasemum Om. (=H. erythropoecilum Dahlst.) and H. stenolepis Lindeb. Reference is made to a paper (in preparation) by S. Nordenstam and G. Wistrand. 
Table 16

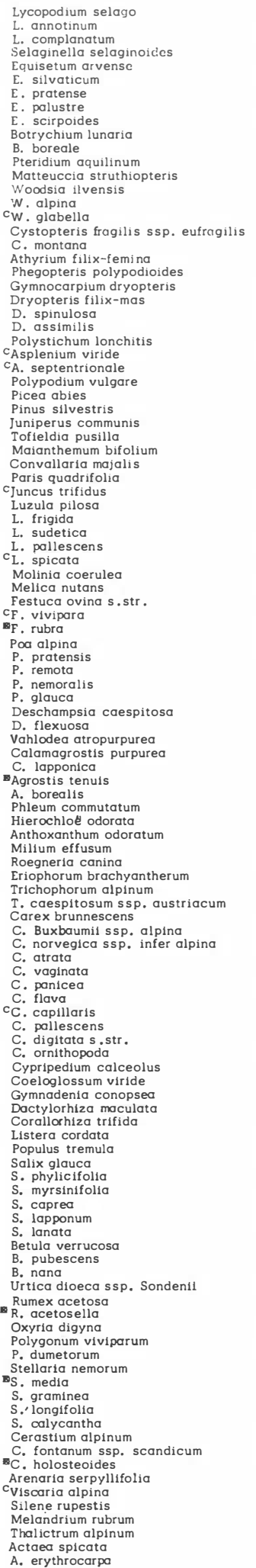

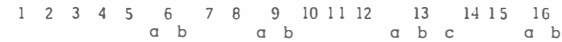
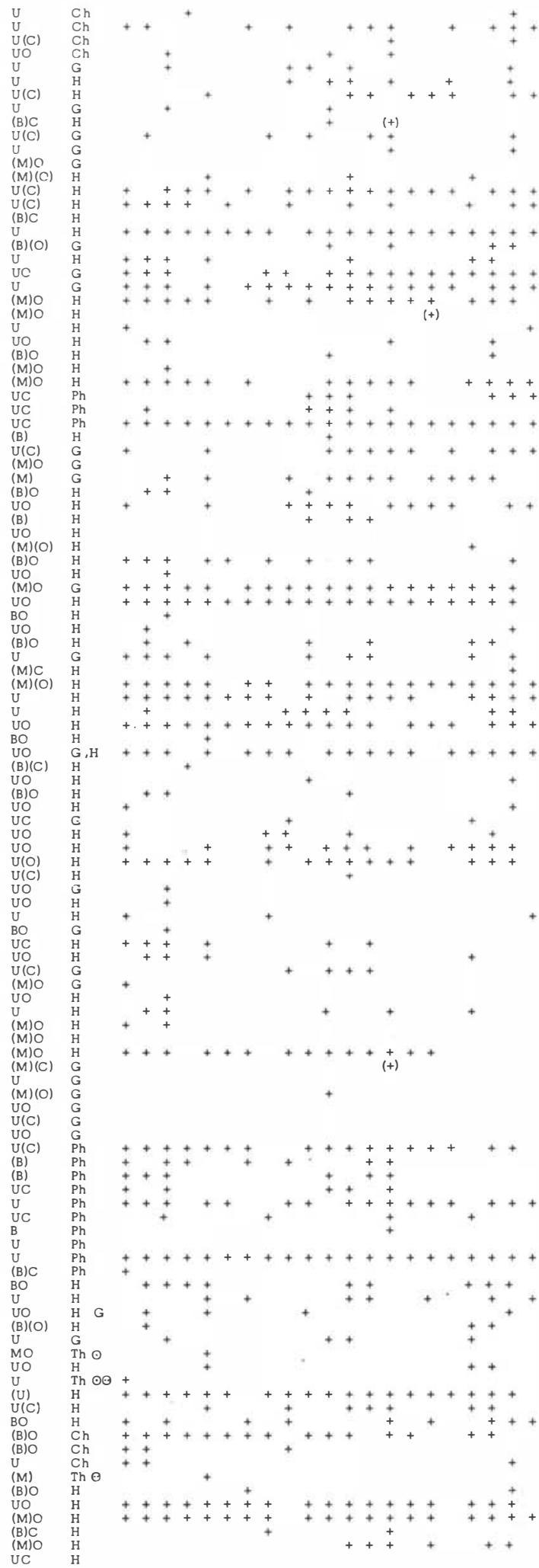

$+++$

$++$

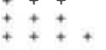

$+$

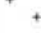

$++++$

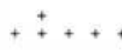

$++$

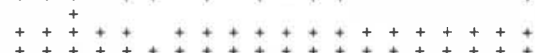

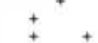

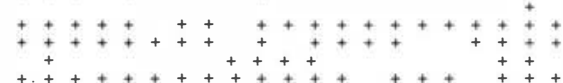

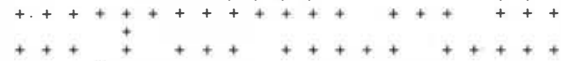

$++$

$+4$

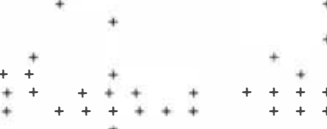

+
+
+
+
+
+
+

$$
+\stackrel{+}{+}+
$$$$
+++\ldots+++++\underset{(+)}{++}
$$
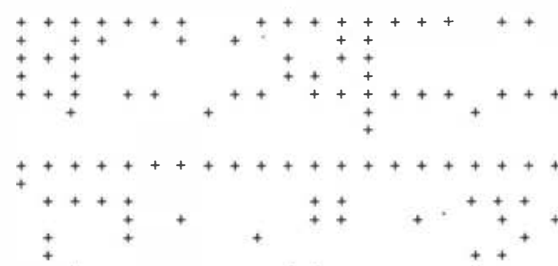

$+$

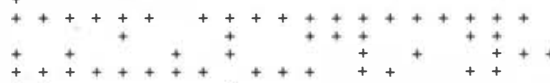

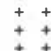

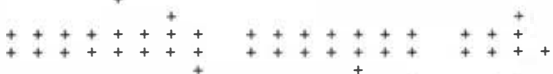

$171819202122232425262728 \quad 29 \quad 303132$

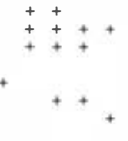


Table 16 , continued

Trollius europaeus Aconitum septentrionale Ranunculus acris s.str. Draba norvegica D. hirta

Barbaraea strict

Arabis hirsuta

Arabidopsis thaliana

Turritis glabra

Erysimum hier

Sedum rosed

S. annuum

Parnassia palustrís

Saxifraga oppositifolia

S. nivalis

S. aizoldes

S. cernuc

. caespitosa

Frilpendula ulmaria

Frunus padus
Rubus saxatilis

Rubus saxaty
$R$. idaeus

Fragaria vesca

Potentilla palustris

${ }^{C}$. multifida

P. argentea

P. Crantzii

ichemilla alpina

A. fillicaulis

A. murbeckiana

A. glomerulans

Rosa majalis

Sorbus aucuparía

Dryas octopet

Anthyllis vulneraria

Astragalus alpinus

Geranium silvaticum

Viola riviniana

v. epipsila s.str.

v. Selkirkil

$v$. biflora

Daphne mezereum

Epiloblum montanum

. collinum

. palustre

E. davurícum

Chamaenerion angustif olium

Cornus suecica

Anthriscus silvestris

Angelica archangelica

Moneses uniflora

Pyrola minor

P. media

P. chlorantha

Ramischía secunda

Phyllodoce coerulea

Arctostaphylos uva-urs

A. alpina

accinium vitis -idae

v. uliginosum

Calluna vulgaris

Empetrum hermaphroditum

Primula stricta

Trientalis europae

Hackelia deflexa

Myosotis silvatica ssp. frigida

$M$. arvensis

Maleopsis bifida

$v$. serpyllifolía

$v$ officinalis

Melampyrum pratense

M. silvaticum

Euphrasia frigida

E. cf. hyperbore

Rhinanthus minor

Bartsia alpina

Pedicularis lapponica

inguicula vulgaris

Galium boreal

G. triflorum

Valeriana sambucifolia

Calerlana sambucifolia

Solidago virgaurea

Erigeron politum

Antennaria dioeca

Gnaphalium silvaticum

G. norvegicum

Achillea millefolium

Saussurea al pina
Cirsium heterophyllum

Lactuca alpina

Crepis tectorum

Total number of species $\begin{array}{llllllllllllllll}1 & 2 & 3 & 4 & 5 & 6 & 7 & 8 & 9 & 10 & 11 & 12 & 13 & 14 & 15 & 16 \\ a^{16} b\end{array}$

$171819202122232425262728 \quad 29 \quad 303132$

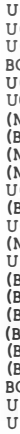

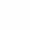

$++2+\infty+$

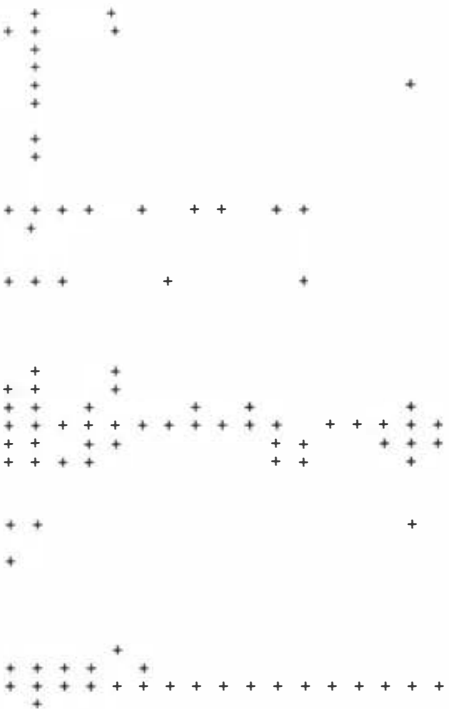

U(B)(C)

(M)

$\mathrm{U}$

(M)O

U

(B)

(B) $(\mathrm{O})$

(M)

BO

U

U(O

UO

U

(M) (O)

(M)

(B)

(B)

U

B

$\mathrm{U}$
$\mathrm{U}(\mathrm{C})$
$\mathrm{UO}$

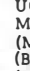

(M)
(B)
(M)
(M)

(M)O
UIO)
U(O)
B(O)

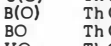

Uo The

(B)
(B)
BIC)

Uo
UO
U(C)

U(C)

Uั

U

$\mathrm{U}$
$\mathrm{U}(\mathrm{O})$

(B)
(B)(O)
(U)

(B)O

(M)

$\stackrel{\mathrm{H}}{\text { Th } \odot \odot ~}$

8188104558735485451667492799555484271839540

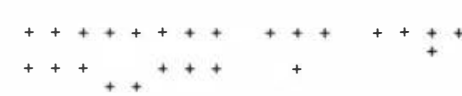

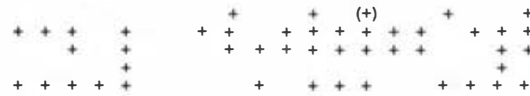
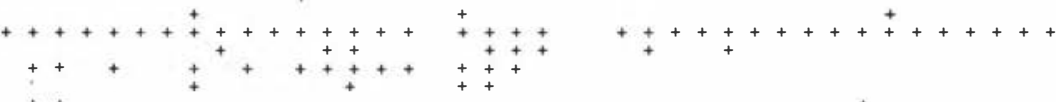$$
+
$$

$++++$
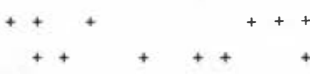

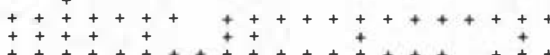

$+++++++++++++++$

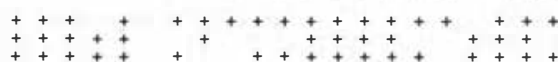

$++^{++}$

++++
+++++
++++

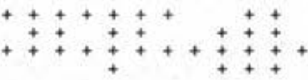

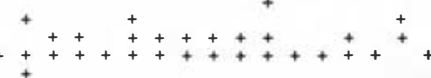
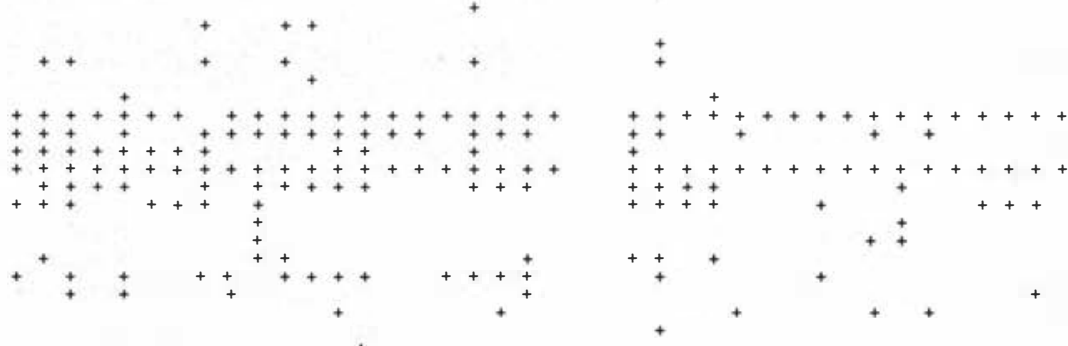

$1111361 \quad 6262 \quad 4037413550594524 \quad 313653 \quad 34$ 
of vegetation and other habitats of the fine scree, as well as stem bases, large boulders etc. In this way the bryophyte list finally became a fairly good parallel to the list of vascular plants although this was not intended at first. Some elements on large boulders of the distal parts of the talus slopes are lacking or noted very sparsely in the list, although the communities in which they occur are almost constantly present. This is the case with e.g. Dicranum elongatum, D. fragilifolium, Orthodicranum montanum, Rhacomitrium heterostichum, Rh. lanuginosum, Sphenolobus saxicolus. They often occur more frequently on slopes of exposures other than near $\mathrm{S}$. As has been stated from NW PL (P. O. Nyman, personal communication, cf. Mårtensson 1956 IIl, p. 34), Seligeria spp., Entodon concinnus etc. are also of this later category. As far as PL is concerned, the number of investigated slopes facing $\mathrm{N}$ or nearly $\mathrm{N}$ is too small to give reliable information on the degree of thermophility. This is shown by the occurrence of Scapania aequiloba in the Torneträsk area (Mårtensson 1956 III, p. 39) and finds of Porella platyphylla and Eurhynchium pulchellum from unfavourable exposures in PL. On Mt. Staburknösen (no. 15) Porella platyphylla grew in $\mathrm{S}$ exposure, in an elevated site at $657 \mathrm{~m}$, thus about $100 \mathrm{~m}$ higher up than in NE to E exposure on the same mountain. The former site is definitely of subalpine character. According to Arnell (1956, p. 247) Porella is a southern lowland plant. Eurhynchium pulchellum grew on the cliff and scree of the NE-facing side of Mt. Aistjakk (no. 16 b). However, in most cases, the bryophytes of a southern distribution type are in all likelihood most abundant on the S-facing sides of mountains, as far as investigations show. The problem is quite as complicated as for the southern vascular plants (see above).

Stroemia obtusifolia was found growing aboundantly on aspen trees of the Viola riviniana forest investigated (p. 105), a site which is hardly a definitely warm locality, although its geographic situation is more towards the SE (map fig. 2) than the NW localities on S-facing sides of mountains.

Probably among the thermophilous bryophytes similar relations exist with regard to the oceanitycontinentality gradient as among the vascular plants (cf. Lye 1967, pp. 88 et seq.). Too little is known about the detailed distribution of mosses in the Arctic and Boreal zones to provide exact information on the area characteristics, as is possible in vascular plants. An example of this is Orthotrichum pallens which is probably more widely distributed in the Boreal zone than it was thought to be. However, in $\mathrm{PL}$ this species is found only on S- to SW-facing mountain slopes as an epiphyte on aspen trees. Thus it could be somewhat thermophilous: at least it is a definite southern element in the flora of Lappland (not known from the Torneträsk area). These examples show that the relations to the meridionality-boreality gradient also need further investigation.

Besides the climatic factors there are the substrate factors. For the 16 mountains on Cambro-Silurian rocks of the NW there is an average number of 52 bryophytes, while the corresponding number for the 16 mountains on Archaean rocks of the SE is 44, thus a substantial reduction for the unfavourable rocks. Although the seepage water of the cliffs may be quite high in electrolytes even on Archaean rocks, it is not sufficiently rich to support the more demanding elements, which thus are concentrated to the NW. Yet there is no sharp borderline for those species which are thought to be mainly confined to calcareous substrates (see e.g. the distribution of Distichium capillaceum, Tortella fragilis and T. tortuosa). As was mentioned above (p. 20) there are also occurrences of more favourable substrates in the $\mathrm{SE}$, in addition to bird perches and tree stumps, which may be valuable in providing the elements required if the species is to do well. In certain places with a richer flora it may be quite hard to decide whether the shade or a better substrate is decisive. This is true for the Gully of Mt. Gaddaberget in SE (no. 31), where some species rare in the SE were found (e.g. Tortella fragilis and Orthotrichum alpestre). In some cases the dryness of the cliffs is limiting. Although most of the bryophytes seem to avoid cliffs which are too dry there is less evidence that they prefer very shady localities (cf. on the other hand Porella platyphylla above; this species was also found in the Gully of Mt. Gaddaberget).

The fact that the mosses have quite narrow amplitudes in other respects probably make them less valuable as indicators of "warm sites". To the problems is added the factor of snow cover in winter, which will be effective especially for the bryophytes that are abundant on tree stems in S Sweden, but almost completely vanish from such substrates in the $\mathbf{N}$. This is true especially of Leucodon sciuroides, Anomodon viticulosus, Isothecium myosuroides, Homalothecium sericeum and Radula complanata. The number and abundance of the epiphytic bryophytes are thus low, and the epiphytic moss vegetation does not appreciably ascend above the snow cover in winter. The only tree with its bark rich in epiphytes (Du Rietz 1945, p. 147) is Populus tremula, which is often abundant. Salix coaetanea and Sorbus aucuparia are also good substrates and are common, as is birch (Betula pubescens), with its poor bark. A 
birch with rich bark communities was seen only once (Mt. W Ramanpakte, no. 3) in the drip zone from the cliff. Animal refuse also affects the distribution of mosses, including bird perches, (e.g. Hypnum revolutum, see Mårtensson 1956 I11, p. 32), but the extent and amount of this influence is fairly unimportant on the mountains concerned.

The total number of bryophyte species reported here is 195 . Of these only 38 are hepatics. This may seem to be a low number, but considering that most of the localities are sunny and dry localities of the coniferous belt (in fact only one, no. 7, is definitely a subalpine locality) the number may be reliable. Anyway, the number of overlooked hepatics is probably not very high. Unfortunately an estimate of the total number of Hepaticae and Musci collected within the whole of PL is impossible, as the material has not been revised. The cliff and scree localities of PL are here compared with two well-known areas in N Fennoscandia (Tuomikoski 1939, p. 97; Auer 1944, p. 2; cf. Mårtensson 1956 III, p. 40).

The two areas available for comparison are much more variable, as all kinds of habitat are included (alpine areas, mires, shores, etc.). This accounts for the much higher total figures.

\begin{tabular}{|c|c|c|c|}
\hline & $\begin{array}{l}\text { Total } \\
\text { no. }\end{array}$ & Musci & $\begin{array}{l}\text { Нера- } \\
\text { ticae }\end{array}$ \\
\hline Torne lappmark (TL) & 487 & 333 & 154 \\
\hline Regio kuusamoënsis ( $R K$ ) & 450 & 328 & 122 \\
\hline Pite Lappmark (PL) & 194 & 156 & 38 \\
\hline
\end{tabular}

In the above number of Musci, Sphagnales (in RK also Andreaeales) were excluded. As the percentage of Hepaticae in the total bryophyte flora of PL probably does not deviate much from the number given for $\mathrm{TL}$, the comparatively small percentage of $\mathrm{He}$ paticce on cliffs and screes is striking. With regard to the NW-SE distribution of hepatics in the PL localities (Table 17) the SE localities generally have lower numbers, and the total number of bryophytes is also lower (cf. above).

For most mountainous areas of Fennoscandia the number of bryophytes is approximately the same as the number of vascular plants. As in this case 224 vascular plants were reported (excluding more or less occasional occurrences of anthropochorous plants) the number of bryophytes may seem low. This is an indication that the localities are comparatively unfavourable for bryophytes, which does not exclude the possibility that some of them show a preference for the hillside localities.

In the following list only some interesting bryophytes were included. The autecology of most of them seem to agree very well with their occurrence within TL, as investigated by Mårtensson (195556, I-III. Because of this, reference can be made to the two first parts of his work where generally complete statements are given about the total ecological range of the species (the parts were abbreviated $M$ I and M II). Collections (at the Institute of Ecological Botany, Uppsala) are generally macrosamples from surfaces of rocks and boulders, crevices, caves and fine screes, and no exact statement on habitat was made on the labels. Some uncertain Brya and Pohliae were excluded from the list. The nomenclature mainly follows Mårtensson (op. cit.), and Arnell \& Nyholm (I, 1956; II, 1954-1966). Statements about the species being "new to PL" (10 species) generally mean earlier unpublished for PL. As a rule this also means that no material had previously been collected (material in the official herbaria of Sweden only of three unrevised collections of Grimmia ovata (G. ovalis?) in the Botanical Museum, Uppsala, collectors S. O. Lindberg in 1856 and 1859; H. W. Arnell in 1869).

Sphagnuin robustum. M II, p. 12. In sparse pure patches immediately below the cliff on stable scree where there is some oligotrophic seepage water.

Fissidens osmundoides. M II, p. 44. On wet ledges and in crevices and caves. Sparse.

Ditrichum flexicaule. M II, p. 47. In fairly pure patches or among other somewhat eutrophic mosses on cliffs, in crevices. Less often on scree.

Distichium capillaceum. M !I, p. 49. Fairly abundant in crevices on not too poor substrates, as pure patches or mixed among other mosses.

Saelania glaucescens. M II, p. 50. Sparsely mixed among other mosses in caves or in crevices. Seldom on scree.

Ceratodon purpureus. M II, p. 50. Common in most of the habitats of cliffs and screes, also in fairly shady communities with herbs (see Table 18).

Seligeria spp. Not seen, although sought (see the text above).

Blindia acuta. M II, p. 55. Only on cliffs in places where there is an abundant supply of water. Sparse.

Dicranella cerviculata. M II, p. 60. Found only once (as fruiting) on the ground in a cave (used by Lapps in old times as cult site). Sparse.

Rhahdoweissia fugax. M II, p. 61. Very sparse among Cynodontium spp. on poor substrates, in crevices and on ledges.

Cnestrum schisti and Cn. alpestre. M II, pp. 6162. Very sparse occurrences in crevices of rock walls.

Encalypta streptocarpa. M II, p. 91. Found only once in a sample with other mosses from a cave below the rock wall. 
Tortula ruralis. M II, p. 93. Fairly abundant in most habitats on the better substrates.

Desmatodon latifolius. M II, p. 95. Found sparsely both on rock walls and on scree. Also Merk Gorge.

Barbula recurvirostra. M II, p. 100. Sparse among other mosses in crevices and caves. Seldom on scree.

Gymnostomum aeruginosum. M II, p. 101. Sparse in the same habitats as Barbula recurvirostra. Rarely on scree.

G. recurvirostrum. M II, p. 102. Found only once in a shady cave (where a sample of seepage water was taken, Table 14, sample no. 3).

Schistidum strictum. M II, p. 112. Nomenclature and taxonomy, see M II, p. 110. Sparse. S. trichodon and S. boreale (Poelt 1953, p. 253) were not seen.

Grimmia commutata. M II, p. 114. Found only once sparsely on a surface of a cliff facing S. New to $\mathrm{PI}$.

Grimmia unicolor. M II, p. 114. Sparsely in rock crevices among other oligotrophic species.

G. incurva. M II, p. 120. Found only once, on boulder scree.

G. torquata. M II, p. 121. Fairly abundant in crevices as pure patches or among other (undemanding) mosses. Occasionally on scree.

G. hartmanii var. anomala. Möller 1933, pp. 9799. Found both on rock walls (localities nos. 2, 4) and on pebbles of the scree (no. 11). Very sparse.

Rhacomitrium fasciculare. M II, p. 127. Found only once, in the splash zone on a cliff near a stream (see p. 109).

Leptobryum pyriforme. M II, p. 142. Mostly as non-fruiting in pure patches on open scree. Probably overlooked.

Pohlia elongata (as $P$. acuminata Hoppe \& Hornsch. ex Hornsch. in M II, pp. 142-143). Found only in crevices of cliffs. Sparse.

Pohlia longicolla. M II, p. 143. In pure patches or among other mosses in crevices and on the surface of rock walls. Fairly abundant.

$P$. bulbifera (M II, p. 151) and P. proligera (M II, p. 153). As rare elements among other mosses on wet rock surfaces. Seen growing together only once in a mountain-side locality (however, P. bulbifera, especially, is abundant on the shores of lakes of NW PL, e.g. Rebnisjaure).

Bryum spp. Some of the less common species could certainly have been overlooked.

Bryum argenteum. M II, p. 162. Seen only once on a rock surface facing $S$. Very sparse.

B. cirrhatum (M II, p. 168) and B. pallescens (M II, p. 171). These species are in some cases hard to separate from each other. Both are frequent in rock crevices and on screes and show a large variation in habitats.

B. inclinatum. M II, p. 174. Sparse in crevices and on scree.

B. archangelicum. M II, p. 176. Found only once on scree.

Rhodobryum roseum. M II, p. 188. Sparse on screes in communities with tall herbs (Table 18).

Mnium spp. Sparse to fairly abundant in moist rock crevices among other mosses or in tall communities on screes, especially below outflows of seepage water. Some (especially Mn. orthorrhynchum. Mn. serratum, Mn. stellare and $M n$. cuspidatum) found mainly in moist rock crevices together with acrocarpous mosses (M II, pp. 189 et seq.).

Cyrtomnium hymenophylloides. M II, p. 198. Rare in moist crevices among other mosses, seldom on scree.

Cinclidium stygium. M II p. 200. On moist ledges on rocks or (seldom) on screes below outflows of seepage water.

Aulacomnium palustre (M II, p. 202) and A. turgidum (M II, p. 203). In moist crevices or on moist ledges or (sparse) on stable scree below outflows of seepage water.

Conostomum tetragonum. M II, p. 211. In almost pure patches on ledges of poor rocks. Rare and very sparse.

Philonotis calcarea and Ph. fontana M II, p. 213). Sparse in moist rock crevices. Seen fruiting only once (together).

Orthotrichum blyttii. M II, p. 221. Seen only once on a rock wall surface. Probably overlooked.

$O$. anomalum. Seen only once, on a perpendicular rock wall surface together with Porella platyphylla in the lowermost part of the rock wall (snow cover in winter). Rare and very sparse. New to PL.

$O$. pallens. Only on rich bark (once on birch in drip zone of the rock wall, locality no. 3) of trees growing on scree. Fairly abundant, in some localities sparse. New to PL.

Stroemia obtusifolia. M II, p. 223. Only on bark of aspen on scree. In most localities sparse.

Leucodon sciuroides. M II, p. 227. On the rock wall base, on boulders of the scree, or rich bark. Fairly abundant.

Neckera pumila. Found only once, below a large boulder immediately above the low cliff in the $W$ parts of Mt. Gaddaberget (no. 31).

Neckera complanata. On rims of rock ledges and in caves, as fairly pure hanging carpets. Sparse. New to PL.

Myurella apiculata. M II, p. 230. Sparsely inter- 
mingled with other mosses in moist crevices and in caves.

Pseudoleskeella tectorum (M II, p. 233) and P. papillosa (M II, p. 240). Under boulders of the scree or in caves. Sparse.

Anomodon viticulosus. M II, p. 241. Found only once, on the rim of a ledge in the lowermost part of the rock wall. New to PL.

Isothecium myosuroides. Found only once, on a boulder in the scree (see p. 78 and Fig. 42). New to PL.

Cratoneurum filicinum. M II, p. 243. Seen only once, in the cave where sample of seepage water was taken (Table 14, sample no. 3).

Drepanocladus exannulatus. M II, p. 256. Seen only once, near a small trickle on stable scree.

Calliergon sarmentosum. M II, p. 276. On wet rock walls or below the cliff on stable scree where there is an abundant water supply. Sparse.

Hygrohypnum alpestre. M II, p. 267. Together with Drepanocladus exannulatus. See above. Very sparse.

Campylium: chrysophyllum. M II, p. 249. Abundant to sparse on rocks or boulders of the scree, in fairly pure patches.

C. sommerfeltii. M II, p. 250. Among other mosses on decaying wood or in tall communities (Table 18). Sparse.

C. halleri. M II, p. 250. On moist cliffs or in caves of ten i pure patches. Sparse.

Amblystegium serpens. M II, p. 251. On humified wood on the scree as a pure patch. Seen only once, sparse.

A mblystegiella sprucei. M II, p. 253. Among other mosses in crevices or on screes with tall herbs and rich production of humus. Sparse to abundant.

Eurhynchium pulchellum. M II, p. 288. Most abundant as an epiphyte on Juniperus or on Juniperus litter in the scrub zone of screes. Also in crevices.

Brachythecium erythrorrhizon (not in the list Table 17). Found only once (as certain), on the Sfacing scree of Mt. Långsjöberget (near Hällbacken). Analyses of a stand with $B$. erythrorrhizon, see Table 21 and 26.

B. plumosum. M II, p. 286 (not in the list Table 17). There are some localities of this species in the Scandes of PL (collections in HS; P. O. Nyman, personal communication), but the species was not found, although sought.

B. velutinum. M II, p. 284. Sometimes abundant in sheltered caves in the lowermost part of the rock wall or under boulders of the scree. New to PL.

B. starkei. M II, p. 282. On the rock wall, on stabilized scree (mostly on logs and stumps of trees or on bark). Abundant to sparse.

Homalotheciuın sericeum. On rock walls covering small perpendicular surfaces. On the $\mathrm{N}$ side of River Rånekjokk, see Fig. 2; (Herman Persson and $\mathrm{Hj}$. Möller, found again by the present author), seen on the edge of a large boulder in SE exposure in the geolittoral zone of the river.

Orthothecium intricatum. M II, p. 291. Seen only once, on a cliff facing NE, interspersed among other mosses.

Pylaisia polyantha. M II, p. 299. On rock walls among other mosses or (epiphytic and epixylic) on screes. Sometimes abundant, mostly sparse. New to PL.

Hypnum revolutum. M II, p. 303. On cliffs mixed with other mosses. Occasionally on stabilized boulders of the scree or on bird droppings. Sparse.

Ptilium crista-castrensis. On or between stabilized boulders of the scree. Sparse to abundant.

Rhytidiadelphus triquetrus. M II, p. 309. Only in highly productive moist stands of Lactucion alpinae on the scree. Sparse. More abundant on the lowermost parts of wet scree slopes with transition to meadow birch forests.

Climacium dendroides. M II, p. 226. On moist and shady scree slopes with stands of tall herbs. Sparse.

Plagiothecium piliferum. M II, p. 296. On rock walls or on screes as sparse admixture with other mosses.

P. laetum and P. denticulatum. M II, pp. 296-297. $P$. laetum seems to prefer somewhat more calcareous substrates than $P$. denticulatum, but is probably overlooked in the SE (cf. Persson 1929, p. 245). Both of them on rocks, in crevices or on (humus-rich) screes. Abundant.

P. succulentum. M II, p. 298. Seen only once, on a scree with a stand of Dryopteris filix-mas (see p. 88 and Table 18). Probably overlooked.

Metzgeria furcata. M I, p. 14. Under boulders of the scree or in caves. Sparse.

Blepharostoma trichophyllum. M I, p. 21. Found in most of the habitats but most often found as intermingled among other mosses on rock surfaces or in crevices. Generally sparse.

Lepidozia reptans. M I, p. 99. Very sparse among other mosses on shaded rocks and screes.

Calypogeia meylanii. M I, p. 100. Sparse on wet scree slopes below outflows of seepage water.

Cephaloziella sp. M I, p. 89. Probably in most cases Cephaloziella arctica. Most of ten found in moist rock surfaces or in crevices entangled among other bryophytes. Sparse. 
Barbilophozia barbata. M I, p. 24. Mostly found on cliffs, in crevices or on ledges. Also on scree. Seen fruiting (locality no. 16a). Sparse to fairly abundant.

Leiocolea gillmanii. M I, p. 43. Seen only once, on a shaded rock wall facing NE. Very sparse.

L. heterocolpos. M I, p. 44. Found in most habitats, sparsely intermingled among other mosses. Most abundant below outflows of seepage water.

Lophozia alpestris. M I, p. 35. Very sparse on shady or wet rock surfaces.

L. cf. marchica. A hepatic determined provisionally to this species grew among Sphagnum robustum below an outflow of oligotrophic seepage water. Very sparse.

Lophozia excisa. M I, p. 37. Mainly collected from fine screes with humus-rich soil. Also in crevices. Sparse.

Orthocaulis spp. M I, pp. 26-28. The species are mainly found on irrigated and shaded rock surfaces or ledges, but also on screes below outflows of seepage water.

Sphenolobus saxicolus. M I, p. 49. Preferring the large stable boulders of the lowermost part of the scree. More seldom on the rock wall. Generally abundant.

Tritomaria scitula. M I, p. 50. Sparsely intermingled among other mosses in crevices and caves or on moist rock walls. Because of the find in locality no. 21 it must be considered as rather "indifferent" about the substrate.

Diplophyllum taxifolium. M I, p. 74. Fairly abundant in moist or shady rock crevices or in caves, as pure patches or mixed with other mosses. Also among boulders of the scree.

Scapania irriguc. M I, p. 79. Fairly abundant in most of the habitats but most often in wet crevices, in caves or below outflows of seepage water. It is very variable in the localities, and in some cases hard to identify.

Cephalozia spp. Only on two occasions were fruiting specimens seen which could be identified.

Marsupella sphacelata. M I, p. 61. Seen only once (as var. sullivanti), on an irrigated rock wall near an outflow of seepage water. Sparse.

Radula complanata. M I, p. 102. Abundant under boulders of the scree or on the rock wall (often in caves). Rare on stem bases of aspen trees.
Porella cordeana. M I, p. 103. In fairly abundant carpets in caves on the lowermost part of the rock wall. New to PL.

$P$. platyphylla. On shady perpendicular rock walls or in caves in fairly abundant carpets. New to PL.

Marchantia alpestris. M I, p. 12. Seen only once on wet scree below outflow of seepage water.

Preissia quadrata. M I, p. 11. On wet cliffs near outflows of seepage water. Generally sparse.

\section{Conclusions}

Considering the climatic factors in relation to present-day and postglacial ranges, the interrelations between oceanic or continental trends and the development of floras have been much discussed (cf., e.g., Gams 1931, Kotilainen 1933, Böcher 1943, Meusel 1943, Firbas 1949, Jalas 1950, Hintikka 1963, Meusel, Jäger \& Weinert 1965, Lye 1967). All these investigations show that a full understanding of the concepts, oceanic or continental, cannot be achieved unless the competition factor and the historical aspects of soil formation, etc., are also considered. The same is true with regard to thermophily, or southern and northern trends in the flora. This points to a classification founded on vegetation or biotic regions (Sjörs 1955, p. 163). Climatology may then be used to clarify one important side of the formation of vegetation regions, as pedology may be used to explain the distribution types of, e.g., calciphile plants.

It was stated that the types of microdistribution the bryophytes of $\mathrm{N}$ Sweden, in particular, are still too incompletely known to support statements on thermophily. For these reasons, only some clearly thermophilous plants could be distinguished, on the basis of the present investigations. They are:

Asplenium septentrionale
Polygonum dumetorum
Arenaria serpyllifolia
Arabis hirsuta
Arabidopsis thaliana
Turritis glabra
Sedum acre
Potentilla argentea
Epilobium montanum
E. collinum
Myosotis stricta

Grimmia commutata. Bryum archangelicum Orthotrichum anomalum O. pallens

Leucodon sciuroides Anomodon viticulosus Isothecium myosuroides Brachythecium velutinum Pylaisia polyantha Metzgeria furcata Radula complanata Porella platyphylla (?) 


\section{THE VEGETATION}

\section{Introduction}

The most important alliances of subalpine and alpine chasm:ophytic vegetation and vegetation on talus in the Scandes are (see Nordhagen 1936, pp. 12-13, 1943, pp. 542 et seq.; cf. Bringer 1961, 1965, p. 1):

1. Saxifragion cotyledonis mainly on cliffs poor or relatively poor in Ca. According to Nordhagen (1943, p. 569) it is an impoverished outpost of the Central European Androsacion multiflorae Braun-Blanquet 1926.

2. Kobresieto-Dryadion (Dryadion) on circumneutral or somewhat basic screes and ledges (not the most common habitat for this community). See Bringer 1961.

3. Asplenion viridis subarcticum on $\mathrm{Ca}$ - and $\mathrm{Mg}$ rich rocks (Nordhagen 1936, p. 13, 1943, p. 568; Rune, O. $1957 b$, p. 7). An impoverished outpost of the Central European Potentillion caulescentis Braun-Blanquet 1926 .

4. A very poor and unassociable vegetation on talus of extremely hard and Ca-poor bedrocks.

5. Veronico-Poion glaucae on debris rich in nutrients but usually not very rich in $\mathrm{Ca}$ (in Sikilsdalen pH 5.35-6.26, Nordhagen 1943, p. 546, see also this paper, p. 27). Some of the local or regional preferential species may also be found on cliffs, in crevices and on ledges. See the discussion below.

6. Arenarion norvegicae on debris from calcareous, dolomitic or schistose rocks constituting "Kalkschuttgesellschaft", an equivalent of the Central European Thlaspeion rotundifolii Braun-Blanquet 1926, see Nordhagen 1943, p. 544, and Rune, O. $1957 b$, p. 7.

According to O. Rune (op. cit.) the special fragments of plant communities found on serpentine are also common in the coniferous belt. The serpentines, as do the screes in general, provide favourable habitats for many sparse relic populations of Arctic origin which for one reason or other are unable to spread outside their present-day localities. The position of these relics is mainly caused by the occurrence of the particular habitats and not by the nearness of presumptive icefree areas during the glacial epoch (Rune, O. $1957 a$, p. 60).

Very little was known earlier about the chasmophytic communities and the low to rather tall com- munities on screes in the coniferous belt of $\mathrm{N}$ Scandinavia, although it could be assumed from the above that the vegetation should not deviate very much from that in similar habitats in the subalpine and alpine areas of the Scandes. Therefore the analyses had to be compared with the above cited communities.

The already published results (Lundqvist 1961) may be summarized as follows:

(a) An association equivalent to Nordhagen's Veronico-Poetum glaucae seems to be the most common one of the tall communities alongside the base of the rock walls and in the upper woods on screes in PL.

(b) Veronico-Poetum glaucae or its equivalent in PL seems to be dependent on $\mathrm{Ca}$ in the bedrock, but where this factor is sufficient, other important factors, viz. local climate (especially heat and light) and the water conditions are decisive.

(c) It is remarkable that there are in the scrub zone, i.e. a transition zone between the upper wood and the open boulder scree, several vascular plants that are almost exclusively found in this zone.

(d) A community characteristic of the lower wood on stable boulder screes is a thicket rich in mosses equivalent to Nordhagen's "mosrikt einer-dvergmispelkratt".

Beside the mainly synecological investigation which has been the main interest of the present author there are also some observations of autecological interest. Through a closer comparison with the associations described by Nordhagen some local and regional deviations have been found. Because of this Nordhagen's system has been replaced by a more detailed subdivision.

\section{Terminology and methodology}

When delimiting the plant communities the methods and terminology generally used in recent years by the Uppsala school have been applied (see, e.g., Du Rietz 1957). It has not been found inconvenient to use present-day methods in the study of the vegetation units of screes. It might probably have been so with the concepts used by the Uppsala school in the 1920's (see Du Rietz 1924, pp. 100, 115; JennyLips 1930 , p. 149). The delimitation of the vegeta- 


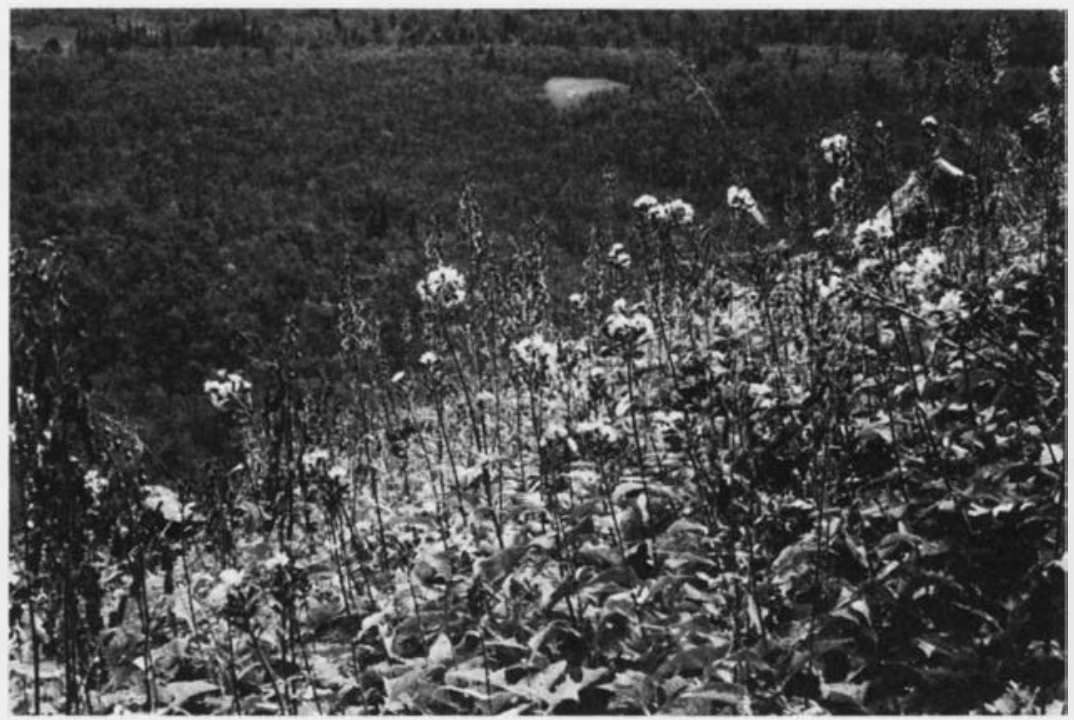

Fig. 36. Tall stand of flowering Lactuca alpina and Aconitum septentrionale in an extremely well-watered site on the $\mathrm{S}$-facing side of Mt. Barturtevalle (a mountain immediately S of Mt. Kebnevare, no. 6), at $755 \mathrm{~m}$ above sea-level (subalpine locality). 23 August, 1965.

tion units was then primarily founded on the concept of constants for which large quadrats were necessary (cf. Du Rietz et al. 1920, p. 23). Moreover, the cliff and scree vegetation is never rich in constants except perhaps those of a local status. Later on the concept of synusiae, or one-layer communities, was much discussed (Du Rietz 1936, p. 584; Nordhagen 1943, pp. 31 et seq.).

The vegetation studied seems to be well stabilized (p. 101) and much more so than is the case in the corresponding sites of the Alps (cf. Du Rietz 1924, pp. 100, 115) or in some areas in Norway with extremely rapidly weathering bedrock. Such districts of the Scandes with very unstable screes are to be found e.g. in Junkerdalen, N Norway, near the NW border of PL, and in some other calcium-rich districts. The vegetation, when not totally absent from the most extreme sites, deviates much from that found on the present screes. Because of the fact that the "optimal" stage may be nearly always reached at least in some parts of the fine screes, where a tree layer is well developed, it was found appropriate to regard the synusiae only as subordinate units of the different stands. In other words, the synusiae could not be grouped together irrespective of the stratification of the vegetation, because stands with trees, stands with shrubs or stands with only a field or bottom layer had to be regarded as different seral stages with respect to the succession of vegetation. The succession of the vegetation units will be further discussed on p. 101.

Because the conditions in the Scandes and nearby areas may be highly variable, it must be emphasized that the vegetation units established may find their full application only within the studied area (see
Sjörs 1946 b, p. 8; Persson 1961, p. 17). On the other hand the material may well be exploited for regional comparisons, undertaken in one case (Sikilsdalen, S Norway, see below).

When grouping the phytocoenoses into plant communities of different rank it is for obvious reasons a great advantage to apply a fully developed sociological nomenclature. In recent years so many vegetation monographs have been founded on the present system that a full treatment of its principles and their advantages or disadvantages is superfluous here. One of the prerequisites for the application of a particular system is that it should be easy to use.

In the study of the vegetation units the foundation has been the study of the association and its delimitation within the alliance. Associations, now considered to be medium-rank communities, have thus been regarded as fundamental. Lower vegetation units defined on the basis of conditions of dominance or similar principles (sociations) would have been of less importance for the study of the alliance as a whole. To get a survey of all the low-rank communities present would have been extremely time-consuming. It was also found, through survey analyses, that typical seral stages of screes nearly always were occupied by typical associations. The corresponding ecosystems could then be considered to be the most important components for the evaluation of the great hillside ecosystem. The study of low-rank communities would also have deserved much more time for the study of the mainly one-layer communities on rock debris of different exposure etc. The microconditions existing within a particular quadrat were for obvious reasons neglected.

The concepts of exclusive and preferential species 
(Swed. "ledart" and "preferensart", respectively) have been defined by Du Rietz (cf., e.g., Du Rietz 1942, p. 125). A differential species ("skiljeart" according to Du Rietz) is a plant species which appears in one community but is absent or almost absent in another. "Indicator species" are exclusive, preferential or differential species. The different associations have been separated mainly on the basis of differential species. Intensive analyses if the bryophyte vegetation within the stands (or segments, Schmid according to Du Rietz 1957, p. 28) have been considered decisive for the classification. The bryophytes, although many times reflecting the microconditions, have mostly been found to be confined to certain communities with rather a high degree of fidelity. They have thus in certain cases been valid even as exclusive species for a certain association. When the occurrences of a species within a stand are rare it will have a reduced usefullness as an indicator of a plant community. The fidelity is not always so great among the vascular plants, but as their occurrence within the area concerned is much better known they are most valuable as far as they indicate certain habitat conditions. Really exclusive species among the vascular plants seem to be rather few for the Scandian area (see, e.g., Bringer 1961, p. 353; Persson 1961, p. 18). Instead, at least for N Swedish vegetation, preferential species may be regarded as more useful in the classifying of plant communities (see Sjörs 1954, p. 35).

A quadrat of $1 / 4 \mathrm{~m}^{2}$ has been used in the present study. The small size of the quadrat has permitted the study of rather bouldery screes without violating the claim for homogeneity. As will be shown later, in boulder screes is present a Sphenolobus variant of the Dicrano-Polytrichetum, a community which for due reasons is very difficult to analyze with the quadrat method (see p. 94).

The percentage of the total cover of the shrub, field and bottom layers was noted. This percentage will make possible an estimate of the percentage of uncovered rock debris in the analyses. In some very humus-rich stands the percentage of cover of the litter (not covered by bryophytes) was noted. A completing of the noted quadrat, with areas outside it replacing dissimilar microcommunities inside it, was thought of but not performed as a general rule. Fragments of alien medium-rank communities (or variants of these) have been avoided when a particular quadrat was laid out. However, some untypical elements were noted outside the analyses, even when they were mainly to be restricted to other medium rank communities (as + in the Survey Table, Table 26). Border communities and mixed stands were avoided except when forming extensive and more or less typical transition seres in some parts of the fine screes (p. 92 below). Anyway these stands were not recorded in the Survey Table. As to the tree layer, the occurrence within the small surface straight above the field and bottom layer analyses was recorded with the same statistical method completed with an estimation of a larger quadrat above a certain stand or an exact mapping of the canopy, for instance above belt transects, see Figs. 30 and 41 .

The degree of cover in the Hult-Sernander-Du Rietz scale is the following (middle of cover class according to Persson 1961 , p. 23, for obtaining the "characteristic degree of cover" in accordance with a method originally proposed by Malmer):

$\begin{array}{llc}\text { Degree of cover } & \begin{array}{l}\text { Covered part of } \\ \text { the quadrat }\end{array} & \begin{array}{c}\text { Middle of } \\ \text { cover class }\end{array} \\ 1 & 1 / 16 & 1 / 32 \\ 2 & 1 / 16-1 / 8 & 3 / 32 \\ 3 & 1 / 8-1 / 4 & 6 / 32 \\ 4 & 1 / 4-1 / 2 & 12 / 32 \\ 5 & 1 / 2-1 & 24 / 32\end{array}$

As in the Survey Table + has been used to designate the presence of a certain species within a stand (or a quadrat, respectively) without noting the exact degree of cover, e.g. all the bottom layer species when their individual degree of cover could not easily be estimated, $s$ has been used to designate the presence of one or more seedlings of a vascular plant species within a quadrat. In bryophytes, fragmentary occurience was not especially noted, but extremely scanty occurrence of very occasional species was omitted in the tables. Nor was vigour or sociability noted in the tables.

All the stands within a certain community were not summarized in the Survey Table. Stands represented by less than 5 analyses were left out, but in these cases the values for frequency and characteristic degree of cover (see be'ow) were given for all the community, to the right in the special tables. Communities completely represented in the Survey Table as values of frequency and characteristic degree of cover for the different stands were not summarized in a right hand column.

The "characteristic degree of cover" was calculated according to the following method: "The degrees of cover are converted into the middles of the classes into which the cover is divided. The middles are added and the sum is divided by the number of squares where the species occurs" (Persson 1961, p. 23). The method used by other investigators (see also Sjörs 1954, p. 35) differs in the division, which is by all squares, not only those where the species is present. In the tables, $F$ designates frequency within the 
quadrats and $c$ (as an exponent, $F^{c}$ ) characteristic degree of cover within the quadrats where the species is present. The method, more fully discussed by Persson (l.c.) makes it possible to study sociability of the species in a concentrated and summarized form.

It has not been found important or even necessary to study all the different plant communities of the hillsides with the same degree of exactness. Thus within the alliance Veronico-Poion glaucae the association Dicrano-Polytrichetum is not considered to have been fully studied in all its range of variation. An approximation for the richer communities of the alliance Veronico-Poion glaucae gives a minimal area ("Minimalraum" in the sense of Braun-Blanquet 1964 , p. 84 ) of ca. $4 \mathrm{~m}^{2}$ when the species-area curve of the small quadrats is summed up. However, as pointed out by Du Rietz (1957, p. 33) the small quadrat method gives certain advantages with regard to the better homogeneity within the sample quadrats. In the present investigation there was an obvious demand for a method giving a high degree of homogeneity of the individual quadrat even when the minimal area based on the constants-area curve (see Du Rietz, l.c.) was not reached.

\section{The vegetation types of the hillsides}

General remarks. Some of the more important communities are briefly commented on in Lundqvist, J. 1961, pp. 154-166. Attention was paid to the fact that the species and the vegetation often constitute zones. There is generally a regular stratification of the screes on mountain-sides in the coniferous belt of PL. Certain of the associations preliminarily distinguished display great similarities with the associations of Nordhagen (cf. above, Nordhagen 1943, p. 546). The equivalent alliance Veronico-Poion glaucae found on screes or on rock walls in PL may be considered a local type containing some of the typical talus species of $\mathrm{N}$ Sweden. The communities studied by Nordhagen (l.c.) were again inspected in the field by the present author (see below). This was considered important for a closer study of the local differences, particularly as the methods used by Nordhagen deviate from those used here. Nor was the bryophyte flora of the communities studied by Nordhagen known in detail.

Although the present study is focused on Veronico-Poion glaucae there occur some other more or less important alliances in hillside localities in PL, most of which display similarities to the subalpine and alpine alliances of the Scandes mentioned above in the Introduction. Pure dwarf shrub communities (e.g. equivalents of Loiseleurieto-Arctostaphylion,

Kalliola 1939, p. 174) are present but they have not been dealt with by the present author. Nor has epilithic or epiphytic vegetation been studied sociologically (with the exception of Dicrano-Polytrichetum, a community with some epilithic variants, see $p$. 94 below).

As exclusive or nearly exclusive species for the alliance Veronico-Poion glaucae in PL, the following species could te considered (cf. also Survey Table, Table 26):

$\begin{array}{ll}\text { Woodsia ilvensis } & \text { Viola Selkirkii } \\ \text { W. alpina } & \text { Myosotis stricta } \\ \text { Poa glauca } & \text { Hackelia def.exa } \\ \text { Arabis hirsuta } & \text { Veronica fruticans } \\ \text { Arabidopsis thaliana } & \text { Crepis tectorum } \\ \text { Turritis glabra } & \end{array}$

Many of them are classed as "Boreo-meridional" (symbols $\mathrm{M}$ and $(\mathrm{M})$ in the previous chapter) thus indicating a rather high degree of thermophily for the present alliance. The content of Boreal species, i.e. species designated with the symbols $\mathrm{B}$ and (B), is rather low as compared with the total flora of flowering plants of the hillsides (see Table 32 p. 106). As stated in the previous paper (Lundqvist, J. 1961) many of the vascular plants comprising the southern element of the flora could only be classed as preferential species for the special association of fine screes of the NW, viz. Nordhagen's Veronico-Poetum glaucae (a close parallel to the association Tortulo-Poetum dealt with here).

Preferential species (cf. Table 26) for the alliance, mostly luxuriating in the association Tortulo-Poetum, are:

\section{Cystopteris fragilis}

Carex ornithopoda

Poa nemoralis

Silene rupestris

Fragaria vesca

Rubus idaeus

These species are often found also in other plant communities in PL, but the plants with southern tendencies among them are preferably found in more elevated sites (with higher nocturnal minima) above the valley bottoms of the NW or in microclimatically favoured sites. However, some of them, especially Carex ornithopoda, Poa nemoralis and Fragaria vesca are also found on the shores of lakes and rivers which are microclimatically favoured sites of valley bottoms, or in the immediate neighbourhood of shores, in sheltered groves etc. This is also true for Anthyllis vulneraria ssp. lapponica immediately out- 
side the region (Anthyllis not mentioned in the lists above, although probably preferential).

A closer study of the lists displays that many of the scree elements found in Veronico-Poion glaucae are hapaxanthic plants (see Tables 16 and 32). Beside the climatic aspects mentioned (p. 66) the deciding factor may be the unstable substrate. The perennial p!ants have powerful root systems adjusted for the growth on stable ground. They seem to have a disadvantage in the competition with some of the more rapidly colonizing hapaxanthic plants. Thus the edaphic conditions and not always the climatic conditions might be decisive. The monocarpic hapaxanthic plants are much more fluctuating in their presence and abundance on screes from one year to the next, as the luxuriance is largely due to the conditions during germination. No great fluctuations are seen among the polycarpic plants, e.g. Arabis hirsuta, Silene rupestris and Fragaria vesca. On the whole the alliance seems to be fairly stable in its general composition from year to year, but the studies in these respects are not completed (see the section on Succession).

Veronico-Poion glaucae in PL may be divided into the following four important associations which are named after some characteristic species present: Poeto-Lactucetum, Tortulo-Poetum, Rhytidietum and Dicrano-Polytrichetum. They all display decidedly different environmental demands and physiognomy. A survey of the different exclusive and differential species, dominants etc. is given in the Survey Table where all the vascular plants and bryophytes present in the vegetation analyses have been summarized (Table 26; vegetation tables behind the text).

\section{Poeto-Lactucetum}

Nordhagen wrote (1936, p. 32): "Im Sikkilsdal tritt sonst eine interessante Vereinsgruppe, aber nur in sonnigen Geröllhalden, auf, wofiir ich den provisorischen Namen 'Chamaenerieto-Poion nemoralisglaucae' geschaffen habe. Dieselbe nähert sich an das 'Aconition septentrionalis'; sie muss aber in Verbindung mit gewissen thermophilen Vereinen niedrigerer Stufen gesehen werden." A plant community which is almost identical with the transition type described from Sikilsdalen is very common on hillsides of NW PL. It has been brought to VeronicoPoion glaucae by the present author to designate its close attachment to the plant communities of other types of thermophile communities on talus slopes of N Sweden. Kalela (1939, p. 226) gives evidence of a similar community of transition type being situated on the Rybachiy Peninsula on sun-exposed screes. The local aspect of this plant community is present on most of those S-facing screes in PL where there is some supply of seepage water from the rock wall or the habitat is shaded (the Gully of Mt. Gaddaberget) and the substrate is not too acid.

In its local aspects, the plant community shows great affinities to the meadow birch forest on tillcovered moist slopes, now called Lactucion, see Nordhagen 1943, p. 313, and Holmen 1965, p. 242. It forms a transition to the association Tortulo-Poetum (as defined here) which has a central position within the Veronico-Poion. Poeto-Lactucetum and Tortulo-Poetum, in similar aspects to the ones studied in PL, were recognized by the present author in Sikilsdalen (see p. 96 where some analyses of the Sikilsdalen aspect of Tortulo-Poetum is presented).

Typical in Poeto-Lactucetum is the presence of some scree elements not found in meadow birch forests. The Boreo-meridional tall species typical for Lactucion, viz. Matteuccia struthiopteris, Dryopteris filix-mas and Actaea spicata are sometimes present in rather high abundance and have high vigour. Other species recognized from the tall-herb meadow forest are Melica nutans, Poa nemoralis, Melandrium rubrum and Chamaenerion angustifolium most of which are still more abundant in Poeto-Lactucetum, although they may be lacking in some segments. As to the bottom layer, one of the most typical plants of Lactucion, Brachythecium reflexum (sometimes replaced by $B$. salebrosum), is also present here in practically all the investigated segments of the community. The litter which is generally abundant may be locally replaced by some mineral debris with very little humus on it. These islets of a deviating substrate may support microcommunities of the bottom layer constituted by occasional elements with preference for non-erratic boulders. Rarely they may be found on litter or residues of tufts fallen down from the cliff. Tufts peeled off by rain and wind from the rock wall may be locally important in Poeto-Lactucetum due to its situation on fine screes in close contact with the rock wall.

Nordhagen (1943, p. 313) proposed the name Mulgedion alpini (or Lactucion alpini) instead of Aconition septentrionalis for the closely related alliance with tall herbs and ferns. As appears from his lists (I.c., p. 327) even in the latter community (at least with the delimitation proposed by Nordhagen) some talus species may occur, provided the segment is favourably exposed, e.g. Arabis hirsuta, Epilobium collinum and Fragaria vesca. The bottom layer was not analysed in all the stands by Nordhagen, and because of this the segments studied by him cannot be completely compared with those from PL. It seems that at least Arabis hirsuta and Poa glauca are ex- 
clusively confined to Veronico-Poion glaucae in talus sites of PL.

The tree layer is mostly very sparse (containing Salix caprea, some Betula, occasionally Sorbus aucuparia or Populus tremula) or completely lacking. The structure greatly resembles some subalpine aspects of Lactucion. A Salix shrub layer of ten present in the subalpine belt is absent or substituted-in some stands-by Rubus idaeus and Rosa majalis as the most important shrubs. This particular type of vegetation overlaps with some types of the Fruticeto-Tortuletum subassociation (see below). A high Geophyte percentage (see Table 32) is not typical and due (in this case) to the occurrence of some forest Geophytes, of which Trientalis europaea may even be classed as a Hemicryptophyte.

A high water level (cf. Holmen 1965, p. 245) is non-existent in Poeto-Lactucetum, but the moisture conditions of the substrate are still quite favourable because of a regular supply of seepage water from the nearby cliff. The reaction of the substrate (e.g. soil samples nos. $2,38,42-44$, Table 1) is generally more acid and the content of calcium lower than in related drier meadow communities of the hillsides. The soil conditions are probably best illustrated by the changes along a belt transect with Poeto-Lactucetum and Tortulo-Poetum communities, Table 2 B and Fig. 9.

Quadrat size: $1 / 4 \mathrm{~m}^{2}$. Table 18 .

I. Mt. E Ramanpakte (no. 2), the S-facing scree immediately below the rock wall, ca. $620 \mathrm{~m}$. Dip ca. $20^{\circ}$ towards the SE. Soil sample no. 2, Table 1; water sample no. 2, Table 14. 30 July, 1963.

There are no trees in the over-storey where the analyses were performed, and even on the rest of the fine scree of the hillside there is a sparse cover of trees (foremost Betula pubescens). The cover of the field and bottom layers varies very little (90-95\%). The segment forms a ca. $2 \mathrm{~m}$ broad and $20 \mathrm{~m}$ long strip near the rock wall, which is wetted by seepage water. The occurrences of Cerastium alpinum, Campylium sommerfeltii, Distichium capillaceum and Myurella julacea are at the rim of the stand. The litter production is abundant, but there are some pebbles reaching above it.

II. Mt. Märkepakte (no. 12), the S-facing scree immediately below the rock wall, ca. $470 \mathrm{~m}$. Dip ca. $25^{\circ}$ towards the $\mathrm{S}$. Water sample no. 5, Table 14.

There are trees of Salix caprea at the lower rim of the stand, which together with some smaller birches produce shade during the afternoon. The cover varies between 70 and $95 \%$. The total area covered by the stand is ca. $2 \times 10$ $\mathrm{m}$. On the rims are stands with Vaccinium myrtillus. The ssrub zone below the Poeto-Lactucetu:n comr.unity is cxtensive, with Juniperus, Ribes spicatum ssp. lapponicum, Prunus padus, colonizing far into the boulder scree. The cliff is wetted with sparse seepage water.

III. Mt. Lulep Istjakk (no. 18), the S-facing scree immeciately below the rock wall near the belt transest (see p. 99), ca. $560 \mathrm{~m}$. Dip ca. $35^{\circ}$ towards the S. Soil camples, see Table 2 B. Water sample no. 6, Table 14. 12 August, 1965.
The vegetation around the belt transect on Mt. Lulep Istjakk is discussed in detail pp. 99 et szq.

IV. Mt. Fiskträskberget (no. 27), the S-facing scree below the rock wall, ca. $535 \mathrm{~m}$. Dip ca. $30^{\circ}$ towards the S. 6 August, 1963.

There are some trees of Salix caprea (coaetanea) in the tree layer, which is sparse. The greater parts of the slope are occupied by Picea wood, which is not very dense on account of the larger boulders. The community is situated just below a small transient trickle of seepage water on the rock wall, and vanishes rather abruptly towards the coarse scree with uncovered boulders. Cover of the field layer 85$100 \%$, area covered by the stand ca. $15 \mathrm{~m}^{2}$.

V. Mt. Harrejaurliden (no. 28), the SW-facing scree immediately below an (elevated) section of the rock wall, ca. $570 \mathrm{~m}$. Dip ca. $30^{\circ}$ towards the S. Soil sample no. 38, Table 1. 18 August, 1964.

There are no trees or shrubs in the stand but a fairly large Picea abies and some smaller Betulae and Salix caprea on the rims. Lower down on the scree there is a Picea wood of Gymnocarpium type, with Pyrola media and Convallaria. The Picea wood gives sufficient shade for the community. The water supply is very sparse. The field layer is totally covering. The extension of the stand is ca. $6 \times 13 \mathrm{~m}$.

As in the other studied segments of the community there are no or very occasional occurrences of lichens. In this case there was a fragment of Peltigera sp. in one of the quadrats.

VI. Mt. Gaddaberget (no. 31), the S-facing (but shaded) scree in the Gully (see p. 127), ca. $410 \mathrm{~m}$. Din ca. $30^{\circ}$ towards the SE. Soil samples nos. 42-44, Table 1. 5 August, 1963.

There are no trees in the Gully, but the decidedly shady character is due to the relatively narrow opening of the niche (ca. $5 \mathrm{~m}$ ) and the dark colour of the rock walls. The deep mull layer is occasionally broken by crests of boulders protruding or covered with less deep humus. Fragments of mosses which had fallen down from the rock wall were seen (Abietinella abietina, Hedwigia ciliata and Pterigynandrum filiforme). The total extension of the stand which is totally covering is ca. $3 \times 15 \mathrm{~m}$.

Outside the Gully the vegetation completely alters its character to Pinus wood of Vaccinium type with few herbs (see p. 126).

\section{Tortulo-Poetum}

This community is the most important one in those upper woods that are situated below cliffs in exposures around $\mathrm{S}$, provided the vegetation is fully exposed to the sun, the soil reaction is subcircumneutral to slightly acid and the leaching processes are counteracted to some extent, at least near the surface, due to a continuous supply of fresh mineral debris from the cliff. The content of acid-soluble calcium (as measured in the total soil sample) may be low (ca. $0.2 \%$ ) in almost pure mineral soil, but in these cases the rock will also release a certain amount of other nutrients, which is the case in easily weathered rocks. The community obviously does not receive any considerable delivery of water from the cliff. In the immediate neighbourhood of crevices with an abundant supply of water the community changes into a Poeto- 
Fig. 37. Extremely luxuriant type of Populeto-Tortuletum community on the S-facing side of Mt. Lulep Istjakk, no. 18. Dryopteris filix-mas in the field layer and Populus tremula (with epiphytic Orthotrichum pallens) in the tree layer. 12 August, 1965.

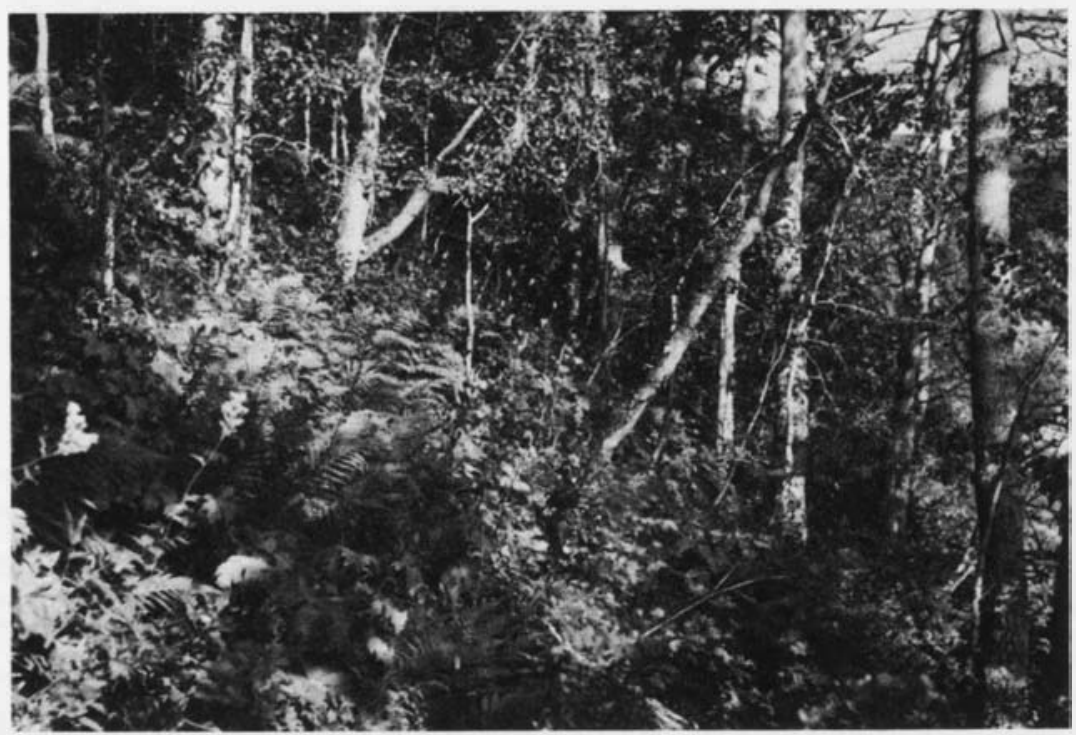

Lactucetum. Where on the other hand drying out is more effective a transition into Vaccinium heaths take place (especially the parts of the scree where the snow thaws early in spring; see below and Table 22).

The subdivision proposed here is based on the two subassociations Populeto-Tortuletum and FruticetoTortuletum, the last one with a Rubus idaeus variant and a Juniperus communis variant.

Populeto-Tortuletum. This community forms a transition between the previously discussed PoetoLactucetum and the Fruticeto-Tortuletum community. As trees of Populus tremula are always quite abundant in the stands on not too unstable substrate, the delimination towards the other communities is always easily done. In the field and bottom layers the differences might be less evident. Tall plants which show a preference for Poeto-Lactucetum may still be present, for instance the tall grasses Calamagrostis purpurea and Milium effusum, and the fern and herbs Dryopteris filix-mas, Aconitum septentrionale and Melandrium rubrum.

However the field layer shows a definitely more open type of vegetation than Poeto-Lactucetum. Viola montana, Geranium silvaticum, Rubus saxatilis and Solidago virgaurea are the only plants that display any greater abundance. As differential species towards Poeto-Lactucetum (see Survey Table, Table 26) may be considered for instance Veronica fruticans, Carex ornithopoda, Saxifraga adscendens, Sedum annuum and Tortula ruralis which mostly demand an open substrate or are sensitive to competition. In more closed stands of Populus tremula these plants vanish or become very rare. But when the light conditions are more favourable, there is a transition into photophilous (and thermophilous) types which show resemblances to the Fruticetc-Tortuletum subassociation discussed below. The higher Therophyte percentage (when even true biennial plants are classed as Therophytes, see p. 68) is a relevant feature of the field layer (Table 32 p. 106).

Schistidium apocarpum is one of the most undemanding of the plants present in the subassociation. It has a fairly wide ecological range and is in certain sites the only plant that can stand a strongly sunexposed and poor ground depleted of minerals. Another reason for its doing well in these meadows may be found in the fact that the plant cover is of ten broken by larger debris (pebbles, cobbles) with no litter on it, and there are good light conditions with oscasional sun-spots (Fig. $14 b$ ) even with full foliation of the aspen trees. The upper stone-airlayer (p. 24) may thus be rather deep, also a reason why large trees do well. Beside Schistidium apocarpum, which is rather sporadic in Populeto-Tortuletum, only Lescuraea radicosa, Pseudoleskeella nervosa and Brachythecium reflexum sometimes find gcod habitats in the bottom layer. However, there are no constants among the mosses except perhaps Tortula ruralis (in some stands), and hepatics as well as lichens are very rare (the epiphytic flora was not considered).

The number of plants in the analyses $\left(1 / 4 \mathrm{~m}^{2}\right)$ is somewhat less in this community $(15 \pm 4)$ as compared with Fruticeto-Tortuletum $(18 \pm 6)$, a rather insignificant difference. At least the thermophilous elements of the flora (see above p. 82) are chiefly found in Fruticeto-Tortuletum. In Populeto-Tortu- 
letum, only Arabis hirsuta could be classed as strictly thermophilous.

Nothing is known about the distribution and composition of the community in other parts of Eurasia, and the distribution and ecology of Populus tremula and Tortula ruralis could only give some indications. It seems that Populus tremula has a preference for certain successional stages in S-facing localities of similar appearance even in the inner parts of Asia (T. Arnborg 1961, personal communication; as to the ecology in Hercynia, see Drude 1902, p. 118). Tortula ruralis is widely distributed in Holarctic regions in similar habitats (cf. Malmström 1934, p. 121). Especially in the $S$, it appears in all kinds of habitats.

The soil conditions of Populeto-Tortuletum (cf. Lundqvist, J. 1961, pp. 156-57) may be illustrated, on the loss-on-ignition basis, by soil samples nos. 2829, Table 1. They show a mull soil profile typical for Populus stands in similar sites, a slightly acid litter and a moderate calcium content in the humus. In comparison with Poeto-Lactucetum the reaction of the substrate is less acid, and the content of calcium is higher. See also the soil conditions of belt transect Table $2 \mathrm{~A}$.

Quadrat size: $1 / 4 \mathrm{~m}^{2}$. Table 19.

I. Mt. Lulep Istjakk (no. 18), the S-facing scree, ca. 540 m. Dip ca. $30^{\circ}$ towards the S. 26 July, 1966.

The plant community is characterized by almost totally covered rock debris and very abundant production of litter. The stand is in this particular place much shaded by tall (ca. $15 \mathrm{~m}$ ) aspen trees and birches, the latter quite unimportant. Degree of cover of field and bottom layers ca. $90-100 \%$. The hillside is covered by the plant community for a long stretch (see Lundqvist 1961, Pl. II, and this paper, Fig. 37). No or very little supply of seepage water from the cliff.

II. Mt. Märkepakte (no. 12), the S-facing side below the rock wall, ca. $475 \mathrm{~m}$. Dip ca. $30^{\circ}$ towards the S. 29 June, 1961.

The field and bottom layers were not completely covering in all the quadrats (cover $70-100^{\circ}$ ) although they were almost fully developed, in spite of the early phase of the vegetation period. In some parts the scree is rather loose and there are quite a lot of pebbles and small boulders. Euphrasia frigida, which occurs abundantly on the mountain-side, shows a preference for this particular community. There is no seepage water on the rock wall.

1II. Mt. Märkepakte (no. 12), the S-facing side below the rock wall, ca. $475 \mathrm{~m}$. Dip ca. $30^{\circ}$ towards the S. For soil conditions, see quadrat no. 6 Table 2 A. 27 June, 1961.

The field and bottom layers are thin and the height of the field layer also less than in the previous cases, ca. $20 \mathrm{~cm}$. The tree layer is more open. The substrate consists of fine mineral debris and is quite loose. No seepage water.

Fruticeto-Tortuletum. Rubus idaeus variant. In the zonation generally found on simple talus slopes of PL, i.e. talus slopes where the talus cone forma- tion is not particularly expressed (see above p. 18), this community (from Latin fruticetum $=$ shrub or thicket) is present as a typical fringe community at the outermost edge of the Populus stands towards the open scree. The Rubus idaeus variant is partly replaced by the Juniperus variant, and the ecological conditions for the two variants seem to be almost identical, at least the primary conditions in the colonizing stage. On some talus slopes Fruticeto-Tortuletum, especially the Juniperus variant, is almost the only community present instead of Populeto-Tortuletum (e.g. Mt. Akkapakte, no. 1). The presence of tree stands is thus not necessary, but probably in some cases favourable for the development of a special fringe community.

The most obvious differential species towards Populeto-Tortuletum are some very photophilous plants such as Potentilla argentea, Polygonum dumetorum, Arabidopsis thaliana, Myosotis stricta and Turritis glabra. All these plants are classed as thermophilous plants in this paper. The field layer does not seem to differ much in general structure in most localities, and Aconitum septentrionale, Anthriscus silvestris, Geranium silvaticum, Valeriana sambucifolia etc. still reach fairly high cover classes. Bryum spp. (B. capillare, B. pallescens and B. cirrhatum) and Tortula ruralis are abundant in the bottom layer. A case where Poeto-Lactucetum is bordered by Fruticeto-Tortuletum towards the open scree is shown on p. 99 (belt transect on Mt. Lulep Istjakk).

The hapaxanthic plants show high vigour in this community (cf. on the other hand the Therophytes as defined here, Table 32, which have a fairly low percentage, especially in segments with looser substrate). The prevailing types of more stable substrate generally found in the transition zone to the open boulder scree make the Hemicryptophyte percentage rather high.

A comparison with a talus cone with no trees might be of interest (Fig. 43) as this shows a zonation not found on compound talus slopes, consisting of several talus cones, or on simple talus slopes (cf. above). See the section on Succession below.

The soil conditions show generally higher $\mathrm{pH}$ and Ca content than at the corresponding depths of the Populeto-Tortuletum or the Poeto-Lactucetum profiles. Especially where Fruticeto-Tortuletum is in immediate contact with the above communities there is an obvious increase in these values.

Quadrat size: $1 / 4 \mathrm{~m}^{2}$. Table 20 .

I. Mt. Ardnapakte (no. 5), the SE-facing side, ca. $540 \mathrm{~m}$. Dip 20-30 towards the SE. 4 September, 1962.

There are no trees in the stand, but birches and aspen trees grow in the immediate neighbourhood. The cover varies 
Fig. 38. Mt. Lulep Istjakk, the S-facing side. Very large boulders in the central parts of the scree. In contrast to this is the luxuriant upper wood below the cliff (Fig. 37). 12 August, 1965.

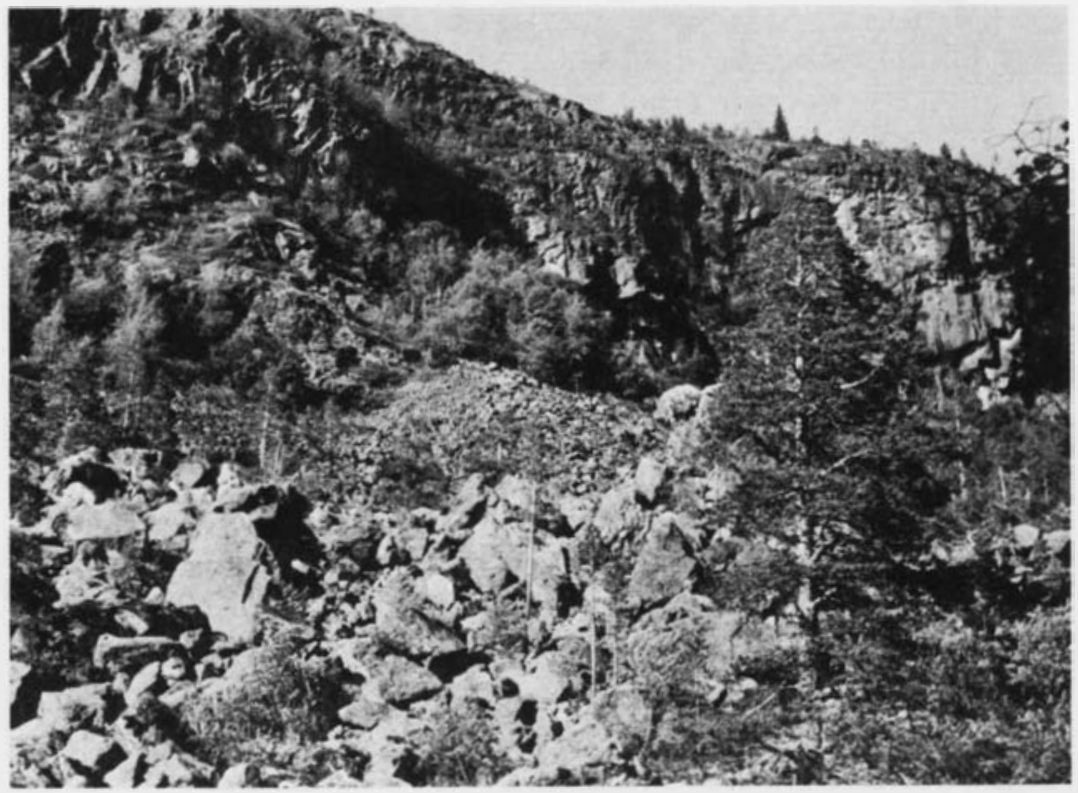

between $70-100 \%$ for the shrub and field layers. It is generally a tall community with abundant Valeriana sambucifolia and Anthriscus silvestris. The litter supply is abundant, but small boulders and pebbles break the litter cover in places. There is no seepage water on the rock wall, but the drying out due to sun exposure is not very pronounced.

II. Mt. Aistjakk (no. $16 a$ ), the SW-facing scree immediately below the rock wall, ca. $550 \mathrm{~m}$. Dip ca. $35^{\circ}$ towards the SW. Soil samples nos. 21-23, Table 1. Seepage water, see p. 62.4 July, 1962

No trees, the cover of shrub and field layers $70-95 \%$. Tall community, just influenced by grazing and tramping by reindeer. On a spot where there is presumably sometimes drip from the rock wall grows Mnium cuspidatum. The presence of Achillea millefolium (not in the analyses) indicates a possible influence of domestic animals. The seepage water is ephemeral.

III. Mt. Aistjakk (no. 16a). The same stand as the preceding one, but belt transect from the rock wall towards the open scree. 15 August, 1961.

IV. Mt. Ardnapakte (no. 5), the S-facing side, ca. $540 \mathrm{~m}$. Dip $25-30^{\circ}$ towards the S. Sparse seepage water. 4 September, 1962.

The stand has a sparse and low shrub and field layer, in some places (cover ca. $70 \%$ ), but the bottom layer (with Tortula ruralis) is more conspicuous. The talus slope is in certain places very loose and unstable, and in these places only fragments of vegetation occur. In the studied stand the substrate is somewhat more stable.

It seems that the two variants of the FruticetoTortuletum subassociation are widely distributed within the Caledonian area and the nearby situated area of the Skärfa-series with calcareous rocks. On more unfavourable Archaean rocks they suddenly vanish as do all the Tortulo-Poetum and Rhytidietum associations. See the preferential species for these associations, Tables 16 and 17.
Fruticeto-Tortuletum, Juniperus communis variant. The Juniperus scrubs generally found at the outer fringe of aspen woods on fine screes, or below rock walls where there is no closed tree layer present (e.g. Mt. Akkapakte, no. 1), are to be placed within the Tortulo-Poetum community. These scrubs have many plants in common with the Rubus idaeus variant, especially when the scrubs are not closed enough to prevent the entry of some herbs, e.g. Chamaenerion angustifolium, Hackelia deflexa etc. (see Table 21). The Brachythecium, Eurhynchium pulchellum and Pylaisia polyantha carpets colonizing partly as epiphytes are always typical for the stands, which, for obvious reasons, are generally of small extent. In these stands lichens, partly as epiphytes, may be abundant, especially Parmelia, Cladonia and Cetraria species.

Although there may be species in common with the Rubus idaeus variant, the general composition of the flora is extremely different (Table 32), the community displaying continental trends in contrast to the Rubus idaeus variant, which is largely of oceanic trend. However, the Therophyte percentage is rather high in the Juniperus variant, at least it appears so from the sparse material of analyses.

Juniper scrubs of this kind are very common on exposures around S (cf. Resvoll-Holmsen, H. 1920, p. 63; Nordhagen 1943, p. 558). These scrubs may be compared with similar scrubs of the Dicrano-Polytrichetum association which have other types of field and bottom layers and generally are less demanding with regard to microclimate and substrate. The juniper shrub has a very wide ecological range 
and may not be said to be favoured by some special factor. Seedlings of Juniperus are present in most of the communities on steep hillsides. On the other hand, this special Tortulo-Poetum community has very special demands and seems to be most favoured in a zone of stable scree at the outer edge of fine screes below the rock wall where there is very early melting of the snow, good light and thermal conditions and still fairly good conditions of the substrate. There are microclimatic conditions developing within very closed stands of juniper, partly due to interception of rain, partly to changed temperature and light conditions for the bottom layer. The piling up of acid juniper litter (Table $2 \mathrm{~A}$, point $d$; cf. Fig. 40) obviously gives a good substrate for the development of the Rhytidietum community, one of the reasons why the juniper scrub zone is often followed by a fringe of Rhytidietum further down on the slope.

Quadrat size: $1 / 4 \mathrm{~m}^{2}$. Table 21 .

I. Mt. Långsjöberget, hill immediately W of Mt. Storberget, no. 13, the S-facing side, ca. $550 \mathrm{~m}$. Dip ca. $35^{\circ}$ towards the S. 14 September, 1962.

The scrub is somewhat more open, and herbs are present. Eurhynchium pulchellum was replaced completely by Brachythecium salebrosum. In comparison with other S-facing screes of the Caledonian area of PL the scrubs do not form a regular zone but are rather irregularly spread on the hillside, as well as the tree stands.

II. Mt. Märkepakte. the S-facing side, ca. $475 \mathrm{~m}$. Dip ca. $25^{\circ}$ towards the S. 13 September, 1962.

This is a very thick scrub (Fig. 39) allowing almost no vascular plants to occur in the stand. The bottom layer is on the other hand very similar to that of the previous stand, but in addition Eurhynchium pulchellum and Schistidium apocarpum are present.

\section{Stands with Vaccinium vitis-idaea or other} dwarf shrubs

Mixed stands with Vaccinium vitis-idaea or other forest dwarf shrubs intermingled with Tortulo-Poetum communities are often seen on the talus slopes of the NW. They are seen on a fairly wide variety of differently stabilized substrates, such as rock walls, proximal or distal parts of screes, but nearly always in close contact with ordinary forest communities at the edges of the hillsides with screes. The factors favourable for the development of these mixed stands may be the rather deep subterranean runners (Leach 1930 , p. 330) and an early thawing of the snow in spring (see above), especially in front of the rock walls with maximum exposure. Such places are nearly always exposed to very extreme microclimatic conditions in the early spring with high irradiation by day but fairly low nocturnal minima, i.e. conditions with wide temperature fluctuations within short intervals. Most often Vaccinium vitis-idaea is seen as the first and only heath element invading screes, but in other cases other typical forest or heath plants may join the communities, especially on more stabilized sections. The substrate conditions are nearly always almost identical with those in ordinary Tortulo-Poetum stands (see point $a$, Table $2 \mathrm{~A}$ ), except, in general, for a greater content of the coarser fractions, especially pebbles and small boulders. The presence of Bryum spp., Tortula ruralis, typically colonizing on the finer fractions, show a rather high content of finer mineral fractions.

The factors for development of stands with Arctostaphylos uva-ursi as dominant may be nearly identical with the conditions described above, but generally Arctostaphylos uva-ursi (having no subterranean runners) prefers more stabilized parts of screes, or the rock walls. The composition and physiognomy of the stands is on the other hand entirely different, as is also the case with stands with Calluna vulgaris (see Table 25, stand no. II). Stands with Vaccinium myrtillus are more common on other exposures than near $S$ but may join in from the sides on certain screes, even when the exposure is around $\mathrm{S}$. This is the case especially where Vaccinium myrtillus is dominant in the surrounding forest and the snow thaw is not too early.

In unfavourable exposures heath forest communities are nearly totally covering (e.g. Mt. Aistjakk, the NE-facing slope). The substrate conditions here display a high degree of leaching and thus a low content of nutrients in the soil (see soil samples nos. 24-27, Table 1).

\section{Quadrat size: $1 / 4 \mathrm{~m}^{2}$. Table 22 .}

I. Mt. Märkepakte, the S-facing side below the rock wall (situation, see Fig. 43), ca. $475 \mathrm{~m}$. Dip ca. $39^{\circ}$ towards the S. 3 July, 1961.

There is of course no seepage water on the rock wall. The over-storey is sparse (Populus tremula, near to belt transect p. 98), and there are occasionally some Juniperus shrubs in immediate contact with the rock wall. Except for Vaccinium vitis-idaea, itself, the field and bottom layers are almost identical with the common Tortulo-Poetum. The cover is low, ca. $50-70 \%$. As to the soil conditions, see point $a$, Table $2 \mathrm{~A}$.

II. Mt. Laisvare, the upper talus slope (no. $9 a$ ) on the SW-facing side, ca. $570 \mathrm{~m}$. Dip ca. $35^{\circ}$ towards the SW. 21 August, 1964.

In contrast to the previous stand this one lacks a tree cover, but the field and bottom layers are nevertheless nearly identical. More shaded types are present at about the same elevation, but in these there is more litter and some tall herbs, e.g. Anthriscus silvestris, Aconitum septentrionale, Valeriana sambucifolia, and also some forest plants, e.g. $R a$ mischia secunda and Luzula pilosa. In the open sites with Vaccinium vitis-idaea also Melandrium rubrum, Erysimum hieraciifolium, Deschampsia flexuosa and Melampyrum silvaticum are met with. Small shrubs are present, as e.g. Sorbus aucuparia, Rubus idaeus and Daphne mezereum. The 
cover of the field and bottom layers is only $50-60 \%$, occasionally $70 \%$. The substrate contains a fairly large percentage of pebbles which are almost stabilized.

\section{Rhytidietum}

This community is clearly delimitated from the Tortulo-Poetum community. Certainly there are many transition types between these two communities as well at between other plant communities on S-facing hillsides, but the qualitative and quantitative composition is generally fairly obviously separated from other types of communities. For these reasons the community was considered a separate association. As will be shown, Rhytidietum has other habitat demands than the previously treated communities. Some closely related types of communities have been described in the literature e.g. by Nordhagen 1928, 1943, and in other papers, Du Rietz 1942, Hedberg 1947, 1952, Mårtensson 1956, Bringer 1961. These authors describe a Dryas heath (Dryadion) in which Rhytidium rugosum (and Abietinella abietina) are partly dominant. This is especially true in the Tetragono-Dryadetum hylocomietosum according to Bringer. As is seen from analyses in similar sites in Sikilsdalen (Table 27, stand no. II) there are close resemblances or probably transitory types existing between the Rhytidietum described here and the Dryas heath.

Rhytidietum is an extremely xerophilous community. On the talus slopes of PI it grows on stable scree with maximum exposure and drying out. A high percentage of trees (Table 32) is insignificant as the stands are generally open towards the $\mathrm{S}$, thus allowing maximum drying out during the middle of the day. The community is also fairly common on the ledges of the rock wall when they are exposed to the sun. On screes it is most common in a centrally situated zone below or on the fringe of fine screes. It may probably in these cases be regarded as a transition type between the meadow series of the upper wood on fine screes and the heath series in the lower wood on boulder screes, but differs from both in its great demand for insolation of the bottom layer. A Hylocomium facies (not especially studied here, cf. analyses nos. 9 and 12, p. 163 in Lundqvist J. 1961) is present on some talus slopes and may come in close contact with the lower woods on boulder screes. Here transition types are seen towards synusiae of the mixed coniferous forest (with birch).

Apart from the authors mentioned above, many scientists have investigated the ecology of Rhytidium rugosum, above all Herzog 1926, Herzog \& Höfler 1944, Albertsson 1940, and in other papers. Hall- berg (1959, p. 55) demonstrated a close connection between a Rhytidium rugosum community on the West Coast of Sweden and the Camptothecium federation on open sun-exposed dry meadows in Central Sweden (v. Krusenstjerna 1945, p. 118).

Rhytidium in all its distributional area seems to prefer almost identical habitat factors: sun-exposed, thermophilous dry meadows on calcareous ground (or on gypsum, see Braun-Blanquet 1964, p. 370) of ten on the S-facing side of woods or walls etc. (cf. v. Krusenstjerna 1954 p. 30). In NW PL (the NW coniferous woodland area) Rhytidietum is mainly a fringe community of the scrub zone towards the open boulder scree.

The floristic composition shows (Table 32) that the Boreal percentage is quite low, in these respects differing from the Dryas heath. The vascular plants occurring in Rhytidietum in most cases only have preference for this special community, whereas some bryophytes are good differential species. The best differential species, in most cases also dominant, is Rhytidium itself. Abietinella abietina, Pseudoleskeella tectorum and Encalypta ciliata display a high degree of fidelity. Cladonia and Peltigera species are also fairly abundant, in contrast to their scarcity in Tortulo-Poetum. The cover of the field layer is mostly very low. The more prominent bottom layer almost completely covers the boulders or the ledges of the rock wall with a generally deep mull layer underneath (cf. below). However, largely epilithic fragments of this community may grow on some boulders (belt transect, p. 100) having an area of only some few cm².

The most common among the Cladonia species are Cladonia silvatica, $C$. pyxidata, $C$. gracilis, $C$. coenotea etc. (confirm. Du Rietz).

The substrate has the characteristics depicted on Table $2 \mathrm{~A}$ (the belt transect on Mt. Märkepakte). Because of accumulation of juniper litter in this case $\mathrm{pH}$ is not very high $(6.0-6.3)$ and the calcium content (in the humus) quite low at the surface as compared with the conditions in the Populeto-Tortuletum. The mull soil layer may be rather deep; in this case there was still $28.4 \%$ loss on ignition at $30 \mathrm{~cm}$ depth, a remarkably high value in comparison with the Populeto-Tortuletum higher up on the talus slope. The cover of the field and bottom layers (cf. below) shows that there is a low percentage of uncovered larger debris on which Rhytidietum only very slowly colonizes.

\section{Quadrat size: $1 / 4 \mathrm{~m}^{2}$. Table 23 .}

I. Mt. Märkepakte, the S-facing scree, ca. $475 \mathrm{~m}$. Dip $20-30^{\circ}$ towards the S. 2 July, 1962. 
The stand growi on debris (small boulders, pebbles) at $5-10 \mathrm{~m}$ from the steep rock wall. The cover varies between 60 and $90 \%$. There is some ssepage water on the rosk wall, as the stand is situated below the stand of Poeto-Lactucetum described (see above). This is apparenty of minor importance at this distance from the rock wall. Holes in the very thick cover of Rhytidium rugosum and Abietinella abietina with somewhat looser substrate are favourable for the other bryophytes (Radula complanata mostly on the sides of boulders).

II. Mt. Långsjöberget (hill immediately W of Mt. Storberget, no. 13), the S-facing side, ca. $550 \mathrm{~m}$. Dip ca. $35^{\circ}$ towards the S. 14 September, 1962.

The vegetation is almost identical with the previous stand, the substrate being scree. The cover is $70-80 \%$ in the two quadrats analysed.

I11. Mt. Aistjakk, the SW-facing side, ca. $555 \mathrm{~m}$. Ledges on the rock wall with dips ca. $20-30^{\circ}$ towards the $\mathrm{S}$ and SW. 4 July, 1962, and 20 August, 1963.

The cover is $90-100 \%$. The segments of Rhytidietum being situated on the rock wall, such species are present as Luzula spicata, Saxifraga nivalis, Encalypta ciliata and Mnium orthorrhynchum. On the edges of the ledges are often tufts of micro-communities otherwise mostly found in crevices, or on other parts of the rock wall. The field layer is generally sparser than in the corresponding community on scree, and there is less fine soil.

IV. Mt. Ardnapakte, the S-facing side, on scree, immediately in front of the rock wall. Dip ca. $20^{\circ}$ towards the SW. 4 September, 1962.

The fragmentary occurrence of the community on this hillside did not permit a large number of analyses by the usual method, but the conformity with the analyses from other hillsides was good. Grimmia ovalis, present here, is quite rare, mostly colonizing not too calcareous boulders and rock walls. The bordering communities, here as well as on the other hillsides, are mostly Tortulo-Poetum subassociations and variants.

\section{Dicrano-Polytrichetum}

Sphenolobus variant. In the lower wood, situated on the distal part of the boulder scree on the talus slopes facing $S$, there are plant communities that in their composition approach pure forest synusiae, such as were described e.g. by Arnborg (1943, 1945, etc.) and Malmström (1949). These parts of the screes are the most stable ones, and fine soil material is found only at quite great depths (p. 24). Mixed coniferous forest with birch is the most usual type of forest below screes. There the litter production may locally be fairly abundant, allowing a kind of humus similar to mull to develop between the boulders (see, e.g., Lundqvist, J. 1961, pp. 164, 169, Fig. $4 b$; cf. Lye $1967 a$, p. 299) and in which decaying parts of mosses play a great role. There may be an appreciable admixture with such species of bryophytes and lichens as are normally more typical of open stands and boulders on which they succeed each other at different stages of development (cf. Lye, l.c.). The bryophytes which are al- most exclusive for the community when developed among boulders are in these sites Rhacomitrium spp., Grimmia ovalis and Andraea rupestris. Mainly these bryophytes form epilithic synusiae on top of the boulders, succeeded by synusiae with Chandonanthus setiformis and Sphenolobus saxicolus. They are characteristic species for the community, here designated variant, called the Sphenolobus variant. Dicranum fuscescens, Hylocomium splendens and other forest bryophytes are very abundant in most stands with an ample supply of litter from trees. In more exposed sites the association may change into a Rhytidietum or may show affinities with the closely related Cladonia variant. There are many transition types comprising different successional stages between the two variants as described here.

Nordhagen (1943, p. 562) described a closely related type on boulder scree in Sikilsdalen (also studied by the present author during the visits to Sikilsdalen, cf. below). A shrub layer is often lacking, and therefore this community (or communities, if including the Cladonia variant) should not be named after any occasional shrub present. In certain stands, however, shrubs are common, in PL above all Betula pubescens, Juniperus communis, Prunus padus, Ribes spicatum var. lapponicum, Rubus idaeus and Sorbus aucuparia, occasionally also Salix caprea. On screes with very large boulders the community mostly has a fragmentary character and is reduced to a onelayer community. This made it necessary to characterize it on the basis of the most obvious bryophytes, although a closer study of the different synusiae and succession stages of the bottom layer was not performed.

In PL, the community is most common on talus slopes of unfavourable exposure (e.g. the NE-facing side of Mt. Aistjakk) or, in the SE, also on screes (in some cases ledges) which are not so deeply shaded in the parts under consideration.

The truly epilithic communities that grow in contact with this particular variant are dominated above all by lichens, such as Cladonia silvatica, $C$. rangiferina, $C$. uncialis, $C$. cornuta, $C$. pyxidata and Stereocaulon paschale. Most of these species are also found in the Cladonia variant where lichens are abundant.

As stated above the litter production may constitute the most important gradient within the association and its variants, as certain fragments are definitely epilithic, others on the other hand growing on very deep humus layers. $\mathrm{pH}$ is generally low and the $\mathrm{Ca}$ content in the humus is about the lowest reported for screes (see soil samples nos. 6, 7, 10 Table 1). 
Quadrat size: $1 / 4 \mathrm{~m}^{2}$. Table 24 .

I. Mt. Märkepakte, the S-facing side, the lowermost part of the scree, ca. $465 \mathrm{~m}$. Dip. $10-20^{\circ}$ towards the S. 5 July, 1962.

The often co-dominant Chandonanthus setiformis and Sphenolobus saxicolus are the most obvious species in this site. The vegetation of vascular plants is very sparse and poor in species. The boulders are here about $0.5 \mathrm{~m}$ in diameter, the cover $50-100 \%$. Only very rarely does rock debris fall down to this level of the scree, and then always of the size of boulders. A shrub layer is very sparse or totally absent. Due to the forest below the scree (mixed pine forest with birch), the situation is shady.

II. Mt. Ardnapakte, the S-facing side, the lowermost part of the scree, ca. $490 \mathrm{~m}$. Dip 0-20 towards the S. 4-6 September, 1962.

The boulder scree consists of very large boulders, allowing no dwarf shrubs to establish. The cover varies between 70 and $90 \%$. The general aspect is much the same as on Mt. Märkepakte, but Chandonanthus and Sphenolobus are here quite sparse.

Cladonia variant. This community is of ten seen on talus slopes on more acid substrate, and is for this reason more common outside the Caledonian area. The community does not occur on very calcareous substrate. At least as far as PL is concerned, it is frequent in favourable exposures, where at least some southern elements are present. On Mt. Gaddaberget (no. 31) the community is the only one that shows an abundance in southern plants, some of them distinctly thermophilous. But not all southern or thermophilous plants can grow in this extremely acid environment, some plants being absent that would probably otherwise have grown here. Interrelations between the climatic and the edaphic factors normally determine the constitution of the community, but in this case the non-calcareous substrate may be limiting and not the climatic factors. The local climate is certainly warmer than in the other sites, but nevertheless the vegetation is poor.

Of the species present the majority have small demands on the substrate, but due to the fairly rich lichen flora, the total number of species may be high, at least as high as in the previously treated communities. The number of bryophytes is also high, Polytrichum and Pogonatum species being characteristic and constantly present. In spite of the high number of species, the general appearance of a lichen-rich type poor in vascular plants indicates an undemanding community approaching certain synusiae in heath-forests.

The Cladonia variant obviously requires a stable substrate of similar appearance as the Sphenolobus variant, often occupying the upper surfaces of boulders. Also finer screes are sometimes occupied by the community (as, e.g., the upper talus slope on Mt.
Laisvare). It is favoured also by frequent drying-out and strong irradiation, and because of these circumstances it is often seen on the central parts of screes or on the ledges of the rock wall. When the bedrock is an acid type of mylonite, the community may settle on top of large boulders, or it may occur in an environment where the leaching of the substrate is appreciable. It is a xerophilous community, and is usually clearly delimited from the other communities of the Veronico-Poion alliance. In most cases the humus layer (here designated "forest mull") is thin, in some cases almost absent, giving the community an epilithic appearance (cf. above about the Sphenolobus variant). Dwarf shrubs may invade in transition zones towards the forest-heath communitics. The community is certainly more variable than is evident from the material reported on here.

See soil samples nos. 36,37 and 41 , Table 1 .

Quadrat size: $1 / 4 \mathrm{~m}^{2}$. Table 25 .

I. Mt. Laisvare, the upper talus slope (no. $9 a$ ) on the SWfacing side, ca. $590 \mathrm{~m}$. Dip ca. $35^{\circ}$ towards the SW. 27 July, 1963.

No seepage water is present on the rock wali. There is no tree layer and shrubs are sparse. The same type of community is present on some of the ledges of the rock wall. The stand, which has a fragmentary character, grades into Tortulo-Poetum types on rather fine scree immediately below the rock wall. Tortulo-Poetum communities leading over to poorer types of dwarf shrub and similar communities are fairly abundant on this scree (see above p. 92). On the other hand tall-growing communities are also present but are mostly of small extension. Erigeron politum is present also in TortuloPoetum, the Fruticeto-Tortuletum subassociation (see belt transect on Mt. Lulep Istjakk below). Some plants, although more occasional, may probably be considered as preferential for this community.

II. Mt. Ailesvare, the S-facing side, ledges of the rock wall, ca. $550 \mathrm{~m}$. Dip ca. $30^{\circ}$ towards the S. 26 June, 1963.

This type of community is related to certain dwarf shrub heaths, as Calluna vulgaris is present. The substrate on the ledges is ca. $10 \mathrm{~cm}$ deep, consisting of humus rich in rock debris, but presumably of acid character. The cover is 95$100 \%$. There is a little shade from Populus tress further down on the slope. Shrubs (Rosa majalis) are present. Cladonia phyllocladia are abundant (undeterminable).

III. Mt. Fiskträskberget, the S-facing side below the rock wall, ca. $530 \mathrm{~m}$. Dip ca. $30^{\circ}$ towards the S. 24 July, 1963.

This poor community, of which some segments also occur on the ledges of the rock wall, grows in the immediate neighbourhood of the stand of Dryopteris filix-mas (see p. 88). There is no seepage water on the rock wall above the analysed site. The cover varies between 80 and $100 \%$. The substrate has a very low content of humic matter in spite of the fine type of scree and the presence of broadleaved trees (Salix caprea, Betula pubescens). Shrubs of Populus tremula are present.

IV. Mt. Gaddaberget, the S-facing side, ledges on the rock wall, ca. $380-400 \mathrm{~m}$. Dip $10-30^{\circ}$ towards the S and SE. 12-13 July, 1962, 24 June, 1963.

The general appearance of the hillside is very dry (but for the Gully, see p. 126), but in spite of this there is a 
certain effect of the water supply beneath the rock wall (p. 59). The lower parts of the rock wall are not very steep, forming in places rather wide ledges, which are nearly always occupied by this community. The cover is $80-100 \%$. Shrubs, especially of Rubus idaeus, are present. The soil layer is up to $20 \mathrm{~cm}$ deep, the upper part of the profile approaching mor (see p. 25 and sample no. 41 , Table 1).

\section{A comparison with the vegetation on talus slopes in Sikilsdalen}

It was already pointed out above that great resemblances exist between the plant communities described by Nordhagen from Sikilsdalen, S Norway (1943), and the plant communities on talus slopes in PL. But with regard to his association Veronico-Poetum glaucae nothing was known about the composition of the tottom layer. A comparison was also made difficult because of the fact that Nordhagen used a quadrat size of $4 \mathrm{~m}^{2}$. Therefore the screes above Upper Sikilsdalsvatn were studied in two summers by the present author (Table 27), in about the same place as where Nordhagen made his analyses.

The sites in Sikilsdalen are subalpine (one young Pinus silvestris seen by the present author near Sikilsdalsseter further $\mathrm{E}$ at ca. $1010 \mathrm{~m}$ ) and the bedrock is gabbro. Nevertheless the similarity to the scree vegetation in PL is evident. What particularly characterizes the screes of Sikilsdalen, being better exposed to sunlight, is a mixing of the Scandian and lowland elements, especially in the flora of vascular plants. However, the "Chamaenerium-ConvallariaPoa nemoralis-sociasjonen" (Nordhagen 1943, pp. 547 et seq.) shows great resemblances with the Fruticeto-Tortuletum subassociation, Rubus idaeus variant, as described here. The plant community described from Sikilsdalen (sez also Table 27, stand no. I, showing a closely related type) may be regarded as a vicariating community, at home at higher elevations in the mountains of S Scandinavia.

At higher elevations on the screes of Sikilsdalen the most abundant bryophytes seem to be Desmatodon latifolius, Pseudoleskeella nervosa and Tortula ruralis. The first one is very rare on screes in the coniferous belt of the Scandes (from PL only in the analyses in Table 22; otherwise mostly on the rock wall, see the section on the bryophyte flora). Another moss, Brachythecium velutinum, which is a southern lowland plant, is not characteristic of the scree communities studied in PL, but is occasionally present (belt transect, Table 28).

A Rhytidietum community is also present (Table 27 , stand no. II) with much the same structure as the one known from PL but more closely resembling some Dryas heath fragments found on some screes at high altitudes or (in PL) e.g. on the E-facing side of Mt. Svartberget, see below p. 113. Quite pure Khytidium rugosum-Abietinella abietina carpets are seen cnly rarely in similar sites in PL. The admixture of Carex rupestris in Sikilsdalen is probably significant.

Besides the exposure, a subcircumneutral to slightiy acid substrate quite high in nutrients is a common feature of Veronico-Poion communities. Table 1 , soil samples nos. 55-57, shows that the mull soil present in Sikilsdalen is quite similar in chemical characters, except for the humus content which is generally low at the surface, due to the absence of any litter production from closed tree stands.

Quadrat size: $1 / 4 \mathrm{~m}^{2}$. Table 27.

I. Mt. Sikilsdalshornet, the S-facing side below the rock wall, ca. $1200 \mathrm{~m}$. Dip 25-35० towards the S. 22 August, 1962, 9 August, 1964.

There is a temporary flow of water on the rock wall 50 $\mathrm{m}$ above the analyses nos. 1-6. The cover of the field and bottom layers is $80-95 \%$ and the scree is rather stable. Analyses 7-11 were made on a stable section in front of the rock wall, which is not overhanging in this particular place. Further below on the talus slope, which has no trees on it, there is a "scrub zone" consisting of Cotoneaster, Juniperus, Rosa majalis and Rubus idacus. Further downslope the rather bouldery scree is devoid of vegetation with the exception of lichens. The cover in front of the rock wall is $90-100 \%$ and there is no seepage water. The vegetation of the rock wall is a Saxifragion cotyledonis (Nordhagen 1936).

II. Mt. Sikilsdalshornet, the S-facing side below the rock wall, ca. $1200 \mathrm{~m}$. Dip ca. $30^{\circ}$ towards the SW. 8 August, 1964

There is no seepage water on the rock wall which overhangs $(1-2 \mathrm{~m})$ in its lower section. Strictly beneath the outer edge of the rock wall, as projected vertically down on the scree, there is a Juniperus scrub: further downslope, i.e. 3-20 $m$ from the rock wall, comes the Rhytidietum. Still further downslope there is an Arctostaphyletum uvae-ursi, partly mixed with the Rhytidietum community. The general character of the talus slope is that of an open upper wood with some Betula pubescens, Sorbus aucuparia and Prumus padus, but these small trees are always solitary. There are also some Juniperus shrubs in the community (not in the analyses). Some pebbles without vegetation occur within the community (mostly only small patches of crustal lichens on them, but no mosses). In spite of this the cover is rather high, 85$95 \%$. No other lichens are present.

Here, also, the rock wall is occupied by the Saxifragion cotyledonis community. The crevices are mostly dominated by Amphidium spp.

\section{Zonation of vegetation on talus slopes}

In Lundqvist, J. 1961 , p. 154 , it was stated that the vegetation on well developed screes facing more or less $\mathrm{S}$ is arranged in a definite zonation, including from above (1) a zone with broad-leaved trees, foremost Populus tremula, (2) a zone with shrubs such as Juniperus communis, Rubus idaeus, Rosa majalis etc. (3) a zone devoid of higher plants in the central parts of the scree and (4) the lower talus slope with sparse forest trees, called "the lower wood". In (1) 


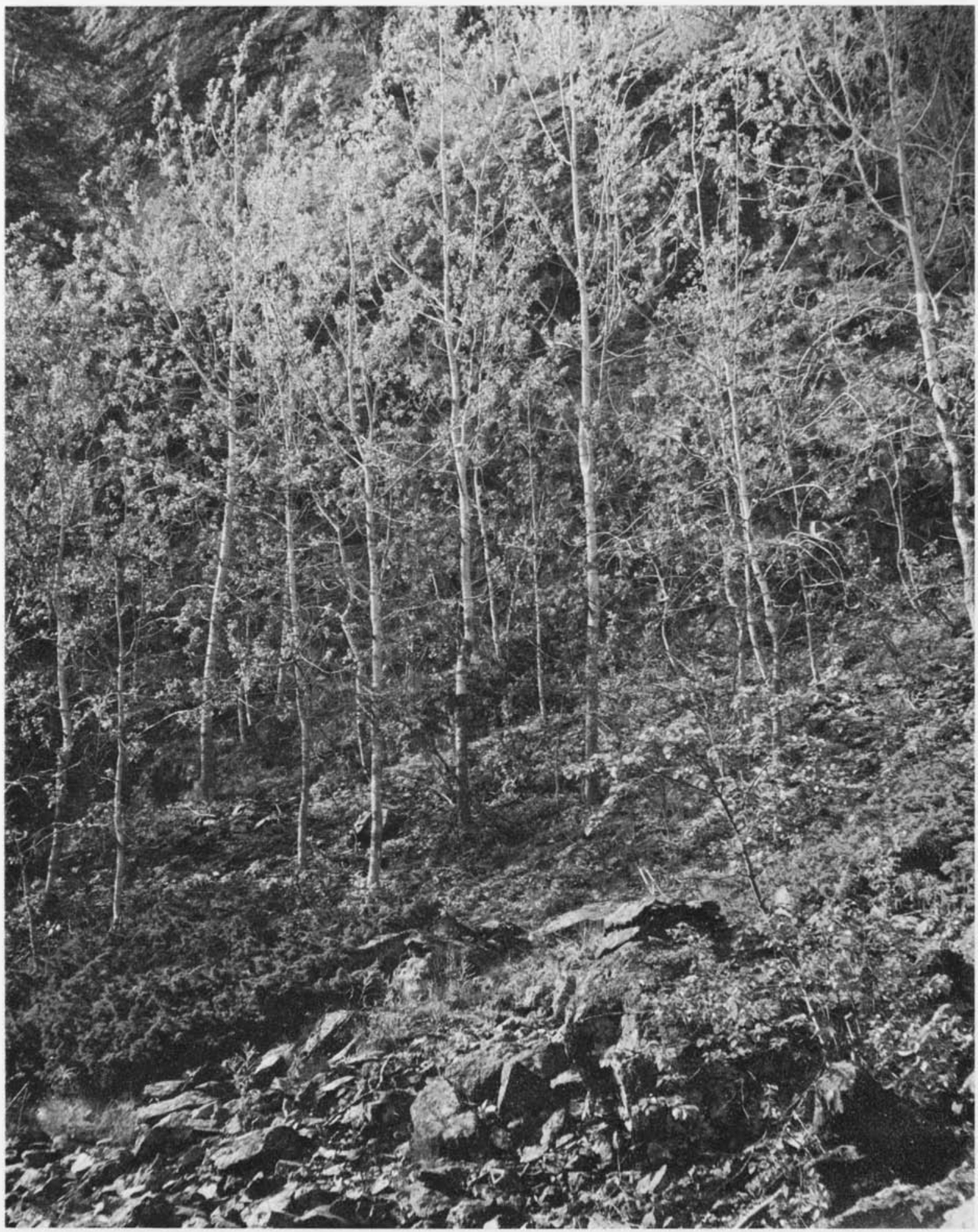

Fig. 39. The small aspen wood on Mt. Märkepakte described in the text (belt transect). In the foreground the open scree and the scrub zone (with Juniperus communis etc.). 5 July, 1962. 


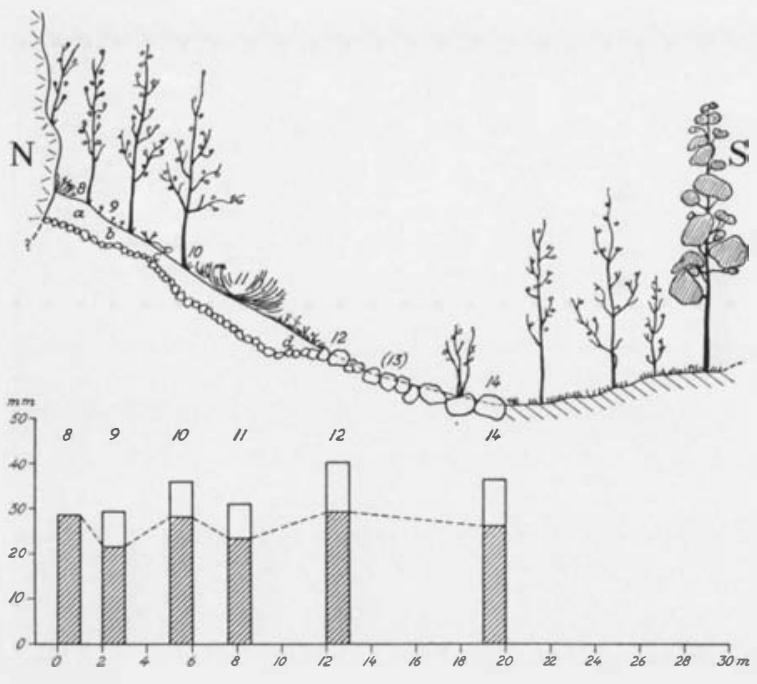

Fig. 40. Belt transect on the S-facing slope of Mt. Märkepakte in 1961. The position of the rain gauges nos. 8-14 and the amounts of precipitation during two different periods (piles unfilled 23-28 June, diagonally lined 9-12 July, for gauge no. 8 no values available for the period 23-28 June). The situation of the trees, scrubs, etc., indicated. The lower stone-air-layer is hypothetical as it was measured in one point only $(c) . a, b, c$ and $d$ are places for sampling of soil

is often discernible a special subzone similar to (2) in close contact with the rock wall. A similar zonation on talus slopes was described from Sweden already by Sernander $(1920$, p. 112) but was not treated in detail in the botanical literature.

There are several factors which could be regarded as determinant for the zonation in question. Because of the increase downwards in size and stability of the material, different seral stages are developed (see below), which are also influenced by other factors than the age and kind of substrate. Such factors are the turbulence of the air, the increasing light and air temperature upwards, and its warming effect especially on the upper parts of the soil profile (see the section on the local climate and the microclimate). The light and heat conditions are further modified by the structure of the vegetation itself, especially under a typically developed tree layer. The condition of the soil is strongly influenced by the litter falling on it. Other factors are the influence caused by man or animal. Even sudden catastrophes may occur, such as rapid rockslides, certain earth-slides, avalanches and forest fires. All these factors except the influence of man and fire could be regarded as important when a long period is considered. However, where no great sudden changes have occurred and the vegetation thus has had an opportunity of stabilizing, the typical zonation is mostly found.
Some belt transects were investigated in the summer of 1961 in order to study this zonation in detail, and they were always placed at right angles to the cliff where a typical zonation was discernible. At the same time the influence of the differing substrates was analysed. In this section the general characters of two belt transects will be summarized, the former with a tree layer, the latter with very sparse trees in recent time (see Figs. 39-42).

Belt transect on Mt. Märkepakte. The vegetation (Table 28; see also Fig. 39) shows the following characteristic features: The uppermost part of the scree (the fine scree) is covered by aspen wood (Populeto-Tortuletum; the section in front of the rock wall is a mixed stand with Vaccinium vitis-idaea and Juniperus communis). The dry meadow below the canopy of the trees is dominated by Solidago virgaurea and Rubus saxatilis, and there is a rather abundant admixture of Fragaria vesca. The substrate is here mostly pebbles and small boulders, in the more proximal parts (towards the Vaccinium community) with a good supply of finer rock debris. The fine soil section is subdominated by Sedum annuum and Euphrasia frigida. The Vaccinium community (dealt with in detail above, p. 92) has a very sparse bottom layer (Tortula ruralis and Brachythecium reflexum) but in the rest of the bottom layer of the wood Schistidium apocarpum and Pseudoleskeella nervosa occur, growing especially on the pebbles. The lowermost aspen trees overhang the dense juniper scrub (the Juniperus communis variant of the Fruticeto-Tortuletum subassociation, quadrats nos. 16-23) occurring further down on the slope at the outer edge of the Populeto-Tortuletum community. In this scrub Eurhynchium pulchellum is the most characteristic moss species. The juniper litter almost covers the pebbles and small boulders of this zone.

At the lower edge of the juniper community comes the Rhytidietum community, quite typically. The dominants are Festuca ovina and Rhytidium rugosum. In some places to the side of the belt transect is also Chamaenerion angustifolium. Lower down the vegetation gets a very fragmentary appearance among the boulders which are quite large here (some ca. $70 \mathrm{~cm}$ in diameter, outside of the transect even larger boulders). On the lowermost part of the talus slope (the lower wood) there is a Dicrano-Polytrichetum, Sphenolobus variant. Plants from the forest invade (Betula pubescens, Empetrum hermaphroditum), and on the base of the scree there is a typical mixed coniferous forest stand with Pinus silvestris and Betula pubescens. In the Dicrano-Polytrichetum almost no field layer is present and the vegetation consists of partly epilithic lichen communities. 
The strictly epilithic communities with hardly any humus production were not analysed. The zenith surfaces of boulders are often overgrown by lightdemanding lichens and bryophytes, whereas the undersides are dominated by Radula complanata, Pseudoleskeella nervosa, P. tectorum and Neckera oligocarpa. Metzgeria furcata often admixes and co-dominates with Radula complanata. Both of them are regarded as thermophilous although they prefer a shaded site (p. 82).

Although the studied belt transect may be regarded as typical for S-facing screes in NW PL, there are frequently other types of zonation present in similar sites. The Cladonia variant of Dicrano-Polytrichetum on convex cone mantles etc. has about a similar position on the scree as Rhytidietum or is situated between (fragments of) a Rhytidietum and the Sphenolobus community, of which examples are also seen on Mt. Märkepakte. In unfavourable aspects Dicrano-Polytrichetum and forest communities almost totally cover the talus slopes, conditions which will be further described below when dealing with the hillsides with unfavourable exposure.

The substrate (see Table $2 \mathrm{~A}$ ), consisting of debris of mylonite and sparagmite in proportions about $5: 3$ (quadrat 13 with 70 pebbles of $2-20 \mathrm{~cm}$ diam. in the litter on the surface) provides fairly good chemical conditions. The total amounts of the nutrients are high and the litter production is good. The calcium content is nearly constant as are $\mathrm{pH}$ and $\mathrm{AL}$ soluble potassium. The variations within the transect, where the scree is quite stable, are for these reasons primarily referable to the supply of fine debris, the light conditions and the snow conditions during thaw. Fine particles may have been transported a little downslope with the precipitation water from the rock wall and may have gathered in the compact mull soil layer at the edge of the fine scree (the Rhytidietum community). The higher clay content of this section of the scree could either be due to these circumstances or to a higher weathering rate in the zone in question.

Belt transect on Mt. Lulep Istjakk. As there was some seepage water on the rock wall in this case (sample no. 6, Table 14) the bryophytes growing under its influence, mainly in crevices, will be briefly commented on.

The dominant bryophytes are Amphidium lapponicum and $A$. mougeotii in not too wet crevices. Associated bryophytes are: Grimmia unicolor, $G$. torquata, Bryum pallescens and Plagiochila asplenioides etc. Some other rather dry crevices are occupied by Tortella tortuosa, Pseudoleskeella nervosa and Barbilophozia barbata. The wettest crevices are

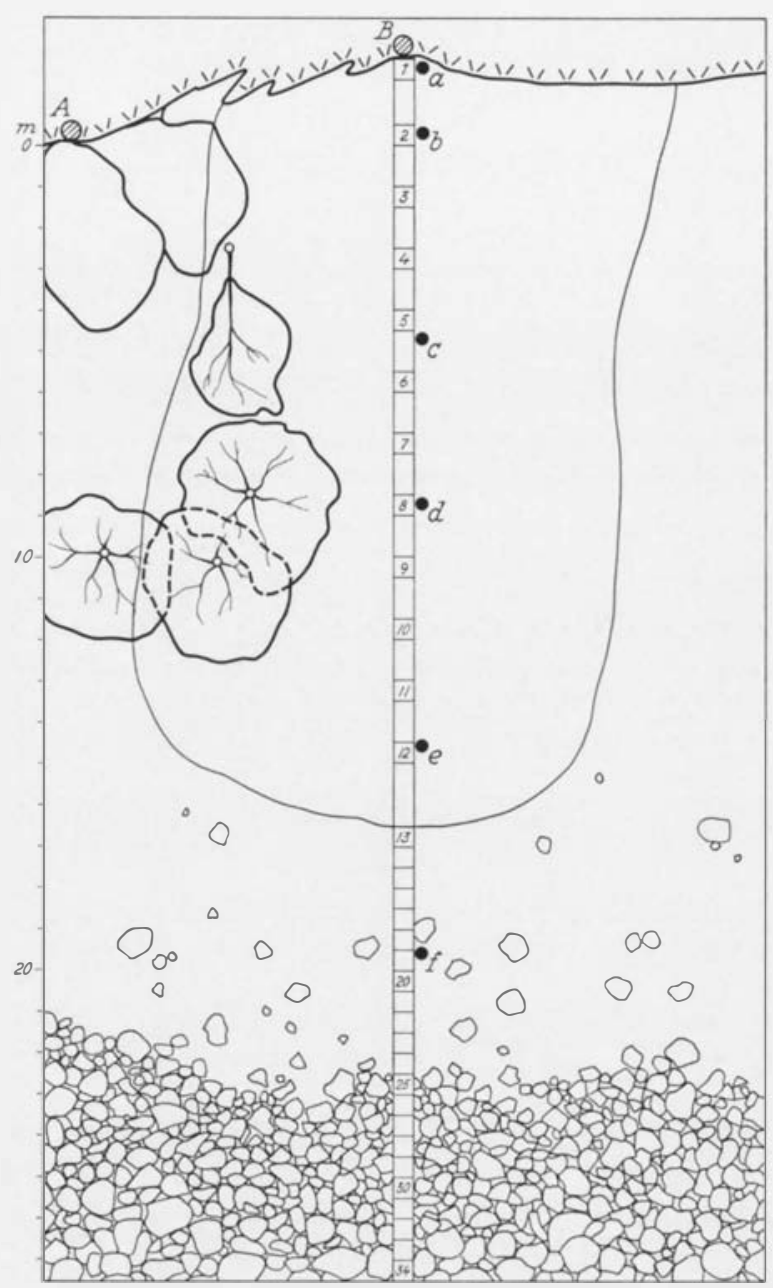

Fig. 41. The belt transect on Mt. Lulep Istjakk. $A$ and $B$, Places for sampling of seepage water, $a-f$, places for sampling soil. Extension of the community dominated by Filipendula ulmaria. Position of trees to the left in the upper half of the figure and position of the boulder scree (approximately). See Fig. 42.

dominated by the Philonotis spp. (p. 80) and Bryum pseudotriquetrum coll.

There are very few trees in the vegetation on the talus slope (Table 29), of which the first 12 quadrats have an interspace of ca. $1.2 \mathrm{~m}$ (see Figs. 41 and 42). Near the central part of the transect grow two aspen trees ca. $10 \mathrm{~m}$ high, the upper one $18 \mathrm{~cm}$ in diam. at $150 \mathrm{~cm}$ above the ground, the lower one $21 \mathrm{~cm}$ in diam. Situated more on the side is a third aspen tree of about the same dimensions, $17 \mathrm{~cm}$ in diam. (see Fig. $42 b$ ). They form a relatively thin canopy and shade the transect only very little. A little above the aspens there is also a birch tree, leaning downslope (see Fig. 41). Small aspens, up to ca. $2 \mathrm{~m}$ high, grown in the Filipendula community. Rosa majalis and Rubus idaeus shrubs are frequent 


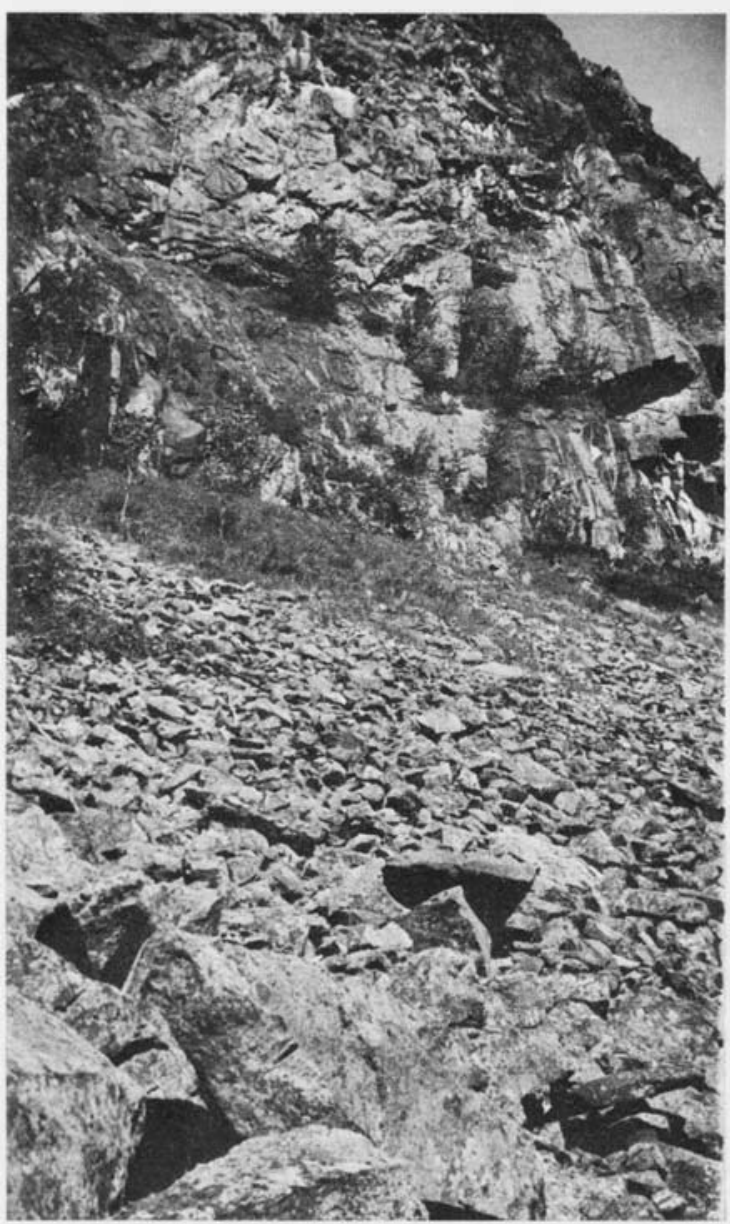

a

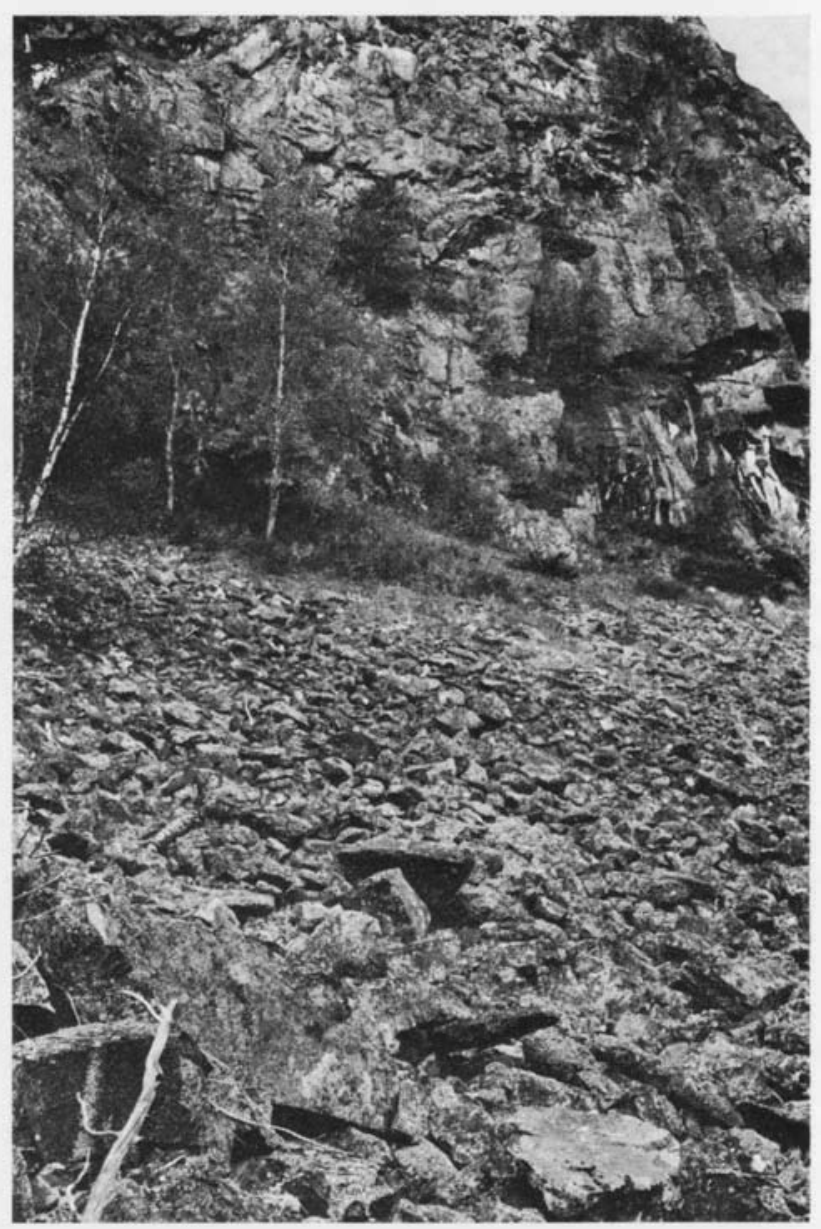

b

Fig. 42. (a) Mt. Lulep Istjakk, the S-facing slope. Photo: G. Wistrand, 1 July, 1936. (b) Photograph taken from the same place to show possible changes. The section of the scree was more closely investigated (see the text). The only locality for $M y o s o t i s$ stricta on the mountain and the only known locality for Isothecium myosuroides in PL. The 30 years between the two photographs seem to have been of little significance in bringing about changes in scree material and vegetation. 7 September, 1966.

especially at the outer edge of the Filipendula community.

The Filipendula ulmaria community, here classified as a Poeto-Lactucetum community (Table 18), is fairly extensive below the wet rock wall. It is a homogeneous stand $1.3-1.5 \mathrm{~m}$ tall. There is also, especially at the outer edges, an admixture of Paris quadrifolia, Calamagrostis purpurea, Milium effusum, Aconitum septentrionale and Brachythecium reflexum.

The transition to the Fruticeto-Tortuletum community further downslope is very sharp. The bottom layer, which is very sparse in the Filipendula community, suddenly becomes plentiful, totally covering the finer debris between pebbles and small boulders. Some light and warmth demanding plants equally abruptly become fairly abundant and show high vigour, e.g. Polygonum dumetorum, Barbaraea stricta and Sedum annuum.

Further downslope there are fragments of Rhytidietum (with the rare moss Isothecium myosuroides) and the Cladonia variant of Dicrano-Polytrichetum (with Rhacomitrium lanuginosum and many Cladonia species).

The bedrock was described on p. 22. The dyke with pegmatite (partly aplite) is at least $5 \mathrm{~m}$ high on the precipitous cliff. Nothing is known about the bedrock higher up on the rock wall, but presumably it contains some rocks with a certain content of calcium (see p. 22).

The amount of pebbles and cobbles at different levels in the transect was approximately estimated (Table $2 \mathrm{~B}$ ). In quadrat 18 there is still some fine soil present near the surface. Quadrat 31 has no fine 
soil but 3 boulders ( $>20 \mathrm{~cm}$ in diam.), 71 pebbles and cobbles $6-20 \mathrm{~cm}$ diam. and 8 pebbles $2-6 \mathrm{~cm}$ in diam. Below the belt transect there are almost only boulders of different sizes.

The humus content is fairly high in the upper parts of the transect, and the litter production is abundant. The water content (soil moisture) is not highest near the rock wall, in spite of the supply of water from the rock, because of the fact that the soil there is low in humus. The higher water content in the central part is also dependent on drops falling from the rock wall during rain (see p. 26), and on a better supply of rain at a distance from the wall. There is a remarkably high soil moisture at the edge of the fine scree which may be due, in part, to the abundant rains in the summer of 1961 .

The calcium content and $\mathrm{pH}$ vary largely due to leaching (in the tall herb stand) and higher evaporation at the outer edges. There are no great differences in the composition of the debris material.

Comparison between the two transects. The upper part of the belt transect on Mt. Lulep Istjakk is occupied by a Poeto-Lactucetum community because of a temporarily abundant water supply from the cliff at least in spring and in rainy periods. In summer the soil moisture is much more influenced by rain showers, and by the variable content of humus at the surface. A shading tree layer is not a prerequisite for a meadow vegetation on screes to develop when the water capacity of the fine soil is fairly high, and the conditions otherwise are favourable. In certain sites on hillsides are seen stands approaching Poeto-Lactucetum where the tree layer is closed but no seepage water runs down the cliff.

For due reasons the zonations are very variable. The Rhytidietum community, which is fairly common in suitable sites on Mt. Märkepakte, is only seen as fragments on the scree of Mt. Lulep Istjakk. The same is true of the Cladonia variant of the Dicrano-Polytrichetum on Mt. Lulep Istjakk. The Sphenolobus variant is on the other hand fairly extensive on Mt. Lulep Istjakk, as the greater part of the scree consists of very large boulders, in some places with occurrences of forest elements on them.

On Mt. Märkepakte the 39 quadrats accounted for the total extent of the scree from top to bottom, whereas on Mt. Lulep Istjakk, with much greater extension of the talus slope, only a comparatively short section of the proximal part was analysed. This is one probable reason for the lower number of plants, at about the same transect length.

Some of the details with regard to the soil conditions are almost identical, especially the distribution

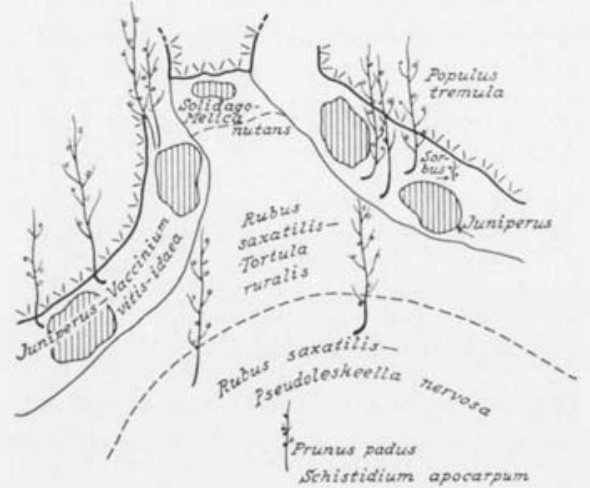

Fig. 43. The major plant communities and more important plant species on a talus cone mantle (schistose gravel) on Mt. Märkepakte, the S-facing side. The rock wall denoted $\backslash \bigvee \vee V$. See text.

of the finer soil particles on the slopes (see Table 2). There is no measurable tendency towards higher calcium content of the humus at the edge of the fine scree on Mt. Märkepakte, which primarily might be due to the extreme production of juniper litter. There is less air movement in the scree because of the compact fine soil layer here. The obvious thing is that, at least on similar stabilized sections of fine screes, the soil conditions are primarily determined by the vegetation growing on it, and the interrelations between the dominating vegetation and the substrate, and not by the weathering of the rock wall.

\section{The succession of vegetation}

As Leach $(1930$, p. 321$)$ pointed out "the problem is particularly attractive because one is able to obtain much reliable information regarding successional changes by direct observation, without the necessity of resorting to such long and tedious processes as the mapping of quadrats etc." See op. cit., pp. 322 et seq., for further discussions.

Nordhagen (1943, p. 566) observed that the succession of vegetation on screes in Scandinavia occurs at a very slow rate in recent time. The same is true for the majority of talus cones on the extensive talus slopes on Spitsbergen (Rapp $1960 a$, pp. 76, 77), although it was considered earlier that denudation works fairly rapidly on Spitsbergen (op. cit., p. 3; cf. p. 91). Rapp (op cit., p. 77) found that the slide tongues, herb cushions and lichen patches had not changed since 1882, and that the scree was fairly well stabilized, at least where no considerable avalanches or heavy debris falls had occurred.

The same is obviously true for the talus slopes in PL (Fig. 42). The denudation works very slowly and equilibrium stages are allowed to develop. Smaller changes are probably to be found foremost in the 
zone with the most striking microclimatic changes, because here temporary drought will cause changes in soil moisture tension, etc. Abrupt changes are occasionally seen on these hillsides (cf. Fig. 46), but where the conditions have been stabilized for a fairly long time a typical succession can be observed to occur (Leach 1930, p. 321; Nordhagen 1943, p. 567). Avalanches only rarely prevent the trees from developing in similar sites in PL, but their importance should not be neglected.

In PL, a simple talus cone generally has the least stable substrate and is generally very sparsely overgrown with trees (Fig. 43). At the top of the cone there is a community (Tortulo-Poetum) dominated by Solidago virgaurea and Melica nutans. Further downslope there is a zone dominated by Rubus saxatilis and Tortula ruralis, still further down Rubus saxatilis and Pseudoleskeella nervosa generally with some Populus tremula (low trees). Next follows a sparse scrub zone (Juniperus or Rubus idaeus variant), next Rhytidietum or the Cladonia variant of Dicrano-Polytrichetum, and the still lower parts are overgrown with (fragments of) the Sphenolobus variant of Dicrano-Polytrichetum.

The downslope zonation here also represents a succession, as far as the talus development is working backwards at a slow rate. However, not all features of the zonation are easily interpreted as successional. It should be noted, for instance, that in this case the least stable parts are not at the top of the cone, but about where a Fruticeto-Tortuletum shows the initial stages of development (only Schistidium apocarpum and some sparse shrubs present).

In front of the mountain wall, but on the sides of the cone mantle, there is a drought-resistant and stabilized community with Juniperus communis and Vaccinium vitis-idaea, not influenced by seepage water in this case (see Table 22, stand no. 1). This community is a heath community transitional to a normally developed stand of Populeto-Tortuletum (see Fig. 39) further downslope.

It is evident from a comparison with the vegetation on talus slopes in Sikilsdalen (see above p. 96) that the initial stages of Tortulo-Poetum community precedes more closed meadow and shrub communities on loose scree, but that especially the Juniperus communis variant has preference for the more stabilized parts succeeding the Populeto-Tortuletum meadow woods. Succeeding the Fruticeto-Tortuletum community on stabilized scree is the Rhytidietum which in some places (see p. 96) is changing in turn into an Arctostaphyletum uvae-ursi, in other places into the Cladonia variant of the Dicrano-Polytrichetum association. Lastly, regarding the PoetoLactucetum community, the suggestion by Nordhagen $(1943$, p. 567) that it is succeeding certain more stabilized types of Tortulo-Poetum on moist scree is certainly valid. This explains the stabilized appearance of the community in question around the belt transect on Mt. Lulep Istjakk and in other sites. 


\section{THERMOPHILOUS PLANT COMMUNITIES OUTSIDE THE HILLSIDE ECOSYSTEM}

There are good reasons to believe that the tall herb meadow communities of the Scandes have remained relatively unchanged throughout the postglacial period (Blytt 1897, p. 49; cf. Nordhagen 1943, p. 312). Little change since the warm period is anticipated for such sheltered sites which support some Borealmontane plants of a southern distribution type, found chiefly in the montane belt of Central and S Europe (see above p. 68) but primarily of a lowland distribution type in the $\mathrm{N}$. The protected sites with good soil conditions still contain elements which may justify the description of the particular stands as "relic thermophilous communities". The tree layer, however, may have changed to a great extent in some cases as the climate became colder and the soil conditions altered (Blytt, 1. c.; Nordhagen 1.c.; Firbas 1949, pp. 275-277). Yet with regard to the trees, especially in the NW, certain sheltered stands with Populus tremula and Alnus incana, rarely also Ulmus glabra var. montana (Malmström 1934, p. 111; Rönning 1954, p. 197; Rune, O. 1965, pp. 68, 69) could be regarded as "relic sites" where even the tree flora has not changed too much in postglacial time. In the SE of PL, some Picea abies forests, which historically are younger, also, provide unexpected habitats for some thermophilous southern or southeastern elements. Cf. Andersson \& Birger 1912, p. 152.

In this section two types of sheltered woods will be dealt with. One is an Alnus incana wood and adjacent communities of the NW, and the other is a type of Picea abies forest occurring in the SE coniferous woodland area.

\section{The flora and vegetation of the Merk Gorge}

The Merk Gorge (Lundqvist, J. 1963, p. 81, Swed. "Merkklyftan") is a remarkable erosion valley at the W end of Lake Storlaisan close to the E side of Mt. Märkepakte, surrounded on both sides by steep rockwalls (Fig. 29). The eastern rock wall projects ca. 7 $\mathrm{m}$ above the valley bottom and is ca. $30 \mathrm{~m}$ high. The plateau on this side is occupied by a dry pine wood on almost bare rock, whereas the western plateau has a more sheltered mixed stand with aspen trees and birches with a thicker humus carpet. The main plant communities and their situation are shown on Fig. 29 (p. 57; the width of the Gorge is exaggerated). Because it is $30-40 \mathrm{~m}$ deep it affords very protected and rather shaded habitats, including screes of different exposures. The E-facing scree, which is the most shaded one, carries a forest heath with the common forest dwarf shrubs in the field layer and some scattered birches in the tree layer. The W-facing scree (in the innermost part of the Gorge it faces SW) is much more varied with regard to vegetation, with different demands for soil moisture, arranged in a beautiful zonation. The driest parts display scattered occurrences of Saxifraga adscendens; only found here and on the S-facing side of Mt. Märkepakte in the whole of PL. On the bottom of the Gorge is a moist grey alder wood with Circaea alpina (not found elsewhere in PL either). At the entrance are lake shore communities. The western plateau is very rich in calciphiles, e.g. Cypripedium calceolus. This species in $\mathrm{PL}$ prefers $\mathrm{S}$-facing slopes on calcareous ground, and occurs in this case in openings of mixed Populus and Betula stands (vegetation analyses see Lundqvist, J. 1966, p. 194; soil analyses see this paper Table 1, samples nos. 45-47, which illustrate the conditions of the similar Cypripedium locality near Simselet, Skellefte River). Even the fairly dry eastern plateau contains calcareous strips (Fig. 32), because of easily evaporating seepage water on the cliff. The overhanging cliff protects from rain and snow and gives in spite of the seepage water a very dry meadow at its foot; in part vegetation is even lacking in the most extreme sites (see p. 57).

Because of this rather unique constellation of calciphilous and somewhat thermophilous plants which are very rare in PL and most other parts of $N$ Sweden, the Gorge and adjacent areas have been studied in detail. Here are given analyses of two high-productive stands on the bottom of the Gorge (Table 30).

Those somewhat thermophilous elements of the Merk Gorge that were not dealt with above in the section on the Flora will be briefly discussed here.

Saxifraga adscendens $\mathrm{L}$. is by some authors considered to be "southern" because of its occurrence in the lowland lo- 
calities in Fennoscandia and its absence from the extreme NE part of the Scandes (cf. Wistrand 1962, p. 187). Its relationship to the definitely southern $S$. tridactylites $\mathrm{L}$. and the intermediate $S$. osloensis Knaben is thoroughly discussed by Knaben (1954, 1961), who also discussed the ecology and life cycles of the three species in detail. $S$. adscendens could alternatively be considered a northern taxon within a very variable compound species, $S$. tridactylites s.l., in which it was included by Engler \& Irmscher (1916, p. 217) and Engler (1919, p. 3). Some of the S Swedish plants earlier believed to be $S$. adscendens should be placed within the intermediate $S$. osloensis, occurring where the distribution areas of $S$. tridactylites s.str. and $S$. adscendens s.str. overlap. The distribution of $S$. adscendens s.str. in Europe is similar to that of Carex ornithopoda, for example, belonging in the group of European Boreal-montane plants with a large gap in Central Europe between the $\mathrm{N}$ and $\mathrm{S}$ areas (cf. Hultén, 1950 , p. 54). Selander (1950 I, p. 66), who considered a Rocky Mountain taxon to be conspecific, placed it among the "amphi-Atlantic-Alpine" plants. The specialization to climatically less favourable areas, as evident from the gap, could be relatively recent but yet may be pre-Weichselian. $S$. adscendens is by some authors considered to be a glacial survivor in Scandinavia (Selander, l.c.,; Knaben 1954, p. 133). In the $\mathrm{N}, S$. adscendens occurs in the crevices and on the ledges of cliffs, on screes and on unstable, dry or sometimes moist, sandy or gravelly soil (cf. Benum 1958, p. 248; Lundqvist, J. 1963, p. 79). Because of its elevated occurrences in the Alps (to $3480 \mathrm{~m}$; Huber 1961, p. 191) it was placed here among the Boreal (B) plants (Table 16).

The driest parts of the Gorge (with sparse occurrence of Saxifraga adscendens) consist of tussocks of dry meadow dominated by Festuca ovina and Abietinella abietina on top of them and Equisetum pratense, Polygonum viviparum, Trollius europaeus, Aconitum septentrionale and Viola biflora sparsely interspersed among the tussocks. On the belt transect at the owl's nest (Fig. 29) near rain gauges nos. 2-3, there is a mixed meadow community without shrubs and trees of the following composition (frequency and characteristic degree of cover of 10 quadrats; quadrat size $\left.1 / 4 \mathrm{~m}^{2}\right)$ :

Carex sp. $\left(40^{1}\right)$

Equisetum pratense $\left(100^{1}\right)$

Festuca ovina $\left(100^{4}\right)$

Poa nemoralis $\left(10^{3}\right)$

Roegneria canina $\left(40^{1}\right)$

Aconitum septentrionale (202)

Anthriscus silvestris (20)

Campanula rotundifolia $\left(80^{1}\right)$

Cerastium al pinum (10²)

Chamaenerion angustifolium (201)

Cystopteris fragilis (40)

Erysimum hieraciifolium $\left(40^{1}\right)$

Hackelia deflexa $\left(60^{1}\right)$

Polygonum viviparum $\left(10^{1}\right)$

Potentilla Crantzii $\left(20^{1}\right)$

Rubus saxatilis $\left(10^{1}\right)$
Saxifraga nivalis (+)

Solidago virgaurea $\left(90^{2}\right)$

Trollius europaeus (40)

Urtica dioeca ssp. Sondenii (201)

Valeriana sambucifolia $\left(10^{1}\right)$

Viola biflora $\left(30^{1}\right)$

Abietinella abietina $(+)$

Hypnum lindbergii (+)

Rhytidium rugosum (+)

The substrate conditions, although with identical rock debris material (samples nos. 11-13, Table 1; cf. nos. 14-20), are characterized by a much more rapid increase in $\mathrm{Ca}$ with increasing depth and by higher $\mathrm{Ca}$ and $\mathrm{P}$ values than in the lower parts of the transect, near and on the bottom of the Gorge. The changes in $\mathrm{Ca}$ and $\mathrm{P}$ contents do not correspond with any major changes in $\mathrm{pH}$.

Circaea alpina L. was classed as a S Scandinavian species by Andersson \& Birger 1912, p. 93. Selander (1950 I, p. 96) placed it among the postglacial southern immigrants in the flora of Lappland. It is Boreal-circumpolar and has a Boreal-montane distribution in Europe (see Hultén 1950, group 16). In the Alps the main distribution is in the Fagus-Abies and Picea belts (Saxer 1955, p. 45), thus not appreciably deviating from other southern elements in Lappland. In its northernmost localities it has often been found on screes which are fairly well stabilized and of S exposure; however, it is a very shade-tolerant plant. The site for it in the Merk Gorge (Table 30 ) is very similar to its habitats in the more $\mathrm{S}$ parts of the distribution area: moist woods with tall herbs, groves along streams etc. Its preference for this kind of habitat is displayed in the Merk Gorge by the fact that the adjacent lower parts of the scree (stand no. II, cf. no. I) totally lack this species.

Circaea alpina may probably (like Alnus incana) be regarded as an old postglacial element (cf. above), because of its warmth demands presumably being a relic from the warm postglacial period. No microclimatological observations have been made in the Merk Gorge with the exception of the rain measurements in 1961 (Table 13). The locality is certainly not favoured by day, having only a few hours sunshine in the middle of the day. However, the Gorge is protected from cold or dry winds. The closed tree and field layers and the steep hillsides around the Gorge, protect low plants like Circaea from strong eradiation at night. Night frosts in summer might anyway be comparatively few, as a so-called cold trough cannot be developed so near the shore of the lake.

The substrate factors are illustrated by the soil samples nos. 18-20, Table 1, cf. nos. 14-17 of the Matteuccia community. Circaea alpina and Alnus incana grow on the moist bottom of the Gorge, which may be partly inundated in spring by the lake, but 
at least Circaea seems to prefer the upper parts which are very rarely flooded. Throughout the vegetation period there is water trickling along the gently sloping bottom covered with schistose gravel. The depth of the groundwater surface is $20-25 \mathrm{~cm}$ in not too dry summers. The bifurcated small stream surrounding the Alnus incana-Filipendula ulmaria community with Circaea alpina very rarely dries out in dry summers.

N Swedish grey alder woods are relatively little known plant-ecologically (see Holmen 1959, p. 33, and Sjörs 1960, p. 152). Sjörs (op. cit., pp. 143 et seq.) gave a good description of their former importance to man, although some of them are as little influenced by cultural factors as that in the Merk Gorge.

Quadrat size: $1 / 4 \mathrm{~m}^{2}$. Table 30 .

I. The Merk Gorge between the two furrows of the stream, ca. $427 \mathrm{~m}$. Almost level ground. 26 July, 1960.

The cover of the tree layer (Alrus incana, dominant, Betula pubescens, Sorbus aucuparia and Prunus padus) is ca. $60-80 \%$. The field layer is totally covering $(100 \%)$. There are no lichens in the bottom layer and the bryophytes are fairly sparse. Small basidiomycetes are numerous (Clitocybe, Lepiota etc.).

II. The Merk Gorge at the foot of the W-facing scree, ca. $428 \mathrm{~m}$. Dip $10-25^{\circ}$ towards the W and SW. 3 August, 1960.

There is no tree layer and the field layer is totally covering and ca. $1.5 \mathrm{~m}$ tall. The bottom layer is very sparse and there are no basidiomycetes. Indeterminable Cladonia sp. in three quadrats as fragments.

\section{The flora and vegetation in an old river valley}

The old river valley near the Tjäutjanåive hill in E Arjeplog (see the map Fig. 2) is remarkable both geologically (especially with regard to the postglacial history) and phytogeographically. The former river bottom is along the greater part of its course filled with polished boulders among which grow only very sparsely some higher plants. The valley descends from Lake Gubblijaure $(430 \mathrm{~m})$ with a very gentle dip, the watershed between the water systems of Skellefte River and Pite River being situated only a few metres in vertical height above the surface of the Lake at its $\mathrm{E}$ end. Ca. $7 \mathrm{~km}$ downstream the Lake is the site where Viola riviniana grows in a Picea forest $(402 \mathrm{~m}$, Paulin altimeter). Still further downstream a small stream occupies the former river bottom, the shores of which display elements which are otherwise only seen along the course of larger rivers originating in the Scandes.

The area around the ancient bifurcation was probably drained due to the unequal postglacial land uplift and the blocking by moraines. This created the two shallow lakes Uddjaure and Storavan (cf. Ahlenius 1901 , p. 48; Högbom 1906, p. 245). The area is very rich in old dwelling-places with remains from the Stone Age (Johansson, O. H. \& Fries, M. 1962, pp. 212, 225 et seq.). Phytogeographically interesting finds from the old river valley are also to be seen in the Museum at Arjeplog, e.g. an old stump of arborescent juniper (Juniperus communis; Norra Västerbotten 23 Oct., 1965), now found only in S Sweden. The finds indicate a very favourable climate in middle postglacial times. Pollen-analytical investigations show a fairly late immigration of Picea in the area concerned (Fries, M., l.c.: ca. 1000 B. Chr.).

The Picea forest under consideration is situated on the $\mathrm{N}$ shore of the old river (with a boulder field), ca. $10 \mathrm{~m}$ from the outer edge of the boulder field and up to $2 \mathrm{~m}$ above the lowermost point of the river bottom, on level ground. Besides Viola riviniana, which was found only in a small part (ca. $50 \times 50 \mathrm{~m}$ ) of the forest, the following few southern plants grow there: Melica nutans, Gymnadenia conopsea, Daphne mezereum and Stroemia obtusifolia. The tree layer is in part a closed stand of Picea abies (dominant), Betula pubescens, Populus tremula, Sorbus aucuparia and Alnus incana (Prunus padus mostly as shrubs). The epiphytic Stroemia obtusifolia is abundant on the large old aspen trees occurring in the forest. There is a rich occurrence of certain Hieracium species which are otherwise rare in PL (S. Nordenstam, personal communication).

The distribution and ecology of Viola riviniana, which was also found on a hillside (Mt. Gaddaberget), is discussed above in the chapter on the flora of the hillsides. In the locality studied, as well as in other N Swedish localities studied by the author (e.g. Mt. Balsberget, Angermanland), it often forms hybrids with $V$. montana.

The bedrock largely consists of basic lavas as is reflected by the high base mineral indexes (soil samples nos. 48-50, Table 1). It provides a favourable soil with a fairly high content of $\mathrm{Ca}$ and other nutrients especially at greater depths (ca. $50 \mathrm{~cm}$ ). There is a very humus-rich layer on top, resting on a deeply rust-brown subsoil which continues downward as far as investigated (to $70 \mathrm{~cm}$ depth). It could not be verified whether there are boulders underneath. If this were the case the Picea forest had probably originally been a boulder meadow (Swed. "skraveläng", Vretlind 1930, p. 74; cf. Wistrand 1962, p. 28 ) in the parts close to the former river.

Quadrat size: $1 / 4 \mathrm{~m}^{2}$. Table 31 .

Old river course near Tjäutjanåive hill, ca. $402 \mathrm{~m}$. Level ground. 6 September, 1965. 
Table 32. The percentages of the different phytogeographical groups and life-forms present in the flora of flowering plants of the hillsides, in Veronico-Poion glaucae and in the various communities of Veronico-Poion glaucae

The classification is made in accordance with the chapter on the flora, see Fig. 35 and Tables 15-16. The various phytogeographical groups include species designated by the capital in brackets

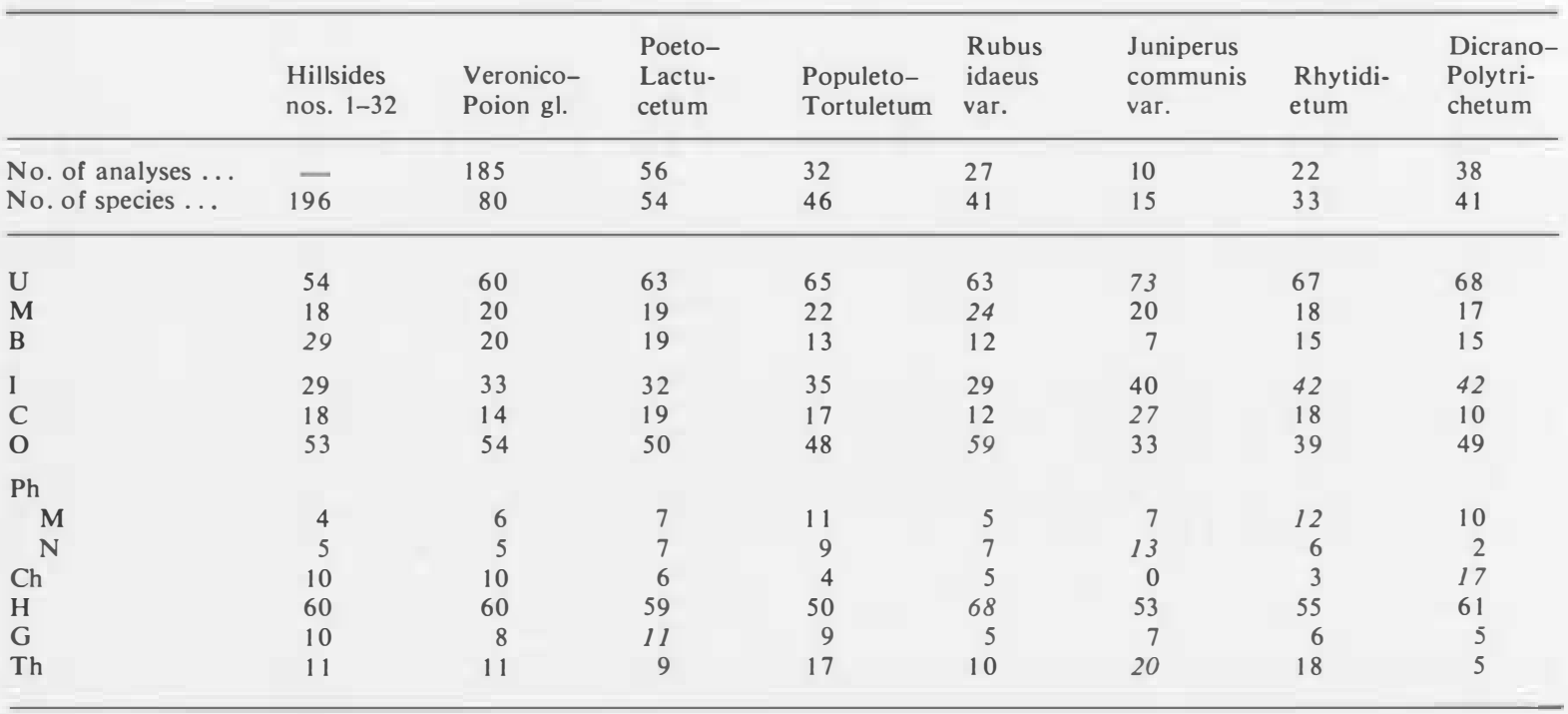

The analysed small quadrats are all within a square $10 \times 10$ $\mathrm{m}$ with a representative tree layer (cover Betula pubescens $25 \%$, Picea abies $50 \%$ ). There are no lichens in the bottom layer.

\section{Concluding remarks on the study of the vegetation}

Finally, some of the more important results of the present synecological studies will be summarized. Some clearly differentiated plant communities have been named, mainly with a starting-point from Nordhagen's work on the vegetation of Sikilsdalen. A closer investigation of the floristic composition, frequency and cover, gave the characteristics summarized in the Survey Table (Table 26). In this table all the plant species are enumerated, with the exception of lichens and those bryophytes which have very sporadic and sparse occurrences. In Table 32 are summarized the phytogeographic and life-form characteristics which may be of interest in the discussion, already started in the chapter on the flora of the hillsides (see Table 15 and Fig. 35). The survey shows that the alliance Veronico-Poion glaucae comprises 80 flowering plants of the hillsides or $41 \%$ of the total number of 196 species of flowering plants dealt with in Tables 15-16. Because of the number of vegetation analyses in the different com- munities being rather irregularly distributed, the results can only give some general characteristics.

In some especially interesting cases, belt transects from the rock wall down onto the open boulder scree have been studied. Of these belt transects, two have been described in the present work and have been discussed with regard to vegetation and the factors of substrate, supply of seepage water etc. A brief comparison with the corresponding communities on the talus slopes of Sikilsdalen was performed, based on investigations in the field. During some of these investigations, interest was focused on the study of the succession of plant communities on talus.

The southern plants Cypripedium calceolus, Circaea alpina and Viola riviniana, and the phytogeographically interesting Saxifraga adscendens which were found new to PL, were investigated with regard to their ecology, in their respective sites.

The ecology of the different communities has been studied in some detail, especially as regards the factors of substrate. As a conclusion drawn from this material, it seems clear that most Boreo-meridional plants, in the broad sense, growing in the vegetation studied, are more or less dependent on the comparatively good edaphic conditions prevailing in their respective habitats. 


\section{HILLSIDES LOCATED IN THE CALEDONIAN AREA}

The following is a closer description of some relevant features of each investigated hillside. It was considered important to give the main ecological characteristics of each locality with the background of location, altitude, exposure, substrate and moisture conditions. The descriptions of the vegetation could be considered as synchorological complements to the survey of the main vegetation units in the chapter on the vegetation of the hillsides. Minor recordings of the vegetation follow the same principles as those used in the chapter on the vegetation.

The flora of the hillsides is summarized in Tables 16 (p. 75) and 17 (behind the text). The species lists comprise the parts of the rock walls that have been investigable (quite unimportant parts of the hillsides in the Caledonian area, somewhat better recordings of the hillsides in the area of Primary rocks treated below) and the talus (scree); foremost the fine scree of the proximal part of talus slopes. Plants recorded from below the boulder scree (coarse scree) or on the sides of screes in other types of habitats by the present author have been denoted by $(+)$. Some recordings made from the literature are uncertain as to their exact hillside localities. Some species almost always present in the Cladonia and Sphenolobus communities = the Cladonia and Sphenolobus variants of Dicrano-Polytrichetum (Tables 24 and 25) may be absent in the lists, as may also be the case with other plants from the distal parts of screes (especially bryophytes). Enumerations of species in the following text are mostly in the systematic order when the plants could not be enumerated in order of importance.

The Lappish names are briefly explained when a derivation of the particular words has been possible (see Collinder 1964). Alep $=$ (situated) upstream: lulep $=($ situated $)$ downstream. Pakte $=$ steep hillside; puoda, vardo $=$ mountain cap; tjahko $\quad($ tjakk $)=$ mountain summit; vare (diminutive varats, varatj) $=$ small mountain. The Swedish names are not always direct translations of the Lappish names of the same mountain. Berg (determinate form: berget), knös (knösen, in accordance with Norwegian)= mountain, hill; lid $($ liden $)=$ till-covered forested mountain ridge .

Altitudes are given in the following order: height of summit (sometimes lacking; noted -), height of rock wall base at its lowermost point and height of valley bottom in the neighbourhood of the mountain (see the chapter on Altitude).

Rockwall inclination is estimated approximately. Scree inclination (dip) (not given here) is generally between $25^{\circ}$ and $42^{\circ}$ but small sections (cf. Fig. 6) are even horizontal. Meridian Clinometer for exact measurements was only used for the hillsides where there have been climatological investigations (see Table 4). Azimuth $=$ the angular distance from the south point of the horizon to the foot of the vertical circle, through an imagined heavenly body corresponding with the exposure direction of the hillside. Given according to compass measurements of larger sections of the rock wall. Azimuth is measured clockwise $(+)$ or anti-clockwise $(-)$ from the $S$.

Dates of visits to the hillsides are complete and precise only with regard to the field notes of the later visitors Wistrand, Nordenstam and Lundqvist. Statements on the locality visited and the dates of visits of former visitors (e.g. L. L. Laestadius, Th. Arwidsson) are sometimes too inexact.

1. Mt. Akkapakte (Lapp. ahka $=$ old woman; in heathen religion $=$ thunder-god's wife)

Position: $66^{\circ} 38^{\prime} \mathrm{N}, 17^{\circ} 42^{\prime} \mathrm{E}$.

Altitude: (838) $610,453 \mathrm{~m}$.

Exposure: Rock-wall inclination $80-90^{\circ}$, azimuth $0^{\circ}$ to $+40^{\circ}$.

Bedrock: See p. 21.

Ground: Fine scree with feebly developed mull layer; coarse scree.

Water: Table 14, sample no. 1 .

The steep hillsides nos. 1,2 and 3 are the topographical terminations towards the $\mathrm{S}$ of an extensive mountain plateau, reaching up into the alpine belt. One of its summits is called Rissatjåkko (altitude $838 \mathrm{~m}$, probably uncertain). There are several scarps constituting Mt. Akkapakte. The one investigated, situated immediately $\mathrm{N}$ of a settlement with the same name, has a rock wall about $1 \mathrm{~km}$ long and fairly high. The water supply from the cliff is sparse.

The little dissected rock wall has a very sparse vegetation, mostly consisting of bryophyte communities in crevices and on the edge of ledges and in 
smaller caves, and lichen communities. With the seepage water are associated the following species

Distichium capillaceum (very sparse)

Tortella tortuosa

Pohlia cruda

Bryum pallescens coll.

Mnium orthorrhynchum

Philonotis caespitosa

Amphidium mougeotii (dom. in crevice)

Campylium stellatum (dom. on ground)

C. sommerfeltii

Amblystegiella sprucei

Leiocolea sp. (very sparse)

Plagiochila asplenioides

In front of the rock wall on the same spot were noted Juniperus communis, Festuca ovina, Carex norvegica ssp. inferalpina, Betula pubescens, Fragaria vesca, Sorbus aucuparia and Vaccinium vitisidaea.

The vegetation gives a poor impression along the greater part of the fine scree. The relative poverty of the vegetation is in part due to a sparse seepage water, displaying low $\mathrm{pH}$ and conductivity values. However, the number of species is fairly high ( 72 species of vascular plants; see Tables 16 and 17). The fine scree zone is mostly very narrow and there are only a small number of trees. Meadow vegetation is present only in fragments. Locally the vegetation consists of a strip of juniper scrub, the Juniperus communis variant of Fruticeto-Tortuletum. Partly this scrub is combined with Drepanocladus uncinatus carpets, approaching the bottom layer of a heath forest, especially where Hylocomium splendens is taking over the dominance. In several places the sparse birch wood present can be said to be a pure heath birch wood with forest dwarf shrubs as dominants in the field layer. A true Rhytidietum community was not found although Rhytidium is present in patches.

The boulder scree is fairly high and consists of boulders of moderate size. The boulders carry a sparse pine wood with admixture of birch (Betula pubescens) and Sorbus aucuparia.

Visits by C. G. Alm in 1927, by Wistrand on 20 August, 1938, and by the present author on 1 August, 1963.

\section{Mt. E Ramanpakte (Lapp. rapma=edge; or:}

ramanj, rames $=$ powerful)

The form "raman" was used in the work where the topograhic feature was originally described (Svenonius F. 1894 , p. 2). Wistrand (1962, p. 46) used the form "ramanj". The name of the topographic map is Mt. Tjeggelvaspakte. See p. 21.
Position: $66^{\circ} 37^{\prime} \mathrm{N}, 17^{\circ} 38^{\prime} \mathrm{E}$.

Altitude: (838) 621, $453 \mathrm{~m}$.

Exposure: Rock-wall inclination $80-90^{\circ}$, azimuth $0^{\circ}$ to $+40^{\circ}$.

Bedrock: See p. 21.

Ground: Fine scree with thin to moderately deep mull layer, coarse scree.

Water: Table 14, sample no. 2.

This mountain-side is the most imposing of those in PL (Wistrand 1962, p. 19), immediately rising about $300 \mathrm{~m}$ above the surface or Lake Tjeggelvas. In spite of the tower-like silhouette of the mountain the plateau is rather level and smooth (see Wistrand, l.c., Fig. 3, cf. Fig. 4).

Although the talus slope at first looks dry and sparse, there is in some places a temporary flow of seepage water, which provides better conditions and attracts more demanding plants. But the rock wall is in general very sparse in mosses or higher plants, and the plant communities present of the Veronico-Poion glaucae alliance are mostly fragments.

The fine scree only supports a narrow strip of vegetation, dominated by a sparse heath-like scree birch wood. There are large gaps in the tree layer and junipers play an important role. Here and there fragments of tall meadow communities are present (Poeto-Lactucetum, Table 18, stand no. 1). Large carpets of the Cladonia variant of Dicrano-Polytrichetum (often with strikingly poor field layer) are present. These are often situated in open treeless parts of the fine scree. Rhytidium rugosum is not found. The subalpine character is strongly augmented by frequent interspersion of Alchemilla alpina in several communities of the hillside.

The most remarkable find is probably Grimmia hartmanii var. anomala (found on cliff). On the whole the moss seems to be rare in the mountains of Sweden. It was first found in PL by $\mathrm{Hj}$. Möller.

The E-facing side of the same mountain has a similar appearance, but the rock wall is not so high. The vegetation is lusher in some places because of a more abundant water supply (Wistrand, personal communication; visit on 27 July, 1966).

The S-facing side has certainly been visited by several naturalists (cf. Svenonius 1894; Kulling 1948, p. 33). Also visits by Wistrand (20 July, 1938), and the present author (30 July, 1963, 26 July, 1967).

\section{Mt. W Ramanpakte}

Position: $66^{\circ} 37^{\prime} \mathrm{N}, 17^{\circ} 38^{\prime} \mathrm{E}$.

Altitude: (838) $497,453 \mathrm{~m}$.

Exposure: Rock-wall inclination $80-90^{\circ}$, azimuth $-20^{\circ}$ to $+40^{\circ}$. 
Bedrock: See p. 21.

Ground: Fine scree with faint to moderate, locally deep mull layer, coarse scree.

The rock wall is mostly poor in plants (especially bryophytes), but some more rare occurrences are reported (Wistrand 1962, pp. 115-116): Potentilla multifida. ( $P$. norvegica from the scree). The base of the rock wall is on average much lower in altitude than the previous hillsides $(575 \mathrm{~m}$ max. altitude in the $\mathrm{E}$ part, soon dropping to ca. $525 \mathrm{~m}$ ). Because of this the subalpine impression is definitely less pronounced, and the percentage of southern elements is higher (Fig. 35).

Seepage water is present, but evidently it has no major influence on the vegetation. In one place a small stream runs directly from the plateau down the rock wall. There are many ledges and the vegetation on them and on the scree in the immediate neighbourhood is very dissimilar with hydrophilous plants (Molinia coerulea meadow, in the crevices e.g. Saxifraga aizoides).

The hillside has a fine scree of varying breadth and in general a lush meadow vegetation in front of the rock wall. Populeto-Tortuletum is frequently present, in contrast to the hillsides previously described. Betula pubescens is a frequent admixture but is also often solitary. Poeto-Lactucetum and especially Fruticeto-Tortuletum are very extensive communities, with the more unusual element Angelica silvestris, and occasional dominance by Rosa majalis and Rubus idaeus. In part, Juniperus communis extends to large carpets. Very small fragments of Rhytidietum were seen on the scree but never on the rock wall. Polytrichum-Cladonia carpets are rare, but found in some places in the transition zone to the open boulder scree. The carpets seen here are dominated by Cladonia and other lichens.

The mountain-side was visited by Wistrand on 22 July, 1947 , and by the present author on 31 July, 1963, and on 26 July, 1967.

\section{Paktesuolo (Lapp. suolo $=$ island, islet)}

Position: $66^{\circ} 36^{\prime} \mathrm{N}, 17^{\circ} 37^{\prime} \mathrm{E}$.

Altitude: (-) 467, $453 \mathrm{~m}$.

Exposure: Rock-wall inclination $70-90^{\circ}$, azimuth $0^{\circ}$ (approx.).

Bedrock: See p. 21.

Ground: Fine scree with thin mull layer, coarse scree (partly below the surface of the lake).

There is no seepage water on the cliff, which is comparatively low (see Wistrand 1962, p. 19, Fig. 3 to the left). Crevices and ledges have the rare element Potentilla multifida in an impoverished and very dry type of plant community, partly classed as fragments of Tortulo-Poetum (Fruticeto-Tortuletum). The Cladonia variant of Dicrano-Polytrichetum is also very common on similar sites on hillsides in the $\mathrm{N}$ parts of PL, but was not actually seen. Rhytidietum is less extensive and forest heaths are common only on the edges of larger hillsides or on terraces and ledges of smaller ones (lichen and bryophyte synusiae were left out of consideration). In this case Rhytidietum is absent from the lower parts of the rock wall, although fragments might be expected, as Dryas octopetala is present on the islet (Johnsson 1930 , p. 138) and the two communities are supposed to interfere.

For the reasons mentioned, the scree is relatively dry but nevertheless the upper wood is meadow-like (Populeto-Tortuletum and Fruticeto-Tortuletum). The tree layer may be partly less well developed but shrub thickets are abundant, even on boulder scree. Juniperus communis and Prunus padus are probably the most important. Often dominant plants in the upper wood are Fragaria vesca, Festuca ovina and Poa nemoralis; Schistidium apocarpum on bare rock debris. In the easternmost part of the hillside heath birch wood penetrates from the side.

Because of the dry aspect and limited extent of the hillside the number of species is low, but there are some other species of interest (see Tables 16 and 17).

The islet got a wide reputation at the end of the last century because of E. Nyman's find in 1892 of Potentilla multifida (Nyman 1895). It was a new find for the Scandinavian peninsula.

Earlier visitors have been numerous. Some botanists are E. Nyman in 1892, F. Dahlstedt in 1918 and N. Johnsson in 1928 (Johnsson, N. 1930). Also visits by Wistrand on 17 and 20 July, 1938, and on 10 August, 1965; and hy the present author on 2 August, 1963, and on 10 August, 1965 (together with Wistrand and S. Nordenstam).

\section{5. . . Ardnapakte (Lapp. ardnas = eagle)}

Position: $66^{\circ} 35^{\prime} \mathrm{N}, 17^{\circ} 34^{\prime} \mathrm{E}$.

Altitude: (728) 488, $453 \mathrm{~m}$.

Exposure: Rock-wall inclination $80-90^{\circ}$, azimuth $-10^{\circ}$ to $+40^{\circ}$.

Bedrock: See p. 10.

Ground: Fine scree with moderate to thick mull layer, coarse scree.

The $\mathrm{E}$ edge of the mountain Tuolpakvare was called Ardnapakte by Wistrand (1962, p. 46). Correct spelling should be Ardnaspakte according to I. Ruong.

The water supply may be partly abundant, partly very scarce. Probably it has about the same content 
as in the other places with Laisberg sandstone, see p. 62 and Table 14

The S-facing slope consists of a number of extremly regular talus cones, the top of which is mostly situated at a fault line in the rock wall.

The fine scree is fairly broad in places, and the vegetation on it is predominantly meadow woods. On the sides, especially the E edge, heath birch wood mixes up with true talus elements, and the slope is wooded from the cliff to the foot of the scree. Mixed stands with Vaccinium vitis-idaea are very common here. Farther W, Tortulo-Poetum takes over, even if small heath-like parts typically dominated by $D e$ schampsia flexuosa come in now and then. The juniper shrub is fairly common everywhere, especially in the $\mathrm{E}$ parts. Populeto-Tortuletum is present although of more limited extent. The field layer is luxurious, and in one place includes Epilobium montanum. In the more western sections of the hillside the talus cones are dominant and the tree layer is missing. Solitary trees are present. In the extreme $\mathrm{W}$ part the scree (boulder scree) is very low, and Galium triflorum is present in the transitional types to heath forest.

The rare elements Polygonum dumetorum and Arenaria serpyllifolia are present in the FruticetoTortuletum community. This type of community is fairly abundant especially on the talus cones. Other luxuriant plants in the community are Campanula rotundifolia, Urtica dioeca ssp. Sondenii and Hieracium erythropoecilum.

Rhytidietum seems to be of less importance and is always very fragmentary (p. 93).

Visits by Wistrand on 24 July, 1947, by the present author on 3-6 September, 1962, on 2 August, 1963, and (together with Wistrand and S. Nordenstam) on 10 August, 1965.

\section{6. $M t$. Kebnevare (Lapp. kiebne $=$ kettle $)$}

Position: $66^{\circ} 33^{\prime} \mathrm{N}$ (the Arctic Circle), $17^{\circ} 40^{\prime} \mathrm{E}$. Altitude: (793) (a) 670, (b) 553; $453 \mathrm{~m}$.

Exposure: Rock-wall inclination (a) 80-90 $70-90^{\circ}$; azimuth $(a)+30^{\circ}$ to $+60^{\circ},(b)$ $-60^{\circ}$ to $-120^{\circ}$.

Bedrock: See p. 10.

Ground: (a) Scree without mull layer, schistose gravel and smaller boulders.

(b) Mostly coarse scree and thin mull layer, partly forest mull.

(a) The rock wall has a very sparse flora and the bryophytes mostly occupy only crevices and caves in a shaded situation. Lichens are also very sparse. The S- to SW-facing upper scree of the mountain has a very poor vegetation partly because of the absence of seepage water and the subalpine situation. There are very few trees and single specimens of aspens, junipers and birches closely attached to the surface of the scree are the most obvious features. There are also single specimens of vascular plants with only fragments of a bottom layer (dominated by Polytrichum species, foremost Polytrichum piliferum). Tortula ruralis is rare on the cliff and in a Geranium-dominated meadow fragment of the fine scree. The dominant communities are pure Vaccinium vitis-idaea and Arctostaphylos uva-ursi heaths and Juniperus thickets.

(b) The bryophyte flora of the cliff is somewhat richer than the previous slope, and ledges with $D i$ cranum fuscescens dominance are numerous, partly intermingled with Vaccinium heath. On these were found, very sparsely, Sedum annuum, Silene rupestris, Fragaria vesca and Carex ornithopoda. The proximal parts of the E-facing scree are dominated by a thin birch wood with sparse intergrowth of shrubs and single specimens of Geranium, Chamaenerion etc. Vaccinium patches are abundant. Occasionally there are patches with dominant Aconitum septentrionale (the Lactucion alliance). In the $S$ part of the scree, which is more exposed to the sun, the Sphenolobus variant of Dicrano-Polytrichetum takes over (with Poa glauca especially on the upper surfaces of boulders where there is some fine debris).

Visits by Wistrand on 13 August, 1962, by the present author on 22 August, 1963, and on 23 August, 1965.

$6 \mathrm{~km} \mathrm{SSW}$ of Mt. Kebnevare is a high mountain ridge called Bartutvalle ((893) 755, $453 \mathrm{~m}$; exposure NE-S). Some parts of the huge screes surrounding the plateau are abundantly wetted, partly with seepage water, partly with long persisting small streams from snow drifts on the plateau. The conditions, at least on the S-facing slope, are very favourable for tall herb meadows to be developed (Fig. 36). More sparsely wetted or dry parts are evidently to be classed as Tortulo-Poetum of a subalpine character (but with e.g. Fragaria vesca). In this type there are no trees but some shrubs.

On drier parts of the rock wall are Dryas heath fragments (with Carex rupestris and C. arctogena).

The Hieracium flora of the mountain and the surroundings is very rich (S. Nordenstam, personal communication), containing several species not found elsewhere in PL.

Visits by Wistrand on 19-20 July 1947, on 15 July 1963 , (together with Nordenstam) on 22 July and on 10 August, 1966, and by Wistrand, Nordenstam and Lundquist on 9 August, 1965. 


\section{Mt. Kaldopakte (Lapp. kaldo $=$ cold spring)}

Position: $66^{\circ} 37^{\prime} \mathrm{N}, 17^{\circ} 9^{\prime} \mathrm{E}$.

Altitude: (1177) 703, $623 \mathrm{~m}$.

Exposure: Rock-wall inclination $70-90^{\circ}$, azimuth $-10^{\circ}$ to $+20^{\circ}$.

Bedrock: See p. 21.

Ground: Fine scree with thin mull layer, coarse scree.

This high mountain is situated $22 \mathrm{~km} \mathrm{~W}$ of the SE border of the Caledonides, or "glint line" constituting the previously discussed hillsides. The area (with Lake Partaure) is lacking coniferous trees because of the high altitude of the valley bottom. The S-facing side is extensive and only the part constituting a small scree in the immediate neighbourhood of the lake has been investigated.

There are crevices with an abundant water supply on the rock wall and Philonotis dominance. Below outflows there are Geranium and Aconitum meadows with Epilobium lactiflorum, Angelica archangelica etc. The Geranium meadows are fragments of Tortulo-Poetum, as there are several typical talus elements present: Sedum annuum, Silene rupestris, Erysimum hieraciifolium, Viola montana, Hackelia deflexa, Botrychium lunaria and Poa glauca. The upper wood is dominated by Betula pubescens and some small specimens of Sorbus aucuparia and Prunus padus (aspen trees are rare). Juniperus, Ribes spicatum var. lapponicum and Salix lapponum are abundant. Daphne mezereum was not seen. Vaccinium myrtillus heath is fairly extensive on the Sfacing side, especially on the sides and lower parts of the talus.

It seems that we have here the northwesternmost occurrences of Tortulo-Poetum community (the Fruticeto-Tortuletum variant). Many of the talus elements mentioned vanish completely further towards the NW or are very rare. Tortula ruralis is still present as a facultative talus element, but the tendency to be confined to the rock wall is pronounced (cf. the previous locality, no. $6 a$ ).

The mountain-side was visited by the present author on 23 July, 1965, and on 7 August, 1966 (together with S. Nordenstam).

\section{Mt. Jokkokvarats $($ Lapp. johko $=$ small} stream, brook)

Position: $66^{\circ} 26^{\prime} \mathrm{N}, 17^{\circ} 19^{\prime} \mathrm{E}$.

Altitude: (-) 517, $502 \mathrm{~m}$.

Exposure: Rock-wall inclination $60-90^{\circ}$ (partly overhanging), azimuth $0^{\circ}$ to $+30^{\circ}$.

Bedrock: See p. 21.

Ground: Coarse scree with forest mull.
There is a sparse water supply on the cliff, on which there are several scarps. The cliff is only 5-20 $\mathrm{m}$ high and the scree is also quite small. The foot of it is immediately above the upper surface of the lake (Lake Rebnisjaure) when the dam will be in operation (to $513 \mathrm{~m}$ ).

The perpendicular surfaces of the rock wall are covered by large cushions of Bartramia spp. and Amphidium spp. Eurhynchium pulchellum dominates on ledges.

The scree is totally covered by a thin birch wood with an admixture of Sorbus aucuparia and Salix caprea. Dwarf shrubs are present throughout, also in front of the rock wall. The juniper in part forms an almost complete cover (Viola Selkirkii as sparse admixture). The most extensive parts of the boulder scree in front of the rock wall are covered by the following type of vegetation (degree of cover for a typical stand in parentheses):

Juniperus communis (2)

Ribes spicatum var. lapp. (1)

Empetrum hermaphroditum (2)

Vaccinium vitis-idaea (2)

Linnaea borealis (2)

Festuca ovina (2)

Chamaenerion angustifolium (1)

Rubus saxatilis (2)

Solidago virgaurea (1)

Stellaria longifolia (1)

Viola Selkirkii (1)

Barbilophozia hatcheri (1)

Brachythecium salebrosum (2)

Hylocomium splendens (2)

Psedoleskeella nervosa (2)

Ptilidium ciliare (1)

Schistidium apocarpum (1)

In this vegetation Melica nutans is a more or less abundant admixture, in spots it may be almost dominant.

The vegetation discussed above is, with the probable exception of Viola Sclkirkii, typical for the less extensive screes with small cliffs in which forest heath intermingles. Especially in the NW, the birch is the dominant tree in similar sites with very old and stabilized boulder screes.

There are several small screes facing SW on the NE side of Lake Rebnisjaure. Most of them seem to have a similar vegetation to the one discussed above and with sparse interspersion of Paris quadrifolia, Melica nutans, Milium effusum, Carex ornithopoda, Populus tremula, Stellaria longifolia, Melandrium rubrum, Actaea spicata, Silene rupestris, Fragaria 
vesca and Daphne mezereum. These species were all present on a more elevated scree (ca. $550 \mathrm{~m}$ ) in the neighbourhood of Mt. Jokkokvarats. The more demanding elements Carex ornithopoda and Fragaria vesca were found on the rock wall only. Carex ornithopoda is also found as a rare element in the geolittoral zone of the lake.

Visits by the present author on 13 August, 1963, and on 21 July, 1967.

The locality Simselet, $17 \mathrm{~km} \mathrm{~W}$ of the locality, in the main river valley of Skellefte River, is remarkable for its flora, which comprises many southern and calciphilous plant species (see Lundqvist, J. 1966, pp. 194 et seq), e.g. Cypripedium calceolus, Myosotis laxa ssp. caespitosa, Peltigera praetextata etc. The locality is situated on S-facing ground below a smaller scarp of cliff, on calcareous till-covered ground which is rather moist (analyses of the soil, see samples nos. 45-47, Table 1). The crevices of the small cliff are dominated by Distichium capillaceum, Tortella tortuosa, Myurella julacea, Encalypta spp. and Plagiopus oederi, species which all indicate very favourable substrate.

Visits by the present author on 11 August, 1963, and on 21 July, 1964 (together with Wistrand).

9. Mt. Laisvare (Derivation of the name uncertain) Position: $66^{\circ} 15^{\prime} \mathrm{N}, 17^{\circ} 25^{\prime} \mathrm{E}$.

Altitude: (705) (a) 592, (b) 551; $425 \mathrm{~m}$.

Exposure: Rock-wall inclination (both) $80-90^{\circ}$, azimuth (both) $+40^{\circ}$ to $+50^{\circ}$.

Bedrock: Kaskajaure-complex and Laisberg sandstone, see p. 21.

Ground: (a) Schistose gravel (pebbles, boulders) with thin mull.

(b) Coarse scree with thick forest mull layer, partly meadow mull.

Water: Table 14, sample no. 3 .

(a) The SW-facing upper scree has only sparse temporary water supply. The general impression is of a dry and poor slope, but the vegetation has not the definite subalpine character of the parallel Mt. Kebnevare (see above). There are no trees in front of the cliff, Betula pubescens stands come lower down on the scree. The field and bottom layers of the proximal parts of the talus are also sparse with patches of the Cladonia variant of Dicrano-Polytrichetum (analyses see Table 25, stand no. 1). Some small patches with dominance of Tortula ruralis are interspersed in some places. The more shaded stands of the lower parts of the scree have tall herbs (partly intermingled with Vaccinium vitis-idaea, see Table
22, stand no. 2). Some small Populeto-Tortuletum stands are present. Grasses are often dominant (Festuca ovina, Poa nemoralis and Deschampsia flexuosa).

Rhytidietum is not present. The bryophyte flora of the rock wall is poor although there are many crevices and ledges.

(b) The most rare occurrences are found on the cliff, i.e. Bryum argenteum and Collema tenax var. expansum, the latter in the cave where the water sample was taken (confirm. Degelius). Taraxacum cochleatum is also found on scree. In all, 125 species of higher plants are known from Mt. Laisvare. Hence it is one of the richest localities in PL. The water supply is much better on this slope. There are even caves with water pools where the scree is dipping inwards towards the rock wall or plane. The forest cover of the stabilized scree is almost closed stands of spruce and pine forest with Betula pubescens, Sorbus aucuparia, Prunus padus, Salix phylicifolia and $S$. myrsinifolia. The field and bottom layers are in part a Vaccinium-Hylocomium type with admixture of Fragaria vesca, Veronica officinalis and other herbs. The drier parts are dominated by lichens (Cladonia spp.) in one case with the rare admixture Arabis hirsuta, probably to be classed as Dicrano-Polytrichetum. There are no other communities of the Veronico-Poion glaucae alliance present on the scree, but there are fragments on the rock wall.

Mt. Laisvare was visited by Birger in 1909 , by Wistrand on 6 July, 1938, and by the present author on 27 June and 27 July, 1963, on 21 August 1964, on 2 and 8 July, 1965, and on 16 April, 1966.

\section{Mt. Fabmevare (Lapp. fapmu= power)}

Position: $66^{\circ} 16^{\prime} \mathrm{N}, 17^{\circ} 19^{\prime} \mathrm{E}$.

Altitude: (598) 546, $425 \mathrm{~m}$.

Exposure: Rock-wall inclination $80-90^{\circ}$, azimuth $+30^{\circ}$.

Bedrock: Kaskajaure-complex, see p. 22. No sandstone.

Ground: Thin to thick mull layer, fine scree and coarse scree.

The mountain is only $6 \mathrm{~km} \mathrm{NW}$ of the previous mountain, somewhat isolated beside the river valley. It is low enough for trees to grow on the cap.

There is no or very little water supply on the cliff. In spite of this the bryophyte synusiae of the rock wall are fairly well differentiated and rich in species. Rhytidietum community is common on ledges. Potentilla argentea is present only on the rock wall. 
The talus slope is almost wholly covered with $\mathrm{Be}$ tula pubescens with varying under-growth, but Populus tremula stands are present in smaller patches. Especially on the sides, forest heath communities are common, but in the $\mathrm{E}$ there are extensive patches of Poeto-Lactucetum or true Lactucion woods with dominance of Actaea spicata, Paris quadrifolia, Aconitum septentrionale, Matteuccia struthiopteris etc. in different stands. Shrubs of Ribes spicatum var. lapponicum are frequently interspersed. FruticetoTortuletum stands below the rock wall have the rare elements Viola Selkirkii and Pylaisia polyantha.

The Dicrano-Polytrichetum community, especially the Sphenolobus variant, is locally important on the boulder scree.

Visits by Wistrand on 20 July, 1934, on 12 July, 1947, and on 28 July, 1965, by the present author on 9 August, 1963, and on 6 July, 1965.

Mt. Svartberget is an E-facing hillside $7 \mathrm{~km} \mathrm{~N}$ of Mt. Fabmevare, with screes directly sloping below the surface of Lake Hornavan (as locality no. 5 in Lundqvist, J. 1961, p. 171). The flora on the cliff comprises fragments of the Dryas heath (Dryas octopetala, Salix reticulata, Saxifraga aizoides, S. oppositifolia, Carex capillaris etc.). The very loose schistose gravel of the scree is partly bare of vegetation, but there are sparse patches of the Cladonia variant of Dicrano-Polytrichetum, together with a few hillside elements (Silene rupestris, Sedum annuum); further down, Puris quadrifolia, Melica nutans, Barbarea stricta and Daphne mezereum and even in some places again Dryas heath fragments, together with the usual forest heath fragments in more stabilized parts.-There is a scarp of the same hill towards the $\mathrm{S}$ with some Tortulo-Poetum fragments, especially on the cliff, and a coarse scree at the base of the hillside. See Wistrand 1934.

Visits by Wistrand on 19 August, 1932, on 25 July, 1934, and (together with Nordenstam, Evers and Olrog) on 27 July, 1967, by the present author on 16-18 July, 1959.

\section{Mi. Korpberget $($ Swed. korp $=$ raven)}

Position: $66^{\circ} 16^{\prime} \mathrm{N}, 16^{\circ} 47^{\prime} \mathrm{E}$.

Altitude: (?) $580,452 \mathrm{~m}$.

Exposure: Rock-wall inclination $80-90^{\circ}$, azimuth $0^{\circ}$ to $-60^{\circ}$.

Bedrock: The Kaskajaure-complex, see p. 22.

Ground: Fine scree with thin or rather deep mull layer, coarse scree.

There are larger scarps of rock wall at different elevations, the upper one at $672 \mathrm{~m}$. Only the vege-

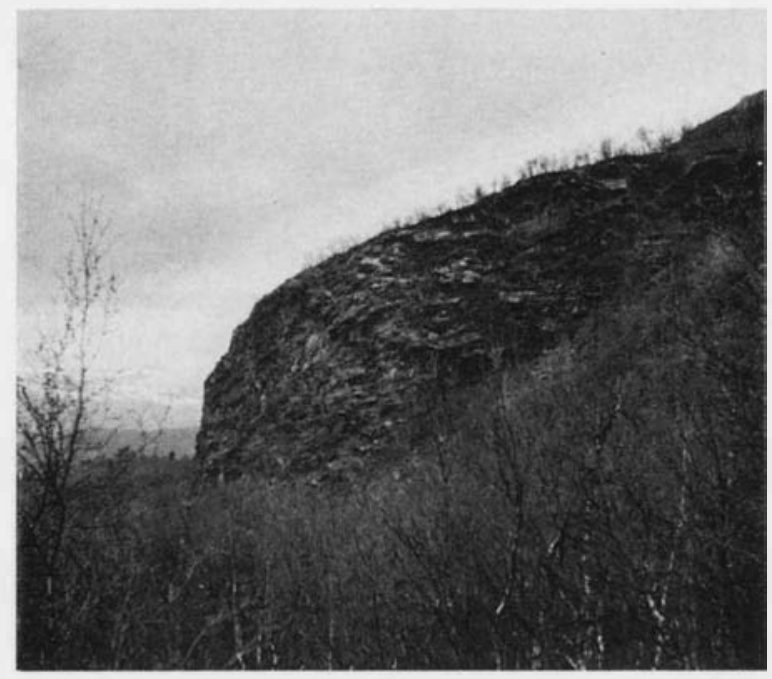

Fig. 44. Mt. Korpberget (no. 11), the lower scarp, towards the W. There are very few individuals of pine (Pinus silvestris) in the birchdominated forest $(600 \mathrm{~m}) .9$ June, 1964.

tation on the lower hillside will be described. The cap of the mountain is treeless.

There is a sparse water supply, but the part of the rock wall facing $\mathrm{S}$ has a shaded cave suitable for many of the less common bryophytes.

The fine scree is dominated by Betula pubescens and Populus tremula. Juniperus shrubs are very common. The field layer may be partly dominated by grasses (Deschampsia flexuosa, Poa glauca and nemoralis), partly by herbs, among which the most abundant are Geranium silvaticum, Aconitum septentrionale, Chamaenerion angustifolium and Fragaria vesca. In one place there is dominance by Vaccinium myrtillus and $V$. vitis-idaea, reminding one that the communities are rather mixed with forest heath. The bottom layer is dominated by Brachythecium reflexum, Tortula ruralis and Pseudoleskeella nervosa. Schistidium apocarpum is most abundant on the rock wall.

The most interesting species are mostly found on the rock wall (Cerastium alpinum $\times C$. glabratum, Saxifraga cernua), but Grimmia hartmanii var. anomala was found on scree.

Visits by the present author on 15 August, 1958, on 9 June, 1964 , on 25 August, 1966, together with Wistrand on 16 July, 1963, and together with Nordenstam and Wistrand on 6 August, 1965.

\section{Mt. Märkepakte (Lapp. märhka $=$ mark)}

Position: $66^{\circ} 13^{\prime} \mathrm{N}, 16^{\circ} 54^{\prime} \mathrm{E}$.

Altitude: (538) 473, $424 \mathrm{~m}$.

Expoure: Rock-wall inclination $60-90^{\circ}$, azimuth $-10^{\circ}$ to $+20^{\circ}$. 
Bedrock: The Kaskajaure-complex, see p. 22.

Ground: Fine scree with moderate to deep mull layer, coarse scree.

Water: Table 14, sample no. 5 .

The seepage water of the cliff is sparse and temporary, present only in a place in the $\mathrm{W}$ part of the hillside, after thaw or periods of rain. Strips of calcium carbonate are common on the rock wall. The crevices are generally dominated by Torte!la tortuosa, even in the more dry E part.

The S-facing fine scree is dominated by stands of Populus tremula intermingled with Salix caprea, Betula pubescens and Pinus silvestris, the pine represented by one single tree on the foot of the rock wall. In one place, below the outflow of seepage water, is a stand of Poeto-Lactucetum (Table 18, stand no. 2). Representative stands of the other types of communities are noted in Tables 19-24 (see the notes to tables, pp. 88 et seq.). The plant communities of the fine scree are mostly of very typical appearance, including segments with Arctostaphylos uvaursi (border community towards the open boulder scree or on the rock wall), Vaccinium vitis-idaea (Table 23, stand no. 1, see also Fig. 43) and Vaccinium myrtillus (in the $\mathrm{W}$ part below the gently sloping rock wall with much snow accumulation in winter). The most common types of meadows are dominated by Rubus saxatilis, Geranium silvaticum, Valeriana sambucifolia and shrubs, and the scree has a very typical zonation (p. 98). The boulder scree is dominated by lichen communities and there are fragments of the Sphenolobus community (Table 24). On the lower part there is a change to the poor forest heath with pine and birch dominating the slope outside the talus slope.

There are screes of SE and NE aspect on the same mountain, with forest heath or Dicrano-Polytrichetum communities. The SE-facing side displays very mull-rich types of boulder scree, dominated by $\mathrm{Hy}$ locomium sp'endens, but with sparse admixture, in lower stands, of Rhytidium rugosum and Abietinella abietina. On the slope outside this scree is found Cypripedium calceolus. See also p. 103.

There have been continuous investigations by the present author in 1961-66. Visited together with Wistrand on $29 \mathrm{July}$, 1962.

\section{Mt. Storberget $($ Swed. stor $=$ large $)$}

Position: $66^{\circ} 14^{\prime} \mathrm{N}, 16^{\circ} 58^{\prime} \mathrm{E}$

Altitude: (660) (a) 556, (b) 584, (c) 450; $424 \mathrm{~m}$.

Exposure: Rock-wall inclination (a) $60-80^{\circ},(b)$ $80-90^{\circ}$, (c) $60-90^{\circ}$; azimuth $(a)+5^{\circ}$ to $+10^{\circ}$, (b) $0^{\circ}$, (c) $0^{\circ}$ to $+30^{\circ}$.
Bedrock: $(a)$ and (b) Kaskajaure-complex (c) Yrafcomplex, (Kautsky 1940).

Ground: (a) Fine scree with thin to rather deep mull layer, coarse scree.

(b) Fine scree with thin mull layer, schistose gravel and some boulders.

(c) Poorly developed fine scree, coarse scree and forest ground.

(a) There is only a sparse water supply and the cliff is mostly poor in bryophytes and other plants, Juniperus communis being dominant on the ledges. There are small caves at the foot of the rock wall (with Brachythecium velutinum). Rhytidietum community is present in spots (with Dicranum muehlenbeckii). Potentilla argentea is also present only on the rock wall.

The fine scree is covered with open stands of Populus tremula with admixture of Betula pubescens and Salix caprea. The admixture of forest dwarf shrubs is always fairly great in the field layer, but there are sparse tall herbs. Pure Tortulo-Poetum communities are rare.

Below the low scree there is a moist depression and a plateau with pine and birch.

(b) There is no seepage water on the cliff, which is low (see Fig. 24) and consists of several scarps of different exposure and dip. The vegetation of the cliff is mostly poor heath types with Juniperus communis and forest dwarf shrubs, especially Vaccinium vitis-idaea.

Most of the plant communities present are considered to be mixed stands, and hence there are no vegetation analyses recorded here. However, the especially high percentage of southern plants is interesting (Fig. 35), more of them being found also outside the screes in meadow birch forests etc. on the same hillside.

The open stand of trees is dominated by Betula pubescens and Populus tremula, the latter mostly stunted. Sorbus aucuparia and Salix caprea are intermingled. The upper parts of the scree in particular are fairly loose and there are even bare patches (dip $42^{\circ}$ at maximum). Arabis hirsuta, Sedum annuum, Silene rupestris and Tortula ruralis are abundant at the edge towards the more open patches. Fragaria vesca and Veronica officinalis are present in the more shaded types. The foot of the scree and the forest below are dominated by tall meadow communities in which Aconitum septentrionale, especially, and Dryopteris filix-mas grow luxuriantly. Because of the relatively lush field layer nourished by the wet lower slope, and in part rather closed stands of trees the hillside has a character which is defi- 
nitely different from the boulder-rich screes described earlier.

Dryopteris spinulosa, Carex ornithopoda, Stellaria longifolia, Fragaria vesca and Veronica officinalis are present in the more shaded meadow birch forests, partly on almost level ground, which are present at different altitudes on the hillside, but particularly at higher elevations. Veronica officinalis is present in the following type of birch wood with sparse trees (ca. $10 \times 10 \mathrm{~m}$; only more important plants noted; degree of cover in parentheses):

Juniperus communis (2)

Vaccinium myrtillus (3)

Anthoxanthum odoratum (2)

Festuca ovina (4)

Geranium silvaticum (2)

Gnaphalium norvegicum (1)

Gymnocarpium dryopteris (1)

Hieracium sp. (1)

Luzula pilosa (1)

Ranunculus acris (1)

Solidago virgaurea (2)

Trientalis europaea (1)

Trollius europaeus (1)

Veronica officinalis (1)

Viola biflora (2)

Hylocomium splendens (3)

Barbilophozia lycopodioides (2)

Rhodobryum roseum (1)

Fragaria vesca is not present here but is present in similar types of woods, especially on Mt. Korpberget, Mt. Storberget and Mt. Laisvare; on Mt. Storberget in pure Lactucion woods.

(c) The lowermost rock wall of the E part of Mt. Storberget is the most imposing of the hillsides $\mathbf{N}$ of Hällbacken (called Östreberget), forming a scarp which is about $50 \mathrm{~m}$ high. There is sparse seepage water in places, and the vegetation of the rock wall is fairly rich, dependent on many ledges and crevices of different exposures. Junipers, dry grass meadows, Vaccinium and Arctostaphylos heaths play an important role.

The greater part of the slope below the rock wall is covered by birch forest with admixture of pine and especially aspen trees. The smaller patches with fine scree are covered with Populus stands, partly mixed types. Junipers are also important below the rock wall, on boulder scree. In the rather open thickets grows Viola Selkirkii (Dicrano-Polytrichetum type). Other shrubs are abundant on the stabilized substrate but meadow-dominated stands are sparse, especially those with southern and more light-de- manding plants. Epilobium collinum is found mostly on the rock wall, in open caves.

Investigations by the present author in 1958-63 and 196566. Visited by Wistrand on 6 August, 1934.

The highermost peak of the largely birch forest clad ridge $\mathrm{N}$ of Hällbacken (Fig. 4) is called Puoudak ((744) 560, $424 \mathrm{~m}$ ) and is bare on top. The S-facing side has a steep rock wall, descending from $710 \mathrm{~m}$ close to the summit area and comprising a stabilized small scree largely covered by birch and scrub vegetation. The field layer is mostly dominated by Vaccinium dwarf shrubs and some herbs, e.g. Fragaria vesca and Veronica officinalis. The lowermost part of the rock wall has hardly any scree in front of it, and the vegetation below the scree is meadow birch forest.

There are several S-facing hillsides in the upper valley of River Laisälven, none of which has as rich a flora as hillsides nos. 11-13. $24 \mathrm{~km} \mathrm{NW}$ of Mt. Korpberget, with the northwesternmost occurrences of pine on it, is Mt. Plassavardo ((789) 520, $500 \mathrm{~m}$; the values are approximate). There is hardly any typical scree, but there is a SE-facing rock wall with birch wood on the bouldery ground below it. On this ground, on which Populus tremula, Salix caprea and Sorbus aucuparia are rather important, there are some interesting species present partly in the mainly Vaccinium dominated wood, e.g. Polypodium vul. gare, Paris quadrifolia, Melica nutans, Poa nemoralis, P. glauca, Milium effusum, Stellaria longifolia Rubus idaeus and Arctostaphylos uva-ursi. In the E part of the mountain, at about the same altitude as the uppermost pines in the $\mathrm{W}$ part of the same mountain $(630 \mathrm{~m})$, Populus tremula is still a huge tree ca. $17 \mathrm{~m}$ high and $30 \mathrm{~cm}$ in maximum diameter $1.4 \mathrm{~m}$ above the ground. The community is heath forest.

Still further E is the S-facing till-covered slope of Mt. Vallåive. As the bedrock is partly pure limestone, the flora is extremely luxurious for the NW locality. Here Daphne mezereum, in its northwesternmost locality, displays enormous thickets probably unique for N Sweden (C. Grill, personal communication).

\section{Visits by the present author in September, 1961.}

$1 \mathrm{~km} \mathrm{~W}$ of locality no. $13 a$ is Mt. Långsjöberget on the $\mathrm{N}$ side of a smaller lake. The cliff steeps abruptly from ca. 570 to $550 \mathrm{~m}$ and is S-exposed with a fairly typical scree between it and the surface of the lake. The flora comprises all the common hillside elements. The vegetation below the rock wall is a mixed aspen and birch wood of fragmentary 
character and many shrubs, especially junipers, interspersed (Table 21, stand no. 2). The rare occurrences of Brachythecium erythrorrhizon and Pylaisia polyantha indicates the locality being rather rich.

Visits by the present author on 8 July, 1958, on 14 September, 1962, and on 10 August, 1966.

14. Mt. Alep Nadok (derivation of the name uncertain, probably nadda = low mountain-projection)

Fosition: $66^{\circ} 10^{\prime} \mathrm{N}, 17^{\circ} 8^{\prime} \mathrm{E}$.

Altitude: (-) $471,424 \mathrm{~m}$.

Exposure: Rock-wall inclination $80-90^{\circ}$, azimuth $-80^{\circ}$ to $-90^{\circ}$.

Bedrock: Yraf-complex (Kautsky 1940).

Ground: Fine scree with moderate to thick mull layer, coarse scree.

The water supply of the cliff is good, and the bryophyte communities on the rock wall are fairly well developed with many hepatics (Pellia sp. and Marsupella sphacelata var. sullivantii in the wettest places). The drier places are poor, but fragments of Rhytidietum are present (also on scree, then often dominated by Abietinella abietina). Ledges and crevices of the ca. $50 \mathrm{~m}$ high cliff are numerous. There are two scarps but only the lower E-facing one with its scree was investigated.

From a closed stand of spruce forest one climbs an almost treeless scree, with only some solitary $\mathrm{Be}$ tula pubescens and Salix caprea on fine scree below the rock wall. Shrubs (Rubus idaeus, Ribes spicatum var. lapponicum etc.) are more common but there are no dwarf shrubs. The most extensive surface of the fine scree is dominated by Aconitum and Matteuccia stands with abundant interspersion in the bottom layer of Mnium spp. Other spots are listed under Tortulo-Poetum, because of dominant Pseudoleskeella nervosa in the bottom layer, even if Tortula ruralis is usually sparse, sometimes even absent. The main impression may be a rather hydrophilous appearance of the plant communities with Parnassia palustris, Angelica archangelica (also in one place on wet ledges). Dry meadows are present, especially in the transition zone towards the open boulder scree. Chamaenerion angustifolium and Urtica dioeca ssp. Sondenii are often dominant in these drier meadows. Fragaria vesca is present only in the more open type of vegetation on scree. The other southern elements, of which there is rather a high percentage, are also seen on the rock wall.

The hillside situated close to Mt. Alep Nadok (called Lulep Nadok) is exposed towards the SE. The seepage water is sparse, the vegetation more impov- erished. However, only a small patch is dominated by Vaccinium spp. on fine scree (in a more shaded part also Rubus chamaemorus, never found on fine scree before). Some spots have a rather lush field layer. The scarps of the rock wall have many crevices, shelves and caves and have a rich bryophyte flora. Tortula ruralis and Rhytidium rugosum are only found on the rock wall in the more exposed SE part.

Visited together with Wistrand on 26 July, 1964.

\section{Mt. Staburknösen $($ Swed. stabur $=$ cage $)$}

The name on the topographic map is Buoskvarats but Wistrand (1962, p. 46) used the name given by Swedish settlers; derivation of the Lappish name uncertain.

Position: $66^{\circ} 5^{\prime} \mathrm{N}, 17^{\circ} 8^{\prime} \mathrm{E}$.

Altitude: (840) 567, $424 \mathrm{~m}$.

Exposure: Rock-wall inclination $80-90^{\circ}$, azimuth $-90^{\circ}$ to $-110^{\circ}$.

Bedrock: Kaskajaure-complex, see p. 22.

Ground: Fine scree with moderate to thick mull layer, coarse scree.

The mountain, which is a northern projection of Mt. Nebsuort $(912 \mathrm{~m})$, is cone-shaped and the upper parts are treeless. The rock wall on the E-facing side has a successively rising base from 567 to $657 \mathrm{~m}$, where there is a rather abrupt passage to the S-facing side (no plants recorded in the lists from that side). The lower parts of the rock wall, especially, are rich in seepage water and bryophyte communities are well developed, partly because of the shaded aspect. Porella platyphylla and Orthothecium intricatum are good examples of extreme southern and northern elements found.

The fine scree is mostly treeless and there are lush meadows dominated by Aconitum septentrionale and Dryopteris filix-mas etc. Drier types are less common, and the occurrence of Fruticeto-Tortuletum and Rhytidietum communities is very sparse, mostly fragmentary. The southern elements are mostly only seen on the rock wall. It is remarkable that Epilobium montanum is more common than E. collinum. Fragaria vesca is present only at the $657 \mathrm{~m}$-level and on the S-facing side, where the meadows are drier, in part changing to Vaccinium heath.

The lower part of the scree, the coarse scree and the lower wood are dominated by the Sphenolobus community, and changing into spruce forest communities. Here are rather wet parts with tall herbs, as well as true Vaccinium myrtillus types with Oxalis 
acetosella, which is found in only a few localities in PL.

Visited by Wistrand on 3 August, 1934, and by Wistrand and the present author on 24 July, 1964.

16. Mt. Aistjakk (derivation uncertain, probably from asse $=$ forested ridge)

Position: $66^{\circ} 5^{\prime} \mathrm{N}, 17^{\circ} 16^{\prime} \mathrm{E}$.

Altitude: (616) (a) 555, (b) 560; $419 \mathrm{~m}$.

Exposure: Rock-wall inclination (both) $80-90^{\circ}$, azimuth (a) $+34^{\circ}$ to $+40^{\circ},(b)-120^{\circ}$ to $-140^{\circ}$.

Bedrock: Kaskajaure-complex, see p. 22.

Ground: (a) Fine scree with thin to thick mull layer, coarse scree.

(b) Very sparse fine scree, coarse scree with thin to thick forest mull layer.

(a) The cliff, which is fairly high (Fig. 25), produces abundant seepage water especially after thaw and periods of rain. Some caves at the base are wet throughout the summer and rich in less common bryophytes, e.g. Porella platyphylla and Homalothecium sericeum. The rare element Orthotrichum anomalum is found on the edge of a rather wet ledge. The Rhytidietum community is common on ledges in the lower part of the rock wall. Cystopteris fragilis ssp. dickieana is also found on the rock wall.

The $\mathrm{E}$ part of the fine scree is dominated by poor dwarf shrub heaths with an over-storey of Betula pubescens and Picea abies. There are also some smaller patches with meadow communities. The epilithic moss flora on the cliff and the scree is luxuriant. Farther $W$ the spruce disappears completely and birch becomes dominant. At the same time the field layer becomes lusher and is partly dominated by tall herbs (Poeto-Lactucetum communities). In the open patches further towards the $\mathrm{W}$ is the Fruticeto-Tortuletum community described (p. 91), and still further W pure Populeto-Tortuletum stands with typical under-growth. On the W side, forest heath communities, Juniperus shrubs etc. are again interspersed. Viola Selkirkii is also found here.

The coarse scree is extensive, and almost treeless, being dominated by poor lichen communities on the boulders and the fragments of the Sphenolobus community among them. Below the scree is a spruce forest, the wetter parts of which have some more demanding calciphilous elements (Cystopteris montana, Carex capillaris etc.) and the less common natural occurrence of Tussilago farfara.

(b) There is a sparse water supply in several places, especially above the place with the temperature screen, with drips and seepage water even after fairly long periods of drought. Here are, of course, the most abundant patches of bryophyte communities, on ledges, interspersed with Eurhynchium pulchellum in some places. Poa glauca is also mostly found on the rock wall, in crevices. In one place it is also found on scree on a large boulder, together with Hylocomium splendens, Dicranum fuscescens and Pogonatum alpinum.

There is practically only coarse scree present, dominated by Picea-Vaccinium myrtillus ${ }^{-H y l o c o-}$ mium splendens wood with an admixture of herbs and shrubs in some places. The wetter places below outflows of seepage water give an impression of somewhat lusher types with Aconitum and Dryopteris assimilis stands (some dominated by Phegopteris polypodioides). The bottom layer is mostly dominated by Brachythecium reflexum and B. salebrosum, Rhodobryum roseum and Mnium spp., although the admixture of Hylocomium splendens may also be rather important here. The rich supply of litter to the ground may give an impression of "fine scree". In the drier heath wood with Gymnocarpium dryopteris, Cornus suecica may also be locally abundant.

The open boulder scree is largely overgrown with Hylocomium splendens and its companions, Barbilophozia spp., Pleurozium schreberi and Pohlia nutans. Of the community is also present the initial stages richer in Dicranum fuscescens, Polytrichum juniperinum, Chandonanthus setiformis, Andraea rupestris and Rhacomitrium microcarpum. These five species are especially abundant on the upper sides of the boulders, together with lichens.

Visits by Wistrand to the SW-facing side on 1 August, 1934, and to the NE-facing side on 27 July, 1965. Mt. Aistjakk has been investigated by the present author in 1962-66. 


\section{HILLSIDES LOCATED IN THE AREA OF PRIMARY ROCKS}

17. Mt. Pellavardo (derivation uncertain, probably from Lapp. pieles, pällan $=$ on the side of, beside)

Position: $66^{\circ} 28^{\prime} \mathrm{N}, 17^{\circ} 56^{\prime} \mathrm{E}$.

Altitude: (766) 480, $452 \mathrm{~m}$.

Exposure: Rock-wall inclination $80-90^{\circ}$, azimuth $0^{\circ}$ to $-45^{\circ}$.

Bedrock: The Skärfa series, see p. 10.

Ground: Fine scree with thin to rather thick mull layer, coarse scree.

There is only a temporary water supply on the cliff, and the general appearance is of a dry broken up rock wall with large ledges and clefts, and with some solitary trees and forest heath communities. Strips of calcium carbonate occur locally. In the lower parts are some ledges with Rhytidietum and dry Tortulo-Poetum meadows. Cystopteris fragilis ssp. dickieana is a more uncommon species found here.

The fine scree is mostly covered with stands of Populus tremula and Betula pubescens, but there are, especially in the zone towards the open scree, true Fruticeto-Tortuletum communities intermingled with the Cladonia variant of Dicrano-Polytrichetum and Rhytidietum. In this zone (Fruticeto-Tortuletum) is found the rare Polygonum dumetorum. The sides of the scree are damper, with tall herb communities and transition types to spruce forest with calciphilous species.

The slope below the scree is rather damp and there are even springs. The slope in the immediate neighbourhood is dominated by spruce, soon changing to dry pine woods on the sandy moraine surrounding the mountain.

Mt. Skärfaåive is the name of a small mountain facing NE on the opposite side of the same lake (Lake Skärfajaure). The bedrock is the same. The water supply is fairly abundant and there are large patches with true Lactucion communities (dominants Aconitum septentrionale and Lactuca alpina, with a sparse admixture of Arabis alpina, a true Scandian plant). Dry meadows of Tortulo-Poetum type are lacking, but fragments of the Sphenolobus community occupy the interspaces between the boulders. Here also, there are Picea forest communities lower down.
The hillsides were visited by H. E. Johansson in July, 1918, and by Wistrand and the present author on 7-8 August, 1962.

18. Mt. Lulep Istjakk (derivation of the name uncertain)

Position: $66^{\circ} 12^{\prime} \mathrm{N}, 17^{\circ} 48^{\prime} \mathrm{E}$.

Altitude: (808) $458,425 \mathrm{~m}$.

Exposure: Rock-wall inclination $80-90^{\circ}$, azimuth $-30^{\circ}$ to $+45^{\circ}$.

Bedrock: The Skärfa series and adjacent rocks, see p. 10.

Ground: Fine scree with thin to deep mull layer, coarse scree.

Water: Table 14, sample no. 6 (column to the left $=$ point $\mathrm{B}$, Fig. 41 ; column to the right $=$ point A).

The water supply is ephemeral, nowhere of definite artesian character, illustrated by the rather high temperature of the water, see Table 14 . However, because of a large rock wall the collected amounts of precipitation are probably rather large, affecting the vegetation favourably (cf. Fig. 37). The cliff is dry in most places, apparently consisting of oligotrophic rocks in the lower parts. Although there are many ledges and crevices there is a poor flora on the rock wall, with the exception of a large open cave in the SW part, giving more shade. Here bryophytes, at least, do well.

The fine scree is mostly occupied by fairly typical Populeto-Tortuletum stands, here and there interrupted by the Fruticeto-Tortuletum communities or openings with Poeto-Lactucetum or transitory types. There are even small patches with dwarf shrubs in a zone near the open boulder scree. Some patches in the Fruticeto-Tortuletum community (also on the rock wall) consist of fairly fresh mineral soil most usually dominated by Bryum spp. and with many demanding talus species, especially in places most exposed to the sun. Otherwise obligate cliff elements may also occur, rarely, in this community, e.g. Saxifraga nivalis (Lundqvist, J. 1961, pp. 159, 160).

The most obvious feature of the hillside, apart from the lofty rock wall, is the huge coarse scree with its tremendous boulders, making climbing in some places impossible. However, especially in the 


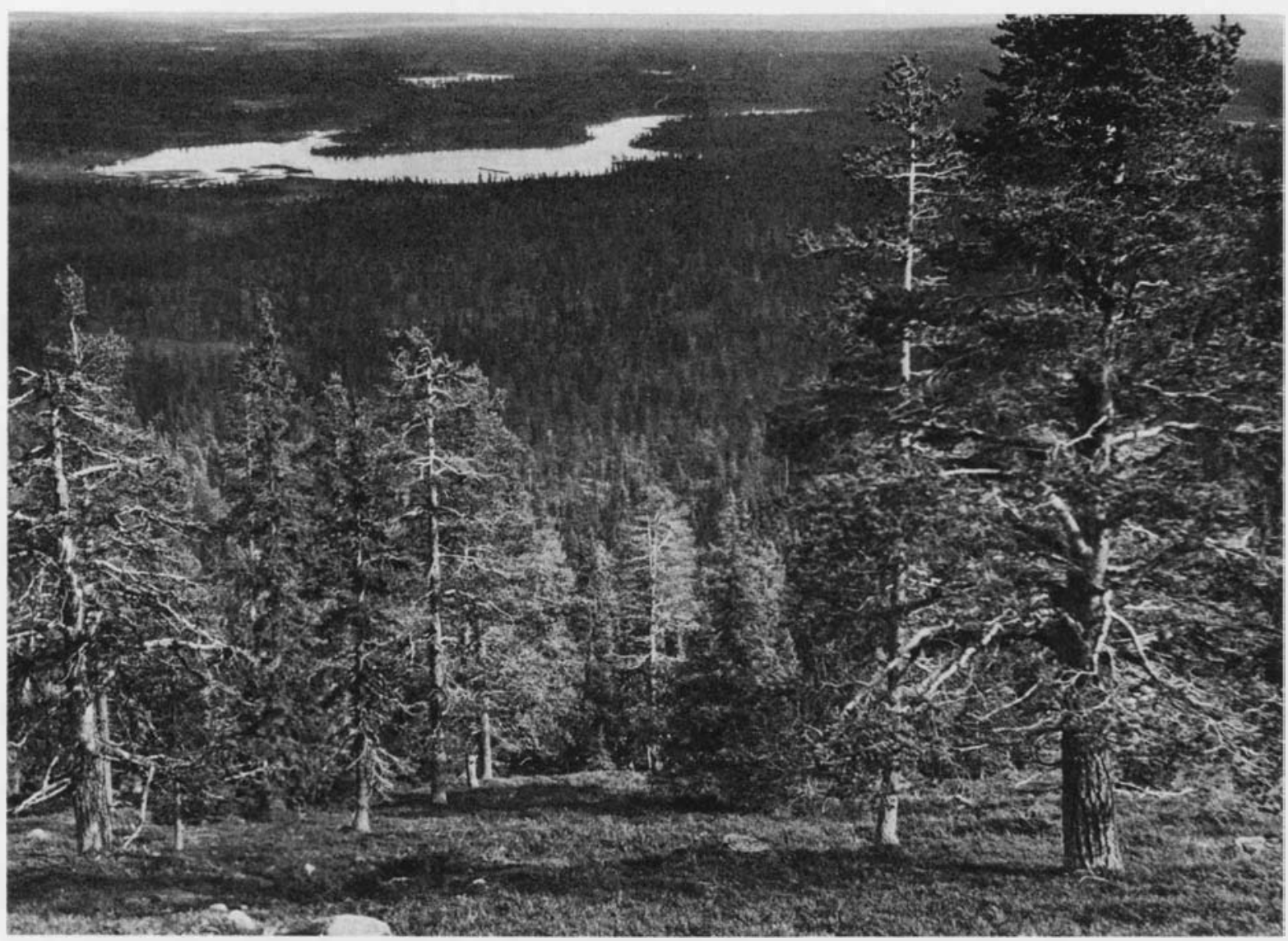

Fig. 45. Mt. Välbmapuoda (no. 24), the S-facing side. Forest limit of pine (Pinus silvestris), a unique condition for N Sweden. Altitude 630 m. Photo: G. Wistrand, 13 July, 1936.

central and lower parts of the scree, there are colonists from the forest below, viz. pine and birch trees with typical under-growth. Likewise, on the sides there are transitory types to forest heath, mostly interspersed with some herbs.

There are several interesting finds in the rich flora, e.g. Asplenium septentrionale, Sedum acre, Myosotis stricta, Orthotrichum pallens and Isothecium myosuroides, the first two only on the rock wall, the other three on scree. At least Orthotrichum pallens, the first locality of which in PL was found in 1963 by the present author, seems to be abundant on aspen trees below the rock wall. The number of species of vascular plants is the highest recorded for similar screes and rock walls in PL (113), whereas the number of bryophytes (61) points to less favourable conditions for these plants.

The hillside has been visited by many botanists. As early as the 1820 s (probably both in 1820 and 1824) it was visited by L. L. Læstadius (Lastadius 1824). Some successors were N. J. Andersson in 1845 (Andersson 1846), Björnström in 1856 (1856, p. 12), Grapengiesser 1916 (1917, p. 265), H. E. Johansson 1918 (Johansson 1933 and original notes). Wistrand visited the locality on 1 July, 1936, 7 July, 1942, 12 August, 1965, and (together with Nordenstam and the present author) on $26 \mathrm{July,} 1966$. Also visited by the present author several times during 1959-67.

Mt. Strömnäsberget, which is a SW-facing slope of the same mountain situated further NW (Fig. 34), has a somewhat dissimilar flora, with only 69 species of vascular plants recorded (Wistrand, personal communication). However, some rare elements have up to now been found only on this slope, e.g. Normandina pulchella and Anthyllis vulneraria ssp. lapponica, and not on the slope of Mt. Lulep Istjakk. The lower number of species is certainly caused by the lesser extent of the talus slope and rock wall.

Visits by H. E. Johansson in 1918 and by Wistrand on 30 July, 1936.

Mt. Alep Istjakk situated $7 \mathrm{~km}$ further NW has screes at ca. $600-700 \mathrm{~m}$, of $\mathrm{S}$ and SE aspects. The mountain is definitely outside the Skärfa series, but the flora is fairly rich, including 98 species of vascular plants (Wistrand, personal communication). The most interesting finds are Pteridium aquilinum 
(beside the scree on the S-facing side; first found by H. E. Johansson, see Wistrand 1962, p. 50) and Festuca vivipara (on the rock wall; op. cit., p. 63), a remarkable Scandian element in the flora of the hillsides.

Visits by Grapengiesser in 1916, by H. E. Johansson in 1918, and by Wistrand on 9 July, 1942.

19. Mt. Vuornats (Lapp. dim. form of vourne $=$ horn, projecting smaller mountain)

Position: $66^{\circ} 6^{\prime} \mathrm{N}, 17^{\circ} 57^{\prime} \mathrm{E}$.

Altitude: (一) 435, $425 \mathrm{~m}$.

Exposure: Rock-wall inclination $70-90^{\circ}$, azimuth $0^{\circ}$ to $-30^{\circ}$.

Bedrock: Granite, mica schist.

Ground: Fine scree with thin mull layer, coarse scree.

There is almost no seepage water on the rock wall. The only favourable places for bryophytes are the small open caves at the base, providing shade. Tortula ruralis and the other demanding elements are seen exclusively at the base of the rock wall, preferably on the edge of caves or in crevices.

The fine scree, which is almost absent, mostly has very sparse forest heath communities, in some cases mixed with grasses and herbs. The trees are Picea, Betula pubescens and Salix caprea, Populus tremula being rare. Some meadow fragments are dominated by Calamagrostis purpurea and Fragaria vesca, but the bottom layer is mainly Hylocomium splendens.

The boulder scree reaches the rock wall in several places. It is mostly treeless and the fragments of the Sphenolobus and Cladonia variants are common. As a rule the Cladonia variant is also dominant on the rock wall on these rather poor hillsides.

Pine wood is the main constituent of the surrounding till-covered ground. Only the lower scarp of the mountain was investigated.

Visits by Wahlenberg in 1807 (when he discovered Woodsia. glabella), Björnström in 1856, Birger in 1909, Grapengiesser in 1916, H. E. Johansson in 1918. Wistrand visited the hillside on 1 April, 1945, and on 24 July, 1965, the present author on 22 July, 1959, and on 11 September, 1965.

A hillside called Oberget is situated opposite Mt. Vuornats on the other side of the streams near Arjeplog. The rock seems to be only granite and the exposure is ENE. The vegetation of the scree is poor forest heath with an admixture of Polypodium vulgare (among the boulders), Phegopteris polypodioides, Gymnocarpium dryopteris, Melica nutans, Festuca rubra, Equisetum arvense and Trientalis europaea.
$13 \mathrm{~km} \mathrm{NW}$ of Arjeplog is Mt. Akkelis with a few small screes on the $\mathrm{S}$ side. The rock here is also granite and the altitude is ca. $600 \mathrm{~m}$. Hence, the number of vascular plants is small (34), mostly comprising less demanding elements. Some interesting plants are Melica nutans, Silene rupestris, Melandrium rubrum, Sedum annuum, Viola montana, Rhytidium rugosum (the last one as a fragment on a ledge). The dominant community on the ledges is the Cladonia variant of Dicrano-Polytrichetum, with Deschampsia flexuosa a partly dominant grass.

The most interesting plant in the flora of Mt. Akkelis is probably Calamagrostis epigeios, with no other localities in PL. It was found as early as 1824 by Læstadius (Wistrand 1962, p. 67) and not found again. The type of habitat is unknown.

Visits by Wistrand in July, 1932, and on 29 July, 1936, and by the present author on 16 June, 1964 .

20. Mt. Jutavare (derivation of the name uncertain, probably from Lapp. juta-varhpe, see Collinder 1964, p. 71)

Position: $66^{\circ} 6^{\prime} \mathrm{N}, 17^{\circ} 31^{\prime} \mathrm{E}$.

Altitude: (592) 425, $419 \mathrm{~m}$.

Exposure: Rock-wall inclination $50-60^{\circ}$, azimuth $-10^{\circ}$ to $+10^{\circ}$.

Bedrock: Granite.

Ground: Fine scree with thin to moderately deep mull layer, coarse scree.

The mountain is terminated towards the $\mathrm{S}$ by two main scarps, the $\mathrm{E}$ one consisting of two smaller ones at different altitudes. They all have screes between them.

There is no seepage water on the rock walls but, at least in caves, the crevices are moist even after drought. In these caves there are sometimes some unusual bryophytes for the region, e.g. Brachythecium velutinum and Encalypta streptocarpa (the Encalypta found only here and on an E-facing slope of Mt. Aistjakk, see Persson 1929, p. 237). Otherwise, the dominant communities are poor forest heath in which junipers play an important part, and the Cladonia variant of Dicrano-Polytrichetum. As the rockwalls are not very steep, they collect considerable precipitation, and this will partly compensate for the lack of seepage water. This will also favour the scree below the cliff.

The fine scree is to a large extent covered with poor forest heath with an admixture of some herbs. Betula pubescens, Salix caprea, Sorbus aucuparia are the most important of the trees, but there are also pines and aspens. There is only one fairly luxuriant place, between the two main screes, where Paris 
quadrifolia and Galium triflorum are present. The southern elements are sparse or locally luxuriant, e.g. Fragaria vesca.

The coarse scree on which pine is the dominant tree has fragments of the Sphenolobus community between the boulders. Below a larger boulder in the lower part of the E scree there are some more demanding bryophytes, e.g. Metzgeria furcata and Brachythecium velutinum.

Visits by Wistrand in July, 1932, on 4 August, 1934, and (together with the present author) on $11 \mathrm{July}$, 1963, by the present author alone on 18 June, 1964, and on 19 September, 1966.

$11 \mathrm{~km} \mathrm{SE}$ of Mt. Aistjakk (no. 16) there is a hill called Kidnavare the hillside of which is exposed to the SW. As the general appearance is very dry, because there is no seepage water and only a small rock wall, there are no demanding plants. Woodsia ilvensis, Polypodium vulgare and Silene rupestris are the only plants worth mentioning.

Visited by Wistrand on 24 July, 1943, and by the present author in July, 1962.

$11 \mathrm{~km}$ further SE is Mt. Askevare, a low mountain bare on top (Wistrand 1962, p. 172, described the adjacent Mt. Uljepuoda; $779 \mathrm{~m}$ ). Both have screes on their SW-facing sides. Only the NE part of the mountain massif (called Askevare) was investigated by the present author.

The altitude of the scree slope is ca. $480 \mathrm{~m}$. The SW-exposed slope is dominated by spruce with an admixture of birch and pine (on the lower part also some aspens). The field layer is everywhere dominated by dwarf shrubs (on the more exposed parts is also Calluna vulgaris or Arctostaphylos uva-ursi). Ferns and herbs are Cystopteris fragilis, Phegopteris polypodioides, Gymnocarpium dryopteris, Maianthemum bifolium, Silene rupestris, Chamaenerion angustifolium, Trientalis europaea, Melampyrum silvaticum, Solidago virgaurea and the grasses Calamagrostis purpurea and Deschampsia flexuosa.

Visited by Wistrand on 11 August, 1936, and by the present author on 13 June, 1964.

\section{Mt. Dalktjapakte (Lapp. tadtja $=$ Swede, foreigner)}

Position: $65^{\circ} 42^{\prime} \mathrm{N}, 17^{\circ} 37^{\prime} \mathrm{E}$.

Altitude: (704) 548, $391 \mathrm{~m}$.

Exposure: Rock-wall inclination $60-80^{\circ}$, azimuth $-110^{\circ}$ to $-135^{\circ}$.

Bedrock: Quartz porphyry, see p. 22.

Ground: Fine scree with thin to rather thick mull layer, course scree. Table 1, sample no. 33.

There is in some places an abundant water supply on the cliff, even a small stream in one place. Espe- cially in these places there is a luxuriant vegetation with some less common species, e.g. Carex atrata and Tritomaria scitula. Otherwise there are also poor heath types on the rock wall, with herbs interspersed. Poa glauca and Tortula ruralis are not seen anywhere on the hillside.

The Geranium-Gymnocarpium forest heath is most common towards the $\mathrm{N}$ of the fine scree, with Betula pubescens as the dominant tree. Vaccinium myrtillus is the dominant dwarf shrub, and there are single individuals of Cystopteris fragilis, Dryopteris spinulosa, Melica nutans and Rumex acetosa. Further to the $S$ are quite well-developed scrubs of $R i$ bes spicatum var. lapponicum, and Rubus idaeus, but nowhere with the intergrowth typical for the Fruticeto-Tortuletum community of the Caledonian area. Stellaria nemorum, Melandrium rubrum, Aconitum septentrionale and Myosotis silvatica ssp. frigida join the community when the substrate is a little wetter. Here there are also Picea abies and Sorbus aucuparia in the tree layer, but Populus is absent.

The most interesting part is around the small stream, which probably dries out in some periods. There is a luxuriant green patch of Lactucion community, with no trees, seen from far off on the hillside. The dominants on the proximal part of the scree are Matteuccia struthiopteris and Athyrium filix-femina. Around the banks of the small stream are the bryophytes Drepanocladus exannulatus and Hygrohypnum alpestre. In the lower parts, ca. $75 \mathrm{~m}$ below, the dominance is taken over by Aconitum septentrionale and Chamaenerion angustifolium, but the boulders are still completely covered by litter. Further down is the boulder scree proper, with its fragments of the Spenolobus community.

Visits by the present author on 31 July and 1 August, 1961, and on 20 July, 1966.

\section{Mt. Ailesvare (Lapp. ailes $=$ sacred)}

Position: $66^{\circ} 19^{\prime} \mathrm{N}, 18^{\circ} 6^{\prime} \mathrm{E}$.

Altitude: (722) $531,452 \mathrm{~m}$.

Exposure: Rock-wall inclination $60-70^{\circ}$, azimuth $-10^{\circ}$ to $+30^{\circ}$.

Bedrock: Granite.

Ground: Poorly developed fine scree, coarse scree with thin forest mull layer.

There is no seepage water on the rock wall. It is dominated by Calluna and Vaccinium heaths, but there are small patches of the Cladonia community (stand no. 2, Table 25). There are single individuals of pine, birch etc.

Immediately in front of the rock wall a piece of rock has formed a cave (a holy place for the Lapps in 
heathen times), with some interesting bryophytes, e.g. Dicranella cerviculata, seen fruiting nowhere else on the hillsides of PL. The vegetation of the proximal parts of the scree is covered with heath birch forest with an admixture of Populus tremula, Pinus silvestris and (sparse) Picea abies. Gymnocarpium dryopteris, Rubus saxatilis, Geranium silvaticum and Solidago virgaurea are the most common herbs interspersed in the field layer. Tortulo-Poetum communities are absent.

On the lower parts of the scree pine is the dominant tree, and the boulders are more or less covered by poor forest heath types. Juniper is fairly common everywhere, especially on the rock wall.

The typical hillside elements are sparse and mostly found on the rock wall (Silene rupestris, Sedum annuum and Veronica officinalis).

Visited by H. E. Johansson in 1918, by Wistrand in July, 1932, on 15 August, 1934, and by the present author on 26 June and 23 August, 1963, on 23 August, 1965, and on 31 August, 1966.

23. Mt. Måfevare (derivation of the name uncertain)

Position: $66^{\circ} 12^{\prime} \mathrm{N}, 17^{\circ} 59^{\prime} \mathrm{E}$.

Altitude: (746) $529,433 \mathrm{~m}$.

Exposure: Rock-wall inclination $70-80^{\circ}$, azimuth $-60^{\circ}$ to $-120^{\circ}$.

Bedrock: Granite.

Ground: Poorly developed fine scree, coarse scree with forest mull.

Water: Table 14, sample no. 7.

The tree limits are discussed by Enquist (1933, p. 162; the mountain is erroneously called Måsevare).

There are several terraces and scarps of the rock wall which have ledges covered with debris or scree. There are also many crevices, clefts and small open caves which together with the seepage water in some places produce a luxuriant bryophyte vegetation. However, there are, of course, no definitie calciphilous species and there are patches of Sphagnum on the scree in stabilized parts near the rock wall where there is some seepage water.

The proximal parts of the scree are dominated by heath birch forest with sparse admixture of spruce. In some places the herbs are rather abundant, the Geranium-Gymnocarpium type of wood. In this Viola montana is present in one place. On the whole, the hillside shows many traces of a more westerly flora, although situated in the area of Primary rocks. Southern elements are very sparse.

The lower parts of the scree where there are some treeless areas, are dominated between the boulders by the Sphenolobus community. The upper surfaces of the boulders are mostly dominated by very Cladoniarich types.

Visits by the present author on 14 July, 1964, on 1 July, 1965 , and on 18 September, 1966

24. Mt. Välbmapuoda (Lapp. vielmes $=$ calm water in stream)

Position: $65^{\circ} 53^{\prime} \mathrm{N}, 17^{\circ} 3^{\prime} \mathrm{E}$.

Altitude: (710) 535, $419 \mathrm{~m}$.

Exposure: Rock-wall inclination $70-80^{\circ}$, azimuth $+45^{\circ}$ to $+60^{\circ}$

Bedrock: Granite.

Ground: Poorly developed fine scree, coarse scree with forest mull.

The projecting part of the rock wall on this hillside is very low, only about 5-6 m, and consists of several scarps all with different exposure, but the main aspect is SW. There is no seepage water, and the recharge area above the steep cliff is rather limited as there is a depression between the summit area of the mountain and the hillside in question. Consequently the rock wall is generally dry, the Cladonia variant of Dicrano-Polytrichetum being the most abundant community. There are also heaths with Calluna vulgaris and Arctostaphylos uva-ursi. The most remarkable element is Euphrasia hyperborea (preliminary determination).

The scree below the rock wall is mostly dominated by heath birch wood (Betula pubescens, some B. verrucosa). Populus tremula, Sorbus aucuparia, Pinus silvestris and Picea abies are interspersed. Juniperus communis is fairly abundant. In some favourable places there may be a rather dense interspersion of ferns and grasses, e.g. Gymnocarpium dryopteris, Melica nutans and (only in patches) Dryopteris filixmas. Less common for the area of Primary rocks are the finds of Neckera oligocarpa and Metzgeria furcata.

The coarse scree is interrupted by places with boulder-rich moraine covered by sparse pine wood with an admixture of birches. Here was found Ptilium crista-castrensis (not in Table 17).

The mountain was visited by Wistrand in July, 1932, on 5 July, 1943, and on 20 July, 1964, and by the present author on 20 August, 1964, and on 5 June, 1967.

\section{Mt. Kuottavare (derivation of the name uncertain)}

Position: $65^{\circ} 55^{\prime} \mathrm{N}, 18^{\circ} 16^{\prime} \mathrm{E}$.

Altitude: (680) $601,498 \mathrm{~m}$.

Exposure: Rock-wall inclination $60-80^{\circ}$, azimuth $0^{\circ}$ to $+30^{\circ}$. 
Fig. 46. The S-facing side of Mt. Stärpatsvare, no. 26. A poorly regenerating clearing in the foreground (ca. $670 \mathrm{~m}$ ) and a spruce-wood ("upper silvine belt") below the mountain-side. The last earth-slide to the right was observed to have taken place in 1920 (Zenzén 1926, p. 172) and is still quite poorly covered by vegetation. The talus slope is at the left edge of the photograph, hidden behind trees.

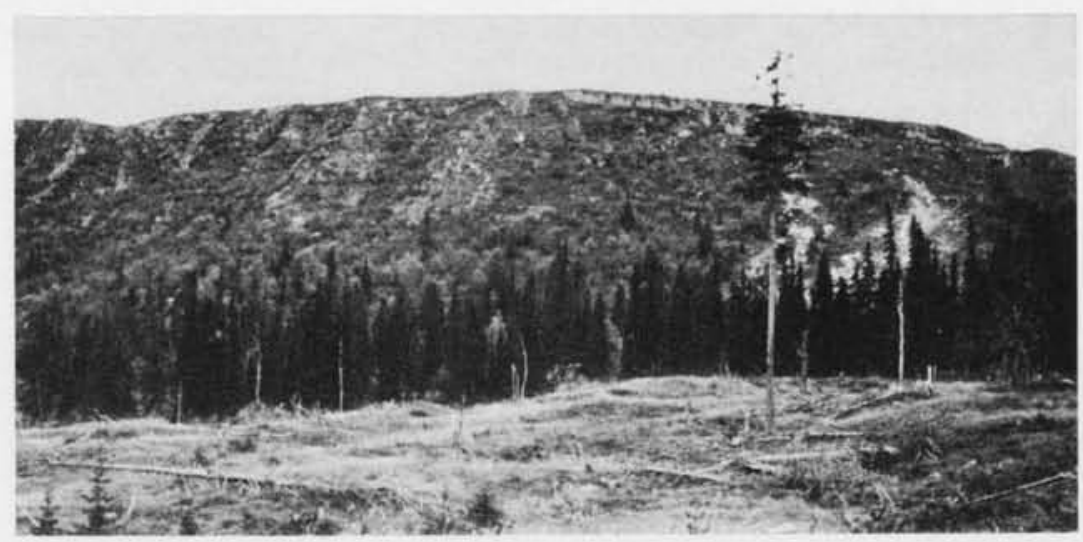

Bedrock: Granite.

Ground: Poorly developed fine scree with thin forest mull, coarse scree.

There is no seepage water on the rock wall. It is fairly high, abruptly falling from the area close in front of the summit, and with many crevices and ledges. On these extremely dry ledges there are only poor heath types with junipers and shrub-like Betula pubescens, Populus tremula and Sorbus aucuparia. The field layer is mostly Vaccinium dwarf shrubs and Arctostaphylos uva-ursi with an admixture of grasses (Festuca ovina and Deschampsia flexuosa) and some herbs, e.g. Chamaenerion angustifolium, Trientalis europaea and Solidago virgaurea. In the fragments of the Cladonia variant of Dicrano-Polytrichetum, besides the typical bottom layer, there are Poa glauca and Silene rupestris, occasionally also $P$. nemoralis. There are no real caves at the foot of the rock wall and because of this together with the extremely dry habitat, there are only 24 species recorded (together with a few species taken on the scree; Table 16).

The narrow strip of plant cover in front of the rock wall is also dominated by forest heath types with an admixture of Picea and Pinus (only some single dead individuals of Pinus). The admixture of herbs is sparse (Gymnocarpium dryopteris. Chamaenerion), the grasses sometimes being rather important (Calamagrostis purpurea). There are patches which could be classified as the Cladonia or Sphenolobus variant, but none of the other hillside communities described.

The boulder scree is fairly extensive and treeless (with Polypodium vulgare, Chandonanthus setiformis etc. between the boulders), and the forest below the mountain is dominated by Picea.

Visits by Wistrand in June, 1932, and by the present author on 25 June, 1963, and on 24 August, 1965.
26. Mt. E Stiirpatsvare (derivation of the name uncertain)

Position: $65^{\circ} 51^{\prime} \mathrm{N}, 18^{\circ} 17^{\prime} \mathrm{E}$.

Altitude: (784) $681,478 \mathrm{~m}$.

Exposure: Rock-wall inclination ca. $60^{\circ}$, azimuth $-30^{\circ}$ to $+30^{\circ}$.

Bedrock: Granite etc., see p. 23.

Ground: Fine scree with thin forest mull, coarse scree. Table 1, soil samples nos. 34-35.

The water supply on the rock wall is sparse and temporary, in one place probably persisting throughout the vegetation period and supporting a Sphagnum robustum cushion close to the rock wall. There are many ledges of different dip and exposure, crevices and clefts, but hardly any caves. The bryophytes are sparse, the most rare for these areas being Desmatodon latifolius and Conostomum tetragonum (the latter also on Mt. Välbmapuoda, no. 24, see Table 17). The general impression is subalpine because of the considerable altitude. On the till-covered rock beside the scree earth-slides occur (Fig. 46) and there is a poorly regenerating vegetation. The ledges of the rock wall are mostly covered with dwarf shrubs but there may locally be some stands dominated by Calamagrostis purpurea, Chamaenerion etc.

There is hardly any typical fine scree developed, and as on the other scree slopes on Primary rock, all the sections are very stabilized and favourable for the final forest heath types to be developed. Debris falls or rock slides are very rare, at least on the steep rock wall. However, the better supply of water in some places immediately allows some stands with tall plants (Pteridium aquilinum, Athyrium filix-femina, Lactuca alpina etc.) and a thicker litter cover. Dryopteris filix-mas, Milium effusum, Melandrium rubrum and Hieracium spp. play an important role in these lusher patches. They are always fairly well exposed towards the sun as the tree layer of the otherwise 
dominant spruce and birch is sparse and the dip is rather steep.

There is also an almost covering tree layer on the lower parts of the scree, and the fragments of vegetation are forest heath patches. On the upper surfaces of some boulders and on the rock wall there are fragments of the Cladonia variant of DicranoPolytrichetum. Typical hillside species are very sparse or absent, Carex digitata (Wistrand 1962, p. 80) and Pteridium aquilinum (found by the present author) are the only more remarkable southern elements.

Visits by Wistrand in June 1932, on 23 July, 1936, and on 17, July, 1963, and (together with the present author) on 21 July, 1966, by the present author alone on 30-31 August, 1962, and on 24 August, 1965.

27. Mt. Fiskträskberget (Swed. fisk = fish; träsk $=$ lake)

Position: $65^{\circ} 35^{\prime} \mathrm{N}, 18^{\circ} 32^{\prime} \mathrm{E}$.

Altitude: (660) 530, $464 \mathrm{~m}$.

Expoure: Rock-wall inclination $70-80^{\circ}$, azimuth $-10^{\circ}$ to $+10^{\circ}$.

Bedrock: Quartz porphyry.

Ground: Poorly developed fine scree with thin forest mull layer, coarse scree. Table 1, samples nos. 36-37.

There is only a sparse temporary water supply on the rock wall, with undemanding bryophytes associated with it (Mnium stellare, Mn. punctatum, Aulacomnium palustre, Leiocolea heterocolpos and Scapania irrigua). However, some parts of the rock wall are rather rich in bryophytes and, as far as the total number is concerned, are a remarkable contrast to the two previously discussed hillsides (nos. 25 and 26). Some crevices even contain some species unexpected on this type of rock (Distichium capillaceum and Tortella tortuosa; fragments of Myurella julacea). The most extensive parts are, however, occupied by poor dwarf shrub carpets, junipers or small trees, with fragments of the Cladonia variant of Dicrano-Polytrichetum between them. Especially on the lower parts of the rock wall, the ledges may be partly dominated by grasses and herbs, e.g. Poa nemoralis, Calamagrostis purpurea and Chamaenerion angustifolium.

The vegetation of the fine scree and coarse scree in front of the rock wall is locally fairly luxurious and in spite of the rather unfavourable substrate. Besides the general forest heath communities, it is differentiated into two or three different types, one Dicrano-Polytrichetum of the Cladonia variant, rich in anthropochorous species (Table 25, stand no. 3), and one Poeto-Lactucetum with segments dominated by
Dryopteris filix-mas (Table 18, stand no. 4) and Geranium silvaticum. These latter communities are dependent on the seepage water present in one place on the rock wall, whereas the other community is partly a transitory type to the forest heath. The only less common species among the vascular plants is Epilobium lactiflorum, sparse in the Poeto-Lactucetum community and (very occasional) in the nearby segment of Dicrano-Polytrichetum. Milium effusum is also quite rare in the SE conif erous woodland area.

There are almost no uncovered parts of the coarse scree, as it is low and dominated by dense spruce forest at the lower levels.

The hillside was visited by Wistrand on 14 July, 1943, and on 19 July 1966, and (together with the present author) on 19 July, 1963, and by the present author alone on 24 July, on 6 August, 1963, and on 17 July, 1964.

28. Mt. Harrejaurliden (Lapp. harre=grayling; jaure $=$ lake)

Position: $65^{\circ} 51^{\prime} \mathrm{N}, 19^{\circ} 15^{\prime} \mathrm{E}$.

Altitude: (647) 549, $428 \mathrm{~m}$.

Exposure: Rock-wall inclination $80-90^{\circ}$, azimuth $+10^{\circ}$ to $+60^{\circ}$.

Bedrock: Quartz porphyry, see p. 23.

Ground: Fine scree with thin to moderately thick mull layer, coarse scree. Table 1, sample no. 38 .

There is a temporary water supply on the cliff, especially after periods of rain. This probably explains the high number of bryophytes for this type of slope (60; Table 17). Pohlia longicolla, Philonotis caespitosa and Calliergon sarmentosum are some of the less common mosses found on the rock wall. The flora definitely has a more northwesterly trend than would be expected from the position of the mountain (Viscaria alpina and Saxifraga nivalis are found on the cliff; most of the northwesterly elements are found on scree in tall communities). The dry parts of the rock wall are covered with poor Cladonia variant of Dicrano-Polytrichetum with Woodsia ilvensis, Poa glauca, Sedum annuum etc.

The fine scree in some places has a rather lush vegetation of the Poeto-Lactucetum type (Table 18, stand no. 5) with many northwestern species, but also with Convallaria majalis, a species common only in the SE. The drier parts are always dominated by poor forest heath types, with an admixture of some grasses and herbs, especially in the immediate neighbourhood of the rock wall. The tree layer is dominated by Picea, and other trees are sparse (Betula pubescens, Populus tremula, Salix caprea, Pinus silvestris), although producing sufficient litter for the boulder scree to be partly covered by poor forest mull types. 
Fig. 47. Mt. Bärberget, towards the NE. A clearing in the foreground. 21 August 1965.

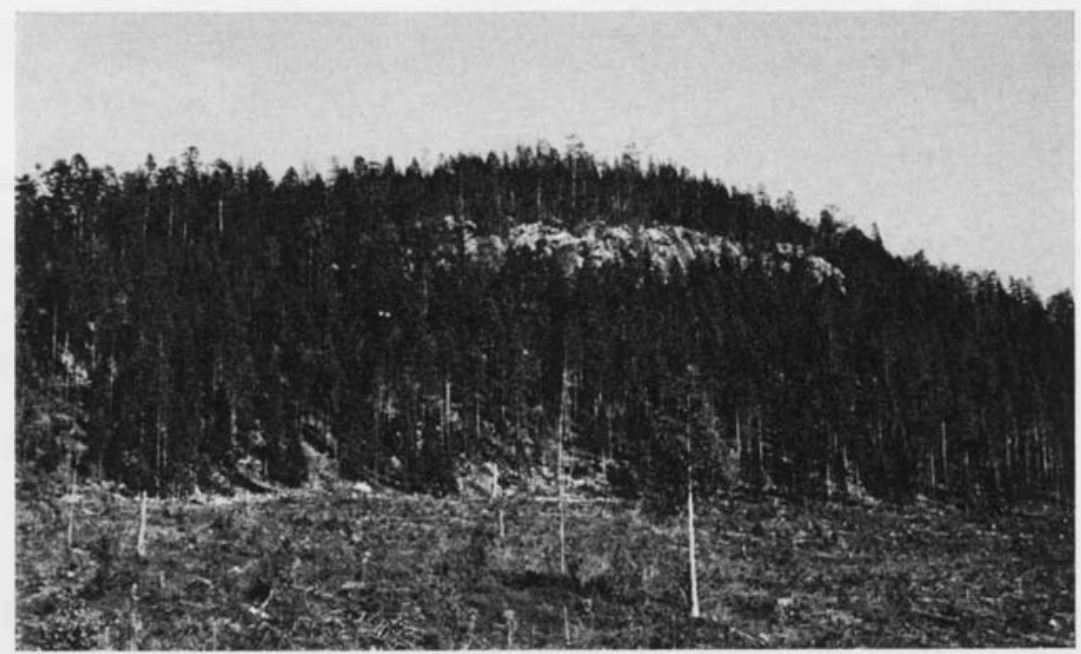

Patches with Maianthemum bifolium, Convallaria majalis and Geranium silvaticum are also fairly common on the central and lower parts of the scree, in dwarf-shrub heath, and occasionally there are even some rarer species, e.g. Pyrola media.

Below the hillside the pine takes over the dominance.

Visits by Wistrand on 5 July, 1946, and by the present author on 15 June and on 18 August, 1964, and on 5 July, 1966.

$11 \mathrm{~km} \mathrm{SW}$ of Mt. Harrejaurliden there is a hill called Kuorpatjåkko ((632) 537, $456 \mathrm{~m}$; azimuth $-120^{\circ}$ ) in the Reivo nature reserve (cf. Oldertz \& Bäckström 1961, p. 224) with a steep hillside. As there is in some places some seepage water on the rock wall, tall plants are intermingled in the otherwise poor forest heath carpets (Athyrium filix-femina, Dryopteris assimilis) on the scree. There are almost no southern plants and Polypodium vulgare and Melica nutans are the only ones seen. A remarkable find is Saxifraga nivalis on the rock wall (found by Wistrand).

Visits by Wistrand on 9 July, 1963, and by the present author on 17 August, 1964, and on 6 July, 1966.

\section{Mt. Brunberget $($ Swed. brun $=$ brown)}

Position: $65^{\circ} 45^{\prime} \mathrm{N}, 19^{\circ} 38^{\prime} \mathrm{E}$.

Altitude: (515) (a) 419, (b) 426; $328 \mathrm{~m}$.

Exposure: Rock-wall inclination (both) $60-90^{\circ}$, azimuth a) $-110^{\circ}$ to $-140^{\circ}$ b) $-60^{\circ}$ to $-85^{\circ}$.

Bedrock: Granite.

Ground: Poorly developed fine scree with forest mull, coarse scree.

(a) There is no seepage water on the rock wall. Because of the dry aspect, and the paucity of niches or cave-like depressions at the foot of the rock wall, the bryophyte flora consists only of common elements, always found in crevices and on ledges on similar substrate: Polytrichum spp., Cynodontium spp., Dicranum spp., Pohlia cruda and P. nutans, Bartramia ithyphylla, Ulota curvifolia, Pterygynandrum filiforme, Drepanocladus uncinatus etc. However, even on these very dry cliffs, the crevices seem to retain some moisture even after periods of drought, partly because of the shaded aspect. At least in some spots the cushions are very dense and swelling, only the most exposed parts being occupied by the drought-resistant Paraleucobryum longifolium, Schistidium apocarpum, Hedwigia ciliata etc. On the ledges the forest heath fragments are also usually found, dominated by Vaccinium vitis-idaea or (occasionally) Arctostaphylos uva-ursi.

There is practically no fine scree, and the vegetation is poor forest heath with the trees Betula pubescens, B. verrucosa, Populus tremula, Pinus and Picea the most important. The herbs are very few and Deschampsia flexuosa is the common grass. There are no patches with a richer vegetation.

The coarse scree is for the most part overgrown with forest trees but there are fragments with Chandonanthus setiformis among the boulders in more open places.

(b) This slope has many features in common with the former one, but there are terraces on the rock wall, which at least in the upper part is much more exposed towards the sun. The ledges are more rich in grasses, foremost Festuca ovina. Woodsia alpina is present, and Arctostaphylos uva-ursi is rather common. There is a Scandian element also among the bryophytes, viz. Cnestrum alpestre.

On the whole the bryophyte flora is poorer than on the previous slope, whereas the vascular plants 


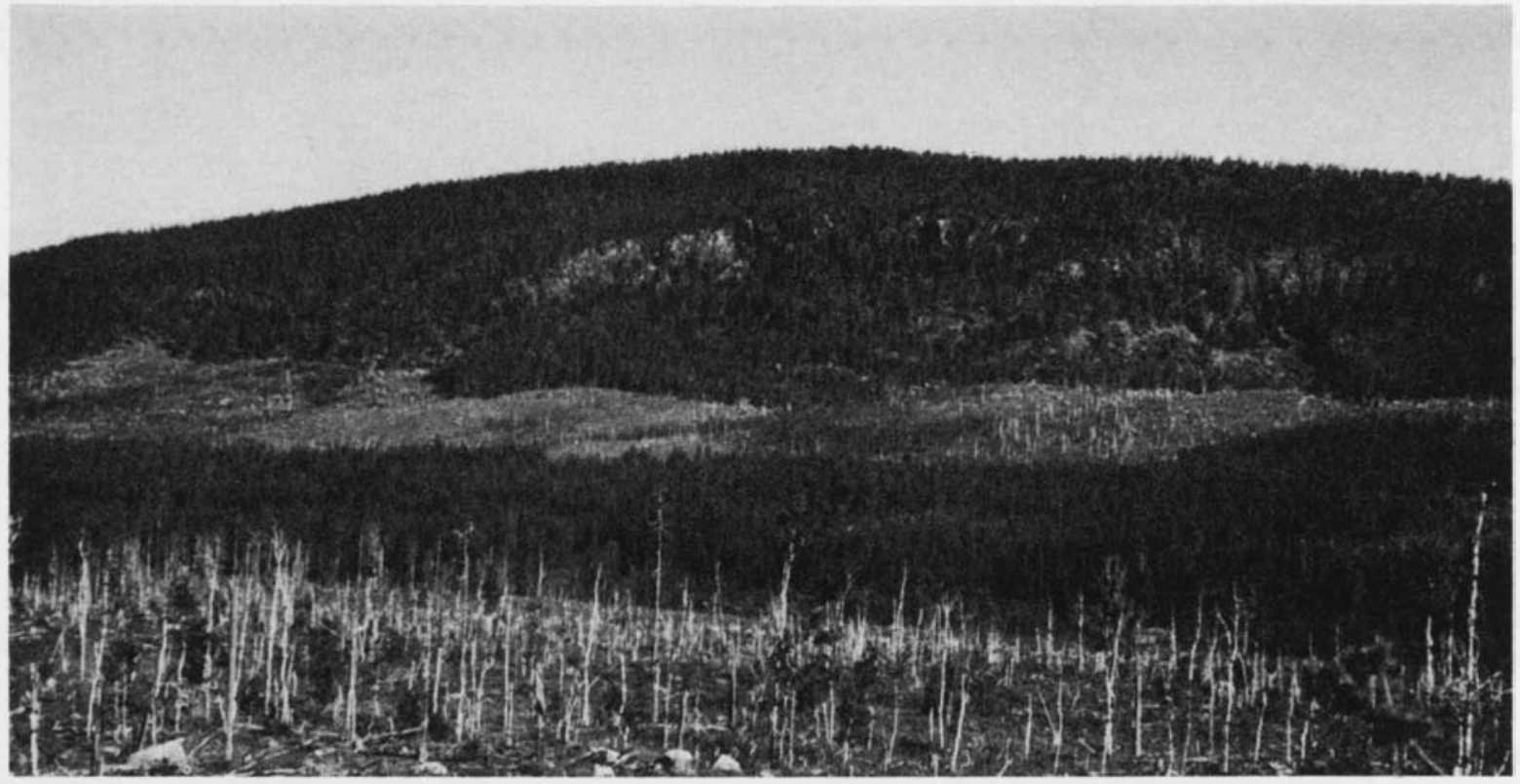

Fig. 48. Mt. Gaddaberget towards the NW. Large clearings made in the 1950s. To the right (shaded by trees) is the Gully with Actaea spp. There is a depression between the lower rocky hill ( $484 \mathrm{~m}$ on top) and the forested ridge in the background. In the valley River Grundselån, a tributary of the Pite River. 21 August, 1965.

have somewhat better conditions, at least on the scree. However, the scree is also dominated here by forest heath, but the herbs and grasses are somewhat more abundant. The conditions could be partly caused by the rather small change in azimuth angel. The sun exposure makes its impact also on the very poor forest flora constituting the bulk of species on Primary rocks.

Visits by the present author on 23 July, 1963, and on 21 August, 1965.

\section{Mt. Bärberget (Swed. bär $=$ berry, berries)}

Position: $65^{\circ} 46^{\prime} \mathrm{N}, 19^{\circ} 44^{\prime} \mathrm{E}$.

Altitude: (483) 429, $322 \mathrm{~m}$.

Exposure: Rock-wall inclination $80-90^{\circ}$, azimuth $0^{\circ}$ to $+30^{\circ}$.

Bedrock: Granite.

Ground: Poorly developed fine scree with forest mull, coarse scree.

This cliff has no supply of seepage water. In the composition of the flora this slope differs very little from the previous one (no. $29 \mathrm{~b}$ ). Although there are some otherwise typical hillside plants missing (Poa nemoralis, $P$. glauca) the ledge communities could probably in some cases be classed as the Cladonia variant of Dicrano-Polytrichetum.

The fine scree and coarse scree are almost hidden by trees, and because of this it is more shaded in the upper parts than is usual on extensive slopes (Fig.
47). In front of the rock wall there are some clumps of the typical plants (Phegopteris polypodioides, Melica nutans, Rubus saxatilis etc.). Even the less expected elements Carex digitata, Rubus idaeus and Hypnum revolutum are found. Lower down Pyrola media and $P$. chlorantha, are found but the general appearance is of a poor pine heath, very sparsely interspersed with herbs.

Visits by Wistrand on $18 \mathrm{July}, 1959$, and by the present author on 25 June, 1963, and on 21 August, 1965.

\section{Mt. Gaddaberget (Swed. dial. gadda $=$ tooth)}

Position: $65^{\circ} 43^{\prime} \mathrm{N}, 20^{\circ} 2^{\prime} \mathrm{E}$.

Altitude: (553) 379, $295 \mathrm{~m}$ (see below).

Exposure: Rock-wall inclination $60-90^{\circ}$, azimuth $0^{\circ}$ to $+30^{\circ}$.

Bedrock: Granite and amphibolite, see p. 23.

Ground: Poorly developed fine scree with thin or locally moderately thick mull layer, coarse scree.

There is a depression in the upper parts of the mountain (Fig. 48), between the plateau above the steep cliff and the summit area. The plateau above the cliff is much lower $(484 \mathrm{~m})$, the real height of the cliff thus about $100 \mathrm{~m}$.

The seepage water is very sparse, mostly absent in summer. However, there is an ephemeral small stream in the W parts of the mountain (with Viola riviniana), beside the rock wall, and a shaded gully 
in the E parts. The drier parts of the rock wall do not differ very much from the previously discussed hillsides, but the fragments with the Cladonia variant of Dicrano-Polytrichetum are generally larger and fairly typical, containing a few southern species (Table 25, stand no. 4). The more demanding elements among the bryophytes are usually found only in the gully, which for these reasons has an appearance not expected on such a hillside with mainly acid rocks (however, one of the rock walls in the gully is amphibolite, see p. 23). Some of the unusual elements of the gully were discussed above in the chapter on the bryophyte flora of the hillsides.

The fine scree is usually poorly developed and covered by a thin forest mull layer (see the analyses of the soil). The dominant vegetation is the forest heath, usually with a sparse interspersion of herbs and grasses. One of the most common types with herbs has Convallaria majalis as a subdominant, at least in some stands below the rock wall. The numbers of deciduous trees in the otherwise dominant pine forest may be greater in these places (Populus tremula, Betula verrucosa, Salix caprea and Sorbus aucuparia). The shrub, field and bottom layers may have the following composition (degree of cover of a typical stand in parentheses):

\section{Juniperus communis (2)}

Empetrum hermaphroditum (1)

Linnaea borealis (1)

Vaccinium myrtillus (2)

V. vitis-idaea (2)

Deschampsia flexuosa (2)

Convallaria majalis (2-3)

Geranium silvaticum (1)

Melampyrum pratense (1)

Solidago virgaurea (1)

Brachythecium reflexum (1)

Bryum spp. (1)

Dicranum spp. (2)

Pleurozium schreberi (1)

Pohlia nutans (1)

Hepaticae coll. (1)

Sparsely mixed in the vegetation are also Calluna vulgaris, Melica nutans, Poa nemoralis and Rubus saxatilis. The conditions for this transitory heath type to be developed are generally to be found in very ephemeral seepage water or a better water supply during rain showers (Fig. 31).

The vegetation on the fine scree on the bottom of the gully has been classed as a Poeto-Lactucetum community (Table 18, stand no. 6) and is the only tall meadow fragment seen on the hillside. Although there is no seepage water in the gully, the conditions are favourable for the development of a plant community which is very unusual for the area in question. The accumulation of humus is fairly great, due to the abundant supply of litter from the community itself and the pulling down by wind and rain of moss tufts from the rock wall.

The coarse scree, mainly covered with pine forest, is also present in the E parts on horizontal ground. The coarsest parts have no forest trees, and the boulders are covered only by lichens or very small moss tufts. Below very large boulders are found the less common elements Neckera oligocarpa and Metzgeria furcata.

Visits by Wistrand on 15 July, 1955, on 8 August, 1956, and (together with the present author) on 18 July, 1963, by the present author alone on 11-13 July, 1962, on 24 June, and on 5 August, 1963, on 20 August, 1965, on 29-30 August, 1966, and on 15 September, 1967.

\section{Mt. Hålberget $($ Swed. hål $=$ hole $)$}

Position: $65^{\circ} 22^{\prime} \mathrm{N}, 19^{\circ} 32^{\prime} \mathrm{E}$.

Altitude: (520) $418,377 \mathrm{~m}$.

Exposure: Rock-wall inclination $60-90^{\circ}$, azimuth $0^{\circ}$ to $+30^{\circ}$.

Bedrock: Quartz porphyry and granite.

Ground: Poorly developed fine scree with thin forest mull, coarse scree.

There is no seepage water on the rock wall and because of this there is a rather sparse bryophyte vegetation of the common type, dwarf-shrub heath communities being dominant. On the whole hillside, the only less common bryophytes are Rhabdoweissia fugax, Pseudoleskeella papillosa and Lepidozia reptans. The Cladonia variant of Dicrano-Polytrichetum is present in a depauperated state (with Poa glauca, Polypodium vulgare).

In the sparse birch forest on the scree are interspersed mainly Populus tremula, Picea abies and Betula verrucosa, but generally the trees produce too little litter for a thicker forest mull layer to be developed. The herbs and grasses, as on the other slopes of similar appearance, are very sparsely intermingled in the forest heath types.

Very different from the vegetation on the scree is the E hillslope on till-covered ground. As it is moist in several places, with spring outlets, small streams etc. the vegetation is much more luxuriant, with several more demanding plants (e.g. Dryopteris filixmas, Milium effusum, Orchis maculata etc.). Although the exposure is $\mathrm{S}$, the stands are rather shaded by Picea trees. The forest is much influenced by man.

Visits by Wistrand on 9 August, 1937, and by the present author on 23-24 July, 1963, and on 20 August, 1965. 


\section{RÉSUMÉ}

La couverture végétale et l'habitat des flancs escarpés des collines de Pite Lappmark.

\section{INTRODUCTION}

Pite Lappmark (Lapponia pitensis, abréviation : PL) est, un territoire extensif, situé dans les régions centrales de la Laponie suédoise, entre $65^{\circ} 9^{\prime}$ et $67^{\circ} 10^{\prime} \mathrm{N}$. Sa surface totale couvre $20715 \mathrm{~km}^{2}$, dont $13645 \mathrm{~km}^{2}$ au NW font partie de la paroisse de Arjeplog, et $6070 \mathrm{~km}^{2}$ au SE, font partie de la paroisse d'Arvidsjaur.

Le cercle polaire traverse la partie $\mathrm{N}$ d'Arjeplog (voir les cartes, figs. 1 et 2 ).

Au NW, dans les montagnes calédoniennes (les Scandes, Ljungner 1948), d'immenses étendues de terres stériles occupent des surfaces considérables. L'étage alpin comprend les régions situées au-dessus de la limite supérieure du bouleau, Betula pubescens (tortuosa), à environ 700-800 m d'altitude. Dans les montagnes du SE, dans le SE d'Arjeplog et dans Arvidsjaur, l'épicéa, Picea abies, ou le pin sylvestre, Pinus silvestris, forme la limite supérieure des arbres, et de ce point de vue, diffère du reste du NW de l'Europe. Dans certains cas, la présence des conifères en haute altitude est un indice évident de l'amélioration du climat durant les dernières décades (Wistrand 1965, p. 220).

La topographie de la région des Scandes au NW a été décrite brièvement par Arwidsson (en allemand; 1943, p. 13). La cime élevée d'une haute montagne, le Mt Sulitelma (1914 m), se situe près du coin NW de PL, du côté de la Norvège. Un autre sommet, de cette même montagne, est le plus élevé de PL (1869 m; d'après les données géographiques récentes).

Les basses montagnes du SE et les cimes boisées sont considérées comme les " monadnocks » d'une ancienne pénéplaine (Magnusson, Lundqvist et Regnell 1963, p. 355). Elles peuvent atteindre des altitudes considérables, $(608$ et $601 \mathrm{~m})$ même dans le voisinage immédiat de la frontière SE du côté de la région côtière. Elles ont été soumises à une plus grande dénudation que les Calédonides dans le NW, lesquelles sont jeunes et conséquemment ont normalement des profils plus abrupts. Néanmoins, il arrive que l'on rencontre de hautes murailles rocheuses verticales, des blocs et des éboulis à certains endroits.

La position géographique de l'aire inventoriée, avec les 32 montagnes formant la base d'étude, apparaît sur les cartes (figs. 1 et 2). Pour un examen plus approfondi de la topographie, se référer aux données du Generalstabens Karta över Sverige (partie N, édition 1890-1895).
Au point de vue géologique, l'aire se divise en deux parties majeures, i. e. : la partie calédonienne dans le NW et celle des roches Archéennes dans le SE. La série limitrophe des Calédonides consiste en une frange étroite d'arkose, de pelite, de grès et d'argile schisteuse qui sont d'âge Précambrien et Cambrien dans le district concerné (Grip 1960). Dans le grès, on trouve certains minéraux tels que la galène, la sphalérite et la pyrite (voir plus bas, p. 139). Au-dessus des séries autochtones, viennent les conglomérats, les mylonites des roches archéennes (surtout syénite et granit), les schistes séricitechlorite, les sparagmites, les quartzites et les phyllites. Les schistes de mica apparaissent fréquemment dans certains districts. En général, les murailles rocheuses de ces montagnes consistent en roches qui, dans leur partie supérieure, résistent à l'altération sur place comme les tenaces mylonites ou les roches métamorphiques archéennes. On considère cependant que la partie inférieure est constituée de roches plus tendres et peu résistantes à l'action des éléments. Par conséquent, cette disposition a favorisé la formation d'une topographie particulièrement typique. Ainsi, bon nombre de flancs de collines de PL sont verticaux ou presque, et exposés au SE ou SW ou au moins, possèdent une topographie beaucoup plus escarpée que les autres.

Se basant sur la géologie, le climat et la végétation, Wistrand (1962, p. 39) divise la région en deux parties principales :

A. La région scandienne (Suéd. " fjällområdet »). Elle comprend les étages alpins et subalpins du NW jusqu'à la limite supérieure de la forêt coniférienne. Les caractéristiques principales sont : un climat estival froid (température de juillet un peu au-dessus de $+10^{\circ} \mathrm{C}$ ), une précipitation annuelle élevée (1000 $\mathrm{mm}$ ou plus), et une flore comprenant un grand nombre d'espèces alpines et montagnardes. Les espèces montagnardes, selon Wistrand (1962, p. 161), sont celles dont l'aire de distribution est pratiquement restreinte aux Scandes, et qui sont un élément caractéristique de la forêt mixte pré-alpine (conifères-bouleaux), présentent à la fois dans la région alpine et subalpine. Les espèces alpines, d'autre part, sont pratiquement restreintes à l'étage alpin, au-dessus de la limite du bouleau. Arwidsson (1943) donne une description détaillée de la flore.

B. La région forestière coniférienne comprend la plus grande partie de la région cambro-silurienne, et la région 
des roches archéennes. Au sens où on l'entend ici, la région cambro-silurienne comprend au NW, les forêts de pins (Pinus silvestris) et d'épicéas (Piceaabies) s'étendant jusqu'à la limite supérieure de la forêt coniférienne. En fait, cette région ne coïncide pas très bien, dans la partie NW, aveccelle desassisesgéologiques cambro-siluriennes. Elle comprend les parties les plus basses des vallées dont les assises sont d'un autre type calédonien, jusqu'à une limite supérieure variant autour de 570 à $600 \mathrm{~m}$ d'altitude. Dans ces conditions, la région forestière coniférienne du $N W$ aurait sans doute été un nom plus exact. La bordure SE de cette région coïncide avec la bordure SE des Calédonides. Les montagnes du NW décrites dans ce travail sont incluses dans cette région. Les caractéristiques principales sont : un climat estival froid (température de juillet : +10 à $+13^{\circ} \mathrm{C}$ ), une précipitation annuelle assez élevée (500-700 $\mathrm{mm}$ ), et une plus grande abondance d'espèces des basses-terres, e. g. Woodsia ilvensis, Athyrium filix-femina, Paris quadrifolia, Melica nutans, Roegneria canina, Populus tremula ( $P$. tremula apparaît cependant dans des stations assez élevées, près de la limite supérieure du bouleau) et Barbaraea stricta.

La région des roches archéennes, ou (d'une façon plus exacte) la région forestière coniférienne $d u S E$, est généralement recouverte par un type de végétation plus pauvre, principalement constituée par de grandes étendues de forêt clairsemées à buissons nains (avec Betula verrucosa) et par des tourbières. Mis à part les montagnes décrites ici, les rivages des rivières, des ruisseaux et des lacs, possèdent une flore et une végétation plus variées (cf. Wistrand et Lundqvist, 1964) dont Convallaria majalis, Rosa majalis, Phalaris arundinacea et Lysimachia thyrsiflora par exemple, sont des éléments caractéristiques. Ces espèces peuvent être considérées comme des indices du climat estival plus chaud et plus continental qui prévaut dans cette région.

\section{L'H AB ITAT}

\section{INTRODUCTION}

Au cercle polaire, de grandes différences dans la flore et la végétation existent selon les différentes pentes des montagnes, spécialement là, où les caractéristiques climatiques sont accentuées par la présence d'escarpements verticaux ou d'habitats ouverts où la radiation solaire peut attcindre le sol. L'effet de l'augmentation de la radiation due à l'altitude n'est pas négligeable non plus. D'autre part, les collines à faibles pentes et les crêtes dépourvues de forêt ne montrent généralement pas de différences quant à l'exposition.

La comparaison de la flore et la végétation des flancs de collines favorisées thermiquement, montre en général, des différences appréciables entre les localités pauvres et les localités riches. La richesse de la flore peut être mesurée par le nombre d'espèces, et ce nombre peut être jusqu'à quatre fois plus grand sur une colline riche que sur une colline pauvre. Les différences dans la végétation ne peuvent pas être exprimées numériquement, mais on note quand même une différence appréciable entre les luxuriantes prairies d'herbacées des riches collines, et les broussailles d'arbustes des collines pauvres.

On ne doit quand même pas oublier qu'il n'y a pas toujours coïncidence entre une flore riche en espèces et une végétation luxuriante.

Halden (1950, p. 546) suggère que l'importance accordée à l'exposition $\mathrm{S}$ a été exagérée et que la « légende du flanc $\mathrm{S}$ des collines » n'a en fait, que peu de fondement. Dans la région étudiée, il nous semble que beaucoup d'espèces vasculaires et bryophytiques ne sont pas vrai- ment adaptées à des flancs insolés, mais qu'elles exigent une exposition plus ou moins $S$, indépendamment de la richesse ou de la pauvreté en chaux de la station.

\section{ALTITUDE}

Thécriquement, on pourrait s'attendre à une corrélation entre l'altitude d'un flanc de montagne (au-dessus du niveau de la mer) et le nombre d'espèces thermophiles de sa flore. Mais en fait, la région à l'étude ne permet pas d'élucider la question. Dans une même région géologique, la base des murailles rocheuses de beaucoup de basses montagnes se situe entre 500 et $600 \mathrm{~m}$ au-dessus du niveau de la mer. Il devient donc difficile de déceler quelques différences dues à l'altitude dans des limites si restreintes. La plus grande différence en altitude, de la montagne la plus au SE à la montagne la plus au NW, est de $324 \mathrm{~m}$, la mesure étant effectuée à la base de la muraille rocheuse. Les extrêmes sont no. 31 : Mt Gaddaberget, $379 \mathrm{~m}$ et no. 7 : Mt Kaldopakte, $703 \mathrm{~m}$. Cependant, la distance, relativement grande entre ces deux dernières, indique que ces montagnes sont situées dans des régions différentes du point de vue climatique, géologique et floristique. D'autres facteurs peuvent affecter le climat comme par exemple : la continentalité et la latitude. D'autres facteurs diminuent l'importance relative de l'altitude tels que l'élévation par rapport au fond des vallées, qui a une incidence particulière sur les températures nocturnes, et l'orientation de l'exposition. La flore de la partie supérieure des pentes d’éboulis 
pierreux (no. 7) ne possède qu'une espèce vasculaire un peu thermophile, viz. Erysimum hieraciifolium, indiquant ainsi que cette montagne possède un climat trop froid pour qu'une flore plus riche puisse y croître. Dans l'intervalle de 500 à $600 \mathrm{~m}$ d'altitude, le climat est considérablement meilleur et les conditions géologiques sont aussi favorables. En conséquence, le nombre d'espèces thermophiles est passablement élevé. Vers le SE, d'autre part, les différences du point de vue géologique produisent beaucoup plus de différences apparentes que ne le font les variations en altitude.

Les étages d'altitude (adapté d'après Wistrand 1962, p. $40 ; 1965$, p. 219) sont :

1. L'étage alpin (sans arbre); typiquement développé dans le NW (la région scandienne). Dont les communautés prédominantes sont surtout, des landes à a rbustes prostrés et des prairies alpines (Du Rietz 1942) auxquelles s'ajoutent les communautés chionophiles (Gjærevoll 1965 , p. 262), les broussailles de saules, les champs de blocs et les saillies de rochers recouverts de lichens et de mousses. La flore de PL a été décrite par Arwidsson (1943). Il est généralement accepté que les sommets des montagnes du SE font partie de l'étage alpin (Wistrand 1965 , p. 220). Une caractéristique de ces massifs détachés est la présence, jusqu'à $800 \mathrm{~m}$ et plus d'altitude, de conifères éparpillés ici et là sous forme de baliveaux ou de semis. Les bouleaux demeurent cependant souvent absents aux niveaux correspondants. La limite supérieure des arbres a probablement oscillée. Ces oscillations sont sans doute dues aux feux de forêts, et principalement ceux du dernier millénaire (Wistrand, cf. aussi Högbom 1934).

2. L'étage subalpin (peuplement pur de bouleaux, étage de bouleaux); dont le développement typique n'existe qu'au NW. Le sous-étage de ces peuplements de bouleaux comprend des communautés végétales composées d'herbacées de grande taille (Holmen 1965, pp. 240 et suivantes), s'entremêlant aux buissons nains à dominantes de Vaccinium myrtillus et de Deschampsia flexuosa, et aussi des broussailles de suales et de genévrier. Les tourbières et autres surfaces sans arbre sont aussi nombreuses.

3. L'étage pré-alpin (peuplements de bouleaux avec quelques épicéas isolés, ou quelques pins dans certains districts). Bien développé dans la région forestière coniférienne du NW, ce type de végétation est généralement moins commun des massifs alpins isolés du SE. A PL (Wistrand 1962, p. 40), il existe un faciès NW composé de bouleaux et de pins («région du pin» de Wahlenberg) et un autre faciès composé de bouleaux et d'épicéas. Le bouleau tend à occuper des surfaces considérables dans le fond des vallées, et les stations de conifères les plus au NW sont invariablement situées du côté $\mathrm{N}$ des vallées (exposition $\mathrm{S}$ à $\mathrm{SW}$ ). Ce trait bio-climatologique particulier est d'un grand intérêt. Le sous-étage de ces forêts est très similaire à celui de l'étage subalpin. La limite inférieure peut être tracée là où apparaissent Ledum palustre et Betula verrucosa (Rune S. 1965, p. 225), c'està-dire approximativement à $450 \mathrm{~m}$ d'altitude en Laponie centrale.

4. L'étage sylvatique supérieur (constitué, dans les cas typiques, de peuplements purs d'épicéas; " étage d'épicéas»). C'est le trait commun des montagnes isolées du SE qui peuvent être complètement entourées par la forêt d'épicéas. Plus au NW (entre les montagnes nos. 19 et 22), il ne subsiste plus que des peuplements de faibles dimensions. Sur le Mt Staburknösen (no. 15), dans le voisinage immédiat du Mt Nebsuort, un peuplement pur d'épicéas atteint la région des Scandes (Wistrand 1962, p. 42). Certaines espèces (Pteridium aquilinum, Calypso bulbosa, Viola riviniana et Oxalis acetosella) et certains types de végétations semblent plus fréquents dans cette forêt, mais la forêt à buissons nains et lichens (Pineto-Cladinetum) est absente.

5. L'étage sylvatique inférieur (peuplements d'épicéas et de pins, mélangés ou purs). Cet étage comprend le plus bas étage des montagnes du SE (nos. 31 et 32) et le plateau du SE de PL. Telles que mentionnées plus haut, la flore et la végétation possèdent les caractères de celles des basses-terres, en particulier le long des cours d'eau.

Les caractéristiques principales de la zonation altitudinale ont d'abord été reconnues et définies par Wahlenberg (1808, 1812, 1824-26; cf. Rune O. 1965, p. 64; Sjörs 1965, p. 58). L'étage sylvatique supérieur (Wistrand) semble avoir été reconnu comme un prolongement vers le SE de la sous-région pré-alpine (sensu Du Rietz, Du Rietz 1950, 1964 : cf. la carte des régions forestières de Suède dans Sjörs 1965, p. 51).

\section{SOL ET ROCHE EN PLACE}

\section{Les propriétés chimiques}

La comparaison entre les différentes montagnes à l'intérieur de PL, montre clairement que seules les montagnes pourvues d'une certaine quantité de minéraux calcaires, peuvent supporter une flore riche en espèces et une végétation typique à dominance d'herbacées. Toutefois, le contenu en calcium peut être assez faible. C'est le cas du Mt Märkepakte (no. 12) où la teneur en calcium du sol minéral, presque dépourvu de matière organique, peut être aussi faible que $0.3 \% \mathrm{Ca}$ (mesurée à partie de l'échantillon total de sol) et du Mt Vuornats (no. 19) où la roche en place est presqu'exclusivement constituée de roches archéennes à faible teneur en minéraux calcaires. Néanmoins la flore des crevasses du Mt Vuornats est passablement riche (présence locale de Tortella tortuosa et $T$. fragilis), et l'on trouve des fragments de prairies d'herbacées sur les éboulis à particules fines. 
Il est évident que les conditions édaphiques, des éboulis à particules fines et des corniches des murailles rocheuses, ne sont pas influencées seulement par lesconditions minéralogiques à la surface, mais aussi par celles prévalant au sein même de la muraille. Les eaux d'infiltration pénètrent des couches de caractéristiques variables et dissolvent des ions minéraux, les transportant à la surface de l'escarpement. De cette manière, les pentes pauvres en chaux et en autres minéraux facilement solubles, jouissent en surface, d'un apport de minéraux qu'il ne nous est pas possible de mesurer. Cet état de fait réduit quelque peu la possibilité de corrélation entre la flore et les propriétés de la roche en place.

Dans la partie SE de la région, plusieurs localités de pentes d'éboulis pierreux ne montrent pratiquement aucune trace d'un effet dû à la chaux. Les crêtes boisées de cette région sont remarquablement peu influencées par la présence de roches archéennes basiques, à l'intérieur de la région d'Arvidsjaur. Seulement sur quelques rares montagnes, par exemple, les Mts Harrejaurliden (no. 28) et Gaddaberget (no. 31), on discerne un certain effet dû à la chaux, mais qui est probablement exagéré par les conditions climatiques particulièrement favorables de ces pentes montagneuses.

Au NW de la bordure cambro-silurienne, le contenu en chaux de la roche en place exposée dans les escarpements et les éboulis, semble être partout suffisant pour les besoin de la flore et de la végétation calcicole. Ceci semble vrai, non seulement pour les sédiments autochtones facilement altérés sur place, mais aussi pour les roches dures et tenaces plus ou moins métamorphiques. Les facteurs limitatifs sont ici d'une autre nature, notamment l'apport en eau.

Sur le plateau montagneux, l'érosion est lente, la percolation est verticale, et le processus de délavage conduit à la formation de sols podzoliques, de " hardpans », etc. D'autre part, sur la pente, la percolation est fortement latérale et l'eau peut être successivement enrichie en éléments nutritifs. Pour un certain angle d'inclinaison et en fonction du type de sol et des précipitations (dans les régions arctico-alpines, aussi sur pergélisol), l'érosion est accrue par le transport fait par l'eau de particules minérales; par des glissements locaux, et (en hiver) par les avalanches. Ces conditions créent souvent des types extrazonaux de sol brun, notamment sous un couvert de feuillues (Tamm O. 1930, 1931). Les escarpements quasiverticaux sont des exemples extrêmes de topographie trés escarpée.

Le substrat de la végétation des éboulis est formé par l'altération sur place de la roche-mère provenant des débris de la muraille rocheuse (voir plus haut). A ce substrat, s'ajoute annuellement un nouvel apport de litière, assez abondant sur les sites où croissent les hautes herbes et les arbres, et généralement suffisant pour couvrir les nouveaux apports d'éboulis jusqu'à la taille des blocs. Tous les types intermédiaires existent entre le tapis fermé de végétation et les éboulis dénudés.

A la suite de l'apport de matériaux nouveaux et de l'altération sur place des débris rocheux, le développement du profil et l'entraînement des matériaux interviennent. Par développement du profil on entend: Le mouvement vertical de matériaux, y compris la décomposition et la remise en cycle de la litière et de l'humus. Par la minéralisation de l'humus, l'azote, le phosphore et le soufre deviennent disponibles pour les plantes. L'altération chimique y compris, l'hydratation et l'oxydation, aussi bien que l'altération physique et biologique, produiront éventuellement un ensemble de fines particules et d'aggrégats dans le sol. Le transport de matériaux, par lequel on entend le mouvement des matériaux vers le bas de la pente de l'éboulis pierreux, est, dans le cas des éboulis stabilisés, d'abord dû aux mouvements de l'eau. Par ce procédé, les plus fines particules sont déplacées à moins qu'elles ne fassent déjà partie d'une structure du sol déjà fixée. Dans le cas des éboulis non-stabilisés, le transport des matériaux s'opère à intervalles; en particulier par glissements ou encore par reptations. Enfin, les matériaux accumulés à la base de la pente de l'éboulis peuvent être à nouveau déplacés et entraînés comme par exemple lors de l'érosion opérée par les rivières.

Les sols des éboulis sont des substrats favorables à la flore et à la végétation à cause de leur renouvellement successif par l'apport de matériaux neufs provenant des murailles rocheuses. Les processus de lessivage sont obstrués a lors qu'ils sont les caractéristiques de la plupart des sols forestiers du $\mathrm{N}$ de la Suède sur matériaux stables en pente faible. La quantité et le taux d'apport de matériaux nouveaux deviennent alors des facteurs d'importance fondamentale. A ce point de vue, de grandes variations existent sur notre territoire. Elles sont dues en grande partie à la composition chimique et physique de la roche en place, et à la topographie des murailles rocheuses et des éboulis (voir plus haut).

Comme l'a démontré Jenny-Lips (1930, p. 130), un enrichissement en matière organique à lieu à la partie supérieure du profil, lorsqu'il y a croissance prolifique de végétaux. Ainsi, à la partie proximale de la pente de l'éboulis pierreux tel que décrite ici, immédiatement située sous la muraille rocheuse, la partie supérieure de la couche de pierre et d'air (telle que définit par J.-L.) est souvent remplacée totalement ou en partie, par une couche de pierre, de litière et d'air (cf. Lundqvist $\mathrm{J}$. 1961, p. 169). L'épaisseur de cette couche est variable, elle dépend de l'altération sur place, et du taux de décomposition des matériaux. Si le taux de renouvellement est bas, comme c'est le cas lorsque la roche est faiblement altérée sur place, ou encore lorsque l'exposi- 
tion n'est pas favorable; l'épaisseur de cette couche peut être considérable, à condition que l'apport de litière soit important. Comme il y a des petits fragments de débris plus fins, un type d'humus ressemblant au mull, peut se développer, spécialement au sommet des blocs et des pierres, là où les plantes ont une bonne nutrition. Le développement des coussinets de mousses et de plantes vasculaires sur les éboulis à particules fines n'est pas très prononcé.

Les recherches pédologiques ont été effectuées dans le but premier de connaître les différences entre la région Archéenne SE et la région NW des Calédonides, au point de vue des caractères du sol sous les communautée végétales principales. Nous avons aussi étudié les différences au niveau du sol entre la partie supérieure de l'éboulis située juste sous l'escarpement, et qui porte une végétation arborescente, et la zone de transition jusqu'au bas de la pente de l'éboulis, d'où les arbres sont absents. Lorsque des plantes thermophiles intéressantes ont été observées dans d'autres écosystèmes que les flancs de collines isolées, les conditions du sol de l'habitat ont été aussi étudiées.

Les analyses de sol ont été résumées aux tableaux $1-2$, le dernier indiquant les conditions le long des deux transepts (en fin de volume).

Les types d'humus étudiés sont pour la plupart, des humus doux se développant sous une végétation de prairie. Dans ces habitats, l'apport de litière au sol est assez abondant et le taux de décomposition diffère selon l'origine.

A certains endroits, là où la litière se compose surtout de feuilles, de tremble (cf. Julin 1948, p. 37), qui s'accumulent et se décomposent lentement, et à d'autres endroits, sous couverture végétale à productivité élevée (transept, p. 145); la teneur en matière organique de la partie supérieure du sol est extrêmement élevée (ca. $85 \%$ de perte par ignition) alors qu'ailleurs, même la partie supérieure du sol est constituée presqu'exclusivement de matière minérale. Un équilibre pourra être atteint, dépendant surtout de la nature des minéraux dans le sol, de la taille des particules, de l'aération, du climat, de l'apport en litière et du contenu en organismes vivants dans le sol (cf. Stålfelt 1960, p. 144). Pour le développement d'un humus doux, un certain contenu, en éléments minéraux de base, est nécessaire même pour les sites favorisés du point de vue climat. En dépit d'un apport de minéraux nouveaux au sol, il existe des conditions édaphiquement défavorables lorsque l'exposition est elle-même défavorable, comme par exemple sur le flanc NE du Mt Aistjakk (échantillons 24 à 27). En général, on trouve à ces endroits une eau basique et riche en oxygène qui, d'une certaine façon, compense les plus basses températures et les plus bas contenus en phosphate et en calcium de l'humus.
Sur les roches archéennes, là où l'apport en matériaux à grains fins est faible, et par conséquent, où l'éboulis est plus ou moins stabilisé, la végétation est dominée par les conifères et les forêts à lande buissonneuse naine. Là où le contenu en minéraux de base est faible ou l'exposition défavorable, la nitrification semble faible ou inexistante. A certains endroits, on peut trouver une couche d'humus brut ressemblant à celui qui se développe sur un terrain normal recouvert d'un dépôt morainique (la couche d'humus brut peut aussi s'appeler mor). Une couche de mycorhization peut aussi se développer au-dessus d'un mull forestier d'un type assez pauvre. Ce type de mull se développe sous une végétation à productivité très faible. 11 ne semble pas y avoir de relation intime entre la fraction organique et minéralogique du sol et l'abondance des hyphes de champignons (mycorhizes), alors que les petits animaux et les micro-organismes autres que les hyphes sont apparemment de moindre importance. Dans les types de mull forestiers étudiés sur le Mt Gaddaberget (échantillons 39 à 41), un tapis riche en mycorhizes occupait la partie supérieure du profil alors que la partie sous-jacente, constituée presqu'uniquement de sol minéral, montrait différents degrés d'accumulation d'oxydes ferriques, processus que l'on retrouve dans l'horizon B des sols podzoliques. Les profils typiques à mull ont été rencontrés uniquement dans le ravin (ca. une niche de $5 \mathrm{~m}$ de largeur et $20 \mathrm{~m}$ de profondeur dans la muraille, avec un éboulis à la base; échantillons 42 à 44 , tableau 1; en fin de volume). C'est pratiquement le seul endroit de l'éboulis exposé au $\mathrm{S}$, au pied de l'escarpement, où l'on trouve un assemblage de grandes herbacées formant un groupement végétal à productivité élevée. L'apport de matériel nouveau aux éboulis sur roche archéenne, est souvent très faible. Les forêts conifériennes les envahissent et produisent une litière acide. Fréquemment le sousétage est typiquement constitué de buissons nains, entremêlé de quelques herbacées éparses. Les conditions favorisent donc l'existence d'un humus brut à couche de fermentation faiblement humifiée, même si l'exposition est presque S. Seules les plantes à faibles exigences peuvent subsister alors que les plantes de prairie disparaissent des sites extrêmes.

A PL, les arbres feuillus sont pratiquement les seuls constituants de la partie supérieure de la forêt au pied de l'escarpement, sur roche en place cambro-silurienne. Le sous-étage est constitué d'herbacées occasionnellement accompagnées par quelques individus buissonneux nains de Vaccinium ou Arctostaphylos uva-ursi (la présence de ces quelques arbustes nains est due aux conditions particulières durant le dégel, p. 137). En aucun cas, nous n'avons pu observer sur un éboulis à exposition $\mathrm{S}$, un type de sol à mull forestier ressemblant à celui décrit pour la région des roches archéennes. Un bon exemple 
du développement du sol sous forêt de conifères, sur un éboulis cambro-silurien, a été observé sur le Mt Peruken (échantillons 52-54), où croissaient quelques épicéas au pied de la muraille rocheuse sur l'éboulis à particules fines. Le profil du sol, jusqu'à la couche d'air et de roche la plus inférieure, à $60 \mathrm{~cm}$ de profondeur, semble avoir évolué, à partir d'un sol à mull assez bien développé,jusqu'aux conditions actuelles, par l'empilement de litières faiblement humifiées et riches en mycorhizes et, par destruction du profil original. Les herbacées croissant dans leur voisinage immédiat, étaient totalement absentes tout près des épicéas, où le substrat acide est moins favorable. A cause de la teneur assez élevée en argile, de la partie minérale du sol située sous l'humus et qui est presque dépourvue de matière organique, les résultats, des analyses chimiques, obtenues en tenant compte de la perte en ignition, sont probablement trop élevés. Evidemment, ce type de sol, désigné ici par "mull forestier », se développe même s'il existe une infiltration d'eau riche en ions en provenance de l'escarpement ( $\mathrm{pH}=7,6)$ et l'effet, des minéraux solubles, est considérable. Voir aussi échantillon de sol 51, tableau 1; en fin de volume.

Méthodes. Afin d'obtenir des données comparables (Sjörs 1961, p. 5), les valeurs doivent être calculées par unité de contenu en humus. Ainsi, la perte par ignition peut être déterminée. Les particules minérales présentes dans la couche d'humus sont alors considérées comme des additions inactives aux colloïdes de l'humus. Cependant, les colloïdes inorganiques peuvent aussi agir comme échangeurs d'ions. En plus, la dissolution de certains minéraux est possible. La capacité d'échange des minéraux argileux et de l'humus peut varier selon les différents sols. Les données disponibles pour les sols naturels doivent être au moins comparables, et autant que possible déterminées, selon la même méthode d'analyse. Malheureusement, dans le cas présent, seules des méthodes d'analyses commerciales ont été utilisées au laboratoire (par Statens Lantbrukskemiska Laboratorium), et des échantillons secs furent utilisés. Lors de la prise d'échantillons, la difficulté d'un échantillonnage représentatif sous chacune des diverses communautés végétales, nous apparut, elle fut surmontée d'une certaine façon, par la prise d'échantillons à plusieurs endroits d'habitat similaire (le long des transepts); et aussi en mélangeant plusieurs sous-échantillons prélevés au même niveau, tout autour de la fosse creusée pour l'examen du profil de sol. Comme le creusage d'un profil, dans un éboulis à gros blocs, présente des problèmes, un petit nombre seulement de places-échantillons ont été choisies, et la profondeur du profil creusé ne dépassait généralement pas $50 \mathrm{~cm}$.

Sites d'échantillonnage. Dans certains cas, l'échantillonnage a été effectué simplement pour compléter les a nalyses de l'eau et de la roche, alors qu'ailleurs les pro- fils ont été aussi examinés. Les analyses de la végétation furent exécutées afin d'acquérir une connaissance aussi complète et compréhensible que possible de la station. Le manque d'espace nous oblige à ne donner qu'une brève description des stations et des profils des sols. L'énumération des échantillons est identique à celle employée pour les montagnes (tableau 1).

\section{LE CLIMAT LOCAL ET L'EXPOSITION SOLAIRE}

\section{Introduction}

Wahlenberg qui fut un des premiers botanistes à faire une description phytogéographique en tenant compte des différentes exigeances du climat et des facteurs édaphiques et historiques (1812, p. XLI), calcula les données pour la température, l'humidité de l'air et la précipitation. Se basant sur les résultats obtenus, il lui fut alors possible de distinguer les différentes régions de la Laponie au point de vue climatique et aussi quant à la dominance des espèces végétales.

Pour autant que la Laponie soit concernée, les régions de Wahlenberg sont entièremient demeurées valides jusqu'à présent, comme classification de la zonation générale de la végétation, même si les régions et les étages ont reçu des noms plus appropriés, donnés par d'autres chercheurs. Ce qui est surtout important, c'est que Wahlenberg, comme quelques pionniers tels Soulavie et Saussure, comprit clairement l'importance décisive du climat, et qu'il vit dans les différentes régions, l'expression du changement dans le climat saisonnier avec la latitude et l'altitude. Il ne voulut certainement pas apporter la confusion dans les zonations climatiques et biotiques, mais voulut plutôt élucider le problème de l'intéraction dans la nature, problème qui forme la base de l'écologie.

La présente étude sur les facteurs thermiques ne prétend pas être de quelque utilité dans la classification des groupements végétaux de cet écosystème spécial. Elle constitue plutôt un trait-d'union d'importance pour la compréhension et l'interprétation de certaines conditions phytogéographiques et édaphiques très particulières. Ces facteurs ont déjà été discutés à fond dans le travail classique de Andersson et Birger (1912). Ils ont été aussi plus récemment décrits pour Pite Lappmark par Wistrand (1934, 1962, pp. 24 et suivantes). Le mot suédois "sydberg " signifie actuellement, le côté d'une colline ou d'une montagne exposé au sud; Mais il a été utilisé par plusieurs auteurs, incluant Andersson et Birger et Wistrand, pour désigner un écosystème sur pente escarpée, et non toujours le côté exposé au sud des collines avec ses espèces boréo-méridionales. D'autres termes furent substitués e.g. par Halden (1950) et Du Rietz (1954). 
On doit tenter d'identifier les facteurs thermiques en relation avec les facteurs édaphiques importants. Cette idée est d'ailleurs appuyée par un grand nombre d'observations faites par différents chercheurs.

Le travail, que nous présentons ici, fut entrepris durant la saison de végétation des années 1959-62 et 1965-66 aux Mts no. 12 (Märkepakte), no. 13 (Storberget) et no. 16 (Aistjakk, flanc SW et NE). Le Mt Aist jakk est situé sur l'extrême bord des nappes de chevauchement des Calédonides; et les deux autres montagnes quelque peu au NW du no. 16. En été, la région semble être définitivement plus océanique que la station météorologique d'Arjeplog située le plus à l'E (voir plus bas, p. 137), mais pas autant que ne l'est Tärnaby à $100 \mathrm{~km}$ au SW. De plus, Tärnaby se trouve à une latitude favorable en comparaison avec les stations étudiées, tandis que Kvikkjokk au NNE est favorisé par sa basse altitude. Dans la région inventoriée, des montagnes relativement élevées (Mt Nebsuort 912 m, Mt Krappesvare 1024 m, Mt Peljekaise $1122 \mathrm{~m}$ ) sont séparées par des crêtes boisées, des basses montagnes et des collines (Mt Märkepakte 538 m, Mt Aistjakk 646 m, Mt Puoudak 744 m). Les fonds des vallées sont respectivement à 419 et $424 \mathrm{~m}$. Nous avons tiré avantage de la topographie lors des recherches entreprises, dans le dessein d'élucider le problème des associations végétales thermophiles et leurs rapports avec le climat local et le microclimat de la station.

Les objectifs principaux des présentes études climatologiques furent:

1. D’enregistrer les températures sur les pentes des collines exposées au soleil durant la période de végétation, et comparer les valeurs obtenues avec celles provenant du réseau météorologique de Suède.

2. En plus, de procéder à des études purement microclimatologiques de quelques stations, afin de connaître: a) la température à la surface et dans le sol, $b$ ) la température des murailles rocheuses et $c$ ) la température des associations végétales typiques.

3. Etablir les conditions de luminosité et le bilan énergétique dans un couple de stations. Au niveau des caractéristiques générales, les conditions de milieu des pentes exposées en différentes directions, pourraient être calculées d'une façon théorique (cf. Lunelund 1940).

4. La phénologie des pentes favorisées au printemps et tôt en été, complétée par quelques notes sur la phénologie en automne.

5. Etudier, les conditions de neige à la fin de l'hiver et au printemps (phase de dégel).

6. Elucider, les problèmes concernant les conditions de précipitation.

\section{Le bilan radiatif des pentes de montagnes}

Il a toujours été admis que le climat des pentes dépend en tout premier lieu de la quantité de radiations solaires ou d'énergie qui atteint les diverses surfaces inclinées, par comparaison à une surface horizontale (cf. la dérivation du mot grec: climat). Ce n'est que depuis quelque temps seulement, que les méthodes d'investigations et les instruments disponibles sont suffisamment précis pour nous permettre une évaluation du bilan radiatif de différentes stations (Anderson M. 1964, Geiger 1965). Cependant, les méthodes utilisées n'ont jamais été exactement les mêmes, ni les résultats de ces investigations, strictement comparables. Quant au climat lumineux des pentes, il nous faut par exemple, comparer les résultats de Grunow (1952) avec ceux établis pour des latitudes plus nordiques par Lunelund (1940, cf. fig. 13). Lunelund montre des différences très marquées entre les pentes d'exposition différente. Le phénomène est dû à la décroissance abrupte de la turbidité de l'air entre 30 et $60^{\circ}$ de latitude $\mathrm{N}$. En conséquence, la partie de la lumière qui atteint la terre sous forme diffuse, est relativement faible au N. Dans l'extrême N $\left(70^{\circ}\right.$ lat. N) les conditions des pentes exposées dans d'autres directions que le sud, deviennent encore moins inférieures à celles des pentes à exposition $\mathbf{S}$ en été, car la période lumineuse diurne augmente ou souvent devient continue pendant un certain temps.

Les courbes de radiation, pour l'année, considérées comme la somme de la radiation des jours clairs, ont été calculées pour $66^{\circ}$ de latitude $N$ (fig. 13), et sont basées sur les valeurs publiées par Aurén (1939, p. 24), pour les surfaces horizontales. Pour les surfaces verticales et les pentes de différente exposition, nous avons interpolé les valeurs données par Lunelund (1940). Les courbes de la fig. $13 a$ sont applicables aux conditions qui prévalent sur les escarpements verticaux, sauf pour les surfaces horizontales, tandis que les courbes de la fig. $13 b$ sont approximativement applicables aux plus basses pentes d'éboulis. Immédiatement sous un escarpement, la pente de l'éboulis pierreux est à l'ombre pendant une certaine période du jour, et les conditions sont, d'une certainefaçon, plus similaires à celles des escarpements. Les moyennes des courbes (qui n'apparaissent pas dans les figures) seront applicables aux expositions SW, NW, NE et SE.

Au printemps et au début de l'été 1966, quelques essais ont été tentés afin d'étudier le bilan énergétique de deux flancs opposés du Mt Aist jakk, près des stations 7 et 8 . La radiation thermique nette peut seulement être estimée approximativement (cf. Geiger 1965, pp. 20-22), de même que pour l'évaporation, à cause du manque d'instruments. Mais les autres facteurs en cause; la température de l'air et du sol à différents niveaux, la température des murailles rocheuses et la vélocité du vent (horizontal et vertical) à $50 \mathrm{~cm}$ au-dessus du sol, furent mesurés par la même occasion, pendant les jours et les nuits clairs ou presque. Des actinographes bimétall iques Robitsch de construction japonaise furent utilisés. 
Lorsque l'on calcule la dépense effective des radiations, nous devons présumer que les appareils enregistreurs, le sol et les escarpements sont approximativement aux même conditions de température. L'intensité de la lumière diffuse, qui atteint les escarpements tôt le matin, pourrait bien être aussi considérable que celle atteignant une surface horizontale, à cause de la lumière réfléchie par la neige, produisant ainsi une radiation nette positive. Les calculs furent faits en présumant que la pression de la vapeur d'eau à $150 \mathrm{~cm}$ au-dessus du sol était constante. Il est possible de démontrer mathématiquement que la dépense effective de radiations d'un escarpement vertical, est la moitié de celle d'un surface horizontale totalement exposée sous une atmosphère exempte de vapeur d'eau. Lauscher (selon Geiger 1965, p. 24) trouva une valeur de $39.2 \%$ à $5.4 \mathrm{~mm} \mathrm{Hg}$ ou $7.2 \mathrm{mb}$ de pression de vapeur d'eau. Comme les pressions de vapeur d'eau étaient passablement basses dans ces cas, nous avons supposé que la dépense effective de radiation était un peu plus élevée que celle calculée selon Lauscher. Nous avons utilisé la formule de Brunt avec les constantes données par Möller (1951, p. 39). La formule de Ångström (1916) donna à peu près les mêmes résultats. Les surfaces où s'effectuèrent les mesures, furent considérées comme totalement noires (dans le cas des murailles rocheuses, les mesures de température des surfaces foncées furent prisent en considération). Voir tableaux 3 et 9 et figs. 14 et 21 .

\section{Les abris de thermomètre et leur emplacement}

Les abris de thermomètre utilisés pour le présent travail, étaient identiques à ceux des stations météorologiques de Suède. Dans ces abris, nous avons utilisé des thermomètres et des thermographes calibrés. Les thermomètres furent placés à une hauteur de ca. $160 \mathrm{~cm}$ au-dessus du sol, alors que la lame de bimétal du thermographe fut placée à une hauteur de ca. $150 \mathrm{~cm}$.

Comme nous le montre le profil (fig. 15) de terrain autour de Hällbacken $\left(66^{\circ} 14^{\prime} \mathrm{N}, 16^{\circ} 58^{\prime} \mathrm{E}\right)$, les abris furent établis à différents niveaux et à certains endroits à climat local différent, sur la montagne au $\mathrm{N}$ de Hällbacken et dans la vallée. En 1965 des abris (nos. 7 et 8) furent aussi installés sur les flancs du Mt Aistjakk $\left(66^{\circ}\right.$ $\left.5-6^{\prime} \mathrm{N}, 17^{\circ} 16^{\prime} \mathrm{E}\right)$, situés à $20 \mathrm{~km}$ au SE de Hällbacken, et dans une tourbière du voisinage (no. 6). Le tableau 4 à la p. 36, montre la position des stations (nos 1-8), la pente, l'exposition et l'élévation.

\section{Les températures moyennes mensuelles des stations et} leur dépendance vis-à-vis du climat

Le climat local des stations nos $2,4,6,7$ et 8 , fut comparé au climat standard de quelques stations avoisinantes du réseau météorologique de Suède. Parmi celles-ci, Arjeplog est la plus près. Elle est située à $30 \mathrm{~km}$ à
l'E des stations 6-8, et à $47 \mathrm{~km}$ à l'ESE des stations 1-5 (en usage seulement depuis 1946). Kvikkjokk est situé à 90-100 km au NNE et Tärnaby, à $100 \mathrm{~km}$ au SW de ces stations. Les stations utilisées pour la comparaison ont, en général, une situation favorable au fond des vallées, et possèdent des température moyennes assez élevées pendant la saison chaude. Le climat de Tärnaby est plus influencé par les vents de l'Atlantique, à cause de sa situation beaucoup plus à l'ouest.

Pour obtenir une image réelle de l'effet favorable de l'orientation des flancs de montagnes, on aura à recalculer les valeurs des stations comparées afin qu'elles coïncident en latitude et en altitude avec la station en question. Quant à la difficile question de la dépendance de la température par rapport à l'altitude et à la latitude des stations nordiques de la Suède, on peut avoir recours aux travaux de Johansson (1927), Ångström (1938) et Rudberg (1957, p. 41). Un autre facteur important à se rappeler lorsque l'on compare les stations, est la déviation par rapport aux températures normales, lesquelles diffèrent d'un mois à l'autre et d'une station à l'autre. Considérant tous ces facteurs, nous obtenons de remarquables anomalies positives pour les stations de montagnes.

Voir tableau 5, en fin de volume, et fig. 16, p. 38. Dans le tableau 5, $a=$ altitude en $\mathrm{m}, b=$ la hauteur au-dessus du fond de la vallée, $c=$ la hauteur du thermomètre audessus de la surface du sol aux différentes stations. $t_{h}$ indique le gradient de température $\left({ }^{\circ} \mathrm{C}\right)$ par $100 \mathrm{~m}$ de hauteur, $t_{\varphi}$ le gradient par degré de latitude ( $N$ de la Suède).

A la figure 16 sont données : la variation de température diurne moyenne, de quelques stations à flancs de collines et au fond des vallées, durant les saisons de végétation de 1965-66.

a) En mai 1965, en dépit du déficit général d'ensoleillement, il y eut une différence appréciable entre les flancs exposés au S et ceux exposés au SW du Mt Storberget (St. no. 4) et du Mt Aistjakk (7). La position, plus au NW, de la station no. 4, est probablement de quelque importance comme facteur de l'abaissement de la température. D'autres facteurs s'ajoutent aussi, comme la situation de la station dans la vallée la plus étroite, et probablement aussi la différence dans l'exposition, la forme et la hauteur de l'escarpement, alors que la différence en altitude est presque négligeable. (ca. $30 \mathrm{~m}$ ).

b) En juin 1965, les mêmes tendances qu'au mois de mai, se manifestent lorsque l'on compare les deux pentes.

c) La différence entre les pentes du Mt Storberget (4) et le fond de la vallée (2), a été examinée en détail dans le texte. La différence dans les variations diurnes est présentée d'après les données enregistrées par le thermographe pour juillet 1965 . 
d) Le fond de la vallée à Hällbacken (2), situé à basse altitude et dont on considère la position comme favorable, est cependant définitivement plus froid que le flanc SW du Mt Aistjakk (7). Le climat de cette pente pourrait être considéré comme représentatif des pentes avec escarpements exposées au SW de la bordure des Calédonides de cette région (fig. 2). La tourbière près du Mt Aistjakk (6) est la station la moins favorable, quoiqu'elle ne soit située qu'à $100 \mathrm{~m}$ plus bas que la station (7). Juillet 1965.

e) Le mois d'août montre des tendances similaires à celles du mois de juillet, et la température sur la pente SW est considérablement plus élevée. Sauf pour une courte période le matin, lorsque la pente SW est à l'ombre, la température dans la tourbière est plus élevée que celle de la pente.

$f$ ) En septembre, les conditions sont changées. La plus haute température sur les pentes, durant les périodes d'ensoleillement, est devenue maintenant assez peu apparente, tandis que c'est encore plus chaud aux températures minimales, en raison des inversions durant la nuit.

g) Juin 1966 fut très ensoleillé et très chaud, et les températures sur la pente SW (7) furent beaucoup plus élevées durant la période chaude du jour, que celles sur la pente NE de la même montagne (8).

h) Juillet 1966 fut assez froid et de faible ensoleillement, comparé au mois de juin. Par conséquent, la pente SW reçut moins d'énergie calorifique en surplus durant le jour. Les différences des températures moyennes mensuelles (jour et nuit) entre les stations nos 7 et 8 , sont assez insignifiantes pour juin $\left(0.5^{\circ}\right)$ et pour juillet $\left(0.4^{\circ}\right)$.

\section{Les températures minimales}

Les recherches débutèrent par l'observation des températures minimales et maximales reliées directement aux conditions climatiques dominantes. Une attention particulière fut portée à l'importance des inversions nocturnes, et à la fréquence des gelées nocturnes durant la période de végétation. Voir le tableau 8 (p. 42), où $a=$ le nombre de nuits avec gelée, et $b=$ la fréquence des gelées en \% des stations 1-5. P. 43 (cf. aussi tableau 5), la moyenne des minima fut calculée.

Le terme d'étage thermique (en anglais " thermal belt »), peut être appliqué à zone altitudinale oì les températures minimales durant la période de végétation ne descendent pas au-dessous de $0^{\circ} \mathrm{C}$ en aucun cas. La terminologie climatologique n'indique pas la limite altitudinale inférieure de cette zone. Le fait que des espèces boréo-méridionales telles que Epilobium collinum, $\mathrm{Ga}$ leopsis bifida et Carex ornithopoda, peuvent atteindre $450 \mathrm{~m}$ comme altitude minimale sur la pente $\mathrm{S}$ d'une montagne, indique que la limite inférieure de l'étage thermique peut se trouver à une altitude passablement basse. Sur un graphique, si nous plaçons la hauteur audessus du fond de la vallée en ordonnée, et les températures minimales en abscisse, nous obtenons une idée de l'étage thermique et l'écart de température dans les différentes zones (fig. 17).

\section{Les températures maximales}

Quant au climat local des pentes exposées au S et au SW, nous ne pouvons pas négliger leur avantage relatif durant les jours ensoleillés en comparaison avec les autres pentes (fig. $16 \mathrm{~g}$ ). Tel qu'il a été démontré, le microclimat (et jusqu'à un certain point le climat local) est dépendant en grande partie du degré d’insolation, lequel pour une grande partie des montagnes scandinaves n'est pas très favorable en été. A cet égard, les montagnes autour d'Abisko, au NW de la Laponie, sont les plus favorisées, à cause des faibles précipitations et de longue durée d'ensoleillement pendant l'été (Sandberg 1960).

Pendant les périodes extrêmement chaudes et sèches du 8 au 21 juin 1966, les températures maximales enregistrées étaient des températures extrêmes pour la Laponie. Elles furent donc précieuses pour une étude des dommages possibles causés par une trop forte chaleur. Pendant les étés normaux, les maxima de température absolus sont de 23 à $26^{\circ} \mathrm{C}$, mais pendant l'été 1966 , une température de $30.7^{\circ} \mathrm{C}$ fut enregistrée (à $150 \mathrm{~cm}$ au-dessus du sol) sur la pente SW du Mt Aistjakk. Les vélocités du vent pendant les jours les plus chauds étaient appréciables ( 1.5 à $2.0 \mathrm{~m} / \mathrm{s}$ au-dessus de la couverture végétale), et en fait, aucun dommage ne fut observé.

La fig. 21 montre les conditions microclimatiques nocturnes et diurnes de l'habitat de deux pentes d'éboulis pierreux d'aspect opposé, près des stations nos 7 et 8, au début de la période chaude du 8 au 21 juin 1966 : les températures du sol (incluant, le 20 juin, la plus haute température enregistrée de 20 à $50 \mathrm{~cm}$ au-dessous de la surface du sol, pendant la période de végétation de 1966), les températures des murailles rocheuses (indiquées sur la ligne 0), la température de l'air à différentes hauteurs et l'humidité relative, la température à l'intérieur de l'abri à $150 \mathrm{~cm}$ au-dessus du sol (indiquée sur la ligne 150 avec les données de l'humidité relative). Les diagrammes des vents, dont les données ont été recueillies presqu'à la même période, apparaissent à la fig. $23 a$ et $b$, et le bilan énergétique au tableau 9. La hauteur moyenne de la strate herbacée (station no. 7) c) et $d$ ) a été indiqué par ++++ (hauteur maximum 20 $\mathrm{cm})$. Les landes à Vaccinium myrtillus de la station no. 8 , ne semblaient pas avoir commencées leur développement. Ciel clair; lever du soleil à $00^{\mathrm{h}} 40$. St. no. 7 0 Fruticeto-Tortuletum thermophile (p. 144); St. no. $8---\square$ forêt clairsemée de Picea-Vaccinium (p. 47).

La fig. 22 montre pour la station no. 7, dont la strate 
herbacée atteint $90 \mathrm{~cm}$ de hauteur, les conditions microclimatologiques au milieu du jour, pendant les jours clairs de l'été dont la température et les conditions de vent sont normales $\left(\max .+18.3^{\circ}, \min .+4.0^{\circ}\right.$, $\max .1 .4$ $\mathrm{m} / \mathrm{s}$ à $150 \mathrm{~cm}$ de hauteur). Pour comparaison, nous avons aussi indiqué les données recueillies sous une forêt de Picea de type Gymnocarpium-Vaccinium (températures à l'ombre) située au bas de la pente SW. Des conditions presque similaires ont été observées dans le FruticetoTortuletum thermophile et sans arbre, immédiatement situé au-dessous de l'escarpement, à environ $80 \mathrm{~m}$ en hauteur verticale au-dessus de la forêt de Picea située sur sol horizontal. Selon le thermographe, les températures simultanées dans l'abri, étaient de +16.6 à $+17.3^{\circ}$ lorsque les mesures furent prises dans la forêt de Picea. La température à l'intérieur de l'abri demeura constamment à $+17.4^{\circ}$ pendant toute la durée des observations auprès de l'abri. Les parties insolées de couleur foncée des murailles rocheuses, dont la plupart consistent en surfaces presque verticales et exposées au SW, possèdent une température moyenne de $+37.5^{\circ}$ (à $\left.15^{\mathrm{h}} 15\right)$; 13 août 1965. a) forêt de Picea au bas de la pente (thermomètre à l'ombre); $b$ ) Fruticeto-Tortuletum thermophile (thermomètre à l'ombre); c) Fruticeto-Tortuletum thermophile (thermomètre à découvert).

Les figures peuvent illustrer des conditions typiques autour des maxima d'un été normal, sur les deux pentes opposées du Mt Aistjakk et dans une forêt située au bas de la pente $S W$. Nous observons que le maximum diurne de la pente NE fut enregistré à $09^{\mathrm{h}} 00$ immédiatement avant que le soleil ne quitte cette pente, tandis que sur la pente $\mathrm{SW}$, le maximum fut mesuré (dans ce cas) à $13^{\mathrm{h}} 30$. Tel que mentionné plus haut (p. 135), le bilan radiatif des ondes longues fut calculé selon la formule de Brunt, modifiée par Möller (1951). Les valeurs de la température de l'air et de l'humidité relative à 150 $\mathrm{cm}$ au-dessus du sol furent utilisées. Pour les surfaces verticales, lesquelles furent considérées comme étant complètement noires, une correction fut faite pour les températures réelles de surface. Le tableau 9 (p. 48) montre le bilan énergétique de la surface horizontale à une élévation de $60^{\circ}$ derrière le point de mesure 1) et la muraille rocheuse 2 ) de la pente opposée au NE (indiqué par ----, courbes $a$ et $b$ de la fig. 21) et au SW (courbes $c$ et $d$ ) du Mt Aistjakk; 9 et 10 juin 1966. Les vélocités du vent indiquées sont la moyenne des vélocités enregistrées durant 2 minutes, à intervalles de 10 sec et à $50 \mathrm{~cm}$ au-dessus du sol. La vélocité des vents horizontaux et verticaux indiquée (voir aussi fig. $23 a$ et $b$ ).

L'effet maritime ou la continentalité du climat est décelable sur des distances horizontales relativement courtes. Ainsi, en été, Ar jeplog possède un type de climat plus continental qu'aucune autre des stations nos 1 à 8 .
Un couple de stations pourrait être utilisé pour une comparaison plus élaborée. Au tableau 6 (p. 41), les stations d'Arjeplog et de Jäckvik, situées à ca. $430 \mathrm{~m}$ d'altitude, sont comparées. Elles se trouvent respectivement à 200 et $150 \mathrm{~km}$ de la côte Atlantique. Nous avons utilisé les moyennes mensuelles et annuelles calculées pour la période de 1946 à 1960 (SMHI).

\section{Les températures du sol}

Afin d'étudier l'importance de l'orientation des pentes, une série de thermomètres fut insérée dans le sol, près des abris des stations nos 7 et 8 , en 1966. Les deux séries de thermomètres sont situées sur des éboulis, mais les profils du sol ne sont pas absolument comparables.

Il ne nous fut malheureusement pas possible d'effectuer les observations simultanément (tableau 10, p. 50). Elles étaient habituellement effectuées tôt le matin, quand il n'y avait encore que très peu de soleil (ou pas du tout) sur la pente exposée au SW, alors que l'heure d'insolation maximum atteignait justement la pente exposée au NE $\left(09^{\mathrm{h}} 00\right.$, heure critique à laquelle le soleil quitte la pente NE et passe à la pente SW; cf. fig. 11).

Il ressort de ces observations, que l'exposition au SW d'une pente est généralement avantageuse, même si à l'heure matinale où sont faites les observations, les températures à $2 \mathrm{~cm}$ de profondeur sont assez élevées sur la pente NE et dépassent fréquemment celles de la pente SW. A une profondeur de $50 \mathrm{~cm}$, on n'observa que de très petites fluctuations d'une semaine à l'autre. Durant toute la période d'observations, on nota une hausse générale des températures. On nota une élévation de température à la plus grande profondeur dans le sol, durant toute la période particulièrement chaude du 8 au 21 juin. On observa les suites de ce réchauffement aussi tard que le 27 juin.

\section{Les conditions de neige pendant le dégel}

Le taux maximum de dégel ne coïncide pas avec les températures journalières maximales (voir les diagrammes dans Lundqvist J. 1965, p. 217). Au lieu d'une irradiation plus élevée, d'autres facteurs semblent produire un effet beaucoup plus important sur la fonte de la neige tels que : la situation en pente du terrain (qui reçoit plus d'énergie), le rayonnement de l'escarpement et les vélocités décroissantes du vent en face de l'escarpement. Les plus hautes températures nocturnes sur les pentes de montagnes ont probablement aussi une certaine importance. Durant le mois d'avril, ces températures peuvent dépasser considérablement celles observées au fond des vallées (e. g. les minima nocturnes du 3 avril 1961 : station no. $2:-23.4^{\circ}$, station no. 4 : $-11.3^{\circ}$. cf. p. 46 , figs. $18-20$ ).

Comme conséquence de ces conditions, la neige disparaît d'abord de la partie supérieure des pentes d'ébou- 
lis pierreux, le long d'une ligne parallèle à la muraille rocheuse (fig. 24). Cette limite migre ensuite graduellement vers le bas de la pente de l'éboulis. Dans la partie libérée de neige, les conditions sont d'abord très sévères pour les plantes, à cause de la forte irradiation durant le jour, et du refroidissement très considérable durant la nuit. On note ici et là des différences importantes dans la couverture végétale de la partie supérieure de l'éboulis (p. 92), différences qui pourraient dépendre de facteurs écologiques liés à la couverture de neige et sa fonte.

\section{Phénologie}

Au printemps 1961, lors des mesures de profondeur de neige, il nous fut possible de faire quelques observations sur la phénologie des espèces végétales. Le 2 mai, a u Mt Aistjakk, au moment où une épaisse couverture de neige était encore présente dans les forêts sur terrain horizontal, les feuilles basales de Anthriscus silvestris, Valeriana sambucifolia, Turritis glabra et Hackelia deflexa étaient déjà vertes et la plupart pleinement développées (fig. 26a). On observa aussi de petits semis de Galeopsis bifida, une espèce annuelle à germination printanière (fig. 26b). Les bourgeons de Daphne mezereum étaient prêts à s'ouvrir, et à un endroit on trouva même des fleurs sur une ramille près du sol. Prunus padus, Ribes spicatum var. lapponicum et Betula pubescens, l'arbre le plus commun sur la pente SW de cette montagne, avait des bourgeons verts gonflés. On vit aussi des vipères (Vipera berus), dont un nouveau-né, à la partie supérieure de l'éboulis pierreux (fig. 27). Cette observation est probablement unique pour la Laponie à cette période de l'année. Prunus padus, dont le débourrement des bourgeons est plus hâtif que chez les autres feuillus, montrait, le 16 mai, des dommages dûs au gel (fig. 26d) probablement causés durant la période de gel du 4 au 7 mai (alors qu'il y avait encore un peu de neige). Le 16 mai, une abeille fut aussi aperçue au Mt Aistjakk. Les conditions de neige et le développement phénologique de 1961, peuvent être considérés comme normaux.

\section{APPROVISIONNEMENT EN EAU}

\section{Précipitation et interception}

Nous nous référons aux publications du SMHI, pour les conditions de précipitation durant les années de recherches en Laponie centrale. La précipitation moyenne est cartographiée par Wallén C. C., 1953 (Atlas över Sverige) et discutée par Wistrand 1962 (pp. 31 et suivantes). La précipitation moyenne annuelle pour la période 1922-44 (Wistrand) se situe entre 395 mm (Jäkna) et 565 mm (Jäckvik); les deux extrêmes enregistrés pour le territoire à l'étude. Il y a de grandes variations d'une année à l'autre, dans les totaux saisonniers et annuels.

Au S de la Scandinavie, l'existence de la plus riche flore bryologique et lichénologique, du côté sous le vent des collines, s'explique d'abord par la plus grande quantité de précipitation qui atteint ces pentes à certains endroits, et par les différences dans l'exposition au soleil et aux vents desséchants. Au N de la Scandinavie, où les précipitation sont abondantes tout au long de l'année, et la sécheresse moindre pendant la période de végétation, à cause du haut degré de nébulosité, il est encore possible de trouver des espèces subocéaniques (e.g. Normandina pulchella), même à des endroits exposés au SW.

Ainsi qu'il l'a été démontré par Hudleston (1928) et Geiger (cf. Geiger 1965, p. 419), l'action du vent détermine largement la distribution des précipitations autour des collines. Ainsi, la distance, des élévations escarpées au point où sont prises les mesures, doit être prise en considération. Sur les surfaces presque verticales, les effets de protection et de déflexion deviennent beaucoup plus importants.

On peut s'en rendre compte facilement en hiver, car la neige peut être défléchie plus facilement que la pluie. La neige est normalement défléchie à partir du côté face au vent des collines modérément abruptes, et accumulée en énormes monceaux du côté sous le vent. Cependant, sous un escarpement en surplomb, la déflexion de la neige du côté du vent, est diminuée à cause de la rapide décroissance de la vitesse du vent. Si le surplomb est suffisamment important, il arrive qu'au moins la pluie puisse être complètement écartée. Du côté sous le vent, un escarpement à $90^{\circ}$ ne reçoit pratiquement pas de précipitation. La quantité de précipitation augmente graduellement à mesure que l'on s'éloigne de l'escarpement. Le degré d'inclinaison d'une pente abrupte, qui agira comme écran protecteur d'un point de mesure situé complètement du côté sous le vent, dépend de la vélocité du vent, des tourbillons d'air, de la distance de la jauge à l'écran protecteur et, par-dessus tout, du type de précipitation.

\section{L'eau à la surface et dans le sol}

L'eau d'infiltration et l'enrichissement chimique potentiel, ont été longuement discutés dans les revues. On considère qu'ils sont pour les espèces boréo-méridionales et sur les flancs de montagnes, d'importants facteurs locaux (cf. Du Rietz 1954, p. 181).

$\mathrm{D}$ 'après nos travaux dans $\mathrm{PL}$, les ions $\mathrm{Ca}$ et $\mathrm{SO}_{4}$ sont ceux dont la concentration est la plus variable dans différentes eaux d'infiltration. On peut s'attendre à un tel phénomène, si l'on considère les conditions physiographiques du territoire. Le contenu en gypse peut être particulièrement élevé dans le grès Laisberg (échantillons 
nos 3 et 4, tableau 14). Ce grès affleure dans une crevasse ouverte au Mt Laisvare (Laisberget) d'où il tire son nom. Il forme des lits dans les séries autochtones de roches sédimentaires Eo-Cambriennes et Cambro-Siluriennes, le long de la bordure SE des Calédonides. On trouve, dans le SW de PL, des minéraux de plomb et de zinc dans la série de grès Précambriens. Depuis 1942, on extrait du minerai de plomb du gisement de Laisvall, bien connu des géologues. Avec la galène, on extrait aussi la sphalérite et la pyrite (Grip 1960, p. 153).

On peut déceler la présence du métal dans l'eau et sur une grande surface. Néanmoins, l'eau provenant de ce grès est potable. Le contenu de l'eau en ions est exceptionnellement élevé pour PL, par suite de la présence de calcite, de barytine et fluorite sous forme de gros poeciloblastes (Grip 1960, p. 154). L'eau a probablement dû subir de hautes pressions, car les nappes de chevauchement superposées atteignent $100 \mathrm{~m}$ d'épaisseur et souvent plus. Au Mt Laisvare, la roche en place et l'eau semblent avoir une influence favorable sur la végétation (voir la description du Mt Laisvare plus bas). En dépit du contenu extraordinairement élevé de l'eau en minéraux, a ucun effet toxique ni aucun cristal précipité n'ont été observés sur les plantes.

Des eaux provenant de la même roche en place possèdent des caractéristiques différentes selon leur origine hydrologique. Dans le grès Laisberg de la mine, des échantillons d'eau, dont la température se situait entre 3.8 et $5.9^{\circ} \mathrm{C}$, ont été prélevés. Leur valeur de conductance, située entre 129 et 141 , est beaucoup plus basse que celles indiquées dans la table (tableau 14).

\section{LA FLORE DES FLANCS DES COLLINES}

\section{Introduction}

A partir de l'étude des patrons de distribution, de l'écologie et de l'histoire individuelle des espèces subsistant sur les flancs $\mathrm{S}$ des collines, d'importantes discussions ont eu lieu à propos des éléments floraux. Dans l'ouvrage classique d'Andersson et Birger (1912), les relations, entre certains groupes importants de plantes vasculaires et les facteurs du climat, furent discutées en détail. L'arrangement des espèces en classes de thermophilie croissante, forme la base de la discussion écologique de ce travail. Les éléments les plus thermophiles sont appelés « espèces $\mathrm{S}$ Scandinaves » et les moins thermophiles: " espèces de montagne » (Suèd. fjällarter, op. c., p. 70). Plus tard, Sjörs (1950, p. 177) utilisa le terme de « plantes scandiennes » pour désigner les espèces que l'on retrouve surtout dans les Scandes. Néanmoins, ces dernières sont bien représentées et même sur les escarpements exposés au $\mathrm{S}$. On peut conséquemment supposer que la distribution de ce dernier groupe de plantes, de même que les espèces $\mathrm{S}$ Scandinaves pourraient être grandement influencées par les facteurs de compétition. On ne peut cependant qu'esquisser les grandes lignes de l'écologie de ces deux groupes de plantes et en particulier le problème difficile de la thermophilie.

\section{La flore vasculaire}

Lorsque l' on considère les aires de distribution, il nous faut tenir compte des zones ou régions floristiques auxquelles appartient chaque espèce individuellement, comme il a d'ailleurs été fait dans les atlas modernes de distribution des espèces végétales (voir Meusel et al. 1965 , p. 15), car la chorologie des espèces est la réflexion des tendances de la végétation terrestre (Schmid 1954, p. 8). La végétation nous donne un meilleur estimé de l'effet total de l'impact climatique sur la vie, que les seules variables climatiques (cf. Sjörs 1963, p. 110). Il existe beaucoup de similarités quant à la zonation régionale de la terre, quoique celle d'Europe soit plus déplacée vers le nord. Ainsi, si l'on considère différents secteurs longitudinaux de la terre, les facteurs d'océanité et de continentalité agissent sur les régions biotiques correspondantes. Au NW de l'Europe, les espèces montrant une tendance océanique ou continentale, sont plus ou moins influencées par la variable $\mathrm{W}-\mathrm{E}$, du point de vue vigueur, abondance et fréquence. Elles possèdent des aires de distribution dont les centres se situent dans les parties continentales les plus extrêmes des continents, ou encore, leurs limites de distribution et de fréquence sont parallèles aux lignes côtières. Au sens biogéographique, l'océanité ou la continentalité devrait inclure la position régionale des stations les plus écartées. La variable $\mathrm{S}-\mathrm{N}$ indique : méridionalité contre boréalité. $\mathrm{Au}$ sens biogéographique, méridionalité et boréalité incluent la position des zones de stations d'espèces situées les plus au $\mathrm{N}$ ou les plus au $\mathrm{S}$. Si les unités taxonomiques sont caractérisées en se reférant à des régions et des zones spéciales, il est quelquefois possible d'établir une comparaison entre les tendances biogéographiques et bioclimatiques de grandes régions.

En pratique, les aires de distribution établies par Meusel et al. (1965) ont pu être utilsées pour toutes les espèces dont il est question ici (tableau 16, p. 75), jusqu'aux Leguminosae inclusivement. Dans les autres cas, les cartes de distribution publiées dans les travaux de Hul- 
tén $(1950,1958,1962)$ furent consultées. Quelques incertitudes surgirent ici et là, lorsque nous utilisâmes les distributions données par Hegi (1909 et suivantes) et quelques autres flores. Les caractéristiques générales de la flore et de la végétation, à partir de l'extrême NW jusqu'à l'extrême SE, peuvent être déduites de l'étude des variables biogéographiques, aussi bien $\mathrm{SN}$ que WE de la flore concernée (fig. 35, p. 67). Seuls les aspects biologiques furent pris en considération lors des analyses (voir plus haut). Les symboles pour les différents degrés d'océanité et de continentalité (cf. Böcher 1943, p. 360, et Meusel et al. 1965, p. 19) furent résumés à la p. 66.

Les symboles d'océanité et de continentalité entre parenthèses, indiquent (comme dans Meusel et al.) que les espèces montrent seulement une faible tendance océanique ou continentale.

Lorsque l'on considère la thermophilie, l'intérêt est surtout porté sur le groupe de plantes méridionales du $\mathrm{N}$ de la Scandinavie ou les plantes (selon Meusel et al. 1965) dont l'aire de distribution indique qu'elles atteignent localement des régions situées plus au $\mathrm{N}$ que la zone Boréo-Némorale (i.e. "plantes boréo-méridionales " et les symboles utilisés ici : $\mathbf{M}$ - dont l'aire de distribution ne s'étend pas ou s'étend seulement localement au $\mathrm{N}$ de la zone Boréo-Nemorale, et $(\mathrm{M})$ - espèce qui possède quelques stations de plus dans la zone Boréale; la terminologie des zones est celle de Regel 1950, 1952 et de Sjörs 1963 p. 111). Toutes ces plantes devraient être étudiées en tenant compte de leur relation avec le facteur insolation-exposition (voir Boyko 1947 et Rey 1960). De cette façon, il serait possible de mieux comprendre le comportement des plantes vis-à-vis des facteurs thermiques, sur des substrats différents, et vis-à-vis du facteur océanité-continentalité. Jusqu'à ce que l'autécologie des différentes espèces soit mieux connue, il nous est seulement possible de tirer des conclusions générales basées sur un classement très subjectif. Comme il est démontré par l'exemple ci-joint (fig. 35, voir aussi ci-haut p. 42), la flore des pentes exposées au $S$ au SW des collines de PL, montre un degré d'océanité qui peut être plus ou moins grand, dépendant du type de classement et de l'amplitude des termes utilisés. Dans ce cas, il est important que le groupe contrasté de plantes continentales soit comparable au point de vue terminologie. Les exemples montrent que l'océanité, au sens biogéographique utilisé ici, est plus grande sur les pentes exposées au $\mathrm{S}$ que sur celles exposées au N ou NE (e.g. Mt Aistjakk, no. 16). D'autre part, les pentes exposées au $\mathrm{N}$ sont même moins boréales que celles exposées au $\mathrm{S}$.

Le terme " boréal » a été assigné ici à une espèce de plante, lorsque ses distributions arctique et boréale s'étendent localement au-delà de la limite $\mathrm{S}$ de la zone Boréale (symbole $\mathrm{B}$, tableau 16 ), ou encore lorsque quel- ques stations de plus se trouvent dans la zone Némorale jusqu'à la zone Méridionale, mais qui se situe de préférence dans les étages alpins et subalpins des montagnes (symbole (B))

La flore triviale ubiquiste, que forme le reste des espèces, est définitivement plus abondante sur les sites dont l'exposition est défavorable. Les escarpements et les éboulis exposés au $\mathrm{N}$ sont de trop faibles dimensions et trop ombragés pour les plantes exigeantes vis-à-vis de la lumière. La grande majorité des espèces boréo-méridionales du $\mathrm{N}$ de la Scandinavie, montrent une affinité manifeste quant aux parties les plus océaniques de l'W Fennoscandinavie. Ainsi, on pourrait croire que l'océanité est la caractéristique la plus importante des espèces thermophiles. En fait, lorsque l'on considère le climat local sur de longues périodes, on s'aperçoit que les flancs des collines et des montagnes envahis par des plant es boréo-méridionales, sont les parties les plus océaniques des vallées (cf. d'autre part, les micro-climats considérés sur de courtes périodes, qui peuvent être passablement continentaux, Jalas 1950 , p. 208, ou encore la relative continentalité assignée à l'étage subalpin de bouleaux de la Laponie, Hämet-Ahti 1963, p. 31. Cf. Rune O. 1965, p. 73). Voir aussi p. 47.

On réalise facilement que les plantes qui montrent des tendances à l'océanité et qui croissent aussi loin à l'intérieur des terres, choisissent en fait, les stations les plus favorisées du point de vue climat. Les deux espèces boréo-méridionales strictes du $\mathrm{N}$ de la Scandinavie, qui montrent des tendances à l'océanité, Polygonum dumetorum et Myosotis stricta, semblent elles aussi, éviter les districts côtiers, où les températures du début de l'été sont plus basses qu'à l'intérieur des terres, devenant ainsi moins océaniques vers le $\mathrm{N}$. Même à l'intérieur des terres, les stations sont très peu nombreuses. D'autre part, Fragaria vesca est beaucoup plus fréquent sur les côtes de Norvège, et est aussi assez fréquent à l'intérieur des terres, sur les crêtes et les flancs de collines exposées au S. Beaucoup d'autres exemples pourraient être mentionnés (voir plus bas). D'autres exemples sont aussi donnés, démontrant que beaucoup de plantes boréo-méridionales, pris au sens le plus large pour inclure aussi les plantes (M), peuvent croitre sur les montagnes à des altitudes assez élevées (e.g. Carex panicea) parce que le facteur humidité agissant sur ces plantes à tendances océaniques, est beaucoup plus important que le facteur thermique.

Wistrand (1962, p. 185) indique qu'il existe à PL deux grands groupes de plantes thermophiles qui diffèrent entre elles par leur distribution horizontale : les espèces dont l'aire de distribution sur notre territoire, est en connection avec leur distribution à l'E et au SE, près du golfe de Botnie, et les espèces qui sont plus ou moins isolées au centre de PL, près de la bordure SE des Calédo- 
nides. Les plantes à distribution au SE, croissent dans les vallées presque toujours autour ou dans l'eau, dans les bosquets près des ruisseaux et dans les marécages calcaires, mais sauf quelques exceptions, sont absentes des éboulis. Ceci est probablement dû au fait que ces espèces appartiennent au groupe de plantes les plus continentales, dont les centres de distribution se situent en Europe du SE et en Asie. Comme on peut le voir plus bas, les plantes boréo-méridionales à type de distribution continentale (symbole (M) C), ont été rarement vues sur les éboulis mais, probablement vers le NW, elles montrent une plus grande préférence pour les pentes exposées au $\mathrm{S}$ et de basse altitude, et pour les marécages extrêmement calcaires. Certaines de ces plantes sont forestières, à prédominance dans les forêts de conifères. L'autre groupe de plantes thermophiles, c'est-àdire celles dont la distribution est au centre et au NW de PL (Wistrand, l.c.), comprend les plantes à distribution plus océanique et qui possèdent quelques stations isolées sur les éboulis exposés au S (voir plus haut).

Il serait peut-être intéressant de comparer les thermophiles du NW de PL du point de vue des restrictions à certains étages de végétation (Vegetationsgiurtel, cf. Sch mid 1954, p. 3), par rapport à leur chorologie et leur écologie, dans les Alpes et le Jura. Cette comparaison (voir, e.g. Saxer 1955, pp. 30 et suivantes), établira clairement que ces plantes sont confinées à l'étage de Fagus et Abies, et spécialement les sites de basse altitude favorisés du point de vue climat et sol. Certaines d'entre elles possèdent des exigeances qui coïncident avec celles du hêtre (Fagus silvatica); c'est-à-dire qu'elles évitent les localités humides, trop à l'ombre et à gelées tardives (mais aussi les localités trop sèches), mais qu'elles préfèrent une saison de végétation d'au moins cinq mois et de très bonnes conditions du sol (Saxer 1955, p. 15 : le comportement du hêtre a été aussi discuté par Hjelmquist 1940 , pp. 16 et suivantes). Du point de vue épiontologique, on trouve qu'il existe une relation étroite entre les espèces prises individuellement, et l'étage de végétation à laquelle elle est confinée (Saxer 1955, p. 27).

D'une certaine façon il est possible d'estimer le degré d'océanité versus continentalité et le degré de boréalité versus méridionalité, en établissant le spectre des pourcentage de distribution des espèces de plantes à fleurs, parmi les formes biologiques, pour chacun des flancs de montagne (fig. 35, section inférieure). Un pourcentage élevé en Thérophytes devrait vraisemblablement être caractéristique des montagnes de la région forestière coniférienne du NW, alors qu'un pourcentage élevé des Géophytes serait plus apparent dans la flore du SE. Même si les différences peuvent être faibles et les résultats très variables à cause des déviations, la tendance, spécialement pour les montagnes de l'extrême SE, demeure évidente. A propos des Chamaephytes, dont l'a- bondance est caractéristique en climat boréal, les résultats peuvent être quelque peu douteux. Dans ces cas, le rôle des Chamaephytes forestières est évidemment plus prononcé au $\mathrm{SE}$ où le nombre d'espèces herbacées diminue manifestement.

La liste des plantes boréo-méridionales de PL (p. 69 et suivantes) est présentée de telle sorte qu'elle puisse montrer les tendances générales de la distribution et de l'écologie des espèces. Certaines observations d'intérêt concernant PL et quelques régions voisines, ont été ajoutées. Les descriptions montreront qu'il n'existe pas d'exigeances particulières quant à l'exposition au $\mathrm{S}$ dans beaucoup de cas, et que tout classement climatique en groupes thermophiles ne convient pas. Pour les groupes de plantes boréo-montagnardes Eurasiatiques (Hultén 1950), il est souvent difficile et dans certains cas impossible, d'établir des limites entre les différents degrés de méridionalité-boréalité.

Saxifraga adscendens L. est une espèce que certains auteurs ont tenté de placer à l'intérieur du groupe des (M) plantes, à cause de ses quelques rares stations au $\mathrm{N}$.

Au tableau 16 p. 75, apparaît la flore des plantes vasculaires des montagnes nos 1-32. Sur la carte (fig. 2) sont indiquées les montagnes et leur numéro respectif. L'exposition et les statistiques de la flore des montagnes se trouvant à la fig. 35. La liste provient d'abord des observations personnelles de l'auteur, auxquelles ont été ajoutées les informations publiées dans les revues scientifiques (dans certains cas, des communications personnelles de Wistrand). Les Taraxaca et les Hieracia ont été exclus de la iiste. Les formes biologiques (Raunkiær, avec quelques modifications aux Thérophytes) sont : $P h=$ Phanérophytes, $C h=$ Chamaephytes, $H=$ Hémicryptophytes, $G=$ Géophytes, $T h=$ Thérophytes. Les plantes monocarpiques sont indiquées par : $\odot$, annuelles, croissance au printemps; $\odot$, annuelles, croissance à l'automne; $\odot \odot$, bisannuelles.

Le signe $\otimes$ devant une plante, indique que l'espèce est sûrement d'origine anthropochore, mais qu'elle est maintenant complètement naturalisée à PL. Certaines plantes anthropochores rencontrées occasionnellement dans certaines localités, ont été omises de la liste, mais ajoutées entre parenthèses dans l'Addenda. Dans la plupart des cas, les mentions proviennent des revues scientifiques et l'espèce n'a pas été trouvée à nouveau. Le signe ${ }^{c}$ indique un élément strict de la flore des escarpements.

\section{La flore des bryophytes}

L'étude approfondie de la flore des bryophytes des pentes de montagnes de PL, ne fut pas amorcée avant 1963. Elle débuta avec l'inventaire des espèces les plus communes et les plus abondantes sur les murailles rocheuses. Au cours de ce travail, quelques rares espèces furent trouvées et en plus, les conditions écologiques 
furent examinées. On présuma que les bryophytes reflétaient les facteurs des microhabitats avec plus de précision que les plantes vasculaires. Du reste, quelquesunes des bryophytes appartenant aux synusies des crevasses, des murailles rocheuses et des éboulis dénudés, sont de bonnes espèces indicatrices. De telles synusies, situées dans d'autres parties du $\mathrm{N}$ de la Suède, ont été décrites (voir e.g. v. Krusenstjerna 1954). Toutes les bryophytes mentionnées plus bas dans les analyses de végétation furent incluses dans la liste. Nous avons aussi ajouté des espèces provenant des parties d'éboulis à couverture végétale continue, et aussi celles provenant d'autres habitats sur éboulis à fines particules, et même celles croissant à la base des tiges, sur les gros blocs, etc... De cette façon, la liste des bryophytes (tableau 17, en fin de volume) devint finalement un assez bon parallèle à la liste des plantes vasculaires, bien que l'on n'y ait pas songé au début. Quelques éléments exclusifs aux gros blocs des parties distales des pentes d'éboulis pierreux, manquent encore, ou sont notés seulement ça et là dans la liste. Le manque de données sur la flore épilithique et épixilique ne nous a pas permis d'en donner la liste complète.

Chez les bryophytes thermophiles, il existe probablement comme chez les plantes vasculaires, des relations similaires quant au gradient océanité-continentalité. Nous ne connaissons que trop peu de choses à propos de la distribution détaillée des mousses dans les zones Arctique et Boréale, pour fournir des indications exactes sur les caractéristiques de notre territoire, comme il est possible de le faire chez les plantes vasculaires. Un exemple nous en est donné par Orthotrichum pallens qui est probablement plus largement répandu qu'on ne le croyait dans la zone Boréale. Cependant, dans PL, cette espèce se rencontre seulement sur les pentes de montagnes orientées au S ou SW, comme une épiphyte sur les trembles. Ainsi, elle pourrait être quelque peu thermophile, tout au moins, c'est définitivement un élément boréo-méridional de la flore de la Laponie (inconnue dans la région de Torneträsk). Ces exemples démontrent que les relations quant aux gradients méridionalitéboréalité ont aussi besoin d'être approfondies.

Outre les facteurs climatiques, les facteurs du substrat doivent être aussi considérés. Sur 16 montagnes du NW, formées de roches cambro-siluriennes, on compte 52 bryophytes, alors que sur 16 montagnes du SE, de roches Archéennes, on n'en compte que 44. Cette réduction substantielle est due aux conditions défavorables du substrat. Même si le contenu en électrolyte de l'eau d'infiltration des escarpements peut être assez élevé même sur les roches Archéennes, il n'est pas suffisamment riche pour supporter les éléments les plus exigeants, qui sont d'ailleurs concentrés au NW. Il n'existe pas encore de limite stricte pour ces espèces que l'on croit être principalement confinées aux substrats calcaires (voir e.g. la distribution de Distichium capillaceum, Tortella fragilis et $T$. tortuosa). Tel que mentionné plus haut (p. 131), on trouve aussi des substrats plus favorables dans le SE, en plus des perchoirs d'oiseaux et des souches d'arbres qui peuvent fournir certains éléments nutritifs qui peuvent convenir à certaines espèces. A certains endroits où la flore est plus riche, il est parfois assez difficile de décider si c'est l'ombre ou un meilleur substrat qui est le facteur décisif. C'est lecas du ravin du Mt Gaddaberget au SE (no. 31), où furent trouvées quelques espèces rares au SE (e.g. Tortella fragilis et Orthotrichum alpestre). Dans quelques cas, la sécheresse des escarpements est un facteur limitatif. Bien que la plupart des bryophytes semblent éviter les escarpements trop secs, il est moins évident qu'elles préfèrent les localités très ombragées (cf. d'autre part Porella platyphylla; cette espèce fut aussi trouvée dans le ravin au Mt Gaddaberget).

Le fait que les mousses possèdent, par certains côtés, des amplitudes assez restreintes, les rend probablement moins valables comme indicateurs de "localités chaudes ». A ces problèmes s'ajoute le facteur de la couverture de neige en hiver, qui est effectif spécialement pour les bryophytes abondants sur les troncs d'arbres au $\mathrm{S}$ de la Suède, alors que la plupart sont complètement disparus de tels substrats au N. Ceci s'applique surtout à Leucodon sciuroides, Anomodon viticulosus, Isothecium myosuroides, Homalothecium sericeum et Radula complanata. Le nombre et l'abondance de bryophytes épiphytes sont donc faibles, et la végétation muscinale épiphytique ne dépasse pas d'une façon appréciable la couverture de neige en hiver.

Les deux régions du $\mathrm{N}$ de la Scandinavie, disponibles pour une comparaison, sont beaucoup plus variables, car tous les types d'habitats y sont inclus (régions alpines, tourbières, rivages, etc.). C'est l'explication des nombres totaux les plus élevés (voir Tuomikoski 1939, p. 97; Auer 1944, p. 2; cf. Mårtensson 1956, III, p. 40 et p. 79).

Dans les régions les plus montagneuses de la Fennoscandinavie, le nombre des bryophytes est approximativement le même que celui des plantes vasculaires. Comme dans ce cas, 224 plantes vasculaires furent signalées (à l'exclusion de la présence plus ou moins occasionnelle de plantes anthropochores), le nombre des bryophytes (195) peut sembler faible. C'est une indication que les localités sont comparativement défavorables pour les bryophytes, ce qui n'exclue pas la possibilité que quelques-unes montrent une préférence pour les stations à flancs de colline.

Dans la liste p. 79, seules quelques bryophytes intéressantes furent incluses, en particulier celles qui ne sont pas notées dans les analyses de végétation. L'autécologie 
de la plupart d'entre elles semble concorder très bien avec leur présence dans TL (Mårtensson 1955-56, I-III).

Conclusions à propos de la flore. Nous avons établi que les types de microdistribution des bryophytes du $\mathrm{N}$ de la Suède en particulier, sont encore insufisamment connus pour que l'on puisse affirmer quoi que ce soit à propos de la thermophilie. C'est qu'à la suite de nos travaux, il ne nous est seulement possible de distinguer que quelques plantes nettement thermophiles. Elles sont notées à la page 82 .

\section{LA VÉGÉTATION}

\section{Introduction}

Les principales alliances de la végétation chasmophyte alpine et subalpine et la végétation des éboulis dans les Scandes sont (voir Nordhagen 1936, pp. 12-13, 1943, pp. 542 et suivantes; cf. Bringer 1961, 1965, p. 1) :

1. Saxifragion cotyledonis principalement sur les escarpements pauvres ou relativement pauvres en Ca. Selon Nordhagen (1943, p. 569), c'est une réminiscence appauvrie de l'Androsacion multiflorae (Braun-Blanquet 1926) de l'Europe Centrale.

2. Kobresieto-Dryadion (Dryadion) sur les éboulis et les corniches quelque peu basiques ou voisins de la neutralité (mais ce n'est pas l'habitat le plus commun de ce groupement végétal). Voir Bringer 1961.

3. Asplenion viridis subarcticum sur roches riches en $\mathrm{Ca}$ et $\mathrm{Mg}$ (Nordhagen 1936, p. 13, 1943, p. 568). Une réminiscence appauvrie du Potentillon caulescentis (BraunBlanquet 1926) de l'Europe Centrale.

4. Une végétation très pauvre et impossible à classifier croissant sur les éboulis dont les blocs de pierre sont extrêmement durs et pauvres en Ca.

5. Veronico-Poion glaucae sur les débris de roches riches en éléments nutritifs mais pauvres en $\mathrm{Ca}$ (dans Sikilsdalen pH 5.35-6.26, Nordhagen 1943, p. 546, voir aussi ce travail, p. 27). Quelques-unes des espèces exclusives locales ou régionales peuvent aussi être rencontrées sur les escarpements, dans les crevasses et sur les corniches. Voir discussion plus bas.

6. Arenarion norvegicae sur les débris de roches calcaires, dolomitiques ou schisteuse, constituant le « Kalkschuttgesellschaft ", un équivalent du Thlaspeion rotundifolii central européen de Braun-Blanquet 1926, voir Nordhagen 1943, p. 549.

On ne connaissait que très peu de choses à propos des communautés végétales, des groupements chasmophytes jusqu'à ceux qui atteignent une assez grande taille, envahissant les éboulis de l'étage coniférien du $\mathrm{N}$ de la Scandinavie. En raison de ces circonstances, les analyses ont dû être comparées avec les communautés végétales des étages alpins et subalpins des Scandes plus haut mentionnées.

\section{Terminologie et méthodologie}

Lors de l'étude des communautés végétales, nous avons appliqué la terminologie et la méthodologie généralement utilisées ces dernières années, par l'école d'Uppsala (voir, e.g., Du Rietz 1957). On ne trouva aucun inconvénient à utiliser les méthodes modernes lors de l'étude des unités de végétation des éboulis, comme cela aurait probablement été le cas lors des années 20 (voir Du Rietz 1924, pp. 100, 115; Jenny-Lips 1930, p. 149). La délimitation des unités de végétation, était alors d'abord fondée sur les concepts des constantes pour lesquels, souvent de larges quadrats étaient nécessaires (cf. Du Rietz et al. 1920, p. 23). Plus tard, ce fut le concept de synusie, ou de communauté à une seule strate, qui fut d'ailleurs beaucoup discuté (Du Rietz 1936, p. 584; Nordhagen 1943, pp. 31 et suivantes). Les synusies ne devraient pas être groupées ensembles, sans tenir compte de la stratification de la végétation, car les groupements arborescents, arbustifs, à herbacées et à muscinées et lichens, peuvent être considérés, par rapport à la succession de la végétation sur les éboulis, comme différents stages d'une série. La végétation étudiée semble être assez parfaitement stabilisée. Elle l'est beaucoup plus que celle qui occupe des sites analogues dans les Alpes (Du Rietz 1924, pp. 100-115) et dans certaines régions de la Norvège, où la roche en place subit une altération sur place extrêmement rapide.

Dans la présente étude, nous avons utilisé un quadrat de $1 / 4 \mathrm{~m}^{2}$ de surface. Le petit quadrat a permis l'étude d'éboulis assez grossiers, sans que les exigeances d'homogénéité en fussent affectées.

Dans les tableaux, le signe + a été utilisé pour désigner la présence de certaines espèces à l'intérieur d'un quadrat ou d'un groupement végétal, sans noter le degré exact de couverture, e.g. toutes les espèces de la strate inférieure, quand leur degré individuel de couverture n'a pu être facilement estimé. La lettre $s$ a été utilisée pour désigner la présence à l'intérieur du quadrat, d'un semis (quelquefois plus) d'une espèce vasculaire. Chez les bryophytes, la présence fragmentaire de certaines espèces ne fut pas spécialement notée, mais la présence 
trop rare d'espèces très occasionnelles, est omise dans les tableaux, de même que la vitalité et la sociabilité.

Le détail de chacun des groupements présents à l'intérieur de certaines communautés, n'a pas été indiqué au tableau des relevés (tableau 26), parce que nous ne disposions que d'un très petit nombre d'analyses (moins de 5). Dans ces cas, la fréquence et le degré de couverture furent indiqués pour toute la communauté, à droite dans les tableaux spéciaux (en fin de volume).

\section{Poeto-Lactucetum (Tableau 18)}

Cette communauté végétale qui est presque identique au "Chamaenerieto-Poion nemoralis-glaucae » décrit par Nordhagen (1936, p. 32), est très commune sur les pentes des collines du NW de PL. L'auteur la réfère au Veronico-Poion glaucae, pour désigner son rapport étroit avec les groupements végétaux d'autres types de communautés thermophiles, sur pentes d'éboulis du $\mathrm{N}$ de la Suède. Kalela (1939, p. 226) indique la présence à Rybachi Péninsule d'un groupement végétal similaire d'un type transitoire envahissant les éboulis exposés au soleil. Cette communauté végétale est présente dans PL, sur la plupart des éboulis exposés au $\mathrm{S}$, où il existe un certain approvisionnement en eau d'infiltration provenant des murailles, ou lorsque l'habitat est ombragé (le ravin du Mt Gaddaberget) et le substrat peu acide.

\section{Tortulo-Poetum}

Cette communauté est l'une des plus importante de la partie supérieure des forêts situées juste au pied des murailles rocheuses, orientées plus ou moins vers le $S$, là où l'exposition au soleil est totale. La réaction du sol est près de la neutralité ou faiblement acide, et les processus de lessivage sont obstrués au moins à la surface. Ce blocage est dû à l'approvisionnement continu en débris frais provenant de la muraille. La teneur en calcium de la partie minérale de sol (exempte ou presque de matière organique) peut être faible (ca. $0,2 \%$, mesurée à partie de l'échantillon total de sol). Mais dans ces cas, la roche devra libérer une plus grande quantité d'autres éléments nutritifs, comme c'est le cas des roches facilement altérées sur place. Manifestement, cette communauté végétale ne supporterait pas un plus grand débit d'eau en provenance de la muraille. Dans le voisinage immédiat des crevasses, où l'approvisionnenemt en eau est abondant, le groupement végétal tend vers un PoetoLactucetum. Là où l'asséchement est plus apparent, les buissons nains à Vaccinium prennent place (en particulier sur les parties de l'éboulis où la neige fond très tôt au printemps : tableau 22).

La délimitation proposée ici, est basée sur deux subassociations; Populeto-Tortuletum (tableau 19) et Fruticeto-Tortuletum, ce dernier avec une variante à Rubus idaeus (tableau 20) et une varianteà Juniperus(tableau 21).
Les conditions édaphiques du Populeto-Tortuletum peuvent être illustrées par les résultats d'analyses tenant compte de la perte en ignition, des échantillons de sol nos 28-29, tableau 1. Elles révèlent un profil de sol à mull typique pour le peuplement à Populus, une litière faiblement acide et un contenu modéré en calcium dans l'humus. Si l'on compare avec Poeto-Lactucetum (e.g. échantillons de sol nos 2, 38, 42-44), la réaction du substrat est plus basique, et le contenu en calcium est plus élevé. Voir aussi les conditions du sol des transepts, tableau 2 A points $b$ et $c$, cf. fig. 40 .

\section{Rhytidietum (Tableau 23)}

Rhytidium rugosum, dans toute son aire de distribution, semble préférer les sites dont les conditions du milieu sont à peu près identiques : exposition au soleil, prairies sèches thermophiles sur sol calcaire, souvent sur les murailles ou les forêts exposées au $\mathrm{S}$, etc... Au NW de PL (la région forestière coniférienne du NW), il occupe la bordure des zones de broussailles (FruticetoTortuletum) vers l'éboulis dénudé formé de gros blocs. Il est aussi commun sur les corniches des murailles rocheuses.

Le substrat montre les caractéristiques décrites au tableau 2A (le transept au Mt Märkepakte; point $d$ ). Dans ce cas, l'amoncellement de la litière formée de débris de genévrier produit un $\mathrm{pH}$ faible $(6.0-6.3)$ et le contenu en calcium (de l'humus) est assez faible en surface si on le compare à celui obtenu dans le PopuletoTortuletum. L'humus de type mull peut atteindre une épaisseur assez importante. Dans ce cas, à $30 \mathrm{~cm}$ de profondeur, la perte par ignition atteint encore $28.4 \%$, valeur considérablement élevée comparée au PopuletoTortuletum situé à un niveau plus éievé sur la pente de l’éboulis.

\section{Dicrano-Polytrichetum}

Variante à Sphenolobus (Tableau 24). Dans les parties basses des forêts, sur pentes d'éboulis pierreux, situées sur les éboulis à gros blocs, à la partie distale de la pente et aux endroits dont l'exposition est défavorable, on rencontre des communautés végétales qui sont semblables aux synusies forestières pures décrites é.g. par Arnborg (1943 etc...) et Malmström (1949). C'est la partie la plus stable de l'éboulis et les particules fines se trouvent à une profondeur assez considérable (p. 24).

La productions de litière semble être le gradient le plus important à l'intérieur de l'association et de la variante, car certains éléments sont définitivement épilithiques alors que d'autres, d'autre part, croissent sur d'épaisses couches d'humus. Le $\mathrm{pH}$ est généralement bas et le contenu en $\mathrm{Ca}$ de l'humus est le plus bas que nous ayons rencontré sur les éboulis (voir les échantillons de sol nos 6, 7, 10, tableau 1). 
Variante à Cladonia (Tableau 25). Cette communauté végétale exige un substrat stable, souvent à gros blocs, mais quelquefois, des éboulis à particules fines sont aussi envahis par la communauté (la partie supérieure de la pente de l'éboulis au Mt Laisvare, no. $9 b$ ). Le maximum de sécheresse et d'irradiation favorise cette variante. C'est pour cette raison qu'on la retrouve souvent à la partie centrale des éboulis et sur les corniches des murailles rocheuses. Lorsque la roche en place est formée d'un type de mylonite plus acide, ou que le substrat est délavé au maximum, le groupement peut s'installer au sommet des gros blocs. C'est une communauté extrêmement xérophile, ayant le plus souvent une délimitation très nette vis-à-vis des autres communautés de l'alliance Veronico-Poion. Dans la plupart des cas, la couche d'humus est mince, et dans certains cas, totalement absente. On croirait alors que le groupement est épilithique (voir plus haut à propos de la variante à Sphenolobus). Les zones de transition peuvent être envahies par un type de forêt à arbustes rabougris, conduisant aux véritables communautés forestières. Cette communauté végétale est certainement plus variable que ce qu'il nous est possible d'en connaître ici. Voir les échantillons de sol nos 36, 37 et 41 au tableau 1 .

Comparaisons avec la végétation des pentes d'éboulis pierreux de Sikilsdalen

Nous avons déjà établi plus haut, qu'il existe de grandes ressemblances entre les communautés végétales de Sikilsdalen (au $\mathrm{S}$ de la Norvège) décrites par Nordhagen, et celles des pentes d'éboulis de PL décrites dans le présent travail. Cependant, nous ne savons rien de la flore cryptogamique des strates inférieures de son association Veronico-Poetum glaucae. Il ne fut pas possible non plus d'utiliser les données de Nordhagen, car ce dernier utilisa des quadrats de $4 \mathrm{~m}^{2}$ de surface. Afin d'obtenir des données comparables, le présent auteur, durant deux étés, étudia les éboulis du Haut Sikilsdalsvatn, à peu près au même endroit où Nordhagen fit ses analyses (tableau 27).

\section{Zonation de la végétation sur les pentes d'éboulis pierreux}

Selon Lundqvist J., 1961, p. 154, il existe une zonation de la végétation qui envahit les éboulis bien développés, à exposition $\mathrm{S}$. Cette zonation s'établit dans un ordre défini; elle comprend : 1) une zone de feuillus, surtout Populus tremula, 2) une zone de broussailles à Juniperus communis, Rubus idaeus, Rosa majalis, etc..., 3) une zone presque dépourvue de plantes supérieures, située à la partie centrale de l'éboulis, 4) la partie inférieure de la pente de l'éboulis envahie par une forêt clairsemée, appelée "forêt du bas de l'éboulis ». Une zonation similaire sur des pentes d'éboulis de Suède a été décrite par Sernander (1920, p. 112), où l'auteur ne donne cependant que trop peu de détails.

Deux transepts (tableaux 28 et 29, voir aussi figs. 30, 40 et 41 ) ont été réalisés et comparés entre eux. Les dissimilarités sont surtout dues à l'approvisionnement en eau d'infiltration, le degré de couverture du feuillage arborescent et les conditions édaphiques (Tableaux $2 \mathrm{~A}$ et B; cf. fig. 9).

\section{La succession de la végétation}

Nordhagen (1943, p. 566) fait remarquer que la succession de la végétation sur les éboulis en Scandinavie, est très lente à l'époque actuelle. C'est d'ailleurs le cas pour la plupart des cônes d'éboulis sur de vastes pentes d'éboulis pierreux au Spitsbergen (Rapp 1960, pp. 7677).

Le même phénomène se produit sur les pentes d'éboulis de PL (fig. 42). La dénudation est très lente et permet le développement de stages d'équilibre déterminé.

Un simple cône d'éboulis possède généralement le substrat le moins stable et une couverture arborescente très clairsemée (fig. 43).

Après la comparaison avec la végétation des pentes d'éboulis de Sikilsdalen (voir plus haut), il devient évident que la communauté Tortulo-Poetum a un stage qui précède l'installation de communautés végétales de prairies à couverture plus importante, sur éboulis nonconsolidés. D'autre part, la variante à Juniperus communis en particulier, préfère les parties les plus consolidées de l'éboulis, où elle succède au Populeto-Tortuletum. Sur les parties stabilisées de l'éboulis, le Rhytidieium succède au Fruticeto-Tortuletum. A certains endroits, le Rhytidietum se change immédiatement en un Arctostaphyletum uvae-ursi, ou à d'autres endroits, les variantes de l'association Dicrano-Polytrichetum forment des stages de succession sur blocs consolidés. Enfin, le PoetoLactucetum succède à des types plus stabilisés de Tortulo-Poetum sur éboulis humides.

Les communautés de plantes thermophiles à l'extérieur des écosystèmes des flancs de collines

Nous avons de bonnes raisons de croire que les communautés de prairies à grandes herbes des Scandes, ont relativement peu évoluées dans la période post-glaciaire (Blytt 1897, pp. 35-55; cf. Nordhagen 1943, p. 312). Une évolution lente depuis la période chaude s'applique certainement aux localités abritées, qui fournissent des conditions convenant à certaines espèces boréo-montagnardes, à type de distribution boréo-méridionale. Ces espèces, qui se rencontrent dans l'étage montagnard du centre et du S de l'Europe (voir plus haut p. 141), possèdent, dans le $\mathrm{N}$, un type de distribution dans les basses-terres. La couverture arborescente a dû changer considérablement lorsque le climat devint plus froid et 
les conditions édaphiques altérées (Blytt, 1.c., Nordhagen, 1.c.; Firbas 1949, pp. 275-277). Cependant, les sites protégés dont les conditions édaphiques demeurent bonnes, contiennent encore des éléments dont la présence justifie la description de ces groupements particuliers, comme des "communautés thermophiles reliques". Certains peuplements arborescents protégés, en particulier au NW, formés de Populus tremula et d'Alnus incana, auxquels s'ajoute, mais plus rarement, Ulmus glabra var. montana (Malmström 1934, p. 111; Rönning 1954, p. 197; Rune, O. 1965, pp. 68-69), peuvent être considérés comme " localités reliques ».
Nous avons étudié une broussaille à Alnus incana (contenant Circaea alpina), le groupement végétal adjacent et une forêt de Picea abies dans la région forestière coniférienne du SE (contenant Viola riviniana); tableaux 30 et 31$)$.

Les deux derniers chapitres contiennent une description plus détaillée, surtout de la végétation, des flancs des collines, de la région des Calédonides (1-16) et de celle des roches primaires (17-32). 


\section{REFERENCES}

When summaries in non-Scandinavian languages occur, the full titles of these have as a rule been given.

\section{Abbreviations}

APhS Acta Phytogeographica Suecica

$B N \quad$ Botaniska Notiser

$K V A \quad$ Kungl. Svenska Vetenskaps-Akademien

$S B T \quad$ Svensk Botanisk Tidskrift

$S G U \quad$ Sveriges Geologiska Undersökning

SMHA Statens Meteorologisk-Hydrografiska anstalt

SMHI Sveriges Meteorologiska och Hydrologiska Institut

Ahlenius, K., 1901, Beiträge zur Kenntnis der Seenkettenregion in Schwedish-Lappland. - Bull. Geol. Inst. Ups. 5. Uppsala.

Albertson, N., 1940, Rhytidium rugosum (Hedw.) Lindb. i Fennoskandia. - SBT 34. Stockholm.

Almén, B. \& Almén, O., 1959, Kärlväxternas höjdgränser i Sulitelmafjällen. I. (With English summary.) - BN 1959. Lund.

Almquist, E., 1965, Flora Upsaliensis. Uppsalatraktens växter. - Uppsala.

Amtsblatt des Deutschen Wetterdienstes. Die Grosswetterlagen Mitteleuropas 1959, 1961. - Offenbach a.M.

Anderson, M. C., 1964, Light relations of terrestrial plant communities and their measurement. - Biol. Rev. 39. Cambridge.

Andersson, J. S., 1961, The occurrence of some invertebrate animal groups in the south bluffs in northern Sweden. - Oikos 12 (1961). Copenhagen.

Andersson, G. \& Birger, S., 1912, Den norrländska florans geografiska fördelning och invandringshistoria med särskild hänsyn till dess sydskandinaviska arter. - Norrl. Handbibl. 5. Uppsala.

Andersson, N. J., 1846, Anteckningar under en resa i Umeå, Piteå och Luleå Lappmarker sommaren 1845. - BN 1846. Lund.

Andersson, T., 1963, On the accuracy of rain measurements and statistical results from rain studies with dense networks (Project Pluvius). - Ark. f. Geofys. 4. Stockholm.

- 1964, Further studies on the accuracy of rain measurements. - Ibid. 4. Stockholm.

Angström, A., 1916, Über die Gegenstrahlung der Atmosphäre. - Meteorol. Zeitschr. 33. Braunschweig.

- 1938, Lufttemperatur och temperaturanomalier i Sverige 1901-1930. (Temperature in Sweden 1901-30.) - SMHA Medd. 7. Stockholm.

- 1958, Sveriges klimat. 2nd ed. - Stockholm.

Anvisningar för bakteriologiska och fysikalisk-kemiska vattenundersökningar. - Svenska Kommunal Tekniska Föreningen. Stockholm, 1953.

Arnborg, T., 1943, Granberget. En växtbiologisk undersökning av ett sydlappländskt granskogsområde med särskild hänsyn till skogstyper och föryngring. (Granberget. Eine pflanzenbiologische Untersuchung eines siidlappländischen Fichtenwaldegebiets unter besonderer Beriicksichtigung von Waldtypen und Verjiingung.) Diss. - Norrl. Handbibl. 14. Uppsala.

- 1945, Det nordsvenska skogstypsschemat. - Stockholm. [Several later editions.]

- 1963, Muddus nationalpark. - Natur i Lappland. Uppsala.

Arnell, S., 1956, Hepaticae. - Illustrated Moss Flora of Fennoscandia I. Lund.

Arwidsson, Th., 1943, Studien iiber die Gefässpflanzen in den Hochgebirgen der Pite Lappmark. Diss. - APhS 17. Uppsala.

Ashbel, D., 1942, Solar Radiation and Soil Temperature. Jerusalem.

Atlas över Sverige. - Stockholm 1953-.

Auer, A. V., 1944, Kuusamon maksasammalkasviston aineistoa. - Ann. Bot. Soc. Vanamo 21:1 Helsinki.

Aurén, T. E., 1939, Radiation climate in Scandinavian peninsula. - Ark. f. Mat., Astr. o. Fys. 26 A. Stockholm.

Baumgartner, A., Kleinlein, G. \& Waldmann, G., 1956, Forstlich-phänologische Beobachtungen und Experimente am Grossen Falkenstein (Bayerischer Wald). - Forstwiss. Centralbl. 75. Berlin.

Bear, F. E., 1964, Chemistry of the Soil. 2nd ed. - ACS Monograph 160. New York.

Benum, $P ., 1958$, The Flora of Troms Fylke. - Troms $\varnothing$ Mus. Skr. 6. Troms $\phi$.

Bergeron, T., $1960 a$, Preliminär redogörelse för synoptiskkvantitativa nederbördsstudier med tätt stationsnät. (Preliminary report of synoptic-quantitative rainfall studies with dense networks.) - Jordbrukets Forskningsråd under tio år. Verksamheten 1945-1955. Stockholm.

- $1960 b$, Operation and results of "Project Pluvius". Am. Geophys. Union. Monogr. 5 (1960). W ashington, D.C.

- 1961, Preliminary results of "Project Pluvius". - I.A.S.H. Commission of Land Erosion. Louvain.

Birger, S., 1921, Växtvärlden. Norrbottens lappmarker och kustland. - Sv. Turistför. Resehandb. 25. Stockholm.

Björkman, G., 1939, Kärlväxtfloran inom Stora Sjöfallets nationalpark jämte angränsande delar av norra Lule lappmark. Diss., Uppsala. - KVA Avh. i naturskyddsärenden 2. Stockholm.

— 1965, Tillägg till kärlväxtfloran inom Stora Sjöfallets nationalpark jämte angränsande delar av norra Lule lappmark. (Addition to the flora of vascular plants in the national park of Stora Sjöfallet together with surrounding parts of northern Lule Lappmark, Sweden.) - Ibid. 21. Stockholm

Björkman, O. \& Holmgren, P., 1963, Adaptability of the photosynthetic Apparatus to light intensity in ecotypes from exposed and shaded habitats. - Physiol. Plant. 16. Lund.

Björnström, F. J., 1856, Grunddragen af Piteå Lappmarks växtf ysiognomi. Diss. - Uppsala. 
Blïthgen, J., 1964, Allgemeine Klimageographie. - Lehrbuch der Allgemeinen Geographie. II. Editor: E. Obst. Berlin.

$B l y t t, A$., 1869, Om vegetationsforholdene ved Sognefjorden. (Résumé pour les étrangers.) - Christiania.

- 1897, Vekstliv. - In: Vibe, J., Topografisk-historisk-statistisk beskrivelse over Akershus amt. Norges Land og Folk II. Kristiania.

Böcher, T. W., 1943, Nordische Verbreitungstypen. - SBT 37. Stockholm.

Boyko, H., 1947. On the role of plants as quantitative climate indicators and the geo-ecological law of distribution. - Journ. of Ecol. 35. Oxford.

Braun-Blanquet, J. (in cooperation with Jenny, H.) 1926, Vegetations-Entwicklung und Bodenbildung in der alpinen Stufe der Zentralalpen (Klimaxgebiet des Caricion curvulae). Mit besonderer Berücksichtigung der Verhältnisse im schweizerischen Nationalparkgebiet. - Denkschr. d. Schweiz. Naturf. Gesellsch. 63. Zürich.

- 1964, Pflanzensoziologie. Grundziige der Vegetationskunde. 3rd ed. - Wien.

Bringer, K.-G., 1961, Den lågalpina Dryas-hedens differentiering och ståndortsekologi inom Torneträsk-området. 1-2. (Differentiation and ecology of the low alpine Dryas heath in the Torneträsk area, Northern Swedish Lappland. 1-2.) - SBT 55. Stockholm.

- 1962, Kärlväxtfloran $i$ en serie sydexponerade branter och brantavsnitt på fjället Vakketjåkko, Torne lappmark, samt några iakttagelser rörande sydväxtbergflorans ståndortsekologi. (The vascular plants of south facing bluffs on Vakketjåkko, a mountain in the Torneträsk area, northem Swedish Lappland, and some observations concerning their distribution and ecology.) - BN 1962. Lund.

- 1965, Vegetationen i branter, talus och hällmark inom några kalkstens- och dolomitområden inom Torneträskområdet. (The vegetation of precipices, talus and rocks in some limestone and dolomite areas in the surroundings of Lake Torneträsk, northem Swedish Lapland.) - BN 1965. Lund.

Brotherus, V. F., 1923, Die Laubmoose Fennoskandias. Helsinki.

Bylund, E., 1956, Koloniseringen av Pite Lappmark t.o.m. år 1867. (The colonization of Pite Lappmark until 1867.) Diss. - Geographica 30. Uppsala.

Bylund, E. \& Sundborg, A., 1953, Lokalklimatets inverkan på bebyggelsens läge $\mathrm{i}$ Arvidsjaurs socken (With English Summary.) - Ymer 72 (1952). Stockholm.

Collinder, B., 1964, Ordbok till Sveriges lapska ortnamn. Stockholm.

$D a h l, E$., 1951, On the relation between summer temperature and the distribution of alpine vascular plants in the lowlands of Fennoscandia. - Oikos 3. Copenhagen.

- 1956, Rondane. Mountain vegetation in South Norway and its relation to the environment. Diss. - Skr. Norske Vidensk.-Akad. 1. Mat.-naturv.kl., 1956:3. Oslo.

- 1966, Plantenes varmeveksling med omgivelsene og dens betydning for plantenes morfologi og utbredelse. (The heat exchange of plants and its importance to plant morphology and distribution.) - Blyttia 24. Oslo.

Dahl, O., 1912, Botaniske Unders $\varnothing$ kelser i Helgeland. I. Vidensk.-Selsk. Skr. I. Mat.-naturv.kl., 1911:6. Kristiania.

- 1934, Floraen i Finnmark Fylke. - Nyt Mag. f. Naturvidensk. 69. Oslo.

Davis, S. N. \& DeWiest, R. J. M., 1966. Hydrogeology. New York.

De Candolle, A., 1855, Géographie Botanique Raisonnée. I, II. - Genève.
Degelius, G., 1935, Das ozeanische Element der Strauchund Laubflechtenflora von Skandinavien. Diss. - APhS 7. Uppsala.

- 1945, Ett sydberg i Kebnekaise-området och dess lavflora. (Ein Siidberg im Kebnekaise-Gebiet und seine Flechtenflora.) - BN 1945. Lund.

Drude, O., 1902, Der Hercynische Florenbezirk. - Die Vegetation der Erde. 6. Leipzig.

Du Rietz, G. E., 1924, Studien iiber die Vegetation der Alpen, mit derjenigen Skandinaviens verglichen. - Veröff. Geobot. Inst. Rübel 1. Zürich.

- 1936, Classification and nomenclature of vegetation units 1930-1935. - SBT 30. Stockholm.

- 1942, Rishedsförband i Torneträskområdets lågfjällbälte. (Zwergstrauchheideverbände in der unteralpinen Stufe des Torneträskgebietes.) - SBT 36. Stockholm.

- 1945, Om fattigbark- och rikbarksamhällen. - SBT 39 Stockholm.

- 1950, Phytogeographical excursion to the surroundings of Lake Torneträsk in Torne Lappmark (Northern Sweden). - 7th Intern. Bot. Congr., Stockholm 1950, Excursion Guide C III c. Uppsala.

- 1954, Sydväxtberg. (Sïdpflanzenberge.) - SBT 48. Stockholm.

- 1957, Vegetation analysis in relation to homogenousness and size of sample area. $-8^{\circ}$ Congrès International de Botanique. Paris 1954. Comptes rendus des séances et rapports et communications déposés lors du congrès dans les sections 7 et 8 . Paris.

- 1964, Nordsvenska vegetationsregioner. (Vegetation regions of Northern Sweden.) - Festskr. tillägnad Carl Kempe. Uppsala.

Du Rietz, G. E., Fries, Th. C. E., Osvald, H., \& Tengwall, T. A., 1920, Gesetze der Konstitution natürlicher Pflanzengesellschaften. - Abisko Naturvet. Stat. Medd. 3; Vetensk. o. prakt. unders. i Lappland anordn. av Loussavaara-Kirunavaara Aktiebolag. Flora och Fauna 7. Uppsala \& Stockholm.

Eimern, J. van, 1964, Untersuchungen über das Klima in Pflanzenbeständen als Grundlage einer agrarmeteorologischen Beratung, insbesondere für den Pflanzenschutz. Ber. d. Deutsch. Wetterdienst. No. 96. Offenbach a.M.

Egnér, H., Riehm, H. \& Domingo, W. R., 1960, Untersuchungen über die chemische Bodenanalyse als Grundlage für die Beurteilung des Nährstoffzustandes der Böden. II. Chemische Extraktionsmethoden zur Phosphorund Kaliumbestimmung. - K. Lantbr.högsk. Ann. 26. Stockholm.

Engler, A., 1919, Saxifragaceae-Saxifraga (Pars Generalis). In: Das Pflanzenreich. IV. Editor A. Engler. - Leipzig.

Engler, A. \& Irmscher, E., 1916, Saxifragaceae-Saxifraga I. In: Das Pflanzenreich. IV. Editor A. Engler. - Leipzig.

Enquist, F., 1933, Trädgränsundersökningar. (Baumgrenzuntersuchungen.) - Sv. Skogsvårdsför. Tidskr. 31. Stockholm.

Fabijanowski, J., 1950, Untersuchungen iiber die Zusammenhänge zwischen Exposition, Relief, Mikroklima und Vegetation in der Fallätsche bei Zürich. - Beitr. geobotan. Landesaufn. d. Schweiz. 29. Bern.

Firbas, F., 1949, Spät- und nacheiszeitliche Waldgeschichte Mitteleuropas nördlich der Alpen I. - Jena.

Friedel, H., 1952, Gesetze der Niederschlagsverteilung in Hochgebirge. - Wetter u. Leben 4. Wien.

Fries, M., 1962. See: Johansson, B. O. H. \& Fries, $M$.

Fries, Th. C. E., 1919, Experiment över björkens lövsprick- 
ning i skogsgränser och i dalbottnar. - SBT 13. Stockholm.

- 1925, Ökologische und phänologische Beobachtungen bei Abisko in den Jahren 1917-1919. I. - Sv. Växtsociol. Sällsk. Handl. Uppsala.

Frödin, J., 1915, Några märkliga sydberg i Lule Lappmark. Tvänne nya lokaler för Potentilla multifida. - SBT 9. Stockholm.

- 1917, Iakttagelser i Kebnekaise-områdets sydberg. - SBT 11. Stockholm.

Fuss, $F$., 1959, Nächtliche Temperaturverhältnisse zweier Weinberge im Elbtal. - Zeitschr. f. Angew. Met. 3. Berlin.

Gams, H., 1931, Die klimatische Begrenzung von Pflanzenarealen und die Verteilung der hygrischen Kontinentalität in den Alpen. - Zeitschr. d. Ges. f. Erdkunde zu Berlin $9 / 10$. Berlin.

Gates, D. M., 1962, Energy Exchange in the Biosphere. New York.

Gaunitz, D. \& C. B., 1924, Bidrag till kännedom om kärlväxtfloran i Sorsele socken av Lycksele Lappmark. SBT 18. Uppsala.

Geiger, R., 1927-29, Messung des Expositionsklimas. - Forstwiss. Centralbl. 49-51. Berlin.

- 1965, The Climate Near the Ground. (Das Klima der bodennahen Luftschicht. 4th ed., 1961) - Cambridge, Mass.

Geiger, R., Woeifle, M. \& Seip, L. P., 1933-34, Höhenlage und Spätfrostgefährdung. - Forstwiss. Centralbl. 55-56. Berlin.

Giarevoll, O., 1965, Chionophilous plant communities. In: Gjarevoll, O. \& Bringer, K.-G., Plant Cover of the Alpine Regions. - APhS 50 .Uppsala.

Goto, K., Komatsu, T. \& Furukawa, T., 1962, Rapid colorimetric determination of manganese in waters containing iron. - Anal. Chim. Acta 27. New York \& Amsterdam.

Graebner, $P$., 1910, Die natiirliche Veränderung von Vegetationsformationen und ihre fossiien Reste. In: Die Klimaveränderungen in Deutschland seit der letzten Eiszeit. Zeitschr. d. Deutsch. Geol. Ges. 62. Berlin.

Grapengiesser, S., 1917, Några rika växtlokaler vid Hornavan i Pite Lappmark. - SBT 11. Stockholm.

Grip, E., 1946. Arvidsjaurfältet och dess förhållande till omgivande berggrund. (The Arvidsjaur district and its relation to surrounding rocks.) - SGU, Ser. C, 474. Stockholm.

- 1960, The lead deposits of the eastern border of the Caledonides in Sweden. - Intern. Geol. Congr., Session 21, Norden, part 16. Copenhagen.

Grundmann, W., 1957, Meteorologische Messgeräte am Erdboden. - Linkes Meteorol. Taschenbuch 3. L.eipzig.

Grunow, J., 1952, Beiträge zum Hangklima. - Ber. d. Deutsch. Wetterdienst. in d. US-Zone 5. Bad Kissingen.

- 1953, Niederschlagsmessungen am Hang. - Meteorol. Rundschau 6. Heidelberg.

Gustafsson, L., 1960, Determination of ultramicro amounts of sulphate as methylene blue. - Talanta 4. New York.

Halden, B., 1950, Korpberget vid Viksberg i Salem, Södermanland, jämte några ord om biotoperna för Asplenium Ruta-muraria och hassel. (The Korpberget hill at Viksberg in Salem, prov. Södermanland, Central Sweden, and some notes on the biotopes of Asplenium Ruta-muraria and hazel.) - SBT 44. Stockholm.

- 1956, Sveriges nordligaste hasselförekomster. (The northernmost localities for hazel in Sweden.) - SBT 50. Stockholm.
Hallberg, H. P., 1959, Rhytidium rugosum (L. ex Hedw.) Kindb. i Bohuslän. (Rhytidium rugosum (L. ex Hedw.) Kindb. in Bohuslän, Western Sweden.) - SBT 53. Stockholm.

Hamberg, H. E., 1908, Medeltal och extremer av lufttemperaturen i Sverige 1856-1907. - Bihang t. Meteorol. Iakt. i Sverige 49 (1907). Uppsala.

Hämet-Ahti, L., 1963, Zonation of the mountain birch forests in northernmost Fennoscandia. - Ann. Bot. Soc. Vanamo 34:4. Helsinki.

Handbok för väderleksobservatörer. - SMHA Instruktioner, Editors G. Slettenmark \& A. Angström, Stockholm 1944.

Hasselrot, T. E., 1948, Två isolerade svenska fyndorter för Normandina pulchella (Borr.) Nyl. - SBT 42. Stockholm.

Havas, P. J., 1965, Pflanzenökologische Untersuchungen im Winter. I. Zur Bedeutung der Schneedecke für des Ueberwintern von Heidel- und Preisselbeere. - Aquilo, Ser. Bot. 4. Oulu.

Hedberg, O., 1947, Bidrag till Torne Lappmarks flora. - BN 1947. Lund.

- 1952, Vegetation. In: Hedberg, O., Mårtensson, O. \& Rudberg, $S$., Botanical investigations in the Pältsa region of northernmost Sweden. - BN Suppl. 3:2. Lund

- 1964, Features of Afroalpine Plant Ecology. - APhS 49. Uppsala.

Hegi, G., 1909-31, Illustrierte Flora von Mittel-Europa. 1-7. 1 st ed. - München.

- 1925 -, Illustrierte Flora von Mitteleuropa. 2nd ed. München.

Heigel, K., 1955, Exposition und Höhenlage in ihrer Wirkung auf die Pflanzenentwicklung. - Meteorol. Rundschau 8. Heidelberg.

- 1957, Die Bodenfeuchte in Abhängigkeit von Exposition, Bodenart und Bewuchs. - Wetter u. Leben 9. Wien.

Herzog, Th., 1926, Geographie der Moose. - Jena.

Herzog, Th., \& Höfler, K., 1944, Kalkmoosgesellschaften um Golling. - Hedwigia 82. Dresden.

Hesselman, $H$., 1932, Om klimatets humiditet i vårt land och dess inverkan på mark, vegetation och skog. (Die Humidität des Klimas Schwedens und ihre Einwirkung auf Boden, Vegetation und Wald.) - Stat. Skogsförsöksanst. Medd. 26. Stockholm.

Hintikka, V., 1963, Uber das Grossklima einiger Pflanzenareale in zwei Klimakoordinatensystemen dargestellt. Ann. Bot. Soc. Vanamo 34:5. Helsinki.

Hjelmquist, $H$., 1940, Studien ïber die Abhängigkeit der Baumgrenzen vorn den Temperaturverhältnissen unter besonderer Berücksichtigung der Buche und ihrer Klimarassen. - Lund.

Högbom, A. G., 1906, Norrland. Naturbeskrif ning. - Norrl. Handbibl. 1. Uppsala.

- 1934, Om skogseldar förr och nu och deras roll i skogarnas utvecklingshistoria. - Norrl. Handbibl. 13. Uppsala.

Holmberg, O. R., 1922, Hartmans handbok i Skandinaviens flora. 1 a: 1. - Stockholm.

Holmboe, J., 1912, Vaarens utvikling i Troms $\varnothing$ amt. Bergens Mus. Aarbok (1912). 1. Bergen.

Holmen, $H$., 1959, Vegetation och flora inom dämningsområdet för Ramsele kraftverk. - KVA Avh. i naturskyddsärenden. 17. Stockholm.

- 1964, Forest ecological studies on drained peat land in the province of Uppland, Sweden. I-III. Diss. Uppsala. - Studia Forest. Suec. 16. Stockholm.

- 1965, Subalpine tall herb vegetation, site and standing crop. - APhS 50. Uppsala. 
Huber, H., 1961, Dicotyledones. In: Hegi, G., Illustrierte Flora von Mitteleuropa. 2nd ed. 4:2 A. - München.

Hudleston, F., 1929, Report on experiments with rain-gauge shields and rain-gauges under the lee of a high wood during the period 1st May, 1928, to 30th April, 1929, at Hutton John, Penrith. - Brit. Rainfall 68. London.

Hultén, E., 1937, Outline of the History of Arctic and Boreal Biota during the Quarternary Period. - Stockholm.

- 1950, Atlas över växternas utbredning i Norden. Fanerogamer och ormbunksväxter. (Atlas of the Distribution of Vascular Plants in NW Europe.) - Stockholm.

- 1958, The Amphi-atlantic plants and their phytogeographical connections. - KVA Handl. Ser. 4: 7. No. 1. Stockholm.

- 1962, The circumpolar plants. 1. Vascular cryptogams, conifers, monocotyledons. - KVA Handl. Ser. 4: 8. Stockholm.

Hylander, N., 1953, Nordisk kärlväxtflora. I. - Uppsala.

- 1955, Förteckning över Nordens växter. 1. Kärlväxter. 4th ed. - Lund.

- 1966, Nordisk kärlväxtflora. II. - Uppsala.

Irmscher, E., 1929, Pflanzenverbreitung und Entwicklung der Kontinente. I, II. - Inst. f. Allg. Bot. Mitt. 8. Hamburg.

Iwasaki, 1., Utsumi, S., Hagino, K. \& Ozawa, T., 1956, A new spectrophotometric method for the determination of small amounts of chloride using the mercuric thiocyanate method. - Chem. Soc. Jap. Bull. 29:8. Tokyo.

Jalas, J., 1950, Zur Kausalanalyse der Verbreitung einiger nordischen Os- und Sandpflanzen. - Ann. Bot. Soc. Vanamo 24:1. Helsinki.

Jarvis, M., 1963, A comparison between the water relations of species with contrasting types of geographical distribution in the British Isles. In: The Water Relations of Plants. Editors A. J. Rutter \& F. H. Whitehead. London.

Jarvis, P. G., 1964, The adaptability to light intensity of seedlings of Quercus petraea (Matt.) Liebl. - Journ. Ecol. 52. Oxford.

Jenny-Lips, H., 1930, Vegetationsbedingungen und Pflanzengesellschaften auf Felsschutt. - Beih. z. Bot. Centralbl. 46. Dresden-N.

Jensen, C., 1939, Skandinaviens bladmossflora. - København.

Johansson, B. O. H. \& Fries, M., 1962, Varghalsen, en förhistorisk boplats vid Hornavan. (Varghalsen. Eine prähistorische Siedlung am See Hornavan.) - Fornvännen 4. Stockholm.

Johansson, H. E., 1933, Växttopografiska anteckningar. 1. Lappland jämte övriga delar av Västerbottens och Norrbottens län. [Prep. by S. Grapengiesser.] — BN 1933. Lund.

Johansson, O. V., 1927, Die Temperaturänderung mit der Höhe an der Erdoberfläche in Skandinavien. - Geogr. Ann. 9. Stockholm.

Johnsson, N., 1930, Paktesuolo i Tjeggelvas, ett sydberg. SBT 24. Stockholm.

Julin, E., 1948, Vessers udde. Mark och vegetation i en igenväxande löväng vid Bjärka-Säby. (Vessers udde. Boden und Vegetation in einer verwachsenden Laubwiese bei Bjärka-Säby in Östergötland, Siidschweden.) - APhS 23. Uppsala.

Kalela, A., 1939, Über Wiesen und wiesenartige Pflanzengesellschaften auf der Fischerhalbinsel in Petsamo Lappland. - Acta Forest. Fenn. 48. Helsinki.

Kalliola, R., 1939, Pflanzensoziologische Untersuchungen in der alpinen Stufe Finnisch-Lapplands. - Ann. Bot. Soc. Vanamo 13:2. Helsinki.

Karlsson, N. \& Jonsson, E., 1959, Om sambandet mellan resultat av de gamla jordanalysmetoderna och den nya AL-metoden, beträffande lättlöslig fosforsyra och lättlösligt kali. - Stat. Lantbr.kem. Kontrollanst. Medd. 20. Stockholm.

Kautsky, F., 1940, Das Fenster von Gautojaure im Kirchspiele Arjeplog, Lappland. - Geol. För. Förh. 62. Stockholm.

Keränen, J., 1920, Über die Temperatur des Bodens und der Schneedecke in Sodankylä nach Beobachtungen mit Thermoelementen. - Ann. Acad. Scient. Fenn. S.A. 13:7. Helsinki.

- 1929, Wärme- und Temperaturverhältnisse der obersten Bodenschichten. - Naturwiss. Monogr. u. Lehrbiicher $8: 2$. Berlin.

Kerner, A., 1891, Die Änderung der Bodentemperatur mit der Exposition. - Sitzungsber. d. Akad. d. Wissenschaften. Math.-naturwiss. Kl. Wien.

Knaben, G., 1954, Saxifraga osloensis n.sp., a tetraploid species of the Tridactylites section. - Nyt Mag. f. Bot. 3. Oslo.

- 1961, Videre studier over livssyklus hos norske sildrearter. (Further studies of the life cycles of Norwegian species of the genus Saxifraga.) - Blyttia 19. Oslo.

Koch, H. G., 1961, Die warme Hangzone. - Zeitschr. f. Met. 15. Berlin.

Kolthoff, I. M. \& Kuroda, P. K., 1951, Argentometric amperometric titration of traces of chloride. - A nal. Chem. 23. Washington D.C.

Kotilainen, M. J., 1933, Zur Frage der Verbreitung des atlantischen Florenelementes Fennoskandias. - Ann. Bot. Soc. Vanamo 4:1. Helsinki.

Kreeb, K., 1954, Die Schneeschmelze als phänologischer Faktor. - Meteorol. Rundschau 7. Heidelberg.

Krusenstjerna, E. von, 1940, Några anmärkningsvärda mosssamhällen och mossarter från Västerbotten. - APhS 13 Uppsala.

- 1945, Bladmossvegetation och bladmossflora i Uppsalatrakten. (Moss flora and moss vegetation in the neighbourhood of Uppsala.) Diss. - APhS 19. Uppsala.

- 1954, Mossflora och mossvegetation vid Harsprånget och i Syd-Muddus i Lule Lappmark. (Moss flora and moss vegetation at the Harsprånget Falls and in the southern part of the Muddus National Park, Sweden.) - KVA Avh. i naturskyddsärenden 10. Stockholm.

Kulczynski, S., 1923, Das boreale und arktisch-alpine Element in der Mittel-Europäischen Flora. - Bull. Intern. de l'Acad. Pol. des Sciences. 1-10. Krakow.

Kulling, O., 1948, Fjällkedjans berggrund. In: De svenska fjällens natur. 2nd ed. Editor G. Lundqvist. - Svenska Turistför. handb. om det svenska f jället. Stockholm.

Künkele, T. \& Geiger, R., 1925. Hangrichtung (Exposition) und Pflanzenklima. - Forstwiss. Centralbl. 47. Berlin.

Lastadius, L. L., 1824, Beskrifning öfver några sällsyntare växter från norra delarne af Sverige jemte anmärkningar i Växtgeografien. - KVA Handl. 1824. Stockholm.

Laine, $U$., 1964, Über die floristischen Ziige der nördlichen Waldgrenge der Kiefer in Westteil von Inari-Lappland. - Ann. Univ. Turku A II:32. Turku.

- 1965, Alustavia tuloksia Kevojoen pahtojen kasvistollisesta kartoitus-työstä. (Preliminary observations on the flora of the cliffs in the Kevojoki River Canyon, Finnish Lapland.) - Lapin Tutkimusseuran Vuosikirja 6. Kemi. 
Lauscher, F., 1934, Wärmeausstrahlung und Horizonteinengung. - Sitzungsber. Wien. Akad. 143. Wien.

Leach, W., 1930, A preliminary account of the vegetation of some non-calcareous British screes. - Journ. Ecol. 18. Oxford.

Ljungner, E., 1948, Kölen och Skanderna. (The Kjöl and the Scandes.) - Svensk Geogr. Årsb. 24. Lund.

Lundqvist, J., 1961, Flora och vegetation vid några sydväxtberg i Pite Lappmark. (Flora and vegetation of some hills with southern plants in Pite Lappmark, Sweden.) - BN 1961. Lund.

- 1963, Cypripedium calceolus L., Saxifraga adscendens L. och Circaea alpina L. påträffade i Pite lappmark. (Cypripedium calceolus L., Saxifraga adscendens L., and Circaea alpina L. found in Pite Lappmark, Lapland, Sweden.) - SBT 57. Stockholm.

- 1965, South-facing hills and mountains. In: Lundqvist, J., Wistrand, G. \& Rune, S., Lappland east of the mountains. - APhS 50. Uppsala.

- 1966, Några kärlväxter nya för Pite Lappmark samt nya lokaler för Cypripedium calceolus L. och Polemonium acutiflorum Willd. (Some vascular plants new to Pite Lappmark, Lapland, North Sweden, and new localities for Cypripedium calceolus L. and Polemonium acutiflorum Willd.) - SBT 60. Stockholm.

Lundqvist, J. \& Wistrand, G., 1964. See: Wistrand, G. \& Lundqvist, $J$.

Lunelund, $H ., 1940$, Bestrahlung verschieden orientierter Flächen in Finnland durch Sonne und Himmel. - Soc. Scient. Fenn. Com ment. Phys.-Math. 10:13. Helsinki.

Lye, K. A., 1967a, Studies in the growth and development of oceanic bryophyte communities. - SBT 61. Stockholm.

- 1967b, En ny inndeling av Norges plante-geografiske element. (A new classification of Norwegian plant-geographical elements.) - Blyttia 25. Oslo.

Magnusson, N. H., Lundqvist, G. \& Regnéll, G., 1963, Sveriges geologi. 4th ed. - Stockholm.

Malmström, C., 1934, Almen på sin nordligaste fyndort i Sverige, Skikkisjöberget i Åsele Lappmark. (Die Ulme auf ihrem nördlichsten Standort in Schweden, dem Skikkisjöberg in Åsele Lappmark.) - Svenska Skogsvårdsför. Tidskr. 32. Stockholm.

- 1949, Studier över skogstyper och trädslagsfördelning inom Västerbottens län. (Studien iiber Waldtypen und Baumartenverteilung in Län Västerbotten.) - Stat. Skogsf. Inst. Medd. 37. Stockholm.

Mårtensson, O., 1956, Bryophytes of the Torneträsk Area, Northern Swedish Lappland. I-III. - KVA Avhandl. i naturskyddsärenden $12,14,15$. Stockholm.

Meinzer, O. E., 1923, Outline of ground-water hydrology with definitions. - U.S. Geol. Survey Water-Supply Paper 494. Washington D.C.

Meusel, H., 1943, Vergleichende Arealkunde. 1-2. - BerlinZehlendorf.

- 1959, Arealformen und Florenelemente als Grundlagen einer vergleichenden Phytochorologie. - Forsch. u. Fortschr. 33:6. Berlin.

Meusel, H., Jäger, E. \& Weinert, E., 1965, Vergleichende Chorologie der Zentraleuropäischen Flora. Text und Karten. - Jena.

Millar, A., 1965, The effect of temperature and day length on the height growth of birch (Betula pubescens) at 1900 feet in the northern Pennines. - Journ. Appl. Ecol. 2. Oxford.

Milne, G., 1935, Some suggested units of classification and mapping, particularly for East African soils. - Soil Research. Suppl. Proc. Intern. Soc. Soil Science 4:3. Berlin.

Modén, H., 1939, Beräkning av medeltemperaturen vid svenska stationer. (Computation of the mean monthly temperature at Swedish stations; mimeogr.) - SMHA. Medd. Ser. uppsatser 29. Stockholm.

Möller, F., 1951, Long-wave Radiation. In: Compendium of Meteorology. Editor Th. F. Malone. - Boston, Mass.

Möller, $H j .$, 1911-1936, Lövmossornas utbredning i Sverige. 1-13. - Ark. f. Bot. 10-28. Stockholm.

Müller, D., 1928, Die Kohlensäureassimilation bei arktischen Pflanzen und die Abhängigkeit der Assimilation von der Temperatur. - Planta, Arch. f. wiss. Bot. 6. Berlin.

Mullin, J. B., \& Riley, J. P., 1955, The colorimetric determination of silicate with special reference to sea and natural waters. - Anal. Chim. Acta. 12. Amsterdam.

Munn, R. E., 1966, Descriptive Micrometeorology. - Advances in Geoph. Suppl. 1. New York.

Nannfeldt, J. A., 1966, Dryopteris dilatata och Dr. assimilis i Sverige. (Dryopteris dilatata and Dr. assimilis in Sweden.) - BN 1966. Lund.

Nordhagen, $R$., 1928, Die Vegetation und Flora des Sylenegebietes. 1. Die Vegetation. - Skr. Norske Vidensk.Akad. 1. Mat.-naturvid. kl., 1927:1. Oslo.

- 1936, Versuch einer neuen Einteilung der subalpinenalpinen Vegetation Norwegens. - Bergens Mus. Årbok 1936, Naturvet. rekke 7. Bergen.

- 1943, Sikilsdalen og Norges Fjellbeiter. En plantesosiologisk monografi. - Bergens Mus. Skr. 22. Bergen.

Norman, J. M., 1894, 1900, Norges arktiske flora. I. Speciel plantetopografi. 1, 2. - Kristiania.

Nydahl, F., 1949, The determination of manganese by the peroxidisulphate method. - Anal. Chim. Acta 3. New York \& Amsterdam.

Nyholm, E., 1954-, Musci. - Illustrated Moss Flora of Fennoscandia II. Lund.

Nyman, E., 1895, En för Sverige ny Potentilla. - BN 1895. Lund.

Odin, H., 1964, Skogsmeteorologiska undersökningar i höjdlägen. - K. Skogs- o. Lantbruks-Akad. Tidskr. 103. Stockholm.

Ödman, O. H., 1957, Beskrivning till berggrundskarta över urberget i Norrbottens län. (With English summary.) SGU, Ser. Ca, 41. Stockholm.

Oldertz, C. \& Bäckström, H., 1961, Svenska Nationalparker, naturminnen och domänreservat m. m. 2nd. - Stockholm.

Ordbok öfver Svenska Språket utgifven af Svenska Akademien. IlI. - Lund 1906.

Parker, J., 1952, Environment and forest distribution of the Palouse Range in northern Idaho. - Ecology 33. New York.

Pedersen, A., 1958, Cruciférernes udbredelse i Danmark. (The distribution of the Cruciferae within Denmark.) - Bot. Tidsskr. 54. Kфbenhavn.

Persson, A., 1961, Mire and spring vegetation in an area north of Lake Torneträsk, Torne Lappmark. Sweden. I. Description of the vegetation. - Opera Bot. 6:1. Lund.

Persson, $H ., 1929$, Några mosslokaler jämte ett par artstudier. - BN 1929. Lund.

- 1932, Några för Sverige nya eller anmärkningsvärda mossor jämte ett par ord om det bicentriska problemet. BN 1932. Lund.

- 1945, Till kännedomen om Karlsöarnas mossflora. (A contribution to the knowledge of the bryophytic flora of the Karlsö islands.) - SBT 38 (1944). Stockholm.

Pettersson, B., 1958, Dynamik och konstans i Gotlands flora 
och vegetation. (Dynamik und Konstanz in der Flora und Vegetation von Gotland, Schweden.) Diss. - APhS 40. Uppsala.

Pilström, I., 1966, Växtlokaler från östra Arvidsjaur. (Pflanzenfunde aus dem östlichen Arvidsjaur, Pite Lappmark, Nordschweden.) - SBT 60. Stockholm.

The Plant Cover of Sweden. A study dedicated to G. Einar Du Rietz on his 70th birthday April 25th 1965 by his pupils. [Ed. by Svenska Växtgeografiska Sällskapet.]. APhS 50. Uppsala. 1965.

Poelt, J., 1953, Zur Kenntnis der Gracile-Formen der Sammelart Schistidium apocarpum (L.) Bryol. Eur. - SBT 47. Stockholm.

Polunin, N., 1959, Circumpolar Arctic Flora. - Oxford. Rapp, A., 1957, Studien iiber Schutthalden in Lappland und auf Spitzbergen. - Zeitschr. f. Geomorph. 1:2. Berlin.

- 1960, Talus slopes and mountain walls at Tempelf jorden, Spitsbergen. - Norsk Polarinst. Skr. 119. Oslo.

- 1961, Recent development of mountain slopes in Kärkevagge and surroundings, northern Scandinavia. - Geogr. Ann. 42 (1960). Stockholm.

Raunkiar, C., 1908, Livsformernes Statistik som Grundlag for biologisk Plantegeografi. - Bot. Tidsskr. 29. København.

- 1934, The Statistics of Life-forms as a Basis for Biological Plant Geography. - The Life Forms of Plants and Statistical Plant Geography. Oxford.

Regel, C., 1950, Dynamik von Klima und Pflanzendecke in Nordeuropa. - Ber. Geobotan. Forsch.-Inst. Riibel. 1949. Zürich.

- 1952, Botanische Betrachtungen auf einer Reise in Schweden. - Ibid. 1951. Zürich.

Resvoll-Holmsen, H., 1920, Om fjeldvegetationen i det $\varnothing \mathrm{s}-$ tenf jeldske Norge. - Arch. f. Math. o. Naturvid. 37. Kristiania.

Rey, P., 1960, Essai de Phytocinétique Biogéographique. Paris.

Rodhe, W., 1949, The ionic composition of lake waters. Verh. int. Ver. theoret. angew. Limnol. 10. Stuttgart.

Roller, M., 1953, Über die Auswirkung mikroklimatischer Faktoren auf das Abschmelzen der Winterschneedecke. - Wetter u. Leben 5. Wien.

Rönning, O. I., 1954, The vegetation on the Ulmus glabra locality in Beiarn, northern Norway. - Nytt Mag. f. Bot. 3. Oslo.

Rübel, E., 1935, The replaceability of ecological factors and the law of minimum. - Ecology 16. New York.

Rudberg, S., 1954, Västerbottens berggrundsmorfologi. Ett försök till rekonstruktion av preglaciala erosionsgenerationer i Sverige. (The morphology of Västerbotten. An attempt at the reconstruction of cycles of preglacial erosion in Sweden.) - Geographica 25. Uppsala.

- 1957, Ödemarkerna och den perifera bebyggelsen i inre Nordsverige. En diskussion av vissa orsakssamband bakom fördelningen bygd-obygd. (Unsettled areas and frontier settlement areas in inner northern Sweden - A discussion of some causes underlying this division.) Geographica 33. Uppsala.

Rune, O., $1957 a$, De serpentinicola elementen i Fennoskandiens flora. (The serpentinicolous elements in the flora of Fennoscandia.) - SBT 51. Stockholm.

- $1957 b$, Studier över floran på serpentinbergarter i norra Fennoskandien och nordöstra Nordamerika. (Studies on the flora of serpentine rocks in northern Fennoscandia and northeastern North America.) Diss. - Uppsala.
- 1965, The mountain regions of Lappland. - APhS 50. Uppsala.

Rune, S., 1965. Regional aspects on the flora. In: Lundqvist, J., Wistrand, G. \& Rune, S., Lappland east of the mountains. - APhS 50. Uppsala.

Samuelsson, G., 1910, Über die Verbreitung einiger endemischer Pflanzen. - Ark. f. Bot. 9:12. Stockholm.

Sandberg, G., 1960, Abisko. - Sveriges nationalparker 1. Stockholm.

Sandell, E. B., 1959, Colorimetric Determination of Traces of Metals. - New York.

Saxer, A., 1955, Die Fagus-Abies- und Piceagïrtelarten in der Kontaktzone der Tannen- und Fichtenwälder der Schweiz. - Beitr. geobotan. Landesaufn. d. Schweiz 36. Bern.

Schmid, E., 1954, Anleitung zu Vegetationsaufnahmen. Vierteljahrsschr. d. Naturforsch. Ges. in Zürich. 99:1. Zürich.

Schnelle, F., 1948, Studien zur Phänologie Mitteleuropas. Ber. d. Deutsch. Wetterdienst. in d. US-Zone 1. Bad Kissingen.

Selander, S., $1950 a$, Floristic phytogeography of South-Western Lule Lappmark (Swedish Lapland). 1. Diss. - APhS 27. Uppsala.

- $1950 b$, Floristic phytogeography of South-Western Lule Lappmark (Swedish Lapland). 2. Kärlväxtfloran i sydvästra Lule lappmark. (With English summary.) - APhS 28. Uppsala.

Sernander, R., 1912, Studier öfver lafvarnes biologi. I. Nitrofila lafvar. - SBT 6. Stockholm.

— 1920, Exkursionen till Skåne juni 1919. - SBT 14. Stockholm.

Seyfert, F., 1959, Anleitung zur Durchfiihrung phänologischer Beobachtungen. - Veröff. d. Meteorol. u. Hydrol. Dienst. d. Deutsch. Demokr. Republ. 5. Berlin.

Shanks, R. E. \& Norris, F. H., 1950, Microclimatic variation in a small valley in eastern Tennessee. - Ecology 31. New York.

Sjörs, $H, 1946 a$, Myrar i Muddus. - Sveriges Natur. Stockholm.

- $1946 i$, Myrvegetationen i övıe Långanområdet i Jämtland. (The mire vegetation of upper Långan district in Jämtland (Sweden).) - Ark. f. Bot. 33A: 6. Stockholm.

- 1948, Myrvegetation i Bergslagen. (Mire vegetation in Bergslagen, Sweden.) Diss. - APhS 21. Uppsala.

- 1950, Regional studies in North Swedish mire vegetation. - BN 1950. Lund.

- 1954, Slåtterängar i Grangärde Finnmark. (Meadows in Grangärde Finnmark, SW. Dalarna, Sweden.) - APhS 34. Uppsala.

- 1955, Remarks on ecosystems. - SBT 49. Stockholm.

- 1960, Kärlväxtflora och vegetationstyper vid Ångermanälven mellan Nämforsen och Moforsen. (Vascular flora and types of vegetation between Nämforsen and Moforsen, along the middle Ångerman River, Northern Sweden.) - SBT 54. Stockholm.

- 1961, Some chemical properties of the humus layer in Swedish natural soils. - K. Skogshögsk. Skr. 37. Stockholm.

- 1963, Amphi-Atlantic zonation, Nemoral to Arctic. North Atlantic Biota and their History. Oxford.

- 1965, Forest Regions. - APhS 50. Uppsala.

SMHI, Årsbok 29 (1947) II:2. — Stockholm 1953.

Stålfelt, M. G., 1960, Växtekologi. - Stockholm.

Suzuki, S., 1941, Early strawberries and their cultivation on slopes. - Agric. and Hortic. Japan. 16. Tokyo. 
Svenonius, $F$., 1894, Några svenska fjälltyper. - Svenska Turistför. Årsskr. Stockholm.

Svensson, B., 1965, Meteorologiska Instrument. - Meteorologiska Institutionen. Uppsala. [Mimeogr.]

Tamm, O., 1930, Om brunjorden i Sverige. (Der braune Waldboden in Schweden.) - Svenska Skogsvårdsför. Tidskr. 28. Stockholm.

- 1931, Studier över jordmånstyper och deras förhållande till markens hydrologi i nordsvenska skogsterränger. (Studien iiber Bodentypen und ihre Beziehungen zu den hydrologischen Verhältnissen in nordschwedischen Waldterrains.) - Stat. Skogsförsöksanst. Medd. 26. Stockholm.

- 1934, En snabbmetod för mineralogisk jordartsgranskning. (Eine Schnellmethode fuir mineralogische Bodenuntersuchung.) - Svenska Skogsvårdsför. Tidskr. 32. Stockholm.

- 1940, Den nordsvenska skogsmarken. - Stockholm.

- 1959, Studier över klimatets humiditet i Sverige. (Studien iiber die Humidität des Klimas in Schweden.) - K. Skogshögsk. Skr. 32. Stockholm.

Tengwall, T. A., 1916, Über die Bedeutung des Kalkes für die Verbreitung einiger schwedischer Hochgebirgspflanzen. - SBT 10. Stockholm.

- 1920, Die Vegetation des Sarekgebietes. I. Diss., Uppsala. - Naturwiss. Untersuch. d. Sarekgeb. in Schwed.-Lappland, 3:4. Stockholm.

- 1925 a, Die Gefässpflanzen des Sarekgebietes. - Ibid. 3:7. Stockholm.

- $1925 b$, Die Vegetation des Sarekgebietes. II. - Ibid. 3:8. Stockholm.

Troedsson, T., 1955, Vattnet i skogsmarken. Studier med hänsyn särskilt till ytvattnets, sjunkvattnets och grundvattnets uppkomst och sammansättning. (Das Wasser des Waldbodens. Studien mit besonderer Beriicksichtigung der Entstehung und der chemischen Eigenschaften des Oberflächenwassers, des Sickerwassers und des Grundwassers.) Diss. - K. Skogshögsk. Skr. 20. Stockholm.

- 1956, Marktemperaturen i ytsteniga jordarter. (Soil temperatures in moraines with stony surface layers.) $-\mathrm{K}$. Skogshögsk. Skr. 25. Stockholm.

Troll, C., 1941, Studien zur vergleichenden Geographie der Hochgebirge der Erde. - Bericht der 23. Hauptversammlung der Gesellschaft von Freunden und Förderern der Rhein. Friedrich-Wilhelms-Univ. zu Bonn. Bonn.

Tuomikoski, R., 1939, Materialien zu einer Laubmoosflora des Kuusamo-Gebietes. - Ann. Bot. Soc. Vanamo 12:4. Helsinki.

Turesson, G., 1932, Die Pflanzenart als Klimaindikator. K. Fysiogr. Sällsk. i Lund Förh. 2:4. Lund.
Turrill, W. B., 1939, The principles of plant geography. Kew, Bull. Misc. Inform. 5. London.

Vretlind, E. G., 1930, Från östra Lappland. Om kärlväxtfloran i Malå socken i lidernas region. - SBT 24. Stockholm.

Wahlenberg, G., 1808, Berättelse om mätningar och observationer för att bestämma lappska fjällens höjd och temperatur vid 67 graders polhöjd förrättade år 1807. Stockholm.

- 1812, Flora Lapponica. - Berolini.

- 1824-26, Flora Svecica. Pars I-II. [2nd ed. 1831-33.] - Upsaliæ.

Waldmann, G., 1959, Schnee- und Bodenfrost als Standortsfaktoren am Grossen Falkenstein. - Forstwiss. Centralbl. 78. Berlin.

Wallén, C. C., 1953, Temperaturen under årets olika månader m. m. (With English summary.) - Atlas över Sverige 25-26. Stockholm.

Weaver, J., 1919, The ecological relations of roots. - Carnegie Inst. 286. Washington D.C.

Wistrand, G., 1934, Bidrag till kännedomen om floran i Pite lappmarks barrskogsregion. - SBT 28. Stockholm.

- 1962, Studier i Pite lappmarks kärlväxtflora med särskild hänsyn till skogslandet och de isolerade fjällen. (Studien iiber die Gefässpflanzenflora der Pite Lappmark mit besonderer Beriicksichtigung des Waldlandes und der isolierten niederen Fjelde.) Diss. - APhS 45. Uppsala.

- 1965, Vegetation and flora of alpine outliers; Cultural in fluence on the flora. In: Lundqvist, J., Wistrand, G. \& Rune, S., Lappland east of the mountains. - APhS 50. Uppsala.

Wistrand, G. \& Lundqvist, J., 1964, Kärlväxtflora på och kring stränder inom mellersta Piteälvens vattensystem. (Die Gefässpflanzenflora an und entlang den Ufern im Fluss-System des mittleren Piteälv (Nordschweden).) KVA Skr. i naturskyddsärenden 51. Stockholm.

Wollny, E., 1878, Untersuchungen iiber den Finfluss der Exposition auf die Erwärmung des Bodens. - Forsch. a. d. Geb. d. Agricult.-Phys. 1. Heidelberg.

Wulff, E. V., 1950, An Introduction to Historical Plant Geography. - Waltham, Mass.

Young, F. D., 1921, Nocturnal temperature inversion in Oregon and California. - Monthly Weather Rev. 49. Washington D.C.

Zenzén, $N$., 1926, Några upplysningar rörande jordskredet på Ö. Stårbetjvare i Arjeplog, Pite lappmark, den 3 aug. 1920. (With English summary.) - Geol. För. Förh. 48:2. Stockholm. 

Table 1 . Mull solls from sites with southern or calciphlle plants .

The analyses were made on dried samples. Gravel and fine soll in $\%$ of the total sample, the fine soll fractions in $\%$ of the fine soll. The chemical figures in $100 \mathrm{~g}$ humus (as Ignition loss; no correction value was used, see the text). "Total" refers to determinations in $2 \mathrm{M}$ hydrochloric acid. Lactate value $=\mathrm{mg} \mathrm{P}_{2} \mathrm{O}_{5}$ in $100 \mathrm{~g}$ of the air-dried sample. Base mineral index, see the text. There was no determination of loss on ignition in samples nos. 8-9 and 30-31, see Lundquist J. 1961.

\begin{tabular}{|c|c|c|c|c|c|c|c|c|c|c|c|c|c|c|c|c|}
\hline No. & $\underset{\%}{\text { Gravel }}$ & $\begin{array}{l}\text { Fine } \\
\text { soll } \\
\%\end{array}$ & $\begin{array}{l}\text { Weight } \\
\mathrm{g} / \mathrm{ml}\end{array}$ & $\begin{array}{l}\text { Loss } \\
\text { on Ign. }\end{array}$ & $\begin{array}{c}\text { Coarse } \\
\text { sand }\end{array}$ & $\begin{array}{l}\text { Fine } \\
\text { sand }\end{array}$ & $\underset{\%}{\text { Silt }}$ & $\underset{\%}{\text { Clay }}$ & tota 1 P, & $\underset{A L-s o l .}{m g}$ & total & K, m.eq. & $\underset{\text { total }}{C a, m . e q .}$ & $\mathrm{pH}$ & $\begin{array}{l}\text { Spec. } \\
\text { conduc- } \\
\text { tivity }\end{array}$ & $\begin{array}{l}\text { Base mineral } \\
\text { Index }\end{array}$ \\
\hline 1 & - & - & 0.6 & 19.5 & - & - & - & - & 380 & 7.2 & 79 & 2.7 & 133 & 6.3 & 63 & - \\
\hline 2 & - & - & 0.8 & 18.1 & - & - & - & - & 500 & 39 & 28 & 5.9 & 160 & 5.7 & 350 & - \\
\hline 3 & - & - & - & 66.4 & - & - & - & - & 102 & 23 & 5.0 & 2.5 & 173 & 6.4 & 260 & - \\
\hline 4 & - & - & - & 7.7 & 77 & 13 & 1 & 2 & 1030 & 13 & 70 & 3.0 & 520 & 6.3 & 40 & - \\
\hline 5 & - & - & - & 4.1 & 68 & 23 & 4 & 2 & 1660 & 34 & 140 & 7.2 & 610 & 6.7 & 30 & - \\
\hline 6 & - & - & - & 82.9 & - & - & - & - & 78 & 18 & 1.8 & 1.5 & 150 & 6.0 & 220 & - \\
\hline 7 & - & - & - & 82.7 & - & - & - & - & 90 & 10 & 2.9 & 2.8 & 79 & 5.1 & 290 & - \\
\hline 10 & - & - & - & 73.6 & - & - & - & - & 94 & 22 & 2.4 & 2.2 & 95 & 5.3 & 210 & - \\
\hline 11 & - & - & - & 54.2 & - & - & - & - & 196 & - & 3.8 & - & 194 & 6.8 & 160 & - \\
\hline 12 & - & - & - & 17.9 & 53 & 20 & 4 & 2 & 940 & 10 & 11 & 0.8 & 335 & 6.7 & 50 & - \\
\hline 13 & - & - & - & 4.6 & 82 & 10 & 2 & 2 & 5900 & 143 & 28 & 1.1 & 980 & 6.7 & 30 & - \\
\hline 14 & - & - & - & - & - & - & - & - & - & - & - & - & - & 6.0 & 100 & - \\
\hline 15 & - & - & - & 13.6 & 57 & 20 & 6 & 2 & 1400 & 7.4 & 11 & 0.8 & 294 & 6.0 & 40 & - \\
\hline 16 & - & - & - & 7.3 & 63 & 21 & 6 & 2 & 3220 & 23 & 25 & 0.5 & 410 & 6.1 & 20 & - \\
\hline 17 & - & - & - & 5.4 & 75 & 14 & 3 & 2 & 4810 & 144 & 36 & 0.9 & 560 & 6.0 & 30 & - \\
\hline 18 & - & - & 0.4 & 38.8 & - & - & - & - & 160 & 1.8 & 4.6 & 2.4 & 170 & 6.5 & 160 & - \\
\hline 19 & - & - & 0.4 & 44.2 & - & - & $=$ & - & 149 & 1.1 & 3.1 & 1.4 & 160 & 6.4 & 160 & - \\
\hline 20 & 12.5 & 87.5 & 1.0 & 16.3 & 56 & 16 & 5 & 6 & 400 & 1.2 & 7.1 & 1.3 & 185 & 6.6 & 40 & - \\
\hline 21 & 7.5 & 92.5 & 0.5 & 47.7 & - & - & - & - & 143 & 12 & 8.0 & 3.7 & 200 & 6.6 & 150 & - \\
\hline 22 & 19.6 & 80.4 & 0.7 & 28.2 & - & - & - & - & 181 & 14 & 12 & 2.8 & 250 & 6.2 & 70 & - \\
\hline 23 & 20.2 & 79.8 & 1.2 & 11.3 & 33 & 33 & 13 & 10 & 330 & 6.2 & 24 & 1.5 & 265 & 5.9 & 20 & - \\
\hline 24 & - & - & - & 80.8 & - & - & - & - & 66 & 15 & 3.8 & 2.3 & 24 & 4.3 & 240 & - \\
\hline 25 & - & - & - & 69.8 & - & - & - & - & 76 & 13 & 4.2 & 2.4 & 20 & 4.2 & 150 & - \\
\hline 26 & - & - & - & 40.5 & - & - & - & - & 123 & 16 & 7.0 & 3.1 & 43 & 4.8 & 100 & - \\
\hline 27 & - & - & - & 14.9 & - & - & - & - & 210 & 6.7 & 11 & 1.9 & 27 & 4.4 & 35 & - \\
\hline 28 & - & - & - & 81.4 & - & - & - & - & 93 & 7.6 & 3.0 & 3.0 & 295 & 6.2 & 1440 & - \\
\hline 29 & - & - & - & 41.9 & - & - & - & - & 260 & 55 & 7.9 & 1.8 & 310 & 6.0 & 640 & - \\
\hline 32 & - & - & - & 37.2 & 37 & 16 & 4 & 3 & 220 & 57 & 22 & 1.3 & 380 & 6.2 & 520 & - \\
\hline 33 & - & - & 0.8 & 22.2 & - & - & - & - & 210 & 21 & 8.1 & 3.3 & 90 & 5.4 & 60 & 15 \\
\hline 34 & - & - & 0.8 & 16.1 & - & - & - & - & 230 & 19 & 9.5 & 2.3 & 44 & 4.9 & 49 & - \\
\hline 35 & 21 & 79 & 1.2 & 5.3 & 47 & 35 & 8 & 5 & 260 & 26 & 18 & 2.6 & 57 & 4.7 & 24 & 4 \\
\hline 36 & - & - & 0.7 & 19.3 & - & - & - & - & 280 & 24 & 9.9 & 3.1 & 67 & 5.2 & 51 & - \\
\hline 37 & 19 & 81 & 1.1 & 11.4 & 42 & 31 & 10 & 5 & 1480 & 68 & 10 & 2.0 & 70 & 5.0 & 36 & 9 \\
\hline 38 & 28.5 & 71.5 & 1.1 & 7.1 & 39 & 40 & 7 & 6 & 480 & 23 & 16 & 3.6 & 155 & 5.2 & 57 & 22 \\
\hline 39 & 19 & 81 & 1.5 & 3.9 & 35 & 41 & 17 & 4 & 560 & 15 & 26 & 7.2 & 400 & 6.4 & 23 & - \\
\hline 40 & 22 & 78 & 1.4 & 6.1 & 45 & 37 & 8 & $4^{\prime}$ & 210 & 9.8 & 11 & 1.6 & 80 & 5.2 & 12 & - \\
\hline 41 & 19 & 81 & 1.5 & 4.2 & 49 & 33 & 11 & 2 & 790 & 24 & 18 & 1.2 & 370 & 5.5 & 10 & - \\
\hline 42 & - & - & 0.4 & 40.1 & - & - & - & - & 270 & 44 & 40 & 5.5 & 105 & 5.9 & 190 & - \\
\hline 43 & 29 & 71 & 1.2 & 8.3 & 42 & 28 & 13 & 7 & 1750 & 136 & 300 & 7.4 & 241 & 5.0 & 37 & 45 \\
\hline 44 & 14 & 86 & 1.2 & 7.7 & 40 & 29 & 15 & 8 & 1990 & 156 & 310 & 4.0 & 234 & 5.0 & 22 & 32 \\
\hline 45 & 0 & 100 & 0.2 & 84.7 & 1 & 4 & 5 & 6 & 47 & 5.2 & 2.7 & 2.2 & 217 & 6.6 & 440 & - \\
\hline 46 & 0 & 100 & 0.3 & 82.8 & 1 & 6 & 3 & 8 & 48 & 3.4 & 1.9 & 1.5 & 237 & 6.3 & 510 & - \\
\hline 47 & 0 & 100 & 0.4 & 78.7 & 1 & 6 & 5 & 10 & 58 & 1.3 & 1.0 & 0.6 & 224 & 6.4 & 160 & - \\
\hline 48 & 0 & 100 & 0.2 & 82.0 & 2 & 7 & 3 & 7 & 61 & 0.9 & 1.2 & 0.8 & 70 & 5.5 & 160 & - \\
\hline 49 & 9.3 & 90.7 & 0.5 & 32.1 & 20 & 37 & 6 & 2 & 112 & 0.3 & 2.9 & 0.5 & 50 & 5.8 & 33 & 53 \\
\hline 50 & 42.0 & 58.0 & 1.7 & 2.2 & 59 & 33 & 5 & 2 & 860 & 0.0 & 99 & 5.2 & 640 & 5.7 & 13 & 52 \\
\hline 51 & - & - & 0.7 & 29.0 & - & - & - & - & 370 & 13 & 7.5 & 1.3 & 400 & 7.3 & 160 & 79 \\
\hline 52 & - & - & 0.4 & 63.3 & - & - & - & - & 106 & 17 & 3.0 & 1.8 & 150 & 5.4 & 170 & - \\
\hline 53 & - & - & 1.0 & 10.3 & - & - & - & - & 1170 & 14 & 25 & 3.0 & 245 & 5.0 & 40 & 62 \\
\hline 54 & - & - & 1.2 & 8.8 & - & - & - & 6 & 1400 & 16 & 25 & 2.3 & 340 & 5.6 & 40 & 66 \\
\hline 55 & - & $\ldots$ & 0.8 & 20.0 & - & - & - & - & 600 & 20 & 52 & 6.3 & 205 & 5.9 & 89 & - \\
\hline 56 & 41 & 59 & 1.2 & 8.0 & 49 & 29 & 7 & 3 & 1410 & 18 & 125 & 12 & 400 & 5.9 & 39 & 53 \\
\hline 57 & 54 & $4 \varepsilon$ & 1.5 & 5.7 & 52 & 28 & 4 & 4 & 1810 & 18 & 146 & 11 & 490 & 5.9 & 20 & 56 \\
\hline
\end{tabular}


Table 2 . The soll conditions of belt transects on A. Mt. Märkepakte and B. Mt. Lulep Istjakk.

The analyses were made on dried samples. Coarse soll fractions in $\%$ of the total sample, fine soll fractions in $\%$ of the fine soll. The chemical figures in $100 \mathrm{~g}$ humus (as Ignition loss; see the text). "Total" refers to determinations in $2 \mathrm{M}$ hydrochloric acid. Lactate value $=m g \mathrm{P}_{2} 0_{5}$ in $100 \mathrm{~g}$ of the air-dried sample. Base mineral index, see the text. Distance measured along the surface of the scree. Points $a-d$ and $a$-fare places for sampling of soll.Moisture: loss in weight was determined as percentage of the air-dried sample.

\begin{tabular}{|c|c|c|c|c|c|c|c|c|c|c|c|}
\hline & & & & & & & & & & & \\
\hline Point & a & a & a & b & b & b & c & c & d & d & d \\
\hline Quadrat no. & 3 & 3 & 3 & 6 & 6 & 6 & 13 & 13 & 24 & 24 & 24 \\
\hline $\begin{array}{l}\text { Distance to the } \\
\text { rock wall } \mathrm{m}\end{array}$ & 1.3 & 1.3 & 1.3 & 3.0 & 3.0 & 3.0 & 5.4 & 5.4 & 12.3 & 12.3 & 12.3 \\
\hline Depth cm & 0 & 10 & 30 & 0 & 10 & 30 & 0 & 10 & 0 & 10 & 30 \\
\hline Fine soll $\%$ & - & 22 & - & - & 13 & - & - & - & - & $=$ & - \\
\hline Welght $\mathrm{g} / \mathrm{ml}$ & - & 1.0 & 1.4 & 0.5 & 0.7 & 1.3 & 0.3 & 0.4 & 0.3 & 0.6 & 0.8 \\
\hline Loss on ignition & 48.2 & 20.7 & 6.1 & 40.1 & 25.9 & 6.4 & 78.3 & 63.2 & 57.0 & 35.5 & 28.4 \\
\hline Coarse sand & - & 52 & 62 & 39 & 42 & 55 & 9 & 17 & 24 & 24 & 28 \\
\hline Fine sand & - & 16 & 25 & 12 & 18 & 30 & 4 & 7 & 9 & 22 & 31 \\
\hline Silt & - & 7 & 5 & s & 8 & 6 & 4 & 5 & 5 & 7 & 9 \\
\hline Clay & - & 5 & 1 & 3 & 7 & 1 & 3 & 3 & 3 & 12 & 2 \\
\hline$P, \mathrm{mg}$, total & 145 & 390 & 1100 & 192 & 290 & 1500 & 64 & 84 & 135 & 197 & 260 \\
\hline AL-sol. & 14 & 11 & 12 & 13 & 10 & 11 & 14 & 9.5 & 18 & 12 & 6.0 \\
\hline Lactate value & 9.4 & 2.1 & 0.1 & 6.4 & 3.1 & 0.4 & 15.6 & 7.5 & 14.4 & 5.1 & 1.3 \\
\hline$K$, m.eq.., total & 9.5 & 22 & 69 & 13 & 17 & 64 & 3.3 & 3.6 & 7.2 & 9.0 & 11 \\
\hline AL-sol. & 2.1 & 1.5 & 2.7 & 2.5 & 2.0 & 2.6 & 2.0 & 1.4 & 2.7 & 1.7 & 1.3 \\
\hline Ca, m.eq. , total & 208 & 240 & 330 & 212 & 215 & 235 & 211 & 240 & 114 & 185 & 229 \\
\hline $\mathrm{pH}$ & 6.5 & 6.0 & 6.5 & 6.4 & 6.2 & 6.3 & 6.5 & 6.4 & 6.0 & 6.0 & 6.3 \\
\hline Spec. conductivity & 80 & 30 & 20 & 60 & 50 & 20 & 160 & 90 & 100 & 50 & 40 \\
\hline Base mineral index & - & - & 62 & - & - & 65 & $=$ & $=$ & $=$ & - & $=$ \\
\hline
\end{tabular}

Point

$\begin{array}{llllllllllllll}\text { Quadrat no. } & a & a & b & b & c & c & d & d & e & e & e & f & f \\ & 1 & 1 & 2 & 2 & 5 & 5 & 8 & 8 & 12 & 12 & 12 & 19 & 19\end{array}$

$\begin{array}{llllllllllllllll}\begin{array}{c}\text { Distance to the } \\ \text { rock wall m }\end{array} & 0 & 0 & 1.8 & 1.8 & 6.8 & 6.8 & 10.8 & 10.8 & 16.7 & 16.7 & 16.7 & 21.7 & 21.7\end{array}$

$\begin{array}{llllllllllllll}\text { Depth cm } & 10 & 30 & 10 & 30 & 10 & 30 & 10 & 30 & 0 & 10 & 30 & 0 & 10\end{array}$

$\begin{array}{lrllllllllllll}\text { Pebbles, cobbles } & 6 & 13 & 19 & 18 & 0 & 23 & 12 & 45 & - & 11 & 31 & -\mathbf{x} & 49\end{array}$

$\begin{array}{llllllllllllll}\text { Coarse gravel } & 12 & 15 & 22 & 33 & 23 & 34 & 32 & 26 & - & 26 & 36 & - & 30\end{array}$

$\begin{array}{llllllllllllllll}\text { Fine gravel } & 4 & 14 & 14 & 15 & 3 & 11 & 14 & 9 & - & 9 & 8 & - & 5\end{array}$

$\begin{array}{lllllllllllllllll}\text { Fine soll } \% & 78 & 57 & 46 & 35 & 73 & 33 & 43 & 21 & - & 54 & 25 & - & 15\end{array}$

$\begin{array}{lllllllllllllllll}\text { Soll moisture } \% & 43 & 25 & 62 & 45 & 114 & 54 & 33 & 27 & - & 42 & 54 & - & 45\end{array}$

Weight $\mathrm{g} / \mathrm{ml} 1.2-0.8-0.40 .80 .8-0.70 .6-0.8$

$\begin{array}{lllllllllllllll}\text { Loss on Ignition } & 9.3 & 5.5 & 20.7 & 13.2 & 58.0 & 20.8 & 20.8 & 12.7 & 80.1 & 25.7 & 40.0 & 40.2 & 23.3\end{array}$

$\begin{array}{llllllllllllll}\text { Coarse sand } & 46 & 64 & 41 & 51 & 17 & 45 & 32 & 38 & - & 30 & 25 & 24 & 30\end{array}$

$\begin{array}{llllllllllllll}\text { Fine sand } & 36 & 27 & 27 & 31 & 15 & 24 & 28 & 41 & - & 23 & 24 & 23 & 25\end{array}$

$\begin{array}{llllllllllllll}\text { Silt } & 5 & 1 & 7 & 2 & 4 & 4 & 10 & 4 & - & 13 & 6 & 8 & 10\end{array}$

$\begin{array}{lllllllllllllll}\text { Clay } & 5 & 2 & 5 & 2 & 3 & 3 & 10 & 2 & - & 10 & 3 & 4 & 13\end{array}$

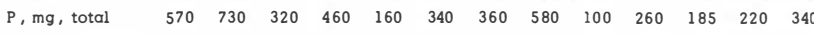

AL-sol. $\quad \begin{array}{lllllllllllll}18 & 26 & 18 & 11 & 14 & 15 & 14 & 13 & 26 & 7.8 & 13 & 20 & 16\end{array}$

$\begin{array}{llllllllllllll}\text { Lactate value } & 0.9 & 0.7 & 2.6 & 0.7 & 6.0 & 2.2 & 2.0 & 0.8 & 34 & 1.0 & 6.3 & 7.5 & 3.1\end{array}$

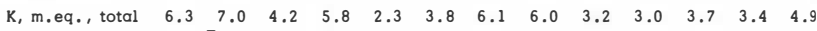

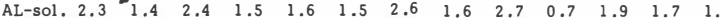
Ca, m.eq., total $650 \begin{array}{llllllllllll}1000 & 290 & 460 & 130 & 285 & 320 & 430 & 156 & 410 & 310 & 320 & 450\end{array}$ $\begin{array}{llllllllllllllll}\mathrm{pH} & 6.0 & 5.8 & 5.7 & 5.7 & 5.5 & 5.6 & 5.8 & 5.8 & 6.4 & 6.7 & 6.6 & 6.6 & 6.8\end{array}$

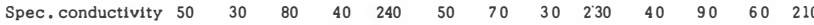

Basemineralindex $54 \quad 58 \quad 55 \quad 50 \quad-\quad \begin{array}{lllllllllll}51 & 52 & 60 & - & 49 & - & - & -\end{array}$

$\mathbf{m}_{\text {quadrat no. } 18 \text {, see the text }}$

Table 5. The local climate of the stations used, as compared to some nearby stations of the meteorological network of Sweden, Mean maximum and mean minimum temperatures are averages of diurnal values read from $19.00 \mathrm{~h}$ to $19.00 \mathrm{~h}$. The thermograph at station no. 7 was not recording during 4-11 September, 1965 . The values in parentheses are directly comparable and denote the mean for the rest of the month. The figure +8.0 as mean for St .no.

7 for the whole month, obtained by a comparison between the rest of the figures, is therefore a little uncertain. The underlinea values are obtained by the more exact method of using 24 values a day as a basis for the calculation (thermograph values).

Latitude, altitude in $\mathrm{m}$ ( $(\mathrm{a})$, height above the valley bottom (b), and the height in $\mathrm{m}$ of the thermometer above the ground surface $(c)$ for the various stations. $t_{\gamma}$ denotes temperature gradient $\left({ }^{\circ} \mathrm{C}\right)$ per $100 \mathrm{~m}$ height distance, $t_{\phi}$ gradient per degree of latitude for the studied months (Rudberg 1957 p. 41).
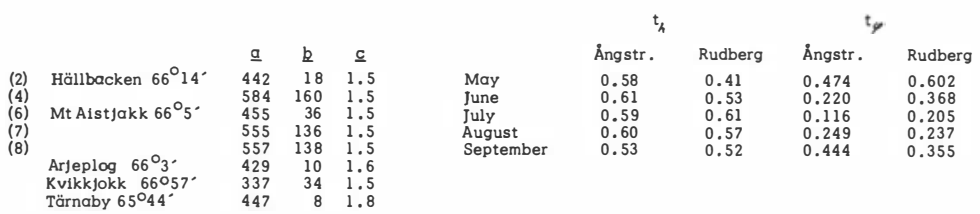

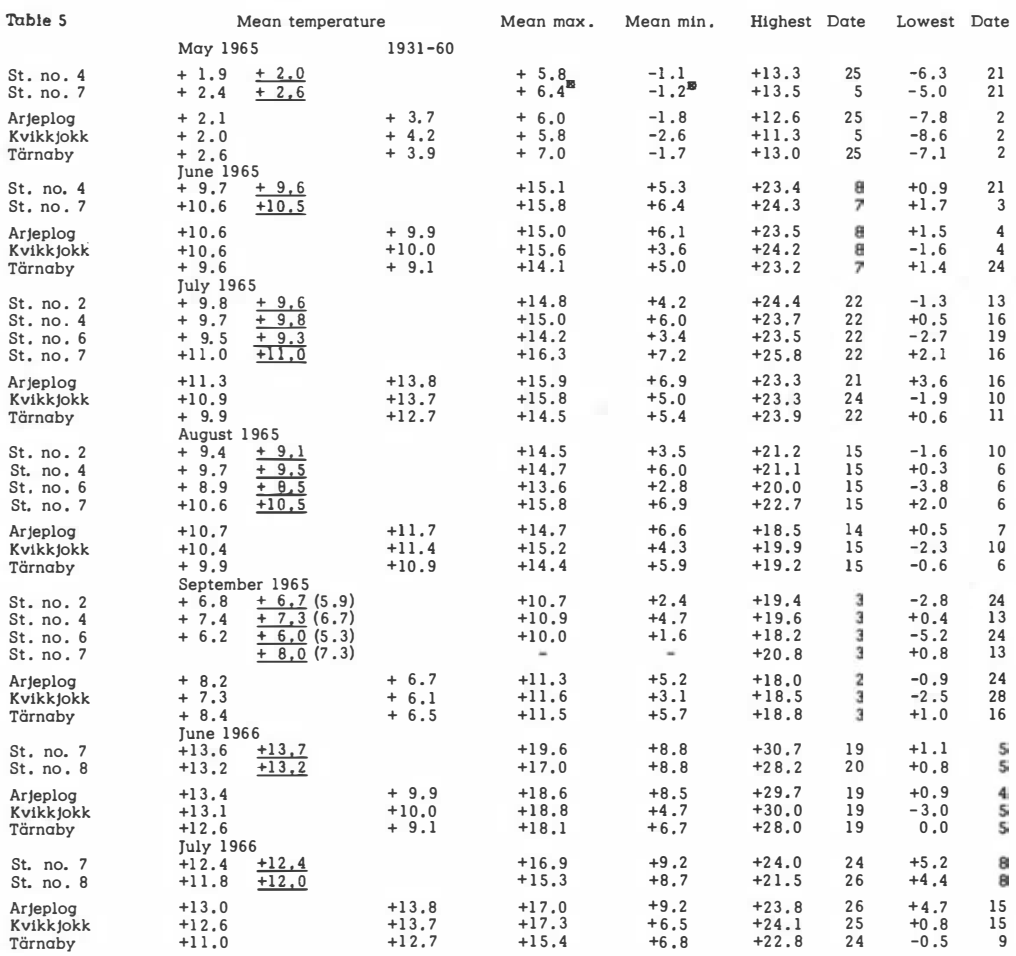


Table 13. The precipitation measurements in the summer of 1961 (cf. the text and the figures).

Gauges no. 1-4 (Merk gorge), no. 5-7 (SE-side of Mt. Mărkepakto) and no. 8-14 (S-side of Mt. Märkepakte)

\begin{tabular}{|c|c|c|c|c|c|c|c|c|c|c|c|c|c|c|c|c|c|c|c|c|c|c|}
\hline \multicolumn{3}{|c|}{ Time of ralnfall } & \multirow{2}{*}{\multicolumn{2}{|c|}{$\begin{array}{l}\text { Time of } \\
\text { reading }\end{array}$}} & \multirow{3}{*}{$\begin{array}{c}\text { Procipitation } \\
\text { type }\end{array}$} & \multirow{3}{*}{$\begin{array}{l}\text { Wind direction } \\
\text { and force } \\
\text { (Beaufort } \\
\text { scalo) }\end{array}$} & \multirow{3}{*}{$\begin{array}{l}\text { Change in } \\
\text { alr pressure }\end{array}$} & \multicolumn{15}{|c|}{ Amounts (mm) } \\
\hline \multirow{2}{*}{\multicolumn{2}{|c|}{ Date }} & \multirow{2}{*}{$\begin{array}{c}\text { Time of } \\
\text { day }\end{array}$} & & & & & & \multicolumn{4}{|c|}{ Merk-gorge } & \multicolumn{3}{|c|}{$\begin{array}{c}\text { SE - side of Mt . } \\
\text { Mărkepakte }\end{array}$} & \multicolumn{7}{|c|}{ S-side of Mt. Märkepakte } & \multirow{2}{*}{\begin{tabular}{|l|} 
Ref. \\
15
\end{tabular}} \\
\hline & & & Date & Hour & & & & 1 & 2 & 3 & 4 & 5 & 6 & 7 & 8 & 9 & 10 & 11 & 12 & 13 & 14 & \\
\hline \multirow[t]{9}{*}{ June } & 8 & $17.55-22.00$ & 9.6 & 9.00 & thunder; showers & Sw 3-7 & constant & 0.1 & 0.6 & - & 10.4 & 9.9 & 9.9 & 11.0 & - & - & - & - & - & - & - & 12.3 \\
\hline & 10 & $2.00-9.45$ & 10.6 & 11.00 & $*$ & 0 & falling & 0.0 & 0.2 & - & 10.1 & 9.1 & 9.5 & 7.9 & - & - & - & - & - & - & - & 10.9 \\
\hline & 10 & $18.35-19.20$ & 12.6 & 12.00 & $"$, shower & Sw 3-7 & rising & 0.0 & 0.1 & $7.5^{11}$ & 2.7 & 2.2 & 2.3 & 2.8 & - & - & - & - & - & - & - & 2.1 \\
\hline & 13 & $3.30-6.00$ & 13.6 & 13.30 & hower & sw 0-1 & falling & 0.0 & 0.1 & 0.4 & 2.3 & 1.8 & 2.3 & 2.6 & - & - & - & - & - & - & - & 2.3 \\
\hline & $13-14$ & $15.05-4.00$ & 14.6 & 10.30 & Incessant rain & sw 0-3 & $\cdots$ & 0.0 & 1.8 & $53.2^{11}$ & $48.6^{11}$ & 24.8 & 30.2 & 25.9 & - & - & - & - & - & - & - & 28.2 \\
\hline & $17-18$ & $13.30-11.30$ & 18.6 & 14.30 & showers & (SE)-SW 2-3 & $\cdots$ & 0.0 & 3.6 & $32.0^{11}$ & $49.0^{11}$ & 24.8 & 29.6 & 27.6 & - & - & - & - & - & - & - & 29.6 \\
\hline & 23 & forenoon & 23.6 & 15.00 & $=-$ & 0 & $\cdots$ & - & - & - & - & - & - & - & - & 0.2 & 0.1 & 0.3 & 0.7 & 0.8 & 0.6 & - \\
\hline & 24 & afternoon & 26.6 & 9.00 & shower & 0 & $\cdots$ & - & - & - & - & - & - & - & - & 2.2 & 1.7 & 2.5 & 3.3 & 3.3 & 3.5 & - \\
\hline & 28 & all day & 29.6 & 9.00 & showers & sw 3-4 & 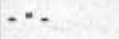 & - & - & - & - & - & - & - & - & 5.3 & 5.9 & 4.9 & 7.1 & 7.0 & 6.4 & - \\
\hline \multirow[t]{3}{*}{ July } & 9 & $7.00-14.00$ & 9.7 & 16.00 & $\cdots$ & Unconstant & $\cdots$ & - & - & - & - & - & - & - & 5.4 & 4.1 & 4.2 & 4.4 & 6.2 & - & 4.8 & 3.9 \\
\hline & $10-11$ & $12.00-9.00$ & 11.7 & 9.00 & $\cdots$ & mostly 0 & $\because$ & - & - & - & - & - & - & - & 10.3 & 8.8 & 9.4 & 9.8 & 11.8 & - & 11.8 & 12.6 \\
\hline & $11-12$ & $9.00-15.45$ & 12.7 & 16.00 & $\cdots$ & E $0-3$ & rising & - & - & - & - & - & - & - & 13.0 & 8.7 & 14.6 & 9.1 & 11.4 & - & 9.6 & 10.0 \\
\hline
\end{tabular}

1) Sprinkle from the rock wall

Table 14. Analyses of some samples of seepage water from the rock wall base on hillsides in PL. For comparison, one sample of water from the lead mine a t Laisvall was taken, $\mathrm{pH}$, colour, $\mathrm{HCO}_{3}$ (denoking total alcalinity), $\mathrm{Pb}$, and $\mathrm{Zn}$ were determined hefore filtrution. The other analyses were made in filterert woter. Dashes designate no determinations. The total amount of cations is made up of the sum of equivalents of $\mathrm{Na}^{+}, \mathrm{K}^{+}, \mathrm{Mg}^{++}$and $\mathrm{Cr}^{++}$(Rodhe 1949 $\mathrm{p}$. 377 ), the total amounts of anlons of $\mathrm{Cl}^{-}$, $\mathrm{HCO}_{3}{ }^{-}$and $\mathrm{SO}_{4}{ }^{--}$.

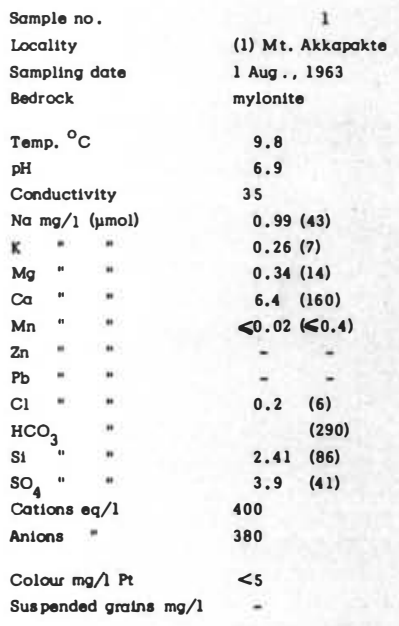

\begin{tabular}{|c|c|c|c|}
\hline \multicolumn{2}{|c|}{2} & \multicolumn{2}{|r|}{3} \\
\hline (2) Mt. E & Ramanpakto & (9b) Mt. & Lalsvare \\
\hline 26 July, & 1967 & 27 June, & 1963 \\
\hline mylonite & & sandston & \\
\hline 6.1 & & 4.3 & \\
\hline $7.8^{\mathrm{n}}$ & & 7.7 & \\
\hline 128 & & 242 & \\
\hline 1.55 & $(67)$ & 1.42 & (62) \\
\hline 0.59 & (15) & 1.25 & (32) \\
\hline 0.68 & (28) & 5.8 & (238) \\
\hline 27.2 & $(680)$ & 32 & $(800)$ \\
\hline$<0.01$ & $(0.2)$ & $<0.02$ & $(<0.4)$ \\
\hline - & - & $<0.05$ & $(<0.8)$ \\
\hline- & - & 0.1 & $(0.5)$ \\
\hline 0.41 & (12) & 0.7 & (20) \\
\hline & $(1330)$ & & $(1650)$ \\
\hline 3.2 & (114) & 2.33 & (83) \\
\hline 8.1 & (84) & 24.8 & (258) \\
\hline 1500 & & 2170 & \\
\hline 1510 & & 2190 & \\
\hline$<5$ & & 5 & \\
\hline 0.4 & & 1.5 & \\
\hline
\end{tabular}

Laisvall lead mine
20 Aug., 1963
sandstone
4.4
7.6
259
$6.89(300)$
$1.47(38)$
$2.52(104)$
$40 \quad(1000)$
$0.11(2)$
$<0.05$ K0.8)
$0.8 \quad(4)$
$6.8 \quad(192)$
$4.20(130)$
$38.9 \quad(405)$
$2550 \quad$
2330
$<5$
20

(12) Mt. Märkepokte
28 July, 1963
mylonite

11.7
7.9

139

$15.0(652)$

0.34 (9)

$0.57(23)$

$10.9(270)$

$<0.02(<0.4)$

$-\quad-$

1.1 (31)

(1010)

$4.06(145)$

$12.1 \quad(126)$

1250

1290

65
6

(18) $\mathrm{Mt}$. Lulep Istjakk (23) Mt. Mớfovare 26 July, $1963 \quad 1$ July, 1965 pegmatite, aplite granite (migmatized)

\begin{tabular}{|c|c|c|c|c|}
\hline 12.0 & & 10.1 & 5.7 & \\
\hline 6.6 & & - & 6.0 & \\
\hline 27 & & 41 & 11 & \\
\hline 0.92 & (40) & - & 0.76 & (33) \\
\hline 0.19 & (5) & - & 0.08 & (2) \\
\hline 0.54 & (22) & - & 0.2 & (8) \\
\hline 4.5 & (112) & - & 1.09 & (27) \\
\hline$<0.02$ & $(<0.4)$ & - & $<0.01$ & $K=0.2)$ \\
\hline- & - & - & - & - \\
\hline - & - & - & - & - \\
\hline 0.4 & (11) & - & 0.31 & (9) \\
\hline & $(180)$ & & & (20) \\
\hline 3.57 & (127) & - & 2.53 & (90) \\
\hline 2.1 & (22) & - & 2.2 & (23) \\
\hline 310 & & - & 110 & \\
\hline 240 & & - & 80 & \\
\hline
\end{tabular}

$<5 \quad 38$ 
D. scoparlum

D. robustum

D. muehlenbeck11

Paraleucobryum longifollum

Encalypta rhabdocarpa

E. clllata

E. brevicolla

E. streptocarpa

Desmatodon latifollus

Barbula recurvirostra

Gymnostomum aeruginosum

Tortella fragllis

T. tortuosa

Schistidium apocarpum

S. strictum

Grimmia commutata

G. unicolor

G. Inalis

G. torquata

. hartmanil var. anomala

Rhacomitrium heterostichum

Rh. microcarpum

$\mathrm{Rh}$. fasciculare
$\mathrm{Rh}$. lanuginosum

Rh. lanuginosum

Pohlla elongata

P. longicolla
P. cruda

P. cruda

P. nutans
P. bulbifera

P. proligera

P. proligera
P. $\mathrm{sp}$.
Bryum argenteum

Bryum argenteum
B. cf. caespiticlum
B. ps eudotriquetrum

B. cirrhatum

B. pallescens
B. capillare

B. capillare
B. Inclinat um

B. archangelicum

Mnlum orthorrhynchum

M. serratum

$M$. spinosum

M. stellare
M. cuspidatum

M. medium

M. medium

$M$. punctatum

$M$. cinclid loides

Cyrtomnium hymenophylloldes Cinclidium styglum

Bartramia halleriano

B. pomiformis
B. Ithyphylla

Conostomum tetragonum

Phllonotis calcarea

$\mathrm{Ph}$. fontand

$\mathrm{Ph}$. tomentella

Amphidium lapponicum

A. mougeotil

Orthotrichum rupestre

. blytti1

O. anomalum
O. alpestre

O. pallens

Stroemia obtusifolla

Ulota curvifolla

Hedwigia cillata
Leucodon sciuroldes
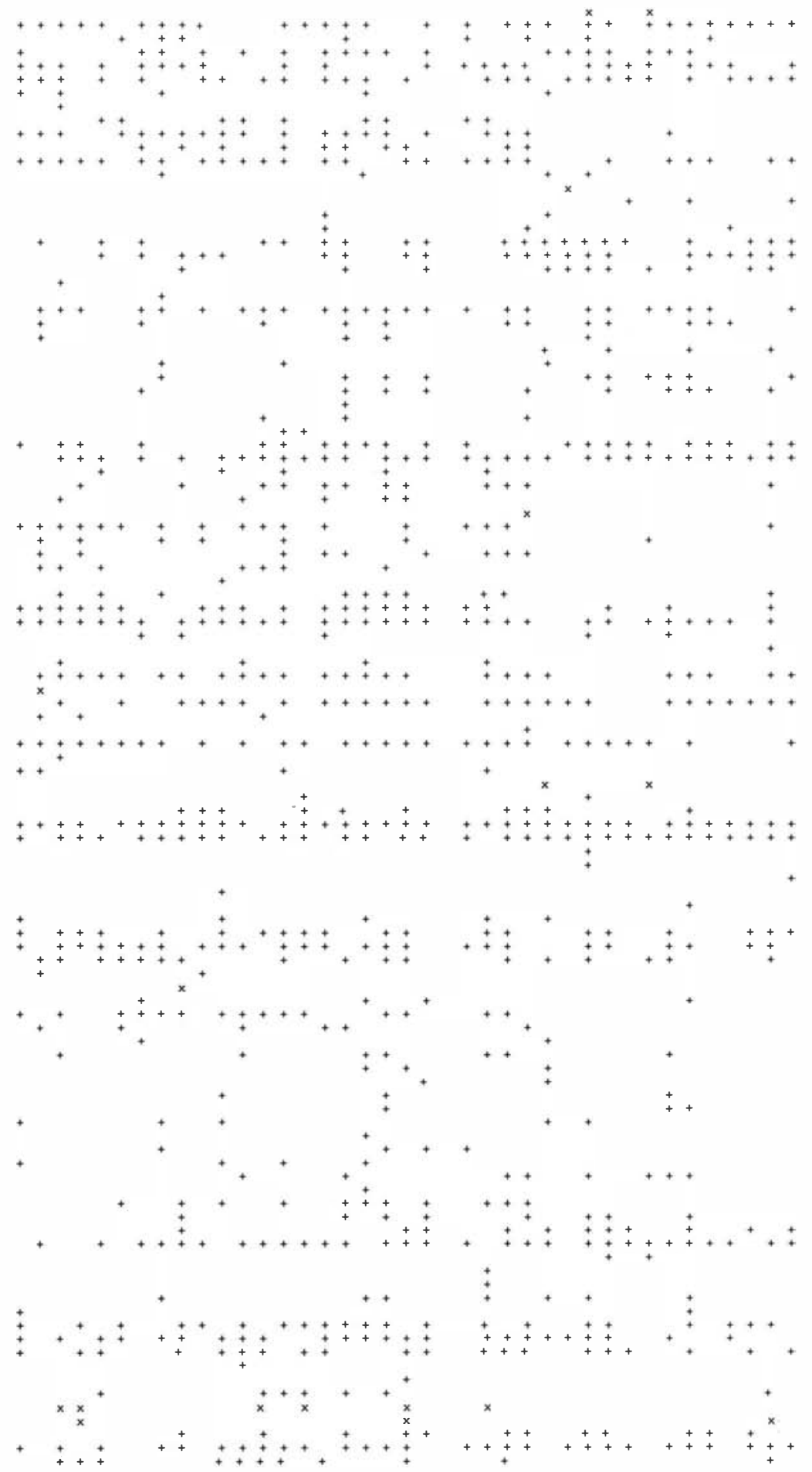
Neckera ollgocarpa N. pumila Myurella Julace M. apiculata
Pseudoleskeella nervosa P. tectorum Lescuraea saxicola
L. radicosa

L. incurvato

Heterocladlum d1morphum Anomodon viticulosus
Abletinella abletina

Pterygynandrum filfforme sotheclum myosuroides Cratoneuron filicinum
Drepanocladus exannulatus Drepanocladus

Calliergon sarmentosum

Hygrohypnum alpestre
Campylium stellatum

C. chrysophyllum

C. sommerfe

Amblysteglum serpens

Amblystegiella spruce

Eurhynchlum pulchellum

Brachytheclum salebrosum

B. velutinum

B. starke1 Homolothecium sericeum
Orthothecium intricatum

Pylaisia polyantha
Hypnum revolutum
H. cupress if orme coll.

H. Cupressiforme coll.
Peillum crista-castrensis

Rhytidium rugosum

Hylocomlum splendens
Rhytidiadelphus triquetrus

Pleurozlum schreber1

sopteryglum pulchellum

Plagiothecium plliferum

P. laetum

P. denticulatum

P. ruccilentu

Metzgeria furcata

Pellia sp.

P. pulcherrimum

Blepharostomo trichophyllum

Lepidozia reptans

Calypogeia meylanil

ephaloziella sp.

B. hatcheri bar

B. lycopodioldes

Lelocolea gillmanil
L. heterocolpos
Lophozla sect. Ventricosae

Lophozia sect.

L. alpestris
L. cf. marchice

L. excisa

. floerkel

O. quadrilobus

Sphenolobus minutus

S. saxicolus

Tritomaria scitula

Piagiochila asplenioldes

Diplophyllum taxifollum

Scapania curta

S. subalpina

Cephalozia ambigua

C. media

Marsupella sphacelata var. sull ivantII

Radula complanat

Porella cordeana

P. platyphyllo

Marchantia alpestris
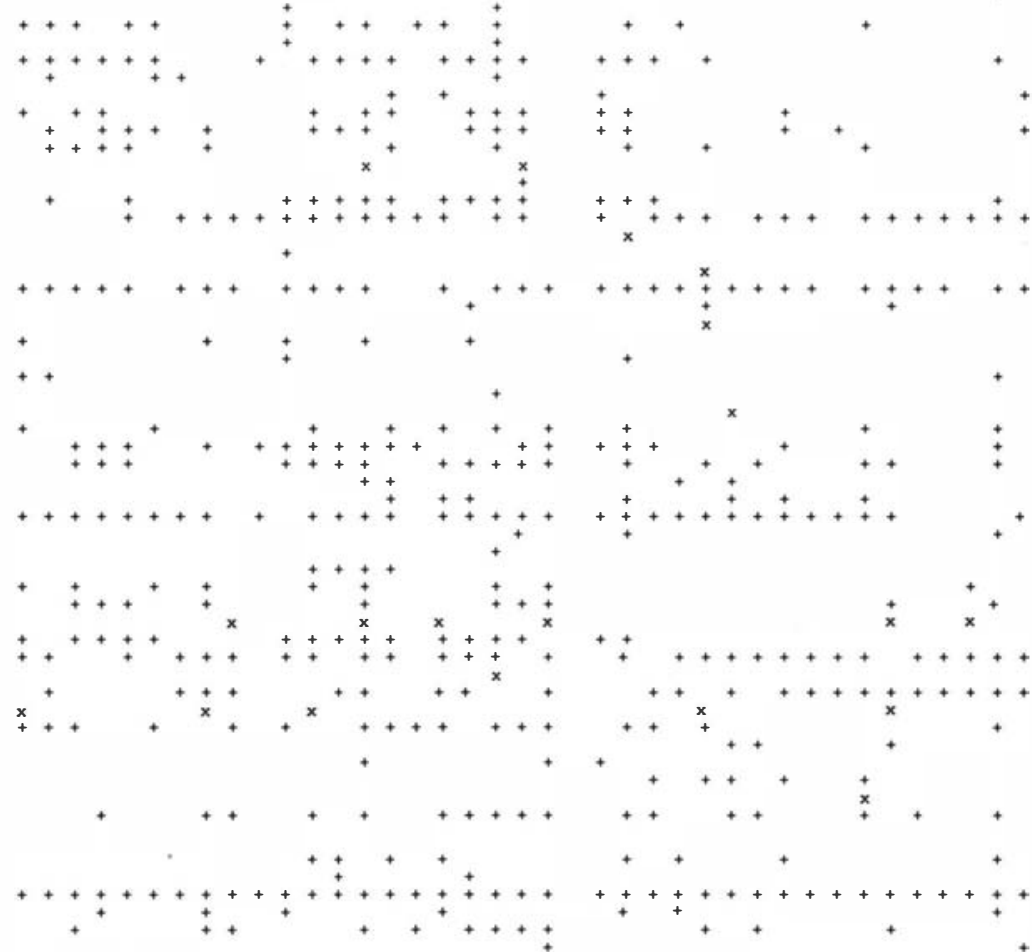

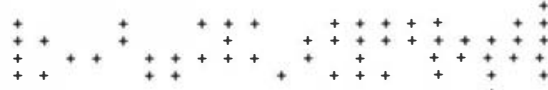

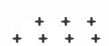
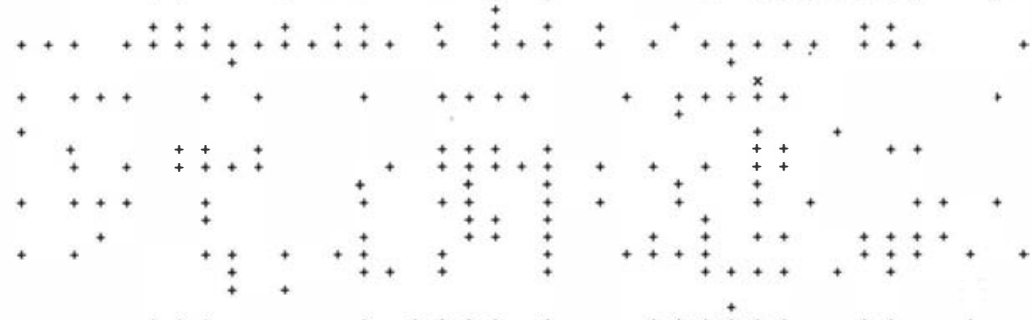

504256414732395746325150498041427559806166 
Table 28. The Poeto-Lactucetum association.

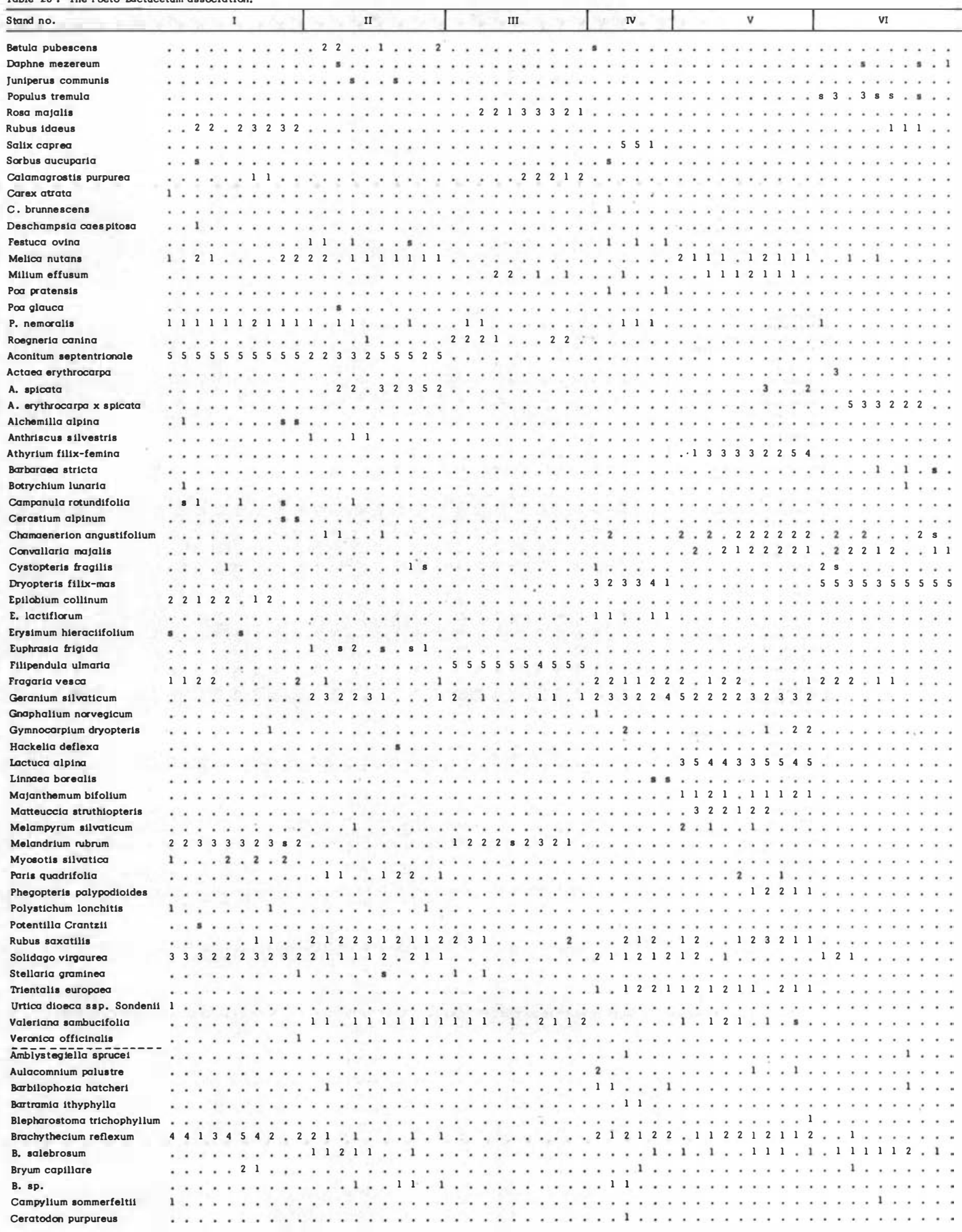


Table 18, continued

Climacium cendroldes

Distichlum capillaceum

Ditrichum flexicaule

Drepanocladus uncinatus

Hylocomium splendens

Hypnum revolutum

Lescuraea incurvata

L. radicosa

Lophozla exciso

Mnlum pseudopunctatum

Myurella julacea

Plaglochila asplenioldes

Plaglothecium denticulatum

P. laetum

P. roeseanum

$P$ succulentum

Pogonatum alpinum

Pohlia cruda

Pseudoleskeella nervosa

Pterigynandrum filiforme

Ptilldium clllare

Radula complanata

Rhodobryum roseum

Schistidium apocarpum

Tortella tortuosa

Tortula ruralis

Total number of species

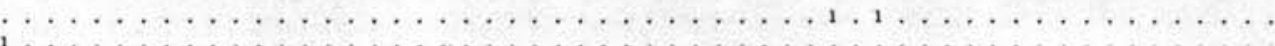

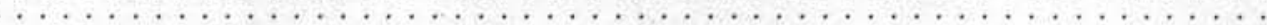

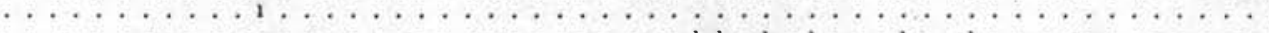

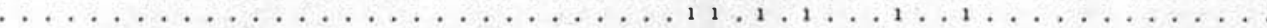

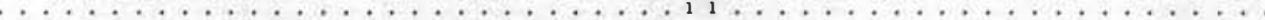

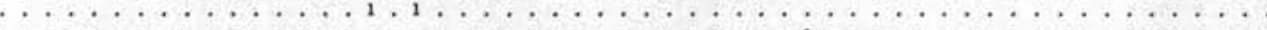

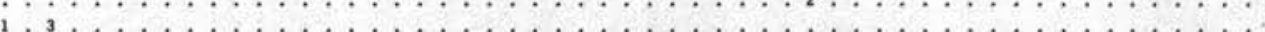

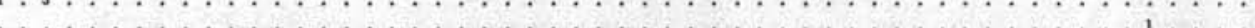

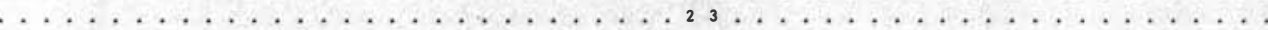

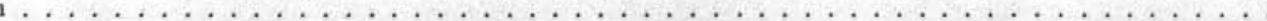

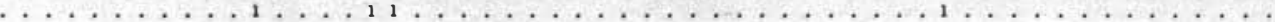

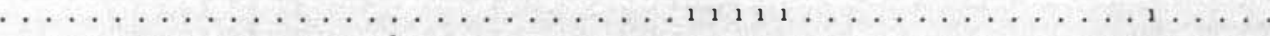

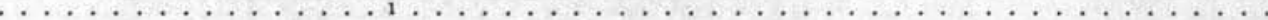

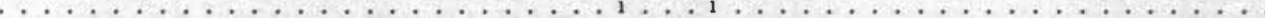

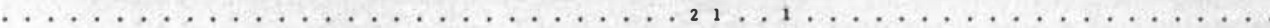

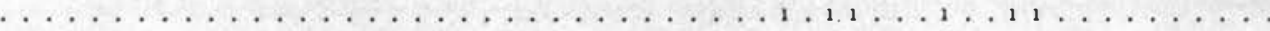

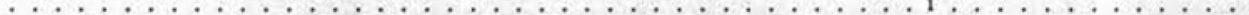

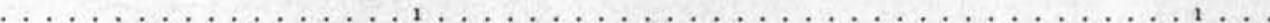

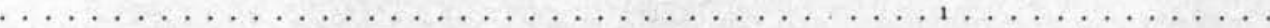

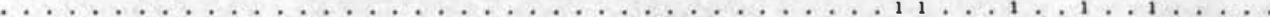

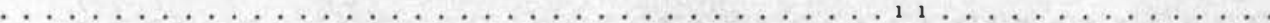

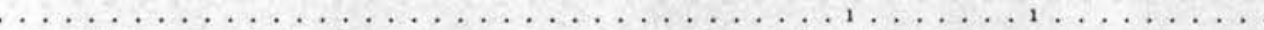

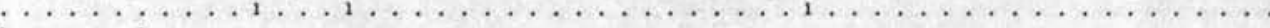
1.... $1 \ldots \ldots \ldots \ldots \ldots \ldots$ 181014989121110121216131791211161112658443677417191614151414131516152017141718611971279653

\begin{tabular}{l|l|l|l|l|l|l}
\hline & II & III & N & V & VI
\end{tabular}


Stond no.

I

Betula pubescens (trees)

Daphne mezereum ....

Juniperus communis (s)

Populus tremula (trees)

Prunus padus

Rubus Idaeus .

Sorbus aucuparia

Carex ornithopoda

Festuca ovina

Melica nutans ....

Poa glavca nut

P. nemorolls

Roegneria canina

Arabls hirsuta

Botrychlum boreale ...............

B. lunaria

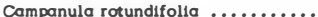

Cystopteris tracto

Draba navegica

Erysimum hieracilfollum

Euphrasia frigida

Fragarla vesca

Galeopsis bifida

Geranium silvaticum

Hackella deflexa

Hieracium spp.

Melampyrum sllvaticum

Melandrium rubrum

P. Crantzil

Rubus soratills

Sedum annuum

Silene rupestris

Solidago virgaurea

Stellaria graminea............

Valeriana sambucifolia ............

Veronica fruticans

V. officinalis

Viola montana

Woodsia llvensis

Brachytheclum reflexum

B. salebrosum

Bryum spp.

Eurhynchlum pulchellum

Hedwigla clllata

Hypnum cupress iforme coll. .......

Lescuraed radicoso

Myurella julacea

Pohlla cruction

Pseudoles keella nervosa ............

Schistidium apocarpum ............

Tortella tortuosa

Tortula ruralis

Total number of species
II

III

.. 541 .....

$2 \ldots . . .$.

.................

423.12 .4542

.............

.............

. .........

........ .

..81... 1 1..

$121, .212222$

. 1 .......

$\begin{array}{lllllllllll}2 & 1 & 1 & 1 & 1 & 1 & 1 & 1 & 1 & 1 & 1\end{array}$

... $81, \ldots 2$

...... 1 . s.

....... . .

1... 1 .....

. 1.111121 .

........

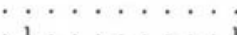

..1.12.2.11

.1112 .1323

...................

$\begin{array}{lllllllllll} & 1 & 2 & 3 & 1 & 3 & 1 & 1 & 1 & 2 & 2\end{array}$

. 1 .......

........

..1.11,...

..............

........ 1 .

121232553312

…...................

$\begin{array}{lllllllllll}2 & 3 & 3 & 2 & 3 & 2 & 2 & 2 & 3 & 3\end{array}$

. 111111111.

$23 . .1122 .22$

.........

. . 1222213 ...

$\begin{array}{lllllllllll}1 & 2 & 3 & 3 & 3 & 2 & 1 & 3 & 3 & 3\end{array}$

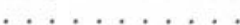

.........

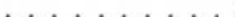

1.... 1.11111

......................

. $1 . . . .$.

... 1 ....

... 12 ...

........

i 1 i 1 . 21 .

$111, \ldots 1,1 \ldots$

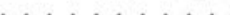

i i i i i . i i

1315191119181418141517
$13 \ldots \ldots$

.......

$\ldots . . . .$.

$.44235 \ldots$.

...............

..... 2 .

........

..... $1,1, \ldots$

12111212.1 .

$1 \ldots .1 \ldots$

. $1111,1,1, \ldots$

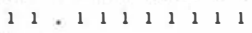

$1 \ldots \ldots 111$

$11 \ldots \ldots . . .1$

.........

..... 1 . 1 ...

11121111212

.........

..., $1,1,1$.

$\therefore \ldots .111$.

121222122

1. $\begin{array}{lllllllll}1 & 1 & 1 & 1 & 1 & 1 & 1 & 1 & 1\end{array}$

.........

$\ldots 121$.

.........

................

$+\cdots$

. . . .

$\begin{array}{lllllllllll}2 & 2 & 3 & 3 & 2 & 5 & 2 & 3 & 4 & 4\end{array}$

$\begin{array}{llllllllll}1 & 1 & 1 & 1 & 1 & 1 & 1 & 1 & 1 & 1\end{array}$

$\begin{array}{lllllllllll}1 & 2 & 1 & 1 & 1 & 1 & 1\end{array}$

$\begin{array}{llllllllllll}2 & 2 & 2 & 1 & 2 & 1 & 2 & 1 & 1 & 1 & 1\end{array}$

, $111 \ldots .11$

$\ldots . . .$.

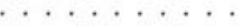

21110

...1.1...

... 1 .... .

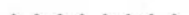

$.1 . .1 .111111$

.....................

$\cdots \cdots$

. . . . .

...............

1 ... 1 . .

$1,1 \ldots . .$.

$11 \ldots . .1 \ldots$

…...................

$\begin{array}{lllllllllll}2 & 2 & 2 & 1 & 1 & 1 & 1 & 1 & 1 & 1 & 1\end{array}$

1616141316161717141412 
Betula pubescens (juv.) ....... Juniperus communis (s)

Rosa majalis

Rubus idaeus $. . . \ldots \ldots \ldots \ldots . . . . .$.

Sorbus aucuparia

Festuca ovina

F. rubra

Luzula pilosa

Melica nutans

Poa glauca

P. nemorolis .

P. pratensis

Roegneria canina

\section{Aconitum septentrionale} Anthriscus sllvestris

Arabis hirsuta

Arobchlum lunaria ................

Campanula rotundifollo

Cerastium alpinum

Chamaenerion angustifollum ....

Cystopteris frugilis .

Eplloblum collinum

Fragaria vesca

Galeopsis bifida

Geranium silvaticum

Hieraclum spp.

Melandrium rubrum

Myosotis silvatica

Potentilla argentea

P. Crantzil

Rubus saxatllis ....

Sedum annuum

Solidago virgaure

Stellaria gramine

Turritis glabra

Urtica dioeca ssp. Sondenil ....

Valeriana sambucifolla

Veronica officinalis

Viola montana

....

$\cdots \cdots$

$\cdots$

2.1222

.....

$\therefore$. . . .

$1 \ldots \ldots$

$\begin{array}{lllll}2 & 1 & 3 & 1 & \cdots\end{array}$

. 1 . 11 ...

1... 11

$\begin{array}{lllllll}2 & 3 & 2 & 3 & 2 & 2\end{array} \ldots$

.....

...... 1

$1 \cdot 1 \cdot 1$

1112221,1

$\therefore 2$.

. $1 .$.

.....

.. 211

......

$211 \cdot 11$

. $1 . .$.

$\cdots \cdots$

.....

..........

$1 \cdots$

111.11

112122212

i i i i

i i . . .

$3 . .23$

112122

1111 ..

.........

$\begin{array}{llllll}2 & 2 & 2 & 2 & 3 & 2\end{array}$

3444333333

.....

111118

...

. $3 . .32$

. 1 ...

.....

11212 .

.....

. 11321

$11 \ldots$

1... 22

11.11 .

.....

.....

$\begin{array}{lllll}3 & 2 & 3 & 2\end{array}$.

.....

.....

121232

12111 .

.....

..........

.....

.....

.....

. . .

. 1 .

.. 111 .

221222

... 8 .

12231

i i i

211111

1. $1 \mathrm{~s} .1$

.....

( 111111

. . 11 . .

$\begin{array}{llllll}1 & 1 & 1 & 1 & 1 & 2\end{array}$

$\begin{array}{llllll}1 & 1 & 1 & 1 & 1 & 1\end{array}$

... 1 ...

.......

................

.........

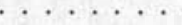

122222222

. 1.11.1 1

$\begin{array}{llllllll}1 & 2 & 2 & 2 & 2 & 1\end{array}$

..........

......

......

..., 1.s.

. . . . .

$\begin{array}{lllll}1 & 1 & 2 & 2 & 2\end{array}$

11.11111111

. 1 ..........

2122222 .

122112211

s 21111111 .

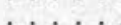

113.1

…........

. 322.2

i)

$11 \cdot 112$

22222321

$\therefore \vdots$.

......

11122

Barbilophozia hatcher

Brachytheclum reflexum

B. salebrosum

Bryum spp.

Ceratodon purpureus

Encalypta $\mathbf{s p}$.

Eurhynchlum pulchellum

Grimmia ovalis

Hedwigia clliata

eterocladium dimorphum .......

Hypnum cupress iforme coll. ...

Lescuraea radicosa

Lophozia s p.

Mnlum cuspldatum

Neckera oligocorpa

Pohlla nutans

Pseudoleskeella nervosa

Ptilldium clllare

Radula complanata

Schistidium apocarpum

Tortula ruralis

$1, \ldots$

12.21.

.....

1.. 1.1

$\begin{array}{lllll}1 & 1 & 1 & 1\end{array}$

11111 .

$\begin{array}{lllllll}2 & 2 & 3 & 3 & 1 & 1\end{array}$

. 1.1

.....

. $1 .$.

$\cdots \cdots$

. $1 .$.

$\cdots$

i...

$\ldots .$.

.....

.122 .1

$111 \ldots$

....

......

212,32

.....

.....

....

. 1,1 .

... 1 .

$\therefore . \cdot$

... 1.

.11 .

....

.. 1 .

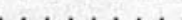

i.

111111.1.

isisi.

$\begin{array}{llllll}1 & 2 & 1 & \ldots\end{array}$

.........

$\therefore$. . . . .

$1 \ldots \ldots$

.......

$\cdots \cdots$

. $1 . . .1$.

.......

$\cdots \cdots$

. . . .

$\ldots \ldots 111, \ldots 12$

....

.. 1.

;..........

i i i

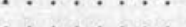

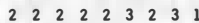

$\cdots \cdot \cdot$

....

....

....

$122 \ldots$

....

....

$221 . .2$

i...

.. 2 . .

....

... 11 .

222221

.....

.....

....

22 2 1 i

.....

121812

$\begin{array}{lllll}1 & 1 & 2 & 2 & 1\end{array}$.

$12 \ldots 2$

2221112

.....

$222 \ldots$.

....

$\cdots \cdot$

$\begin{array}{lllllll}3 & 3 & 1 & 3 & 1 & 1\end{array}$

$\begin{array}{llllll}2 & 1 & 2 & 1 & 1 & 1\end{array}$

…

. 1.2

22,2 .

21222 .

.....

....

111111

.....

.... 1 .

.....

.....

$\cdots \cdot \cdot$

. $1, \ldots$

....

.....

...

.....

....

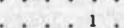

$\begin{array}{llllll}3 & 3 & 4 & 3 & 2 & 3\end{array}$

182419181913

191721231718

212120162118151513

161716131514 
Table 21 . The Fruticeto-Tortuletum subassociation. Juniperus communis variant.

Stand no.

Juniperus communis

Prunus padus .........

Ribes sploatum var. lapp. ....

Rubus Idaeus

Deschampsia flexuosa .........

Festuca ovine

Melica nutans

Poo nemoralis

Clramaenerion angustifollum ... Erysimum hieracilfolium

Galeopsis bifida ....

Hackelia deflexa . .

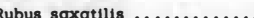

Solidago virgaurea

Stellarta graminea

Barbilophozia barbata

Brachythecium erythrorrhizon.

B . reflexum .

B. salebros

Bryum s p.

Ceratodon purpureus

Dicranum

Drepanocladus uncinatus .......

Eurhynchlum pulchellum

Lescuraea radicosa

Lophozia excis

L. sp.

Plaglothectum roeseanum .......

Pohlia cruda ................

Pseudoleskeella nervosa ......

Pterigynandrum flllforme .......

Ptilldium cillare

Pylaisia polyanthe

Rodula complanato

Rhytidium rugosum

Schistidium apocer pum ........

Tortula rural is

Total number of species

55555

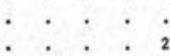

1. $\quad$ i i

.. . .

. 1.2

- $\cdot 1$.

-. 11

- $i^{2}$.

1.123

. . 1

- 22 .

$\begin{array}{llll}i & 1 & 0 & 0\end{array}$

222 .

- 11 .

. 1.

. $\cdot$ i

.$+0^{\circ}$. $\therefore$ i ${ }^{2}$

. 1.1

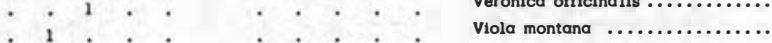

Woodsia Ilvensis.

Barbllophozia hatcheri

Brachytheclum reflexum ...........

Bryum spp. $\ldots \ldots \ldots \ldots \ldots \ldots . . . . .$.

Desmatodon latifolius .

Eurhynchium pulchellum ..........

Hypnum cupressiforme coll. ......

Lophozia excisa

Pohlia cruda ...

Pseudoleskeella nervosa .........

Ptilldium clliare ................

Schistidium apocarpum

Tortella tortuosa

Tortula ruralis

Total number of species and Vaccinium vitis-idaea heath type.

\begin{tabular}{|c|c|c|c|c|c|c|c|c|c|c|c|c|c|c|c|c|}
\hline & & 1 & & & & & & & & I & I & & & & & ${ }_{F}^{C}$ \\
\hline & & & & & & - & & & & & & & & & & $6^{1}$ \\
\hline 4 & 2 & 3 & 4 & 3 & 3 & . & . & . & . & . & . & . . & . & . & & $35^{4}$ \\
\hline . & s & . & 5. & 1 & & . & . & . & . & . & . & . . & . & 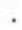 & & $17^{1}$ \\
\hline 4 & 3 & 23 & 33 & 2 & & 2 & 1 & 2 & 1 & 22 & 21 & 2 & 2 & 2 & 2 & $100^{2}$ \\
\hline . & . & . & . 1 & . & & - & . & . & . & . & . & - . & . & . & - & $6^{1}$ \\
\hline 1 & 1 & 2 & 21 & 1 & 1 & 1 & 2 & 2 & 1 & 33 & 32 & 23 & 32 & 2 & 1 & $100^{2}$ \\
\hline 1 & 1 & 1 & 1. & . & • & . & . & . & . & . &. & . & . & 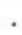 & & $23^{1}$ \\
\hline . & . & 1 & . & . & • & - & . & . & . & . & . . & . . & . & . & & $6^{1}$ \\
\hline 1 & 1 & 1 & 1. & . & . & 2 & 1 & 1 & 1 & .1 & 11 & 1 & 2 & 1 & 2 & $81^{1}$ \\
\hline 1 & . & 1 & 1. & • & . & . & . & . & . & . & . & . . & . & & & $17^{1}$ \\
\hline · & • & . & $\cdot$ & & • & 1 & . & 1 & $\cdot$ & 1. & . & . & s & 1 & - & $29^{1}$ \\
\hline . & . & . & . & • & • & . & . & . & . & . & . 1 & . & . & - & . & $6^{1}$ \\
\hline 1 & 1 & 2 & 11 & 1 & & . & . & . & . & . & . & . & . & - & • & $35^{1}$ \\
\hline $\mathrm{s}$ & . & . & . & • & . & . & . & . & . & . & . & . . & . & - & • & $6^{1}$ \\
\hline . & . & . & . & . & . & . & . & . & . & . 1 & 1. & 1 & & . & & $12^{1}$ \\
\hline . & 1 & 1 & 1 & 1 & & - & . & . & . &. & . & . . & . & - & . & $23^{1}$ \\
\hline . & . & . & . & & s & . & . & $\cdot$ & . & . & . & . & . & . & . & $6^{1}$ \\
\hline 1 & 2 & 1 & 22 & 2 & 2 & 2 & 2 & 2 & 2 & 22 & 22 & 2 & 3 & 2 & 2 & $100^{2}$ \\
\hline 2 & . & . & s 1 & & . & 1 & 1 & 2 & 1 & 22 & 21 & 1 & 1 & 1 & 2 & $81^{1}$ \\
\hline . & . & 1 &. & $\mathrm{~s}$ & & . & . & . & . & . & . & . . & . & . & . & $12^{1}$ \\
\hline 2 & 1 & 3 & 33 & 2 & 2 & 3 & 3 & 3 & 4 & 32 & 22 & 2 & 3 & 3 & 3 & $100^{3}$ \\
\hline . & 1 & . & : & . & . & 1 & 1 & 1 & $\mathbf{s}$ & 11 & 11 & 1 & 1 & 1 & 1 & $70^{1}$ \\
\hline . & . & . & . & 1 & & 1 & 1 & 1 & 1 & 1 & & & 1 & 1 & 1 & $70^{1}$ \\
\hline 2 & 2 & 1 & 22 & & 2 & . & . & . & . & . & . & . & . & . & - & $35^{2}$ \\
\hline 1 & 1 & 1 & . & 1 & & 2 & 1 & 1 & 1 & 11 & 1. & 1 & 1 & 1 & 1 & $81^{1}$ \\
\hline . & . & . & . & & • & . & . & . & . & . & 1 & 2 & . & 1 & 1 & $23^{1}$ \\
\hline 2 & 2 & 3 & 12 & 2 & 2 & 2 & . & . & 1 & 11 & 11 & 1 & 1 & 1 & 1 & $87^{2}$ \\
\hline 1 & 1 & . & . & • & • & - & . & . & . & . & . & . . & . & . & - & $12^{1}$ \\
\hline . & . & . & . 2 & & & . & . & . & • & . . & . . & . & . & - & . & $6^{2}$ \\
\hline 1 & . & $1-$ & .1 & & & . & . & . & . & . 1 & 1. & . . & . & . & . & $23^{1}$ \\
\hline 1 & . & . & . & & & . & 1 & 1 & 1 & 11 & 11 & 1 & 1 & 1 & 1 & $70^{1}$ \\
\hline . & . & . & . & . & . & - & 1 & . & 1 & . & . . & . & . & 1 & . & $17^{1}$ \\
\hline & . & . & . & • & & . & . & . & . & . & . & . . & 1 & 1 & . & $12^{1}$ \\
\hline . & 1 & 1 & . & 1 & 1 & . & . & . & . & . & . . & . . & & & . & $17^{1}$ \\
\hline . & . & . & . & & • & . & . & . & . & . & . & . . & 1 & $\theta$ & & $6^{1}$ \\
\hline 1 & 1 & . & 11 & & . & $\cdot$ & . & . & . & . & . . & . . & . & 1 & & $29^{1}$ \\
\hline . & . & 1 & . & & • & 1 & 1 & . & . & . & . & . & 1 & & & $23^{1}$ \\
\hline & - & $\cdot$ & . & & • & - & - & . & . & 1 & . & . & & & . & $6^{1}$ \\
\hline 1 & . & . & . & & • & . & . & . & 1 & . & . & . & . & & 1 & $17^{1}$ \\
\hline . & & . & . & & & • & & . & 1 & . & . & . . & 1 & & & $12^{1}$ \\
\hline & . & 1 & 11 & & & 3 & 2 & 2 & . & & 11 & 1 & & & & $81^{1}$ \\
\hline
\end{tabular}

$191619141516 \quad 1313121413151314171714$ 


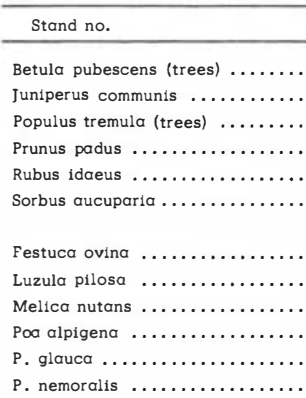

Botrychium boreale Campanula rotundifolia

Cerastium alpinum. Cystopteris fragilis ssp. eufrag ... Draba norvegica

Epiloblum collinum ...............

Erysimum hieracilfolium

Fragaria vesca. ...

Geranium silvaticum .............

Hackelia deflexa

Rubus saxatilis

Saxifraga nivalis...

Sedum annuum

Solidago virgaurea

Stellaria graminea

Turritis glabra

Valeriana sambucifolia

Viola montana

Woodsia alpina

W. ilvensis

Abietinella abletina

Barbilophozia barbata

B. salebrosum

Bryum capillare

B. pallescens (incl. B. cirrhatum) .

Cephalozia sp.

Ceratodon purpureus $. \ldots \ldots \ldots \ldots . . . .$.

Dicranum scoparium

Drepanocladus uncinatus ......

Encalypta cillata...

Eurhynchium pulchellum...$\ldots \ldots$.

Grimmia ovalis

Hedwigia cillata

Hypnum cupress iforme coll . .......

Isopteryglum pulchellum ...

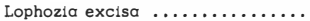

Mnlum orthorrhynchum

Orthotrichum sp.

Plagiopus oeder1

Pohlia cruda

Pseudoles keella nervosa ...........

P, tectorum $\ldots \ldots \ldots \ldots \ldots \ldots \ldots$

Pterigynandrum fillforme.......

Ptilidium ciliare

Radula complanata

Rhytidium rugosum

Saelania glaucescens

Schistidium apocarpum . ...........

Tortella fragllis .

T. tortuosa. ...

Tortula ruralis

Cladonia spp.

Nephroma parile

Peltigera canina

P. erumpens

P. malacea

Stereocaulon paschale

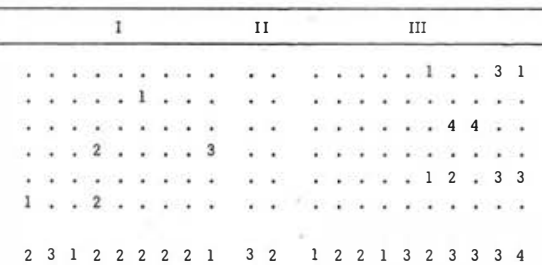

$\begin{array}{lllllllllllllllllllll}2 & 3 & 1 & 2 & 2 & 2 & 2 & 2 & 1 & 3 & 2 & 1 & 2 & 2 & 1 & 3 & 2 & 3 & 3 & 3 & 4\end{array}$

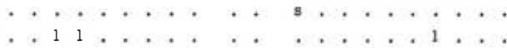

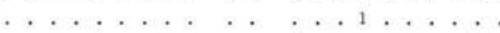

... 2.212 . $212.3221 \% 1$

1.12.1... $1.1 \ldots . . .1 . .$.

$1 \ldots, \ldots . ., \ldots, \ldots, \ldots$

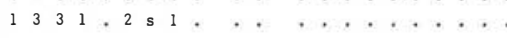

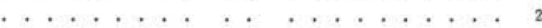

$\ldots 1 \ldots \ldots \ldots$

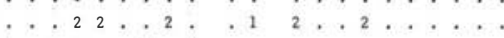

s.1 1 . $1,1 \ldots \ldots \ldots$

. . . . . . . . . . . . . .

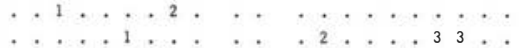

................ . . . .

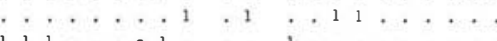

$111 \ldots 51 \ldots \ldots . \ldots$

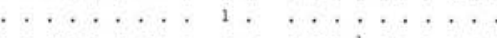

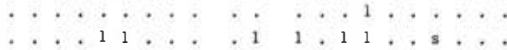

.......... s 1 . . . 2

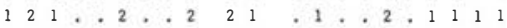

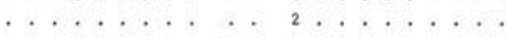

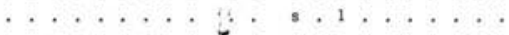

$12, \ldots, \ldots, \ldots, \ldots, \ldots$

.... $1 . .2 \ldots . . . . .$.

. 1... $1.12 i 11 i$

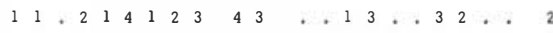

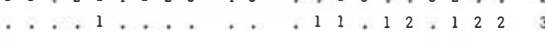

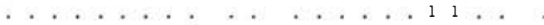

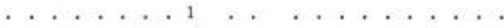

. . . . . . . . . . . 1 . .

$\begin{array}{llllllllllllllllllll}1 & 1 & 1 & 1 & 1 & 1 & 1 & 1 & 1 & 1 & 1 & 0 & 1 & 1 & 1 & 1 & 1 & 1\end{array}$

.... $1 \ldots . . .411111 \ldots$

1...1.... 1.1 .11 .1 .1

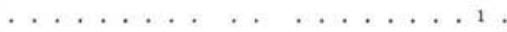

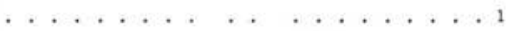

$\ldots \ldots \ldots . \ldots$

.... 11 . . . . . . .

$\ldots \ldots \ldots \ldots . . . \ldots$

.. $11 \ldots \ldots . . .11,21,1 \ldots$

. $11 \ldots . . . . . . . .$.

$\ldots, \ldots, \ldots, \ldots, 1$

................ 11.1

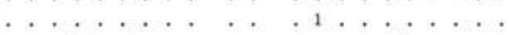

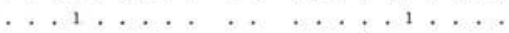

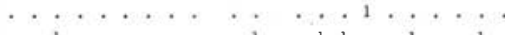

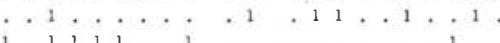

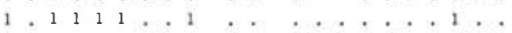

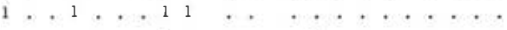

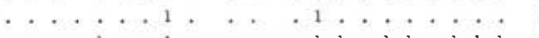

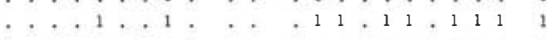

$1,1 \ldots \ldots, 1 \ldots \ldots$

$\begin{array}{lllllllllllllllllllllll}5 & 3 & 3 & 2 & 3 & 1 & 4 & 4 & 2 & 1 & 3 & 5 & 4 & 5 & 2 & 3 & 5 & 2 & 4 & 5 & 2\end{array}$

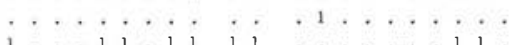

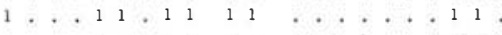

$\ldots \ldots \ldots \ldots . \ldots . \ldots$

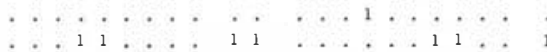

$\begin{array}{lllllllllllllllllllllll}1 & 1 & 1 & 1 & 2 & 1 & 1 & 1 & 1 & 2 & 1 & 1 & 1 & 1 & 0 & 1 & 1 & 2 & 2 & 1 & 2\end{array}$,

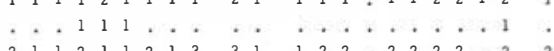

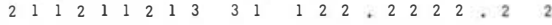

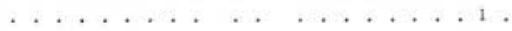

................ 12 .

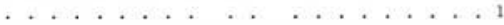

Stand no.

II

Linnaeg borealis

Vaccinium vitis-idaea

Deschampsia flexuosa

Festuca ovina

Poa glauca

P. nemoralis

Chamaenerion angustifolium ....

Andraea rupestris coll.

Barbilophozia hatcheri ............

Brachythecium reflexum

B. Starke1 .

Cephalozia sp

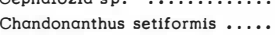

Cynodentium polycarpum

Dicranum fuscescens ...........

Drepanocladus uncinatus .......

Grimmia ovalis

Hylocomium splendens ........

Lophozia excisa

L. sp.

Plagiothecium roeseanum ......

Pleurozium Schreberi ..........

Pogonatum alpinum

Pohlia nutans

Polytrichum juniperinum

P. pillferum ................

Pseudoleskeella nervosa

Ptilidium ciliare

Rhacomitrium lanuginosum ....

Rh. microcarpum ....

Sphenolobus saxicolus ..

Total number of species

... . 2 ....

.. 1 . . . .

. $1 \cdot \cdot$

... 1 .. 22

.... 2 ...

.... . 2 ...

$.1, \ldots$

$\begin{array}{lllllllllll}1 & 1 & 1 & 1 & 1 & 1 & 1 & 1 & 1\end{array}$

. 111110111112

... 1 . . 1 ...

..... 1 ...

. 1.1 .1

$\begin{array}{llllllllll}2 & 4 & 3 & 2 & 3 & 2 & 1 & 2 & 1\end{array}$

. 1 ...............

$\begin{array}{llllllllllll}1 & 3 & 2 & 1 & 1 & 2 & 3 & 2 & 3 & 4 & 4 & 2\end{array}$

$11.1 . \ldots . . .111$

. 1 ... . . . .

. $2 . .112 . .2 .1$

1. $1 \begin{array}{llll}1 & 1 & 1 & 1\end{array}$

.....

$+\cdots, 1$

$1 . . .1$

$1 \quad 1$,

.....

$\begin{array}{llllll}1 & 1 & 1 & 1 & 2\end{array}$

$2,2, \ldots, 1$

$1.1 \ldots+\ldots$

. 1 ... . .

$\begin{array}{llllllllllll}3 & 2 & 3 & 2 & 2 & 1 & 1 & 2 & 1 & 1 & 1 & 2\end{array}$

.. 1 . .

. . . i i i .

$1222212 \ldots \ldots 1$.

$101110101113 \quad 12 \quad 9 \quad 810911$ 
Table 25. The Dicrano-Polytrichetum association. Cladonia variant.

\begin{tabular}{|c|c|c|c|c|c|c|c|c|c|c|c|c|c|c|c|c|c|c|c|c|c|c|c|c|c|c|}
\hline Stand no. & & & I & & & & & II & & & & & II & & & & & & & & IV & & & & & $p^{C}$ \\
\hline 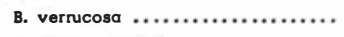 & $\cdot$ & & $\cdot$ & & & & $\cdot$ & & & & - & . & . & & & & - & & • & . $\cdot$ & s & . & - & . & & $4^{1}$ \\
\hline Juniperus communis $\ldots \ldots \ldots \ldots \ldots \ldots$ & . & . & . & 2 & . & & . & s. & . & . & . & . & . & s & . & . & . & . & . & . . & . & . & - & . & . & $12^{1}$ \\
\hline Populus tremula (juv.) ............. & . & . & . & . & . & & 2 & . & . & & . & s & . & 2 & 2 & & . & . & . & . . & . & . & . & . & . & $19^{3}$ \\
\hline Rosa majalis $\ldots \ldots \ldots \ldots \ldots \ldots \ldots$ & . & . & . & . & . & . & 3 & . & . & . & . & . & . & . & . & . & . & . & . & . . & . & . & . & . & . & $4^{3}$ \\
\hline Rubus idaeus $\ldots \ldots \ldots \ldots \ldots \ldots \ldots$ & . & . & . & 1 & . & & . & . & . & . & . & . & . & . & . & . & 3 & 3 & . & . & . & 2 & . & $\therefore$ & . & $15^{3}$ \\
\hline Sorbus aucuparia $\ldots \ldots \ldots \ldots \ldots \ldots$ & . & . & . & . & - . & . & . & . & . & . & - & s & s & . & . & . & . & . & . & . . & . & . & . & . & - & $8^{1}$ \\
\hline Arctostaphylos uva-ursi. $\ldots \ldots \ldots \ldots$ & . & . & . & . & . & . & . & . & . & & . & . & . & . & . & . & . & . & . & . s & . & & . & . & & $4^{1}$ \\
\hline Colluna vulgaris $\ldots \ldots \ldots \ldots \ldots \ldots$ & . & . & . & . & . & . & . & 12 & 1 & & . & . & . & . & . & . & . & . & . & . . & . & 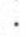 & . & . & . & $12^{1}$ \\
\hline Agrostis borealis . . . . . . . . . . . . . & . & . & . & . & . . & & . & 1. & . & & . & . & . & . & - & . & . & . & . & . . & . & . & . & . & . & $4^{1}$ \\
\hline A. tenuis $\ldots \ldots \ldots \ldots \ldots \ldots \ldots \ldots$ & 2 & . & . & . & . & . & . & . & . & . & . & 1 & . & 1 & . & . & . & . & . & . . & . & . & . & . & . & $12^{1}$ \\
\hline Corex brunnescens $\ldots \ldots \ldots \ldots \ldots \ldots$ & . & . & . & . & . & . & . & . & & . & . & . & 2 & . & . & . & . & . & . & . . & . & & . & . & . & $4^{2}$ \\
\hline Deschampsia flexuosa ............ & . & . & . & 1 & . & . & . & 11 & 1 & 1 & . & . & . & . & . & . & . & . & . & . 1 & 2 & - & . & . & . & $23^{1}$ \\
\hline Festuca ovina $\ldots \ldots \ldots \ldots \ldots \ldots \ldots$ & 2 & 1 & 1 & . & 12 & 2 & . & . & . & . & . & . & . & . & . & 1 & . & . & 1 & . 2 & 1 & 2 & 2 & 1 & . & $46^{1}$ \\
\hline F. rubra $\ldots \ldots \ldots \ldots \ldots \ldots \ldots \ldots \ldots$ & . & . & . & . & . . & . & . & . & . & . & . & . & 1 & . & 1 & . & . & . & . & . . & . & & . & . & . & $8^{1}$ \\
\hline Melica nutans $\ldots \ldots \ldots \ldots \ldots \ldots$ & . & . & . & . & . & . & . & 1 & 1 & & . & 2 & 2 & . & . & . & . & . & . & . . & . & & . & . & . & $15^{2}$ \\
\hline Poa glauca...$\ldots \ldots \ldots \ldots \ldots \ldots$ & . & . & . & . & . & . & 1 & . & & . & 2 & . & . & 1 & . & . & 3 & 2 & . & 1 . & . & & 2 & & 2 & $35^{3}$ \\
\hline P. nemoralls $\ldots \ldots \ldots \ldots \ldots \ldots \ldots$. & 1 & 1 & 2 & 1 & 21 & & . & . & . & . & . & . & . & . & . & i & . & . & . & 1 . & . & . & - & . & . & $31^{1}$ \\
\hline P. pratensis $\ldots \ldots \ldots \ldots \ldots \ldots \ldots$ & . & . & . & . & . & . & . & . & . & . & 1 & . & 1 & 1 & 1 & 1 & . & $\dot{.}$ & . & . & . & . & $\dot{*}$ & . & $\dot{.}$ & $19^{1}$ \\
\hline Antennaria dioeca $\quad \ldots \ldots \ldots \ldots \ldots \ldots$ & . & . & . & . & . . & . & . & . & . & • & . & . & . & . & . & . & . & . & 1. & . . & s & . & . & . & • & $8^{1}$ \\
\hline Cerastium alpinum .............. & . & . & . & 1 & . & . & . & . & . & . & . & . & . & . & . & . & . & $\dot{.}$ & . & . & . & . & . & . & . & $8^{1}$ \\
\hline C. holosteoldes ............... & . & . & . & . & . & . & . & . & . & . & . & 1 & 1 & 1 & 1 & . & . & . & . & . & . & & . & . & . & $15^{1}$ \\
\hline Chamaenerion angustifolium ....... & . & . & . & . & . & . & . & . & & . & . & . & . & . & . & . & . & . & . & . & . & 4 & . & . & • & $4^{4}$ \\
\hline Cystopteris fraglls.$\ldots \ldots \ldots \ldots \ldots$ & . & 1 & 1 & . & . & . & . & . & & . & . & . & . & . & . & . & . & i & . & i. & $\therefore$ & 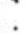 & . & . & • & $8^{1}$ \\
\hline Eplloblum collinum.$\ldots \ldots \ldots \ldots \ldots$ & . & . & . & . & . & . & . & . & & . & $\dot{.}$ & $\dot{.}$ & . & . & . & . & $\dot{.}$ & . & . & . & $\therefore$ & - & - & . & . & $4^{2}$ \\
\hline E. lactiflorum ................. & . & . & . & . & . & . & . & . & & . & . & 1 & . & . & . & . & . & . & . & . & . & : & . & . & . & $4^{1}$ \\
\hline Erigeron politum ................ & . & . & 2 & . & . & . & . & . & . & . & . & . & . & . & . & . & . & . & . & . & . & . & . & . & • & $4^{2}$ \\
\hline Fragaria vesca $\ldots \ldots \ldots \ldots \ldots \ldots$ & 3 & 2 & 2 & 3 & 22 & 2 & . & . & & . & 2 & . & 1 & 2 & 12 & 2 & . & . & 2 & . 2 & 3 & 2 & 3 & 4 & . & $65^{3}$ \\
\hline Geranium sllvaticum $\ldots \ldots \ldots \ldots \ldots$ & . & . & . & s & . . & . & . & . & & . & $\mathbf{s}$ & 2 & 2 & 1 & 1 & 1 & . & . & . & . . & . & - & . & . & . & $27^{1}$ \\
\hline Gnaphalium norvegicum...$\ldots \ldots \ldots$ & . & . & 1 & . & . & . & . & . & & . & 2 & 1 & 1 & 1 & 12 & 2 & . & . & . & . & . & . & . & . & . & $27^{1}$ \\
\hline Hleraclum spp. $\quad \ldots \ldots \ldots \ldots \ldots \ldots$ & . & . & 1 & . & . & & . & . & . & . & . & . & . & . & . & - & . & . & . & . . & $s$ & • & . & . & . & $8^{1}$ \\
\hline Melampyrum silvaticum ........... & . & . & . & . & . & . & . & . & & . & $\dot{*}$ & $\dot{2}$ & $\dot{.}$ & . & . & . & $\dot{*}$ & $\dot{.}$ & . & . & . & - & - & . & . & $4^{2}$ \\
\hline Myosotis sllvatica..$\ldots \ldots \ldots \ldots \ldots$ & . & . & . & 1 & . & . & . & . & . & . & . & . & . & . & . & . & . & . & . & . . & . & - & . & . & . & $4^{1}$ \\
\hline Potentilla argentea $\ldots \ldots \ldots \ldots \ldots$ & . & . & . & . & . & . & . & . & & . & . & . & . & . & . & . & . & . & . & . 1 & . & & . & . & . & $4^{1}$ \\
\hline Rubus sakatills $\ldots \ldots \ldots \ldots \ldots \ldots$ & . & . & 1 & . & 2 & 2 & . & . & . & . & 1 & . & 2 & 1 & 1 & 1 & . & . & . & . . & . & . & . & . & . & $27^{1}$ \\
\hline Rumex acetosella $\ldots \ldots \ldots \ldots \ldots \ldots$ & 1 & 1 & 1 & 1 & 1 & 1 & . & . & . & • & 1 & . & . & . & 1 & . & . & . & . & . & . & . & . & . & . & $31^{1}$ \\
\hline Sedum annuum $\ldots \ldots \ldots \ldots \ldots \ldots$ & . & 1 & 1 & 1 & 1. & . & . & . & & • & 1 & . & . & . & . & . & . & . & . & . & . & - & . & . & . & $19^{1}$ \\
\hline silene rupestris $\ldots \ldots \ldots \ldots \ldots \ldots$ & 2 & 2 & 1 & . & & 1 & 1 & . & & . & . & . & . & . & . & . & . & . & . & . & . & . & . & . & . & $23^{1}$ \\
\hline Solidago virgaurea...$\ldots \ldots \ldots \ldots$. & . & . & . & . & . & . & . & . & & 1 & 2 & 2 & 2 & 2 & 2 & & . & . & . & . & . & & 2 & 2 & . & $42^{2}$ \\
\hline Stellaria gramineo $\ldots \ldots \ldots \ldots \ldots \ldots$ & . & . & 1 & . & . & . & . & . & & . & 1 & 1 & 1 & 1 & 1 & 1 & . & . & . & . & . & & . & . & . & $27^{1}$ \\
\hline Veronica officinalis .............. & 2 & 1 & 2 & . & . & . & 4 & 5 & & 5 & . & . & . & . & . & . & . & . & 23 & 32 & . & . & . & . & . & $38^{4}$ \\
\hline v. serpyllifolla $\ldots \ldots \ldots \ldots \ldots \ldots \ldots$ & . & . & . & . & . & . & . & . & & . & $i$ & $i$ & $i$ & $i$ & $i$ & i & . & . & . & . . & . & . & . & . & . & $23^{1}$ \\
\hline viola montana $\ldots \ldots \ldots \ldots \ldots \ldots$ & . & . & . & . & & . & . & . & & 1 & . & . & . & . & . & . & . & . & . & . & . & & . & . & . & $8^{1}$ \\
\hline Viscaria alpina $\ldots \ldots \ldots \ldots \ldots \ldots$ & . & . & : & . & & . & . & . & & . & . & . & . & . & . & . & 2 & 2 & . & 1 & 1 & & . & . & . & $15^{2}$ \\
\hline Woodsia llvensis ................ & . & . & . & . & & . & . & . & & . & . & . & . & . & . & . & . & 1 & . 1 & 1 . & . & & . & . & . & $8^{1}$ \\
\hline Andraea rupestris coll. ... & . & . & . & & & & . & . & & & & . & . & . & . & & 1 & & & . & & & . & . & & $8^{1}$ \\
\hline Barbllophozia barbata...$\ldots \ldots \ldots$. & . & . & . & . & & . & . & . & & •. & . & . & . & . & . & . & . & • & . & & . & & 1 & i & . & $12^{1}$ \\
\hline B. hatcher1 $\ldots \ldots \ldots \ldots \ldots \ldots$. . . & . & . & . & . & & . & . & . & & & - & . & . & . & - & - & . & • & - & - & 1 & & & & . & $4^{1}$ \\
\hline B. lycopodioldes $\ldots \ldots \ldots \ldots \ldots \ldots$ & . & . & . & . & & . & . & . & & . & . & . & & . & & & . & . & . & & . & 1 & . & . & . & $4^{1}$ \\
\hline Bartramia ithyphylla .............. & . & & & . & & . & . & . & & & 1 & 1 & 1 & 1 & . & & . & 1 & . 1 & 11 & 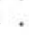 & & . & . & . & $27^{1}$ \\
\hline Blepharostoma trichophyllum ........ & . & . & . & . & & & . & & & & & & & . & & & . & & & & & & & & & \\
\hline
\end{tabular}




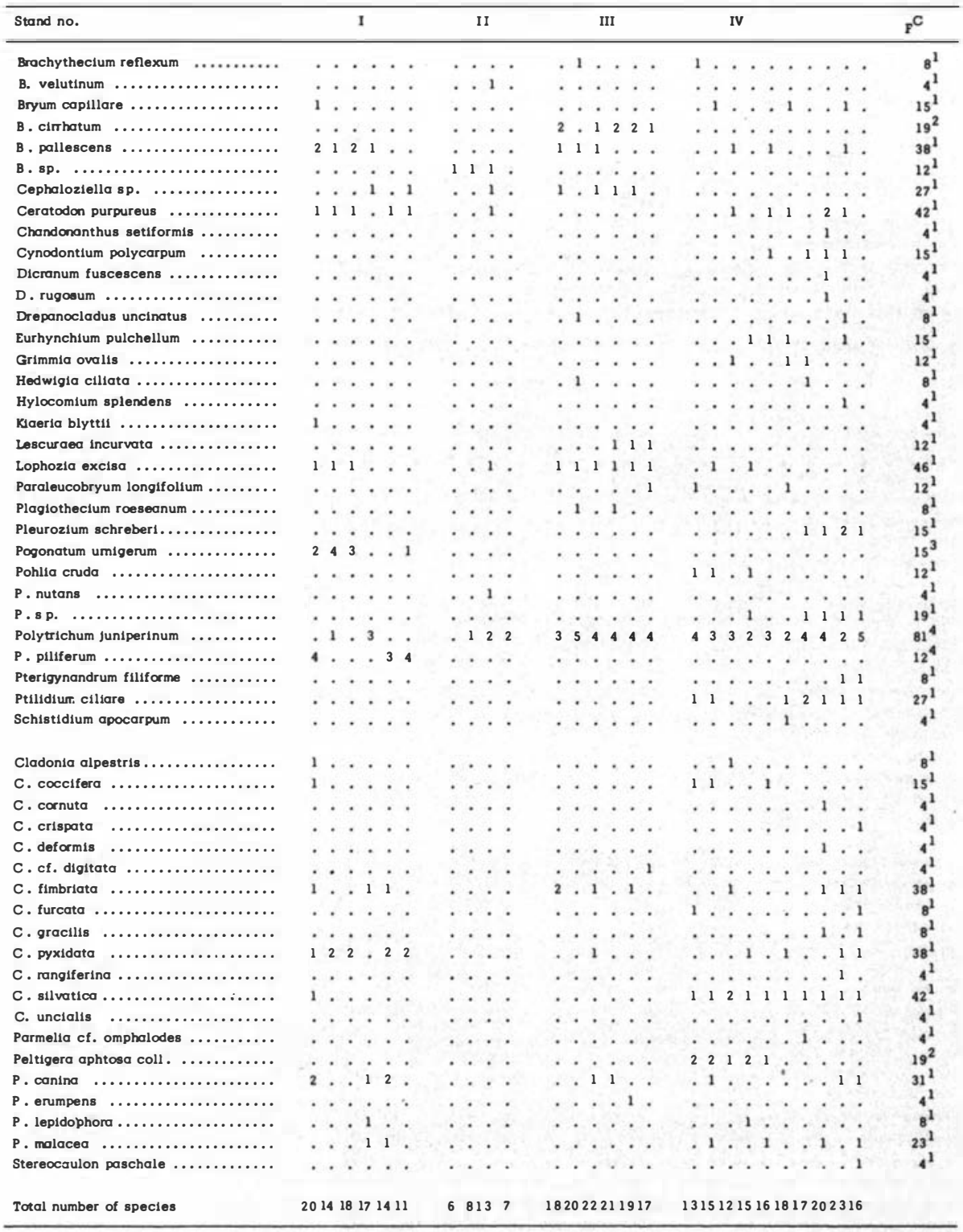


Table 26 . Survey table.

Poeto-Lactucetum Populeto-Tortuletum Fruticeto-Tortuletum Rhytidietum Dicrano-Polytrichetum Rubus idaeus var. Juniperus var.

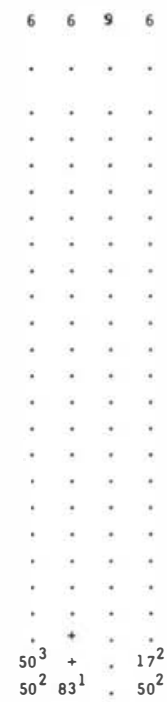

$10 \quad 11 \quad 11$

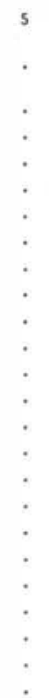

Sphenolobus Cladonia var.

var.
Number of quadrats

Sallx caprea

Alchemilla alpina

Deschampsia caespitosa

Carex atrata

Polystichum lonchitis.

Filipendula ulmaria

Lactuca alpina

Athyrium fillix-femina

Majanthemum bifolium

Matteuccla struthlopteris ........

Phegopteris polypodioldes

Trientalls europaea

Actaea splcata

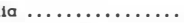

Gymnocarpium dryopteris

Actaea erythrocar pa $\times$ s picata ......

Barbaraea stricta

Actaea erythrocarpa

Convallaria majalis

Dryopteris fillix-mas . .

Aconitum septentrionale

Distichium capillaceum

Hypnum

Ditrichum flexicaule...$\ldots \ldots \ldots$.

Plagiotheclum laetum ..

Mnlum pseudopunctatum

Plaglotheclum succulentum

Climaclum dendroldes

Rhodobryum

Blepharostoma trichophyllum .....

Aulacomnlum palustre...

Plaglochila asplenioldes ..........

Plaglothecium denticulatum .

Amblystegiella sprucel.

Campyllum sommerfelt11

Prunus padus

Daphne mezereum

Populus tremula

Veronica fruticans

Carex omithopoda....

Saxifraga adscendens

Euphrasia frigida . .

Viola montana

Roegneria canina

Botrychium lunaria

Myurella julacea

Rosa majalis

Ribes spicatum var. lapponicum ...

Rubus idaeus..$\ldots \ldots \ldots \ldots \ldots$.

Arabls hirsuta.

Anthriscus sllvestris

Campanula rotundifolia

Valeriana sambucifolia .

Galeopsis bifida

Sedum annuum.

Sllene rupestris

Potentilla argentea

Turritis glabra

Luzula pllosa .

Festuca rubra

Potentilla Crantzil ..............

Ureica dioeca ssp. Sondenil $\begin{array}{llllll}10 & 10 & 10 & 6 & 10 & 10\end{array}$

. $90^{4} \cdot 50^{5}+$.

$30^{1}$
$10^{1}$

$10^{1}$

$20^{1} 10^{1}$

$20^{1} \cdot 100^{5}$

$+100^{4}$

$. \quad . \quad 100^{3}$

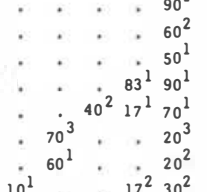

. $60^{1} \cdot \begin{aligned} & 20^{3} \\ & 20^{2} \\ & 10^{2}\end{aligned}$

.$\quad 60^{3}$

. . $.80^{2} 70^{2}$

$100^{5} 100^{4}+100^{3} \cdot 100^{5}$ $100^{3} \cdot 90^{2}$

$10^{1}$

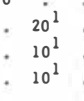

$10^{1}$
.
$.10^{1}$

$33^{3}$
$50^{1}$

. $50^{1}$

.$\quad .20$

- $17^{2} 20^{1}$

$30^{1} \cdot 10^{1}$

$\cdot{ }^{3} 3^{1} \cdot 10^{1}$

$10^{1} \cdot{ }^{1} \cdot 10^{1}$

${ }^{1} \cdot 0^{1} \cdot 50^{1}: 30^{2}$

$20^{2}$

$+0^{1} \cdot 60^{2} 100^{4} 82^{4} 55^{4}$

$30^{1}$

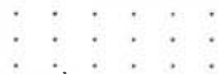

- $60^{1}$

${ }_{10}^{1} 0^{1} 60^{2}: 10^{1}$

. ${ }^{+}{ }^{18}+$

$60^{2} 27^{1} 36$

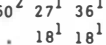

${ }_{83}^{1} \dot{67^{1}} \quad 5_{55^{1}}^{83^{2}}$

$10^{1}$

$10^{1}$

. $80^{2}$

$70^{2} \div \div$

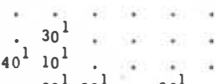

- $90^{1} 80^{1} \cdot 60^{1}$

. . . . .

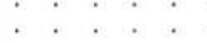

$\begin{array}{llll}\cdot & \cdot & \cdot & \cdot \\ . & \cdot & \cdot & \cdot\end{array}$

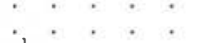

101

$10^{1}$ 
Tortula ruralis

Hedwigla clliata

$10^{1}$

$10^{1} 73^{1} 100^{1}$

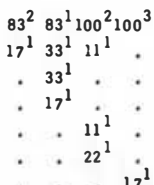

$60^{1} 40^{1}$

$22^{1} 30^{1}$

Mnium cuspldatum

Heterocladium dimarphum

Neckera oligocarpo

Grimmia ovalis

Encolypta sp.

Juniperus communis

$20^{1}$

$10^{1}$

. $33^{1}$.

$100^{5} 100^{5} \quad 11^{1}$

$40^{1}$

Deschampsia flexuosa

$i^{2}$

Brachytheclum erytharhizon ........

Lescuraea radicosa.

Pylaisia polyantha

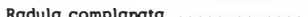

Brachytheclum salebrosum .........

Eurhynchium pulchellum ...........

Pseudoleskeella nervosa

Barbllophozla barbata...

Woodsia al pina ...

Draba norvegica

Drabe nor

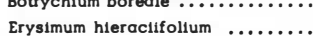

Saxifraga nivalis

Hackelia deflexa

Woodsia Ilvensis

Pseudoleskeella tectorum

Rhytidium rugosum

Abletinella abletina

Orthotrichum sp.

Encalypta clllata

Plagiopus oederi

Scolanla glausescens

Tortella fragilis

1sopterygium pulchellum

Mnlum orthorr hynchum

Tortella tortuos

Hypnum cupressiforme coll

Cephalozia sp.

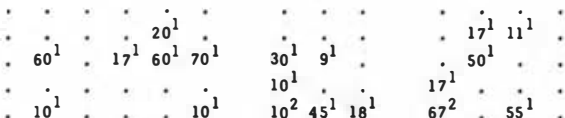

. ${ }_{10}^{1}:{ }^{1} \cdot 0^{1}$

$10^{2} \quad 45^{1} \quad 18$

$67^{2} \cdot 55^{1}$

$40^{1}$

$20^{1}$

$20^{1} 60^{1}$

$80^{2} 20^{1}$

${ }^{1} 80^{2}$

$\begin{array}{llll}80^{2} & 20^{1} & 11^{1} & 70^{1}\end{array}$

$33^{1}$

$22^{1}$

$67^{1} 10^{1}$

$17^{1} 10^{1}$

17

$30^{1}$

$17^{2} 17^{1}$

$17^{1}$

$17^{1} \cdot 20^{2}$

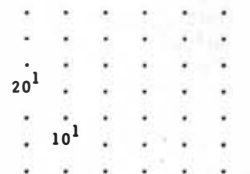

${ }_{10^{1}}: 7_{18^{1}} 7^{1}$

$22^{2}$.

$20^{1}: \quad 11^{1}$

$20^{2}$

${ }_{22^{2}}^{2} \cdot 0^{1}$

$9^{1}+$

$\begin{array}{ll}55^{1} & 10^{1} \\ 11^{1} & 60^{1}\end{array}$

$20^{1}$

$44^{1}$

$100^{4} 100^{4}$

$89^{2} 40^{3}$

$11^{1} 10^{1}$

- $30^{1}$

. $10^{1}$

. $10^{1}$

$\therefore 10^{1}$

. $10^{1}$

$22^{1}{ }^{1} 0^{1}$

${ }_{11}^{1} 50^{1}$

${ }_{50}^{1}$

Vaccinlum vitis-idaed

Linnaea borealis

Rhacomitrium lanuginosum

Cynodontlum polycarpum

Sphenolobus saxicolus

Andraea rupestris

Chandonanthus setiform1s

Pleurozlum schreber1...

Rhocomitr

Brachythecium starkel

Lophozla sp.

Pohlla nutong

Dicranum fuscescens

Erigeron politum

Agrostis tenuls

Rumex acetosella

Gnaphallum norveg!cum

Veronica serpyllifolla. .

Cerastlum holosteoldes

Viscaria alpina

Antennaria dioeca

Arctostaphylos uva-ursi

Pogonatum umigerum

\section{Kiaeria blyttil .}

Polytrichum pillferum

Paraleucobryum longifollum

Bareramia ithyphylla

Pohlla sp.

Barbllophozla lycopodioldes

Dicranum rugosum 
$\begin{array}{llllll}10 & 10 & 10 & 6 & 10 & 10\end{array}$

101111

Betula pubescen

Sorbus aucuparla

Carex brunnescens

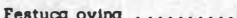

ca nutans

P. nemoralis

P. pratensis .

Cerastlum alpinum $. . . \ldots \ldots \ldots \ldots . .$.

Chamaenerion angustifollum ........

Cystopteris fragills

Eplloblum collinum .

E. lactiflorum

Fragaria vesca ...

Geranlum silvaticum

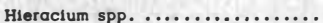

Melampyrum silvaticum

Myosotis s llvatica. .

Rubus saxatllis .

Solidago virgaurea

Stellarla graminea

s. longifolla...

Veronica officinalis

Barbiolophozla hatcheri

Brachytheclum reflexum

Bryum spp.

Ceratodon purpureus.

eus.$\ldots \ldots \ldots \ldots$

Drepanocladus uncinatus ...........

Hylocomlum splendens

Lescuraed incurvata

..............

Lophozia exclsa.

Plaglotheclum roeseanum ...........

Pogonatum alpinum . .

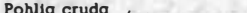

Pterigynandrum filiforme

Ptilldium clllare ........

. $40^{2} \cdot 17^{1} \cdot 30^{5} 27^{4} 18^{2}$

6

696

$10^{1}+.17^{1}$. .

. $40^{1} \cdot 17^{1}$.

$50^{2} 90^{1}+90^{1} 20^{1}$

${ }^{1} 0_{40^{1}}^{1} 0^{1} 0_{50^{1}}: 10^{1}$

$100^{1} 40^{1} 20^{1} 50^{1}: 10^{1}$
.$\quad 33^{1} \cdot$.

$20^{1}$

$30^{1} \cdot 17^{2} 80^{2} 40^{2}$

$\begin{array}{ccc}10^{1} & 20^{1}: 17^{1}: 20^{2} \\ 70^{2} & .\end{array}$

$50^{2} 20^{1} \cdot 100^{2} 50^{2} 50^{2}$

- $70^{2} 50^{1} 100^{3} 100^{3}$.

${ }_{2}^{10}: 30^{1}$

${ }^{4} 0^{2} \cdot 0^{2} \quad 0^{2} \quad 0^{2}$

$100^{3} 90^{1} \quad 100^{2} 30^{1} 30^{1}$

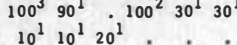

. . . .

$10^{1}+\ldots .+$.

- $10^{1} \cdot 50^{1} \cdot 10^{1}$

$20^{2} 40^{1} \cdot 50^{1} \cdot 10^{1}$

. $.17^{1}$.

- $67^{1} 20^{1}$

. $33^{1}$.

- $+17^{2}$

- $10^{1} 17^{1}$

- $17^{1} 50^{1}$

. . $10^{1}$

$\therefore \quad . \quad 10^{1}$

${ }_{20}^{1} \cdot 17^{130^{1}} 20^{1}$
$+27^{1}$

${ }_{80}^{1} 36^{1} 82^{2}$ $7^{1} \quad 82^{2} 18^{1}$ $10^{1} 9^{1} 55^{1}$ $40^{1} 100^{1} 91^{1}$

+ .

$17^{1}$

$40^{1}:$

$10^{3} 17^{1}$.

- $33^{1}$.

$100^{2} 73^{2} 82^{1}$ $100^{3} 100^{2} 27^{1}$

${ }^{67^{2}}{ }^{2}$

$\cdot{ }^{3} \cdot{ }^{3}$

$100^{4} 100^{3} 100^{3}$ $90^{2} 100^{3} 100^{1}$ $80^{1} 73^{1} 55^{1}$

${ }_{80}^{1} s^{2}$ :

$83^{1} 10^{2} 0_{100^{2}}{ }^{2}$

$83^{1} 100^{2} 100^{2} 100^{2}$

$33^{1} .83$

${ }_{67}^{1} 100^{1}: 100^{2}$

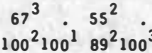

$83^{1} 100^{1} 100^{1} 100^{1}$

- 2 .

$50^{2}+\dot{9}^{1}$ $20^{1} 5^{1} 64^{1}$

$$
17^{1} .
$$

$67^{2} 50^{1} 78^{1}$

${ }_{83^{1}} 100^{2} 78^{1} 100^{1}$

$33^{1} \cdot 33^{1}$.

. . .

. . . .

$\therefore$

$\therefore:$

$+$.

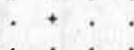

${ }_{33^{1}} \cdot$

${ }_{45^{1}}{ }_{27^{1}} \quad: \quad{ }_{17}^{1}$
55

$9 \quad 10$

$22^{2}{ }^{30^{2}}$

$33^{1} 67^{2}$

$+33^{+}$

$100^{2} 100^{3} \quad 17^{1} 33^{2} \quad 83^{1} 17^{1} 60^{2}$ $22^{1} 10^{1} \cdot 4^{2} 60^{2} \cdot 33^{2} \cdot 3^{2} 60^{2}$ $44^{1} 10^{1} \cdot 17^{2} \quad 100^{1} 17^{1} 10^{1}$ . $10^{1} .43^{1}$.

$33^{1} \cdot$. $33^{1}: 10$ $17^{2}$. . $17^{1}$. $100^{2} 83^{2} 60^{3}$ $17^{1} 100^{1}$. $17^{1} \cdot 10^{1}$ $17^{2}$. $17^{1}$ $33^{2} 83^{1}$ $100^{2} 30^{2}$ $17^{1} 100^{1}$. $50^{2} \cdot 30^{2}$

$67^{1} 100^{1} \quad \cdot \quad \cdot 10^{1}$ $17^{1} 17^{1}: 17^{1} 10^{1}$ . $67^{2} 100^{2} 50^{1}$ . $83^{1} \cdot 50^{1}$

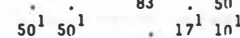
$50^{1} 50^{2} \cdot 10^{1}$

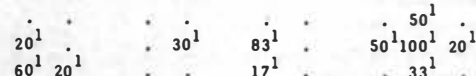
${ }_{40}^{1}: 21^{1} 40^{1}: 17^{1}: 30^{1}$

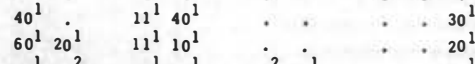
$40^{1} 40^{2} \quad 22^{1} 70^{1} \quad 100^{2} 100^{1} \quad 0^{1} \quad 7^{1}$ 
Table 27 . Analyses of two typical stands of I Tortulo-Poetum, II Rhytidietum on the S-facing scree above Upper S1k1lsdalsvatn, S Norway.

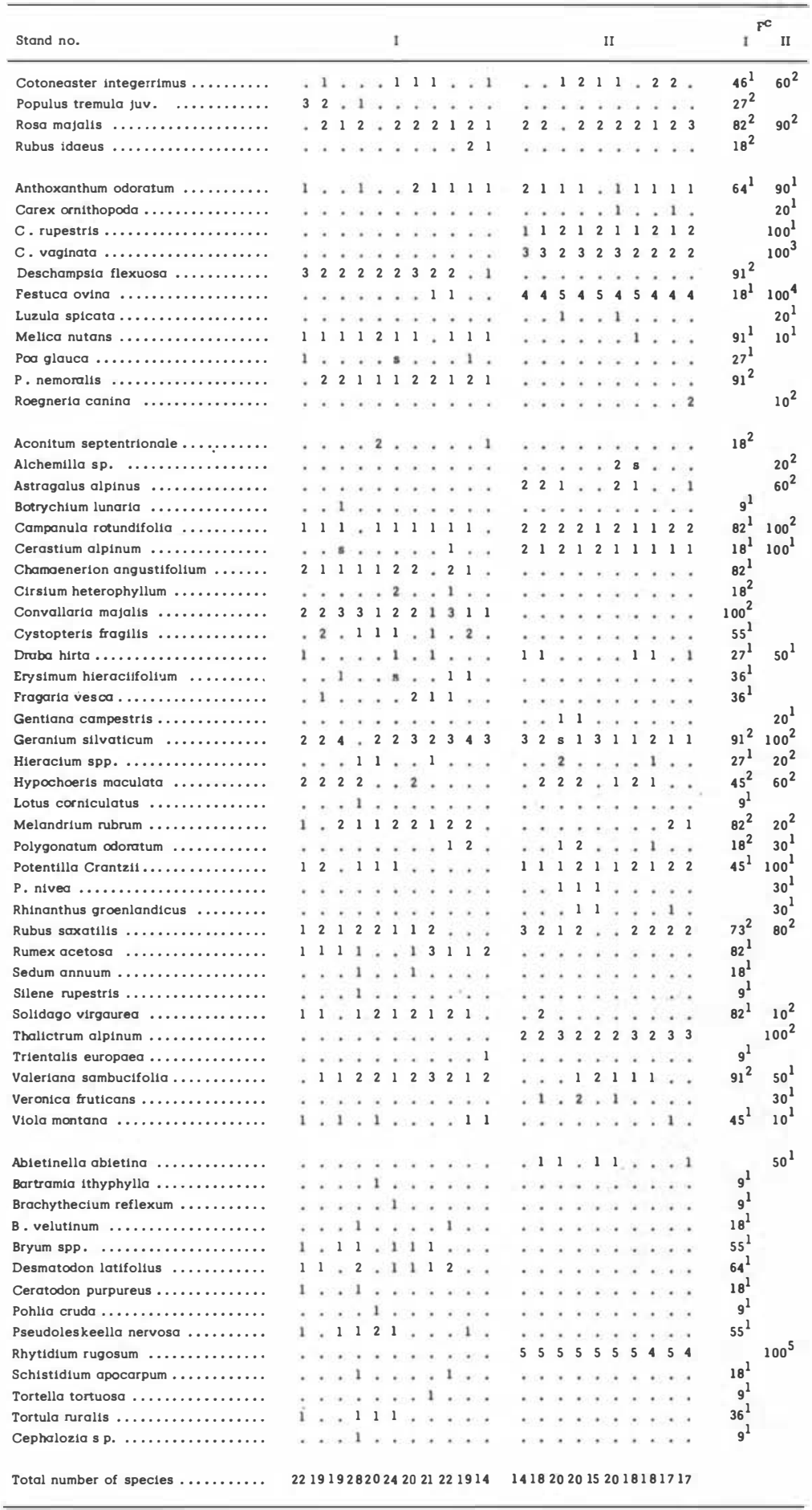


Sorbus aucuparia

Daphne mezereum

Ribes spicatum

Prunus padus

Populus tremula (trees)

Juniperus communis

Betula pubescens (trees) ...

Hieraclum sp.

Sllene rupestris

Sedum annuum....

Euphrasia frigida

Erysimum hic

Stellaria graminea...

Geranium silvaticum

Melica nutans

Viola montana

Draba norvegica

Solidago virgaurea

Botrychlum lunaria

Roegneria cantna

Fragaria vesca

Rubus saxatills

Poa nemoralis

Chamaenerion angustifollum

Poa glauca

Cerastium alpinum

Campanula rotundifolia

Hackella deflexa

Woodsia Ilvensis

Vaccinium uliginosum

v. myrtillus

Empetrum hermaphroditum ...

Linnaed borealls ....

Vaccinium vitis idaed

Festuca ovina

Brachytheclum velutinum ....

B. salebrosum

Pohlla cruda

Bryum pallescens coll

Tortula ruralis

Hedwigla clliata

Heterocladium dimarphum ...

Eurhynchlum pulchellum

Brachytheclum reflexum

Bryum caplllare

Rhytidium rugosurn

Pseudoleskeell

Radula complanata

Neckera ollgocarpa

Rhacomitrium lanuginosum

Cynodontlum strumiferum.

Schistidium apocarpum

Pseudoleskeella nervosa

Isopterygium pulchellum

Tritomaria quinquedentata ...

Tartella tortuosa

Sphenolobus saxicolus

Drepanocladus uncinatus.

Paraleucobryum longifollum .

Barbllophozia lycopodioldes

Andraea rupestris coll

Pleurozium Schreberi

Chandonanthus setiformis ..

Pohlla nutans

Grimmia ovalis

Barbilophozia hatcheri

Lophozia cf. silvicola

Polytrichum juniperinum

Hylocomium splendens. .

Dicranum fuscescens

Ptilidium clliare

Barbllophozla barbata

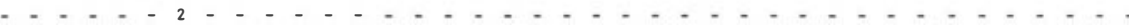

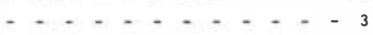

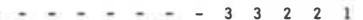

$\begin{array}{llllllllllllllllllll}1 & 1 & 2 & 3 & 3 & 2 & 2 & 4 & 5 & 5 & 5 & 5 & 5 & 5 & 5 & 5 & 5 & 5 & 4 & 2\end{array}$

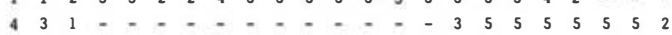

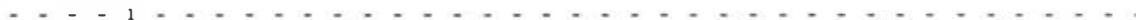

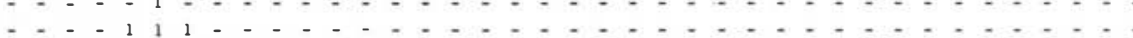

$-\cdots-121$

$-\cdots-\cdots-1$

$\begin{array}{llllllllllll}1 & 1 & 1 & 1 & 1 & 1 & 1 & - & - & - & 1\end{array}$

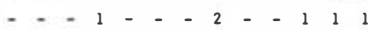

$\begin{array}{lllllllllllllllllllll} & 1 & 1 & - & 1 & 1 & 1 & - & - & - & - & - & 1 & 1\end{array}$

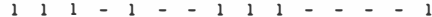

$\begin{array}{lllllllllllllllllllllll}1 & 1 & 1 & 2 & 2 & - & 2 & 2 & 1 & 1 & 1 & 2 & 1 & 2 & 1\end{array}$

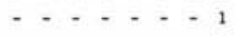

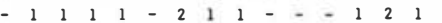

$\begin{array}{llllllllllllllllllllllll}4 & 2 & 3 & 2 & 2 & 3 & 2 & 3 & 3 & 2 & 3 & 4 & 3 & 3 & 3 & 3\end{array}$

$\begin{array}{llllllllllllllllllllllllll}1 & - & 1 & 1 & 1 & 1 & - & 1 & 1 & - & 1 & 1 & 1 & 1 & 1\end{array}$

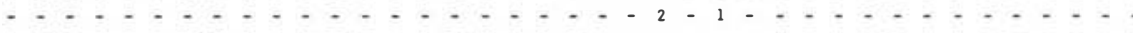

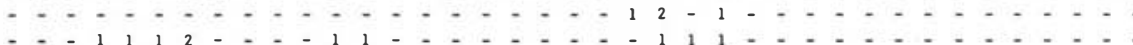

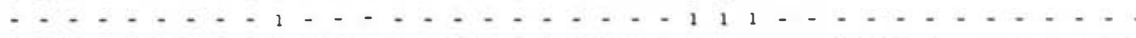

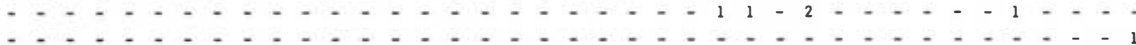

$-1-{ }_{-1}$

- - - - - - - - - - - - - - - - - - - - - - - 1131

- - - - - - - - - - - - - 22122

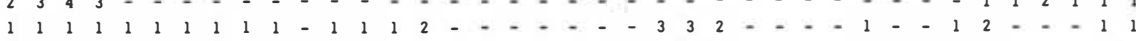

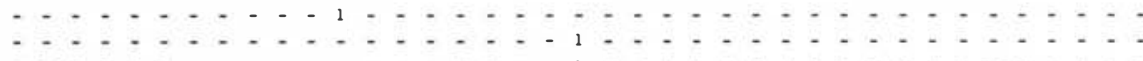

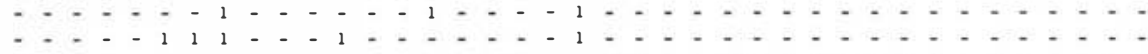

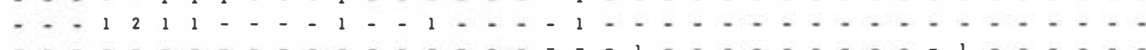

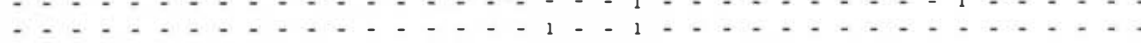

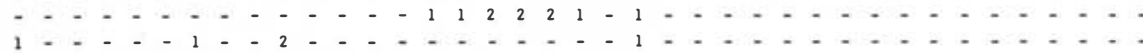

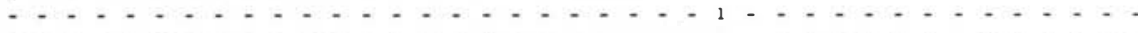

-

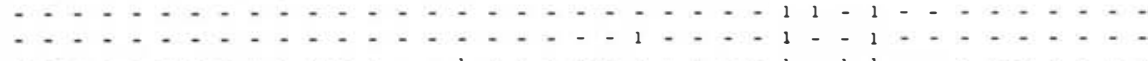
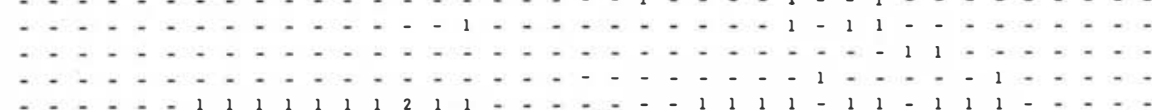

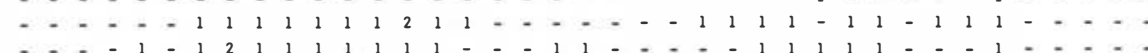

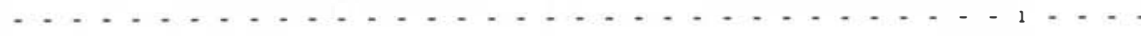

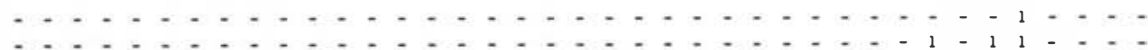

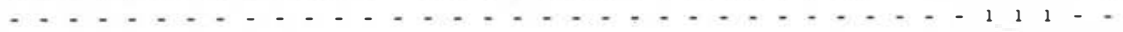

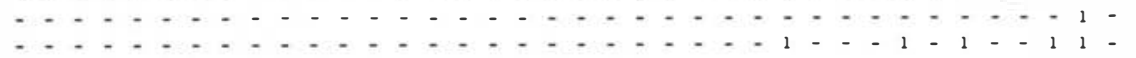

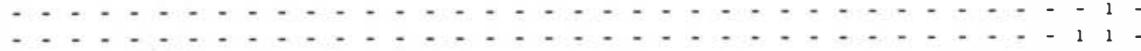

- - - - - - - - - - - - - - - - $1-1-1$

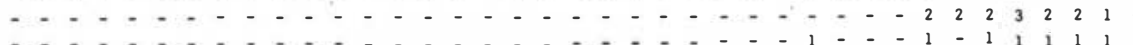

-

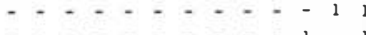

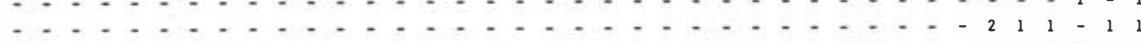

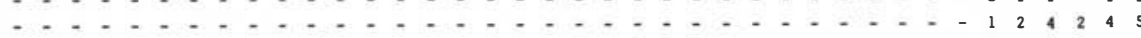

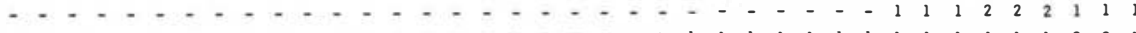

-

Total number of species

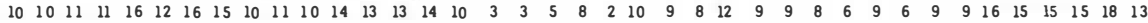


Table 29 . The belt transect on Mt. Lulep Ist jakk.

\begin{tabular}{|c|c|c|c|c|c|c|c|c|c|c|c|c|c|c|c|c|c|c|c|c|c|c|c|c|c|c|c|c|c|c|c|c|c|c|}
\hline Quadrat no. & 1 & 2 & 3 & 4 & 5 & 6 & 7 & 8 & 9 & 10 & 11 & 12 & 13 & 14 & 15 & 16 & 17 & 18 & & 20 & 21 & 22 & & 24 & 25 & 26 & 27 & 28 & & 30 & 31 & 32 & 33 & 34 \\
\hline Rosa majalis $\ldots \ldots \ldots \ldots \ldots$ & - & - & - & 2 & 3 & 2 & 2 & 3 & 2 & 3 & 2 & - & - & - & - & - & - & - & - & - & - & - & - & - & - & - & - & - & - & - & - & - & - & - \\
\hline Dryopteris fillix-mas........ & 1 & - & - & - & - & - & - & - & - & - & - & - & - & - & - & - & - & - & - & - & - & - & - & - & - & - & - & - & - & - & - & - & - & - \\
\hline Valeriana sambucifolia ....... & 2 & 2 & 2 & 1 & 3 & 4 & 4 & 3 & 3 & 3 & 1 & - & - & - & - & - & - & - & - & - & - & - & - & - & - & - & - & - & - & - & - & - & - & - \\
\hline Filipendula ulmaria $\ldots \ldots \ldots$ & 4 & 5 & 5 & 5 & 2 & 3 & 2 & 4 & 4 & 3 & 3 & 3 & - & - & - & - & - & - & - & - & - & - & - & - & - & - & - & - & - & - & - & - & - & - \\
\hline Melandrium rubrum $\ldots \ldots \ldots$ & - & 1 & - & 2 & 1 & 2 & 2 & 1 & 2 & 1 & 1 & - & 1 & - & - & - & - & - & - & - & - & - & - & - & - & - & - & - & - & - & - & - & - & - \\
\hline Rubus saxatilis $\ldots \ldots \ldots \ldots$ & 1 & 2 & 2 & - & s & - & 2 & 2 & 1 & 3 & 4 & 3 & 1 & - & - & - & - & - & - & - & - & - & - & - & - & - & - & - & - & - & - & - & - & - \\
\hline Erigeron politum $\ldots \ldots \ldots \ldots$ & - & - & - & - & - & - & - & - & - & - & - & - & - & 1 & - & - & - & - & - & - & - & - & - & - & - & - & - & - & - & $\cdot$ & - & - & - & - \\
\hline Fragaria vesca $\ldots \ldots \ldots \ldots$ & - & - & - & - & - & - & - & - & - & - & - & - & 2 & 2 & 1 & - & - & - & - & - & - & - & - & - & - & - & - & - & - & - & - & - & - & - \\
\hline Hackelia deflexa $\ldots \ldots \ldots \ldots$ & - & - & - & - & - & - & - & - & - & - & - & - & 1 & s & - & - & s & - & - & - & - & - & - & - & - & - & - & - & - & - & - & - & - & - \\
\hline Crepis tectorum $\ldots \ldots \ldots \ldots$ & - & - & - & - & - & - & - & - & - & - & - & - & - & - & - & - & 1 & 1 & - & - & - & - & - & - & - & - & - & - & - & - & - & - & - & - \\
\hline Viola montana $\ldots \ldots \ldots \ldots$ & - & - & - & - & - & - & - & - & - & - & - & - & - & 2 & - & - & - & 1 & - & - & - & - & - & - & - & - & - & - & - & - & - & - & - & - \\
\hline Melica nutans $\quad \ldots \ldots \ldots \ldots$ & - & - & 1 & $\mathbf{s}$ & - & - & - & 1 & 1 & 2 & - & - & 1 & s & 1 & - & 1 & s & - & - & - & - & - & - & - & - & - & - & - & - & - & - & - & - \\
\hline Roegneria canina $\ldots \ldots \ldots \ldots$ & 1 & 2 & 2 & 1 & 4 & 2 & 2 & 2 & 2 & 2 & 2 & 1 & 2 & - & - & 2 & - & s & - & - & - & - & - & - & - & - & - & - & - & - & - & - & - & - \\
\hline Myosotis stricta $\ldots \ldots \ldots \ldots$ & - & - & - & - & - & - & - & - & - & - & - & - & - & - & - & - & 1 & 1 & 1 & - & - & - & - & - & - & - & - & - & - & - & - & - & - & - \\
\hline Arabidopsis thaliana..$\ldots \ldots$ & - & - & - & - & - & - & - & - & - & - & - & - & - & - & - & - & 1 & 1 & 1 & - & - & - & - & - & - & - & - & - & - & - & - & - & - & - \\
\hline Poa nemoralis $\ldots \ldots \ldots \ldots$. & 1 & - & - & 1 & 1 & - & 1 & - & - & - & 1 & 1 & 1 & 1 & 1 & 1 & 1 & 1 & - & - & - & 1 & - & - & - & - & - & - & - & - & - & - & - & - \\
\hline Sedum annuum..$\ldots \ldots \ldots$ & - & - & - & - & - & - & - & - & - & - & - & - & - & - & - & 1 & 2 & 1 & 1 & 1 & 1 & - & 1 & 1 & - & - & - & - & - & - & - & - & - & - \\
\hline Polygonum dumetorum $\ldots \ldots$ & - & - & - & - & - & - & - & - & - & - & 1 & 1 & 3 & 3 & 1 & 1 & 1 & 2 & 1 & 2 & 1 & 1 & s & 1 & - & - & - & - & - & - & - & - & - & - \\
\hline Geranium silvaticum $\ldots . .$. & 2 & 2 & 4 & 2 & - & 3 & 3 & 3 & 1 & 2 & 3 & 1 & 2 & 1 & 2 & - & $\mathbf{s}$ & 1 & $\mathbf{s}$ & - & - & s & - & s & - & - & - & - & - & - & - & - & - & - \\
\hline Poa alpina $\ldots \ldots \ldots \ldots \ldots$ & - & - & - & - & - & - & - & - & - & - & - & - & - & - & - & - & - & s & 2 & 3 & 2 & 2 & 3 & 4 & - & - & - & - & 2 & - & - & - & - & - \\
\hline P. glauca $\ldots \ldots \ldots \ldots \ldots$ & - & - & - & - & - & - & - & - & - & - & - & - & - & - & - & - & - & - & - & - & - & - & - & - & 1 & - & - & - & 1 & 1 & - & s & - & - \\
\hline Stellaria graminea...$\ldots \ldots$ & - & - & - & - & - & - & - & - & - & - & 1 & - & 1 & 1 & 1 & - & - & 1 & - & - & - & - & - & - & - & - & - & - & - & - & - & 1 & - & - \\
\hline Cystopteris fragllis......... & - & - & - & - & - & - & - & - & - & - & 1 & - & 2 & - & 1 & 3 & 2 & 2 & 2 & - & 2 & 2 & 3 & 1 & - & 1 & - & - & - & - & - & 2 & - & - \\
\hline Barbaraea stricta $\ldots \ldots \ldots \ldots$ & - & - & - & - & - & 1 & - & - & - & - & - & - & 1 & 2 & 2 & 3 & 3 & 2 & s & s & 1 & - & 2 & s & - & - & - & - & s & - & - & 1 & - & - \\
\hline ecium roeseanum $\ldots$ & 1 & - & 1 & - & - & - & - & - & - & - & - & 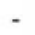 & - & - & - & - & - & - & - & - & - & - & - & - & - & - & - & - & - & - & - & - & - & - \\
\hline Brachytheclum reflexum... & - & - & - & - & - & - & - & - & - & - & - & - & 1 & - & - & - & - & - & - & - & - & - & - & - & - & - & - & - & - & - & - & - & - & - \\
\hline Orthotrichum sp. ........... & - & - & - & - & - & - & - & - & - & - & - & - & 1 & - & - & - & - & - & - & - & - & - & - & - & - & - & - & - & - & - & - & - & - & - \\
\hline Ceratodon purpureus $\ldots \ldots \ldots$ & - & - & - & - & - & - & - & - & - & - & - & - & - & - & - & - & 1 & - & - & - & - & - & - & - & - & - & - & - & - & - & - & - & - & - \\
\hline Rhytidium rugosum $\ldots \ldots \ldots$ & - & - & - & - & - & - & - & - & - & - & - & - & - & - & - & - & - & - & - & - & - & - & - & - & - & 1 & - & - & - & - & - & - & - & - \\
\hline Leuscuraea radicosa $\ldots \ldots \ldots$ & - & - & - & - & - & - & - & - & - & - & - & - & 1 & - & - & - & - & - & - & - & - & - & - & - & - & - & 1 & - & - & - & - & - & - & - \\
\hline Bryum sp. $\quad \ldots \ldots \ldots \ldots \ldots$ & - & 1 & - & - & - & - & - & - & - & - & - & - & - & - & - & 1 & 1 & - & - & - & - & - & 1 & 1 & - & - & - & - & 1 & - & - & - & - & - \\
\hline Isothecium myosuroides $\ldots$. & - & - & - & - & - & - & - & - & - & - & - & - & - & - & - & - & - & - & - & - & - & - & - & - & - & - & - & - & - & 1 & - & - & - & - \\
\hline Abletinella abietina $\ldots \ldots \ldots$ & - & - & - & - & - & - & - & - & - & - & - & - & - & - & - & - & - & - & - & - & - & - & - & - & - & - & - & - & - & - & - & - & 1 & - \\
\hline Pseudoleskeella nervosa .... & - & - & 1 & - & - & - & - & - & - & 1 & - & 2 & 1 & 1 & 1 & 1 & 1 & - & - & - & - & - & - & - & 1 & 1 & 1 & 1 & 1 & 1 & 2 & 2 & 1 & - \\
\hline Rhacomitrium lanuginosum.. & - & - & - & - & - & - & - & - & - & - & - & - & - & - & - & - & - & - & - & - & - & - & - & - & - & - & - & - & - & - & - & - & - & 1 \\
\hline Schistidium apocarpum $\ldots .$. & - & - & - & - & - & - & - & - & - & - & - & - & - & 1 & 1 & 1 & 1 & - & - & - & 1 & 1 & 1 & 1 & 1 & 1 & 1 & 1 & 1 & 1 & 1 & 1 & 1 & 1 \\
\hline Tortula ruralis $\ldots \ldots \ldots \ldots \ldots$ & - & - & - & - & - & - & - & - & - & - & - & 1 & 1 & 3 & 3 & 3 & 3 & 4 & 4 & 5 & 2 & 1 & 3 & 4 & 1 & 1 & - & - & - & - & 1 & - & - & 1 \\
\hline Total number of species & 8 & 7 & 8 & 8 & 7 & 7 & 8 & 8 & 8 & & & 8 & 17 & & & & & & 9 & 5 & 7 & 7 & & 9 & 4 & 5 & & 2 & & 4 & & 6 & & \\
\hline
\end{tabular}


Table 30. Two important communities of the Lactucion allance in the Merk Gorge.

\begin{tabular}{|c|c|c|c|c|c|c|}
\hline \multirow[b]{2}{*}{ Stand no. } & \multirow{2}{*}{\multicolumn{2}{|c|}{1}} & \multirow{2}{*}{\multicolumn{2}{|c|}{ n }} & \multicolumn{2}{|c|}{ re } \\
\hline & & & & & 1 & II \\
\hline Alnus incana (trees) .......... & $11 \ldots$ & 3...... & & & $36^{2}$ & \\
\hline Ribes splcatum v . lapponicum &.$\ldots$ & $1 \ldots=$ & $\ldots \ldots$ & $\cdots \cdots$ & $27^{1}$ & \\
\hline Rubus idaeus ............... & 1233 . & .212 .3 & 1.11. & $=\ldots$ & $73^{2}$ & $40^{1}$ \\
\hline Calamagrostis purpurea & $\ldots 11$ & $1 \ldots \ldots$ & $\ldots$ & $\ldots \ldots$ & $27^{1}$ & \\
\hline Deschampsia caespitosa .......... & 11.1. & $\ldots 2$. & $\ldots \ldots$ & $\ldots \ldots$ & $36^{1}$ & \\
\hline Melica nutans . ................. & $\ldots$ & $\ldots \ldots$ & $\ldots$. & $\ldots \ldots$ & & $10^{1}$ \\
\hline Milium effusum ........... & $\ldots \ldots$ & $\ldots \ldots$ & $\ldots 1$. & $\ldots \ldots 1$ & & $20^{1}$ \\
\hline Poo nemoralis $\ldots \ldots \ldots \ldots \ldots$ & $\ldots$ & $\ldots 11 \ldots$ & $\ldots 1 \cdot 1$ & $\ldots 1$ & $18^{1}$ & $30^{1}$ \\
\hline Aconitum septentrionale ... & 522111 & .3221 .3 & $312=3$ & .5232 & $82^{2}$ & $90^{2}$ \\
\hline Angelica archangelica .. & $\ldots \ldots$ & $=\ldots 1 \mathrm{~s}$ & $\ldots \ldots$ & $\ldots \ldots$ & $27^{1}$ & \\
\hline Anthriscus silvestris . & $\ldots \ldots$ & $\ldots \ldots$ & $\ldots \ldots$ & $\ldots s$ & & $20^{1}$ \\
\hline Circaea alpina ....... & 11.21 & $3=22.2$ & $\ldots \ldots$ & & $82^{2}$ & \\
\hline Cystopteris fragills & $\ldots \ldots$ & $\ldots \ldots$ & . 21. & .2331. & & $50^{2}$ \\
\hline Equisetum pratense . . & $\ldots \ldots$ & $\ldots \ldots$ & $\ldots \ldots$ & $\ldots 2 \ldots$ & & $10^{2}$ \\
\hline Fillpendula ulmaria ......... & 22225 & 242144 & $\ldots \ldots$ & $\ldots \ldots$ & $100^{2}$ & \\
\hline Gymnocarpium dryopteris ......... & $\ldots 2 \ldots$ & $\ldots 2^{2}$. & $\ldots \ldots$ & $2 \ldots 1$ & $18^{2}$ & $20^{2}$ \\
\hline Matteuccia struthiopteris ........ & $\ldots \ldots$ & $\ldots \ldots$ & 32425 & 35555 & & $100^{3}$ \\
\hline Paris quadrifolla ................. & 1111. & $\ldots 1 \ldots$ & $\ldots 1 \ldots$ & $1 \ldots$ & $45^{1}$ & $20^{1}$ \\
\hline Phegopteris polypodioldes $\ldots \ldots \ldots$ & $2 \begin{array}{llll}2 & 2 & 3 & 3\end{array}$ & 24.523 & $1 \ldots$ & $1 \ldots 1$ & $91^{2}$ & $30^{1}$ \\
\hline Rubus saxatilis ............... & $.1 \ldots$ & $\ldots \ldots$ & $\ldots \ldots$ & $\ldots \ldots$ & $9^{1}$ & \\
\hline Solidago virgaurea $\ldots . . . .$. & $\ldots \ldots$ & $\ldots . \ldots$ & $\ldots \ldots$ & $\ldots \ldots$ & $9^{1}$ & \\
\hline Stellaria nemorum ssp.mont. ...... & $\ldots \ldots$ & $\ldots \ldots$ & 22233 & 322222 & & $100^{2}$ \\
\hline Trientalls europaea $\ldots \ldots \ldots \ldots . .$. & 12111 & .211 .2 & $\ldots$ & $\ldots \ldots$ & $82^{1}$ & \\
\hline Trollius europaeus ............. & $\ldots \ldots$ & $\ldots 11 \ldots$ & $\ldots \ldots$ & $\ldots \ldots$ & $18^{1}$ & \\
\hline Urtica dioeca ssp. Sondenil ....... & $\ldots$ & $\ldots \ldots$ & .22 .5 & $1 \ldots$ & & $40^{2}$ \\
\hline Valeriana sambucifolla ...... & $\ldots \ldots$ & $\ldots 11 \ldots$ & $\ldots \ldots$ & $\ldots \ldots$ & $18^{1}$ & \\
\hline Viola biflora ............ & 11111 & 22112. & s.s.s. & $\ldots, \ldots$ & $91^{1}$ & $60^{1}$ \\
\hline v. epipsila $\ldots \ldots \ldots \ldots$ & $\cdots$ & $\ldots 2$ & $\ldots$ & $\cdots \cdots$ & & \\
\hline Barbllophozla hatcher1.. & $\ldots$ & $\ldots+\ldots$ & $\ldots$ & $\ldots \ldots$ & 9 & \\
\hline Brachythectum reflexum . & $\ldots+\ldots+$ & $\ldots+\ldots$ & $+\ldots++$ & $+\ldots+\ldots+$ & 64 & 80 \\
\hline B. salebrosum .......... & $+\ldots++$ & $\ldots+\ldots+$ & $\ldots++$ & $\ldots+\ldots$ & 73 & 40 \\
\hline Campyllum sommerfelt11 $\ldots \ldots \ldots$ & $+\ldots+$ & $+\ldots++$ & $\cdots \cdots$ & $\ldots+\cdots$ & 55 & 10 \\
\hline c. stellatum …............... & ... + + & $++++\ldots$ & $\ldots+$ & $\cdots \cdots$ & 64 & 10 \\
\hline Climacium dendroldes ........... & $\ldots+$ & $\ldots+\ldots+$ & $\ldots \ldots$ & $\ldots \ldots$ & 36 & 10 \\
\hline Drepanocladus uncinatus $\ldots \ldots \ldots$ & $\ldots \ldots$ & $\ldots \ldots$ & $\ldots \ldots$ & $\ldots \ldots$ & 9 & \\
\hline Fissidens adianthoides $\ldots \ldots \ldots \ldots$ & $\ldots \ldots$ & $+\ldots+$ & $\ldots \ldots$ & $\ldots \ldots$ & 18 & \\
\hline Lophozla sp. ............ & $\ldots+$ & $\ldots \ldots$ & $\ldots \ldots$ & $\cdots \cdots$ & & \\
\hline Mnlum medium....... & $+\ldots++$ & $\ldots+\ldots+$ & $\ldots+\ldots$ & $\ldots \ldots$ & 82 & 20 \\
\hline Mn. punctatum & $\ldots \ldots$ & $\ldots+\ldots$ & $\ldots \ldots$ & $\ldots \ldots$ & 9 & \\
\hline Mn, rugicum .. & $\ldots \ldots$ & $+\ldots \ldots$ & $\ldots \ldots$ & $\ldots \ldots$ & 9 & \\
\hline Mn. spinosum ......... & $\ldots+$ & $++\ldots+$ & $\ldots+\cdots$ & $\cdots+\cdots$ & 55 & 60 \\
\hline Plaglochilla asplenioldes .. & ... & $\ldots \ldots+$ & $\cdots+\ldots$ & $\cdots \cdots$ & 9 & 20 \\
\hline Plaglotheclum laetum . ........... & $+\ldots+$ & $\ldots+\ldots$ & $\ldots+\ldots$ & $\ldots+\ldots$ & 27 & 30 \\
\hline P. roeseanum .................... & $+\ldots+$ & $\ldots+\ldots$ & $\ldots \ldots+$ & $\ldots+\ldots+$ & 45 & 40 \\
\hline Pogonatum alpinum . & $\ldots \ldots$ & $\ldots+\ldots+$ & $\cdots \cdots$ & 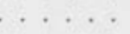 & 18 & \\
\hline & $\ldots$ & $\ldots \ldots+$ & $\ldots$ & $\ldots \ldots$ & 9 & \\
\hline Rhodobryum roseum . & $\ldots$ & $\ldots+\ldots+$ & $\ldots$ & $\ldots \ldots+$ & 27 & 10 \\
\hline
\end{tabular}

Table 31 . The Picea forest near Tjäutjanálve hill.

Quadrat no.

$\begin{array}{llllllllll}1 & 2 & 3 & 4 & 5 & 6 & 7 & 8 & 9 & 10\end{array}$

Betula pubescens (trees)

Picea ables (trees)

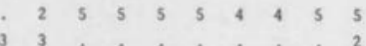

vaccinlum vitis-idaed

$\begin{array}{llllllllll}2 & 3 & 3 & 3 & 3 & 3 & 2 & 2 & 2 & 2\end{array}$

Deschampsia flexuosa

Luzula pilosa

Melica nutans

$\begin{array}{llllllllll}1 & 2 & 1 & 1 & 1 & 1 & 1 & 1 & 1 & 1 \\ 1 & 1 & 1 & 1 & 1 & 1 & 1 & 1 & 1 & \\ 1 & 1 & 1 & 1 & 1 & 1 & 1 & 1 & 1 & \end{array}$

Antennaria dioeca

Coelogloss

Geranium silvaticum

Gymnocorplum dryopteris

Hieracium spp.

Lycopodium annotinum

Majanthemum bifollum

Melampyrum silvaticum

Moneses uniflora

Ramischia secund

Rubus saxatllis

Solidago virgaurea

Trientalis europae

Viola biflora

v. montana

v. riviniana

$\begin{array}{llllllllll}1 & 1 & 1 & 1 & 1 & 1 & 1 & 1 & 1 & 1 \\ 2 & 1 & 2 & 2 & 2 & 2 & 2 & 2 & 2 & 2\end{array}$

Barbilophozla barbata

Brachythecsum reflexum

B. solebrosum .

Dicranum fuscescens

D. majus.

D. scoparium

Hylocomlum splenden

Mnium rugicum

Pleurozium schreberi

Polytrichum commune

Ptllidium pulcherrimu

Rhodobryum roseum

Phadelphus triquetris.

Uncovered litter

Total number of species

$\begin{array}{llllllllll}20 & 23 & 18 & 21 & 17 & 16 & 19 & 18 & 22 & 24\end{array}$ 

Pris 48: - kronor 